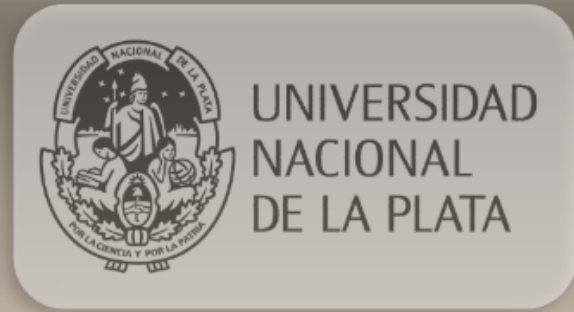

\title{
Análisis del rol \\ de proteínas tipo Lap \\ en la formación de biofilm \\ de Bordetella bronchiseptica
}

Tesis Doctoral

Nicolás M. Ambrosis

2018

Directores

Dra. Julieta Fernández y Dr. Federico Sisti

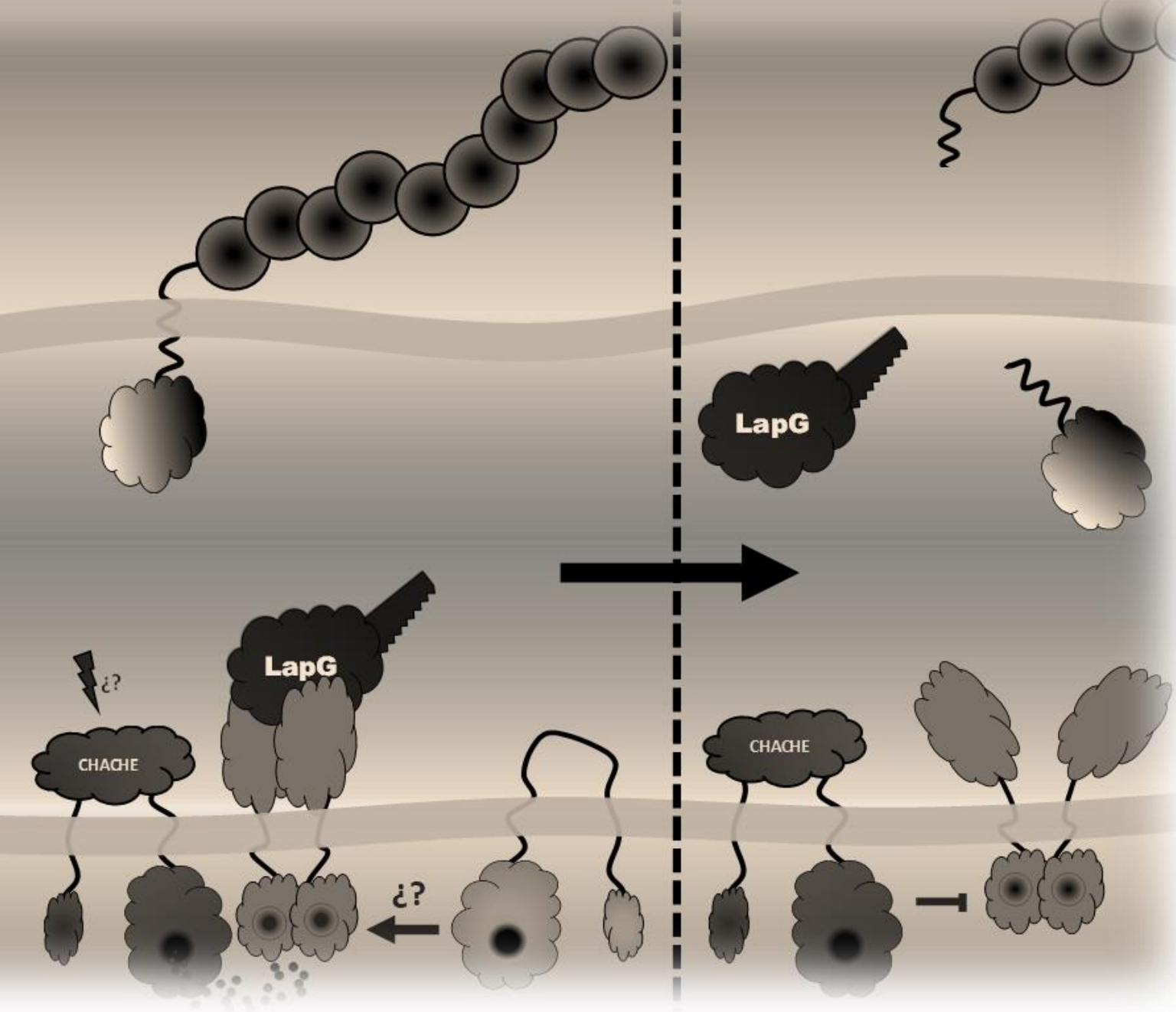





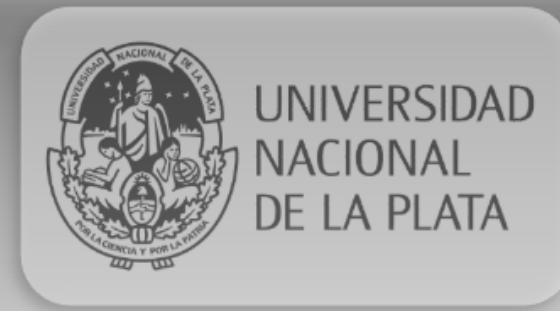

\section{Análisis del rol \\ de proteínas tipo Lap \\ en la formación de biofilm \\ de Bordetella bronchiseptica}

Tesis Doctoral

Nicolás M. Ambrosis

2018

Directores

Dra. Julieta Fernández y Dr. Federico Sisti

Facultad de Ciencias Exactas

Departamento de Ciencias Biológicas

IBBM

(Instituto de Biotecnología y Biología Molecular) 

El presente trabajo de Tesis, para optar por el título de Doctor de la Facultad de Ciencias Exactas, Fue realizado en el Instituto de Biotecnología y Biología Molecular de La Plata (IBBM, UNLP-CONICET) bajo la dirección conjunta de la Profesora Dra. Julieta Fernández y el Profesor Dr. Federico Sisti. 



Parte de los resultados presentados en este trabajo de Tesis han sido publicados en el artículo:

Ambrosis, N., Boyd, C. D., O Toole, G. A., Fernández, J. \& Sisti, F. Homologs of the LapD-LapG c-di-GMP Effector System Control Biofilm Formation by Bordetella bronchiseptica. PLoS One 11, e0158752 (2016). 



\section{Glosario de abreviaturas}

c-di-GMP: diguanilato cíclico

DGC: diguanilato ciclasas

PDE: fosfodiesterasas

GGDEF: Dominio diguanilato ciclasa (excepto dominios degenerados)

EAL: Dominio fosfodiesterasa (excepto dominios degenerados)

HD-GYP: Dominio fosfodiesterasa (excepto dominios degenerados)

GTP: Guanosina trifosfato

pGpG: 5'-fosfoguanilil-(3',5')-guanosina

GMP: Guanosina monofosfato

Rec: Dominio receiver fosforilable

RxxD: Sitio de regulación alostérica de algunos dominios GGDEF

PilZ: dominio de unión a c-di-GMP

RTX: dominio repeats in toxins

FHA: Hemaglutinina filamentosa

PRN: Pertactina

Fim: Fimbria

AC: Adenilato ciclasa

TDN: Toxina dermonecrótica

BACTH: Bacterial $\underline{\text { Adenylate }} \underline{\text { Cyclase }}$ Two-Hybrid System

UM: Unidades de Miller

UFC: Unidades formadoras de colonias

BSA: seroalbúmina bovina

DO: Densidad óptica

ABS: Absorbancia

HA: Epitope de hemaglutinina

Str: Estreptomicina

Gm: Gentamicina

$\mathrm{Km}$ : Kanamicina

$\mathrm{Cb}$ : Carbenicilina 



\section{Índice}

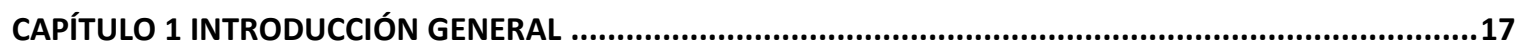

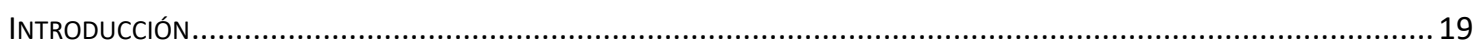

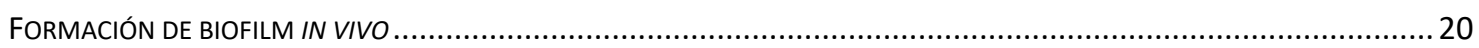

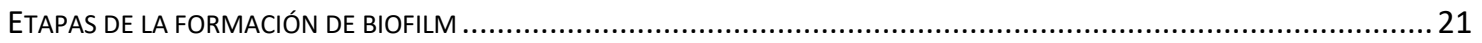

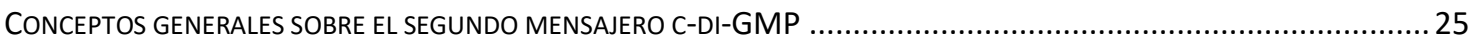

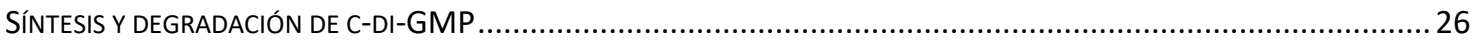

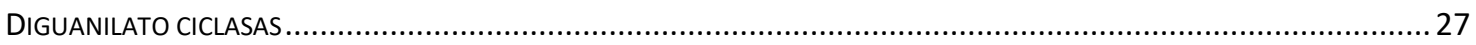

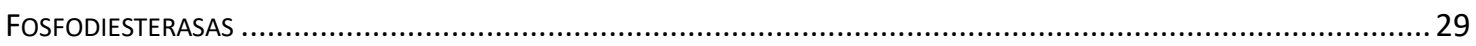

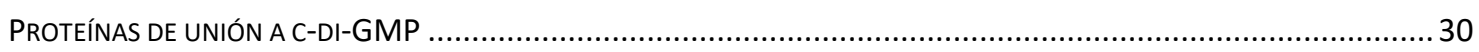

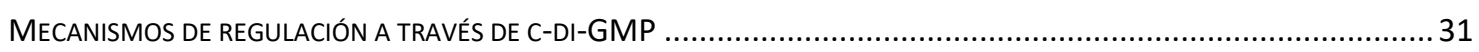

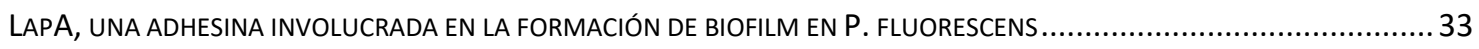

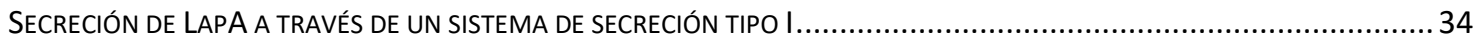

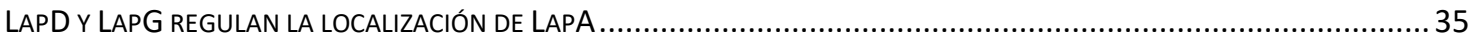

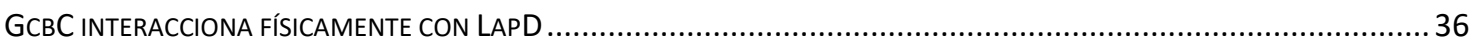

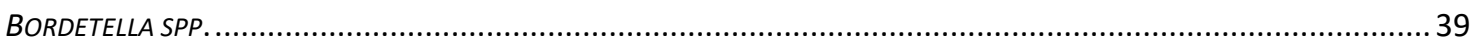

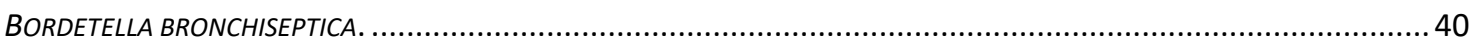

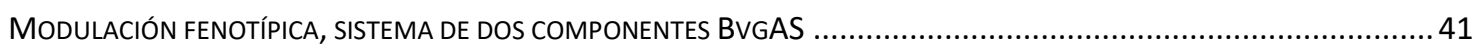

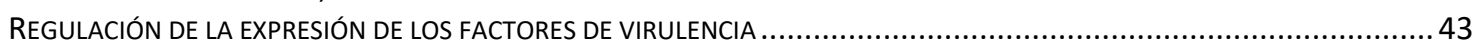

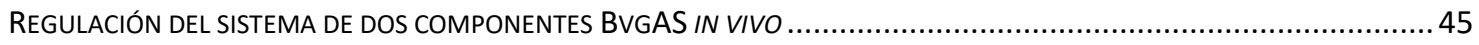

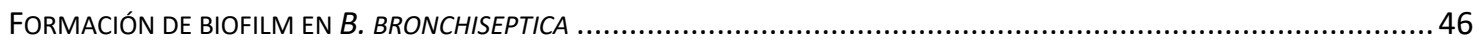

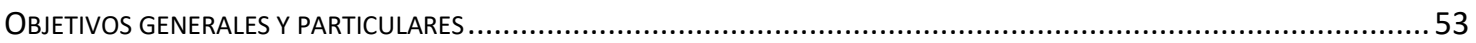

CAPÍTULO 2 BÚSQUEDA DE NUEVOS FACTORES INVOLUCRADOS EN LA FORMACIÓN DE BIOFILM A

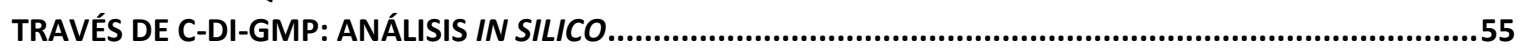

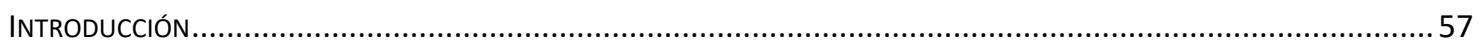

BB1184, BB1185 Y BB186 PODRÍAN REGULAR LA FORMACIÓN DE BIOFILM EN B. BRONCHISEPTICA.............................57

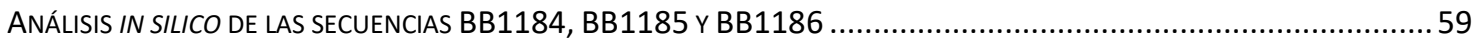

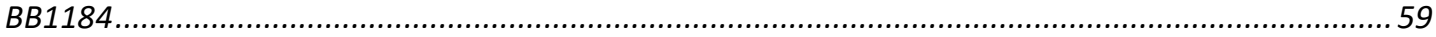

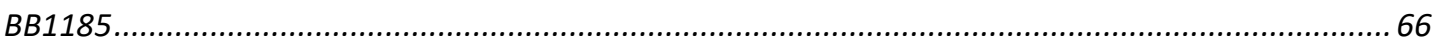

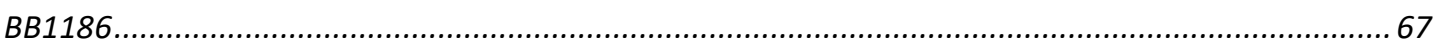

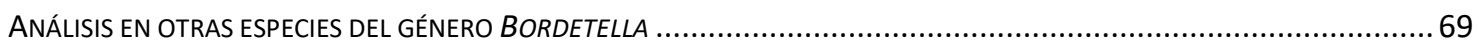

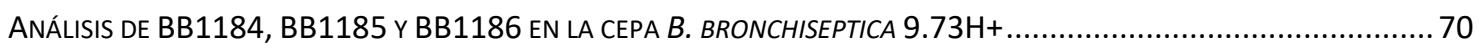

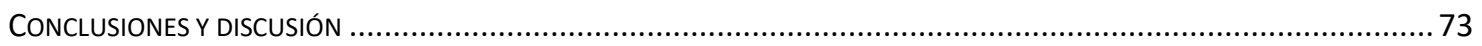

CAPÍTULO 3 BRTA REGULA LA FORMACIÓN DE BIOFILM EN B. BRONCHISEPTICA .................................77

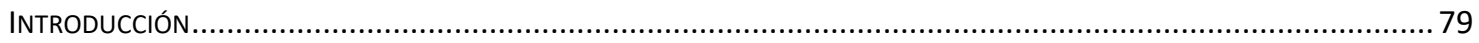

BRTA ES UNA ADHESINA INVOLUCRADA EN LA FORMACIÓN DE BIOFILM EN B BRONCHISEPTICA ....................................79

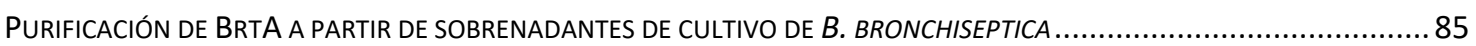

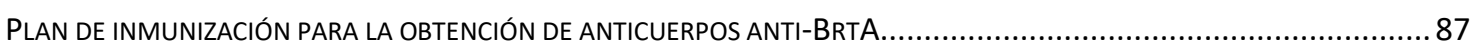

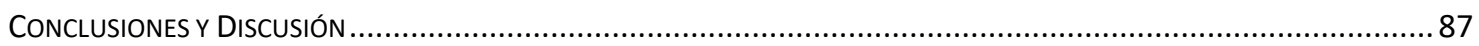

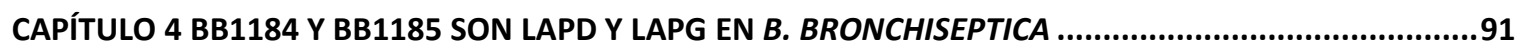

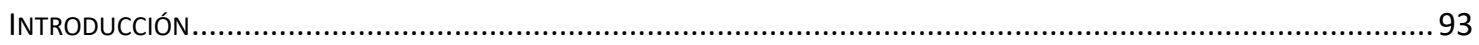

LOS GENES LAPD ${ }_{B B}, L A P G_{B B} Y$ Y BRTA FORMAN PARTE DE UN MISMO OPERÓN .......................................................... 93

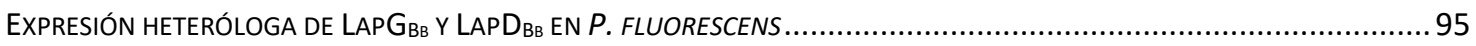

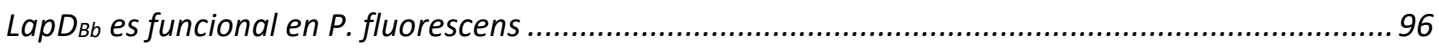

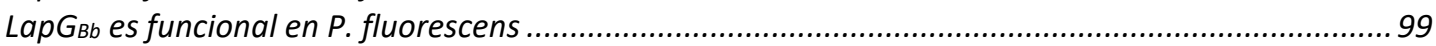

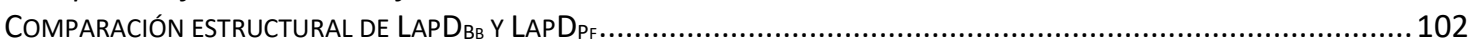

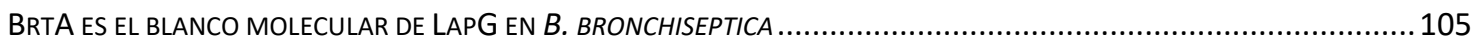

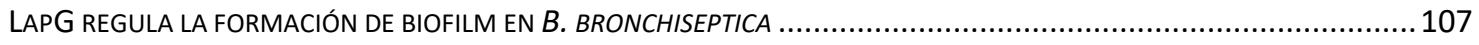

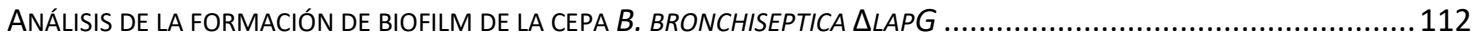

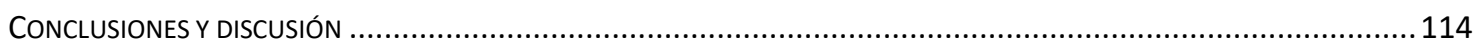

CAPÍTULO 5 ANÁLISIS DE ROL DE LAS PROTEÍNAS LAP DE B. BRONCHISEPTICA IN VIVO.......................119

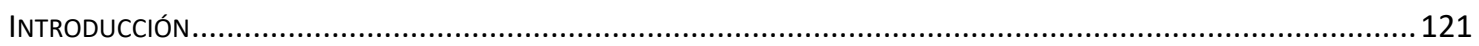

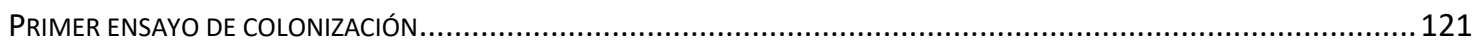

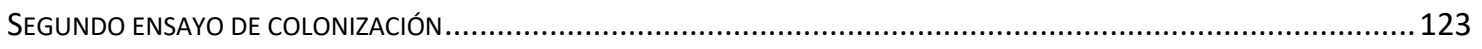

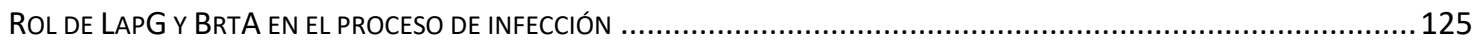

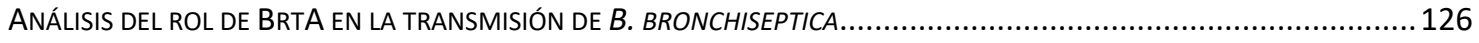


ANÁLISIS DE LA FORMACIÓN DE BIOFILM SOBRE MONOCAPA CELULAR

INTRODUCCIÓN.....

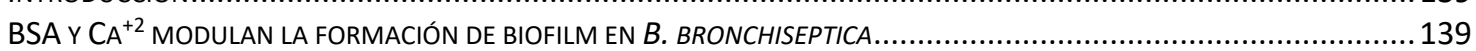

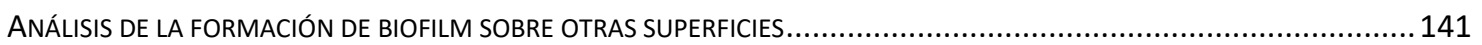

ANÁLISIS DEL ROL DE BRTA EN LA REGULACIÓN DE LA FORMACIÓN DE BIOFILM MEDIADA POR BSA Y CA ${ }^{+2} \ldots \ldots \ldots \ldots \ldots \ldots . . . . . . . .145$

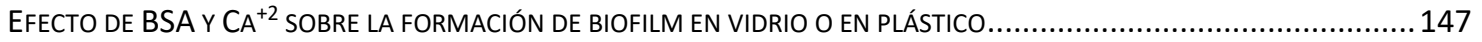

ANÁLISIS DE LA FORMACIÓN DE BIOFILM MEDIANTE MICROSCOPÍA ELECTRÓNICA DE BARRIDO (SEM)...........................149

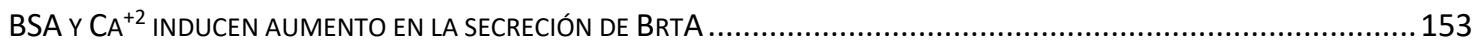

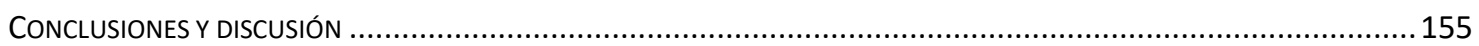

CAPÍTULO 7 REGULACIÓN DE LA FORMACIÓN DE BIOFILM A TRAVÉS DE C-DI-GMP ...........................159

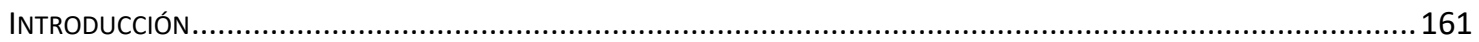

LAPD $_{B B}$ ES UN FACTOR NECESARIO EN LA REGULACIÓN DE LA FORMACIÓN DE BIOFILM A TRAVÉS DE C-DI-GMP ..................162

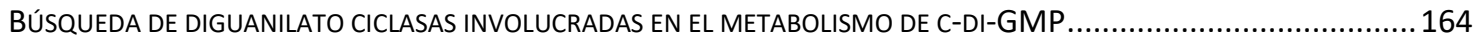

DISEÑO Y EVALUACIÓN DE UN SISTEMA REPORTERO PARA LA BÚSQUEDA DE DIGUANILATO CICLASAS QUE INTERACCIONEN CON

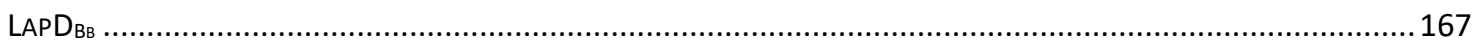

EXPRESIÓN HETERÓLOGA DE POSIBLES DIGUANILATO CICLASAS DE B. BRONCHISEPTICA EN LA CEPA MODELO $P$.

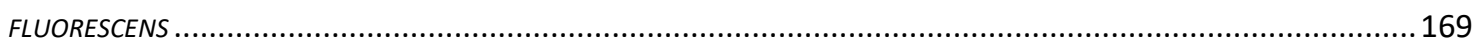

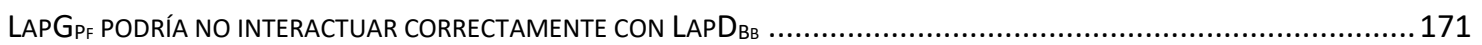

BÚSQUEDA DE DIGUANILATO CICLASAS QUE INTERACCIONEN CON LAPD BB MEDIANTE MODELADO MOLECULAR .................173

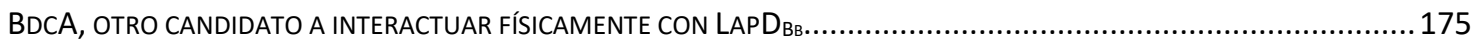

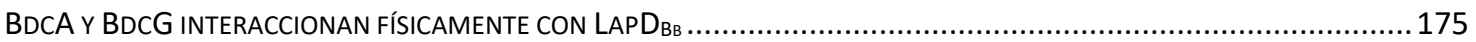

BDCG NO PRESENTA ACTIVIDAD DIGUANILATO CICLASA EN EL MODELO DE DOBLE HÍBRIDO EN BACTERIA .........................179

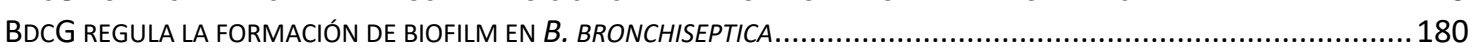

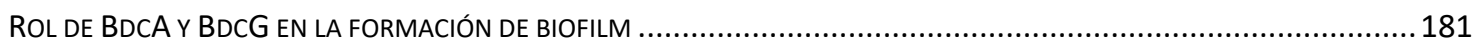

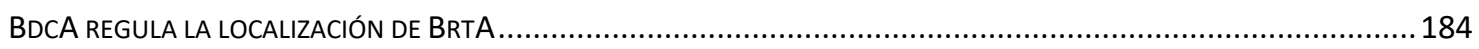

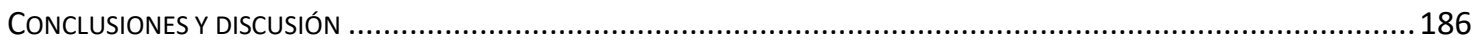

CAPÍTULO 8 CONCLUSIONES GENERALES .....................................................................................191

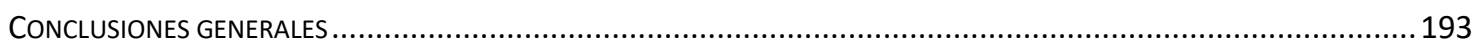

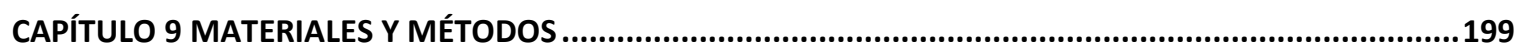

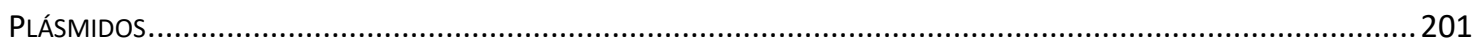

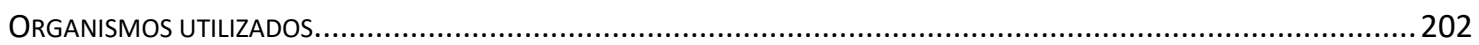

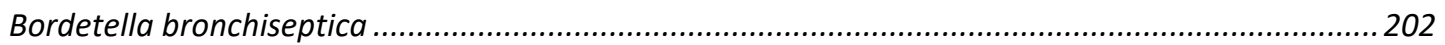

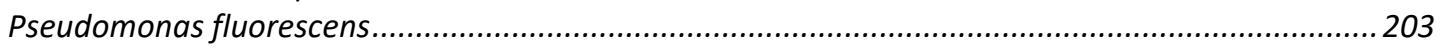

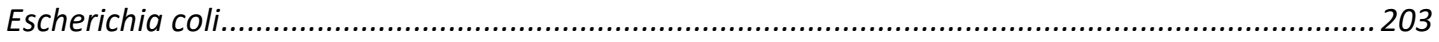

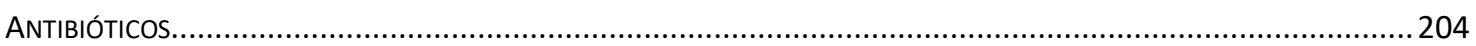

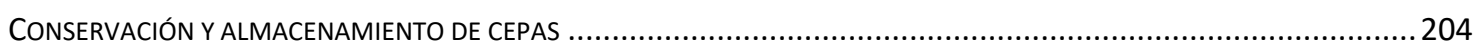

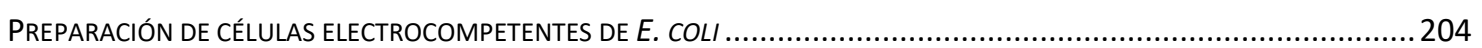

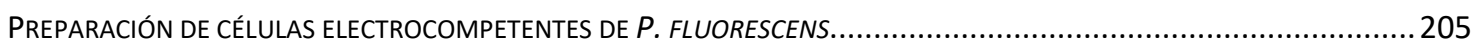

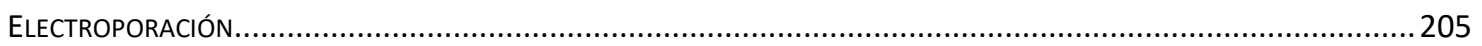

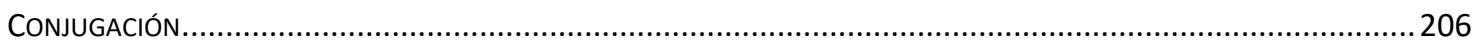

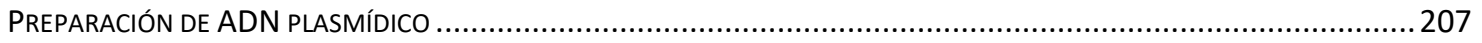

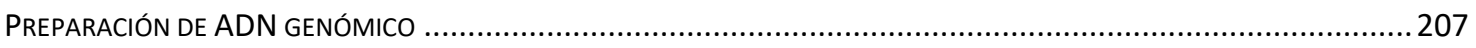

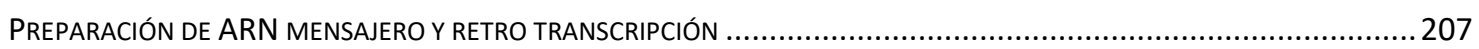

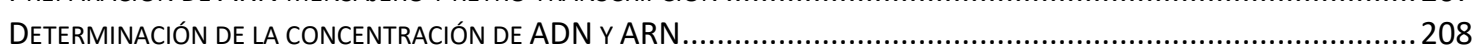

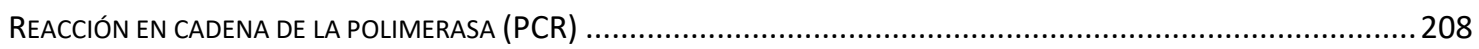

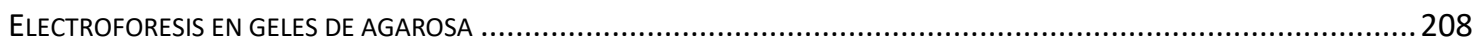

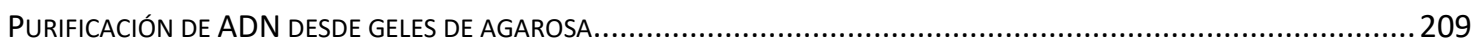

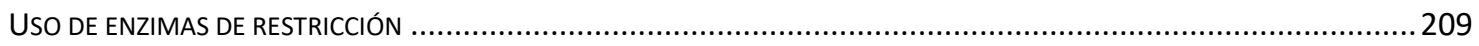

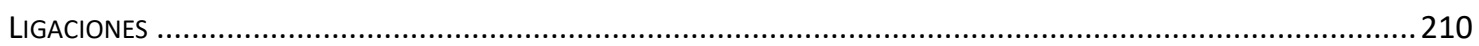

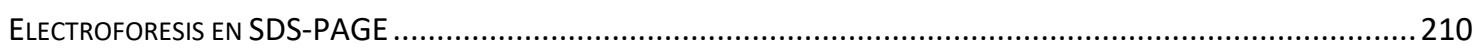

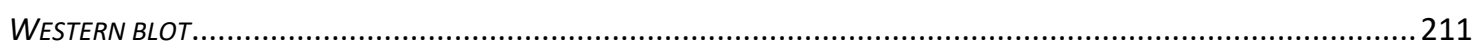

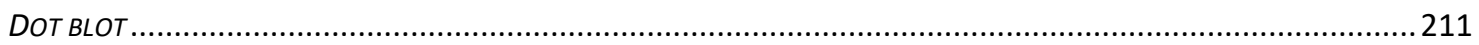

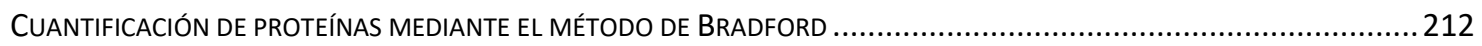

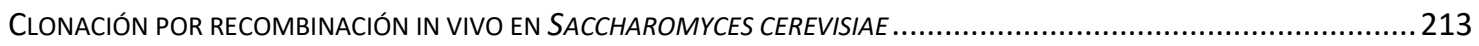


ESTRATEGIA PARA LA OBTENCIÓN DE MUTANTES POR DELECIÓN LIMPIA EN B. BRONCHISEPTICA ................................215

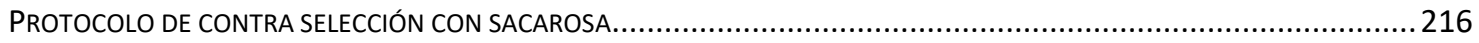

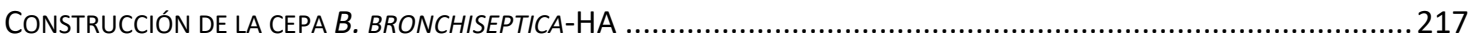

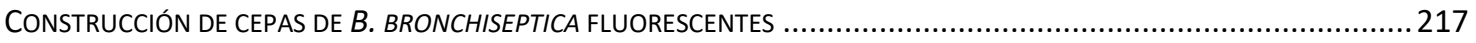

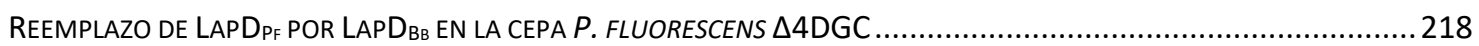

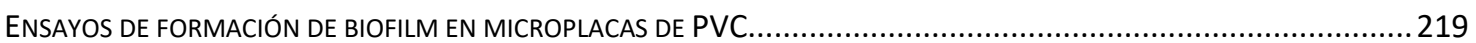

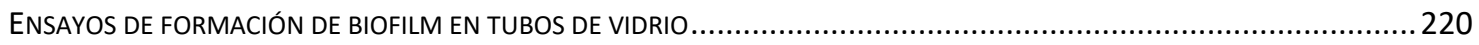

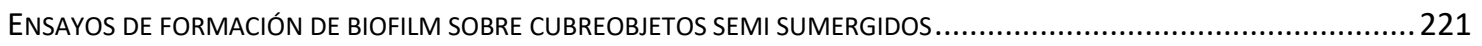

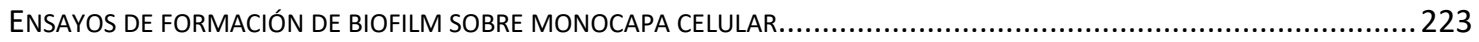

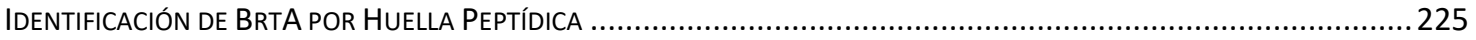

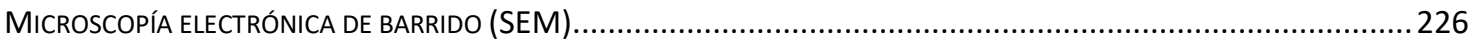

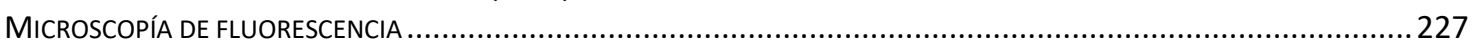

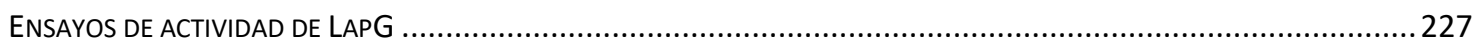

OBTENCIÓN DE MUESTRAS DE SOBRENADANTE Y CÉLULA ENTERA PARA LA DETECCIÓN DE BRTA-HA Y LAPA-HA.............228

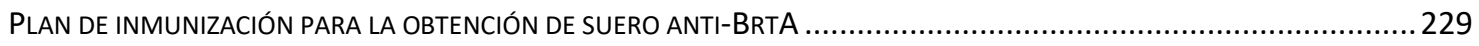

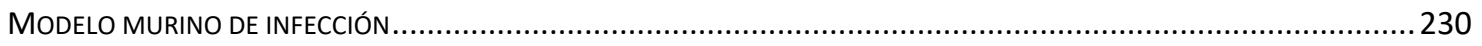

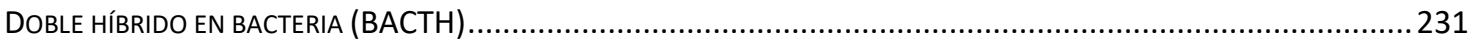

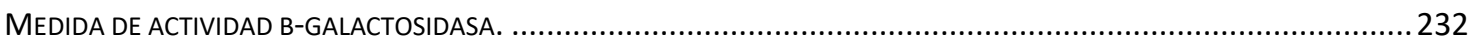

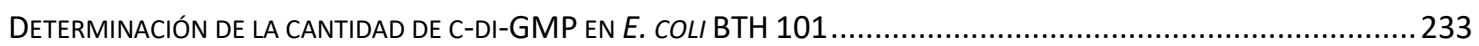

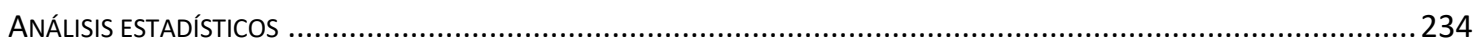

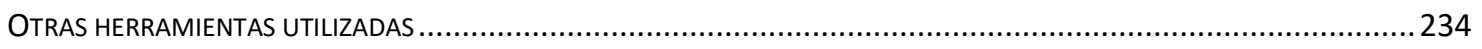

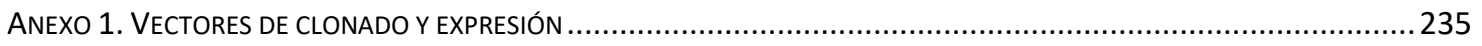

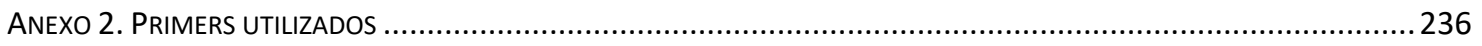

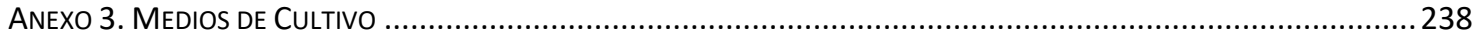

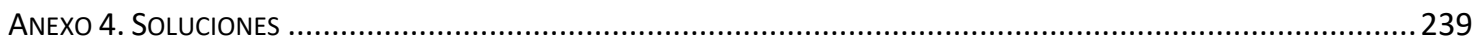

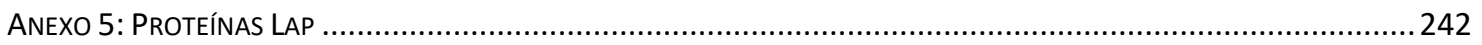

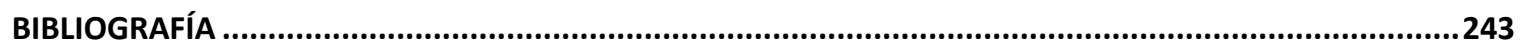





\section{Capítulo 1}

\section{Introducción General}





\section{Introducción}

Históricamente la microbiología ha estudiado el comportamiento y la fisiología bacteriana considerando a estos microorganismos como seres aislados. Esta concepción ha llevado a la microbiología a desarrollar y utilizar estrategias de cultivo en las que los microorganismos proliferan de manera planctónica. No cabe duda de que este método de estudio ha permitido avanzar notablemente en la comprensión de la fisiología bacteriana. Si embargo, la evidencia experimental sugiere que el estilo de vida planctónico no es la forma predominante en la que los microorganismos se encuentran en la naturaleza ${ }^{1-3}$.

A principios del siglo XX Zobell y otros autores describieron la tendencia de muchas bacterias marinas a adherirse a distintos tipos de superficies ${ }^{4,5}$. Curiosamente, las primeras observaciones de organismos creciendo adheridos a superficies no fueron realizadas por los sectores tradicionales de la microbiología. Quienes reconocieron la importancia del desarrollo de esta área de estudio fueron los sectores industriales relacionados a sistemas de tratamientos de aguas y residuos ${ }^{6}$. La presencia de microorganismos creciendo sobre superficies genera procesos de biodeterioro que impactan sobre los sistemas de distribución de agua potable, edificios, pinturas, monumentos históricos y sistemas de calefacción y enfriamiento basados en circulación de agua. ${ }^{7-9}$.

En la segunda mitad del siglo XX William Costerton se convertiría en el principal impulsor y máximo referente del estudio de los microorganismos adheridos a superficies $^{1,10}$. No obstante, no fue sino hasta el año 1981 cuando F. McCoy, D. Bryers J. Robbins y el propio W. Costerton acuñaron el término biofilm para referirse a las "bacterias filamentosas" que se adherían a la superficie de reactores y cañerías industriales (Figura 1.1) $)^{11}$.

Desde aquellos años, hasta nuestros días, la definición de biofilm ha sido adaptada a los conocimientos de la época. Hoy en día, una de las definiciones más aceptadas establece que un biofilm es "una comunidad microbiana sésil, caracterizada por células que están adheridas irreversiblemente a un sustrato o interfase, o unas con otras, embebidas en una matriz de sustancias poliméricas extracelulares que ellas han producido y que expresan un fenotipo propio"12. Esta definición incluye no sólo a comunidades formadas por un solo tipo de bacterias sino también a consorcios formados por múltiples especies o por diferentes tipos de microorganismos (hongos, algas y protozoos). 


\section{Capítulo 1}

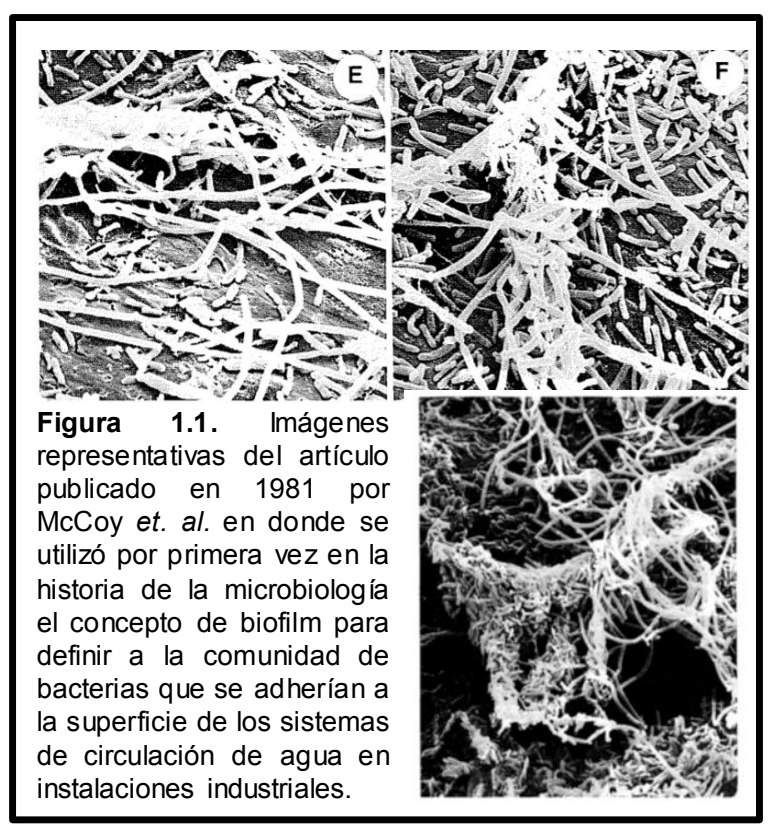

\section{Formación de biofilm in vivo}

La microbiología clínica empezó a tomar real dimensión de la importancia de los biofilms microbianos en la salud humana cuando Niels Høiby describió la presencia de agregados de bacterias rodeados de una sustancia viscosa en muestras de esputo provenientes de pacientes afectados por fibrosis quística (Figura 1.2) ${ }^{13}$.

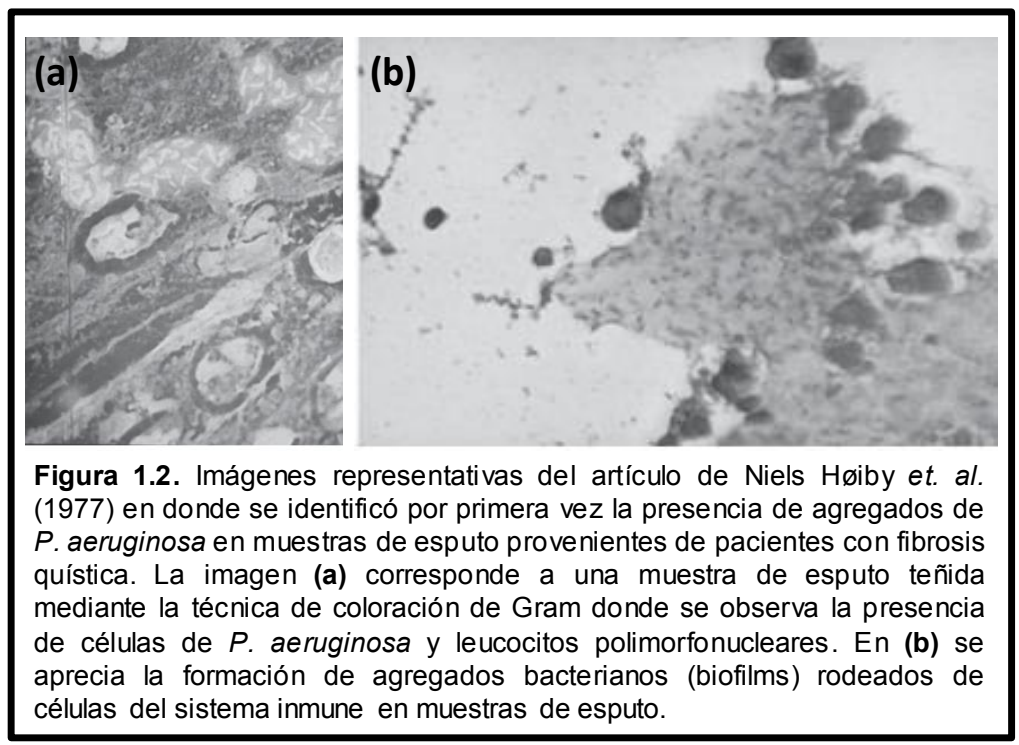

Høiby y sus colaboradores sugirieron con gran atino la relación directa que podía existir entre la formación de esas estructuras y la persistencia observada en infecciones con Pseudomonas aeruginosa en estos pacientes ${ }^{13,14}$. Desde ese momento la importancia de los biofilms en las enfermedades crónicas fue ampliamente reconocida. 


\section{Capítulo 1}

Posteriormente, la presencia de microorganismos formadores de biofilm fue identificada como la causa de una gran variedad de afecciones a la salud humana y animal como por ejemplo otitis media crónica ${ }^{15-17}$, infecciones asociadas a implantes ${ }^{18-21}$, osteomielitis crónica ${ }^{22-24}$, rinosinusitis crónica ${ }^{25,26}$, otras infecciones crónicas ${ }^{27-29}$ e incluso infecciones oculares provenientes de bacterias asociadas a los lentes de contacto ${ }^{30}$; (para más referencias acerca de infecciones crónicas originadas por bacterias formadoras de biofilm se puede consultar la revisión de Costerton et $a l^{31}$ ). Las infecciones que desarrollan biofilm in vivo presentan dos características sobresalientes: son infecciones altamente resistentes a los mecanismos de defensa del sistema inmune y son tolerantes a tratamientos antibióticos a los cuales las mismas bacterias planctónicas no lo son ${ }^{32}$.

La formación de biofilm permite a los microorganismos unicelulares adoptar una forma de vida multicelular que aumenta la probabilidad de supervivencia en ambientes hostiles pero también favorece el crecimiento y desarrollo en ambientes favorables ${ }^{33}$.

Entre las ventajas que confiere a los microorganismos la organización en estructuras comunitarias embebidas en una matriz encontramos:

(i) Permite a los microorganismos permanecer en un ambiente tanto tiempo como sea posible mientras se mantienen las condiciones favorables para el desarrollo.

(ii) Favorece la tolerancia a condiciones adversas como exposición a radiación $U^{34,35}$, exposición a metales tóxicos ${ }^{36,37}$ así como también a altas temperaturas, condiciones de levada salinidad y $\mathrm{pH}$ extremos ${ }^{38}$.

(iii) Permite evadir el ataque de ciertos predadores como organismos unicelulares eucariotas (amebas y protozoos) que sólo son capaces de atacar células planctónicas ${ }^{39}$.

(iv) En las infecciones animales permite evadir el ataque de células fagocíticas del sistema inmune ${ }^{40}$.

(v) Aumenta la tolerancia a antibióticos ${ }^{41-43}$

(vi) La vida en comunidad permite una diferenciación celular y una verdadera división del trabajo ${ }^{44,45}$.

Estas ventajas están conferidas en parte por la presencia de una matriz extracelular que protege a la comunidad, pero también debido a cambios en el estado fisiológico de las bacterias que forman parte de estas comunidades ${ }^{40,46,47}$.

\section{Etapas de la formación de biofilm}

La observación de la naturaleza sugiere que la enorme mayoría de los microorganismos son capaces de crecer formando agregados embebidos en una matriz que puede o no desarrollarse sobre superficies estables ${ }^{33,48}$. Sin embargo, en condiciones 


\section{Capítulo 1}

de laboratorio, sólo algunos microorganismos, como por ejemplo las bacterias del género Pseudomonas, forman biofilm en casi todas las condiciones de cultivo ${ }^{49}$. En el otro extremo, existen microorganismos capaces de formar biofilm sólo bajo condiciones muy específicas como por ejemplo Escherichia coli K12 o Vibrio Cholerae que forman biofilm en medios mínimos suplementados con aminoácidos ${ }^{49}$.

Existen una enorme cantidad de variables que pueden influir en la manera en la que un cultivo bacteriano se desarrolla en forma de biofilm: temperatura ${ }^{50-52}, \mathrm{pH}^{52}$, fuente de carbono ${ }^{53,54}$, la superficie sobre la cual se forma el biofilm ${ }^{50,55}$, entre otras. La formación de biofilm también depende del tipo de cultivo utilizado. No presenta las mismas características el biofilm formado en sistemas de cultivo estático en comparación al biofilm formado en sistemas de cultivo continuo. Más aún distintas velocidades de flujo en los cultivos continuos pueden determinar distintas características de los biofilms ${ }^{56,57}$. En los últimos años se ha empleado también la técnica de cultivo en medio semisólido como modelo de estudio de biofilms ${ }^{58-60}$. Las colonias formadas en este tipo de cultivo presentan características que son atribuidas a los biofilms bacterianos. En esta condición de cultivo la absorción de nutrientes y la eliminación de desechos se produce a través de la zona inferior de la colonia que está en contacto directo con el medio de cultivo agarizado. Los investigadores que desarrollaron este modelo de estudio lo proponen como un modelo que es más semejante a las condiciones naturales en que se desarrollan algunas bacterias, en comparación a los métodos tradicionales en donde el biofilm se desarrolla rodeado de medio de cultivo. Sin embargo, en el caso de los biofilms formados sobre el epitelio pulmonar o en las válvulas cardíacas los nutrientes que llegan a las bacterias que están formando el biofilm pueden hacerlo tanto desde la superficie de contacto como del medio circundante.

La formación de biofilm constituye un proceso que puede ser regulado a través de múltiples vías de señalización. La existencia de estos mecanismos actuando de manera simultánea e incluso convergente da cuenta de un proceso sofisticado y altamente controlado para sensar y responder a diversos estímulos ambientales ${ }^{61,62}$. En un artículo publicado en el año 2000, G. O'Toole, H. Kaplan y R. Kolter fueron los primeros en reconocer en la formación de biofilm un proceso de desarrollo bacteriano gobernado por una serie de pasos finamente organizados que podría asemejarse al del desarrollo de un organismo multicelular ${ }^{49}$.

Hoy en día el área de biofilms está dominada por el estudio del patógeno oportunista $P$. aeruginosa, el cual tal como mencionamos, representa una de las principales complicaciones en la salud de pacientes afectados por fibrosis quística. Otras bacterias Gram negativas como P. fluorescens, E. coli, V. cholerae y Caulobacter crescentus se destacan también como organismos de profundo estudio en el área de 


\section{Capítulo 1}

biofilms. Si bien a nivel molecular el proceso de formación de biofilm puede presentar grandes diferencias entre organismos diferentes, es posible establecer una serie de etapas definidas como parte del proceso global. En este contexto, la formación de biofilm puede ser dividida en: (1) adhesión reversible a la superficie; (2) adhesión irreversible a la superficie; (3) crecimiento y agregación de células en microcolonias; (4) maduración y formación de macrocolonias y (5) desprendimiento y dispersión de células para colonizar otras superficies (Figura 1.3) $)^{49}$.

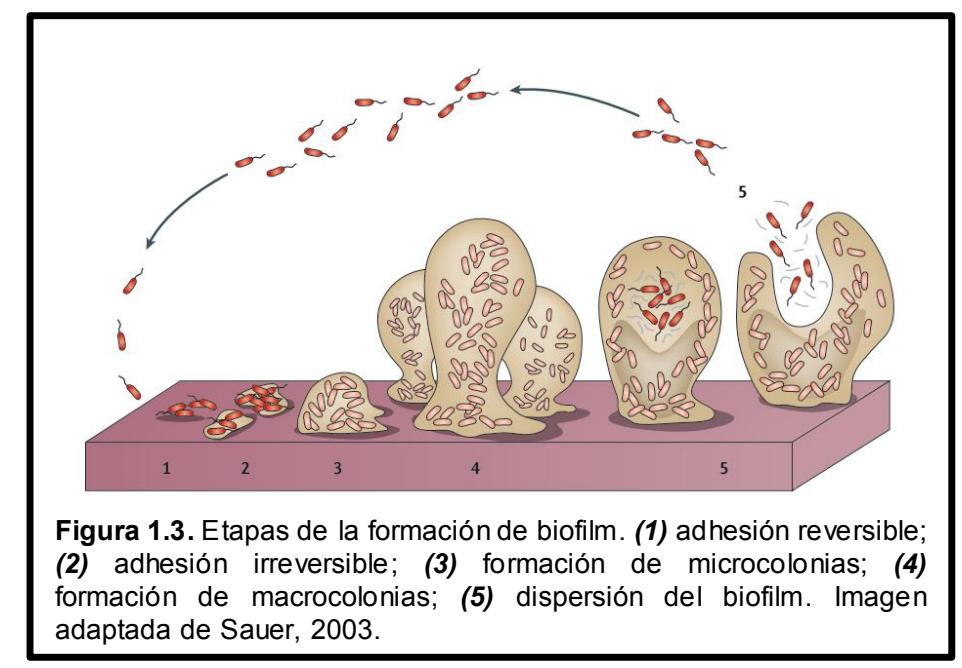

(1) Adhesión reversible a la superficie. En las bacterias móviles el flagelo constituye un elemento fundamental en las primeras etapas del proceso de formación de biofilms. Este elemento permite a la bacteria vencer la fuerzas electrostáticas repulsivas que la mantienen alejadas de la superficie y acercarse lo suficiente como para establecer interacciones reversibles ${ }^{57}$. En la etapa de adhesión reversible, el contacto con la superficie se suele producir a través de uno de los polos de la bacteria ${ }^{63,64}$. De todas las células que en un momento dado interactúan con la superficie, sólo algunas terminarán generando una adhesión suficientemente estable como para empezar el proceso de formación de biofilm.

(2) Adhesión irreversible a la superficie. En algunas bacterias se ha visto que para que el proceso de formación de biofilm progrese hacia un estado irreversible es preciso que la bacteria adopte un contacto con la superficie a través de su eje longitudinal. En $P$. fluorescens, se ha demostrado que sólo aquellas bacterias que establecen un contacto de este tipo con la superficie terminan adhiriéndose de manera irreversible ${ }^{65}$. La adhesina LapA está involucrada en esta etapa de la formación de biofilm, las cepas mutantes en esta adhesina se ven impedidas de progresar desde la etapa de adhesión reversible hacia al etapa irreversible ${ }^{66}$. En otras especies como $P$. aeruginosa o $P$. putida esta etapa 


\section{Capítulo 1}

está caracterizada por la aparición de un movimiento superficial de las bacterias mediado por estructuras contráctiles denominadas pili tipo IV 67,68 .

(3) Formación de microcolonias. La división celular de las bacterias adheridas a la superficie conlleva al crecimiento de la comunidad en pequeñas colonias denominadas microcolonias. En esta etapa se vuelven importantes las adhesinas involucradas en la interacción célula-célula, tal como es el caso de LapF en P. putida ${ }^{69}$. Asimismo, comienza a producirse una matriz extracelular que tiende a evitar la dispersión de las bacterias fundadoras de la colonia. En $P$. aeruginosa, la producción del exopolisacárido alginato es fundamental para establecer esta etapa del proceso ${ }^{70-72}$.

(4) Formación de macrocolonias. Esta etapa se caracteriza por la aparición de un matriz extracelular densa formada principalmente por polisacáridos, proteínas y ADN que da soporte a la estructura del biofilm ${ }^{73,74}$. Cada organismo presenta una composición particular. $P$ aeruginosa presenta una matriz cuyos principales componentes son los polisacáridos alginato, Pel (pellicle formation) y Psl (polysaccharide locus) además de ADN extracelualar ${ }^{75}$. Así mismo, en esta etapa la comunidad adopta estructuras rodeadas por canales a través de los cuales se facilita la absorción de nutrientes y la eliminación de desechos desde y hacia el medio extracelular.

(5) desarmado. Por último, cada biofilm constituye en sí mismo una fuente a partir de las cual se pueden desprender bacterias para colonizar otros nichos. Al día de hoy, esta constituye la etapa menos estudiada del proceso. Algunos autores afirman que el desprendimiento del biofilm podría estar favorecido por la aparición de zonas con escasa llegada de nutrientes ${ }^{49,76}$. Asimismo, a media que el biofilm aumenta en altura y cantidad de células, la fuerzas de corte generadas por la circulación de líquido a su alrededor se hacen más fuertes. Este aumento genera desprendimientos de agregados de bacterias que pueden adherirse a superficies cercanas e iniciar el proceso de formación de un nuevo biofilm ${ }^{77}$. Por ende, esta etapa está dirigida no sólo por cambios fisiológicos de las bacterias dentro del biofilm sino también por esfuerzos mecánicos a ls que están expuestos los biofilms ${ }^{56}$. 


\section{Conceptos generales sobre el segundo mensajero c-di-GMP}

El grupo de investigación dirigido por Moshe Benziman de la Universidad Hebrea de Jerusalén (Israel) determinó, en el año 1987, que la celulosa sintasa de la bacteria Acetobacter xylinum (actualmente Komagataeibacter xylinus) estaba positivamente regulada por un "nuevo dinucleótido circular"78 (Figura 1.4). Esa publicación constituye el primer reporte acerca del diguanilato cíclico (c-di-GMP) en la literatura y marcó el primer paso del desarrollo de un área de estudio de gran impacto en la microbiología de los últimos 30 años. Sin embargo, durante los años posteriores a su

Regulation of cellulose synthesis in Acetobacter xylinum by cyclic diguanylic acid

P. Ross*, H. Weinhouse*, Y. Aloni*, descubrimiento, la importancia de este hallazgo fue, cuando menos, subvalorada. No fue sino hasta comienzos del siglo XXI que la comunidad científica comenzó a tomar real dimensión de la importancia de este compuesto en
D. Michaeli*, P. Weinberger-Ohana*, R. Mayer*, S. Braun*, E. de Vroom $\dagger$, G. A. van der Marel $\dagger$, J. H. van Boom $\dagger$ \& M. Benziman* ${ }^{*}$

* Department of Biological Chemistry, Institute of Life Sciences, The Hebrew University of Jerusalem, 91904 Jerusalem, Israel † Gorlaeus Laboratories, PO Box 9502, 2300 RA Leiden,

The Netherlands

Figura 1.4. Portada del artículo de Moshe Benziman (Ross, P. et al. 1977) en el cual se describe por primera vez el rol de c-di-GMP en la regulación alostérica de la celulosa sintasa de Acetobacter xilium.

la biología bacteriana. Desde ese momento hasta hoy, el c-di-GMP ha emergido como una de las moléculas de señalización más comunes en el universo bacteriano ${ }^{79}$.

El c-di-GMP, o di-GMP cíclico o diguanilato cíclico es un dinucleótido de guanina ciclado a través de los átomos de carbono 3' y 5' de los residuos de ribosa que lo componen (Figura 1.4.a). Este segundo mensajero está involucrado en la regulación de procesos como la formación de biofilm, movilidad, expresión de factores de virulencia y control del ciclo celular ${ }^{80}$. El c-di-GMP es un actor clave en el control de los procesos que regulan los cambios en el estilo de vida de las bacterias incluyendo las transiciones de la vida libre a la vida sésil en comunidades formando biofilms ${ }^{79}$.

La molécula de c-di-GMP presenta una flexibilidad tal que le permite existir en una gran variedad de conformaciones. Estudios cristalográficos de proteínas unidas a c-diGMP muestran a esta última en conformaciones que van desde una estructura apilada hasta una completamente extendida ${ }^{81,82}$ (Figura 1.4.b y c). Esta propiedad de la molécula hace posible la existencia de una gran diversidad de dominios proteicos de unión a c-di$\mathrm{GMP}^{81}$. Si bien en concentraciones fisiológicas la molécula libre se encuentra como monómero, también es posible encontrarla en forma de dímeros. Esta propiedad es fundamental para los mecanismos de regulación alostérica que presentan algunas proteínas encargadas de la síntesis del segundo mensajero ${ }^{83}$. 

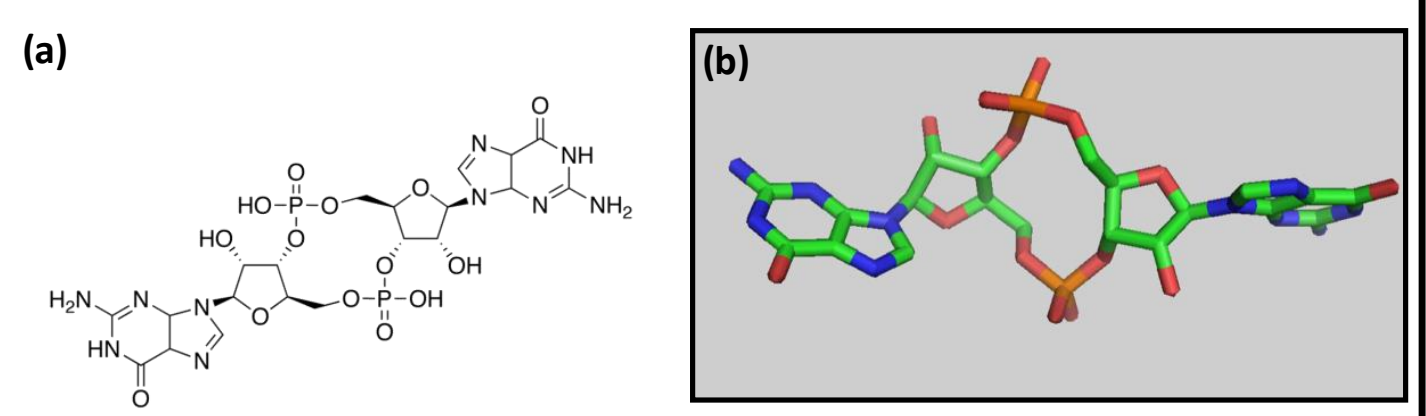

(c)
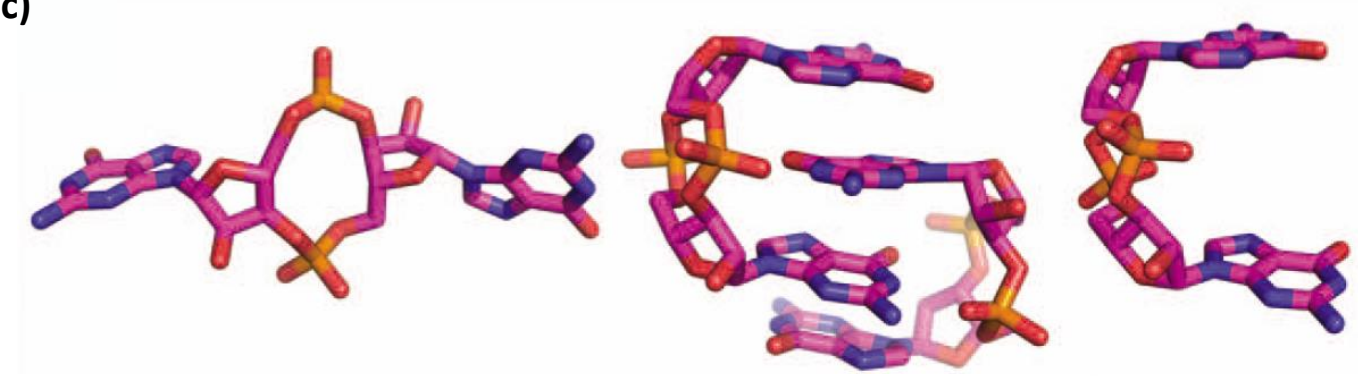

(ej: LapD, FimX, Ykul, BlrP1, TBD1265) (ej: PleD, WspR, PilZ, VpsT)

(ej: PilZ, XcClp)

Figura 1.4. Representaciones de la molécula de c-di-GMP. En la imagen (a) se puede observar los enlaces fosfodiéster formados entre los carbonos 3' y 5' de dos residuos de GMP. En la imagen (b) se observa una de las estructuras tridimensionales que puede adoptar la molécula de c-di-GMP (imagen adaptada de Chou, S. H. \& Galperin, M. Y, 2016). En (c) se visualizan representaciones tridimensionales obtenidas en diferentes estudios de cristalografía de diversas proteínas de unión a c-di-GMP. La imagen muestra algunas de las diversas conformaciones que puede adoptar esta molécula (Imagen adaptada de Krasteva, P. V., 2012).

Gran parte de lo que hoy sabemos acerca de c-di-GMP proviene de estudios realizados en $P$. fluorescens ${ }^{84}, P$. aeruginosa ${ }^{85}, E$. coli $i^{86}, C$. crescentus ${ }^{87}$ y V. cholerae ${ }^{88}$. Estas especies constituyen los principales modelos de estudio que han ayudado a la comprensión del rol de este segundo mensajero en el control de procesos bacterianos.

\section{Síntesis y degradación de c-di-GMP}

Los niveles celulares de c-di-GMP están determinados por las actividades antagónicas pero coordinadas de enzimas diguanilato ciclasas que lo sintetizan (GGDEF) y fosfodiesterasas específicas que lo degradan (EAL o HD-GYP) (Figura 1.5). En un organismo bacteriano dado, a menudo hay múltiples variantes de las dos enzimas, que están fuertemente reguladas por una variedad de señales externas e internas debido a la presencia de dominios sensores o reguladores específicos. 


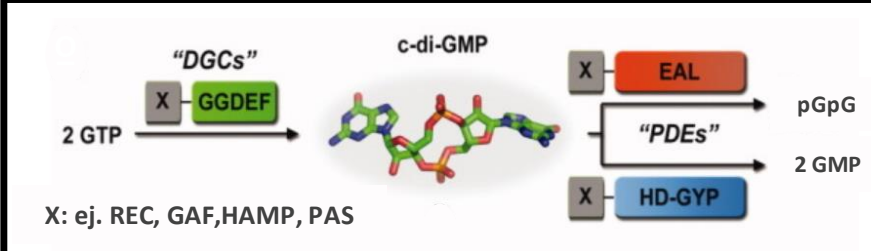

Figura 1.5. Las diguanilato ciclasas (DGCs) contienen dominios GGDEF que catalizan la síntesis de c-di-GMP a partir de dos moléculas de GTP. Las fosfodiesterasas (PDEs) pueden ser de dos tipos: (i) las que contienen dominios EAL catalizan la degradación de c-di-GMP hasta pGpG; (ii) las que contienen dominios HD-GYP degradan el c-di-GMP para dar dos moléculas de GMP. Imagen adaptada de Krasteva, P. V., 2012.

\section{Diguanilato ciclasas}

La reacción de síntesis de c-di-GMP está catalizada por dominios GGDEF (Figura 1.5). El mecanismo de reacción requiere la dimerización de estos dominos ${ }^{89}$. Durante este mecanismo, el acercamiento de dos moléculas de GTP unidas a cada uno de los sitios activos conduce a la condensación intermolecular y formación del dinucleótido cíclico con la concomitante liberación de dos moléculas de fosfato ${ }^{89}$. Hasta el momento, todas las diguanilato ciclasas descriptas dimerizan en estructura homodiméricas, sin embargo, Sarenko et al. recientemente han postulado la posibilidad de la formación de diguanilato ciclasas heterodiméricas ${ }^{90}$.

El domino GGDEF es denominado de esa manera en clara alusión a la secuencia aminoacídica encontrada en el sitio activo de las diguanilato ciclasas (Figura 1.6). Si bien el nombre acuñado para definir este dominio da la idea de una secuencia obligada para el desarrollo de la actividad, encontramos cierta variación dentro de la secuencia del sitio activo de múltiples diguanilato ciclasas. En particular se destaca la variación en la tercera posición de la secuencia en la cual es casi tan frecuente encontrar un residuo de aspartato (GGDEF) como un residuo de glutamato (GGEEF). Ambas secuencias resultan catalíticamente activas. Por este motivo también es frecuente encontrar al dominio diguanilato ciclasa denominado como $G G(D / E) E F^{83}$.

\section{(a) $G \rightarrow$ Guanina \\ (b) \\ $G \rightarrow$ Guanina \\ $D \rightarrow$ Aspartato \\ E $\rightarrow$ Glutamato $\mathrm{F} \rightarrow$ Fenilalanina \\ RxxD GGDEF

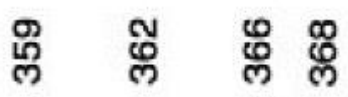

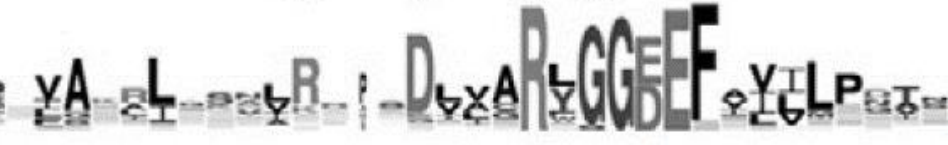

Figura 1.6. (a) Secuencia aminoacídica que define el nombre del dominio GGDEF. (b) WebLogo del alineamiento de 37 dominios GGDEF con actividad diguanilato ciclasa (adaptado de Adaptado de Schirmer, T., 2016). 


\section{Capítulo 1}

Los dominios GGDEF raramente son el único dominio presente en las diguanilato ciclasas. El caso típico, aunque poco común de los llamados dominio stand alone GGDEF es la proteína tDGC del organismo termófilo Thermotoga marítima ${ }^{91}$. En términos generales los dominios GGDEF suelen encontrarse en el extremo C-terminal de proteínas multidominio. En el extremo N-terminal de estas proteínas es común encontrar dominos relacionados con el sensado de señales ambientales (por ejemplo: PAS, GAF, CACHE, GLOBIN) o dominios de fosforilación como (por ejemplo, Rec) lo cual da cuenta del rol de estas proteínas como parte de mecanismos de transducción de señales.

Hasta el momento se han descripto al menos cuatro mecanismos que afectan la actividad de las diguanilato ciclasas mediante mecanismos de fosforilación y regulación alostérica positiva o negativa. (i) La diguanilato ciclasa de BpeGReg de B. pertussis posee un dominio GLOBIN sensor de oxígeno $\left(\mathrm{O}_{2}\right)$ en el extremo $\mathrm{N}$-terminal ${ }^{92}$. En ausencia de $\mathrm{O}_{2}$ BpeGReg se encuentra en forma de homodímero inactivo. La unión de $\mathrm{O}_{2}$ al dominio sensor produce cambios conformacionales que ubican a los dominios GGDEF de cada monómero en la posición adecuada para catalizar la formación de los enlaces fosfodiéster entre las moléculas de GTP que están unidas a cada protómero ${ }^{92,93}$. (ii) En sentido opuesto, la proteína DgcZ (antes llamada YdeH) de E. coli posee un dominio sensor de Zinc $\left(\mathrm{Zn}^{+2}\right)$ en el extremo N-terminal. En ausencia de $\mathrm{Zn}^{+2}$, DgcZ es un homodímero constitutivamente activo ${ }^{89}$. La unión de $\mathrm{Zn}^{+2}$ al dominio sensor $\mathrm{N}$-terminal altera la conformación de la proteína de manera tal que los dominios GGDEF quedan posicionados de un forma no compatible con la síntesis de c-di-GMP. Hasta el momento, constituye el único caso conocido de una diguanilato ciclasa inhibida por unión a ligando. (iii) La proteína PleD de C. crescentus constituye el modelo más estudiado de diguanilato ciclasas activadas por fosforilación. Esta enzima posee en el extremo N-terminal un dominio Rec (receiver). La forma no fosforilada de PleD se encuentra en forma de monómeros inactivos. La fosforilación del dominio Rec induce la dimerización y activación de esta diguanilato ciclasa ${ }^{94}$.iv) el último mecanismo de regulación descripto hasta el momento es la inhibición no competitiva generada como consecuencia de la unión de cdi-GMP al sitio alostérico I ubicado dentro del dominio GGDEF. Este sitio posee una secuencia característica $\operatorname{RxxD}$ (donde $x$ significa cualquier aminoácido) que se localiza dentro del dominio GGDEF a escasos 5 aminoácidos del sitio activo (Figura1.6.b). A pesar de la cercanía en términos de estructura primaria, el plegamiento secundario del dominio determina que el sitio I y el sitio activo queden localizados en sectores diametralmente opuestos. Por ende, su mecanismo de acción no está relacionado con un bloqueo estérico del sitio activo. Cada protómero de la diguanilato ciclasa es capaz de unir una molécula de c-di-GMP a través de este sitio. A su vez la formación de dímeros entre estas moléculas de c-di-GMP genera un aumento en la rigidez de la proteína que 
determina la imposibilidad de catalizar la reacción de síntesis ${ }^{95}$. Se ha sugerido que este mecanismo funciona como un modo de retroalimentación negativa tendiente a evitar el agotamiento de GTP que sería letal para la bacteria ${ }^{96}$. Este mecanismo de regulación está presente en una gran cantidad de diguanilato ciclasas como por ejemplo la ya mencionada PleD de C. crescentus ${ }^{97}$ y WspR de P. aeruginosa ${ }^{95}$.

\section{Fosfodiesterasas}

La actividad fosfodiesterasa de las enzimas encargadas de la degradación de cdi-GMP está asociada a dos clases de dominios: EAL y HD-GYP (Figura 1.5). El dominio EAL fue el primer dominio de degradación específica de c-di-GMP identificado y sigue siendo el mejor caracterizado. El producto de la actividad fosfodiesterasa del dominio EAL es el dinucleótido pGpG (5'-fosfoguanilil-(3',5')-guanosina). La hidrólisis posterior a GMP (guanosina monofosfato) es mucho más lenta y existen dudas acerca de su relevancia en situaciones fisiológicas ${ }^{98}$. Otra enzima, la oligoribonucleasa Orn estaría a cargo de la hidrólisis de $\mathrm{pGpG}$ a GMP ${ }^{99}$. Las fosfodiesterasas de dominio EAL requieren un catión divalente para la actividad enzimática. En la mayoría de los casos se encuentran iones $\mathrm{Mg}^{+2} \circ \mathrm{Mn}^{+2}$ coordinando parte del sitio activo de la enzima, mientras que el $\mathrm{Ca}^{+2} \mathrm{y}$ el $\mathrm{Zn}^{+2}$ inhiben eficazmente la actividad enzimática ${ }^{100}$. Los dominios EAL catalíticamente activos suelen tener una alta afinidad por c-di-GMP en el rango nanomolar, y la unión de c-di-GMP puede aumentar la afinidad de dimerización ${ }^{101}$. Aunque los monómeros pueden ser catalíticamente activos, la dimerización mejora sustancialmente la estabilidad de las proteínas y la actividad catalítica ${ }^{98}$.

Si bien la denominación utilizada para este dominio denota la importancia de los aminoácidos glutamato $(E)$, alanina $(A)$ y lisina $(L)$ en el sitio activo, es preciso destacar que el motivo catalítico podría ser extendido hasta un quinto aminoácido debido a que la mayoría de las fosfodiesterasas EAL presentan una arginina $(R)$ en la quinta posición $(\mathrm{EALxR})^{79,81}$.

El otro tipo de fosfodiesterasas de c-di-GMP son aquellas caracterizadas por la presencia de un dominio HD-GYP. A diferencias de las fosfodiesterasas EAL, las HDGYP son capaces de degradar la molécula de c-di-GMP hasta GMP teniendo a pGpG como un intermediario de la reacción ${ }^{102}$. El prototipo de fosfodiesterasa HD-GYP es el regulador de respuesta RpfG de Xanthomonas campestris ${ }^{103}$. Esta proteína es parte de un sistema de dos componentes que regula la expresión de múltiples factores de virulencia en esta bacteria ${ }^{104}$. La sustitución de cualquiera de ambos aminoácidos del par HD por alanina produce una pérdida total de la actividad enzimática y regulatoria ${ }^{105}$. Por el contrario, la sustitución de cualquiera de los aminoácido de la tríada GYP por alanina 


\section{Capítulo 1}

no tiene efectos sobre la actividad fosfodiesterasa. Sin embargo, estas sustituciones sí afectan la interacción de esta proteína con proteínas GGDEF a través de la cual regula la formación de biofilm y la expresión de factores de virulencia ${ }^{106}$.

\section{Proteínas de unión a c-di-GMP}

Pese a que la descripción de c-di-GMP como modulador alostérico de la celulosa sintasa data del año $1987^{78}$ no fue sino hasta el año 2006 que el primer dominio de unión a c-di-GMP fue descripto ${ }^{107}$. Michael Galperin y sus colaboradores demostraron que la proteína PilZ (PA2960) de P. aeruginosa es capaz de unir c-di-GMP y demostraron además que el dominio a través del cual lo hace está presente en una enorme cantidad de proteínas $^{107}$ (por ejemplo en la proteína BcsB del complejo de la celulosa sintasa descripta por Benziman y colaboradores ${ }^{78}$ ). El nombre PilZ acuñado para este dominio proviene del hecho de que éste es el único dominio presente en la proteína homónima. Posteriormente fue demostrado que la capacidad de unión a c-di-GMP reside en los motivos RxxxR y DxSxxG ${ }^{81,108,109}$.

En este punto del recorrido del estudio de c-di-GMP, las herramientas bioinformáticas de análisis de genomas tomaron una relevancia sobresaliente. Llamó la atención que mucho genomas bacterianos que contenían dominios GGDEF y EAL no contenían ninguna proteína con dominio PilZ predicho. Tal es el caso de bacterias de los géneros Brucella o Rickettsia en los cuales es posible identificar genes que codifican dominios GGDEF y EAL pero ninguno que codifique para un dominio PilZ ${ }^{107}$. Esta observación llevó a la conclusión de que debían existir dominios de unión a c-di-GMP alternativos a PilZ. Asimismo, en un trabajo publicado en el año 2008 Beyhan y colaboradores demostraron que la deleción de todos los genes que codifican para proteínas con dominio PilZ no elimina la regulación por c-di-GMP del fenotipo rugoso de las colonias de $V$. Cholerae ${ }^{110}$. Esta evidencia experimental también sugería la existencia de un dominio de unión a c-di-GMP alternativo a PilZ.

En ese momento, todas las hipótesis indicaban que dominios GGDEF, EAL y HDGYP degenerados podrían cumplir con las funciones de unión a c-di-GMP. Efectivamente, en los años subsiguientes comenzaron a describirse dominios catalíticamente inactivos que mantienen la capacidad de unir c-di-GMP.

La primera proteína de unión a c-di-GMP a través de un dominio GGDEF no conservado fue PelD de $P$. aeruginosa. Esta proteína está involucrada en la síntesis de exopolisacáridos y utiliza el sitio inhibitorio I del domino GGDEF degenerado e inactivo para unir c-di-GMP ${ }^{111}$. PopA de C. crescentus representa otro ejemplo de una proteína de unión a c-di-GMP que lo hace a través del sitio I de un dominio GGDEF degenerado. 
La localización espacio temporal de esta proteína está involucrada en la regulación del ciclo celular en C. crescentus ${ }^{112}$.

Dominios EAL degenerados capaces de unir c-di-GMP también han sido encontrados en una gran variedad de proteínas. FimX de $X$. campestris y LapD de $P$. fluorescens representan los casos más estudiados en la bibliografía. Los dominios EAL degenerados que mantienen la capacidad de unión a c-di-GMP son llamativamente muy diversos en secuencia ${ }^{81}$. En las mencionadas proteínas, si bien ambas tienen la capacidad de unir c-di-GMP, las secuencias de sus motivos EAL son notablemente diferentes: QAFLR en el caso de FimX y KVLSR en el caso de LapD. Esta observación demuestra una escasa conservación a nivel de secuencia en los dominos EAL de unión a c-di-GMP.

Existe un cuarto grupo de proteínas de unión a c-di-GMP que no pueden ser encasilladas en ninguno de los grupos mencionados anteriormente. Estas proteínas unen c-di-GMP a través de dominios que no pueden ser predichos de manera bioinformática, es decir no presentan homología de secuencia con ninguno de los dominios mencionados antes (PilZ, GGDEF o EAL) ${ }^{79,81}$. Tal es el caso del regulador transcripcional de $P$. aeruginosa FleQ el cual tras la unión de c-di-GMP desencadena un proceso que culmina en la regulación de la formación de biofilm ${ }^{113}$. Otro ejemplo de proteínas de unión a c-diGMP de este tipo lo constituye VpsT de V. choleare la cual está involucrada en la regulación de la movilidad y la formación de biofilm ${ }^{114}$.

Para completar el panel de receptores de c-di-GMP involucrados en procesos de señalización tenemos que mencionar los receptores basados en ARN: los riboswitches. En términos generales los riboswitches son secuencias de ARN no codificantes localizadas en el extremo 5' del ARNm que regulan la expresión génica a través de la unión específica de ciertos ligandos ${ }^{115}$. Si bien esta área de estudio no está tan desarrollada como las anteriores, el patógeno intestinal Clostridum difficile representa uno de los organismo donde la regulación génica a través de este mecanismo ha sido más estudiada. En este organismo, la unión de c-di-GMP al ARNm del gen pilA activa su transcripción favoreciendo la agregación celular ${ }^{116}$.

\section{Mecanismos de regulación a través de c-di-GMP}

El concepto más arraigado en torno a c-di-GMP como regulador del comportamiento bacteriano establece que altos niveles de c-di-GMP están asociados con un comportamiento sésil (biofilms) mientras que niveles bajos de c-di-GMP definen un comportamiento móvil. Si bien eso no presenta un error conceptual, hoy en día sabemos 


\section{Capítulo 1}

que esa visión es extremadamente simplista debido a que los procesos regulados por cdi-GMP raramente responden a cambios globales en los niveles del segundo mensajero.

Tal como describimos en los párrafos anteriores el metabolismo de c-di-GMP está controlado por la actividad antagónica de diguanilato ciclasas (GGDEF) y fosfodiesterasas (EAL o HD-GYP). La mayoría de los genomas bacterianos contienen diversa cantidad de estas enzimas, así como también secuencias degeneradas que pueden actuar como proteínas de unión a c-di-GMP. Por ejemplo, el genoma de E. coli K-12 contiene 29 secuencias con dominios GGDEF o EAL de las cuales 12 son diguanilato ciclasas y 13 fosfodiesterasas ${ }^{117,118}$. A pesar de esta multiplicidad de factores involucrados en el metabolismo global, la evidencia experimental indica que los mecanismos de control son altamente específicos ${ }^{119,120}$. Estas evidencias sugieren que para el control de un determinado proceso existe un par diguanilato ciclasa/ fosfodiesterasa específicamente abocado a ese mecanismo de regulación. Además, la actividad de este par tendría efectos a nivel local y no global en todo el citoplasma celular.

En algunos casos se ha demostrado que esta especificidad se consigue a través de la interacción física directa de una diguanilato ciclasa y un proteína efectora del proceso que controla ${ }^{121-123}$. Sin embargo, ese mecanismo no es suficiente para explicar el funcionamiento global de este segundo mensajero. Recientemente Dahlstrom et al. presentaron un análisis generalizado de las proteínas del metabolismo de c-di-GMP en $P$. fluorescens. El análisis de diversas condiciones de cultivos, sumado a experimentos de transcriptómica y ensayos de interacción proteína-proteína, permitió a los autores de este trabajo demostrar que no es posible comprender los procesos de regulación de c-diGMP bajo el concepto clásico "alto c-di-GMP = biofilm", "bajo c-di-GMP = sésil". Los procesos de regulación mediante este segundo mensajero siguen un patrón multimodal que incluye interacciones proteína-proteína, regulación transcripcional y regulación por unión a ligando ${ }^{124}$. Sarenko et al. también abordaron el problema del control global a través de c-di-GMP mediante de un análisis generalizado de diguanilato ciclasas y fosfodiesterasas en E. coli. En este caso demostraron la existencia de pares de diguanilato ciclasa/fosfodiesterasa específicos para el control de procesos celulares y otros grupos inespecíficos que estarían encargados del mantenimiento de los niveles globales de c-di-GMP dentro de ciertos valores ${ }^{90}$. Ambos trabajos han resultado reveladores para el área de estudio de c-di-GMP por demostrar lo complejo de la red de regulación de la que participa este segundo mensajero. 


\section{LapA, una adhesina involucrada en la formación de biofilm en $P$. fluorescens}

Nota: en el Anexo 5 encontrará un esquema del funcionamiento de las proteínas Lap tal como ha sido descrito en $P$. fluorescens. Este esquema puede ser cortado o impreso y será útil para comprender y analizar el funcionamiento de este sistema y los experimentos realizados en este trabajo de Tesis.

$P$. fluorescens es una bacteria Gram-negativa que puede ser aislada tanto en ambientes acuáticos como terrestres ${ }^{125}$. Frecuentemente es encontrada asociada a raíces de plantas en las cuales actúa protegiéndolas del ataque de ciertos agentes patogénicos y promoviendo su crecimiento ${ }^{125}$. En el año 2007 el grupo liderado por George O'Toole de la Universidad de Dartmouth (Hanover, New Hampshire, Estados Unidos) describió que el fosfato inorgánico presente en el suelo actúa como una señal que regula los niveles citoplasmáticos de c-di-GMP en $P$. fluorescens ${ }^{126}$. Este trabajo demuestra que la limitación de fosfato inorgánico en el medio de cultivo induce la expresión de la fosfodiesterasas RapA, y como consecuencia de ello se reducen los niveles de c-di-GMP que conducen a la inhibición de la formación de biofilm ${ }^{126}$. Este mecanismo es dependiente de la adhesina gigante LapA (large adhesin protein $A)^{126}$. El estudio de esta respuesta ha sido el puntapié inicial para la descripción de uno de los mecanismos de regulación a través de c-di-GMP más detallados que conocemos hasta el momento: el sistema formado por las proteínas LapD, LapG y LapA.

LapA es una proteína de membrana de $520 \mathrm{kDa}$ de la familia de las adhesinas y toxinas RTX (repeats-in-toxins) que es secretada a través de un sistema de secreción tipo I y constituye, bajo ciertas condiciones, la principal adhesina de $P$. fluorescens. A lo largo de su gran extensión encontramos diversos dominios involucrados en la secreción, localización y formación de biofilm. Gran parte de la estructura de LapA está formada por una región de 37 repeticiones de 100 aminoácidos cada una ${ }^{127}$. Hacia el extremo Cterminal encontramos un dominio de unión a calcio (Calx- $\beta$ ), un dominio del tipo factor $A$ de von Willebrand (VWA), un dominio RTX y secuencias de señalización para el sistema de secreción tipo I (Figura 1.7).

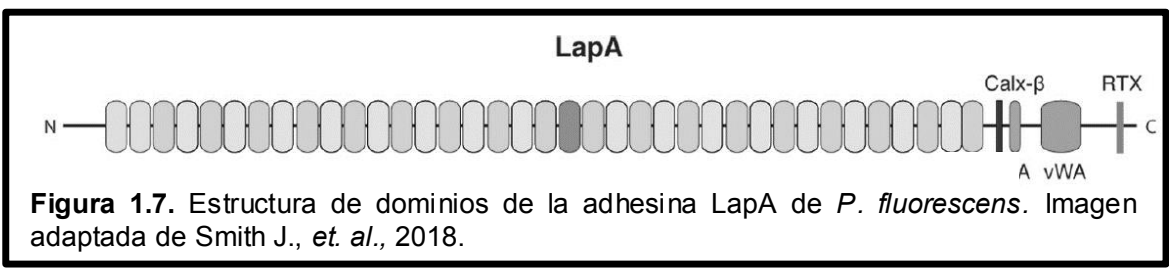




\section{Capítulo 1}

El dominio Calx- $\beta$ fue originalmente descripto en canales intercambiadores $\mathrm{Na}^{+} / \mathrm{Ca}^{+2}$ en células eucariotas en donde se encuentra directamente involucrado en la unión a $\mathrm{Ca}^{+2128,129}$. Sin embargo, en lo que respecta a la adhesina LapA, su función es desconocida ya que la deleción de este dominio no altera la localización de la proteína ni la habilidad de $P$. fluorescens de formar biofilms ${ }^{127,130}$.

Los dominios VWA mejor caracterizados forman parte de proteínas extracelulares de células eucariotas y están involucrados en la adhesión celular y en interacciones proteína-proteína ${ }^{131}$. Este dominio también ha sido encontrado en bacterias Gram positivas como Streptococcus agalactiae en donde está involucrado en la adhesión a células epiteliales $^{132}$. Asimismo, ha sido descripto en bacterias Gram negativas como $P$. aeruginosa en donde el dominio vWA es necesario para la correcta localización de la proteína PilY1 en la membrana plasmática ${ }^{133}$. En el caso de LapA de $P$. fluorescens, este dominio no está involucrado en la localización de la adhesina sobre la membrana plasmática pero sí es necesario para la formación de biofilm ${ }^{127}$.

El dominio RTX es un dominio de unión a $\mathrm{Ca}^{+2}$ encontrado en muchas toxinas y grandes adhesinas que consiste en un número variable de repeticiones de la secuencia rica en glicina $G G x G x D x x x^{134}$. Según un reciente trabajo publicado por el grupo dirigido por Peter Sebo del Instituto de Microbiología de la Academia de Ciencias de la República Checa, el plegamiento de este dominio en el espacio extracelular rico en $\mathrm{Ca}^{+2}$ constituye la fuerza impulsora para el pasaje de grandes proteínas a través del canal del sistema de secreción tipo $\mathrm{I}^{135}$. Los trabajos en $P$. fluorescens reflejan que el dominio RTX podría tener un rol similar en LapA ya que la deleción de esta porción reduce significativamente la localización sobre la membrana plasmática ${ }^{127}$.

\section{Secreción de LapA a través de un sistema de secreción tipo I}

Como mencionamos en la sección anterior, la adhesina LapA es secretada desde el citoplasma a través de un sistema de secreción tipo I (T1SS) ${ }^{126}$. Los genes que codifican para los componentes de este sistema de secreción ( $l a p B$, lapE y lapC) se encuentran codificados en la región adyacente a la adhesina $\operatorname{LapA}^{63}$. A diferencia de otros efectores del T1SS, LapA no es eyectada directamente al espacio extracelular. Esta adhesina constituye el primer caso descripto de un efector del sistema de secreción tipo I secretado en 2 pasos $^{136}$. Esta característica es lo que le da al sistema de proteínas Lap la versatilidad necesaria para controlar la formación de biofilm. LapA es retenida en el canal formado por la proteína LapE del sistema de secreción tipo I de manera tal que su extremo N-terminal queda expuesto al espacio periplasmático (Figura 1.8) ${ }^{136}$. El extremo opuesto C-terminal, rico en dominios involucrados en adhesión y formación de biofilm 
queda expuesto al espacio extracelular. En el extremo Nterminal LapA posee una estructura fundamental para el funcionamiento de todo el sistema: el Módulo de Retención (Figura 1.8). plegamiento de esta región genera una estructura globular que, por su tamaño, es incapaz de atravesar el canal del sistema de secreción tipo I $^{136}$. De esta manera, el Módulo de Retención evita la secreción prematura de LapA en condiciones

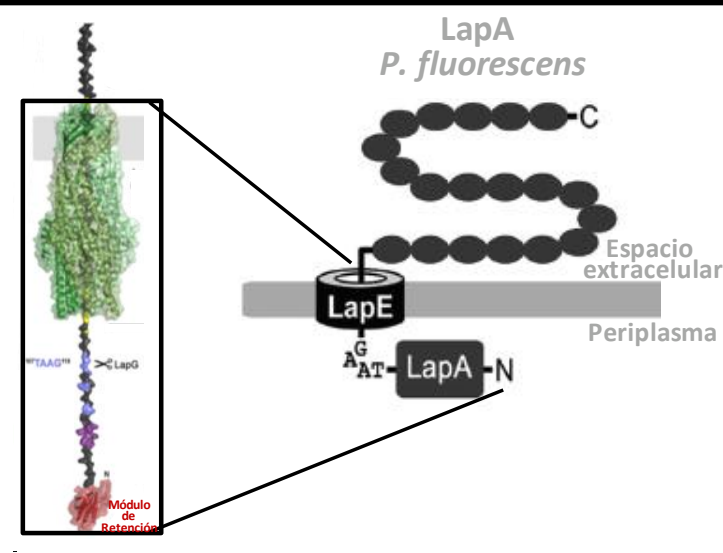

Figura 1.8. Esquema de la adhesina LapA de $P$. fluorescens anclada al canal formado por LapE en la membrana externa. La presencia del Módulo de Retención en el extremo N-terminal, localizado hacia la región periplasmática, impide la secreción prematura de la adhesina. Imagen adaptada de Smith J., et. al., 2018. óptimas para la formación de biofilm.

\section{LapD y LapG regulan la localización de LapA}

LapD es una proteína transmembrana localizada en la membrana interna que funciona como sensor de la concentración intracelular de c-di-GMP ${ }^{84}$ (Figura 1.9). En su porción citoplasmática presenta un dominio EAL y un dominio GGDEF ambos degenerados y catalíticamente inactivos ${ }^{84}$. La porción citoplasmática de LapD está conectada al dominio periplasmático a través de un dominio HAMP, dominio encontrado habitualmente en proteínas transmembrana de transducción de señales ${ }^{137,138}$.

El tercer actor de este mecanismo de regulación es la proteasa periplasmática LapG (Figura 1.9). Esta proteasa localizada en el espacio periplasmático es capaz de interactuar físicamente con la porción periplasmática de LapD ${ }^{130}$.

Cuando los niveles citoplasmáticos de c-di-GMP son elevados, LapD une el segundo mensajero a través de su domino $E A L^{84}$. La unión de c-di-GMP en el lado citoplasmático de LapD genera un cambio conformacional que se transmite desde el citoplasma hacia el periplasma a través del domino HAMP84,139,140.

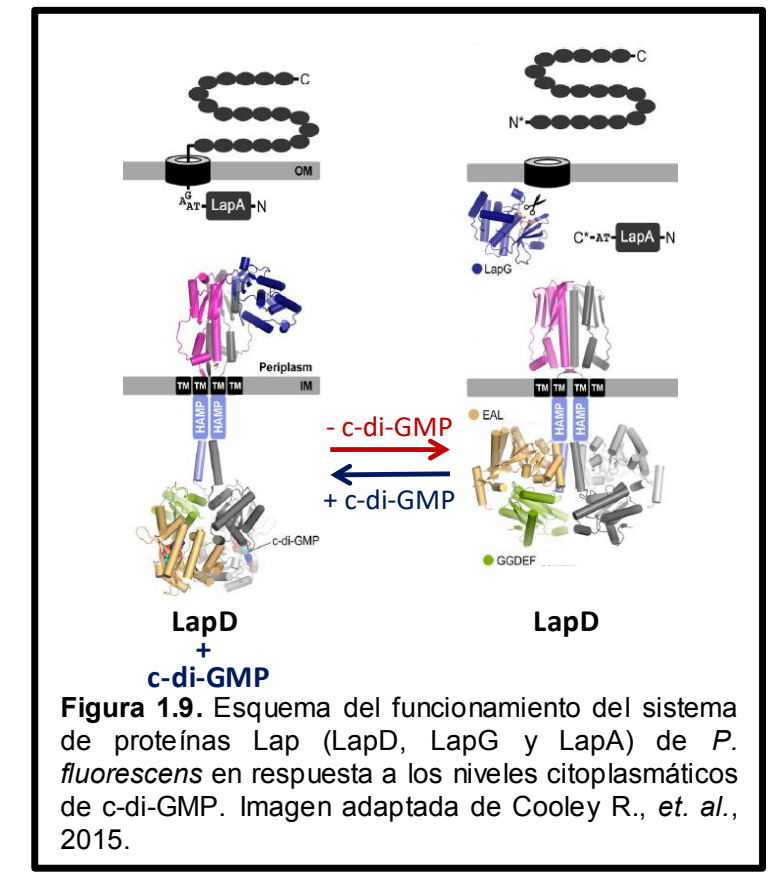




\section{Capítulo 1}

En estas condiciones, el dominio periplasmático de LapD adopta una conformación tal que le permite mantener retenida a LapG e inhibe de esta manera su libre circulación a través del periplasma ${ }^{139-141}$ (Figura 1.9, izquierda). LapA, en estas condiciones (altos niveles de c-di-GMP en el citoplasma), se mantiene localizada sobre la membrana plasmática. De esta manera $P$. fluorescens a través de la adhesina LapA es capaz de adherirse a las superficies y formar biofilm.

Cuando la bacteria se encuentra en condiciones desfavorables para su desarrollo y multiplicación, como por ejemplo en ambientes limitados en fosfato, la concentración citoplasmática de c-di-GMP se ve reducida ${ }^{126}$. En ausencia de c-di-GMP LapD modifica su conformación citoplasmática. Este cambio conformacional es trasmitido a través del dominio HAMP a la porción periplasmática la cual, en estas condiciones, no puede mantener unida a LapG (Figura 1.9, derecha). De esta manera, la proteasa LapG es libre de difundir a través del periplasma y cortar el extremo N-terminal de la adhesina LapA. Este corte libera el extremo que contenía el Módulo de Retención a través del cual LapA era mantenida sobre la membrana externa ${ }^{136}$. Al perder esta estructura, LapA es liberada de la membrana plasmática y así $P$. fluorescens pierde su principal adhesina y se ve anulada su capacidad de formación de biofilm ${ }^{63}$.

\section{GcbC interacciona físicamente con LapD}

Mediante la mutación generalizada de todas las posibles diguanilato ciclasas de $P$. fluorescens Newell et al. demostraron que, en un medio mínimo conteniendo glicerol y triptona como fuentes de carbono y nitrógeno, sólo cuatro de ellas están involucradas en el control de la formación de biofilm: WspR, GcbA, GcbB y $G_{c b C}{ }^{142}$. De ese grupo de cuatro diguanilato ciclasas sólo GcbB y GcbC regulan la formación de biofilm a través de LapA $^{142}$. El mismo estudio encontró 5 fosfodiesterasas cuya deleción generó aumentos en la formación de biofilm. Dado que $P$. fluorescens posee más de 40 proteínas que podrían estar involucradas en el metabolismo de c-di-GMP este escenario vuelve a plantear la incógnita acerca de cómo se coordina ese inmenso pool de diguanilato ciclasas, fosfodiesterasas y proteínas de unión para dirigir el control de un proceso determinado.

La profundidad con la que el grupo liderado por George O'Toole se ha abocado al estudio de las proteínas Lap en $P$. fluorescens ha llevado a la comprensión mecanística acerca del rol específico de GcbC en el control de la formación de biofilm ${ }^{123,142,143}$. GcbC es una diguanilato ciclasa localizada en la membrana interna que posee un dominio CACHE hacia el lado periplasmático y un dominio GGDEF en el lado citoplasmático ${ }^{143}$. Mediante estudios de mutagénesis de GcbC y LapD en combinación con ensayos de 
interacción proteína-proteína lograron determinar de qué manera GcbC regula en forma específica el funcionamiento de las proteínas Lap. Este estudio concluyó que GcbC y LapD interaccionan a través de una superficie que incluye la porción $\mathrm{N}$-terminal de una $\alpha$-hélice localizada en el dominio GGDEF de GcbC y otra $\alpha$-hélice ubicada en dominio EAL de LapD ${ }^{123}$ (Figura 1.10, superficie de GcbC = $\alpha$-hélice roja ). Mutaciones puntuales en los aminoácidos de GcbC involucrados en la interacción con LapD inducen una reducción en la formación de biofilm, no porque se reduzca la actividad de Gcbc sino porque se rompe la interacción LapD-GcbC ${ }^{123}$.

Estudios posteriores determinaron que GcbC es capaz de unir citrato a través de su dominio periplasmático CACHE y que la unión de este ligando potencia la interacción GcbC-LapD ${ }^{143}$. Asimismo, la interacción LapD-GcbC estimula la actividad diguanilato ciclasa de esta última ${ }^{143}$.

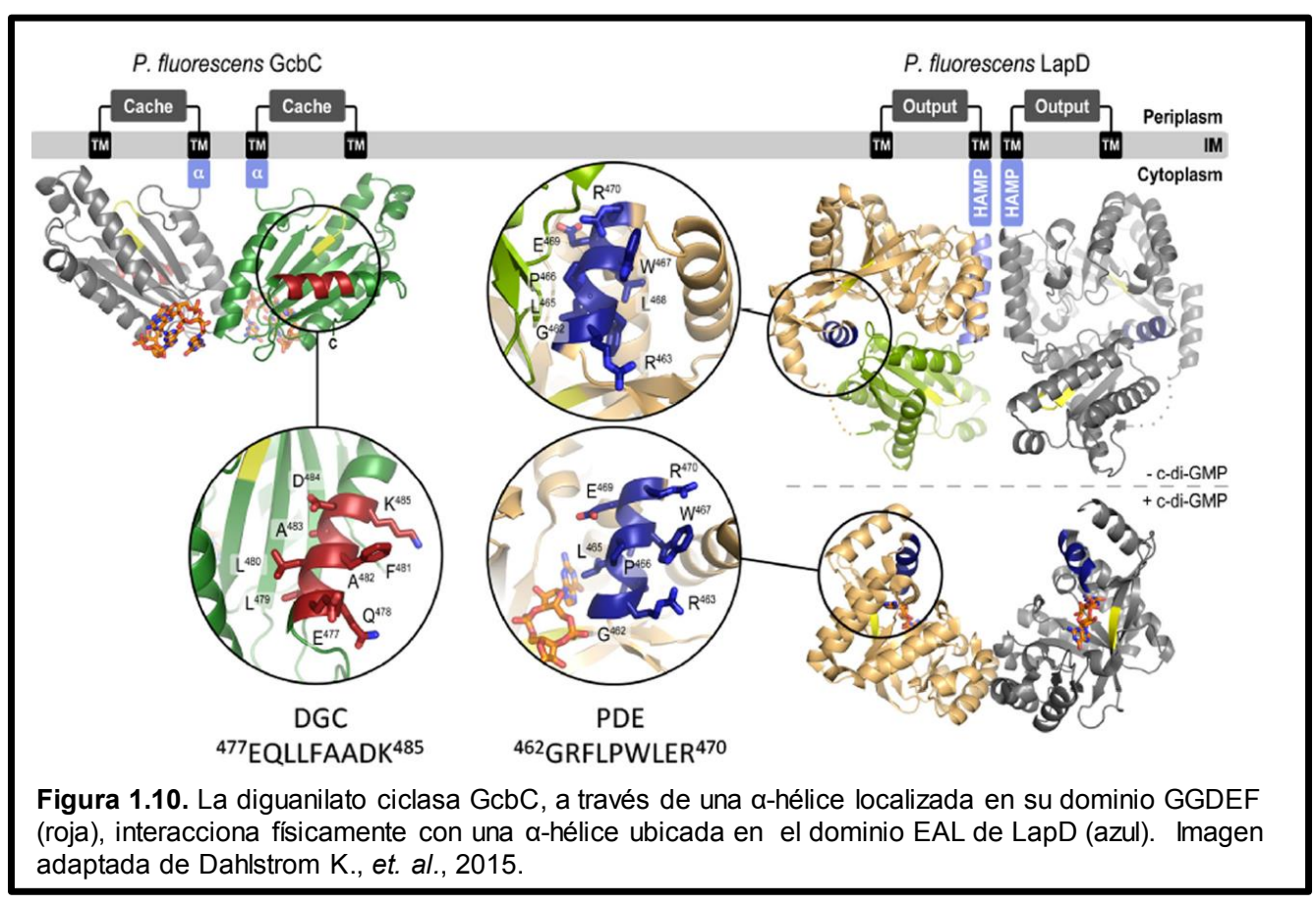

Frente a estos resultados el mecanismo de regulación de la formación de biofilm a través de las proteínas Lap queda desentrañado desde la señal que induce la formación de biofilm hasta el mecanismo que lo posibilita. En forma resumida, en primer lugar, GcbC une citrato a través de su dominio CACHE. La unión de este ligando estimula la interacción física entre GcbC y LapD lo cual a su vez incrementa la actividad diguanilato ciclasas de GcbC. De esta manera GcbC genera un aumento local (no global) de los niveles de c-di-GMP en las cercanías de LapD. Finalmente, la unión de LapD a c-di-GMP genera que LapG sea retenida por la porción periplasmática de LapD y en estas 


\section{Capítulo 1}

condiciones la adhesina LapA permanece localizada en la membrana plasmática contribuyendo significativamente al desarrollo de biofilm. 


\section{Bordetella spp.}

El género Bordetella está constituido por un grupo de organismos de destacada relevancia en salud humana y veterinaria debido a su capacidad de colonización del epitelio respiratorio ${ }^{144}$. La primera especie identificada, la cual da origen al género Bordetella fue, en el año 1906, Bordetella pertussis ${ }^{145,146}$. Este organismo fue aislado a partir de un paciente que presentaba signos de catarro y posteriormente fue identificada como el agente causal de la tos convulsa. Si bien en un principio fue catalogada como Haemophilus pertussis finalmente fue clasificada dentro de un género propio al cual se definió como Bordetella (en honor a su descubridor Jules Bordet) y se acuñó la denominación que conocemos hasta el día de hoy: Bordetella pertussis.

Bordetella bronchiseptica fue aislada por primera vez en el año 1910 de un perro que presentaba síntomas de moquillo ${ }^{147}$. Originalmente fue catalogada con el nombre de Bacillus bronchialis, luego como Bacillus bronchisepticus y finalmente tal como la conocemos hoy en día Bordetella bronchiseptica ${ }^{148}$.

Se han descripto 13 especies dentro del género Bordetella: $B$. pertussis, $B$. bronchiseptica, B. parapertussis (humana), B. parapertusis (bovina), B. avium, B. hinzii, B. holmesii, B. trematum, B. pseudohinzii, B. bronchialis, B. flabilis, B. sputigena y $B$. ansorpii $^{144,149}$.

A pesar de que el número de especies agrupadas dentro del género fue aumentando a través de los años, los estudios de patogénesis, biología molecular y epidemiología se han enfocado en las denominas "Bordetellas clásicas": B. pertussis, $B$. parapertussis y $B$. bronchiseptica. El motivo de este sesgo se debe fundamentalmente a que estas son las especies de mayor relevancia para la salud humana y animal. Otras especies, como $B$. holmesii o $B$. hinzii, están empezando a tomar relevancia y el número de investigaciones se incrementa año a año debido a la aparición cada vez más común de aislamientos provenientes de pacientes humanos ${ }^{150-152}$.

El análisis genómico de $B$. pertussis, B. parapertussis y $B$. bronchiseptica ha llevado a los investigadores a proponer que $B$. bronchiseptica es el ancestro evolutivo común de las otras dos especies ${ }^{153}$. Durante este proceso evolutivo, $B$. pertussis y $B$. parapertussis redujeron significativamente el tamaño de su genoma de manera tal de perder algunas funciones y reducir su rango de huéspedes. Esta es probablemente la causa que explica el gran rango de huéspedes que presenta $B$. bronchiseptica y la especificidad que presentan las otras dos especies ${ }^{153}$. Por otro lado las tres especies presenta un repertorio similar de factores de virulencia ${ }^{144}$. Entre ellos encontramos las adhesinas hemaglutinina filamentosa (FHA), pertactina (PRN), fimbria (Fim), factor de colonización traqueal; las toxinas como adenilato ciclasa $(A C)$, toxina dermonecrótica 


\section{Capítulo 1}

(TDN), citotoxina traqueal y un regulador de la mayoría de los factores de virulencia: el sistema de dos componente BvgAS ${ }^{144}$.

Estas características compartidas constituyen uno de los elementos más importantes que justifica el uso de $B$. bronchiseptica como un modelo de estudio de $B$. pertussis. Esta última posee sólo un reservorio natural conocido, los seres humanos. Esto implica un obstáculo importante para el estudio de la biología de la bacteria. Si bien el modelo de infección murino es utilizado como modelo de estudio de $B$. pertussis, son necesaria dosis bacterianas extremadamente altas para garantizar la colonización del tracto respiratorio del animal de experimentación. Por este motivo, la bibliografía reporta proyectos de investigación en donde $B$. bronchiseptica es utilizada como modelo de estudio debido a que es un patógeno natural de animales de investigación como ratas y ratones.

\section{Bordetella bronchiseptica.}

Bordetella bronchiseptica es un pequeño cocobacilo $(0,2 \mu \mathrm{m}$ por $0,7-1 \mu \mathrm{m})$ Gram negativo perteneciente a la subclase $\beta$ de las Proteobacterias. La clasificación taxonómica la ubica además como miembro del orden de las Burkholderiales dentro de la familia Alcaligenaceae. B. bronchiseptica es principalmente un patógenos de animales (mamíferos terrestres acuáticos y aves) ${ }^{154}$. Presenta un rango de huéspedes notablemente amplio que incluye desde animales domésticos como gatos, perros, cobayos y conejos; animales silvestres como ratones y ratas; animales de campo como cerdos, ovejas, caballos, pavos y hasta animales salvajes como zorros, zorrinos, osos, koalas y animales marinos como focas ${ }^{144,155,156}$. Si bien este rango de hospedadores es amplio, no todos los casos de infecciones reportan signos de enfermedad. Tal es el caso de los aislamientos provenientes de aves y mamíferos salvajes en donde no se observan señales que indiquen el desarrollo de un enfermedad como consecuencia de la infección con $B$. bronchiseptica ${ }^{156}$.

Si bien $B$. bronchiseptica es capaz de infectar humanos, son pocos los casos reportados en comparación a los casos reportados con B. pertussis o B. parapertussis ${ }^{157}$. Asimismo, la incidencia de infecciones en humanos es menor que la reportada para otros mamíferos. La mayoría de los reportes de infección con $B$. bronchiseptica se producen en pacientes con fibrosis quística ${ }^{158,159}$ o en individuos inmunocomprometidos como por ejemplo pacientes con $\mathrm{VIH}^{160}$. Sin embargo, aunque con menor frecuencia, también se han detectado infecciones en individuos sanos e inmunocompetentes ${ }^{161-163}$. La mayoría de estas infecciones se producen en individuos que han estado en contacto con animales infectados ${ }^{164}$. 


\section{Modulación fenotípica, sistema de dos componentes BvgAS}

En el género Bordetella, muchos de los factores de virulencia conocidos están regulados por un locus denominado B-Bordetella virulence gene (bvg, antes designado vir por estar asociado con la regulación de la expresión de los factores de virulencia). Este locus bvg, que codifica para un sistema de dos componentes denominado BvgAS ( $S=$ Sensor de membrana; $A=$ Regulador de respuesta), fue identificado por Weiss et al. en 1989 cuando observaron que la inserción del transposón Tn5 dentro del mismo, abolía simultáneamente la síntesis de la toxina pertussis, FHA, AC y TDN ${ }^{165}$. Las bacterias que contienen mutaciones en el locus bvg dejan de expresar los genes bvg-activados y resultan menos infectivas y menos virulentas. Por este motivo se acuñó la denominación de fase avirulenta a aquella en la cual el locus bvg estaba inactivado y fase virulenta a aquella en la que el locus está activado ${ }^{166}$. Las fases también pueden ser denominadas como Bvg+ (la fase virulenta) o Bvg- (la fase avirulenta) Los genes característicos de la fase virulenta se agrupan dentro de una denominación llamada vag por sus siglas en inglés de virulence activated genes. En concordancia con esta denominación, aquellos genes que no están activados en fase virulenta pero sí lo están en fase avirulenta se agrupan dentro de la denominación vrg por virulence repressed genes.

El locus bvg codifica para la
proteína sensora (BvgS) y el regulador de respuesta $(B v g A)$ de un sistema de dos componentes denominado BvgAS (Figura 1.11). La proteína BvgS es una proteína integral de la membrana citoplasmática que forma homodímeros. Su extremo Nterminal está dirigido hacia el periplasma. En esta región contiene dos dominios receptores de señales del tipo Trampa de Moscas Venus (VTF) ${ }^{167}$ que se comunican a la porción citoplasmática a través de un dominio tipo PAS (PerARNT-Sim) $)^{167}$. El mencionado dominio PAS traduce las señales externas en una cadena de fosforilaciones que comienzan

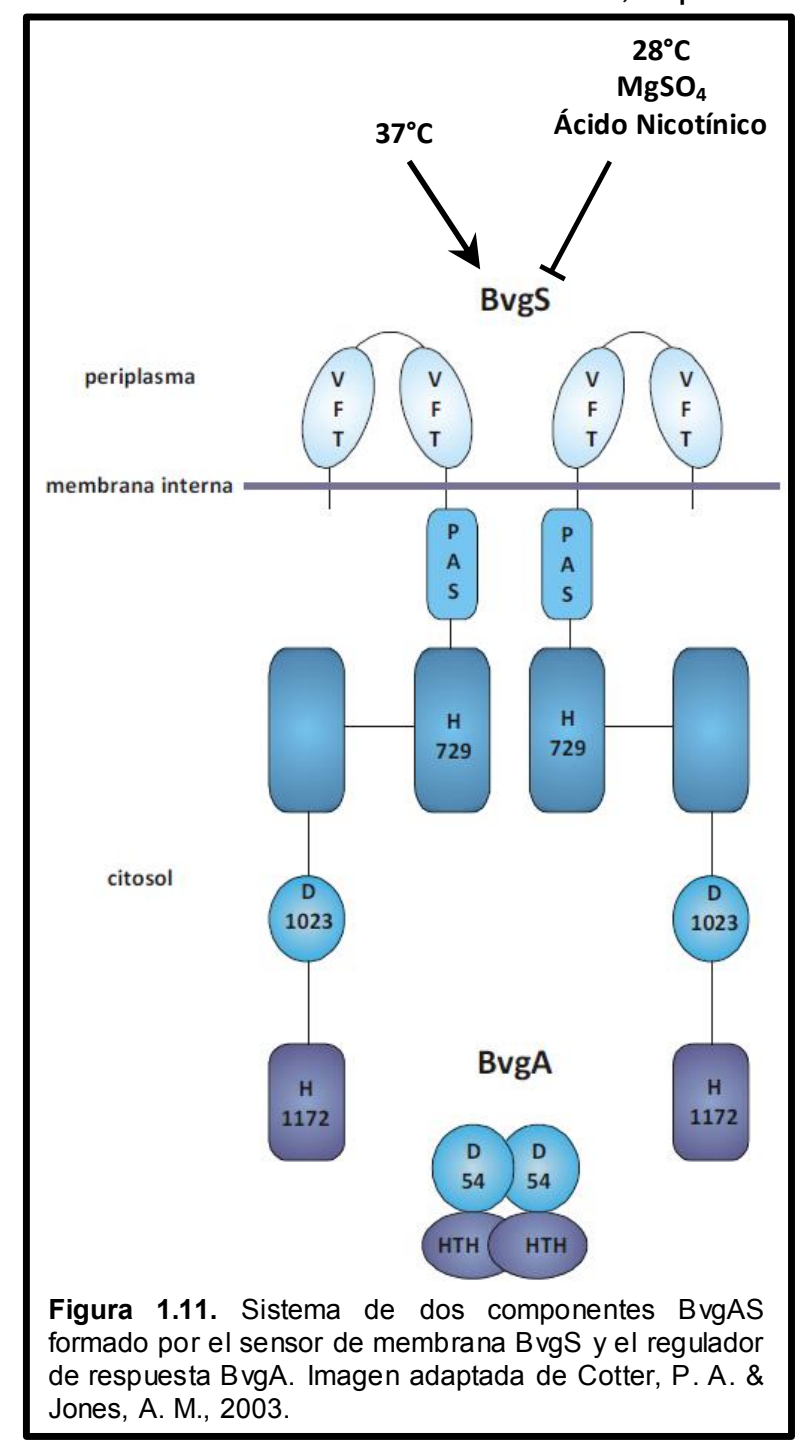




\section{Capítulo 1}

por la auto fosforilación dependiente de ATP de un residuo conservado de histidina (H729), prosigue por la fosforilación de un dominio receptor, para finalmente concluir en la fosforilación de un dominio fosfotransportador $\mathrm{Hpt}^{167}$. La trasferencia de grupos fosfato desde el dominio quinasa hasta el regulador de respuesta puede ser retardada mediante un mecanismo controlado por el dominio receptor. La autofosforilación de este dominio retarda la transferencia del grupo fosfato. Finalmente, la señal de fosforilación es transferida al residuo aspartato D54 del regulador de respuesta BvgA el cual, es su estado fosforilado (BvgA P) activa la expresión de los ya mencionados factores de virulencia regulados por este sistema.

BvgA es una proteína citoplasmática de $23 \mathrm{KDa}$ que está presente en forma de homodímeros. La forma fosforilada de BvgA, BvgA P, es la que posee mayor afinidad por los sitios de unión presentes en los promotores de los genes que codifican para los factores de virulencia regulados por este sistema ${ }^{168,169}$. Como sitio de unión de BvgA P se ha descripto una secuencia TTTCCTA de siete bases y secuencias homólogas que se encuentran de manera directa o invertidas en los genes regulados por $\mathrm{Bvg}^{170}$. Esta secuencia se encuentra, en general, alejada del sitio de inicio de la transcripción sin embargo, una vez que se une un dímero de BvgA P a la secuencia consenso se unen luego sucesivos dímeros hasta alcanzar el sitio de unión de la ARN polimerasa ${ }^{171}$. La interacción de esta última enzima con la molécula de BvgA P adyacente al inicio de transcripción incrementa la eficiencia del inicio de la transcripción ${ }^{172}$.

Experimentos empleando mutantes que expresan constitutivamente las proteínas del sistema BvgAS, o por el contrario defectivos en la expresión del mismo muestran que la fase virulenta $(\mathrm{Bvg}+)$ es necesaria y suficiente para que se desarrolle la infección ${ }^{173}$ mientras que la fase Bvg- o avirulenta sería incapaz de iniciar la infección ${ }^{173-176}$. En el caso de $B$. bronchiseptica la fase avirulenta parece ser la más apta para el desarrollo de la bacteria en condiciones limitantes de cultivo. Estos datos sugieren que la función de BvgAS es sensar si la bacteria se encuentra dentro o fuera del tracto respiratorio del mamífero a fin de activar y reprimir la expresión de un perfil genético óptimo para sobrevivir en ese nicho. Dado que $B$. bronchiseptica y no $B$. pertussis ha sido encontrada fuera del hospedador se ha sugerido que la fase Bvg- en $B$. pertussis es un remanente evolutivo sin una función actual ${ }^{177}$. Sin embargo, resulta interesante que es posible obtener una proteína BvgS insensible a moduladores simplemente cambiando la histidina 570 por una alanina ${ }^{178}$. Hasta el momento no se han encontrado aislamientos de $B$. pertussis con esa mutación si no que por el contrario los aislamientos presentan un sistema de dos componentes sensible a los moduladores conocidos. Esto sugiere que este sistema de dos componentes tiene una función in vivo ${ }^{179}$. 
Hasta el día de hoy se desconoce cuáles serían las señales que podrían activar al sensor de membrana BvgS para desencadenar la cascada de fosforilaciones que conduce a la fosforilación de BvgA. Una hipótesis sugiere que BvgS podría estar constitutivamente activa e inhibirse o modularse por acción de algún ligando hasta hoy desconocido. En condiciones de laboratorio el sistema BvgAS está activo cuando Bordetella es crecida a $37^{\circ} \mathrm{C}$. Esto determina que Bordetella crece en fase virulenta (Bvg+). Si el medio de cultivo es suplementado con cantidades milimolares de sulfato de magnesio $\left(\mathrm{MgSO}_{4}\right)$ o ácido nicotínico se inhibe el sistema BvgAS y Bordetella crece en fase avirulenta (Bvg-) ${ }^{177}$. En estas condiciones se reduce la cantidad de BvgA P y esto es lo que genera la inhibición de la expresión de los factores de virulencia vag ${ }^{177}$. El crecimiento por debajo de $28^{\circ} \mathrm{C}$ también produce una inhibición del sistema BvgAS y un crecimiento en fase Bvg- ${ }^{-177}$.

Durante la activación del sistema BvgAS también se activa otro gen situado corriente abajo del locus, denominada bvgR. La proteína BvgR es responsable de la inhibición de la activación de diversos vrg, incluyendo aquellos involucrados en la síntesis del flagelo ${ }^{176,180}$. La deleción de este gen permite a $B$. bronchiseptica expresar simultáneamente los vrg y vag durante la fase virulenta de la bacteria. Esta expresión simultánea no es perjudicial para un correcto desarrollo de la infección ${ }^{180}$.

Si bien BvgR inhibe la transcripción de diferentes genes ${ }^{181}$, el análisis de su secuencia primaria no muestra la presencia de dominios descriptos con capacidad de unión a ADN. La predicción informática de BvgR muestra la presencia de un dominio EAL severamente degenerado. Algunos autores sugieren que podría presentar actividad fosfodiesterasa y a partir de esa actividad ejercer su regulación ${ }^{181}$. Sin embargo, teniendo en cuenta lo expuesto en esta introducción respecto a los requerimientos en secuencia para que un dominio EAL sea activo, nuestro grupo de trabajo ha propuesto como hipótesis que BvgR no posee actividad y que es probable que una c-di-GMP en lugar de degradarlo (tesis doctoral María de la Paz Gutiérrez, en curso).

\section{Regulación de la expresión de los factores de virulencia}

El funcionamiento del sistema de dos componentes BvgAS de Bordetella spp. fue en un principio considerado como un sistema de encendido/apagado de los genes de virulencia ${ }^{182-184}$. Sin embargo, el hallazgo de proteínas de expresión intermedia que no corresponden ni a los genes vag ni a los $v r g^{185}$ obligó a realizar una reformulación de la hipótesis referente al mecanismo de regulación mediado por BvgAS. Actualmente es considerado un sistema similar a un reóstato, capaz de regular la expresión de los factores de virulencia entre los extremos correspondientes a las clásicas fases de 


\section{Capítulo 1}

virulencia (Bvg+) y de avirulencia (Bvg-) y una tercera fase con un perfil de expresión propio denominada fase intermedia (Bvgi) (Figura 1.11) (186-188. $^{1}$

En esta última fase, se expresan algunos factores característicos de la fase Bvg+ así como también factores propios de Bvgi que no se expresan en ninguna de las otras dos fases (por ejemplo la adhesina BipA) 177,189,190. La proteínas BipA es el factor más característico de esta fase la cual se ha sugerido está involucrada en la transmisión en forma de aerosol de las bacterias entre los hospedadores ${ }^{190}$. Scarlato et al. han sugerido que cuando Bordetella se encuentra con un nuevo hospedador, las adhesinas deben ser expresadas en primer lugar para mediar la adhesión a los tejidos epiteliales, mientras que las toxinas no son expresadas hasta unas horas después ${ }^{191}$. Durante estas primeras horas la bacteria podría avanzar hacia un fenotipo Bvg+ completo o volver al fenotipo Bvg- si es eliminado nuevamente al ambiente. El cambio de promotores entre los factores de virulencia de manera de alterar la cinética de expresión de adhesinas y toxinas impiden la correcta infección de $B$. bronchiseptica en el modelo murino ${ }^{192}$. In vitro, la presencia de los moduladores ácido nicotínico o $\mathrm{MgSO}_{4}$ en concentraciones menores a las necesarias para inducir el crecimiento en fase Bvg- producen un inhibición parcial del sistema BvgAS que induce el crecimiento de Bordetella en fase Bvgi ${ }^{193}$.

Mediante el uso de genes reporteros y estrategias de transcriptómica se ha podido determinar el patrón de expresión de los genes regulados por el sistema de dos componente BvgAS ${ }^{194,195}$. Estos ensayos han sido realizados en condiciones in vitro utilizando ácido nicotínico $0 \mathrm{MgSO}_{4}$ para modular la actividad del sistema de dos componentes. La presencia de cantidades milimolares de estos compuestos induce una modulación del sensor BvgS que reduce la cantidad de BvgA P en forma proporcional a la concentración de los moduladores.

Si bien la modulación fenotípica de Bordetella spp. puede ser dividida en las ya mencionadas 3 fases de virulencia, los genes que se encuentran regulados por el sistema BvgAS han sido agrupados en cuatro clases de acuerdo con su cinética de expresión (Figura 1.12). En condiciones de cultivo in vitro B. bronchiseptica se encuentra en Bvg+ cuando es cultivada a $37^{\circ} \mathrm{C}$ en ausencia de moduladores. En estas condiciones, el sistema BvgAS está completamente activo lo cual genera la expresión máxima de genes que codifican adhesinas (genes de clase 2, como fhaB, fim2 y fim3, niveles de expresión indicados por la línea naranja) y toxinas (genes de clase 1, como cyaA-E, y bsc, niveles de expresión indicados por la línea roja). Asimismo, en estas condiciones se produce una expresión mínima de los genes de clase 3 y clase 4 (niveles de expresión indicados por líneas de color violeta y azul, respectivamente). En presencia de concentraciones de ácido nicotínico $\geq 2 \mathrm{mM}^{196}$ o de sulfato de magnesio $\geq 40 \mathrm{mM}$ Bordetella modula su fase de virulencia a Bvg-. En estas condiciones el sistema BvgAS está inactivo y las bacterias 
presentan una expresión máxima de genes de clase 4 y la expresión mínima de genes de clase 1, 2 y 3 . Por último, cuando $B$. bronchiseptica es cultivada en concentraciones intermedias los moduladores se encuentra en fase Bvgi ${ }^{196,197}$. En esta situación BvgAS está parcialmente activo y se caracteriza por la expresión máxima de genes de clase 2 y 3 y la expresión mínima de genes de clase 1, y 4 . El único gen de clase 3 caracterizado hasta el momento es $\operatorname{bipA}$, que es activado por BvgA en condiciones de fase Bvgi y reprimido por BvgA P en condiciones de fase $\mathrm{Bvg}+{ }^{189}$.

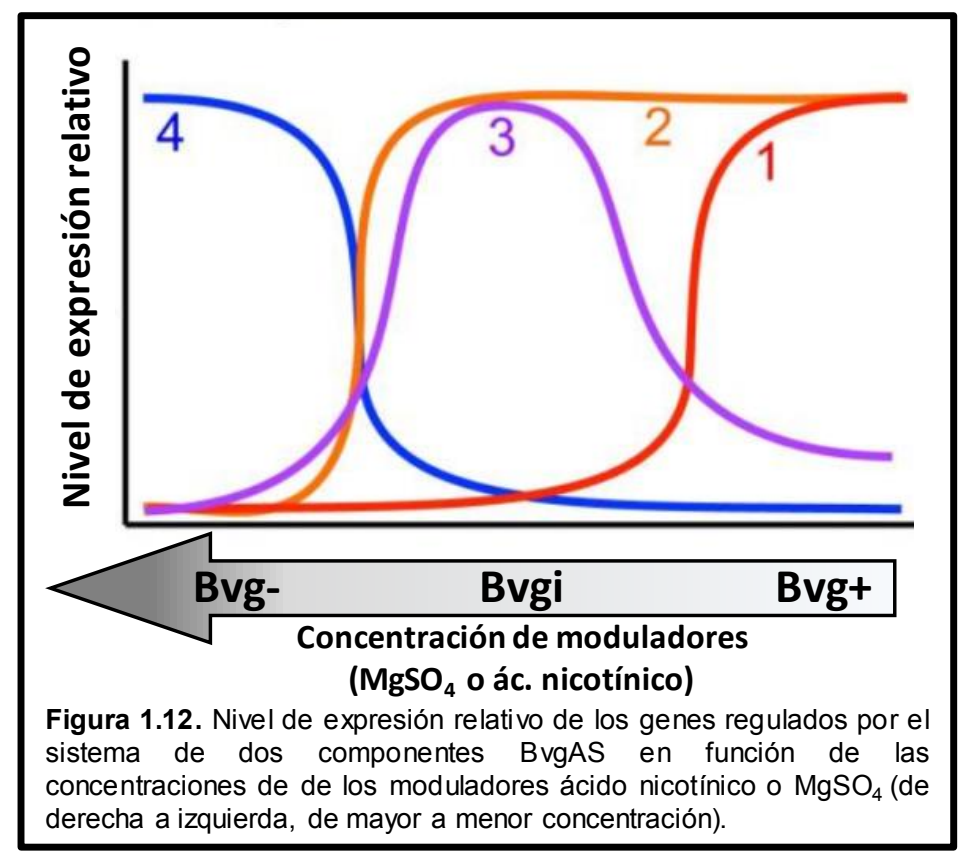

\section{Regulación del sistema de dos componentes BvgAS in vivo}

El rol del sistema de dos componentes in vivo aún hoy se encuentra en discusión. Como mencionamos anteriormente, los experimentos iniciales con cepas bloqueadas en Bvg+ y en Bvg- demuestran que la fase Bvg+ es necesaria y suficiente para establecer la colonización del tracto respiratorio ${ }^{173}$. Mas aún la expresión ectópica de los genes necesarios para la síntesis de un factor característico de fase Bvg- como es el flagelo resulta perjudicial para el establecimiento de la infección y conduce a una reducción en el número de UFC recuperadas de tráquea de ratones infectados ${ }^{198}$. Byrds et al. utilizando un sistema reportero de la activación de promotores regulados por BvgAS demostraron que la expresión del flagelo no se activa en ningún momento durante la infección en el modelo murino ${ }^{199}$. Si bien estos resultados sugieren que el sistema BvgAS no se modularía dentro de los huéspedes no es posible descartar que algunos genes clasificados como Bvg- estén sujetos a mecanismos de regulación aún desconocidos y puedan expresarse in vivo. Por ejemplo, en nuestro laboratorio hemos demostrado que 


\section{Capítulo 1}

la expresión simultánea de vag y vrg (incluido el flagelo) no es perjudicial para el desarrollo de la infección en ratones ${ }^{180}$. En este sentido, Abe et al. desarrollaron una estrategia experimental denominada IVET-IP (In Vivo Expressed-Tag ImmunoPrecipitation) basada en la utilización de anticuerpos anti c-Myc y bibliotecas genómicas que presentan secuencias fusionadas a la marca transcripcional c-Myc demostraron que B. bronchiseptica expresa factores Bvg- durante la infección en ratas ${ }^{200}$. Se desconoce si in vivo la activación de estos genes está controlada por el sistema BvgAS, pero estos resultados ponen de manifiesto la existencia de procesos de regulación complejos que aún no han sido determinados. Hasta el día de hoy no ha sido descripto ningún gen reprimido por el sistema BvgAS que sea indispensable para establecer la colonización de las vías respiratorias en ningún modelo animal analizado.

\section{Formación de biofilm en B. bronchiseptica}

La capacidad de persistencia es particularmente importante en el caso de $B$. bronchiseptica ya que se ha determinado, en varios modelos animales (ratas, ratones y cerdos), que esta bacteria es capaz de colonizar las vías respiratorias durante períodos prolongados de tiempo ${ }^{154,195,201-204}$ y en particular en ratones en donde se ha registrado que la infección no es posible de ser erradicada durante toda la vida de animal ${ }^{205}$. También se ha descripto la persistencia de la infección durante períodos prolongados en humanos ${ }^{159,206}$. Varios autores han relacionado esta característica con la capacidad de B. bronchiseptica de formar biofilms in vivo sobre el epitelio de las vías respiratorias $201,207,208$.

Uno de los factores indispensables para el establecimiento de un biofilm es la presencia de adhesinas que garanticen una apropiada interacción de la bacteria con la superficie ${ }^{209}$. Antes de comenzar con el estudio de biofilms, la comunidad científica de Bordetella reunió abundante información acerca del rol de algunos factores en la adhesión y colonización.

La Hemaglutinina filamentosa (FHA), codificada en el gen fhaB es probablemente la adhesina mejor caracterizada de Bordetella spp. Es una proteína de $220 \mathrm{kDa}$ que tal como su nombre lo sugiere presenta una estructura filamentosa organizada estructuralmente en 19 hojas $\beta$-plegadas que forman una estructura del tipo barril- $\beta$ que atraviesa la membrana externa de la bacteria ${ }^{210}$. A lo largo de su secuencia contiene diferentes dominios involucrados en el pegado a superficies del hospedador, así como también en la modulación de la respuesta inmune. En la región intermedia de su estructura posee un dominio denominado RGD que consiste en un triplete de arginina glicina - aspartato que media la unión de FHA a receptores miembros de la familia de las 
integrinas presentes en la superficie de macrófagos ${ }^{211,212}$. FHA también posee un dominio de reconocimiento de carbohidratos (CRD) que participa de la adhesión a células ciliadas del epitelio respiratorio así como también a macrófagos ${ }^{213,214}$. Un tercer dominio caracterizado por su rol en la adhesión es el dominio tipo lectina que estaría involucrado en la adhesión a células no ciliadas ${ }^{215}$. Experimentos de colonización realizados con mutantes en esta adhesina también demuestran su importancia como parte del proceso patogénico de $B$. bronchiseptica. Los ensayos de infección en ratas publicados por Cotter et al., demuestran que esta adhesina si bien no es necesaria para el establecimiento de la infección en la nariz sí lo es en tráquea ${ }^{216}$. FHA puede ser liberada de la membrana plasmática por la acción de la proteasa SphB1 de la familia de la superfamilia de la subtilisinas $^{217,218}$, sin embargo las señales y los mecanismos de control que gobiernan este proceso no son conocidos.

B. bronchiseptica, al igual que la mayoría de las bacterias Gram negativas, expresa proteínas de superficie de estructura filamentosa llamadas fimbrias (Fim) ${ }^{219}$. B. bronchiseptica presenta en su genoma al menos cuatro tipos diferentes de genes codificantes de fimbrias: $\operatorname{fim} 2, \operatorname{fim} 3, \operatorname{fim} X$ y $\operatorname{fim} A^{220}$. Los productos de estos genes son ensamblados y secretados a través de un único sistema, codificado por el locus fim $B C D$. Las secuencias codificantes de las distintas subunidades de las Fim y el locus fimBCD no son contiguos dentro del cromosoma de esta bacteria. Más aún, el locus fimBCD se encuentra dentro del operón FHA, lo cual sugiere un carácter co-transcripcional ${ }^{221}$. La deleción del locus fimBCD ha demostrado impedir la expresión en la membrana bacteriana de todos los tipos de fimbrias. Esto trae aparejado una disminución en la colonización bacteriana de tráquea de ratas ${ }^{220}$.

En forma casi simultánea Irie et al. y Misrha et al. demostraron que el sistema BvgAS regula la formación de biofilm en $B$. bronchiseptica ${ }^{222,223}$ y en $B$. pertussis ${ }^{223}$. Estos trabajos, así como resultados de nuestro propio grupo demuestran que en ensayos de formación de biofilm en microplaca la formación de biofilm es máxima en condiciones de cultivo Bvgi ${ }^{224}$.

El proceso de formación de biofilm en $B$. bronchiseptica puede ser comprendido en términos de las etapas de desarrollo que han sido explicadas previamente en este trabajo ${ }^{49}$.El análisis secuencial de diferentes tiempos de formación de biofilm muestra una etapa inicial de adhesión de bacterias aisladas a la superficie. En las etapas siguientes se observa el desarrollo de monocapas y a tiempos prolongados la formación de estructuras en 3 dimensiones embebidas en una matriz extracelular y rodeadas por canales $^{225,226}$. Misrha et al. demostraron que la cepa $B$. bronchiseptica bloqueada en fase Bvg- no presenta diferencias en la capacidad de formación de biofilm respecto a la cepa salvaje durante las primeras 4 horas de la formación de biofilm. Una mala interpretación 


\section{Capítulo 1}

de estos resultados llevó a los autores a proponer que la etapa inicial de formación de biofilm en $B$. bronchiseptica sería independiente del control del sistema BvgAS ${ }^{223}$. Ocho años después Nicholson et al. demostraron que en ese tiempo de la formación de biofilm se activan genes de la fase Bvg- (aun cuando el cultivo transcurre en condiciones $\mathrm{Bvg}+)^{226}$. Este resultado permite explicar la observación realizada años antes por Mishra et al. Sin embargo el concepto de que B. bronchiseptica posee una fase inicial de formación de biofilm independiente de BvgAS aún hoy sigue siendo sostenido por algunos autores de la comunidad científica que estudia Bordetella ${ }^{227}$. Por otro lado, el descubrimiento de que en condiciones de cultivo Bvg + se activan genes reprimidos por BvgAS que son característicos de la fase Bvg- pone de manifiesto la existencia de mecanismos de control que aún hoy no son comprendidos.

Tal como mencionamos antes, FHA y fimbria no sólo han sido caracterizadas por su rol como adhesinas, sino que también se ha evaluado su participación en la formación de biofilm. Ambas adhesinas se expresan tanto en fase Bvg+ como en fase Bvgi ${ }^{228}$ sin embargo su contribución a la formación de biofilm en $B$. bronchiseptica no es igual en ambas fases. FHA es especialmente importante en la formación de biofilm en fase Bvgi mientras que las fimbrias lo son en Bvg ${ }^{197}$. La función de FHA en la formación de biofilm no se conoce en detalle, sin embargo, se ha determinado que la toxina adenilato ciclasa (AC) es capaz de inhibir la formación de biofilm a través de su unión a FHA ${ }^{229}$. La deleción de cyaA en el background salvaje induce un aumento en la formación de biofilm en fase Bvg+. Sin embargo al deleción en el background $\Delta$ fhaB no genera el mismo aumento ${ }^{197}$. Hoffman et al. confirmaron posteriormente que la interacción del dominio adenilato ciclasa de $\mathrm{AC}$ con FHA inhibe la adhesión de esta última y el desarrollo de biofilm en fase $\mathrm{Bvg}+{ }^{229}$. En fase Bvgi donde no hay expresión de AC, FHA toma un rol mucho más preponderante $y$ en consecuencia la deleción de fha $B$ reduce significativamente la formación de biofilm ${ }^{197}$.

En etapas más avanzadas, el exopolisacárido producido por B. bronchiseptica (Bps) juega un papel fundamental en la formación de la matriz extracelular y en la maduración del biofilm ${ }^{230}$. Si bien este exopolisacárido no ha sido purificado para realizar un análisis estructural, la evidencia basada en la reactividad frente a anticuerpos anti$\mathrm{PNAG}^{225}$ y la susceptibilidad a enzimas sugiere que sería un polímero de $\mathrm{N}$-acetil-Dglucosamina unido mediante enlaces $\beta-(1,6)$ (PNAG o PGA) ${ }^{201,225}$. La síntesis del Bps depende del locus bpsABCD funcionalmente equivalente al locus pgaABCD de $E$. coli ${ }^{230,231}$. En ensayos de infección se pudo determinar que el Bps es necesario para la colonización y persistencia en nariz así como también para el establecimientos de biofilms robustos en esta zona de las vías respiratorias ${ }^{207}$. A diferencia de otros factores de virulencia mencionados anteriormente la expresión del locus bps $A B C D$ no se encuentra 
bajo el control de BvgAS ${ }^{232}$. La expresión del operón bpsABCD está bajo el control del factor de transcripción BpsR el cual inhibe la transcripción de los genes mencionados. La expresión de este regulador transcripcional está disminuida en bacterias formando biofilm respecto de las bacterias en estado planctónico ${ }^{232}$. Resulta interesante destacar que este regulador, BpsR, también controla el metabolismo de ácido nicotínico ${ }^{233,234}$.

Un segundo locus involucrado en la síntesis de un exopolisacárido ha sido involucrado en el proceso patogénico de $B$. bronchiseptica, aunque no en la formación de biofilm. Utilizando un modelo murino, Dewan et al. demostraron que el locus BB2918BB2934, involucrado en la síntesis de un polisacárido no caracterizado, es fundamental para el proceso de transmisión entre roedores ${ }^{235}$.

Otro de los componentes de la matriz extracelular que es necesario para la formación de biofilm en $B$. bronchiseptica es el ADN extracelular. La observación de que el agregado de ADNasa a los cultivos de $B$. bronchiseptica generaba una inhibición de la formación de biofilm llevó a Conover et al. a proponer que la matriz extracelular de los biofilms de Bordetella spp. debía contener ADN ${ }^{236}$. Por otro lado, el agregado de ADNasa a biofilms preformados sobre superficies de vidrio también produce el desarmado de la estructura de biofilm lo cual sugiere que este compuesto estaría involucrado en la estabilización de la estructura. Contrariamente, la presencia de ADNasa no tiene efectos en las primeras etapas (hasta las 6 horas) sugiriendo que el ADN no participa de la etapa inicial de adhesión a la superifice ${ }^{236}$. Para completar el análisis del rol de ADN en la formación de biofilm, Conover et al. realizaron un tratamiento con ADNasa a biofilms de 14 días formados in vivo en narices de ratones inoculados con B. bronchiseptica. El desarmado de estos biofilms también demostró la presencia de ADN extracelular en los biofilms formados in vivo ${ }^{236}$. En otras bacterias ha sido descripto que este proceso se produce a través de la lisis controlada inducida por la activación de profagos o bien a través de vesículas de membrana ${ }^{237,238}$. Se desconoce, hoy en día, si $B$. bronchiseptica usaría alguno de estos mecanismos para inducir la liberación de ADN hacia la matriz extracelular.

Con el objetivo de analizar la composición promedio de la matriz extracelular, Serra et al., mediante espectroscopía FTIR, demostraron que a medida que madura el biofilm aumenta la relación en composición de carbohidratos/proteínas lo cual indicaría que la matriz extracelular estaría compuesta principalmente por hidratos de carbono ${ }^{239}$. Este resultado es coherente con las descripciones mencionadas anteriormente que dan cuenta de la presencia de ADN y Bps en biofilm maduros.

La porina de membrana externa $\mathrm{OmpQ}$ también ha sido caracterizada como un factor importante para la maduración de los biofilms en $B$. bronchiseptica ${ }^{240}$.Si bien esta proteína no es importante en la adhesión a la superficie, ni en las etapas iniciales de la 


\section{Capítulo 1}

formación de biofilm, la deleción de $o m p Q$ genera defectos en la formación de biofilm a partir de las 48 horas en sistemas de cultivo en microplacas ${ }^{240}$.

Tal como se ha descripto en otro organismos ${ }^{46,241,242}$, la formación de biofilm en $B$. bronchiseptica es un proceso que está finamente regulado y que presenta un programa de desarrollo caracterizado por un perfil de expresión génica propio y diferente del perfil observado en bacterias planctónicas. Este tema ha sido abordado por un estudio de transcriptómica que determinó el perfil de expresión génica en diferentes etapas de la formación de biofilm ${ }^{226}$. Este estudio demuestra que el $33 \%$ de los genes de $B$. bronchiseptica presentan cambios en el patrón de expresión (activación o represión) en bacterias formando biofilm respecto de bacterias en estado planctónico ${ }^{226}$. Estos resultados confirman que la formación de biofilm en $B$. bronchiseptica es un proceso estrictamente regulado y en esta condición las bacterias presentarían diferencias fisiológicas respecto de las bacterias planctónicas. Entre los resultados más destacados de este trabajo encontramos que muchos genes regulados negativamente por el sistema BvgAS están activados durante las primeras etapas de la formación de biofilm. En particular se destaca la activación de fliA, flgS y flaA involucrados en la síntesis del flagelo ${ }^{226}$. Asimismo, se observó un aumento en el nivel de expresión del represor de los genes de virulencia BvgR y en concordancia con este resultado de determinó una reducción de la expresión de fimA, fimC, fimD, fim2, fim3, cyaA, fhaB, fhaC y bvgS 226 .

Otro factor descripto en la regulación de la formación de biofilm de Bordetella es el nucleótido ( $p$ )ppGpp. Esta molécula es un segundo mensajero involucrado en transducción de señales que coordinan respuestas relacionadas al crecimiento celular, supervivencia al estrés y virulencia en una variedad de bacterias ${ }^{243}$. El rol de este segundo mensajero ha sido determinado en $B$. pertussis, pero no en $B$. bronchiseptica. La deleción de relA y spoT, dos enzimas involucradas en la síntesis de ( $p$ )ppGpp genera defectos en la formación de biofilm, reduce la viabilidad en condiciones de limitación de nutrientes y aumenta la susceptibilidad al estrés oxidativo ${ }^{244}$. La observación microscópica de la cepa $\Delta r e l A \Delta s p o T$ mostró una disminución en la presencia de estructuras filamentosas en la membrana plasmática. Estas estructura no serían ninguna de las adhesina conocidas (FHA o fimbrias) por lo que se trataría de una estructura aun no caracterizada ${ }^{244}$.

En el año 2013 nuestro grupo de investigación describió el rol del segundo mensajero c-di-GMP en la biología de $B$. bronchiseptica. En ese trabajo se obtuvieron cepas con expresión inducible de proteínas que sintetizan (Bb-DGC) o degradan (BbPDE) c-di-GMP induciendo una situación de altos o bajos niveles del nucleótido respectivamente. Sobre estas cepas se analizó la capacidad de formar biofilm en placas multipocillo mediante la técnica de cristal violeta. Dado que la regulación de la formación 
de biofilm por parte de BvgAS ya había sido reportada, se analizaron estos fenotipos en presencia de diferentes concentraciones de ácido nicotínico para analizar todo el espectro desde fase virulenta hasta fase avirulenta. La sobreexpresión de una proteína que participa en la síntesis de c-di-GMP genera un aumento en la capacidad de formar biofilm, aún en fase avirulenta, la cual había sido reportada como imposibilitada para formar biofilm ${ }^{222}$. Estos resultados fueron confirmados mediante la visualización de las estructuras formadas mediante microscopía electrónica de barrido (SEM). Además, se demostró que la sobreexpresión de una DGC propia (BdcA) de B. bronchiseptica induce los mismos fenotipos, y aumenta la concentración intracelular de c-di-GMP ${ }^{224}$. Este aumento en la producción de c-di-GMP también estuvo acompañado con una inhibición de la movilidad en forma independiente de la presencia del sistema de dos componentes BvgAS. 



\section{Objetivos generales y particulares}

El presente trabajo de tesis doctoral pretende profundizar en la comprensión de los mecanismos moleculares que dirigen la regulación de la formación de biofilm a través de c-di-GMP en B. bronchiseptica.

El objetivo global de este trabajo consiste en determinar el rol los factores codificaos por las secuencias BB1184, BB1185 y BB1186 en la formación de biofilm dependiente de C-di-GMP en $B$. bronchiseptica.

A fin de dirigirse hacia el cumplimiento del mencionado objetivo se propone avanzar concretamente a través de los siguientes objetivos particulares:

(i) Utilizar un abordaje in silico para determinar si las secuencias BB1184, BB1185 y BB1186 codifican la expresión de las proteínas LapD, LapG y una adhesina de la familia de LapA.

(ii) Describir el funcionamiento de este grupo de proteínas en B. bronchiseptica. Utilizaremos herramientas de ingeniería genética y biología molecular para analizar el rol de BB1184, BB1185 y BB1186 en la formación de biofilm.

(iii) Evaluar el rol de estas proteínas in vivo en ensayos de colonización y trasmisión en modelos animales murinos.

(iv) Determinar cuál a cuáles diguanilato ciclasas codificadas en el genoma de $B$. bronchiseptica participan en el control de las formación de biofilm a través de BB1184, BB1185 y BB1186.

(v) Evaluar el rol de estas proteínas en la formación de biofilm en un medio de cultivo suplementado con albúmina y calcio en concentraciones fisiológicamente relevantes. 



\section{Capítulo 2}

Búsqueda de nuevos factores involucrados en la

formación de biofilm a través de c-di-GMP:

análisis in silico 



\section{Introducción}

Previo al comienzo de esta tesis doctoral, nuestro grupo de investigación demostró que el segundo mensajero c-di-GMP regula la formación de biofilm en Bordetella bronchiseptica ${ }^{224}$. El mencionado trabajo constituye el primero en poner en evidencia el rol de esta molécula de señalización en el control de la formación de biofilm en este organismo. Con el objetivo de profundizar en los mecanismos moleculares que se encuentran detrás de este proceso regulatorio, comenzamos utilizando un abordaje in silico.

A lo largo de este capítulo demostraremos de qué manera encontramos genes candidatos a regular la formación de biofilm a través de c-di-GMP en $B$. bronchiseptica y además presentaremos un análisis pormenorizado de las secuencias aminoacídicas codificadas en esos genes.

Finalmente presentaremos un análisis realizado a fin de determinar le presencia de estos genes en otras especies del género Bordetella y en particular en otras cepas de B. bronchiseptica.

\section{BB1184, BB1185 y BB186 podrían regular la formación de biofilm en B. bronchiseptica}

Con el objetivo de iniciar la búsqueda de factores involucrados en la formación de biofilm comenzamos realizando un análisis in silico del genoma de $B$. bronchiseptica. Al momento de comenzar este trabajo de tesis doctoral no contábamos con la secuencia del genoma de la cepa $B$. bronchiseptica $9.73 \mathrm{H}+245$, cepa con la cual nuestro grupo ha venido trabajando en los últimos años y utilizado para describir el rol de c-di-GMP. Por ese motivo, para realizar el análisis utilizamos la secuencia del genoma de la cepa $B$. bronchiseptica RB50 (ATCC BAA-588; RefSeq: NC_019382.1) la cual se encuentra disponible en la base de datos del Centro Nacional para la Información Biotecnológica (NCBI).

Para realizar esta búsqueda utilizamos como secuencia blanco los 1200 aminoácidos del extremo C-terminal de la proteína LapA (large adhesin protein $A$ ) de $P$. fluorescens, adhesina cuyo rol en la formación de biofilm ha sido muy estudiada en $P$. fluorescens ${ }^{65,126,127,136,140,246}$. 


\section{Capítulo 2}

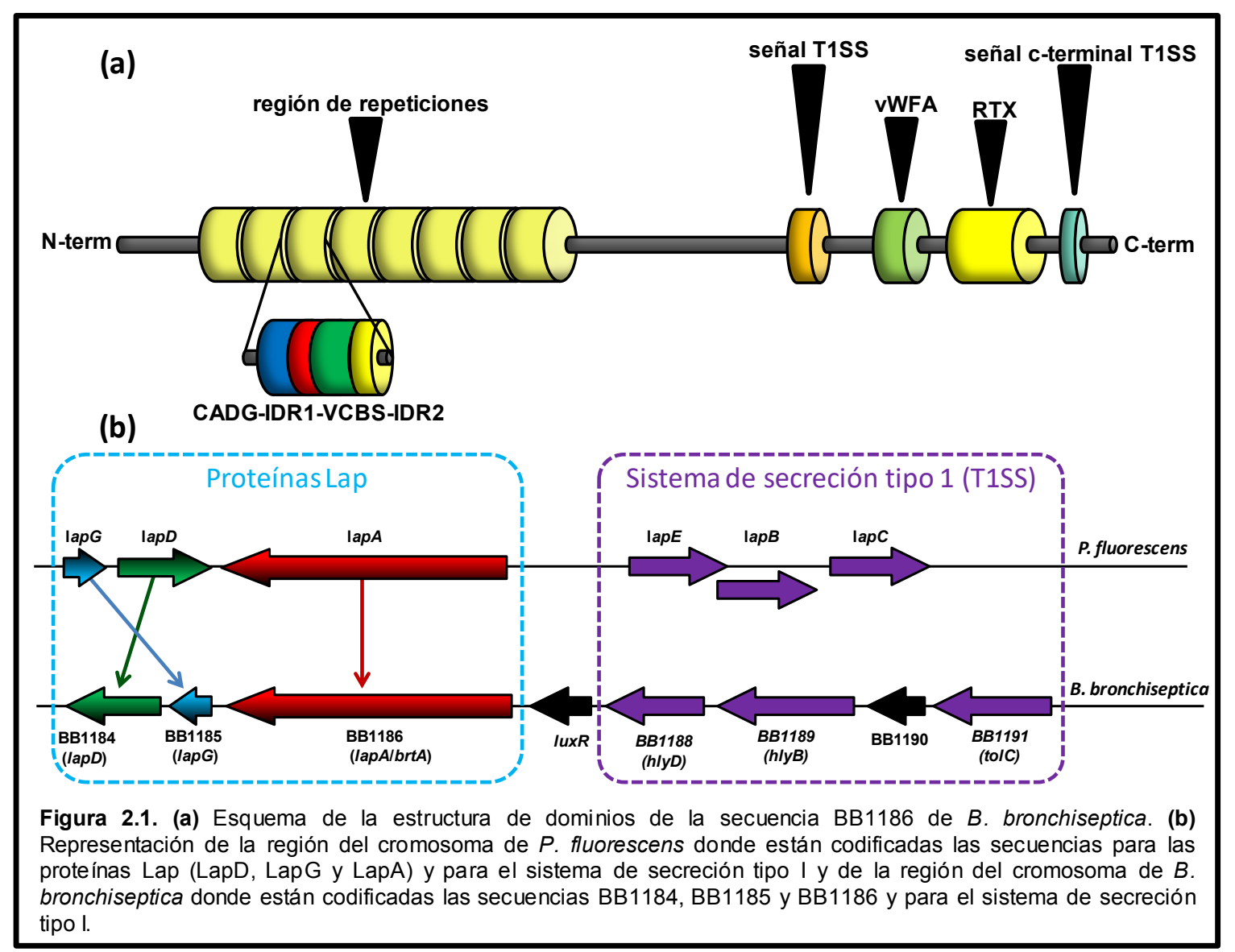

El análisis arrojó como resultado la presencia de la secuencia BB1186 (BB_RS05895), identificada como "probable hemolisina", con características que la hacen un excelente candidato a regular la formación de biofilm a través de c-di-GMP (Figura 2.1). Esta secuencia comparte propiedades estructurales con la proteína LapA de $P$. fluorescens cuyo rol en la formación de biofilm regulada por c-di-GMP ha sido reportado previamente ${ }^{126,127,136,247}$. Si bien la identidad a nivel aminoacídico entre BB1186 y LapA es de sólo un 19,6\%, la presencia de características comunes entre ellas hace pensar que BB1186 podría ser funcionalmente análoga a LapA. En particular se destaca la presencia de una región de repeticiones (CADG y VCBS), en la zona central de la proteína, secuencias de señalización para sistemas de secreción tipo I (T1SS), un dominio del tipo Factor A de Von Willebrand y un motivo RTX cercano al extremo Cterminal (Figura 2.1.a). Asimismo, corriente arriba de la secuencia BB1186, encontramos las secuencias BB1184 y BB1185. La secuencia BB1184 presenta una similitud del $47 \%$ y un porcentaje de identidad a nivel aminoacídico del 30\% (Figura 2.1.b). Asimismo, la secuencia BB1185 presenta una similitud del $62 \%$ con respecto a LapG y un porcentaje de identidad a nivel aminoacídico del 49\% (Figura 2.1.b). Al igual que ocurre en $P$. fluorescens, corriente abajo de las secuencias BB1184-BB1186 encontramos secuencias 
que podrían codificar para los componentes típicos de los sistemas de secreción tipo I (BB1188, BB1189 y BB1190) (Figura 2.1.b).

Toda esta evidencia sugiere que BB1184, BB1185 y BB1186 podrían regular la formación de biofilm tal como LapD, LapG y LapA lo hacen en P. fluorescens.

\section{Análisis in silico de las secuencias BB1184, BB1185 y BB1186}

Gracias a la profundidad con que las proteínas Lap han sido estudiadas en bacterias del género Pseudomonas, en particular en $P$. fluorescens, existe abundante información a nivel molecular y estructural sobre el funcionamiento de este sistema. Esta información nos permitió realizar un análisis bioinformático de las secuencias BB1184, BB1185 y BB1186 con el objetivo de determinar si presentan aquellos aminoácidos y características estructurales que han sido reportadas como importantes para ejecutar sus respectivas funciones.

\section{BB1184}

Tal como fuera mencionado, las secuencias aminoacídicas de LapD de $P$. fluorescens y BB1184 de B. bronchiseptica poseen una identidad a nivel aminoacídico del $30 \%$. Esta información suministra una evidencia en favor de la hipótesis de que BB1184 podría ser LapD en $B$. bronchiseptica. En base a esto, nos propusimos analizar si BB1184 posee aquellos aminoácidos que han sido reportados como importantes para la función de LapD en otros organismos.

LapD de $P$. fluorescens es una proteína localizada en la membrana interna que actúa como un sensor citoplasmático de los niveles de c-di-GMP gracias a la capacidad de su dominio EAL de unir esta molécula ${ }^{84}$. Además del mencionado dominio EAL, posee también un dominio GGDEF, pero ambos resultan catalíticamente inactivos ${ }^{84}$. No se ha reportado, hasta el momento, evidencia de que el dominio GGDEF conserve la capacidad de unir c-di-GMP ${ }^{140}$. LapD posee además un tercer dominio denominado HAMP, encontrado habitualmente en proteínas transmembrana de señalización ${ }^{248}$. Los cambios conformacionales producidos en la región citoplasmática tras la unión de c-di-GMP al dominio EAL, son trasmitidos a través de la membrana interna hasta la porción periplasmática a través del dominio HAMP $84,249,250$. 


\section{Capítulo 2}

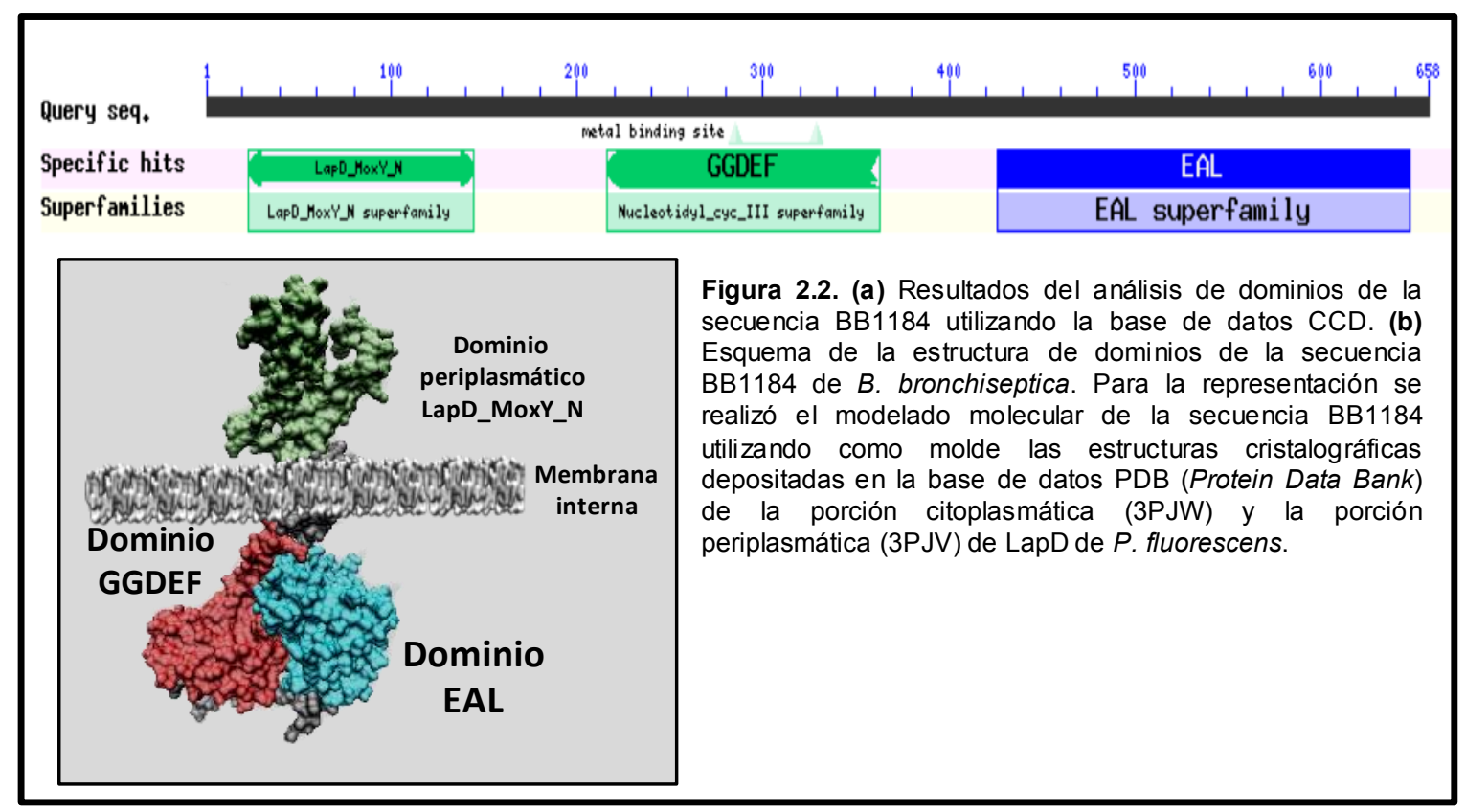

Utilizando la base de datos de dominios CDD de NCBI (CCD: Conserved Domain Database) identificamos en BB1184 la presencia de tres de los cuatro dominios característicos de LapD. Los dominios citoplasmáticos GGDEF (e-value: $1,23 \mathrm{e}^{-15}$ ) y EAL (e-value: $\left.4,95 \mathrm{e}^{-31}\right)$ y el dominio periplasmático LapD_MoxY_N (e-value:2.48e $\left.\mathrm{e}^{-41}\right)$ fueron identificados dentro de la secuencia de BB1184 (Figura 2.2.a y 2.2.b). Mediante este análisis no fue posible identificar la presencia del dominio HAMP que también fuera destacado como parte de la estructura de LapD.

A continuación, realizamos un análisis detallado de las secuencias de los dominios de BB1184 en búsqueda de los aminoácidos que han sido descriptos como importantes para el funcionamiento de LapD en $P$. fluorescens.

Dominio EAL. En la clasificación de dominios EAL propuesta por Ute Römling et al. el dominio EAL de LapD forma parte del grupo Illa. Dentro de este grupo se encuentran además los dominos EAL de FimX de $P$. aeruginosa, Lpg1057 de Legionella pneumophila y PXO_00403 de Xanthomonas oryzae ${ }^{251}$. Todos estos dominios presentan desviaciones respecto de las secuencias catalíticamente activas, pero conservan la capacidad de unión a c-di-GMP. Con el objetivo de analizar si BB1184 podría ser considerada dentro de este grupo de proteínas con dominios EAL degenerado realizamos el alineamiento del dominio EAL de BB1184 junto a las secuencias de los dominios EAL antes mencionados. 


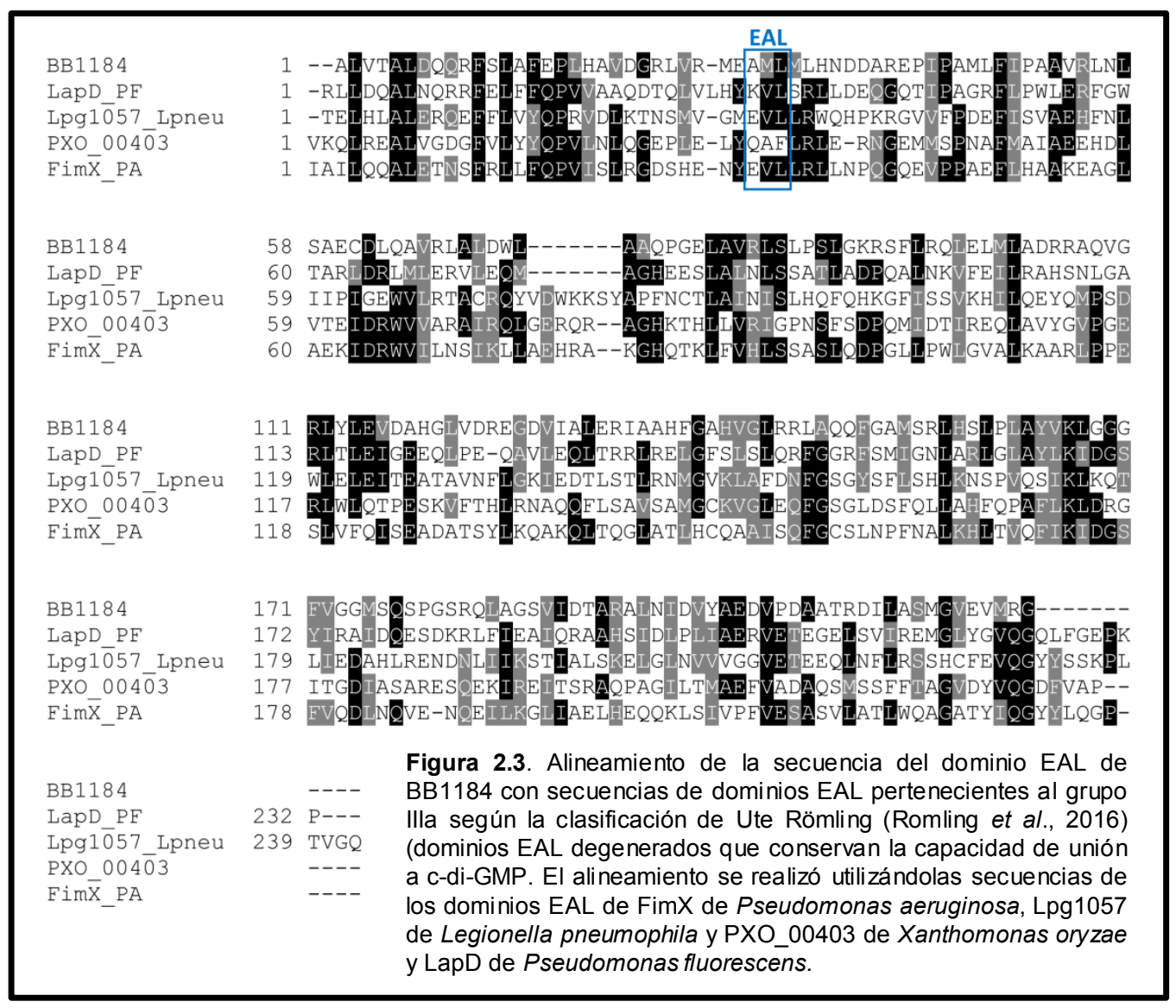

En la Figura 2.3 puede verse que el dominio EAL de BB1184 presenta alineamiento con las secuencias de los otros dominios analizados. Asimismo se observa que BB1184, en la región correspondiente al motivo EAL, presenta la secuencia AML la cual no se encuentra entre las secuencias con capacidad para catalizar la degradación de c-di-GMP ${ }^{81,251}$. Este resultado implica que BB1184, al igual que LapD de $P$. fluorescens carecería de actividad fosfodiesterasa.

Con el objetivo de determinar la presencia o no de otros residuos destacados, realizamos el alineamiento del dominio EAL de BB1184 junto al de proteínas homólogas a LapD de $P$. fluorescens que han sido previamente estudiadas en $P$. aeruginosa, $P$. putida y L. pneumophila (Figura 2.4). 


\section{Capítulo 2}

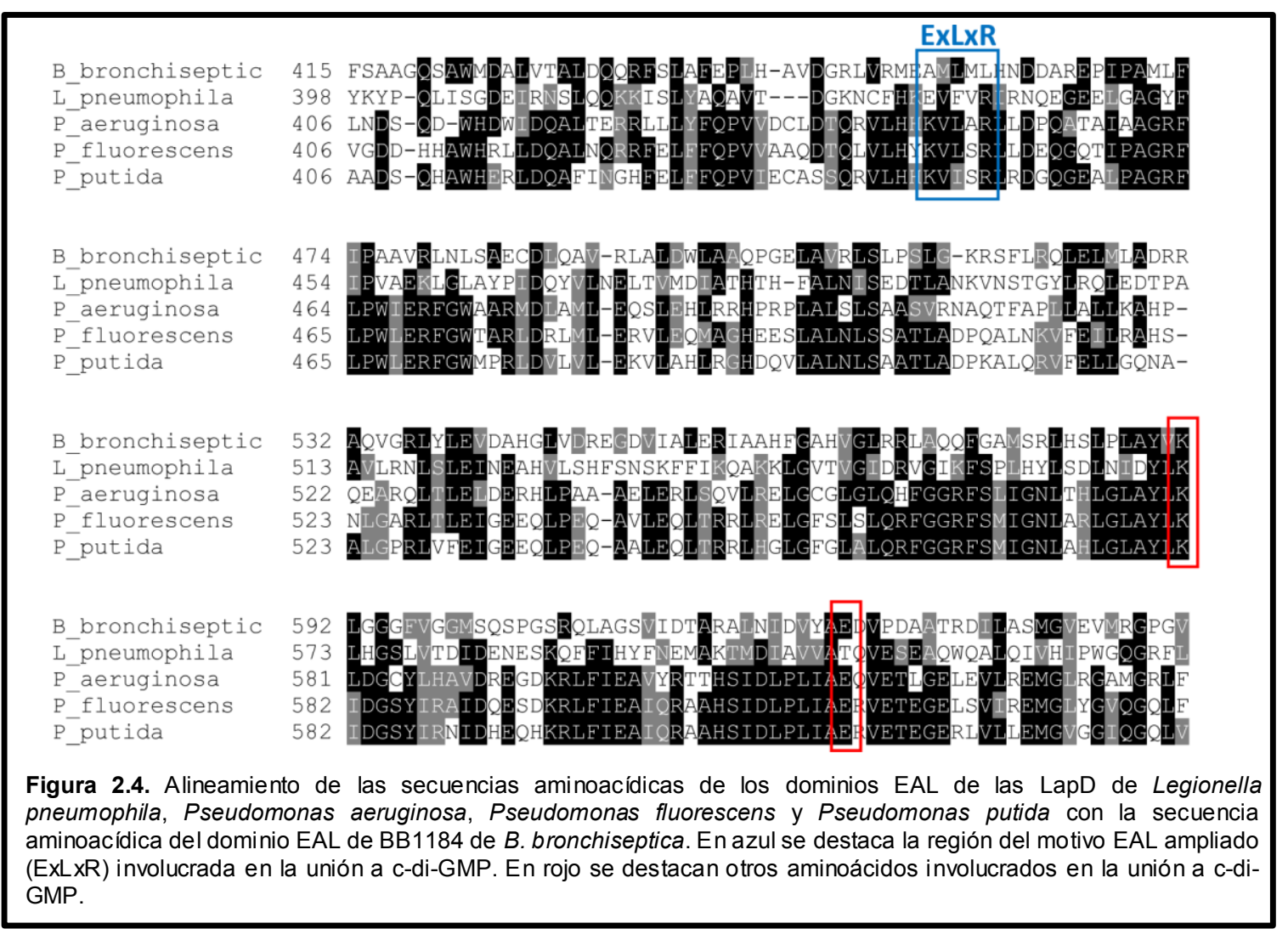

La proteína LapD se encuentra dentro de un grupo de proteínas EAL capaces de unir c-di-GMP a través del motivo ExLXR el cual proviene de una extensión del motivo EAL catalíticamente inactivo ${ }^{81}$. El análisis de la secuencia del dominio EAL de BB1184 en primer lugar pone en evidencia la ausencia de la tríada aminoacídica EAL (Figura 2.4). Esto implica que BB1184, al igual que LapD, no sería capaz de catalizar la hidrólisis de c-di-GMP.

En segundo lugar, vemos que existen diferencias entre la secuencia del sitio de unión a c-di-GMP de LapD y el posible sitio de unión en BB1184. Mientras la secuencia de este sitio en LapD es -KVLSR-, la secuencia de este sitio en BB1184 es -AMLML(Figura 2.4). El sitio de unión a c-di-GMP en BB1184 es notablemente diferente del motivo canónico ExLXR.

Otros dos aminoácidos han sido descriptos como importantes para la unión a cdi-GMP en LapD en $P$. fluorescens, estos son los residuos K581 y E61784, ambos residuos están presentes en BB1184 al igual que en la mayoría de las LapD analizadas siendo LapD de L. pneumophila la única excepción (Figura 2.4).

En resumen, en la secuencia del dominio EAL no existe una conservación total entre aquellos residuos reportados como importantes para el funcionamiento de LapD en $P$. fluorescens y la secuencia en BB1184. En particular, el motivo "AMLML", presente en BB1184, no ha sido descripto en ninguna LapD ni en ninguna proteína con capacidad de 
unir c-di-GMP a través del dominio EAL. La tríada ELR constituye la secuencia más común entre dominios EAL que carecen de actividad catalítica pero mantienen la capacidad de unir c-di-GMP ${ }^{81}$. Notablemente, aunque LapD no presenta ninguno de estos aminoácidos, sí conserva la capacidad de unir c-di-GMP ${ }^{84}$. Por ende, resulta importante destacar la gran variabilidad que existe entre diversos dominios EAL que unen c-di$\mathrm{GMP}^{81,251}$. La evidencia experimental sugiere que es el entorno del motivo EAL el que define su capacidad de unir c-di-GMP y no la secuencia aminoacídica del sitio EAL en sí misma. Debido a la notable flexibilidad que presenta la molécula de c-di-GMP puede adoptar una gran variedad de conformaciones lo cual permite que existan una importante diversidad dominios de unión a c-di-GMP81,252.

Dominio GGDEF. El rol del dominio GGDEF en el funcionamiento de LapD no está absolutamente claro. No existe demasiada información acerca de cuáles son los residuos aminoacídicos de esta región que son indispensables para la función de la proteína. La mayor parte de la información disponible proviene de la resolución cristalográfica de la porción citoplasmática de LapD de $P$. fluorescens que incluye al dominio GGDEF ${ }^{140,253}$.

El dominio GGDEF de BB1184, al igual que el de LapD no presenta un sitio activo conservado. El alineamiento de BB1184 y LapD junto a diguanilato ciclasas de demostrada actividad pone en evidencia la ausencia de los aminoácidos necesarios para catalizar la síntesis de c-di-GMP (Figura 2.5).

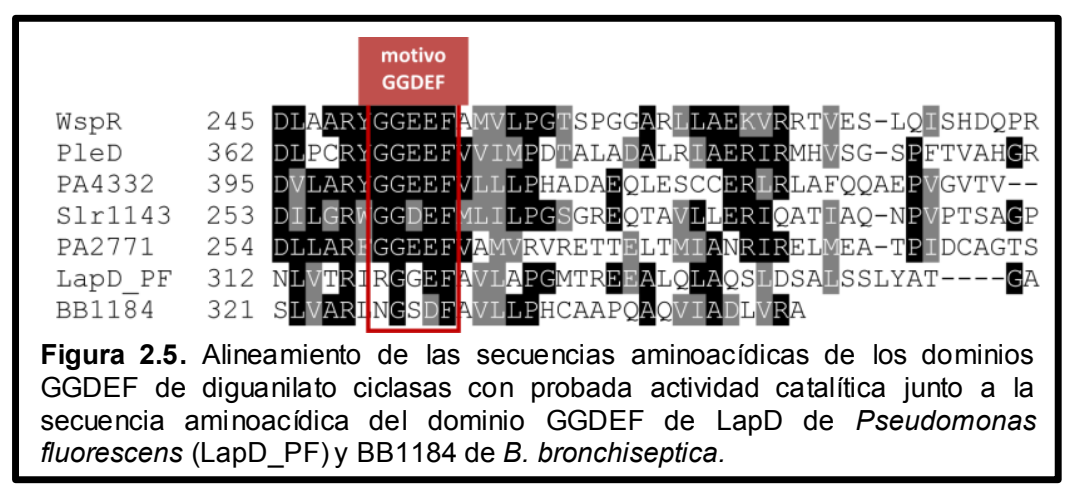

El motivo GGDEF en BB1184 está formado por la secuencia -NGSDF-. En la primera posición encontramos un residuo de asparagina $(\mathrm{N})$, posición en la que las diguanilato ciclasas activas poseen, en general, un residuo de glicina $(G)^{79}$. En la tercera posición del motivo GGDEF, BB1184 tiene un residuo de serina (S) en lugar de aspartato (D) o glutamato (E). Ambos cambios presuponen la imposibilidad del dominio GGDEF de BB1184 de catalizar la síntesis de c-di-GMP. En base a estos resultados BB1184, al igual que LapD, no sería una diguanilato ciclasa activa. 


\section{Capítulo 2}

La resolución cristalográfica de la estructura de LapD de $P$. fluorescens pone en evidencia la importancia de un residuo de glutamato ubicado en la posición 262 (E262). En la conformación auto-inhibida de LapD (en ausencia de c-di-GMP), E262 interacciona con el residuo R450 del dominio EAL impidiendo el acceso de c-di-GMP a su sitio de unión ${ }^{253}$. Estos dos aminoácidos se encuentran altamente conservados entre las LapD del género Pseudomonas, pero encontramos un nivel menor de conservación en especies diferentes ${ }^{253}$. BB1184 no presenta ninguno de estos dos residuos de aminoácidos en las posiciones mencionadas. Sin embargo, no existe evidencia experimental de que estos residuos puedan ser fundamentales para el correcto funcionamiento de LapD.

Dominio HAMP. En la proteína LapD de $P$. fluorescens los dominios citoplasmáticos GGDEF y EAL están conectados al módulo periplasmático a través de un dominio denominado $\mathrm{HAMP}^{84}$. Este dominio ha sido descripto en una gran variedad de proteínas de señalización procariotas y eucariotas ${ }^{137}$. Habitualmente encontrado en proteínas de membrana, conecta dominios sensores extracitoplasmáticos con dominios efectores citoplasmáticos de manera tal de transmitir y convertir señales externas en respuestas internas ${ }^{254}$. A pesar de ser un dominio ampliamente distribuido entre proteínas de señalización existe escasa conservación a nivel aminoacídico ${ }^{138}$. Su conservación funcional reside en una estructura invariante caracterizada por la presencia de dos ahélices antiparalelas (AS-1 y AS-2) conectadas mediante una región no estructurada ${ }^{254}$. La escasa conservación a nivel aminoacídico que existe entre dominios HAMP de diferentes proteínas hace difícil su predicción mediante métodos in sílico ${ }^{138}$.

\begin{tabular}{|c|c|}
\hline $\begin{array}{l}\text { P_fluorescens } \\
\text { B_bronchisept }\end{array}$ & 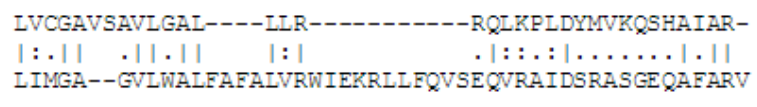 \\
\hline $\begin{array}{l}\text { P_fluorescens } \\
\text { B_bronchisept }\end{array}$ & $\begin{array}{l}\text { REFLSLPD-LPRTPE } \\
\cdot|| \cdots:|| \cdot|\cdot| \cdot \mid \\
\text { AEFSGIVDALAQTRE }\end{array}$ \\
\hline \multicolumn{2}{|c|}{$\begin{array}{l}\text { Figura 2.6. Alineamiento de las secuencias aminoacídicas de los dominios HAMP } \\
\text { de BB1184 de } B \text {. bronchiseptica y LapD de } P \text {. fluorescens. La línea roja destaca la } \\
\text { posición ocupada por el residuo de glutamato presente en todos los dominios } \\
\text { HAMP. }\end{array}$} \\
\hline
\end{tabular}

La Figura 2.6 muestra que el alineamiento de la región de BB1184 que correspondería al dominio HAMP y el dominio HAMP de $P$. fluorescens no arroja buenos resultados. 
El alineamiento de esta secuencia contra la base de datos de NCBI arrojó como resultado la existencia de una proteína en Achromobacter spp. que presenta un $66 \%$ de identidad con la región propuesta de BB1184 y sí se encuentra anotada como HAMP.

Existe otra evidencia de que la región propuesta podría efectivamente tratarse de un dominio HAMP. El residuo de glutamato presente en la posición 230 de LapD de $P$. fluorescens es el único residuo invariante encontrado en las secuencias de todos los dominios HAMP estudiados ${ }^{84,255}$. En BB1184, este residuo está presente en esa posición, lo cual apoyaría la hipótesis de que efectivamente se trata de un dominio HAMP (Figura 2.6).

Dominio LapD_MoxY_N. Este dominio constituye la porción periplasmática de LapD a través de la cual interacciona con LapG. A diferencia de la profundidad con que ha sido estudiada la región citoplasmática de LapD, existe poca información sobre esta parte de la proteína. La presencia de un motivo $G W \times Q$ ha sido destacada como indispensable para garantizar una óptima interacción entre LapD y $\operatorname{LapG}^{139}$. A fin de determinar si este motivo está presente en la región periplasmática de BB1184 realizamos el alineamiento de las secuencias aminoacídicas de los dominio periplasmáticos de BB1184 y de las otras LapD previamente estudiadas.

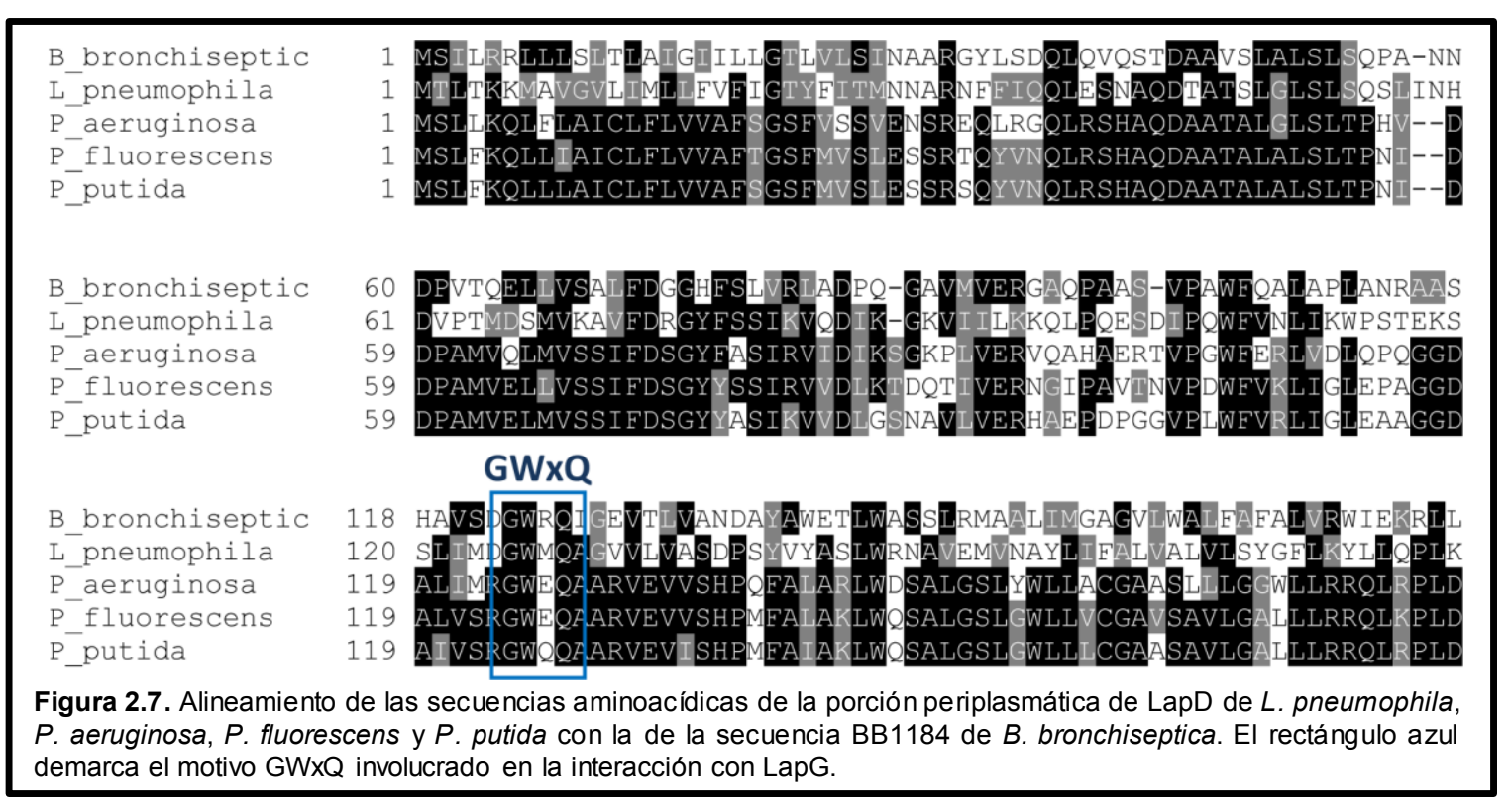

El alineamiento muestra que el motivo $\mathrm{GWxQ}$ está presenta en la porción periplasmática de BB1184 al igual que en todas las otras proteínas LapD estudiadas (Figura 2.7). Este resultado implica que BB1184 podría interactuar con un homólogo a LapG en B. bronchiseptica. 


\section{Capítulo 2}

\section{BB1185}

LapG es una cisteín proteasa dependiente de calcio $\left(\mathrm{Ca}^{+2}\right)$ que ha sido caracterizada desde un punto de vista funcional y estructural en $P$. fluorescens ${ }^{130}$ y en $L$. pneumophila ${ }^{256}$. Basándonos en información proveniente de estudios cristalográficos y funcionales analizamos la presencia de residuos importantes en la secuencia BB1185 a fin de evaluar si esta secuencia podría ser LapG en B. bronchiseptica.

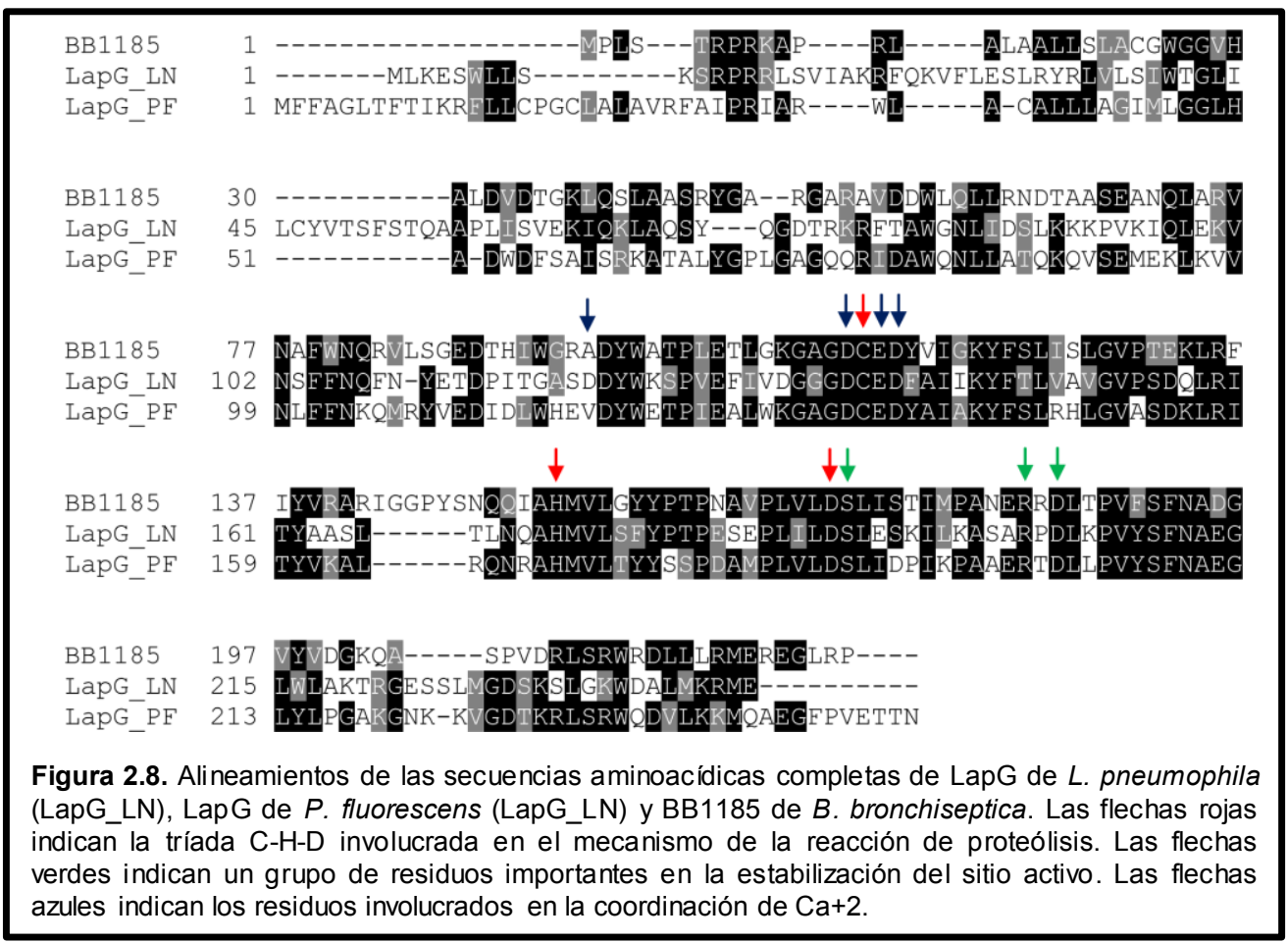

La actividad proteolítica de LapG reside en la tríada catalítica C-H-D (C137, H172 y D189 en la secuencia de LapG de L. pneumophila) $)^{256}$. Realizando un alineamiento de las secuencias de LapG de P. fluorescens, L. pneumophila y BB1185 vemos que BB1185 conserva los residuos aminoacídicos necesarios para desarrollar la actividad proteolítica (Figura 2.8, flechas rojas). Asimismo, existe un segundo grupo de aminoácidos que si bien no participan del mecanismo de reacción son importantes para estabilizar los tres residuos antes mencionados. S190, D203 y R201 son fundamentales para coordinar al residuo D189 en LapG de L. pneumophila y así estabilizar la región del sitio activo ${ }^{256}$. Estos tres residuos también se encuentran en la secuencia de BB1185 (Figura 2.8, flechas verdes).

Un segundo grupo de aminoácidos importantes lo forman aquellos involucrados en la coordinación de $\mathrm{Ca}^{+2}$. Si bien no está absolutamente claro el aporte de los iones $\mathrm{Ca}^{+2}$ al mecanismo de reacción y a la estabilidad de LapG, se ha demostrado que tanto la actividad proteolítica como la interacción con LapD dependen de este ion. En $L$. 
pneumophila los residuos D120, D136, E138 y D139 participan de la coordinación de iones $\mathrm{Ca}^{+2}$ en las cercanías del sitio activo ${ }^{256}$. Mientras D136, E138 y D139 resultan indispensables, la variabilidad encontrada en torno al residuo D120 demuestra su rol secundario en la estabilización del sitio activo. En el caso de $P$. fluorescens, en donde estos residuos han sido estudiados funcionalmente, se determinó que los residuos D134 y E136 son necesarios para que LapG adopte la conformación óptima para interaccionar con LapD ${ }^{130}$. La secuencia BB1185 posee tres de los cuatro aminoácidos reportados como importantes para la unión de calcio (Figura 2.7, flechas azules).

\section{BB1186}

Al comienzo del capítulo describimos que la presencia de elementos comunes a la proteína LapA de $P$. fluorescens nos condujo a la hipótesis de que BB1186 podría ser la adhesina de un sistema regulador de la formación de biofilm dependiente de c-di-GMP en $B$. bronchiseptica. Además de los elementos destacados previamente, existen otros que son importantes para la función de LapA que no fueron considerados en la búsqueda inicial y que requieren de un análisis más profundo.

En P. fluorescens, el desprendimiento de LapA de la membrana plasmática, catalizado por la proteasa LapG, es dependiente de dos elementos ubicados cerca del extremo N-terminal. El mencionado desprendimiento de LapA se produce como consecuencia de un corte proteolítico generado entre un par de residuos de alanina. La mutación de este par de alaninas genera una versión de LapA que no puede ser clivada por LapG ${ }^{140}$. Asimismo, el reconocimiento de este sitio de clivado es dependiente de la estructura secundaria de la secuencia localizada hacia el extremo $\mathrm{N}$ - terminal del par de alaninas. LapG reconoce una hélice- $\alpha$ ubicada 12 aminoácidos antes de sitio de corte y finalmente genera el corte del enlace peptídico entre los mencionados residuos de alanina $^{127}$.

BB1186 posee 3 pares de residuos de alanina entre los primeros 150 aminoácidos del extremo N-terminal que podrían constituir el sitio de clivado para BB1185: 81-AA-82, 96-AA-97 y 111-AA-112 (Figura 2.9.a). 


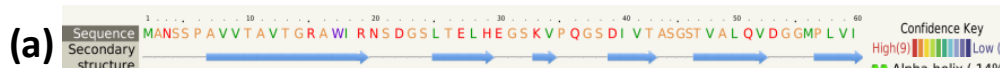

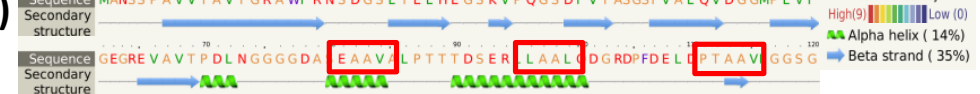

(b)

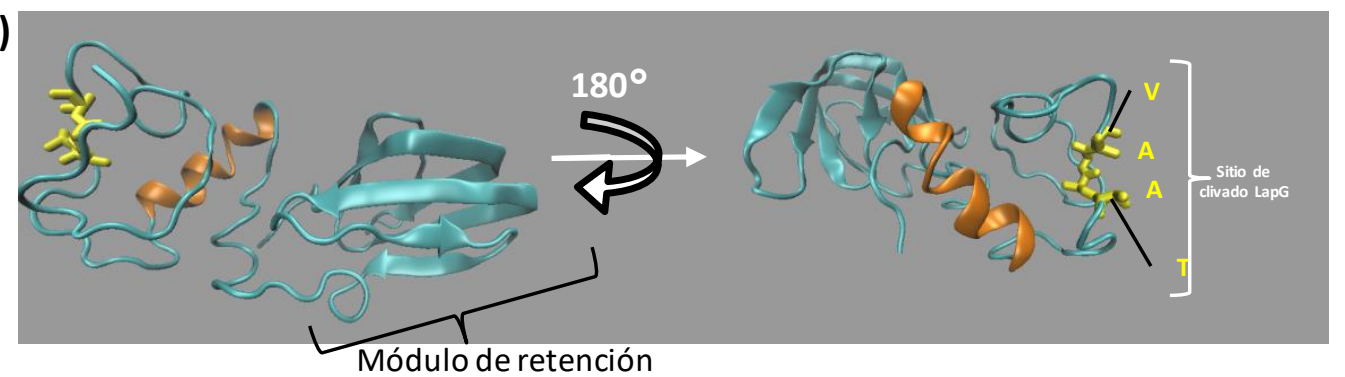

Figura 2.9. (a) El panel superior muestra el resultado del modelado molecular de la porción N-terminal de BB1186 utilizando la herramienta informática Phyre2. Las flechas azules representan regiones que adoptan una estructura secundaria tipo lámina- $\beta$, las hélices verdes representan regiones que adoptan una estructura secundaria del tipo hélice- $\alpha$. (b) Representación tridimensional del modelado molecular de la porción N-terminal de BB1186 utilizando el programa VMD para visualización de proteínas. El módulo de retención se visualiza como una estructura condensada formada por láminas $\beta$. El sitio de corte para LapG, -TAAV- está representado en color amarillo y 12 residuos corriente arriba, coloreada en naranja, se visualiza la hélice- $\alpha$ que participaría del reconocimiento por parte de LapG.

Para realizar el análisis estructural de la porción N-terminal de BB1186 utilizamos la herramienta online Phyre2 que permite determinar la estructura secundaria y terciaria de secuencias aminoacídicas mediante el alineamiento contra secuencias de una base de datos de proteínas cristalizadas ${ }^{257}$. Mediante este modelado identificamos una estructura de hélice- $\alpha 12$ aminoácidos antes del par 111-AA-112 (Figura 2.8.a). Este sitio reúne las dos características que han sido descriptas como necesarias para sustratos de LapG.

El modelado molecular además demuestra la presencia de una estructura tipo barril- $\beta$ cerca del extremo N-terminal (Figura 2.8.b). Esta estructura, denominada módulo de retención, es otra característica típica de las proteínas de la familia de LapA que son sustrato de LapG ${ }^{136}$.

Otra región que resulta importante analizar es la zona central de BB1186 donde se encuentran las repeticiones de los dominios CADG y VCBS (Dystroglycan-type cadherin-like domains y Vibrio, Colwellia, Bradyrhizobium, y Shewanella repeats superfamily respectivamente) (Figura 2.10.a). La secuencia BB1186 presenta ocho repeticiones. Cada unidad repetitiva puede a su vez ser dividida en 4 regiones: un dominio CADG, un dominio VCBS y dos regiones intermedias denominadas ID1 e ID2 (por inter-domain region 1 y 2). La representación tipo WebLogo mostrada en la Figura 2.10.b demuestra un elevado nivel de conservación entre las secuencias de las 8 repeticiones en la zona media de BB186 en la cepa RB50. 


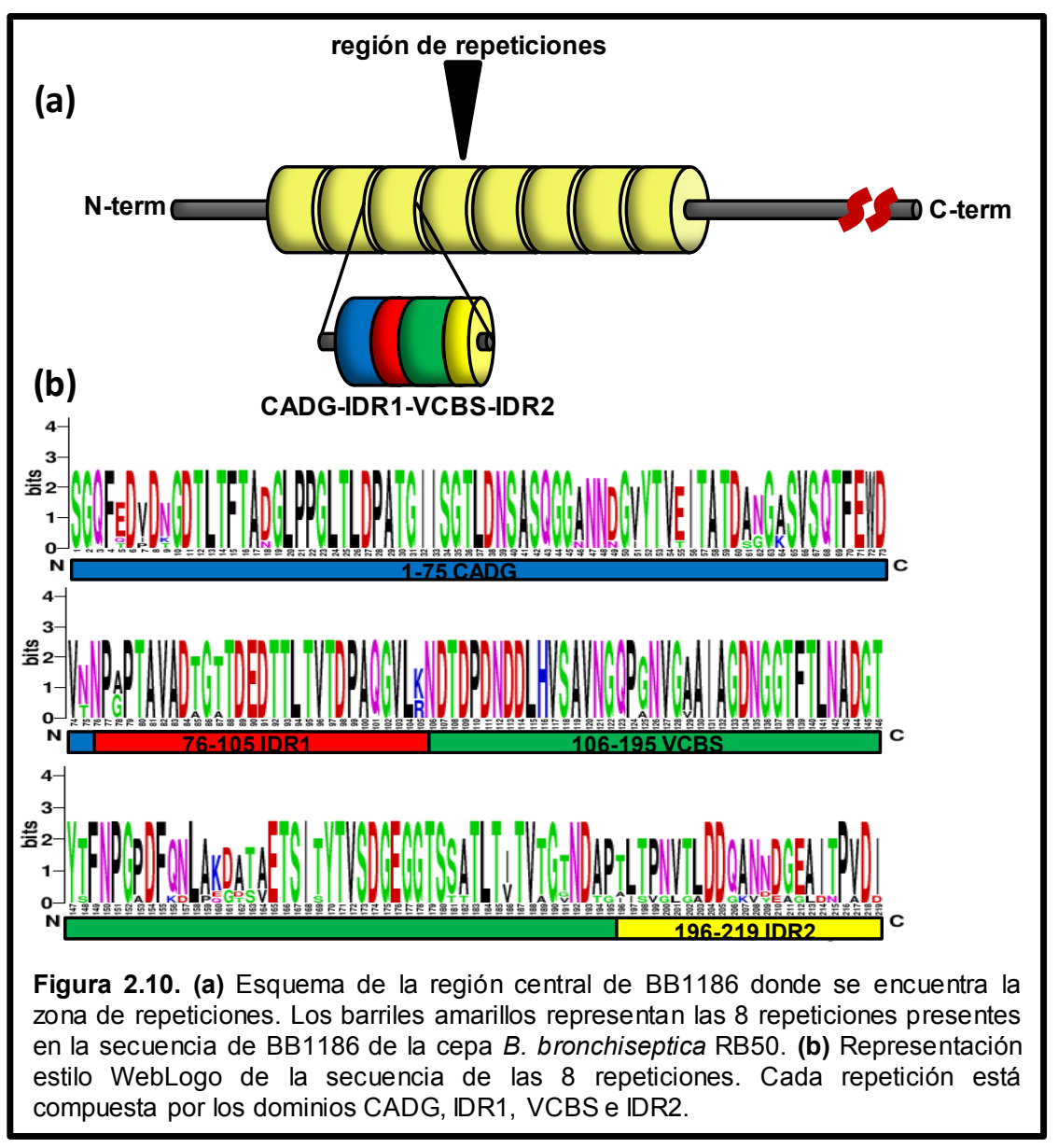

Tal como fuera destacado previamente, la región de repeticiones de BB1186 no presenta homología de secuencia con la región de repeticiones de LapA ni de ninguna otra entre las proteínas de la familia de LapA.

\section{Análisis en otras especies del género Bordetella}

Con el objetivo de determinar si las proteínas Lap podrían ser un mecanismo de regulación extendido a lo largo de todo el género Bordetella utilizamos la secuencia lap $G$ de $P$. fluorescens (BB1185 en $B$. bronchiseptica) para realizar una búsqueda en los genomas del resto de las cepas de Bordetella secuenciadas.

Como resultado de esta búsqueda, secuencias homólogas a lapG fueron encontradas también en $B$. parapertussis (humana y bovina), B. flabilis, B. bronchialis y B. ansorpii (Tabla 2.1). El análisis de las regiones adyacentes a las secuencias encontradas mostró que todas las especies que presentaban una secuencia homóloga a lapG también presentaban secuencias homólogas a lapD y una secuencia con características típicas de las adhesinas tipo LapA (zona intermedia con repeticiones, factor A de von Willebrand, dominio RTX y secuencias de señalización para un sistema de secreción tipo I). Asimismo, todas estas especies presentan, en esta región del 


\section{Capítulo 2}

genoma, secuencias que podrían codificar para los componentes típicos de los sistemas de secreción tipo I (Tabla 2.1).

\begin{tabular}{|c|c|c|c|c|}
\hline Especie & lapD & lapG & lapA & T1SS \\
\hline B. bronchiseptica & BB1184 & BB1185 & BB1186 & $\begin{array}{l}\text { BB1188 } \\
\text { BB1189 } \\
\text { BB1191 }\end{array}$ \\
\hline $\begin{array}{l}\text { B. parapertussis } \\
\text { (humana) }\end{array}$ & BPP0972 & BPP0973 & BPP0974 & $\begin{array}{l}\text { BPP0976 } \\
\text { BPP0977 } \\
\text { BPP0979 }\end{array}$ \\
\hline $\begin{array}{l}\text { B. parapertussis } \\
\text { (ovina) }\end{array}$ & BN117_3692 & BN117_3691 & BN117_3690 & $\begin{array}{l}\text { BN117_3685 } \\
\text { BN117_3687 } \\
\text { BN117_3688 }\end{array}$ \\
\hline B. flabilis & BAU07_15660 & BAU07_15665 & BAU07_15670 & $\begin{array}{l}\text { BAU07_15680 } \\
\text { BAU07_15685 } \\
\text { BAU07_15695 }\end{array}$ \\
\hline B. bronchialis & BAU06_11015 & BAU06_11010 & BAU06_11005 & $\begin{array}{l}\text { BAU06_10995 } \\
\text { BAU06_10990 } \\
\text { BAU06_10980 }\end{array}$ \\
\hline B. ansorpii & SAI71923.1 & SAI71921.1 & SAI71920.1 & $\begin{array}{l}\text { SAI71915.1 } \\
\text { SAI71913.1 } \\
\text { SAI71907.1 }\end{array}$ \\
\hline
\end{tabular}

Llamativamente no encontramos esta secuencia en la especie históricamente más estudiada del este género, $B$. pertussis. Tampoco encontramos evidencia de la presencia de secuencias homólogas a BB1184 o BB1186. Al analizar detalladamente el genoma de la cepa Tohama I de $B$. pertussis encontramos que en la región donde esperaríamos encontrar las secuencias BB1184, BB1185 y BB1186 se produjo una gran deleción. La gran mayoría de los genes de B. bronchiseptica entre BB1183 y BB1269 no están presentes en el genoma de $B$. pertussis. Durante su evolución, $B$. pertussis sufrió un arreglo genómico que la llevó a perder un parte importante de su genoma como consecuencia de la adaptación de la adaptación a su único nicho conocido, el ser humano ${ }^{153}$. Nuestro análisis demuestra que las secuencias analizadas en este trabajo, BB1184, BB1185 y BB1186, se encuentran dentro de ese grupo de genes que $B$. pertussis ha perdido a lo largo de su evolución.

Tampoco se detectó la presencia de estas secuencias en las especies $B$. avium, B hinzii, B. pseudohinzii, B. holmesii o B. trematum.

\section{Análisis de BB1184, BB1185 y BB1186 en la cepa $B$. bronchiseptica $9.73 \mathrm{H+}$}

Los estudios de nuestro grupo de investigación acerca del rol del segundo mensajero c-di-GMP en la regulación de la movilidad y la formación de biofilm de $B$. bronchiseptica fueron desarrollados utilizando la cepa $B$. bronchiseptica $9.73 \mathrm{H}+{ }^{224}$. Al momento de comenzar este trabajo de tesis, el genoma de esta cepa no estaba 
secuenciado, motivo por el cual nuestra búsqueda in silico fue realizada sobre el genoma de la cepa RB50.

Durante el desarrollo de esta tesis, comenzamos con el proyecto de secuenciación de la cepa que es objeto de nuestro estudio. La secuenciación fue realizada en el Departamento de Ciencias Ambientales de la Universidad de Aarhus (Dinamarca) utilizando la plataforma Illumina HiSeq 2000-1 TB.

La secuenciación completa del genoma es una línea de trabajo que excede los objetivos de esta tesis doctoral. Sin embargo, la secuencia de las regiones genómicas que son objeto de estudio de este trabajo constituye una información que aprovechamos para sustentar el análisis pormenorizado que presentamos en las secciones anteriores.

Las secuencias nucleotídicas BB1184 y BB1185 presentan un $100 \%$ de identidad entre las cepas $B$. bronchiseptica RB50 y $9.73 \mathrm{H}+$. Asimismo, las regiones intergénicas se encuentran igualmente conservadas entre las cepas analizadas. La secuencia BB1186 presentó dos regiones que no pudieron ser secuenciadas (Figura 2.11 Seq1 y Seq2).

No resulta llamativo que estos gaps se encuentren en la región correspondiente a la zona media de BB1186, región correspondiente a las repeticiones de los dominios CADG y VCBS. Dada la dificultad de los sistemas experimentales y de las herramientas informáticas para cerrar y determinar secuencias en regiones altamente repetitivas ${ }^{258}$, la secuencia completa de esta región no pudo ser determinada en la primera secuenciación. Con el objetivo de cerrar la secuencia de BB1186 en la cepa 9.73H+ diseñamos primers con homología por las regiones adyacentes a aquellas que no pudieron ser secuenciadas en el primer intento (Figura 2.11.b). Las regiones denominadas Seq1 y Seq2 fueron amplificadas por PCR y secuenciadas.

Los resultados de estas secuenciaciones muestran la presencia sólo de un dominio VDCG y un dominio VCBS lo cual indicaría la presencia de sólo una de las repeticiones descriptas en la cepa RB50 (VDCG-IDR1-VCBS-IDR2). Según estos resultados BB1186 de la cepa $9.73 \mathrm{H}+$ tendría un peso molecular de $208 \mathrm{kDa}$, lo cual representa un valor notablemente bajo para una adhesina tipo LapA. 


\section{Capítulo 2}

(a)

(b)

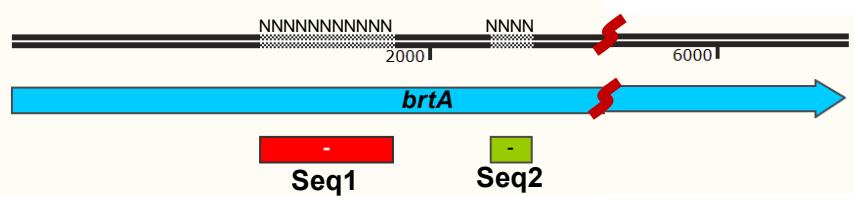

ATGGCCAATTCTTCCCCCGCTGTCGTCACCGCCGTCACCGGCCGTGCCTGGATACGCAACAGCGATGGTTCGCTGACCGAATTGCATGAAGGC AGCAAGGTGCCGCAGGGCAGCGACATCGTCACGGCCTCGGGCTCCACGGTGGCCCTGCAGGTCGATGGCGGCATGCCCCTGGTGATCGGCG AAGGGCGCGAAGTGGCCGTCACGCCGGACCTGAACGGCGGCGGCGGCGACGCTTCCGAGGCCGCGGTGGCCCTGCCGACCACGACCGACTC CGAACGCCTGCTGGCCGCCCTGCAGGATGGCCGCGATCCGTTCGACGAGCTGGATCCCACCGCCGCGGTCATCGGCGGCAGCGGCGACAGC GCCGGCAGCAGCTTCGTGCGCCTGGCCAAGATTCTCGAAAGCACCaCCCCGATGGACCTGGCGTaCCCGAATCCGGGCCGCGGCGAAGACGG TGTGCGCACCTTCCTGGGCGGCGCCACCGCCGGCgCCGATGACGAAGCCGCGCCCGCGCCCGCCAACCAGGCGCCCAACGCGCtGgACGACCT GGGCCAGACCCGCCAGGGCCAGGCGCTGCGCGGCAACCTGATGCTGAACGACTCGGATCCGGACGGCGATCCGCTGACCGTGGTGTCCGTC AATGGCCGGCCGATGACTTCCGGCGGCCTGACGCTGCCCGGCAGCGGCGGCGGCACGTTCACCGTGCAGCCCGACGGCTCGTACACCTTCGT GCCGGGCAATGAGCACCAGTCGTTGGGCGAAGGCCAGACGACCACCACCACCATCACCTATACGATTACCGACCCGTCCGGCGCGACCTCCA CGGCCACGCTGACGGTCACCGTCACCGGCACCAACGACGCGCCCACGCTCACCCCGGGCGTGACCCTGGGCGACCAGGCCAACGACGACGG CGAGGCCATCGCCCCGGTCGACATCTCCGGCCAGTTCCAGGATATCGACAAGGGCGATACGCTGACCTTCACGGCCAATGGCCTGCCGCCGG GCCTGACCCTGGATCCGGCCACCGGCATCATCTCCGGCACGCTGGATAACTCCGCCTCGCAAGGCGGCAACAACGGCGTCTATACCGTCACCA TCACGGCCACCGACTCGGGCGGCAAGAGCGTCAGCCAGACCTTCGAGTGGGACGTGACCAACCCCGCCCCGACCGCCGTGGCCGACGCCGG

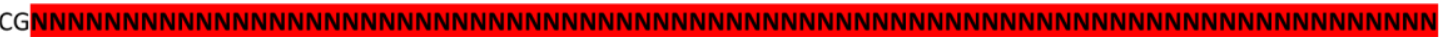

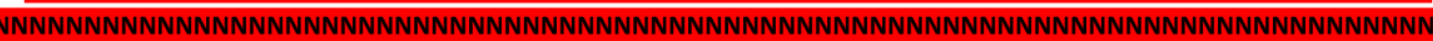

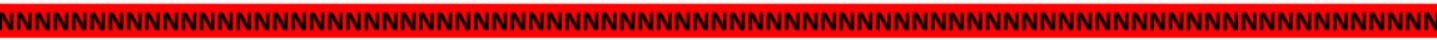

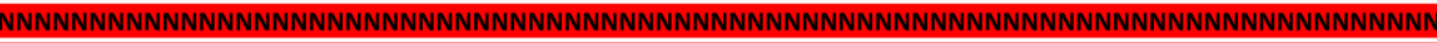

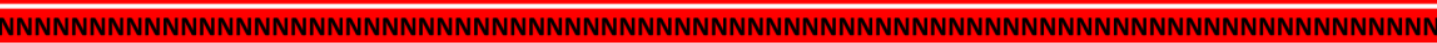

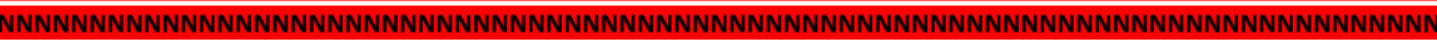

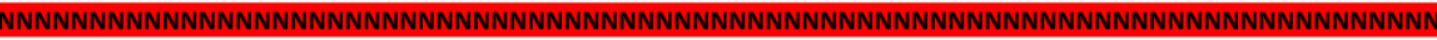

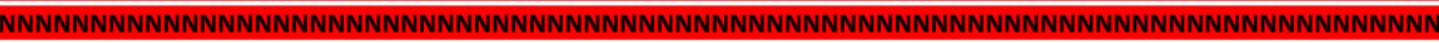

NNNNNNNNNNCGGCCATCGCCGGCGACAACGGCGGCACCTTCACGCTCAACGCCGACGGCACCTACACCTTCAACCCGGGCCCTGACTTCC AGAACCTGGCCAAGGACGCCACCGCCGAGACCTCCATCACCTACACCGTCTCCGACGGCGAAGGCGGCACCTCCTCGGCCACGCTGACGaTC ACCGTCACCGGCACCAACGACGCGCCCACGCTCACCCCGAACGTCACCCTGGACGACCAGGCCAACAACGACGGCGAaGCCATCACCCCGGT CGACATCTCCGGCCAGTTCGAGGACGTCGACAACGGCGACACGCTGACCTTCACCGCCGACGGCCTGCCCCCgGGCCTGACCCTGGATCCGGC CACCGGCATCATCTCGGGCACGCTGGAtAACTCGGCCTCGCAAGGCGGCGCGAACAATGACGGCGTCTACACCGTCGAGATCACCGCCACCG

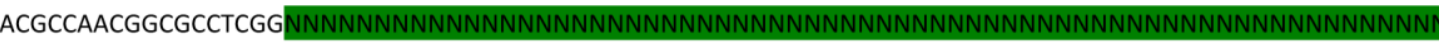

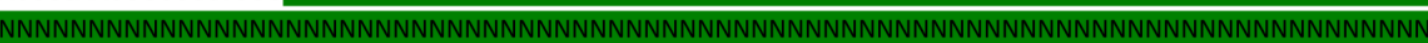
TTGGCCATCGCCGGCGACAACGGCGGCACCTTCACG CTCAACGCCGACGGCACCTACTCCTTCAACCCGGGCCCTGACTTCCAGAACCTGGCCCAGGGCGACAGTGTCGAGACGTCCATCAGCTACACG GTTTCCGACGGCGAAGGCGGCACCTCCACGACGACCCTCACGGTCACCGTAACGGGCGTCAACGACACCGGCGCGATCTCCGTGAACCTGGG CGCCGACGATGGCAAGGTGTACGAAGCCGGGCTGGACAATCCGGCCGACGACAGCGAAACCACCGGC

Figura 2.11. (a) Esquema de la secuencia nucleotídica de BB1186 de la cepa $B$. bronchiseptica $9.73 \mathrm{H}+$. En rojo se muestra la región Seq1 y en verde la región Seq2 cuyas secuencias no pudieron ser determinadas en la primera secuenciación. (b) Secuencia de las 3.000 pares de bases del extremo N-terminal de BB1186 tal como fue obtenida en la primera secuenciación. En letras rojas se detalla la región de hibridación de los primers utilizados para secuenciar la región Seq1; en letras verdes se detalla la región de hibridación de los primers utilizados para secuenciar la región Seq2.

A fin de determinar si el tamaño de BB1186 determinado para la cepa $9.73 \mathrm{H}+$ es igual en otras cepas de B. bronchiseptica, analizamos secuencias homólogas a BB1186 en 58 genomas disponibles en bases de datos. Algunos de estos genomas corresponden a proyectos en desarrollo por lo que aún no han sido curados y también presentan regiones incompletas. La Tabla 2.2 muestra los resultados de ese análisis. 


\begin{tabular}{|c|c|c|c|c|c|}
\hline Huésped & Cepa & número de repeticiones & Huésped & Cepa & número de repeticiones \\
\hline Gato & MBORD635 & Indeterminado & Humano & F4563 & 3 \\
\hline Gato & MBORD782 & Indeterminado & Humano & GA96-01 & Indeterminado \\
\hline Perro & MBORD785 & Indeterminado & Humano & MBORD675 & 3 \\
\hline Perro & MBORD591 & Indeterminado & Humano & $\mathrm{MO} 275$ & Indeterminado \\
\hline Perro & MBORD595 & Indeterminado & Humano & SBL-F6116 & Indeterminado \\
\hline Cobayo & MBORD665 & Indeterminado & Koala & MBORD681 & Indeterminado \\
\hline Cobayo & MBORD668 & Indeterminado & Koala & MBORD698 & 3 \\
\hline Cobayo & MBORD670 & 2 & Cerdo & CARE970018BB & 4 \\
\hline Caballo & MBORD624 & 3 & Conejo & A1-7 & Indeterminado \\
\hline Caballo & MBORD632 & 2 & Conejo & $\mathrm{B} 18-5$ (C3) & 6 \\
\hline Caballo & MBORD731 & 4 & Conejo & B20-10725633 & 7 \\
\hline Humano & 1289 & Indeterminado & Conejo & RB630 & Indeterminado \\
\hline Humano & Bbr77 & 5 & Nutria & SO10328 & 3 \\
\hline Humano & MOI 149 & 11 & Foca & $\mathrm{M} 435 / 02 / 3$ & 2 \\
\hline Humano & 253 & 13 & Foca & $\mathrm{M} 85 / 00 / 2$ & Indeterminado \\
\hline Humano & $00-P-2730$ & Indeterminado & Pavo & CA90 BB02 & Indeterminado \\
\hline Humano & 00-P-2796 & 2 & Pavo & CA90 BB1334 & Indeterminado \\
\hline Humano & 345 & 3 & Pavo & $\mathrm{F}-1$ & 3 \\
\hline
\end{tabular}

Al analizar las secuencias de los 58 genomas publicados encontramos la dificultad de que en muchos casos la región correspondiente a la secuencia homóloga a BB1186 tampoco se encontraba completa. Esto pone de manifiesto la gran dificultad que existe para secuenciar esta región por métodos masivos. En aquellas cepas en donde esta región estaba completa vemos que el número de repeticiones que presenta la secuencia homóloga a BB1186 se encuentra entre 2 y 15 con una media de 3. Ninguna de las cepas analizadas presenta una sola repetición tal como determinamos para nuestra cepa de trabajo. Este resultado podría implicar que el resultado obtenido luego de ambas rondas de secuenciación podría no ser correcto. En capítulos posteriores presentaremos más evidencia a favor de esta hipótesis.

\section{Conclusiones y discusión}

La cantidad y versatilidad de herramientas informáticas sumado a la creciente disponibilidad de datos biológicos con que contamos hoy en día hace casi indispensable comenzar el estudio de cualquier área de la biología molecular empleando estas herramientas disponibles. 


\section{Capítulo 2}

Mediante el análisis in silico del genoma de B. bronchiseptica identificamos un grupo de secuencias que reúnen un conjunto de características que las hacen buenos candidatos a regular la formación de biofilm a través de c-di-GMP. BB1184, BB1185 y BB1186 podrían formar parte, en $B$. bronchiseptica, de un mecanismo de control de la formación de biofilm análogo a las proteínas LapD, LapG y LapA en $P$. fluorescens ${ }^{140}$ (Figura 2.1). Gracias a la profundidad con la que estas proteínas han sido estudiadas existe abundante información sobre el funcionamiento de este sistema a nivel aminoacídico y estructural. Esta información nos permitió realizar un análisis detallado de las secuencias y estructuras de BB1184, BB1185 y BB1186 con el objetivo de determinar la presencia o no de residuos aminoacídicos y características estructurales que han sido reportados como importantes para ejecutar sus respectivas funciones.

Como resultado de ese análisis determinamos que las secuencias encontradas presentan características comunes con las proteínas LapD, LapG y LapA.

El dominio EAL de BB1184 presenta diferencias notables con el dominio EAL de proteínas LapD descriptas en $P$. fluorescens, $P$. putida, $P$. aeruginosa y $L$. pneumophila (Figura 2.4). La gran flexibilidad que presenta la molécula de c-di-GMP le permite adoptar multiplicidad de conformaciones y como consecuencia de ello es que existe una gran diversidad de dominios capaces de unir esta molécula ${ }^{81,251}$. Esta característica de la molécula de c-di-GMP hace difícil predecir por métodos bioinformáticos si un dominio es capaz o no de unir c-di-GMP. Por ende, la diferencia a nivel de secuencia entre el dominio EAL de BB1184 y el dominio EAL de LapD no puede ser considerada como una evidencia de que BB1184 no sería capaz de unir c-di-GMP. Si bien el resto de la evidencia sugiere que BB1184, al igual que LapD sería capaz de unir c-di-GMP, podría ser necesaria la realización de ensayos a fin de determinar empíricamente esta hipótesis. La técnica de calorimetría de titulación isotérmica (ITC), constituye una técnica utilizada para determinar interacciones biológicas entre proteínas o entre proteínas y ligandos que podría ser útil a fin de demostrar esta hipótesis ${ }^{259}$.

En el entorno génico de las secuencia BB1186 encontramos secuencias que podrían codificar para componentes del sistema de secreción tipo I. Este sistema de secreción, al igual que en $P$. fluorescens ${ }^{63,136}$ podría constituir el mecanismo mediante el cual BB1186 es traslocada hasta la membrana plasmática. En forma simultánea pero independiente al desarrollo de nuestro trabajo, el grupo de Y. Horiguchi de la Universidad de Osaka (Japón) identificó y caracterizó estructuralmente la secuencia BB1186²60. Basándose en la presencia del dominio RTX en el extremo C-terminal designaron a la secuencia BB1186 como BrtA por las siglas en inglés de $\underline{B} o r d e t e l l a \underline{R} T X$ family a $\underline{\text { adhesin. }}$ El mencionado trabajo confirma nuestra observación original de que los genes BB1188- 
BB1191 codifican para el sistema de secreción tipo I encargado de la secreción de BrtA $^{260}$.

Adhesinas gigantes de la familia de LapA han sido descriptas en $P$. fluoresces ${ }^{261}$, L. pneumophila ${ }^{262}$, P. putida ${ }^{263}$, Shewanella Oneidensis ${ }^{264}$, Pectobacterium atrosepticum $^{265}$ y $V$. cholerae 266 . Todas estas adhesinas presentan un arreglo de dominios similar al encontrado en BB1186. La presencia de elementos comunes en adhesinas de organismos tan variados demuestra que la funcionalidad del sistema está muy conservada incluso entre organismos filogenéticamente no relacionados. Sin embargo, entre las adhesinas tipo LapA de los organismos antes mencionados existen diferencias importantes en la región media correspondiente a la zona de repeticiones. Las diferencias en esta región se dan no sólo en número sino también a nivel de secuencia. La deleción de esta región en $P$. fluorescens y en $B$. bronchiseptica ha puesto de manifiesto la importancia de esta zona en la adhesión y formación de biofilm ${ }^{127,260}$. Estos datos sugieren que, en cada organismo, esta región ha ido evolucionando en forma particular para adaptarse a las superficies específicas a las que se enfrentan en sus respectivos nichos. El análisis de las secuencias homólogas a BB1186 en 58 aislamientos de $B$. bronchiseptica demuestra también una gran variabilidad en el número de repeticiones incluso dentro de un misma especie. Mediante este análisis, no observamos ninguna correlación entre el número de repeticiones y el origen del aislamiento.

Al analizar el genoma de la cepa $B$. pertussis Tohama I vimos que las secuencias BB1184, BB1185 y BB1186 son parte de un grupo de genes que se perdieron durante el proceso evolutivo de $B$. pertussis. La teoría más aceptada hoy en día indica que la gran reducción en el genoma de $B$. pertussis está directamente relacionada con su adaptación a su único nicho de colonización conocido que son las vías respiratorias de humanos ${ }^{153}$. En este contexto, la pérdida de las secuencias BB1184, BB1185 y BB1186 sugiere que su función no era indispensable para la colonización de este nicho o bien que su función fue reemplazada por otras proteínas.

$\mathrm{Si}$ bien los resultados mostrados hasta el momento constituyen un fuente de información que avala la hipótesis de que un sistema tipo Lap podría funcionar en $B$. bronchiseptica, esto sólo constituye el principio del análisis. El análisis funcional de BB1184, BB1185 y brtA (BB1186) será abordado en los siguientes capítulos. 



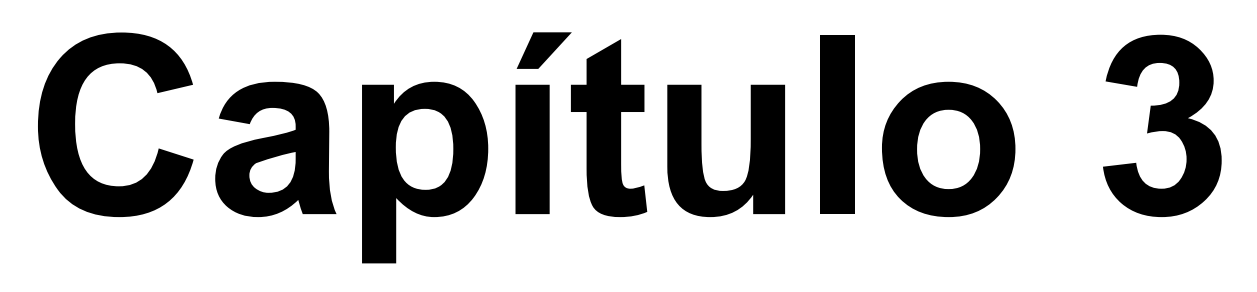

BrtA regula la formación de

biofilm en $B$. bronchiseptica 



\section{Introducción}

La adhesina LapA es un factor indispensable para la formación de biofilm en $P$. fluorescens ${ }^{63}$. La localización de esta proteína sobre la membrana plasmática está controlada de manera post transcripcional a través del segundo mensajero c-di-GMP. Debido a que esta adhesina está involucrada en etapas iniciales del proceso de formación de biofilm, su ausencia conlleva a la imposibilidad de $P$. fluorescens de desarrollar estas estructuras ${ }^{63}$.

Los resultados presentados en el capítulo anterior sugieren que la secuencia BB1186 presenta características comunes con la adhesina LapA de P. fluorescens. BB1186 al igual que LapA presenta una región de repeticiones en la zona media de la proteína y un dominio RTX, un dominio del tipo factor A de Von Willebrand y secuencias de señalización para sistema de secreción tipo I en el extremo C-terminal. Estas observaciones nos condujeron a la hipótesis de que BB1186 podría ser una adhesina involucrada en la formación de biofilm en $B$. bronchiseptica.

La secuencia BB1186 ha sido denominada brtA por el grupo de investigación liderado por Y. Horiguchi de la Universidad de Osaka (Japón) ${ }^{260}$. La denominación acuñada responde al nombre en idioma inglés "Bordetella $\underline{R} T X$-family $\underline{A} d h e s i n$ ". Por lo tanto, de aquí en más adoptaremos esa misma denominación para referirnos a BB1186.

A lo largo de siguiente capítulo presentaremos los resultados del análisis del rol de BrtA en la formación de biofilm de $B$. bronchiseptica. Para el cumplimiento de este objetivo diseñamos y obtuvimos la cepa $\Delta b r t A$ por deleción limpia mediante doble recombinación homóloga y evaluamos su capacidad de formación de biofilm sobre diferentes superficies. Debido a que la formación de biofilm en $B$. bronchiseptica está regulada por el sistema de dos componentes BvgAS, el aporte de BrtA a este proceso fue analizado en todas las fases de virulencia. Además, presentaremos la metodología utilizada para determinar la presencia de esta adhesina en el sobrenadante de cultivo de la cepa $B$. bronchiseptica salvaje y la aplicación de este resultado para la obtención de anticuerpos específicos contra esta proteína.

\section{BrtA es una adhesina involucrada en la formación de biofilm en B bronchiseptica}

Con el objetivo de evaluar la hipótesis de que BrtA (BB1186) es una adhesina involucrada en la formación de biofilm en $B$. bronchiseptica obtuvimos la cepa $\triangle b r t A$ por deleción limpia de la secuencia BB1186. Secuencias de 600 pares de bases río arriba y río debajo de BB1186. fueron amplificadas por PCR y clonadas en el vector PMQ30 no replicativo en $B$. bronchiseptica. Mediante una estrategia basada en la doble 


\section{Capítulo 3}

recombinación homóloga de las secuencias antes amplificadas y la utilización del marcador de contra selección sacB seleccionamos los clones recombinantes. La deleción de la secuencia BB1186 fue corroborada mediante PCR.

En B. bronchiseptica, la formación de biofilm está regulada a través del sistema de dos componentes BvgAS ${ }^{222,223}$. Mientras que en fase virulenta y avirulenta la formación de biofilm es moderada, en fase intermedia se observan altos niveles de formación de biofilm. Debido a que desconocíamos si BrtA participaba de la formación de biofilm en alguna fase en particular, el efecto de la deleción de $b r t A$, tuvo que ser evaluado en condiciones de cultivo que modulen el sistema BvgAS en diferentes fases de virulencia. En condiciones de laboratorio, la actividad del sistema de dos componentes puede ser modulada a través de la adición de concentraciones milimolares de ácido nicotínico al medio de cultivo ${ }^{193}$. Considerando la necesidad de utilizar una estrategia experimental que nos permitiera analizar diversas condiciones de cultivo de manera simultánea decidimos utilizar la estrategia de formación de biofilm en microplacas de policloruro de vinilo $(P V C)^{267}$. Este método experimental constituye una herramienta versátil que ha sido previamente utilizada por integrantes de nuestro laboratorio para la caracterización de la formación de biofilm en $B$. bronchiseptica ${ }^{224}$. Esta estrategia permite el estudio de las etapas iniciales de la formación de biofilm y la identificación de factores necesarios durante esa etapa del proceso ${ }^{267}$.

Para el desarrollo de estos experimentos se prepararon cultivos de la cepa salvaje y $\triangle b r t A$ abarcando un rango de concentraciones de ácido nicotínico desde $0 \mathrm{mM}$ hasta 4,0 mM de manera tal de modular al sistema de dos componentes BvgAS en todas las fases de virulencia. Es preciso destacar que el medio de cultivo SS posee una concentración de ácido nicotínico de 0,032 mM sin embargo, esa concentración no es suficiente para modular el sistema de dos componentes BvgAS $^{233}$. En lo subsiguiente, cada vez que hagamos mención a que el medio de cultivo fue suplementado con ácido nicotínico significa que la concentración indicada fue agregada por sobre el nivel que contiene de base el medio SS. Las microplacas de cultivo fueron incubadas a $37^{\circ} \mathrm{C}$ durante 24 horas y transcurrido ese tiempo se retiró la suspensión bacteriana y se realizaron lavados con agua destilada. A fin de visualizar y cuantificar la formación de biofilm, las fosas fueron incubadas durante 30 minutos con solución de cristal violeta $0,1 \%$. Transcurrido ese tiempo, la solución colorante fue retirada y las fosas fueron lavadas con agua destilada para eliminar los restos de cristal violeta que no hubieran teñido el biofilm. 
El biofilm formado se visualiza como una línea en la región de la fosa de cultivo donde se encontraba la interfase entre la suspensión

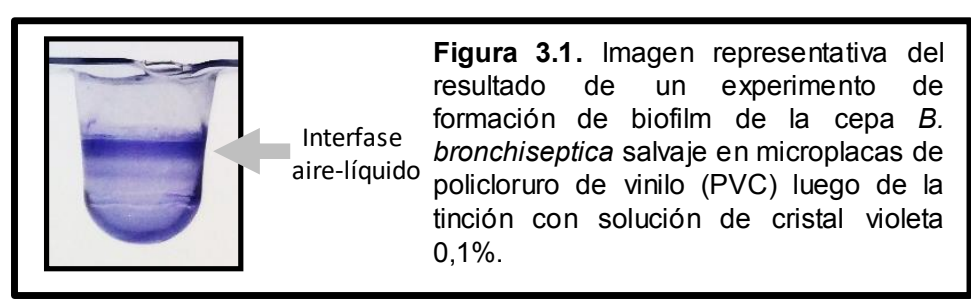
bacteriana y el aire (Figura 3.1).

Por debajo de esta región, alejándonos de la zona correspondiente a la interfase aire-líquido, se aprecia una zona de coloración menos intensa que se reduce gradualmente hasta el fondo de la fosa. Para obtener una medida cuantitativa de este ensayo se deben adicionan $125 \mu \mathrm{L}$ de ácido acético $33 \% \mathrm{v} / \mathrm{v}$ para disolver el cristal violeta y la solución obtenida es cuantificada mediante espectrofotometría a $595 \mathrm{~nm}$.

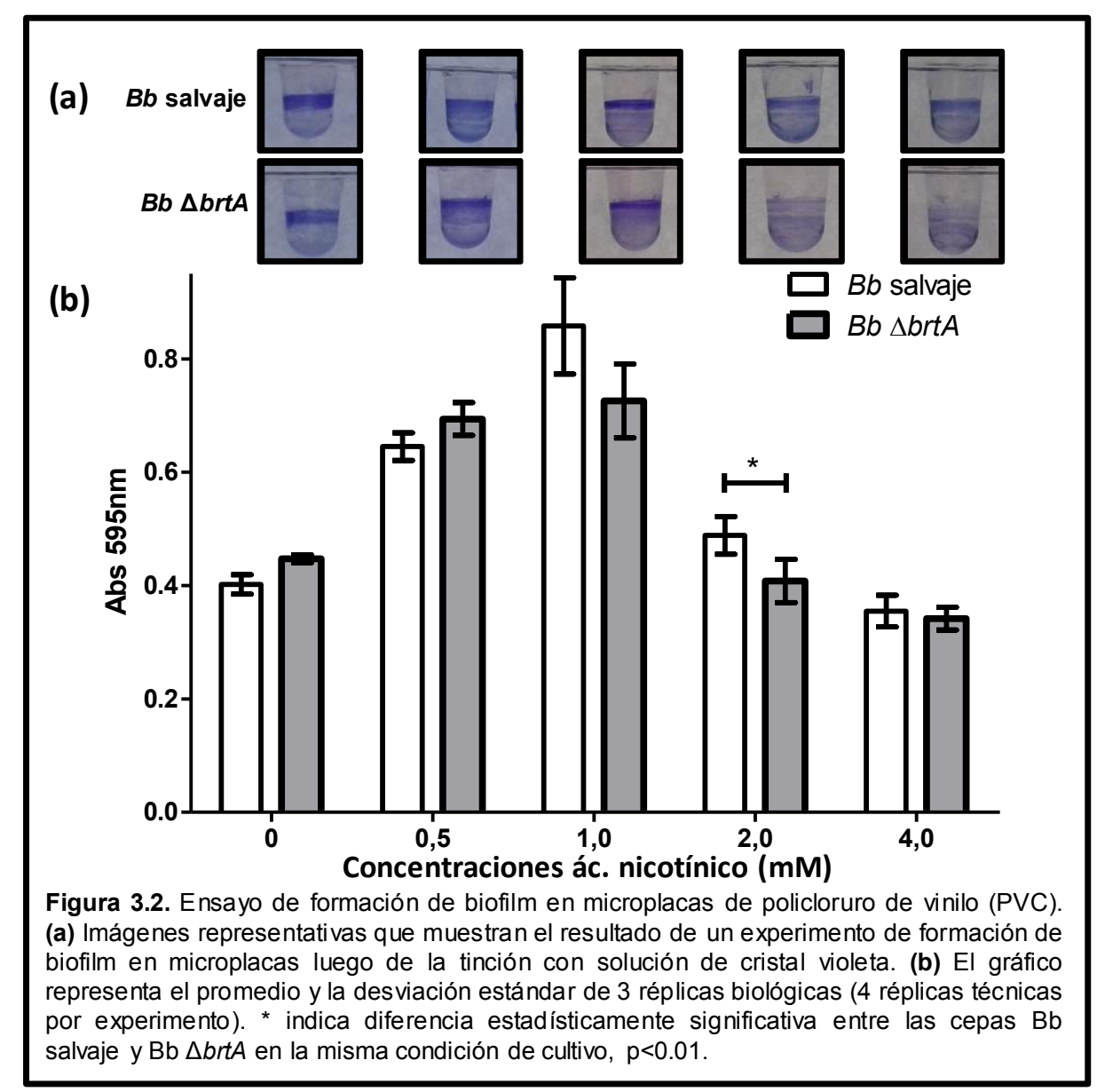

La Figura 3.2 muestra los resultados del experimento de formación de biofilm en microplacas de PVC de la cepa $B$. bronchiseptica salvaje y la cepa $B$. bronchiseptica $\triangle b r t A$ en distintas fases de modulación del sistema de dos componentes BvgAS. En primer lugar, tal como destacáramos previamente, el análisis de la formación de biofilm de la cepa salvaje muestra una región de intensa coloración en la superficie 


\section{Capítulo 3}

correspondiente a la zona de la interfase entre la suspensión bacteriana y el aire. Si bien esta característica se aprecia en todas las condiciones de cultivo, la mayor intensidad y máxima formación de biofilm la encontramos en cultivos realizados con una concentración de 1,0 mM de ácido nicotínico. Esta observación coincide con resultados publicados previamente por nuestro grupo y otros grupos de investigación que dan cuenta de que la máxima formación de biofilm se produce en concentraciones intermedias de ácido nicotínico ${ }^{222-224}$. Estos niveles de ácido nicotínico inducen la modulación fenotípica del sistema BvgAS a una fase de virulencia intermedia ${ }^{193}$.

El análisis cuantitativo de los resultados muestra una reducción modesta pero significativa en la formación de biofilm de $\Delta b r t A$ en comparación a la cepa salvaje en cultivos con una concentración de ácido nicotínico de 2,0 mM ( $p<0.01$ ) (Figura 3.2.b). La inspección directa de las fosas teñidas con cristal violeta nos permite apreciar las diferencias en las características macroscópicas de los biofilms formados por la cepa salvaje y la cepa $\triangle b r t A$. En la Figura 3.2.a se observan diferencias tanto en 2,0 mM como en 4,0 mM. Estas diferencias se produjeron principalmente en la región correspondiente a la interfase aire-líquido. Por debajo de esta región no se aprecian diferencias importantes entre las cepas.

Al comparar los resultados cualitativos con los datos cuantitativos que presentamos previamente, vemos que el análisis cuantitativo de la condición 4,0 mM no mostró diferencias significativas entre la cepa salvaje y la cepa $\Delta b r t A$. Esto puede deberse a que la deleción de brtA no suprimió la formación de biofilm, sino que la redujo en la zona de la interfase, pero casi no la alteró en la región inferior de las fosas.

Los resultados presentados en los párrafos anteriores sustentan la hipótesis de que BrtA participa en la formación de biofilm de B. bronchiseptica, al menos sobre la superficie hidrofóbica de las microplacas de cultivo analizadas. Con el objetivo de estudiar el aporte de BrtA sobre una superficie alternativa, analizamos la formación de biofilm en tubos de vidrio de silicato. A diferencia del material utilizado previamente, el vidrio de silicato presenta propiedades más hidrofílicas que el PVC.

La Figura 3.3 muestra los resultados de formación de biofilm en tubos de vidrio de las cepas $B$. bronchiseptica salvaje y $\triangle b r t A$. Estos resultados muestran una notable diferencia en formación de biofilm de la cepa $\triangle b r t A$ en comparación a la cepa salvaje en cultivos con una concentración de ácido nicotínico de 2,0 mM. Mientras la cantidad de biofilm desarrollada por la cepa salvaje aumentó entre las 48 y las 96 horas, el defecto en la formación de biofilm de la cepa $\Delta b r t A$ no pudo ser revertido aún tras 96 horas de incubación.

Con el objetivo de profundizar el análisis del rol de BrtA, analizamos la formación de biofilm de la cepa salvaje y la cepa $\triangle b r t A$ mediante microscopía electrónica de barrido 
(SEM). Para el desarrollo de estos experimentos, utilizamos un diseño experimental que contempla la formación de biofilm sobre cubreobjetos semi sumergidos en cultivos incubados durante 48 horas a $37^{\circ} \mathrm{C}$ sin agitación. Luego de esta incubación, los biofilms fueron fijados mediante una solución de glutaraldehído-PBS 2,5\% v/v para luego ser sometidos a un tren de deshidratación con alcohol etílico y posteriormente secados por la técnica de punto crítico. Finalmente, las muestras fueron metalizadas con oro para ser observadas mediante microscopía electrónica de barrido (SEM).

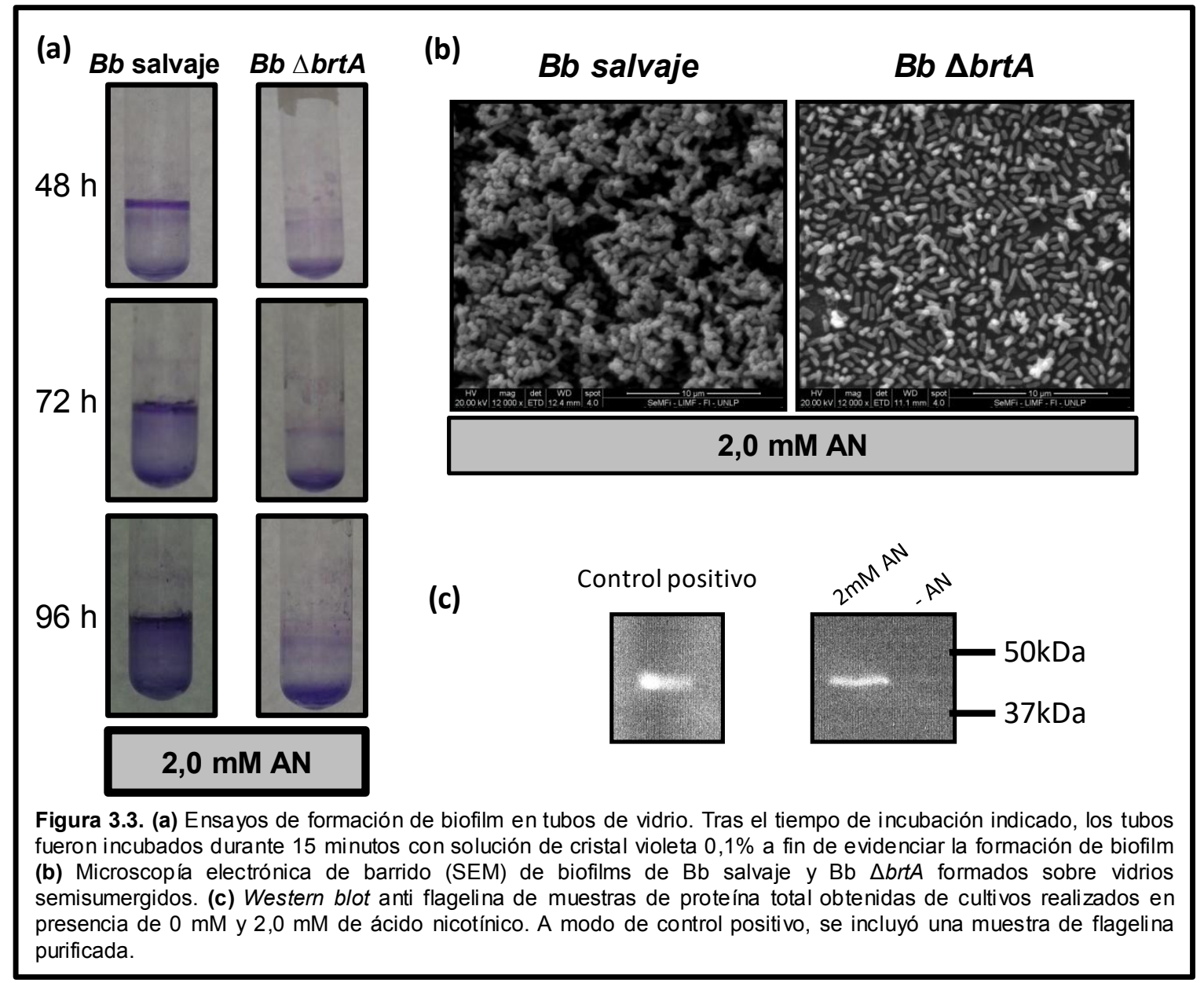

La cepa B. bronchiseptica salvaje muestra estructuras características de la formación de biofilm donde se distinguen aglomeraciones de bacterias con desarrollo en altura y la presencia de canales entre los aglomerados (Figura 3.3.b). Por el contrario, la observación microscópica de la cepa $\Delta b r t A$ pone de manifiesto la imposibilidad de esta cepa de desarrollar estructuras del tipo de biofilm. En estas imágenes se observa que la cepa $\triangle b r t A$ presenta un número menor de bacterias adheridas directamente a la superficie. Por otro lado, también se observan muy pocas bacterias que presenten contacto directo entre ellas (Figura 3.3.b). Estas observaciones podrían sugerir que BrtA 


\section{Capítulo 3}

participaría de la formación de biofilm mediando la interacción de las bacterias a la superficie y también entre bacterias.

Dado que nuestros experimentos muestran el defecto en la formación de biofilm de la cepa $\triangle b r t A$ en presencia de concentraciones de ácido nicotínico de 2,0 mM nos preguntamos a qué fase de virulencia corresponde esta condición de cultivo. Datos de bibliografía indican que por encima de 1,6 mM B. bronchiseptica presenta un modulación fenotípica de fase avirulenta ${ }^{193,222}$. A fin de confirmar si en nuestras manos, en cultivos que presentan una concentración de $2,0 \mathrm{mM}$ de ácido nicotínico $B$. bronchiseptica se encuentra en fase avirulenta, analizamos la presencia de flagelina en muestras de proteína total. El flagelo es un factor de avirulencia que no se expresa en fase virulenta ni intermedia y por lo tanto constituye un reportero confiable de la fase en la que se encuentra la bacteria en nuestras condiciones de cultivo ${ }^{228}$.

Para determinar la presencia de flagelina, realizamos cultivos de 16 horas, a $37^{\circ} \mathrm{C}$ con agitación en condiciones de $0 \mathrm{mM}$ y 2,0 mM de ácido nicotínico. Se prepararon muestras de proteína total y se analizaron mediante Western blot utilizando un anticuerpo primario anti-flagelina.

Los resultados de este ensayo muestran que, en las condiciones de cultivo analizadas, en presencia de 2,0 mM de ácido nicotínico hay expresión de flagelina (Figura 3.3.c). Este resultado confirma, tal como está descripto en la bibliografía, que en cultivos conteniendo una concentración de ácido nicotínico de 2,0 mM B. bronchiseptica se encontraría en fase avirulenta.

En conclusión, los resultados presentados en esta sección demuestran que BrtA es un factor involucrado en la formación de biofilm de $B$. bronchiseptica. En el defecto en la formación de biofilm de la cepa $\Delta b r t A$ se hace mucho más evidente sobre la superficie hidrofílica de los tubos de vidrio de silicato. Este resultado da cuenta de que la contribución de BrtA a la formación de biofilm resulta dependiente de la naturaleza de la superficie. Por último, los resultados del ensayo de microscopía electrónica de barrido confirman la importancia de BrtA y aportan evidencia acerca del rol específico de esta adhesina en el proceso global de formación de biofilm. Estas observaciones podrían indicar que BrtA tendría un rol decisivo en la adhesión de B. bronchiseptica a la superficie, así como también en las interacciones célula-célula que resultan vitales para un óptimo desarrollo de las estructuras características de los biofilm bacterianos. 


\section{Purificación de BrtA a partir de sobrenadantes de cultivo de $B$. bronchiseptica}

Para avanzar con la caracterización funcional de BrtA en B. bronchiseptica y su rol durante la formación de biofilm consideramos importante contar con un método para evaluar la localización de BrtA frente a diversos estímulos a los que los cultivos bacterianos podrían ser expuestos. En este sentido, para el desarrollo de experimentos de Western blot o dot blot es preciso contar con anticuerpos específicos contra BrtA. Con este objetivo nos propusimos purificar BrtA a fin de poder utilizarla como inmunógeno en un plan de inmunización para obtener suero policlonal contra esta adhesina.

Las adhesinas de la familia de LapA pueden encontrarse asociadas a la membrana plasmática o bien secretadas al medio de cultivo. Dado que la complejidad en la composición de los sobrenadantes de cultivo es menor que la de proteínas totales, consideramos factible purificar la adhesina BrtA a partir de sobrenadantes de cultivo de la cepa $B$. bronchiseptica salvaje.

Para estos experimentos realizamos cultivos en medio SS a $37^{\circ} \mathrm{C}$ durante 16 horas con agitación. Transcurrida esta incubación, el paquete celular fue separado por centrifugación y descartado. El sobrenadante de cultivo fue concentrado utilizando filtros Amicon Ultra de $100 \mathrm{kDa}$. Dado que BrtA forma parte de la familia de adhesinas gigantes y que tal como describimos en el Capítulo 2, el tamaño esperado es superior a los 200 $\mathrm{kDa}$, utilizamos filtros de concentración con un límite de corte de $100 \mathrm{kDa}$ a fin de reducir la complejidad de la muestra. Finalmente, las muestras de sobrenadante concentrado fueron analizadas mediante SDS-PAGE. 


\section{Capítulo 3}

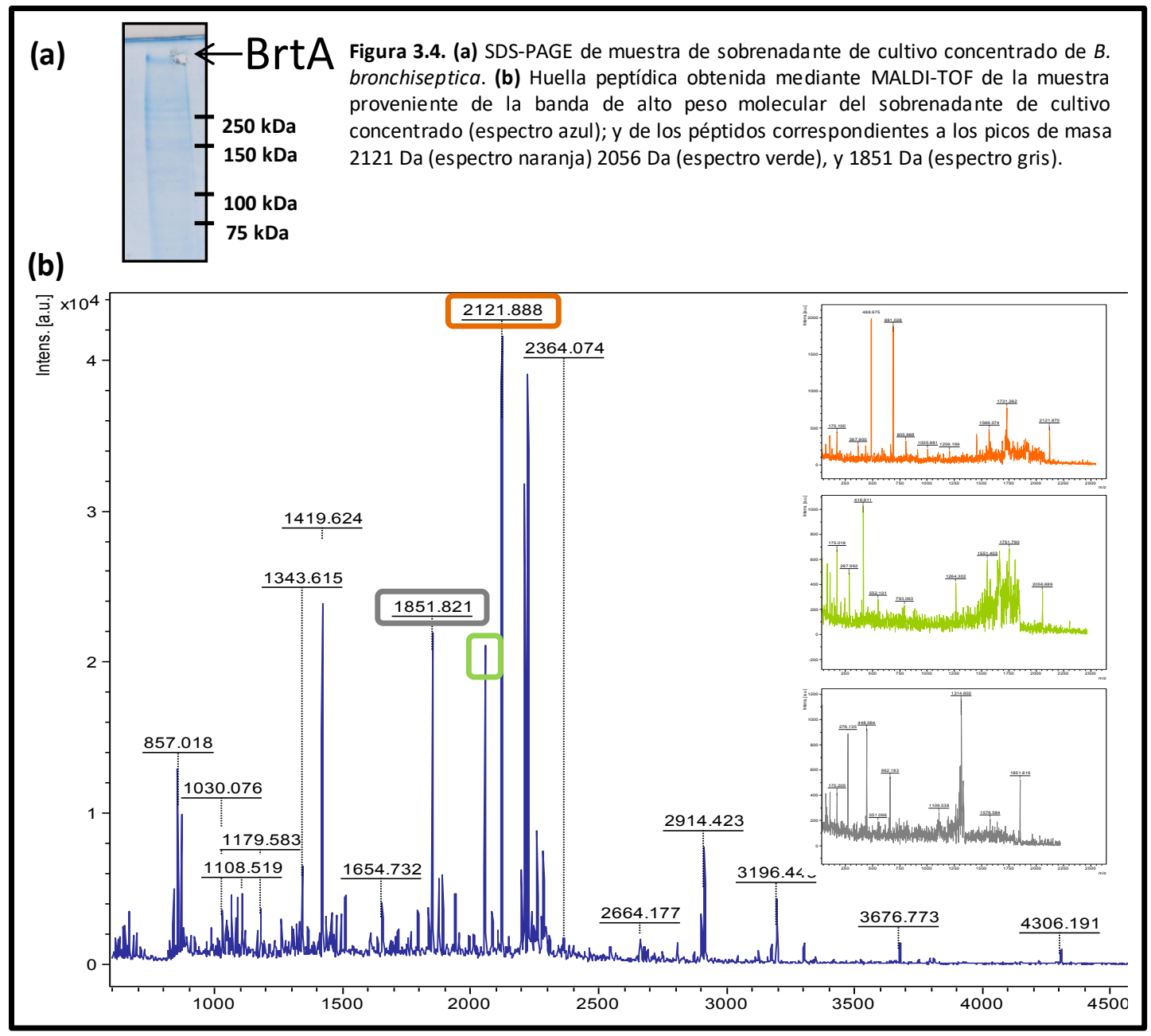

La Figura 3.4.a muestra el resultado de los experimentos de SDS-PAGE de sobrenadantes de cultivo concentrados de la cepa B. bronchiseptica salvaje. El perfil electroforético obtenido muestra la presencia de una banda alto peso molecular ubicada por encima de los $300 \mathrm{kDa}$. Si bien el análisis de los resultados de secuenciación presentados en Capítulo 2 arrojó como resultado que la proteína BrtA de la cepa $9.73 \mathrm{H}+$ tendría un peso molecular de 208 kDa consideramos importante avanzar en la identificación de esta banda a fin de determinar si podría tratarse de BrtA.

Con la intención de determinar si la banda observada corresponde a BrtA realizamos su identificación por Huella Peptídica (PMF por sus siglas en inglés Peptide Mass Fingerprint) mediante MALDI-TOF (Matrix Assisted Laser Desorption/lonizationTime of Flight) ${ }^{268}$ en el servicio del Centro de Estudios Químicos y Biológicos por Espectrometría de Masa (CEQUIBIEM).

Como resultado de la espectroscopía MALDI-TOF logramos identificar y determinar la masa de 14 péptidos producidos tras la digestión tríptica (Figura 3.4.b, espectro azul). Estas masas fueron comparadas con la masa teórica de los péptidos obtenidos por digestión in silico de todas las proteínas bacterianas de la base de datos 
MASCOT ${ }^{269}$. A su vez, tres de esos péptidos fueron fragmentados para determinar su secuencia aminoacídica (paneles de la derecha) ${ }^{270}$. El análisis de este conjunto de datos arrojó como resultado la identificación de BrtA con un score de $265(p<0.05)$ en la muestra proveniente de la banda de alto peso molecular del sobrenadante de cultivo de $B$. bronchiseptica. En base a este resultado, además corroboramos que el peso molecular de BrtA de la cepa $9.73 \mathrm{H}+$ es aproximadamente 300 kDa y no 208 kDa como habíamos determinado en el Capítulo 2.

Este resultado implica, en primer lugar, que BrtA se expresa en las condiciones de cultivo utilizadas. En segundo lugar, pone de manifiesto que BrtA puede ser purificada a partir de sobrenadantes de cultivo de $B$. bronchiseptica.

\section{Plan de inmunización para la obtención de anticuerpos anti-BrtA}

Para la obtención de suero anti-BrtA diseñamos un plan de inmunización que contempló la inoculación intraperitoneal de un ratón BALB/c hembra de 5 semanas de edad. Como agente inmunógeno se utilizó el material proveniente de la banda electroforética correspondiente a la proteína BrtA disgregada mecánicamente (5-10 $\mu \mathrm{g})$. Para potenciar la respuesta inmunológica se utilizó adyuvante de Freund completo, en la primera inoculación, e incompleto en las siguientes. La frecuencia de inoculación fue de 15 días y el plan de inmunización fue seguido mediante ensayos de Western blot.

Al cabo de tres inoculaciones no fue posible detectar la presencia de anticuerpos específicos contra BrtA en el suero obtenido del ratón inoculado. En consecuencia, decidimos discontinuar el desarrollo de este experimento y avanzar hacia estrategias alternativas para poder identificar en forma específica a BrtA. La estrategia y los resultados obtenidos en la marcación específica de BrtA serán presentados en el Capítulo 5.

\section{Conclusiones y Discusión}

Los resultados presentados en este capítulo demuestran que BrtA es un factor involucrado en la formación de biofilm de B. bronchiseptica (Figura 3.2). El rol de esta adhesina en el proceso de formación de biofilm constituye un área de estudio que no había sido abordada hasta el comienzo de este trabajo de tesis. Los resultados del grupo de $\mathrm{Y}$. Horiguchi ${ }^{260}$ fueron publicados en el año 2015 cuando esta tesis se encontraba en pleno desarrollo y los experimentos de este capítulo ya habían sido realizados. Nuestro trabajo y el de Nishikawa et al. ${ }^{260}$. muestran, en forma independiente, que BrtA participa de la formación de biofilm en $B$ bronchiseptica. 


\section{Capítulo 3}

Considerando que el sistema de dos componentes BvgAS regula la formación de biofilm en $B$. bronchiseptica ${ }^{197,223,224}$, consideramos indispensable analizar el rol de BrtA en las distintas fases de virulencia reguladas por este sistema. Utilizamos ácido nicotínico como modulador del sistema de dos componentes de manera tal de abarcar condiciones de cultivos en las cuales las bacterias se encontraran en todas las fases de virulencia. Como resultado de nuestros experimentos determinamos que la ausencia de BrtA induce defectos en la formación de biofilm en condiciones de cultivo que presentan concentraciones de 2,0 mM y 4,0 mM de ácido nicotínico (Figura 3.2). La diferencia entre la cepa salvaje y la cepa $\Delta \mathrm{brtA}$, en $2,0 \mathrm{mM}$, se evidenció tanto de manera cualitativa como cuantitativa. Por el contrario, para la condición 4,0 mM, la observación directa del biofilm teñido con cristal violeta permitió visualizar el defecto de la cepa $\Delta b r t A$, sin embargo, el análisis cuantitativo en esta condición no reflejó la diferencia observada. Nuestro grupo posee experiencia previa en el estudio de biofilm mediante la técnica de cultivo en microplaca y esta aparente contradicción no resulta sorprendente. En más de una oportunidad hemos observado diferencias en la formación de biofilm que luego no se traducen en diferencias estadísticamente significativas tras el procesamiento cuantitativo. Para la determinación cuantitativa del biofilm formado es necesario disolver el cristal violeta con una solución de ácido acético. En esta etapa del protocolo pueden quedar enmascaradas diferencias en la distribución del biofilm. Por este motivo, es importante realizar un análisis visual de la formación de biofilm antes de proceder a la determinación cuantitativa. Esta aparente desventaja del método de análisis utilizado no condiciona, sin embargo, la gran utilidad que posee para analizar una gran cantidad de variables de cultivo en simultáneo.

En ensayos de Western blot detectamos la presencia de flagelina en bacterias provenientes de cultivos realizados en presencia de una concentración de ácido nicotínico de 2,0 mM (Figura 3.2.b). Dado que la flagelina es un factor que sólo se expresa en condiciones de cultivo de fase avirulenta ${ }^{228}$, este resultado sugiere que en esta condición de cultivo las bacterias se encontrarían en fase Bvg- (avirulenta). Este resultado es coherente con reportes previos que indican que en cultivos con concentraciones superiores a 1,6 $\mathrm{mM}$ de ácido nicotínico $B$. bronchiseptica se encontraría en fase Bvg196,222 .

El hecho que el defecto en la formación de biofilm de la cepa $\triangle b r t A$ se ponga de manifiesto en condiciones de cultivo que modulan a la bacteria a fase Bvg- plantea dos escenarios posibles. El primero es que, tal como ha sido propuesto por el grupo de $\mathrm{Y}$. Horiguchi, BrtA sea una proteína que se expresa sólo bajo condiciones Bvg- ${ }^{260}$.Sin embargo, en nuestras manos, fue posible identificar la presencia de BrtA en sobrenadantes concentrados provenientes de cultivos en condiciones Bvg+ (Figura 
3.3.a). Esta observación nos obliga a considerar los motivos por los cuales la cepa $\Delta b r t A$ podría no presentar defectos en la formación de biofilm en cultivos con concentraciones de ácido nicotínico de hasta 1,0 mM. La respuesta a esta pregunta nos lleva al segundo escenario posible. Existen otros factores que han sido descriptos como importantes en las etapas iniciales de la formación de biofilm en Bvg+ y Bvgi. FHA y fimbria son adhesinas que se expresan tanto en Bvg+ como en Bvgi y sin embargo sus contribuciones a la formación de biofilm son diferentes en cada fase. En experimentos realizados con el mismo sistema de cultivo empleado en nuestro trabajo se ha demostrado que fimbria es un factor necesario para la formación de biofilm sobre superficies abióticas en Bvg+ mientras que FHA es necesaria en Bvgi ${ }^{222}$. En este sentido, si bien ambas adhesinas se expresan en ambas fases, la ausencia de FHA no genera defectos en la formación de biofilm in vitro en $\mathrm{Bvg}+{ }^{222}$. De la misma manera, si bien los genes fimBCD (genes que codifican para distintas variantes fenotípicas de fimbria) se expresan en Bvg+ y en Bvgi, la deleción de estas secuencias no genera defectos en la formación de biofilm en Bvgi ${ }^{222}$. Frente a esta evidencia, si bien BrtA se estaría expresando en Bvg+ (Figura 3.3.a), su contribución a la formación de biofilm no sería tan importante como lo es en condiciones Bvg-. Esto sugiere la posibilidad de que exista una redundancia en la función de las adhesinas BrtA, FHA y fimbria. Frente a este escenario, la deleción de brtA genería defectos apreciables sobre la formación de biofilm en fase Bvg+ porque en esta condición no se expresan las otras adhesinas.

La naturaleza de la superficie sobre la cual se desarrolla el biofilm fue otra variable analizada en nuestros experimentos. Los resultados muestran que la cepa $\Delta b r t A$ presenta defectos más severos en la formación de biofilm sobre la superficie hidrofílica de los tubos de vidrio en comparación a la superficie hidrofóbica de las microplacas de cultivo (Figura 3.2 y 3.3). Este resultado implica que BrtA estaría directamente involucrada en la adhesión de la bacteria a la superficie. Para lograr una comprensión más detallada del rol de BrtA en la formación de biofilm, realizamos un análisis mediante microscopía electrónica de barrido (SEM). Estos experimentos mostraron que la ausencia de BrtA no sólo generó defectos en la adhesión a la superficie sino también en la interacción bacteria-bacteria (Figura 2.3.b). Este hecho plantea la posibilidad de que BrtA tenga la doble función de participar tanto de la adhesión a la superficie como de la adhesión entre bacterias. Dada la complejidad de la estructura de BrtA es posible que alguno de sus dominios esté involucrado en la adhesión a la superficie mientras que otro participe en la interacción entre bacterias. El rol de BrtA en la interacción bacteria-bacteria es un área que no ha sido abordada hasta el momento. Nishikawa et al. reportaron experimentos en los cuales demostraron que tanto la región de repeticiones como el factor $A$ de Von Willebrand están involucrados en la interacción a la superficie ${ }^{260}$. 


\section{Capítulo 3}

En este capítulo también presentamos el trabajo realizado con el objetivo de obtener anticuerpos específicos contra BrtA. Durante el desarrollo de estos experimentos determinamos la presencia de esta proteína, mediante la técnica MALDI-TOF, en sobrenadantes de cultivo concentrados. Estos sobrenadantes provenían de cultivos realizados en condiciones de fase virulenta $(\mathrm{Bvg}+)$. Este resultado, a diferencia de lo reportado por Nishikawa et al. ${ }^{260}$, indica que BrtA se expresa en fase virulenta (más adelante presentaremos otros datos que refuerzan esta hipótesis).

A través de los experimentos de SDS-PAGE que nos llevaron a identificar a BrtA determinamos que el peso molecular de esta proteína era superior al calculado previamente en base a resultados de secuenciación. Esta incongruencia entre el tamaño calculado en base a la secuencia nucleotídica reportada y el tamaño observado en experimentos de SDS-PAGE también ha sido destacada por otros investigadores durante el estudio de la proteína BpfA de $S$. oneidensis ${ }^{264}$, otra adhesina de la familia de LapA. El gran tamaño de estas proteínas, sumado a la complejidad de la zona de repeticiones hace sumamente compleja la determinación de la secuencia del gen ${ }^{258}$.

Por último, el plan de inmunización realizado con el objetivo de obtener suero policlonal contra BrtA no resultó exitoso. Entre las razones más relevantes consideramos que la falla puede haber estado en la cantidad de proteína administrada. A partir de los resultados obtenidos consideramos preciso el desarrollo de una estrategia experimental alternativa para poder identificar a BrtA en futuros experimentos. En el Capítulo 5 presentamos la estrategia desarrollada a fin de introducir una fusión transcripcional en la secuencia de BrtA con el objetivo de marcarla de manera específica.

Habiendo presentado evidencias de que BrtA es una adhesina involucrada en la formación de biofilm de $B$. bronchiseptica, el paso siguiente implica la descripción de su mecanismo de regulación. 


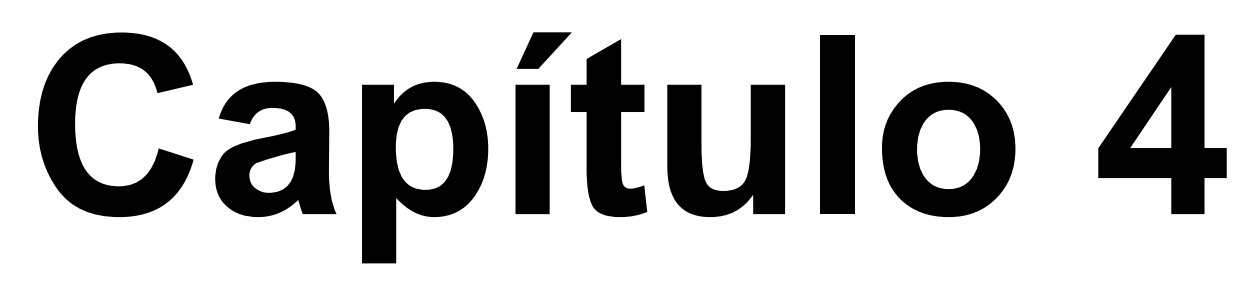

BB1184 y BB1185 son LapD y LapG

\author{
en B. bronchiseptica
}





\section{Introducción}

LapA de $P$. fluorescens es una adhesina gigante cuya localización sobre la membrana externa está regulada de manera post transcripcional a través de las proteínas LapD y LapG. El funcionamiento de este sistema está controlado a través del segundo mensajero c-di-GMP. La unión de c-di-GMP a la porción citoplasmática de LapD induce un estado conformacional que se transfiere a través de su dominio transmembrana hasta el espacio periplasmático. En estas condiciones la proteasa LapG es retenida por el dominio periplasmático de LapD y de esta manera la adhesina LapA es mantenida sobre la superficie celular favoreciendo así la formación de biofilm. La reducción en los niveles citoplasmáticos de c-di-GMP modifica el estado conformacional de LapD de manera tal que su dominio periplasmático libera a la proteasa LapG. En estas condiciones LapG difunde libremente por el periplasma hasta clivar a la adhesina LapA y liberarla de la superficie celular. La pérdida de la adhesina LapA conlleva a una reducción total en la capacidad de formación de biofilm de $P$. fluorescens.

Los resultados que presentamos en los capítulos anteriores constituyen una evidencia de que un sistema de proteínas como el descripto en el párrafo anterior podría funcionar en B. bronchiseptica. Nuestra hipótesis sugiere que BB1184 y BB1185 podrían codificar para LapD y LapG en B. bronchiseptica y regular la localización de la adhesina BrtA.

En el presente capítulo empezaremos analizando la actividad de BB1184 y BB11585 a través de una serie de experimentos de expresión heteróloga en cepas de $P$. fluorescens. La evaluación del fenotipo de formación de biofilm en este organismo nos llevará a determinar si BB1184 y BB1185 son funcionalmente equivalentes a LapD y LapG. Posteriormente analizaremos el rol de estas secuencias en la formación de biofilm en B. bronchiseptica.

A fin de simplificar la lectura e interpretación de los resultados de este capítulo, a partir de este punto reemplazaremos la nomenclatura BB1184 y BB1185 por los términos $L_{a p D} D_{B b}$ L LapG $G_{B b}$, haciendo clara referencia a nuestra hipótesis de que BB1184 y BB1185 serían, respectivamente, LapD y LapG en B. bronchiseptica. Cuando hagamos referencia a las proteínas homólogas en $P$. fluorescens nos referiremos a ellas como LapDPf $y$ LapGPf.

\section{Los genes $l a p D_{B b}$, lap $G_{B b}$ y brtA forman parte de un mismo operón}

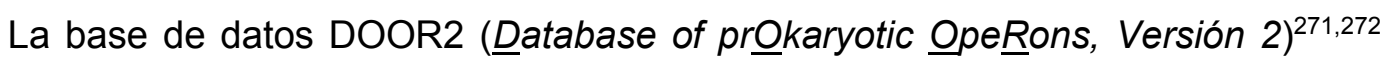
que reúne información sobre operones procariotas indica que el locus formado por lap $G_{B b}$ 


\section{Capítulo 4}

y $l a p D_{B b}$ constituye un operón en $B$. bronchiseptica. Sin embargo, mediante esta estrategia, no se reconoce a la secuencia $b r t A$ como parte del mismo operón.

Con el objetivo de determinar si brtA se transcribe de manera conjunta a lap $D_{B b}$ y $l a p G_{B b}$ realizamos $R T-P C R$ con primers que amplifican la región intergénica lap $G_{B b}-b r t A$. (Figura 4.1). Si lapG y brtA forman parte de un mismo operón, ambas secuencias deberían traducirse en un mismo ARN mensajero (ARNm). La retro transcripción de este ARNm debería generar moléculas de ADNc (ADN complementarios) que contengan las regiones de hibridación de ambos primers (F1Fw y $\mathrm{F} 1 \mathrm{Rv}$ ). Por ende, si brtA y lap $\mathrm{G}_{B b}$ forman parte de un mismo operón, se obtendría un amplicón de 396 pares de bases como resultado final de la $\mathrm{RT}-\mathrm{PCR}$.

Brevemente, la obtención de ARNm se realizó utilizando el kit Illustra RNAspin (GE, USA) de acuerdo con las especificaciones del fabricante. Las muestras fueron obtenidas de cultivos de $B$. bronchiseptica $9.73 \mathrm{H}+$ en fase logarítmica, realizados en diversas concentraciones de ácido nicotínico $(0 \mathrm{mM}, 1,0 \mathrm{mM}$ y 4,0 mM). A modo de control, estas muestras fueron sometidas a PCR de punto final utilizando los primers recAFw y recARv. Aquellas muestras que arrojaron resultados positivos (indicando la presencia de $A D N$ genómico) fueron descartadas y no se utilizaron para continuar con el procedimiento. La retro transcripción fue realizada con el kit Reverse Transcription System (Promega) de acuerdo con las especificaciones del fabricante. Por último, se realizaron controles para confirmar que el protocolo de retro transcripción hubiera sido exitoso. Para esto se utilizaron primers que hibridan en una región interna del gen recA de expresión constitutiva en todas las condiciones de cultivo analizadas.

La Figura 4.1 muestra los resultados y los controles de la RT-PCR de la región intergénica lap $G_{B b}-b r t A$ sobre muestras de $A D N c$ provenientes de bacterias cultivadas en condiciones Bvg+, Bvgi y Bvg-.

En primer lugar, la obtención de una banda por encima de los 100 pares de bases tras la PCR con primeros recA confirma la presencia de ADNc proveniente de la retro transcripción $\mathrm{ARNm}$ en todas las muestras. Esto indica que el protocolo de retro transcripción fue exitoso.

En segundo lugar, la región intergénica $l a p G_{B b}$-brtA pudo ser amplificada a partir de muestras de ADNc provenientes de bacterias en todas las condiciones de cultivo analizadas (Figura 4.1.b). Este resultado indica que las muestras de ADNc contenían moléculas que presentaban simultáneamente la región codificante de $L_{a p} G_{B b}$ y BrtA. Esto sólo puede ser posible si $l a p G_{B b}$ y brtA se transcriben en forma conjunta en un mismo ARNm policistrónico. 


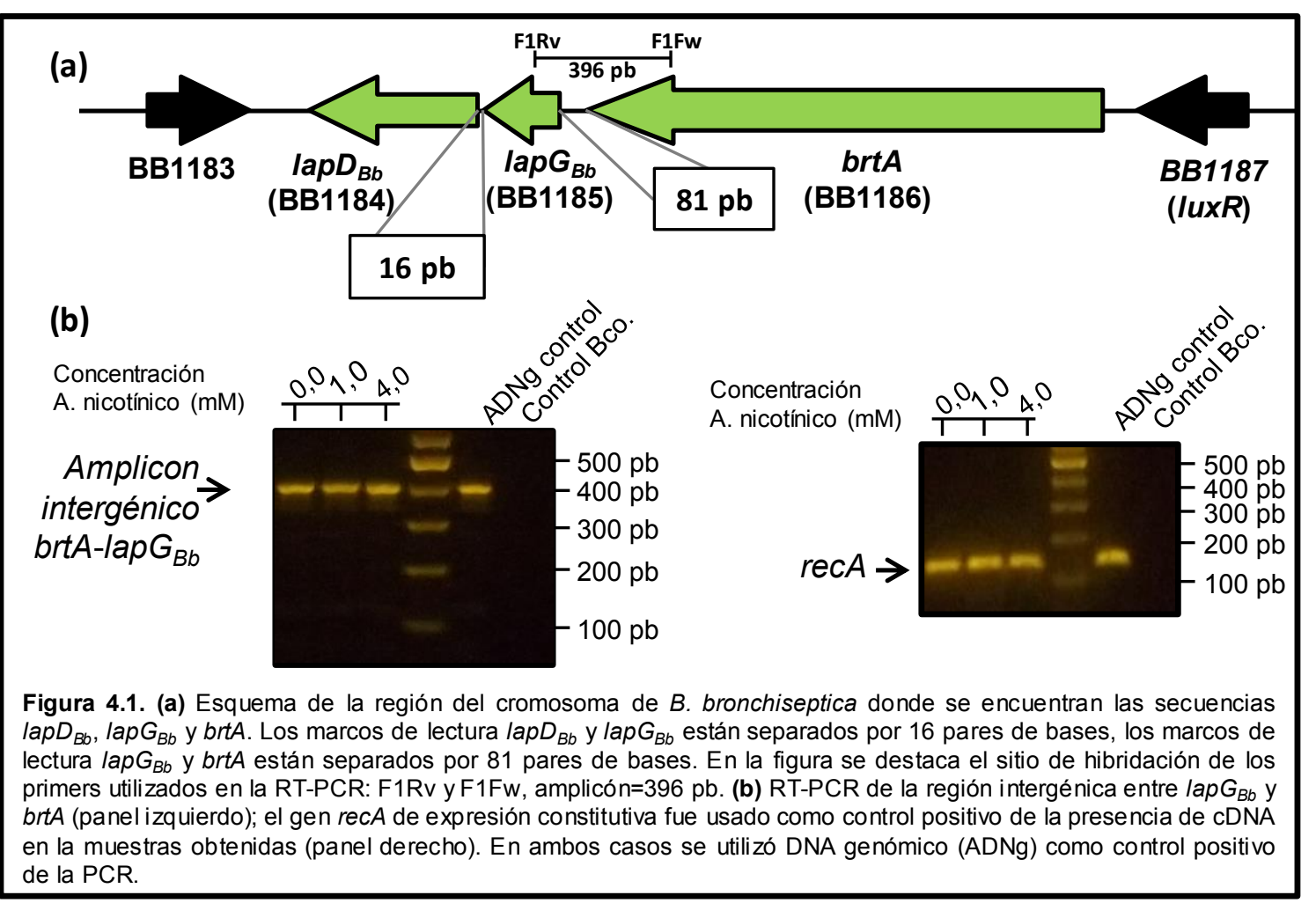

Estos resultados también indican que brtA se transcribe en todas las fases de virulencia. Esto contradice los resultados previos reportados por Nishikawa et al. que indican que brtA es un gen reprimido por el sistema de dos componentes BvgAS y sólo se expresa en condiciones de cultivo que modulan la actividad del sensor de membrana BvgS $^{260}$.

\section{Expresión heteróloga de $\operatorname{LapG}_{\mathrm{Bb}}$ y $\operatorname{LapD}_{\mathrm{Bb}}$ en $\boldsymbol{P}$. fluorescens}

La formación de biofilm es un proceso multifactorial y sujeto a diferentes variables que pueden afectar su desarrollo. En particular, Bordetella spp. posee adhesinas, exopolisacáridos, ADN extracelular y otros factores cuyo rol en la formación de biofilm ha sido demostrado ${ }^{227}$. Muchos de estos factores incluso están regulados por el sistema de dos componentes BvgAS ${ }^{197,223}$.

Como demostramos en el Capítulo 3, la deleción de brtA no genera una inhibición total de la formación de biofilm (al menos no en el sistema de cultivo en microplaca). Esto demuestra que $B$. bronchiseptica es un organismo en el cual la formación de biofilm es un proceso complejo sujeto a una diversidad de variables que aún hoy no han sido estudiadas.

Por el contrario, la formación de biofilm en $P$. fluorescens es un área de estudio mucho más desarrollada. Como resultado de esto, se conocen las condiciones de cultivo 


\section{Capítulo 4}

en las que el sistema formado por $\operatorname{LapD}_{\mathrm{Pf}}$, $\operatorname{LapG}_{\mathrm{Pf}}$ y $\mathrm{LapA}_{\mathrm{p}}$ es particularmente importante. En cultivos de 6 horas, a $37^{\circ} \mathrm{C}$, en microplacas, en un medio K10-T (medio mínimo suplementado con fosfato inorgánico) la cepa salvaje forma un biofilm bien definido en la interfase aire-líquido. Es las condiciones mencionadas, LapA constituye la principal adhesina de esta bacteria y en consecuencia la deleción de lapA o de lap $D_{\mathrm{Pf}}$ producen a una inhibición total de la formación de bioiflm ${ }^{140,253}$.

Con el objetivo de buscar alternativas experimentales para evaluar si $\operatorname{LapD}_{\mathrm{Bb}} \mathrm{y}$

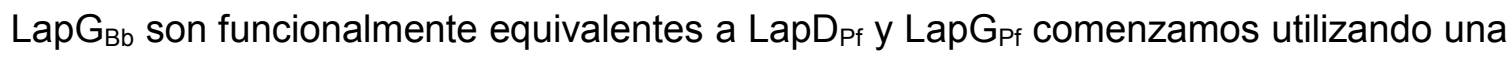
metodología de expresión heteróloga como modelo de estudio. En experimentos de coprecipitación se ha visto que LapG de L. pneumophila interacciona físicamente con la porción periplasmática de LapD de P. fluorescens ${ }^{262}$. Asimismo, LapG de L. pneumophila es capaz de clivar la porción N-terminal de LapA de $P$. fluorescens en ensayos de actividad in vitro ${ }^{262}$. Estos datos sugieren que el sistema de proteínas Lap se encuentra funcionalmente conservado incluso entre organismos filogenéticamente no relacionados. Por lo tanto, es de esperar que si $\operatorname{LapD}_{\mathrm{Bb}}$ y $\operatorname{LapG}_{\mathrm{Bb}}$ son funcionalmente equivalentes a $L_{a p D}$ y $L_{\text {apG }}$ podrían ser funcionales también en $P$. fluorescens.

\section{LapD $_{\mathrm{Bb}}$ es funcional en $\boldsymbol{P}$. fluorescens}

El análisis presentado en los capítulos anteriores sustenta la hipótesis de que

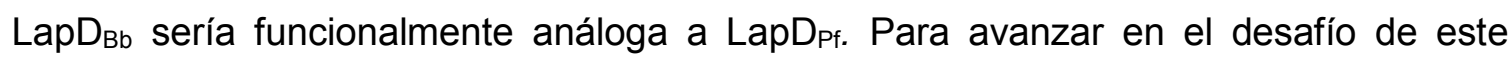
supuesto, decidimos realizar experimentos de expresión heteróloga de $\operatorname{LapD}_{\mathrm{Bb}}$ en $P$. fluorescens.

LapD $D_{\mathrm{Pf}}$ es una proteína localizada en la membrana interna con dominios que se extienden hacia el citoplasma y el periplasma ${ }^{84}$. Este factor controla la localización de LapG $_{\mathrm{Pf}}$ en función de los niveles citoplasmáticos de c-di-GMP ${ }^{140}$. En la cepa $P$. fluorescens $\triangle \mathrm{l} a p D$ la proteasa $\mathrm{LapG}_{\mathrm{Pf}}$ es libre de circular por el periplasma y en consecuencia cliva a la adhesina LapA facilitando su desprendimiento de la membrana plasmática. Como consecuencia de ello, esta cepa es incapaz de formar biofilm ${ }^{84,140,261}$. La complementación de esta cepa con la secuencia lapD $D_{P f}$ clonada el vector pMQ72 restituye los niveles de formación de biofilm a los niveles de la cepa salvaje. Los fenotipos de la cepa $\Delta l a p D_{P f}$ y la cepa complementada son notablemente diferentes por lo tanto este sistema representa un excelente modelo para probar si $\mathrm{LapD}_{\mathrm{Bb}}$ es funcionalmente equivalente a LapD $D_{\mathrm{Pf}}$.

Nuestra hipótesis de trabajo implica que, si $\operatorname{LapD}_{\mathrm{Bb}}$ y $\operatorname{LapD}_{\mathrm{Pf}}$ son funcionalmente equivalentes, $\mathrm{LapD}_{\mathrm{Bb}}$ debería ser capaz de complementar el fenotipo de formación de biofilm de la cepa $P$. fluorescens $\Delta / a p D$. Para poner a prueba esta hipótesis realizamos 
ensayos de formación de biofilm en microplacas con la cepa $P$. fluorescens $\Delta l a p D$ complementada con $L a p D_{B b}$, y los controles $L a p D_{P f}$ y el vector vacío y realizamos el análisis cualitativo y cuantitativo de los resultados.

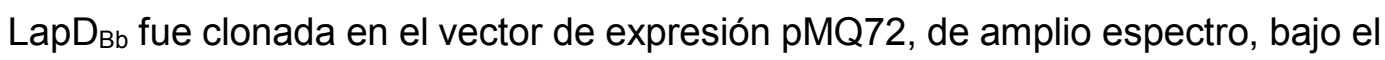
control del promotor $\mathrm{P}_{\mathrm{BAD}}$ inducible por arabinosa. A partir de esta construcción se obtuvo la cepa $P$. fluorescens $\triangle l a p D$ plap $D_{B b}$. Para los controles de este experimento se utilizaron las cepas $P$. fluorescens $\triangle l a p D$ pMQ72 y $P$. fluorescens $\triangle / a p D$ plap $D_{P f}^{84}$.

En estas condiciones experimentales la formación de biofilm de $P$. fluorescens se produce casi exclusivamente en la interfase entre la suspensión bacteriana y el aire (Figura 4.2.a). Este fenotipo ha sido observado previamente en numerosas publicaciones ${ }^{123,127,130,273}$ y resulta notablemente diferente al fenotipo de formación de biofilm de $B$. bronchiseptica observado en el presente trabajo (Capítulo 3, Figuras 3.1 y $3.2)$.

La Figura 4.2.a muestra los resultados del ensayo de expresión de $\operatorname{LapD}_{\mathrm{Bb}}$ en el contexto de la cepa $P$. fluorescens $\triangle l a p D$. La cuantificación de estos ensayos muestra, en primer lugar, que $\operatorname{LapD}_{\mathrm{Bb}}$ complementa parcialmente el fenotipo de formación de biofilm de $P$. fluorescens $\Delta / a p D(p<0,05)$. En segundo lugar, se observa una diferencia estadísticamente significativa entre las cepas complementadas con $\operatorname{LapD}_{\mathrm{Bb}} \mathrm{O}$ con LapD $\mathrm{Pf}_{\mathrm{Pf}}$ $(p<0,01)$. Esta diferencia también se aprecia a través de la inspección directa de las fosas teñidas con cristal violeta. Se puede observar que la línea de biofilm de la cepa $\triangle l a p D$ plap $D_{P f}$ es más ancha que la línea de biofilm de la cepa $\triangle l a p D$ plap $D_{B b}$.

Para profundizar en la comprensión de estos resultados, analizamos de forma cuantitativa la cantidad de LapA localizada en la membrana plasmática. En el contexto de nuestra hipótesis, el aumento en la formación de biofilm de la cepa $P$. fluorescens $\triangle l a p D$ plap $D_{B b}$ debería ser consecuencia de un aumento en la cantidad de LapA en la membrana plasmática. Para confirmar esta hipótesis realizamos ensayos de dot blot a fin de determinar la presencia de esta adhesina en cada una de las cepas evaluadas anteriormente.

Las cepas de $P$. fluorescens utilizadas presentan una fusión transcripcional en la copia cromosómica de LapA para facilitar su detección en ensayos de Western blot y dot blot (LapA-HA). Esta marca consiste en un péptido de 9 residuos de aminoácidos derivado de la hemaglutinina del virus de la gripe. Este epitope puede ser reconocido de manera específica utilizando anticuerpos monoclonales anti-hemaglutinina (anti-HA) ${ }^{126}$. 


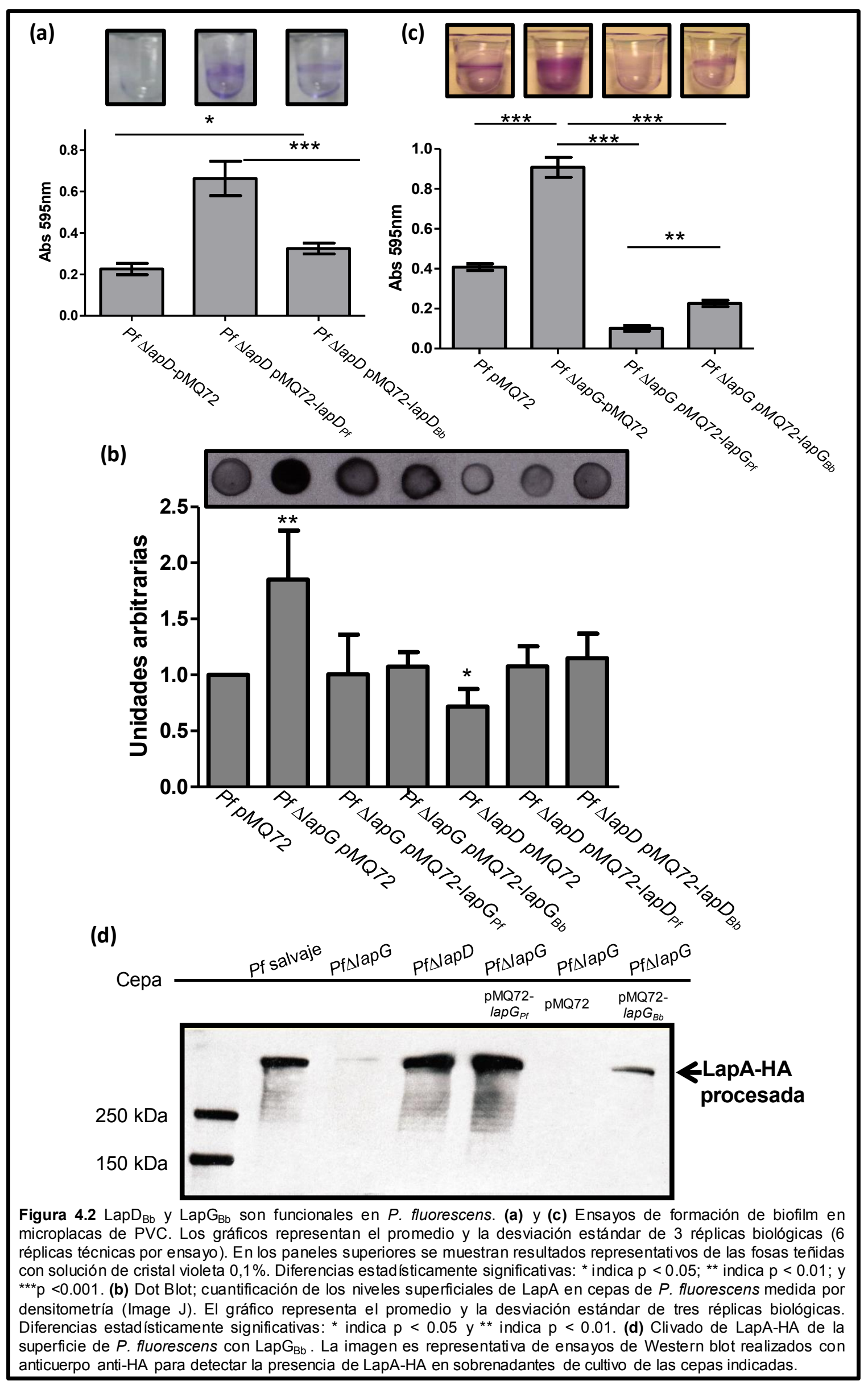


Para la realización de este ensayo, alícuotas de cultivos en fase exponencial de las distintas cepas de $P$. fluorescens fueron centrifugadas y lavadas con medio de cultivo fresco. Luego se prepararon suspensiones de manera tal de normalizar los valores de DO y finalmente $5 \mu \mathrm{L}$ de estas suspensiones se colocaron sobre membranas de nitrocelulosa. Se dejaron secar durante varias horas y luego se utilizó el mismo protocolo utilizado para la realización de Western blot. En estos ensayos, la intensidad de la mancha donde están sembradas las bacterias es proporcional a la cantidad de LapA-HA presente en la membrana plasmática. Para obtener una medida semicuantitativa de la cantidad de LapA-HA en membrana utilizamos el software Image J274. Para esto se tomó una unidad arbitraria definida como densidad integrada (integrated density) y los valores obtenidos para cada cepa fueron normalizados frente al valor de la cepa $P$. fluorescens pMQ72. Esta estrategia ya ha sido utilizada en el pasado para la determinación semicuantitativa de LapA asociada a la membrana ${ }^{84}$.

El análisis de los resultados muestra que, tal como ya ha sido reportado por Newell et al., la cepa $P$. fluorescens $\triangle l a p D$ pMQ72 presenta una menor cantidad de LapA-HA en membrana en comparación a la cepa $P$. fluorescens pMQ72 ${ }^{84}$ (Figura 4.2.d barras 1 y 5). En segundo lugar, tanto la expresión de $\operatorname{LapD}_{\mathrm{Bb}}$ como la de $\mathrm{LapD}_{\mathrm{Pf}}$ complementan el fenotipo mutante incrementando la cantidad de LapA-HA asociada a membrana (Figura 4.2 barras 5,6 y 7). El análisis semicuantitativo de los niveles de LapA-HA no muestra deferencias significativas entre las cepas completadas con $\operatorname{LapD}_{\mathrm{Bb}}$ y $\operatorname{LapD}_{\mathrm{Pf}}$ (barras 6 y 7). Recordemos que estas cepas sí habían presentado diferencias en el ensayo de formación de biofilm en microplaca. La diferencia en estos resultados podría indicar que el ensayo de dot blot no tiene un gran poder de resolución y no es posible poner de manifiesto pequeñas diferencias en la cantidad de LapA asociada a membrana.

\section{LapG $_{\mathrm{Bb}}$ es funcional en $P$. fluorescens}

La evidencia recolectada hasta el momento sostiene la hipótesis de que LapG $_{\mathrm{Bb}}$ en $B$. bronchiseptica sería funcionalmente equivalente a $L a p G_{P f}$ en $P$. fluorescens. Siguiendo la misma lógica que nos llevó a utilizar la cepa $P$. fluorescens $\triangle l a p D$ para estudiar la función de $L a p D_{\mathrm{Bb}}$, utilizamos la cepa $P$. fluorescens $\Delta l a p G$ para estudiar la actividad de $L_{\text {apG }}$ Bb.

En $P$. fluorescens, LapG es una proteasa periplasmática que regula la localización de la adhesina LapA en función de los niveles citoplasmáticos de c-di-GMP ${ }^{140}$. La deleción de lapG produce un fenotipo híper formador de biofilm ${ }^{140}$ debido a que la ausencia de esta proteína induce un aumento en la cantidad de la adhesina LapA asociada a la membrana plasmática. En cepas que sobreexpresan LapG, la capacidad 


\section{Capítulo 4}

de unión de LapD se ve sobrepasada y la presencia de proteína LapG libre en el periplasma produce el desprendimiento de LapA y en consecuencia una reducción de la formación de biofilm por debajo de los niveles de la cepa salvaje ${ }^{140}$.

Como mencionamos anteriormente, el sistema Lap está funcionalmente conservado entre especies filogenéticamente no relacionadas ${ }^{256}$. Además, como demostramos en el Capítulo 2, LapG $G_{\mathrm{Bb}}$ presenta todos los aminoácidos que han sido destacados como importantes para el funcionamiento de LapGpf. Esta evidencia sugiere que, si $L a p G_{B b}$ es funcionalmente equivalente a $L a p G_{p f}$, podría ser activa en $P$. fluorescens. Según esta hipótesis y basados en el funcionamiento del sistema Lap en $P$. fluorescens, la expresión de $\mathrm{LapG}_{\mathrm{Bb}}$ debería reducir los niveles de formación de biofilm de la cepa $P$. fluorescens $\Delta / a p G$.

Para analizar la actividad de $\operatorname{LapG}_{\mathrm{Bb}}$ se utilizaron las mismas estrategias experimentales que antes empleamos con $\mathrm{LapD}_{\mathrm{Bb}}$. Se realizaron ensayos de formación de biofilm en microplaca para evaluar el rol de $L_{a p G_{B b}}$ en la formación de biofilm y ensayos de dot blot para determinar su participación en la regulación de los niveles de LapA-HA asociada a la membrana plasmática.

$\operatorname{LapG}_{\mathrm{Bb}}$ fue clonada en el vector de expresión pMQ72, de amplio espectro, bajo el control del promotor $\mathrm{P}_{\mathrm{BAD}}$ inducible por arabinosa. Como control positivo de estos experimentos se utilizó a $L a p G_{P f}$ cuya actividad complementa el defecto de la cepa $P$. fluorescens $\Delta / a p G^{130,140}$.

En la Figura 4.2.c puede apreciarse, tal como está reportado en la bibliografía ${ }^{130,140}$, que la deleción de lapG en $P$. fluorescens induce un aumento significativo en la formación de biofilm (barras 1 y 2, p<0,05). Puede apreciarse que la cepa $\triangle / a p G$ presenta un anillo de biofilm mucho más ancho y además se observa la fosa teñida muy por debajo de la línea de la interfase; resultados que ya han sido reportados previamente por Newell et al. y Boyd et al. ${ }^{130,140}$. Como puede verse en esta figura, la expresión de $\mathrm{LapG}_{\mathrm{Bb}}$ complementa el fenotipo mutante reduciendo los niveles de formación de biofilm a valores similares a los de la cepa salvaje. Sin embargo, presenta diferencias estadísticamente significativas con la cepa complementada con LapG (barras 3 y $4, p<0,01$ ). El análisis de los datos cuantitativos, así como también la observación directa de las fosas teñidas con cristal violeta, muestra que la expresión de LapG $_{\mathrm{Pf}}$ en el mutante $\triangle l a p G$ inhibe la formación de biofilm. Sin embargo, el mutante complementado con $\mathrm{LapG}_{\mathrm{Bb}}$ presenta una formación de biofilm similar a la cepa salvaje. La capacidad de LapG $_{\mathrm{Bb}}$ de reducir los niveles de formación de biofilm en el contexto de la cepa $\Delta / a p G$ demuestra que es funcionalmente equivalente a LapGpf. Sin embargo, las diferencias en la capacidad de formación de biofilm entre las cepas que sobreexpresan $\operatorname{LapG}_{\mathrm{Bb}}$ y $\mathrm{LapG}_{\mathrm{Pf}}$ ponen de manifiesto alguna diferencia entre estas proteínas. 
Si $L a p G_{B b}$, al igual que $L a p G_{P f}$, es una proteasa periplasmática, la reducción en la formación de biofilm observada en el ensayo anterior debería ser una consecuencia de la disminución en la cantidad de la adhesina LapA-HA asociada a la membrana plasmática. Para confirmar esta hipótesis realizamos el ensayo de dot blot descripto previamente.

Los resultados de estos ensayos muestran que la cantidad de LapA-HA en membrana se redujo como consecuencia de la expresión de $L_{a p G}$ (Figura 4.2 barras 2 y 4). Esto implica que LapA-HA, en el contexto de una expresión heteróloga puede ser sustrato de $L_{a p G_{B b}}$. La expresión de LapG $G_{\mathrm{Pf}}$, utilizada como control positivo en este experimento, generó una reducción similar a la generada por LapG $_{\mathrm{Bb}}$ (Figura 4.2 barras 2, 3 y 4$)$.

Para confirmar que LapA-HA es clivada por LapG $_{\mathrm{Bb}}$ analizamos los sobrenadantes de cultivo de las cepas del ensayo anterior en busca de la porción de LapA-HA desprendida de la membrana plasmática. Las muestras de sobrenadante concentrado fueron analizadas mediante un ensayo de Western blot utilizando un anticuerpo monoclonal anti-HA para el revelado. La presencia de LapA-HA en el sobrenadante de cultivo se pone en evidencia como una banda de tamaño superior a los $250 \mathrm{kDa}$.

Como mencionamos antes, la ausencia de LapG $G_{p f}$ en la cepa $P$. fluorescens $\triangle$ lapG genera una abundancia de LapA en la membrana plasmática. Si nuestra hipótesis es correcta, la expresión de $\mathrm{LapG}_{\mathrm{Bb}}$ debería incrementar la cantidad de LapA-HA liberada al sobrenadante de cultivo.

Como puede verse en la Figura 4.2.d, en las condiciones de cultivo utilizadas, el sobrenadante proveniente de la cepa $P$. fluorescens $\Delta / a p G$ presenta una cantidad menor de LapA-HA en comparación a la cepa salvaje (calle 1 y 2 ). Por el contrario, el sobrenadante de la cepa $\triangle l a p D$, utilizada como control, presenta una cantidad considerablemente mayor. En estas condiciones, la expresión de $L_{a p G}$ pf desde un vector plasmídico revierte el fenotipo de la cepa $\Delta / a p G$ (calles 1 y 4). La expresión de LapG también revierte el fenotipo de la cepa $\Delta / a p G$, sin embargo, no logra hacerlo en la misma magnitud en la que lo hace $\operatorname{LapG}_{\mathrm{pf}}$ (calle 1,4 y 6 ). Este resultado indica que la expresión de $L_{a p G_{B b}}$, comparada con LapGpf, resulta menos eficiente en el clivado de LapA-HA. Como control negativo utilizamos la cepa complementada con el vector vacío y puede verse que no revierte el fenotipo de la cepa $\triangle / a p G$. Este control, confirma que la aparición de una banda de alto peso molecular en el sobrenadante de cultivo de $P$. fluorescens $\Delta / a p G$ plap $G_{B b}$ se da como consecuencia de que LapA-HA puede ser clivada por LapG $G_{B b}$.

Los resultados presentados en esta sección indican que $L_{a p G_{B b}}$ es funcional en $P$. fluorescens. Esto indica que $L_{a p} G_{\mathrm{Bb}}$ es una proteasa que expresada en forma heteróloga en $P$. fluorescens es capaz de procesar a la adhesina LapA. Este resultado 


\section{Capítulo 4}

sugiere que, en $B$. bronchiseptica, su contexto natural, $L_{a p G_{B b}}$ podría ser la proteasa que regule la localización de la adhesina BrtA.

\section{Comparación estructural de $\operatorname{LapD}_{\mathrm{Bb}}$ y LapDPf}

Los resultados presentados en la sección anterior demuestran que BB1184 es funcionalmente equivalentes a LapD de $P$. fluorescens. Sin embargo, tal como destacamos oportunamente, BB1184 no complementa el fenotipo $\Delta / a p D$ en la misma forma en la que lo hace la propia proteína de $P$. fluorescens. Si bien la expresión heteróloga de proteínas suele producir este tipo de resultados, decidimos ahondar en el análisis estructural de $\operatorname{LapD}_{\mathrm{Bb}}(\mathrm{BB} 1184)$ y $\mathrm{LapD}_{\mathrm{Pf}}$ a fin de buscar una explicación a los resultados observados.

Kurt Dahlstrom y sus colaboradores de Dartmouth College (Hanover, Estados

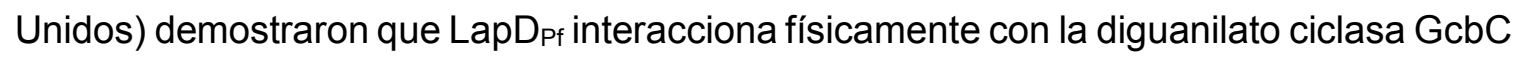
y este mecanismo consigue que GcbC controle de manera específica el funcionamiento del sistema Lap en $P$. fluorescens ${ }^{123}$. Frente a este escenario, cabe la posibilidad de que la región de interacción de $L a p D_{\mathrm{Pf}}$ sea diferente de la región de interacción de $\operatorname{LapD}_{\mathrm{Bb}} \mathrm{Y}$ esta última no sea capaz de interaccionar eficientemente con GcbC. Esta situación podría explicar la menor capacidad de $L_{a p D} D_{\mathrm{Bb}}$ para complementar la cepa $P$. fluorescens $\Delta / a p D$ en comparación a LapD pf.

Para profundizar en esta hipótesis utilizamos el software Phyre2 para analizar detalladamente la región de interacción de LapD $\mathrm{Pf}_{\mathrm{f}}$ con GcbC y compararla con la respectiva región en $L_{a p} D_{B b}$. Con este objetivo, utilizamos la herramienta "one to one" de Phyre2 a fin de modelar el dominio EAL de $\mathrm{LapD}_{\mathrm{Bb}}$ utilizando como molde la estructura cristalográfica del dominio EAL de LapD (Figura 4.3 y 4.4 ).

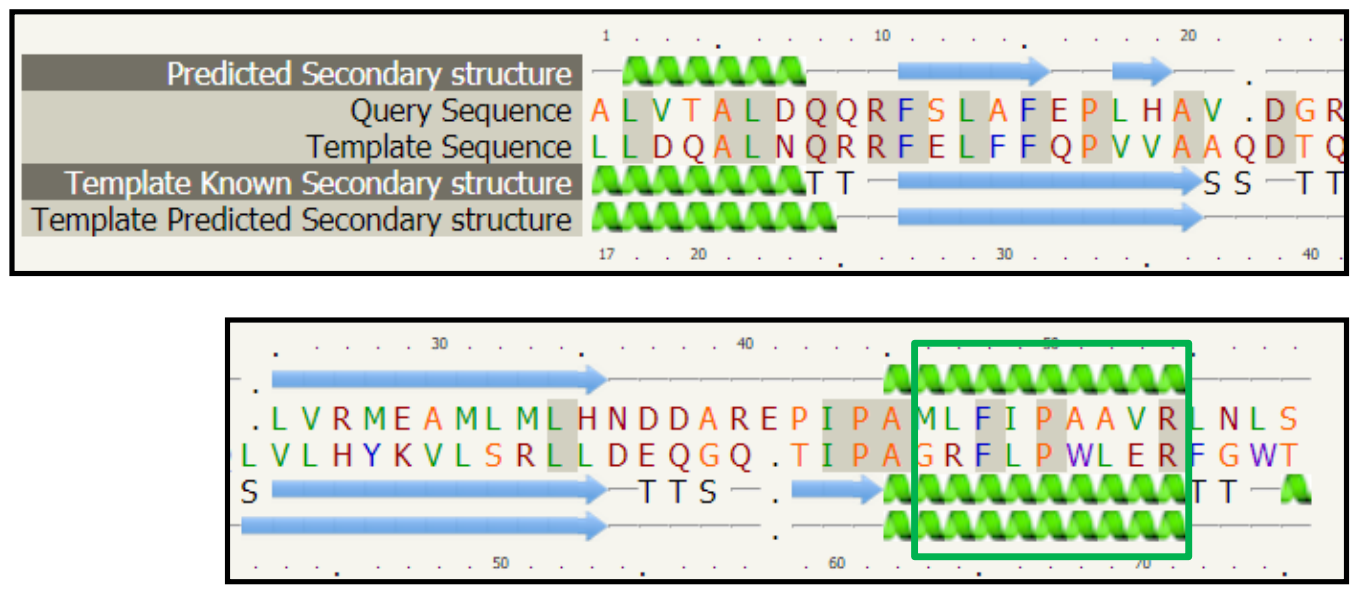

Figura 4.3. Alineamiento de secuencias de $L_{a p D}$ y $L_{a p D}$ utilizando la herramienta web Phyre2. El recuadro verde enmarca las secuencias y estructuras secundarias de la región de $L_{a p D} D_{\mathrm{Pf}}$ y $L_{a p D_{B b}}$ involucradas en la interacción con diguanilato ciclasas. 
El modelado del dominio EAL de $\operatorname{LapD}_{\mathrm{Bb}}$ arrojó como resultado un nivel de confianza del $100 \%$. Esto significa que la secuencia del dominio $E A L$ de $L_{a p D} D_{B b}$ fue correctamente modelada utilizando como base la estructura del dominio $E A L$ de LapD pf.

Los resultados de Dahlstrom et al. muestran que la secuencia de la región de interacción de LapDPf con GcbC es 462-GRFLPWLER-470 ${ }^{123}$. Considerando esta información y analizando el resultado del alineamiento del Phyre2 podemos concluir que la secuencia de la región de interacción de LapD $_{\mathrm{Bb}}$ sería 471-MLFIPAAVR-479 (Figura 4.3).

En la Figura 4.4 pueden observarse las representaciones tridimensionales generadas utilizando el programa de visualización $\mathrm{VMD}^{275}$. Las cadenas laterales de los residuos relevantes para este análisis fueron representadas utilizando un estilo denominado "Licorice" y coloreadas de rojo o azul a partir de un criterio explicado en los siguientes párrafos.

En primer lugar, y tal como demostramos en la Figura 4.3, se aprecia que las secuencias de las regiones de interacción difieren en algunos aminoácidos. Un análisis minucioso de las posiciones que ocupan estos aminoácidos en la hélice- $\alpha$ demuestra que aquellos que no están conservados entre las dos regiones son principalmente los que se encuentran expuestos hacia el lado externo de la hélice (cadenas laterales coloreadas en rojo). Por el contrario, la secuencia de aminoácidos que se encuentra hacia el lado interior del dominio EAL presenta 2 de las 3 posiciones conservadas (cadenas laterales coloreadas en azul).

Si realizamos un análisis aminoácido por aminoácido, vemos que las dos primeras posiciones de las secuencias de interacción son diferentes entre $\operatorname{LapD}_{\mathrm{Pf}} \mathrm{y} \operatorname{LapD}_{\mathrm{Bb}}$. Ha sido demostrado que estas posiciones son importantes para la interacción entre LapD $\mathrm{Pf}_{\mathrm{f}}$ y GcbC, por lo cual podemos considerar que también serían importantes en LapD $D_{\mathrm{Bb}}$. $A$ continuación, encontramos una secuencia de 3 aminoácidos de los cuales 2 de ellos están conservados ente ambas proteínas. En particular, en la segunda posición de esta secuencia de 3 aminoácidos encontramos un residuo de lisina $(L)$ en $L a p D_{\text {Pf }}$ y un residuo de isoleucina (I) en $\mathrm{LapD}_{\mathrm{Bb}}$. Anteriormente ha sido demostrado que este residuo no es importante para la interacción $L_{a p D} D_{\mathrm{Pf}}$ G $\mathrm{GcbC}^{123}$. Esta zona de ambas hélices son las que previamente destacamos que se hallan hacia el lado interno del dominio EAL y por ese motivo no son importantes para la interacción con diguanilato ciclasas. En la última porción de la región encontramos una secuencia de 4 residuos de aminoácidos de los cuales sólo uno de ellos está conservado entre ambos dominios EAL. También ha sido demostrado que esta zona es fundamental para la interacción ${ }^{123}$. 


\section{Capítulo 4}

(a)
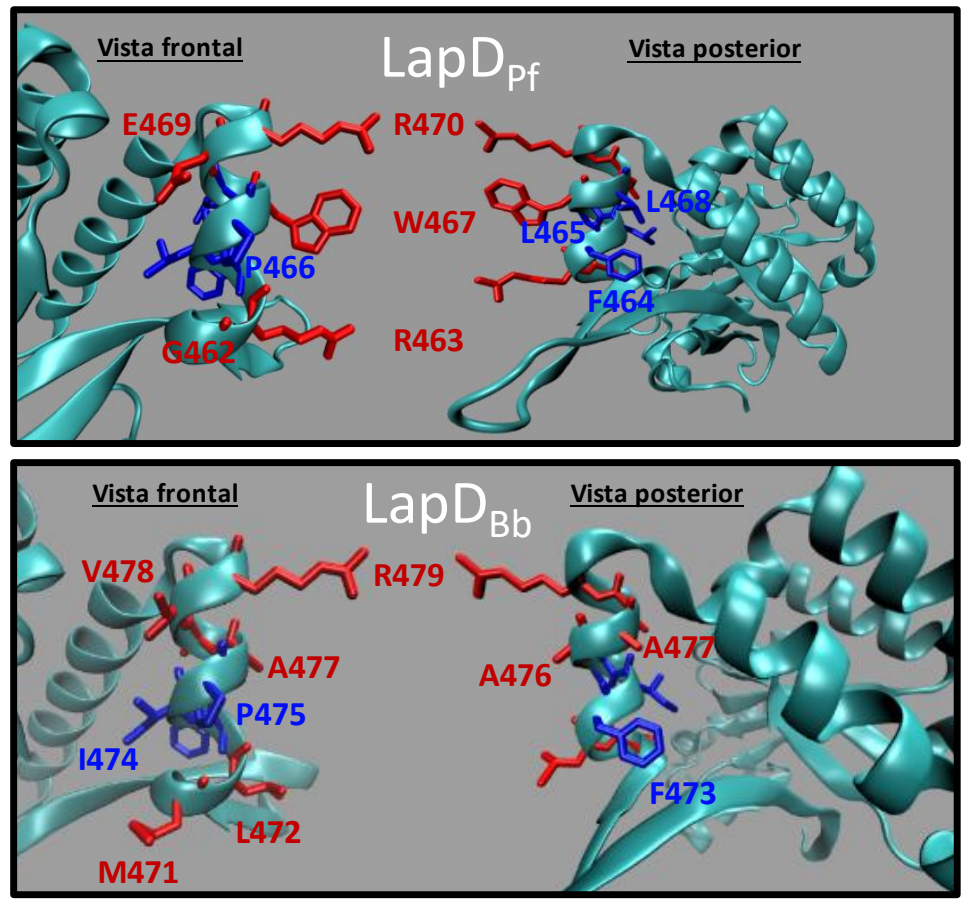

(b)
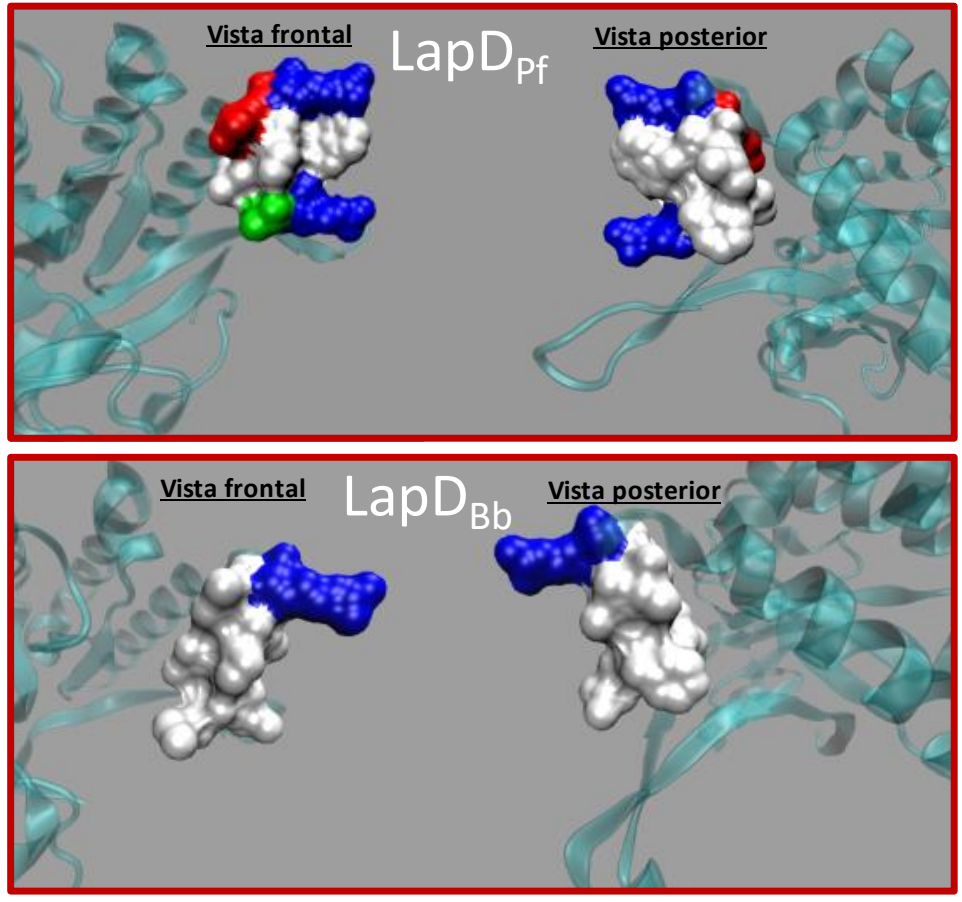

Figura 4.4. Comparación de las regiones de interacción de $L_{a p D_{\mathrm{Pf}}}$ y $\operatorname{LapD}_{\mathrm{Bb}}$. La estructura de del dominios EAL de LapD $D_{\mathrm{Pf}}$ corresponde a la estructura cristalográfica depositada en la base de datos PDB bajo el código 3pju. La estructura del dominio EAL de $\mathrm{LapD}_{\mathrm{Bb}}$ fue obtenida por modelado molecular con la herramienta web Phyre2 utilizando la función "one to one" y usando como molde la estructura $3 \mathrm{pju}$ de $\mathrm{LapD}_{\mathrm{pf}}$. Las representaciones tridimensionales fueron visualizadas utilizando el programa VMD (Visual Molecular Dynamics) desarrollado por la Universidad de Illinois. Las estructuras tridimensionales de los dominios EAL fueron representadas utilizando un formato NewCartoon. En (a) las cadenas laterales de los residuos aminoacídicos de la hélice- $\alpha 2$ de los dominios EAL fueron representadas utilizando un formato Licorice; en (b) la misma región fue representada utilizando el modo Surface y se utilizó un formato de coloración del tipo ResType.

A fin de obtener una visión más general de estas regiones las analizamos utilizando un estilo de representación denominado "Surface" y una coloración 
denominada "ResType" (Figura 4.4.b). En este estilo de coloración las regiones no polares se visualizan de color blanco, las regiones azules corresponden a cadenas laterales con propiedades básicas cargadas negativamente; las zonas rojas corresponden a cadenas laterales ácidas mientras que la regiones coloreadas de verde corresponden a zonas polares no cargadas ${ }^{275}$. Utilizando esta representación podemos ver diferencias importantes en la forma y la distribución de carga de las regiones de interacción de los dominios EAL de $\operatorname{LapD}_{\mathrm{Pf}}$ y $\operatorname{LapD}_{\mathrm{Bb}}$. Ambos dominios presentan una zona con densidad de carga positiva expuesta en el extremo $\mathrm{N}$-terminal que corresponde a la cadena lateral del residuo de arginina $(R)$. Sin embargo, la vista frontal y posterior del dominio de $\mathrm{LapD}_{\mathrm{Bb}}$ demuestra la presencia de una superficie no polar a lo largo de toda el área. Por el contrario, en el dominio EAL de LapD $D_{\mathrm{Pf}}$ encontramos alternadas regiones con densidad de carga positiva y negativa.

Este análisis confirma la existencia de diferencias importantes entre la región de $\mathrm{LapD}_{\mathrm{Pf}}$ involucrada en la interacción con $\mathrm{GcbC}$ y su región correspondiente en $\mathrm{LapD}_{\mathrm{Bb}}$. Estos resultados refuerzan la hipótesis de que la limitada capacidad de $\mathrm{LapD}_{\mathrm{Bb}}$ para complementar la deleción de lapD en $P$. fluorescens podría estar originada en una ineficiente interacción entre $\operatorname{LapD}_{\mathrm{Bb}}$ y $\mathrm{GcbC}$.

\section{BrtA es el blanco molecular de LapG en B. bronchiseptica}

En el Capítulo 3 de este trabajo presentamos evidencias de que BrtA es una adhesina involucrada en la formación de biofilm en $B$. bronchiseptica. Adicionalmente pusimos en evidencia que $L_{a p G}$ es capaz de complementar la cepa $P$. fluorescens $\triangle$ lapG. Profundizando en esta observación logramos determinar que, en $P$. fluorescens LapG $_{\mathrm{Bb}}$, es capaz de clivar a LapA y liberarla al sobrenadante de cultivo. Estos resultados sostienen la hipótesis de que $\mathrm{LapG}_{\mathrm{Bb}}$ es una proteasa con capacidad de regular la localización de adhesinas del tipo de LapA. El siguiente desafío en la descripción de este sistema consiste en determinar si BrtA es el blanco molecular de LapG en $B$. bronchiseptica.

Para avanzar en la demostración de esta hipótesis realizamos un ensayo de actividad in vitro para determinar si $L^{2}{ } G_{B b}$ es capaz de clivar una versión en miniatura de BrtA ( $\mathrm{N}$-term BrtA). Los 330 aminoácidos del extremo N-terminal de BrtA fueron clonados en el vector pMQ72 (Figura 4.5.a). Tal como describimos en el Capítulo 2, esta región contiene el probable sitio de clivado reconocido por LapG $\mathrm{Bb}_{\mathrm{Bb}}\left(-\mathrm{TA} \mathrm{A}^{*} \mathrm{~V}\right.$-). El diseño de N-term-BrtA contempló la incorporación de una marca de hemaglutinina en el extremo C-terminal como fusión transcripcional de manera tal de poder identificarla mediante Western blot. 


\section{Capítulo 4}

Brevemente, para el desarrollo de estos experimentos, sobrenadantes de cultivo de $E$. coli transformada con la construcción pMQ72-n-term-brtA fueron combinados con sobrenadantes de $E$. coli transformadas con pMQ72-lap $G_{B b}$, pMQ72-lap $G_{P f} \circ \mathrm{pMQ72.} \mathrm{A}$ partir de este diseño experimental, si $\mathrm{N}$-term-BrtA es procesada eficientemente se observaría una disminución en el peso molecular de la banda detectada mediante Western blot. El diseño de este ensayo se basó en experimentos previos que demostraban que LapG $_{\mathrm{pf}}$ es capaz de clivar la porción N-terminal de LapA en experimentos in vitro ${ }^{140}$.

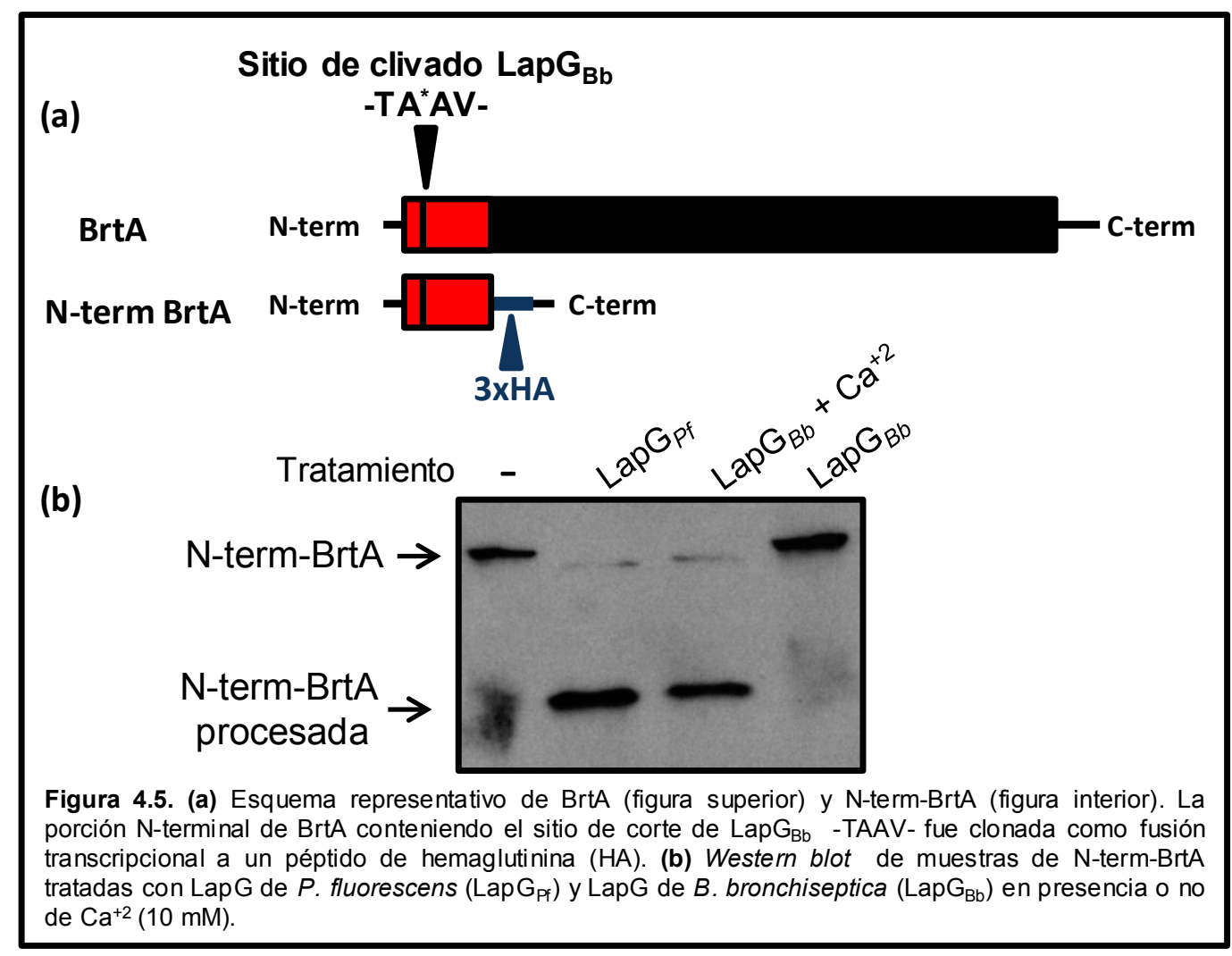

Boyd et al. demostraron que LapG de P. fluorescens y de L. pneumophila necesitan $\mathrm{Ca}^{+2}$ para ejecutar su actividad proteolítica ${ }^{130,256}$. Como mostramos en el Capítulo 2, LapG $\mathrm{Bb}_{\mathrm{Bb}}$ conserva los aminoácidos involucrados en el mecanismo de unión a $\mathrm{Ca}^{+2}$ que han sido descriptos en esos organismos. Por ende, es de esperar que LapG $\mathrm{Bb}_{\mathrm{Bb}}$ también sea una proteasa dependiente de $\mathrm{Ca}^{+2}$. La Figura 4.5.b muestra en el extracto crudo de N-term-BrtA combinado con $\mathrm{LapG}_{\mathrm{Bb}}$ en presencia de $10 \mathrm{mM}$ de $\mathrm{CaCl}_{2}$, la aparición de una banda del tamaño esperado para N-term-BrtA procesada. Esta banda no es observada en la muestra a la cual no le fue adicionado $\mathrm{Ca}^{+2}$. Como control de este experimento, vemos que en la muestra de extracto crudo de $\mathrm{N}$-term-BrtA combinada con LapGpf también se observa la banda correspondiente a $\mathrm{N}$-term-BrtA procesada. Este 
resultado indica que, en presencia de $\mathrm{Ca}^{+2}$, $\mathrm{LapG}_{\mathrm{Bb}}$ fue capaz de cortar la porción Nterminal de BrtA lo cual demuestra que $L_{a p G_{B b}}$ es una proteasa dependiente de $\mathrm{Ca}^{+2} \mathrm{y}$ que BrtA es su blanco molecular en B. bronchiseptica.

\section{LapG regula la formación de biofilm en $B$. bronchiseptica}

La evidencia presentada en el Capítulo 3 demuestra que BrtA es un factor involucrado en la formación de biofilm en B. bronchiseptica. En el presente capítulo, presentamos resultados que indican que $L_{a p G_{B b}}$ sería una proteasa involucrada en el control de la localización de esta adhesina. Estas dos evidencias sugieren que LapG $_{\mathrm{Bb}}$ estaría involucrada en el control de la formación de biofilm mediante la regulación de la localización de BrtA de la misma manera en que LapG $G_{p f}$ regula la localización de LapA en $P$. fluorescens.

Para avanzar en el desafío de esta hipótesis utilizamos una combinación de métodos experimentales que nos permitieran analizar el rol de $L_{a p} G_{B b}$ en la formación de biofilm en $B$. bronchiseptica. La estrategia completa consistió en una combinación de ensayos de formación de biofilm en microplaca y ensayos de microscopía electrónica de barrido (SEM) y de fluorescencia. Los ensayos en microplaca aportan una visión global del proceso de formación de biofilm mientras que los experimentos de microscopía permiten una inspección más detallada de las estructuras de los biofilms.

Análisis de la formación de biofilm en microplaca. En $P$. fluorescens, LapG regula la localización de la adhesina LapA. La sobreexpresión de LapG conduce a una reducción en la formación de biofilm debido a que la capacidad de unión de LapD se ve superada. Como consecuencia de la presencia de moléculas de LapG difundiendo libremente por el periplasma LapA es clivada y desprendida de la membrana plasmática y en estas condiciones la capacidad de formación de biofilm de $P$. fluorescens se ve reducida ${ }^{130,139,276}$. Si en $B$. bronchiseptica el sistema Lap funciona de la misma manera, la sobreexpresión de $L_{a p G}$ debería generar una disminución en los niveles de formación de biofilm.

Para el desarrollo de este experimento, la secuencia $l a p G_{B b}$ fue clonada en el vector de alto número de copias pBBR1-MCS5. Este vector es derivado del plásmido natural pBBR1 aislado de $B$. bronchiseptica ${ }^{277}$ y ha sido previamente utilizado por nuestro grupo para sobre expresar proteínas ${ }^{224}$. La secuencia $\operatorname{lap}_{B b}$ fue clonada bajo el control del promotor $\mathrm{P}_{\text {nptll }}$ (promotor del gen neomicina fosfotransferasa II), un promotor fuerte y de expresión constitutiva en Bordetella spp. A modo de control utilizamos la cepa $B$. 


\section{Capítulo 4}

bronchiseptica pBBR1-MCS5 nptll (pvacío) ${ }^{17}$. El protocolo de cultivo y tinción de las fosas fue el mismo que el presentado previamente, en el Capítulo 3.

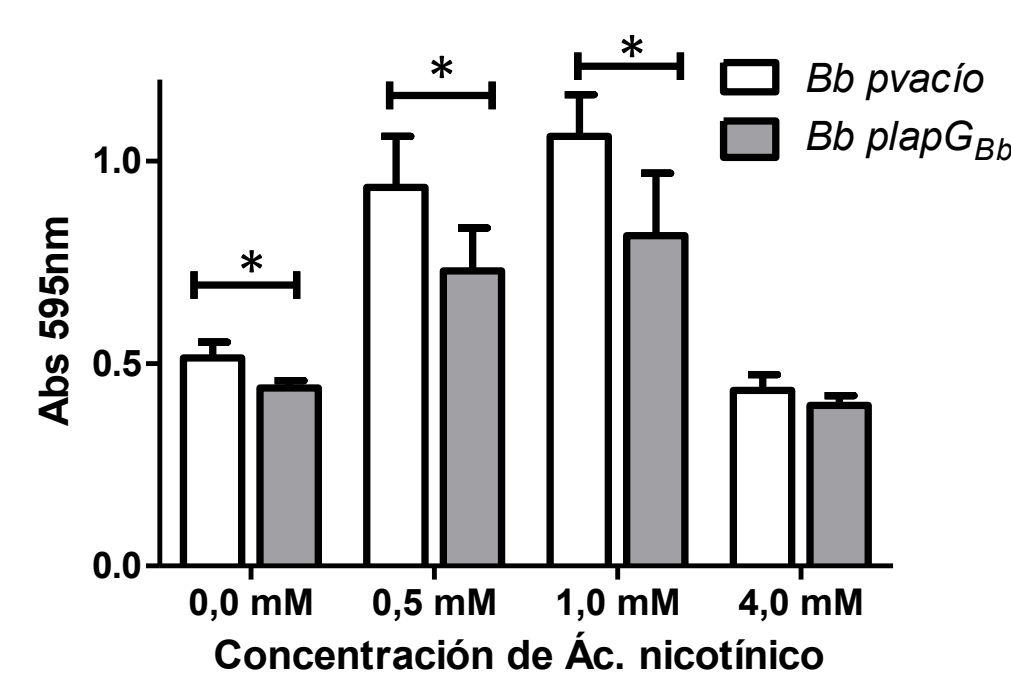

Figura 4.6. Ensayo de formación de biofilm en microplacas. El gráfico representa el promedio y la desviación estándar de 4 réplicas biológicas (con 4 réplicas técnicas por experimento). Las cepas $B$. bronchiseptica pvacío (Bb pvacío) y $B$. bronchiseptica plap $G_{B b}(\mathrm{Bb}$ plap $G_{B b}$ ) fueron incubadas durante 24 horas en medio de cultivo SS suplementado con cantidades crecientes de ácido nicotínico $(0,0$ $\mathrm{mM} ; 0,5 \mathrm{mM} ; 1,0 \mathrm{mM} ; 4,0 \mathrm{mM})$. * indica diferencia estadísticamente significativa entre las cepas $\mathrm{Bb}$ pvacío y $\mathrm{Bb}$ plap $G_{B b}$ en la misma condición de cultivo $(p<0.05)$.

En la Figura 4.6 se observan los resultados del experimento de formación de biofilm con la cepa $B$. bronchiseptica que sobre expresa $L_{a p G_{\mathrm{Bb}}}$ y el control de carga de plásmido. En primer lugar, los valores de Absorbancia a $595 \mathrm{~nm}$ obtenidos para la cepa B. bronchiseptica pvacío se corresponden con los valores reportados previamente para la formación de biofilm de la cepa salvaje ${ }^{224}$. Asimismo, tal como está reportado en bibliografía, concentraciones intermedias de ácido nicotínico producen los máximos niveles de formación de biofilm (entre 0,5 mM y 1,0 mM). En segundo lugar, la sobreexpresión de $\mathrm{LapG}_{\mathrm{Bb}}$ indujo una reducción en los niveles de formación de biofilm en condiciones de cultivo que presentan concentraciones de ácido nicotínico desde $0 \mathrm{mM}$ hasta 1,0 mM $(p<0,01)$. En cultivo con concentraciones de ácido nicotínico de 4,0 mM, donde la formación de biofilm alcanza su mínimo desarrollo, la sobreexpresión de LapG $_{\mathrm{Bb}}$ no redujo los niveles de formación de biofilm.

Análisis de la formación de biofilm mediante microscopía de fluorescencia. Los experimentos presentados en la sección anterior nos permitieron analizar la formación de biofilm desde una perspectiva macroscópica. Para avanzar en la descripción del rol de $L_{a p G_{B b}}$ en la formación de biofilm en $B$. bronchiseptica y poder analizar la estructura de los biofilms a escala microscópica comenzamos realizando estudios de microscopía de fluorescencia.

Para el desarrollo de estos experimentos obtuvimos las cepas fluorescentes usando el vector pGFLIP ${ }^{278}$. Este vector permite la incorporación al cromosoma de $B$. 
bronchiseptica de la secuencia codificante para la proteína fluorescente verde (GFP) mediante una recombinación sitio específica. La secuencia gfp es cotransferida junto a la secuencia npt/l que confiere resistencia a kanamicina y cualquier otra secuencia clonada en el sitio de clonado múltiple que posee este vector (para mayores detalles remitirse al Capítulo Materiales y Métodos).

Mediante esta estrategia obtuvimos las cepas $B$. bronchiseptica-GFP y $B$. bronchiseptica-GFP-LapG $\mathrm{Bb}_{\mathrm{Bb}}$. Esta última construcción presenta la secuencia codificante

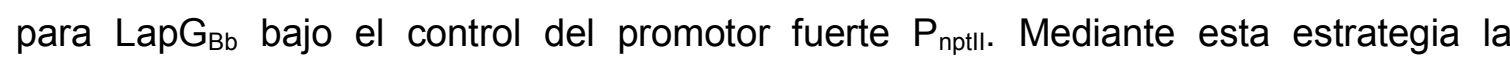
sobreexpresión de $\mathrm{LapG}_{\mathrm{Bb}}$ se consigue gracias a la presencia de este promotor fuerte.

Para el desarrollo de estos experimentos realizamos cultivos de 48 horas a $37^{\circ} \mathrm{C}$, sin agitación, con una concentración de ácido nicotínico de 0,5 mM. Los cultivos fueron realizados en tubos cónicos de $50 \mathrm{~mL}$ y se colocaron cubreobjetos parcialmente sumergidos en la suspensión bacteriana en los que posteriormente se evaluó la formación de biofilm. La condición de ácido nicotínico elegida responde al hecho de que en $0,5 \mathrm{mM}$ es la condición donde las diferencias entre la sepa salvaje y la cepa que sobrexpresa $\mathrm{LapG}_{\mathrm{Bb}}$ presenta las diferencias más importantes.

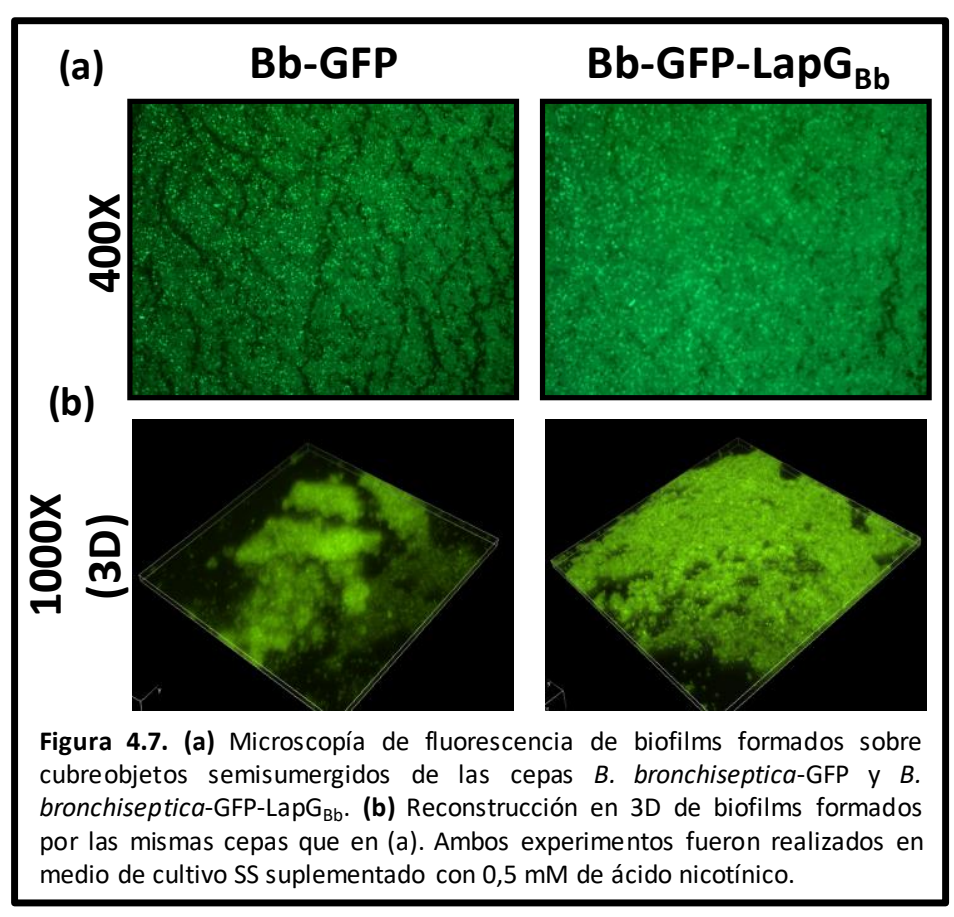

La Figura 4.7 muestra imágenes obtenidas como resultado de esos experimentos. Estas imágenes corresponden a la región de los cubreobjetos que se encontraba en la interfase entre el aire y la suspensión bacteriana y fueron inspeccionadas utilizando un aumento total de 400X (Figura 4.7.a). 


\section{Capítulo 4}

En las imágenes puede observarse que la cepa Bb-GFP presenta una estructura típica de biofilms en la que se observa un desarrollo en altura intercalado por canales en donde no se hallan bacterias. Por el contrario, la cepa Bb-GFP-LapG $G_{B b}$ no presenta esta estructura característica. Por el contrario, se observa una pátina de bacterias sin presencia de los canales típico que componen las estructuras de los biofilms.

Para profundizar en el estudio de la estructura los biofilm producidos por las cepas Bb-GFP y Bb-GFP-LapG $\mathrm{Bb}_{\mathrm{Bb}}$ repetimos el experimento anterior utilizando un microscopio Nikon Eclipse Ti del Departamento de Microbiología de Dartmouth College (Estados Unidos). Este microscopio de fluorescencia, si bien no es un microscopio Confocal, permite reconstruir imágenes en 3D a partir de imágenes en 2D de los diferentes planos de la muestra (Figura 4.7.b). El análisis de estas imágenes confirma que la cepa Bb-GFP produce las estructuras desarrolladas en altura características de los biofilms bacterianos. Confirmando los resultados observados en el ensayo anterior, se observa la presencia de canales alrededor de estas estructuras. Por el contrario, la cepa Bb-GFP. LapG $_{\mathrm{Bb}}$, tal como habíamos destacado antes, no presenta los canales mencionados y produce estructuras que alcanzan un menor desarrollo en altura. La menor altura alcanzada por los biofilms de la cepa Bb-GFP-LapG $G_{B b}$ podría explicar las diferencias observadas en los ensayos de microplaca (Figura 4.6).

\section{Análisis de la formación de biofilm mediante microscopía electrónica de barrido}

(SEM). Para profundizar en la descripción de las diferencias observadas en los ensayos de formación de biofilm y microplacas y en los experimentos de microscopía de fluorescencia realizamos el análisis de la formación de biofilm mediante microscopía electrónica de barrido (SEM).

El desarrollo de este experimento fue realizado de manera idéntica al protocolo descripto en el Capítulo 2 pero utilizando un tiempo de incubación de $48 \mathrm{~h}$. El secado por punto crítico, el metalizado y la observación de las muestras fueron realizados en el servicio de microscopía electrónica de barrido del Centro de Investigación y Desarrollo en Ciencias Aplicadas (CINDECA-CONICET-UNLP)

La Figura 4.8 muestra imágenes obtenidas en los experimentos de formación de biofilm con la cepa $B$. bronchiseptica plap $G_{B b}$ y el control de plásmidos vacío.

En primer lugar, el análisis de las imágenes de la cepa control B. bronchiseptica pvacío muestra un desarrollo máximo de biofilm en condiciones de cultivo con concentraciones de ácido nicotínico entre 0,5 mM y 1,0 mM. Este resultado es consistente con los reportes de bibliografía que indican que la máxima formación de biofilm se da en concentraciones semimodulantes de ácido nicotínico ${ }^{222,224}$. Estos resultados además correlacionan muy bien con los resultados obtenidos en este trabajo en los ensayos de 


\section{Capítulo 4}

formación de biofilm en microplaca. Esto demuestra que la formación de biofilm en vidrio, al igual que en plástico, presenta un pico máximo en concentraciones de 0,5 mM y 1,0 mM de ácido nicotínico.

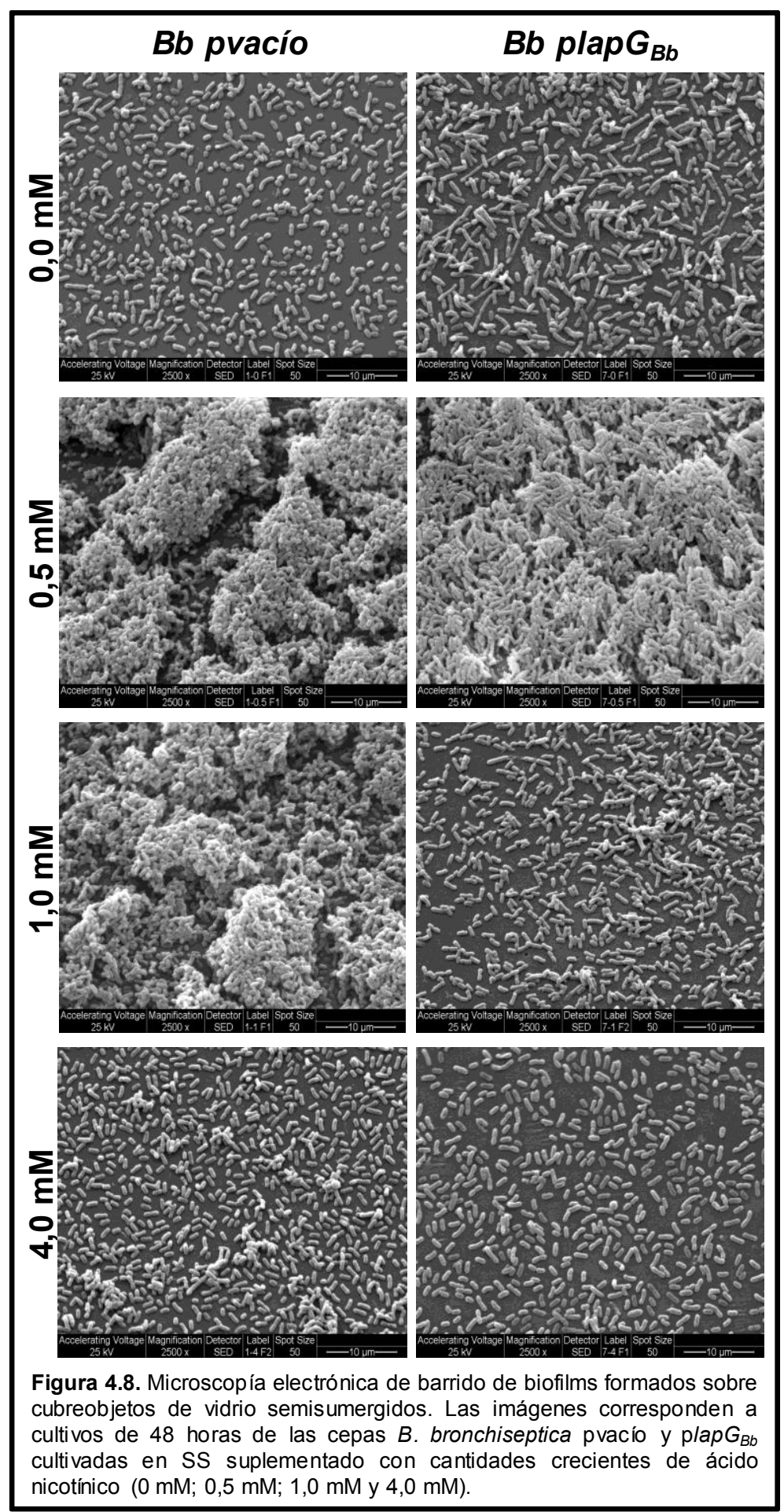




\section{Capítulo 4}

Al comparar la estructura microscópica de los biofilms formados por la cepa que sobrexpresa LapG y el control de pvacío vemos diferencias importantes en condiciones de cultivo que presentan concentraciones de ácido nicotínico entre 0,5 mM y 1,0 mM.

El análisis de las imágenes de $0,5 \mathrm{mM}$ muestra resultados equivalentes a los observados previamente en los ensayos de microscopía de fluorescencia. Nuevamente se ve que la cepa salvaje forma biofilms con una estructura desarrollada en altura y canales entre esas estructuras, mientras que la cepa que sobreexpresa LapG no es capaz de desarrollar esas estructuras.

Las diferencias más importantes las encontramos en la condición de 1,0 mM de ácido nicotínico. En esta condición puede verse que mientras la cepa salvaje forma biofilms con gran desarrollo, la sobreexpresión de LapG $_{\mathrm{Bb}}$ inhibe completamente el desarrollo de biofilm. En forma aislada se observan cúmulos de bacterias que no superan las 10-20 bacterias. Estas formaciones podrían constituir las llamadas microcolonias que son uno de los primeros pasos del desarrollo de biofilms. La sobreexpresión de LapG $\mathrm{Bb}_{\mathrm{Bb}}$ parecería inhibir la progresión hacia etapas posteriores de la formación de biofilm.

En 4,0 mM, condición en la que los ensayos de formación de biofilm en microplaca no mostraron diferencias significativas se aprecia una leve diferencia entre la cepa salvaje y la cepa que sobrexpresa LapG $_{\mathrm{Bb}}$. La cepa salvaje, si bien no desarrolla estructuras de biofilms, presenta microcolonias de entre 5 y 20 bacterias además de bacterias aisladas adheridas a la superficie. La cepa con sobreexpresión de $\operatorname{LapG}_{\mathrm{Bb}}$ no presenta microcolonias, en la fotografía tomada como representativa, ni en ningún sector del cubreobjetos analizado.

\section{Análisis de la formación de biofilm de la cepa $B$. bronchiseptica $\triangle$ lapG}

Para profundizar en el estudio del rol de LapG en B. bronchiseptica realizamos la deleción limpia de la secuencia $l a p G_{B b}$ y evaluamos su fenotipo de formación de biofilm. Para la obtención de esta cepa utilizamos la misma estrategia que previamente habíamos puesto a punto para la obtención del mutante $\Delta b r t A$.

Nuevamente utilizamos una combinación de estrategias de formación de biofilm en microplacas y microscopía para analizar el comportamiento de la cepa mutante $\Delta / a p G$. Como controles de este grupo de experimentos también obtuvimos la cepa complementada $\Delta / a p G$ plap $G_{B b}$ y el control $\Delta / a p G$ pvacío.

La evidencia experimental recolectada hasta el momento sugiere que LapG $_{B b}$ regula la localización de BrtA y de esta manera regularía la capacidad de $B$. bronchiseptica de formar biofilm. Según este modelo, la deleción de lapG generaría una 
acumulación de BrtA superior a la de la cepa salvaje. Si nuestra hipótesis es correcta, la deleción de lapG debería inducir un aumento en los niveles de formación de biofilm.

Los experimentos de formación de biofilm en microplaca fueron realizados siguiendo el mismo protocolo descripto previamente.

La Figura 4.7 muestra los resultados obtenidos en los experimentos de formación de biofilm en microplacas utilizando la cepa salvaje, el mutante $\Delta / a p G$ y el mutante complementado $\triangle \mathrm{lapG}$ plap $G_{B b}$. Como puede verse, la deleción de lapG generó un aumento significativo en los niveles de formación de biofilm en condiciones de cultivo que presentan concentraciones de ácido nicotínico de $2,0 \mathrm{mM}$ y 4,0 mM $(p<0,001)$. Asimismo, en estas condiciones la complementación con la construcción plap $G_{B b}$ restituyó los niveles de formación de biofilm a los valores de la cepa salvaje. Este control confirma que el efecto observado en la cepa mutante $\Delta / a p G$ se da como consecuencia de la ausencia de $L a p G_{B b}$. Los ensayos realizados en 2,0 mM y 4,0 mM de ácido nicotínico corresponden a condiciones de cultivo que modulan el fenotipo de Bordetella a fase Bvg-.

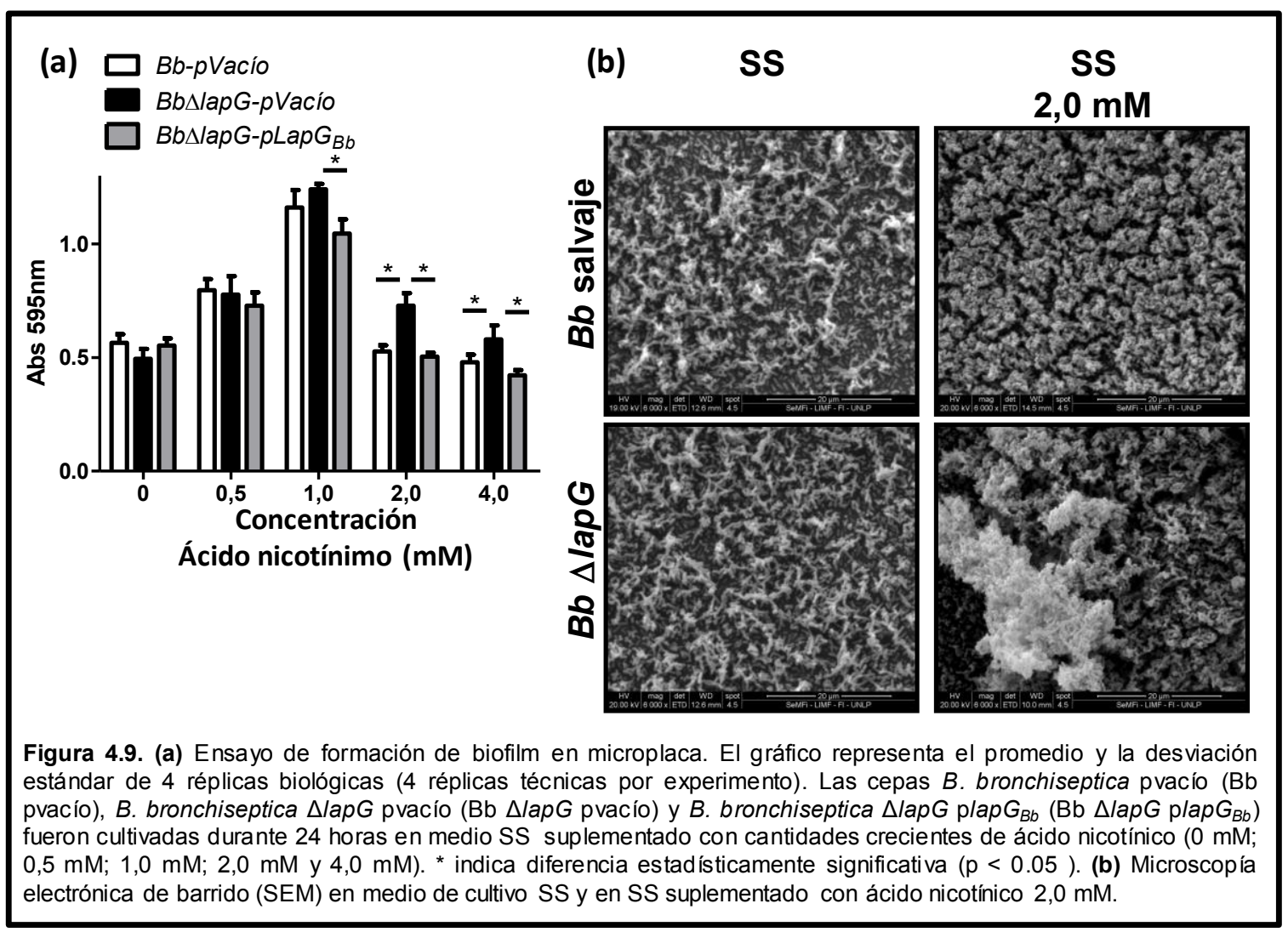

Para evaluar con detalle las diferencias en la formación de biofilm entre la cepa salvaje y $\triangle / a p G$ realizamos ensayos de formación de biofilm sobre vidrio y los analizamos mediante microscopía electrónica de barrido (SEM). En la Figura 4.9.b presenta imágenes correspondientes a la zona de la interfase aire-liquido donde se desarrolla el 


\section{Capítulo 4}

biofilm. En condiciones de cultivo no modulantes $(0,0 \mathrm{mM}$ de ácido nicotínico) ambas cepas muestran un desarrollo de biofilm similar. En las dos cepas se observan cúmulos de bacterias separados por espacios libres en donde se distinguen algunas bacterias aisladas adheridas a la superficie. No se observan diferencias ni en el desarrollo de cúmulos de bacterias ni en la adhesión de bacterias a la superficie. En 2,0 mM por el contrario se ven diferencias importantes entre el desarrollo de biofilm de la cepa salvaje y la cepa $\Delta$ lapG. Si bien ambas cepas presentan biofilm estructurados como cúmulos bacterianos y espacios libres, la cepa $\triangle l a p G$ presenta cúmulos mucho más grandes que la sepa salvaje. Debido al gran número de bacterias, no llega a apreciarse bacterias aisladas adheridas a la superficie.

\section{Conclusiones y discusión}

En los capítulos anteriores demostramos que BrtA es una adhesina involucrada en la formación de biofilm en $B$. bronchiseptica. A lo largo del presente capítulo analizamos la regulación de la localización de esta adhesina. Para ello evaluamos la hipótesis de que las secuencias BB1184 y BB1185 codifican para LapD y LapG en $B$. bronchiseptica.

Para analizar la funcionalidad de BB1184 (LapD $\left.\mathrm{Bb}_{\mathrm{Bb}}\right)$ y BB1185 (LapG $\left.\mathrm{Bb}_{\mathrm{Bb}}\right)$ utilizamos a $P$. fluorescens como modelo de estudio. La idea de expresar de manera heteróloga a $L_{a p D} D_{B b}$ y $L_{a p G}$ Bb surge del hecho que este sistema de proteínas está conservado entre especies no relacionadas ${ }^{279}$. A partir de esta información consideramos como estrategia analizar si $L_{a p D} D_{\mathrm{Bb}}$ y $L_{a p G_{\mathrm{Bb}}}$ eran capaces de complementar los fenotipos de los mutantes respectivos en $P$. fluorescens. La utilización de este sistema heterólogo resultó en una herramienta sumamente útil que nos permitió confirmar que BB1184 y BB1185 son LapD y LapG en B. bronchiseptica.

La expresión de $L_{a p D_{B b}}$ en la cepa $P$. fluorescens $\Delta l a p D$ generó un aumento en los niveles de formación de biofilm y en la cantidad de LapA localizada en la membrana en comparación a la cepa control $P$. fluorescens $\triangle l a p D$ pvacío (Figuras 4.2.a y 4.2.b). Estos datos sustentan la hipótesis de que $\operatorname{LapD}_{\mathrm{Bb}}$ es funcionalmente equivalente a LapD $_{\text {pf. }}$ Sin embargo, no pasa desapercibido el hecho de que la expresión heteróloga de $\operatorname{LapD}_{\mathrm{Bb}}$ no generó niveles de formación de biofilm iguales a los generados mediante la expresión de LapD $D_{\mathrm{pf}}$. Con el objetivo de indagar en las causas que podrían explicar esta diferencia, realizamos un análisis estructural de la región de $L_{a p} D_{P f}$ y $L_{a p} D_{B b}$ que estarían involucradas en la interacción con diguanilato ciclasas. Como resultado de ese análisis determinamos que las regiones de interacción en ambas proteínas tienen una estructura y distribución de carga diferente. $\mathrm{LapD}_{\mathrm{Bb}}$ podría no interactuar eficientemente con $\mathrm{GcbC}$ 
y esto produciría una transferencia deficiente de la señal del citoplasma al periplasma. En estas condiciones, $\operatorname{LapD}_{\mathrm{Bb}}$ sería menos eficiente para mantener retenida a $L a p G_{P f} \mathrm{y}$ esto generaría niveles menores de formación de biofilm. Esta observación podría explicar la menor capacidad de complementación de $\mathrm{LapD}_{\mathrm{Bb}}$ en comparación a $\mathrm{LapD}_{\mathrm{Pf}}$.

Los ensayos de dot blot, a diferencia de los experimentos de biofilm, no mostraron diferencias significativas en la cantidad de LapA localizada en la membrana entre las cepas $P$. fluorescens $\triangle / a p D$ plap $D_{B b}$ y plap $D_{P f}$ (Figura 4.2.b). Esto podría deberse a que la sensibilidad que presenta este ensayo no sea suficiente para poner de manifiesto una pequeña diferencia en la cantidad de LapA.

Utilizando una estrategia análoga, analizamos la funcionalidad de BB1185

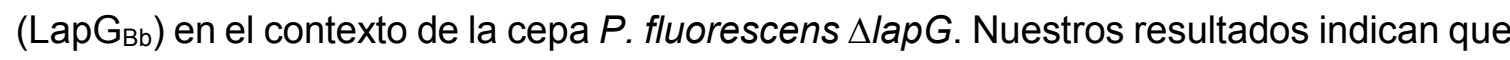
la expresión de $\operatorname{LapG}_{\mathrm{Bb}}$ disminuye la formación de biofilm en el contexto de la cepa $P$. fluorescens $\triangle l a p G$. Por un lado, esto indica que $L_{a p} G_{B b}$ es funcionalmente equivalente a LapG $G_{\mathrm{Pf}}$, pero en este ensayo también observamos diferencias entre las cepas complementadas con ambas secuencias. En primer lugar, la expresión heteróloga de $\mathrm{LapG}_{\mathrm{Bb}}$ podría generar niveles de expresión menores a los niveles de expresión de LapG $G_{\text {f. }}$ En segundo lugar, no podemos descartar que existan diferencias entre ambas proteínas que conlleven a una mayor eficacia de la proteína LapGpf, en su contexto natural, respeto de la expresada de forma heteróloga, al momento de clivar y desprender a LapA de la membrana. Ambos motivos podrían explicar las diferencias destacadas en la complementación con $L_{a p G}$ y y LapGpf.

Para profundizar en la descripción de $L_{a p G_{B b}}$ y avanzar en la compresión del mecanismo de regulación de la formación de biofilm, analizamos la funcionalidad de LapG $_{\mathrm{Bb}}$ en ensayos de actividad in vitro e in vivo. En primer lugar, determinamos que LapG $_{\mathrm{Bb}}$ es capaz de clivar a LapA de $P$. fluorescens y liberarla al sobrenadante del medio de cultivo (Figura 4.2.d). Este resultado refuerza la hipótesis de que $L^{2}{ } G_{B b}$ al igual que LapG $_{\mathrm{Pf}}$ es una proteasa capaz de procesar adhesinas de la familia de LapA. Este ensayo puso en evidencia diferencias entre $L_{a p G}$ y $L a p G_{P f}$ que hacen que la expresión heteróloga de $L_{a p G_{B b}}$ no produzca los mismos resultados que la expresión de la propia LapG de $P$. fluorescens. Las diferencias en la estructura primaria y secundaria que podrían explicar estas observaciones serán analizadas a lo largo del Capítulo 7.

Habiendo confirmado que $L_{a p G}$ era funcionalmente análoga a LapG $G_{\mathrm{Pf}}$, nos enfocamos en el siguiente paso de la descripción de este sistema que consistió en determinar si BrtA es el sustrato natural de $L a p G_{B b}$. Para este ensayo clonamos la porción $\mathrm{N}$-terminal de BrtA que contiene el posible sitio de clivado -TAAV-. Combinando extractos crudos de bacterias conteniendo la versión $\mathrm{N}$-term-BrtA y LapG $_{\mathrm{Bb}}$ demostramos que BrtA es sustrato de LapG en B. bronchiseptica (Figura 4.5). Como parte de este experimento 


\section{Capítulo 4}

determinamos que la presencia de $\mathrm{Ca}^{+2}$ es fundamental para la actividad de LapG $\mathrm{Bb}_{\mathrm{Bb}}$. Esta característica ya ha sido demostrada también para LapG en $P$. fluorescens y en $L$. pneumophila ${ }^{130,256}$.

Según nuestro modelo de trabajo, la presencia de BrtA sobre la membrana plasmática aumentaría la capacidad de $B$. bronchiseptica de formar biofilm, mientras que su ausencia induciría una reducción en los niveles de biofilm.

Para evaluar esta hipótesis analizamos el fenotipo de formación de biofilm mediante ensayos de cultivos en microplacas, microscopía de fluorescencia y microscopía electrónica de barrido, de una cepa que sobre expresa $\operatorname{lap}_{B b}$ y el mutante delecional $\triangle / a p G$.

En experimentos de formación de biofilm en microplaca determinamos que la sobreexpresión de $l a p G_{B b}$ indujo una reducción en la formación de biofilm. Esta reducción se produjo en condiciones de ácido nicotínico en las que la deleción de brtA no había generado diferencias en comparación a la cepa salvaje (Figura 4.6 y 3.2). Este resultado podría indicar la existencia de otros factores involucrados en la formación de biofilm regulados por $L_{a p G} G_{B b}$. En este sentido, recientemente se ha visto que la adhesina LapA de $P$. fluorescens no es el único sustrato de LapG en ese organismo. Pfl01_1463 también es clivada por $\operatorname{LapG}_{\mathrm{Pf}}$ aunque las implicancias biológicas de este proceso aún no han sido determinadas ${ }^{136}$. En B. bronchiseptica, fhaL (BB1936) y fhaS (BB2312) presentan secuencias que podrían ser clivadas por $L_{a p} G_{B b}$. En el extremo C-terminal FhaL presenta un sitio TAAG mientras que FhaS presenta dos sitios TAAG y PAAG que podrían ser blanco de la proteasa $\mathrm{LapG}_{\mathrm{Bb}}$.

En este capítulo también nos enfocamos en el estudio de la expresión de los genes $l a p D_{B b}$, lap $G_{B b}$ y brtA. En un estudio previo, brtA (BB1186) fue clasificado como un gen de avirulencia. En el mencionado estudio, Tracy Nicholson demostró que la expresión de BB1186 es menor en la cepa salvaje en comparación a la variante bloqueada en fase Bvg- ${ }^{280}$. Estos resultados fueron confirmados por Nishikawa et al. quienes demostraron, mediante ensayos de qPCR, que el sistema de dos componentes BvgAS inhibe la expresión de $b r t A^{260}$. En ese mismo trabajo, en ensayos de Western blot se aprecia la presencia de bandas correspondientes a BrtA en muestras provenientes de cultivos realizados en condiciones $\mathrm{Bvg}+$. Esta observación no fue considerada por los autores del mencionado artículo. Nuestros resultados indican que brtA se coexpresa junto a lap $D_{B b} \mathrm{y}$ $l a p G_{B b}$ en todas las fases de virulencia (Figura 4.1). Esta hipótesis se ve reforzada por los resultados presentados en el Capítulo 3 en donde identificamos a BrtA en muestras provenientes de sobrenadantes obtenidos en condiciones de cultivo Bvg+ (Figura 3.4).

Los resultados de Nishikawa et al. también indican que el factor transcripcional regulador de brtA, LuxR (BB1187), y los componentes del sistema de secreción tipo I 
(BB1188, BB1189 y BB1191) se coexpresan como parte de un mismo operón. Combinando los resultados presentados en este capítulo, junto con los resultados de Nishikawa et al. B. bronchiseptica tendría 2 operones relacionados a la formación de biofilm mediada por c-di-GMP. El primero de ellos, asociado a la expresión y secreción de BrtA (BB1187-BB1191). Mientras que el segundo operón contendría la propia secuencia codificante para BrtA junto a los factores involucrados en el control postranscripcional de la localización de esta adhesina (lap $\left.D_{B b}-l a p G_{\mathrm{Bb}}-b r t A\right)$.

Habiendo caracterizado funcionalmente el sistema formado por $\operatorname{LapD}_{\mathrm{Bb}}$, $\operatorname{LapG}_{\mathrm{Bb}} \mathrm{y}$ BrtA resta determinar cuál es la importancia de este sistema durante el proceso de infección natural de $B$. bronchiseptica. Este tema, así como también los mecanismos de control de la actividad de LapD serán temas evaluados en los siguientes capítulos. 



\section{Capítulo 5}

Análisis de rol de las proteínas Lap de

B. bronchiseptica in vivo 



\section{Introducción}

Este capítulo presentará un abordaje complementario no analizado hasta el momento en relación al rol de las proteínas Lap de B. bronchiseptica en la formación de biofilm y en procesos naturales de infección. En los capítulos precedentes hemos evaluado la participación de este grupo de proteínas en la formación de biofilm sobre superficies inertes. Si bien esos modelos de estudio son ampliamente utilizados incluso para el análisis de patógenos como B. bronchiseptica, resulta importante realizar un análisis en condiciones cada vez más cercanas al ambiente natural en el que esta bacteria puede encontrarse. Con ese objetivo como meta, nos planteamos el desarrollo de experimentos de colonización en ratones los cuales constituyen un huésped natural de B. bronchiseptica. G. Sloan et al. demostraron que B. bronchiseptica es capaz de formar biofilm en la cavidad nasal de ratones ${ }^{207}$. Para ello elegimos ratones hembras BALB/c por tratarse del modelo animal más utilizado por la comunidad científica para analizar procesos de infección de B. bronchiseptica. Si bien otras cepas de ratones también han sido utilizadas, en nuestras manos esta cepa es la que mejores resultados nos ha dado en lo que respecta al manejo de los animales y al estudio del proceso de infección.

En segundo lugar, nos adentramos en el análisis de una etapa del proceso de infección poco estudiada: la transmisión entre huéspedes. Para el desarrollo de estos experimentos utilizamos el modelo recientemente desarrollado de transmisión de $B$. bronchiseptica entre ratones deficientes en el receptor de la inmunidad innata TRL4 (Tolllike recpetor 4).

Por último, desarrollamos nuevos experimentos de formación de biofilm, pero en este caso utilizando una superficie biótica como sustrato para la adhesión y el desarrollo del biofilm. Serán presentados, a lo largo del capítulo, experimentos realizados con cultivos celulares de la línea derivada de un paciente fibroquístico CFBE ${ }^{281}$.

\section{Primer ensayo de colonización}

Como primer acercamiento al proceso de colonización decidimos realizar un ensayo utilizando un protocolo de inoculación intranasal tradicional. Para el desarrollo de este experimento se utilizaron las cepas $B$. bronchiseptica pBBR1-MCS5- $P_{n p t l l}(B b$ pvacío) y B. bronchiseptica pBBR1-MCS5- $P_{\text {nptll }}$ lapG (Bb plapG). Brevemente, el protocolo experimental consistió en una inoculación por vía intranasal de $50 \mu \mathrm{L}$ de suspensiones bacterianas de $1.10^{7} \mathrm{UFC} / \mathrm{mL}$. Como primera aproximación al proceso de colonización decidimos evaluar tiempos de infección relativamente prolongados por lo que el sacrificio de los animales de experimentación fue realizado a los 12 y 30 días post-inoculación. 


\section{Capítulo 5}

Mediante estudios de microscopía G. Sloan et al. demostraron que en esos tiempos, $B$. bronchiseptica coloniza el epitelio respiratorio formando las estructuras características de bacterias formadoras de biofilm ${ }^{207}$.

Tal como describimos antes, la sobre expresión de lap $G$ conduce a una reducción en la capacidad de formación de biofilm de $B$. bronchiseptica. Según la hipótesis planteada, esta sobreexpresión reduce la localización de BrtA sobre la membrana externa y esto es lo que conduce a una reducción en la formación de biofilm. Si la localización de BrtA fuera importante durante el proceso de infección es esperable que aquellos ratones inoculados con la cepa que sobre expresa lapG presenten un número menor de UFC al cabo de cierto tiempo de infección.

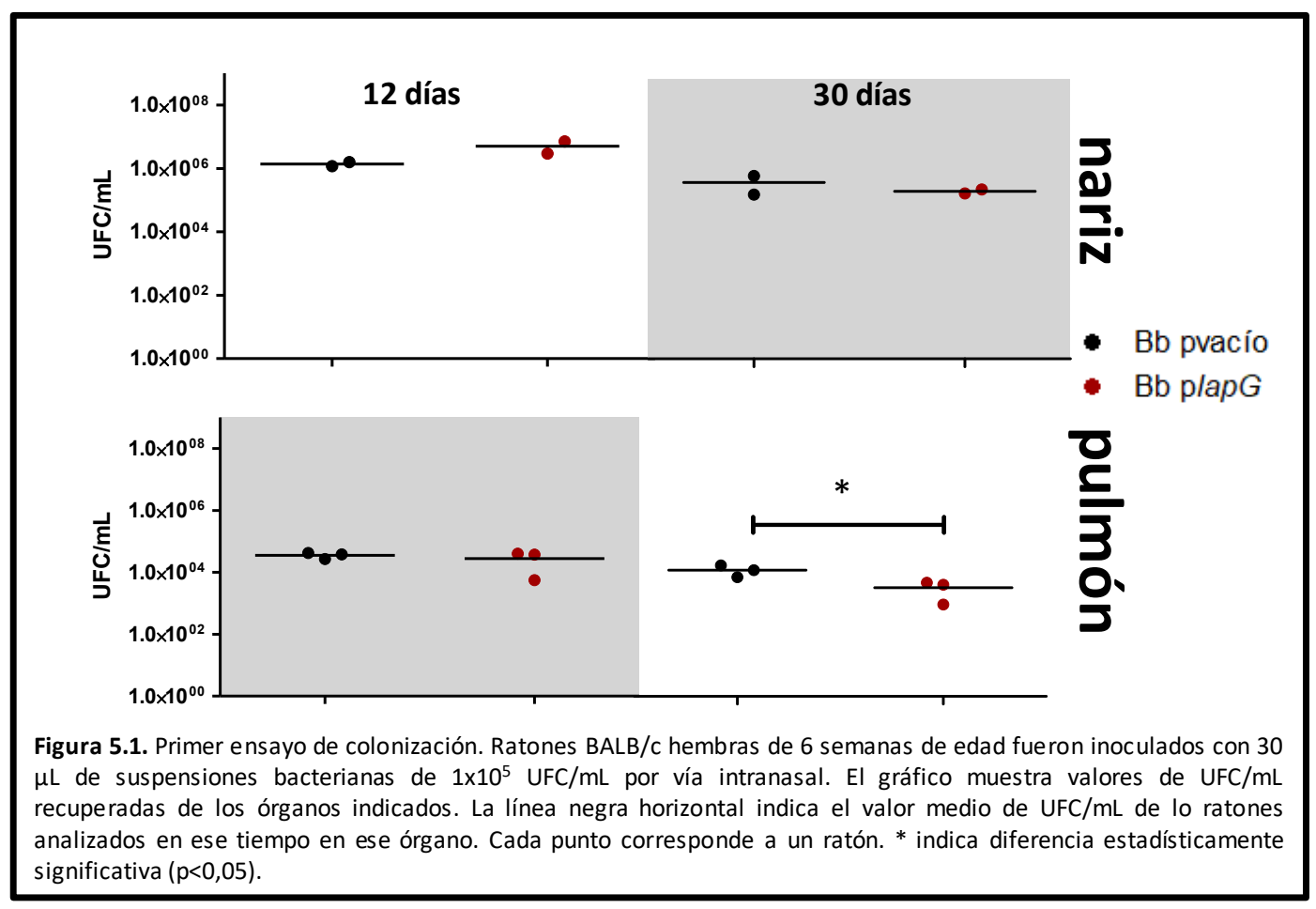

La Figura 5.1 muestra los resultados del primer ensayo de colonización realizado con las cepa Bb pvacío y Bb plapG.

En primer lugar, puede verse que al cabo de 12 días de realizada la inoculación encontramos bacterias tanto en la cavidad nasal como en pulmón siendo ligeramente superior el número de bacterias en nariz. En este tiempo post inoculación no vemos diferencias en el número de bacterias recuperadas de ratones infectados con la cepa salvaje respecto de los ratones inoculados con la cepa $\mathrm{Bb}$. plapG. Al analizar los resultados obtenidos a los 30 días de realizada la inoculación vemos que los pulmones recuperados de ratones infectados con la cepa $\mathrm{Bb}$ plapG presentaban un número de bacterias significativamente menor que los pulmones provenientes de ratones infectados 
con el control Bb pvacío $(p<0,05)$. Por el contrario, no encontramos diferencias en el número de bacterias recuperadas de las narices de los animales sacrificados en este tiempo. Dado que las diferencias encontradas son pequeñas, esta observación podría indicar que las proteínas Lap, si bien no serían indispensables para el desarrollo de la infección, podrían tener un rol secundario en etapas tardías del proceso de infección.

Cabe destacar que el desarrollo de este experimento fue realizado con cepas $B$. bronchiseptica transformadas con construcciones realizadas en el vector plasmídico pBBR1-MCS5. En cada uno de los tiempos indicados realizamos controles que nos permitieron confirmar la estabilidad de las construcciones durante el transcurso de la infección.

\section{Segundo ensayo de colonización}

Las primeras fases del proceso de colonización pueden ser fundamentales para el desarrollo de todo el proceso infectivo. Con el objetivo de evaluar un posible rol de las proteínas Lap durante las primeras etapas del proceso de colonización decidimos analizar las primeras horas después de iniciada la infección.

Para este ensayo utilizamos un protocolo de inoculación alternativo que se asemeja un poco más a un proceso de infección natural. En el primer ensayo de colonización inoculamos a cada ratón con $5.10^{5}$ bacterias $\left(50 \mu \mathrm{L}\right.$ de una suspensión $1.10^{7}$ UFC/mL). Si bien esta dosis es utilizada comúnmente en experimentos de colonización de $B$. bronchiseptica, constituye una carga bacteriana extremadamente alta frente a la cual, en condiciones normales, un ratón salvaje difícilmente pueda encontrarse. Una gran cantidad de bacterias presentes en el inóculo podría enmascarar posibles defectos de las cepas estudiadas durante las primeras etapas del proceso de colonización. Weyrich et al. demostraron que 500 UFC de $B$. bronchiseptica dispensadas en un volumen de $10 \mu \mathrm{L}$ son suficientes para lograr la colonización del $100 \%$ de los ratones inoculados ${ }^{282}$. Utilizando un inóculo inicial menor al mencionado también se puede lograr la colonización de la cavidad nasal, sin embargo en este caso, menos del $80 \%$ de los animales inoculados presenta colonización de los pulmones ${ }^{282}$. Por este motivo decidimos utilizar un protocolo de inoculación de 500 UFC en un volumen de $10 \mu \mathrm{L}$. Para este ensayo utilizamos las cepas Bb pvacío y Bb plapG. Los tiempos elegidos para el sacrificio fueron 2, 24 y 72 horas con el objetivo de evaluar las etapas iniciales del proceso de colonización. 


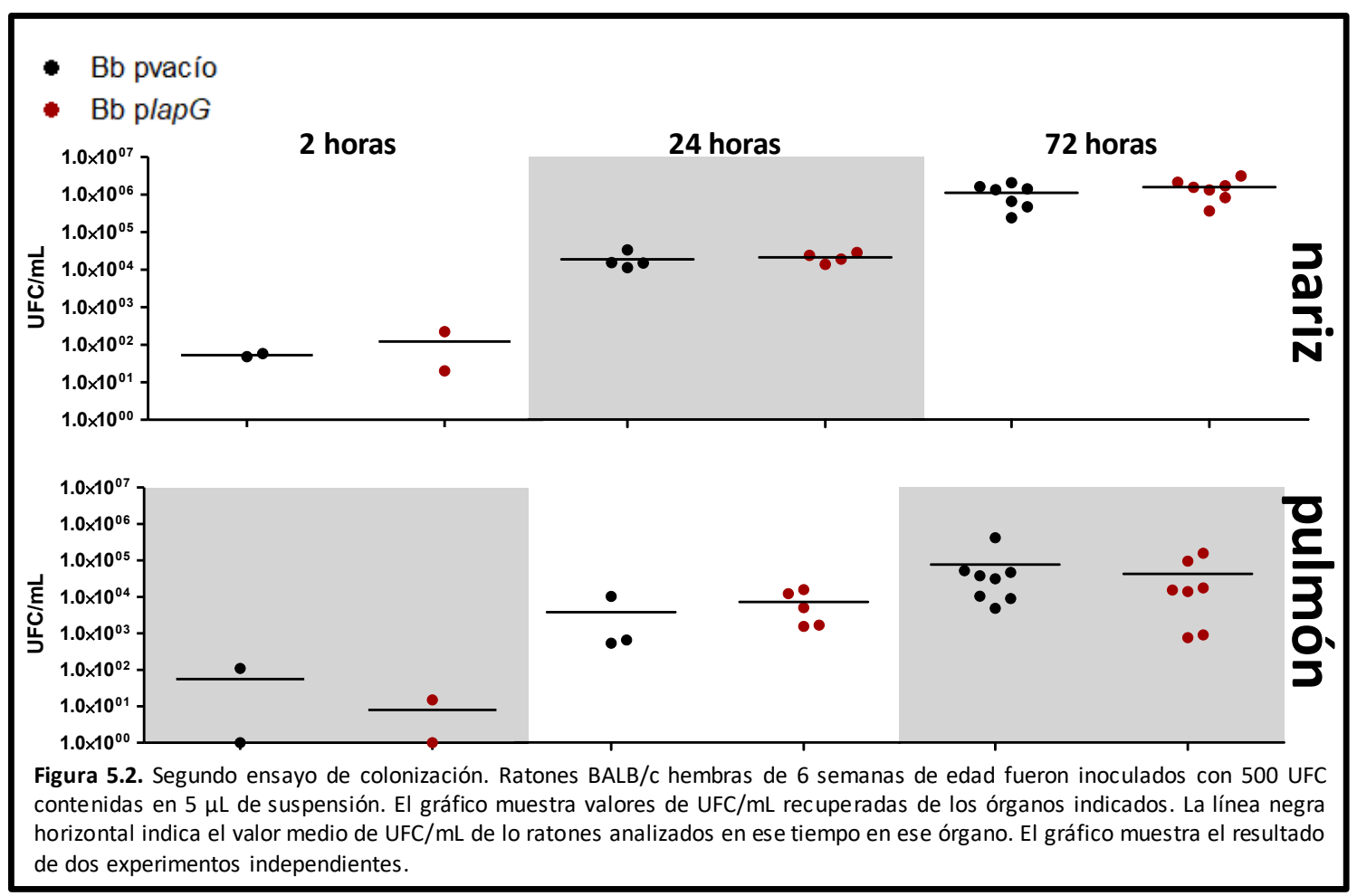

En la Figura 5.2 puede verse el resultado del experimento de colonización realizado para evaluar las primeras horas del proceso de infección.

En primer lugar, vemos que a las 2 horas de realizada la inoculación intranasal fue posible recuperar bacterias de esta región en los 4 ratones analizados. La carga bacteriana recuperada se redujo 1/5 de la carga inoculada originalmente. Por el contrario, si analizamos el resultado del número de bacterias recuperadas de pulmón vemos que, a las 2 horas post-inoculación, la infección no avanzó hasta las vías respiratorias inferiores en todos los ratones. Sólo dos de los cuatro ratones analizados presentaba pulmones colonizados.

Durante las primeras 72 horas post-inoculación vemos que la carga bacteriana presente en nariz se multiplicó. El número de bacterias recuperadas de esta región pasó de $1.10^{2} \mathrm{UFC} / \mathrm{mL}$ a $1.10^{6} \mathrm{UFC} / \mathrm{mL}$. Asimismo, el número de UFC recuperadas en pulmón también creció entre las 2 horas y las 72 horas, aunque alcanzó valores ligeramente menores que los alcanzados en nariz $\left(1.10^{5} \mathrm{UFC} / \mathrm{mL}\right)$.

El análisis estadístico de este experimento no mostró diferencias significativas en el número de UFC/mL recuperadas de los animales infectados con las cepas Bb pvacío en comparación con $\mathrm{Bb}$ plapG en ninguno de los tiempos y órganos analizados. Estos ensayos sugieren que, en el modelo estudiado, las proteínas Lap de B. bronchiseptica no tendrían un rol importante para el establecimiento inicial de la infección en nariz y pulmón. 


\section{Rol de LapG y BrtA en el proceso de infección}

Los resultados de biofilm presentados en los capítulos anteriores muestran que tanto LapG como BrtA tienen un rol importante en la formación de biofilm en $B$. bronchiseptica. A su vez, los primeros ensayos de colonización presentados en este capítulo dan indicios de que las proteínas Lap podrían tener también un rol durante el proceso infeccioso en ratones.

Con el objetivo de avanzar en la comprensión del rol de LapG y BrtA en la fisiopatología de $B$. bronchiseptica realizamos ensayos de colonización con las cepas $B$. bronchiseptica salvaje, $\triangle l a p G$ y $\triangle b r t A$. Para el desarrollo de estos experimentos utilizamos una carga bacteriana de $5.10^{5}$ UFC ( $50 \mu \mathrm{L}$ de suspensiones $1 \times 10^{7} \mathrm{UFC} / \mathrm{mL}$ ) y una vía de inoculación intranasal. Los recuentos de UFC en pulmón y nariz fueron realizados en los tiempo indicados: 2 horas, 7,14 y 21 días.
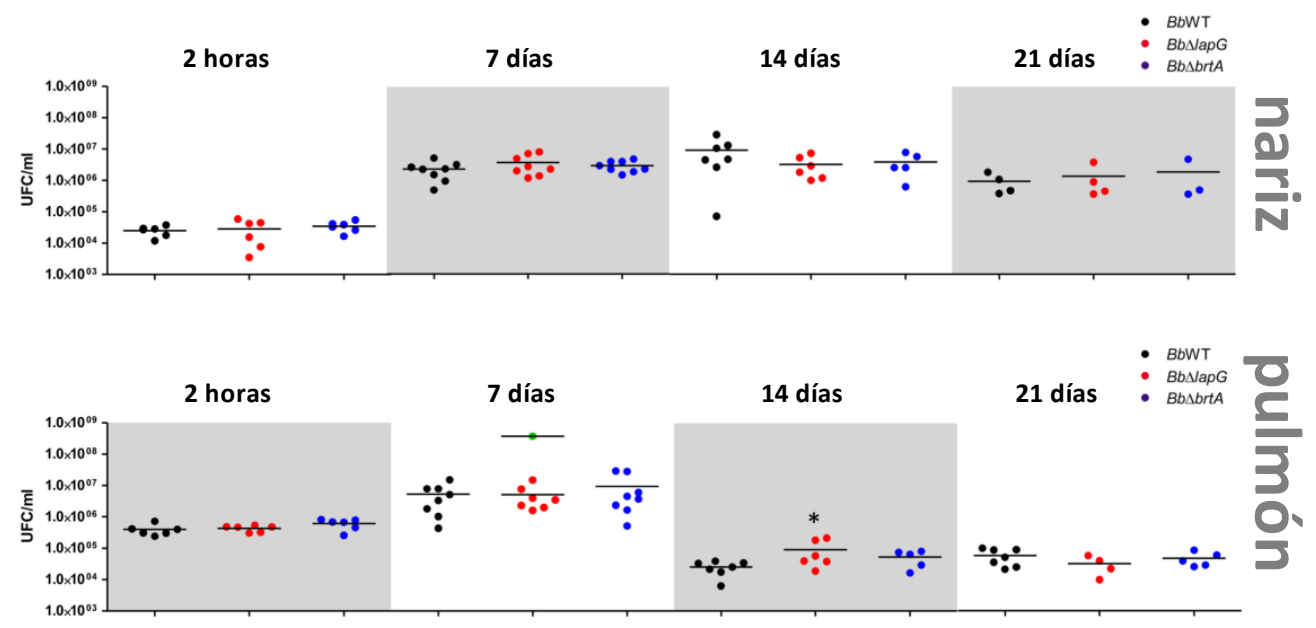

Figura 5.3. Ensayos de colonización con $\triangle b r t A$ y $\triangle / a p G$. Ratones BALB/c de 6 semanas de edad fueron inoculados con $10^{5}$ UFC contenidas en $50 \mu \mathrm{L}$ de suspensión. El gráfico muestra valores de UFC/mL recuperadas de los órganos indicados. La línea negra horizontal indica el valor medio de UFC/mL de lo ratones analizados en ese tiempo en ese órgano. El gráfico muestra el resultado

de dos experimentos independientes. * indica diferencia estadísticamente significativa respecto del control $\mathrm{Bb}$ salvaje $\mathrm{p}<0,05$.

En la Figura 5.3 vemos, en primer lugar, que los valores de $\mathrm{UFC} / \mathrm{mL}$ recuperadas de los órganos infectados con la cepa $B$. bronchiseptica salvaje son equivalentes a los datos reportados previamente en la bibliografía ${ }^{283}$. La cepa salvaje es capaz de persistir tanto en nariz como en pulmón 21 días post infección. La carga bacteriana en pulmón presentó un pico máximo en el día $7\left(10^{7} \mathrm{UFC} / \mathrm{mL}\right)$ para luego comenzar a disminuir gradualmente hasta alcanzar un valor mínimo a los 21 días $\left(10^{5} \mathrm{UFC} / \mathrm{mL}\right)$. Por otro lado, el pico máximo de infección en nariz se observó entre los días 7 y 14 post inoculación y luego se redujo en un orden de magnitud hacia el día 21.

El análisis de los resultados de UFC/mL recuperadas a las 2 horas constituye un control interno y además un resultado per se. Por un lado, la inexistencia de diferencias 


\section{Capítulo 5}

entre las tres cepas constituye una prueba de que los ratones fueron inoculados con cantidades equivalentes de bacterias. Por otro lado, este resultado también corrobora que, tal como sugería el experimento mostrado anteriormente, las proteínas Lap no tienen un rol preponderante en las etapas iniciales del proceso de colonización.

Durante el período de tiempo evaluado no registramos diferencias significativas entre el número de UFC/mL recuperadas de los ratones infectados con la cepa salvaje en comparación a los ratones infectados con la cepa $\Delta b r t A$.

Hacia el día 7 no registramos diferencias entre la cepa salvaje y la cepa $\Delta / a p G$. Sin embargo, el día 14 encontramos una diferencia significativa entre el número de UFC/mL recuperadas de los pulmones de los ratones infectados con $\Delta / a p G$ respecto de los controles infectados con la cepa salvaje $(p<0,05)$. Esta diferencia desapareció en el día 21 momento en el cual los animales infectados con todas las cepas presentaban, en pulmón, una carga bacteriana de $1.10^{5} \mathrm{UFC} / \mathrm{mL}$.

Entre los días 5 y 10 encontramos que el $25 \%$ de los ratones infectados con la cepa $\triangle l a p G$ presentaban signos de enfermedad (pelaje crispado, respiración dificultosa, y escasa respuesta a estímulos externos). Entre estos días algunos ratones fueron encontrados muertos y no fue posible procesar sus órganos. Sin embargo, uno de los ratones que presentaba mayores signos de enfermedad fue sacrificado para evitarle sufrimiento. Posteriormente, sus órganos fueron procesados a fin de realizar el recuento de UFC/mL presentes en pulmón y nariz. El recuento en nariz no difería del resto de los ratones, sin embargo, el recuento en pulmón dio como resultado un número de UFC/mL notablemente superior a la carga bacteriana normal para este día y superior también a la de otros ratones infectados con esta misma cepa (Figura 5.3, círculo verde).

\section{Análisis del rol de BrtA en la transmisión de B. bronchiseptica}

El evento de transmisión de un patógeno desde un hospedador infectado hacia un individuo sano es un proceso que conlleva grandes dificultades para su estudio.

En el caso particular de $B$. bronchiseptica, el proceso de transmisión ha sido reportado sólo por contacto directo o indirecto entre cerdos infectados y cerdos sanos ${ }^{284}$. Asimismo, no ha sido reportada la transmisión entre animales de manejo más sencillo en el laboratorio (ratones, ratas, conejos, etc.). La gran dificultad en el manejo grandes mamíferos, como cerdos, ha relegado el estudio de este evento. Sin embargo, el grupo de investigación liderado por Eric Harvill de la Universidad de Georgia (Athens, Estados Unidos) ha desarrollado un modelo de estudio murino para la transmisión de $B$. bronshiceptica $^{285}$. Investigadores de este grupo demostraron que el receptor de la inmunidad innata TLR4 está involucrado en el control de la transmisión de 
B.bronchiseptica ${ }^{285}$. A partir de este descubrimiento desarrollaron un modelo de estudio para la transmisión de $B$. bronchiseptica que contempla la utilización de una línea de ratones deficiente en el receptor TLR4 $(\mathrm{C} 3 \mathrm{H} / \mathrm{HeJ})^{285}$. Para el desarrollo de los experimentos de transmisión, un ratón infectado con $B$. bronchiseptica es colocado junto a 3 ratones no infectados (ratones naïve) durante 21 días. Transcurrido este tiempo, los animales naïve son sacrificados a fin de determinar la presencia de bacterias en nariz, pulmón y tráquea 285 .

Con el objetivo de estudiar si el sistema de proteínas Lap podría estar involucrado durante el proceso de transmisión entre un huésped infectado y uno sano decidimos utilizar este modelo de estudio.

Tal como describen Rolin et al., para el desarrollo de estos experimentos utilizamos la línea $\mathrm{C} 3 \mathrm{H} / \mathrm{HeJ}$ (TLR4 neg) ${ }^{285}$. Se inocularon por vía intranasal dos ratones con $5 \mu \mathrm{L}$ de una suspensión bacteriana $3.10^{5} \mathrm{UFC} / \mathrm{mL}$, de manera de dispensar $150 \mathrm{UFC}$ sobre la cavidad nasal. Estos animales fueron colocados en jaulas independientes junto a 3 ratones naïve de la misma línea $(n=6)$. Al cabo de 21 días todos los animales fueron sacrificados y los órganos nariz, tráquea y pulmones fueron procesados a fin de determinar el número de UFC totales presentes.

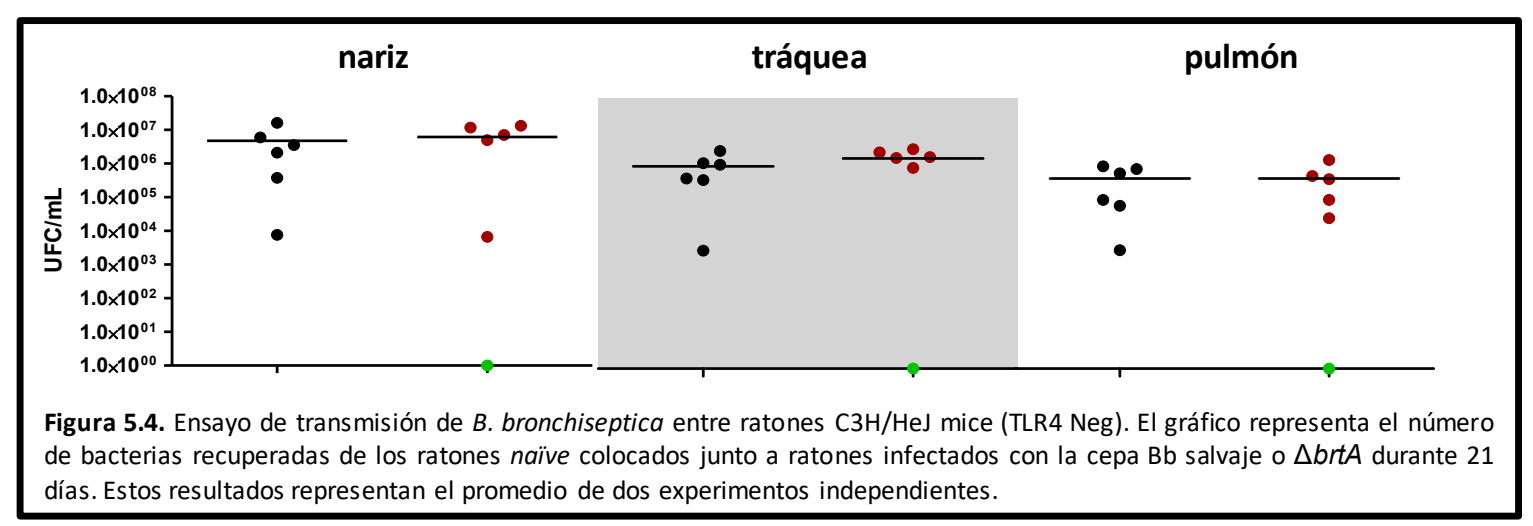

La Figura 5.4 presenta los resultados de un experimento de transmisión entre ratones $\mathrm{C} 3 \mathrm{H} / \mathrm{HeJ}$. Los resultados presentados corresponden al número total UFC presentes en los órganos indicados recuperadas de los ratones inicialmente no inoculados (naïve). Los ratones inicialmente inoculados también fueron sacrificados y sus órganos procesados a fin de determinar el número de CFU en los respectivos órganos a modo de control. Ambos ratones presentaron bacterias en todos los órganos indicando que la infección de los mismos había sido exitosa (resultados no mostrados)

Los resultados de la Figura 5.4 muestran, en primer término, tal como se haya descripto en la bibliografía, que $B$. bronchiseptica es capaz de transmitirse desde un ratón infectado hacia ratones naïve en la línea $\mathrm{C} 3 \mathrm{H} / \mathrm{HeJ}$. Como puede apreciarse en la figura, 


\section{Capítulo 5}

al cabo de 21 días, tanto la cavidad nasal, la tráquea y los pulmones de ratones originalmente no infectados, se encuentran colonizados. En todos los órganos hallamos cantidades de bacterias que van desde $1.10^{4}$ hasta $1.10^{7}$ UFC. La desviación estándar en el número de UFC/mL es mayor que en los experimentos de colonización presentados anteriormente. Esta variabilidad es similar a la reportada en la bibliografía ${ }^{285}$ y podría ser una consecuencia de la manera en que estos ratones son infectados. A diferencia de los ensayos de colonización en donde cada ratón es inoculado con una misma cantidad de bacterias, en estos ensayos, todos los ratones naïve son expuestos a un ambiente infectivo, pero no necesariamente todos se enfrentan al mismo número de bacterias.

Analizando el número de UFC/mL vemos que los ratones naïve que se infectaron con la cepa $\Delta b r t A$ no presentaron diferencias significativas frente a los controles infectados con la cepa salvaje. Sin embargo, encontramos que uno de los ratones no fue infectado (el círculo verde representa diferentes órganos del mismo ratón). Considerando este resultado podemos decir que el proceso de transmisión de la cepa salvaje fue efectivo en 6 de los 6 ratones expuestos a los ratones infectados, sin embargo, 1 de los 6 ratones expuestos a ratones infectados con la cepa $\Delta b r t A$ no fue contagiado. Este resultado, si bien no permite decir que BrtA tenga un rol preponderante durante el proceso de transmisión, podría indicar que contribuiría parcialmente a este proceso.

\section{Análisis de la formación de biofilm sobre monocapa celular}

En los capítulos anteriores presentamos evidencia de que LapG y BrtA tienen roles importantes para el desarrollo de biofilm sobre diferentes superficies. Sin embargo, en todos los casos las superficies evaluadas se trataban de materiales inertes: vidrio o plástico. Con el objetivo de evaluar la capacidad de formación de biofilm de $B$. bronchiseptica sobre una superficie biótica y el rol de LapG y BrtA en este proceso, realizamos ensayos de formación de biofilm sobre monocapas celulares. Para el desarrollo de este experimento utilizamos dos abordajes complementarios. Por un lado, analizamos el número de bacterias que se adhieren a la superficie celular luego de un período de tiempo de co-incubación con la monocapa celular. Asimismo, evaluamos mediante microscopía de fluorescencia, la capacidad de adhesión y de desarrollo de biofilm de diferentes cepas de $B$. bronchiseptica sobre las células epiteliales.

Para el desarrollo de estos experimentos utilizamos la línea celular CFBE (Cystic Fibrosis-derived epithelial cells) inmortalizada a partir de un cultivo primario de células epiteliales de bronquio de un paciente con fibrosis quística ${ }^{281}$. Dado que $B$. bronchiseptica es un patógeno oportunista de humanos, ha sido frecuentemente aislada de pacientes 
fibroquísticos ${ }^{158,206,286}$. Por este motivo, la línea celular elegida presenta características fisiológicamente relevantes para la biología de esta bacteria.

Brevemente, células de la línea CFBE fueron cultivadas en medio MEM en placas de 24 pocillos hasta alcanzar una confluencia del $100 \%\left(2,5.10^{4}-1.10^{5}\right.$ células). En ese momento se inocularon las suspensiones bacterianas sobre la monocapa celular. Una hora después, el sobrenadante fue retirado a fin de eliminar aquellas bacterias que no se hubieran adherido a la monocapa celular. Luego se adicionó medio de cultivo de células y se incubó durante diferentes períodos de tiempo.

Para realizar los recuentos de bacterias, 21 horas post-inoculación se tomaron muestras de $100 \mu \mathrm{L}$ del sobrenadante de cultivo y se realizaron diluciones seriadas a fin de determinar el número de UFC/mL presentes en forma planctónica en el sobrenadante. Posteriormente se aspiró el resto del sobrenadante y se adicionaron $250 \mu \mathrm{L}$ solución reguladora PBS. En forma mecánica se levantaron la monocapa de células junto a las bacterias adheridas a ella para luego tomar muestras de $100 \mu \mathrm{L}$ de estas suspensiones. Finalmente se realizaron diluciones seriadas a fin de determinar el número de bacterias adheridas a la monocapa celular (este recuento también fue expresado en términos de UFC/mL). Para este ensayo se utilizaron las cepas $B$. bronchiseptica salvaje, $\Delta / a p G$ y $\triangle b r t A$.

La Figura 5.5 muestra los resultados de los recuentos de UFC/mL en el sobrenadante de cultivo y sobre la monocapa de células de la línea derivada de un paciente fibroquístico CFBE.
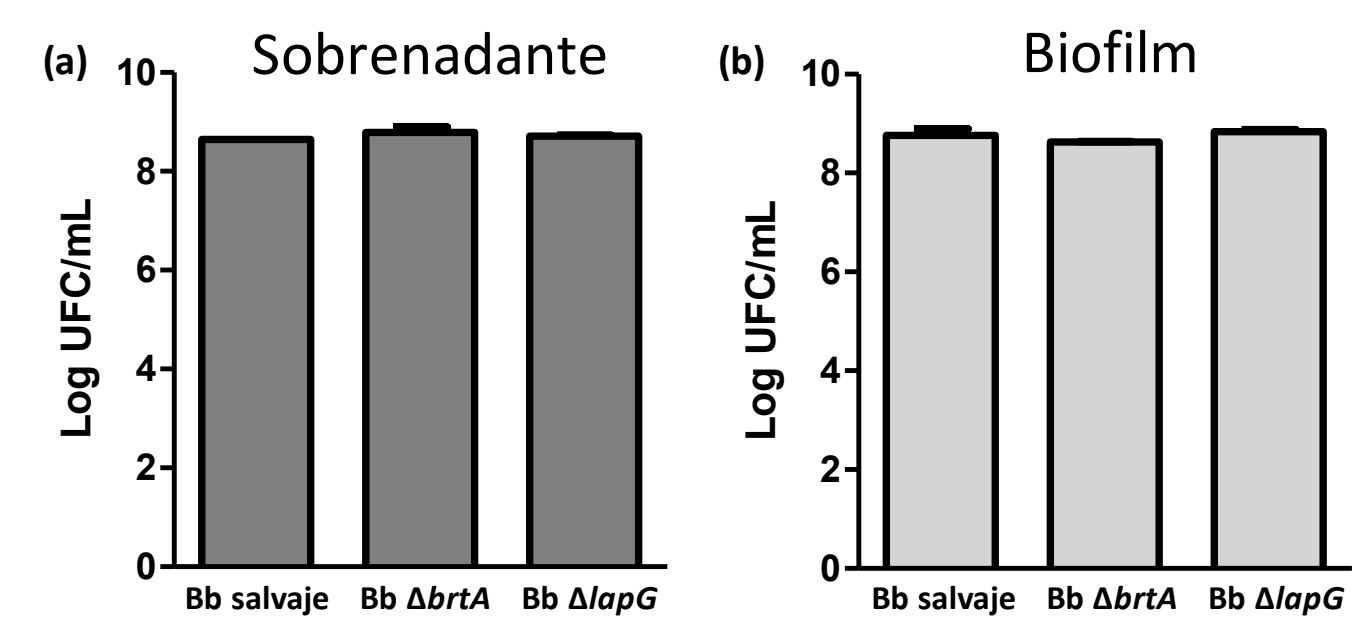

Figura 5.5. Formación de biofilm sobre monocapa celular. Los gráficos representan (a) el número de UFC/mL presentes en el sobrenadante de cultivo y (b) el número de UFC/mL adheridas a células de la línea CFBE co incubadas durante 21 horas con las cepas $B$. bronchiseptica salvaje, $\triangle b r t A$ y $\triangle$ lapG. El grafico representa el promedio y la desviación estándar de dos experimentos independientes cada uno de ellos realizado con 3 réplicas técnicas por cepa $(n=2)$. 


\section{Capítulo 5}

El resultado de los recuentos no mostró diferencias en el número de UFC/mL recuperadas del sobrenadante de células incubadas con $\Delta b r t A$ y $\Delta l a p G$ respecto del control incubado con la cepa B. bronchiseptica salvaje. Asimismo, tampoco encontramos diferencias entre el número de bacterias adheridas a la monocapa entre las cepas mencionadas.

En forma paralela a los ensayos de recuento se realizaron ensayos de microscopía de fluorescencia a fin de determinar la capacidad de adhesión y formación de biofilm sobre la monocapa celular de las cepas $B$. bronchiseptica salvaje, $\triangle b r t A$ y $\triangle l a p G$. Luego de la inoculación de las suspensiones bacterianas sobre la monocapa, tal como se describió en los párrafos anteriores, se realizaron observaciones microscópicas a diferentes tiempos de incubación. Durante el desarrollo de 3 experimentos independientes se analizaron tiempos de coincubacón de 4, 10, 20, 26 y 48 horas utilizando duplicados técnicos en cada uno de los casos. Para el desarrollo de estos experimentos se utilizó un microscopio de Florescencia Nikon Eclipse Ti acoplado a un módulo denominado spinning disk el cual permite la reconstrucción de imágenes en 3D a pesar de que el microscopio utilizado no presenta la tecnología Confocal.

La Figura 5.6 muestra imágenes representativas de los resultados obtenidos de los experimentos de microscopía de fluorescencia realizado para determinar la capacidad de adhesión y formación de biofilm de $B$. bronchiseptica. En primer lugar, se muestran imágenes representativas de los resultados obtenidos para la cepa $B$. bronchiseptica salvaje en cada uno de los tiempos analizados. En estas imágenes puede verse que desde el primer tiempo analizado (4 horas) encontramos bacterias adheridas a la superficie celular. En este tiempo se observan principalmente bacterias aisladas y esporádicamente cúmulos de unas pocas bacterias. Resulta importante destacar que, desde los primeros tiempos de incubación, se observaban células que presentaban signos de daño como por ejemplo una forma redondeada y despegada de la monocapa, así como también irregularidades en las regiones de contacto entre células (flechas blancas). Esta observación indicaría que $B$. bronchiseptica resultaría tóxica y rompería la estructura de monocapa de esta línea celular en la condiciones evaluadas.

Con el aumento del tiempo de incubación es posible observar un aumento en la cantidad de bacterias adheridas a la monocapa. A partir de las 10 horas empiezan a verse aglomerados bacterianos que podrían ser microcolonias desarrolladas como una etapa inicial del proceso de formación de biofilm. 


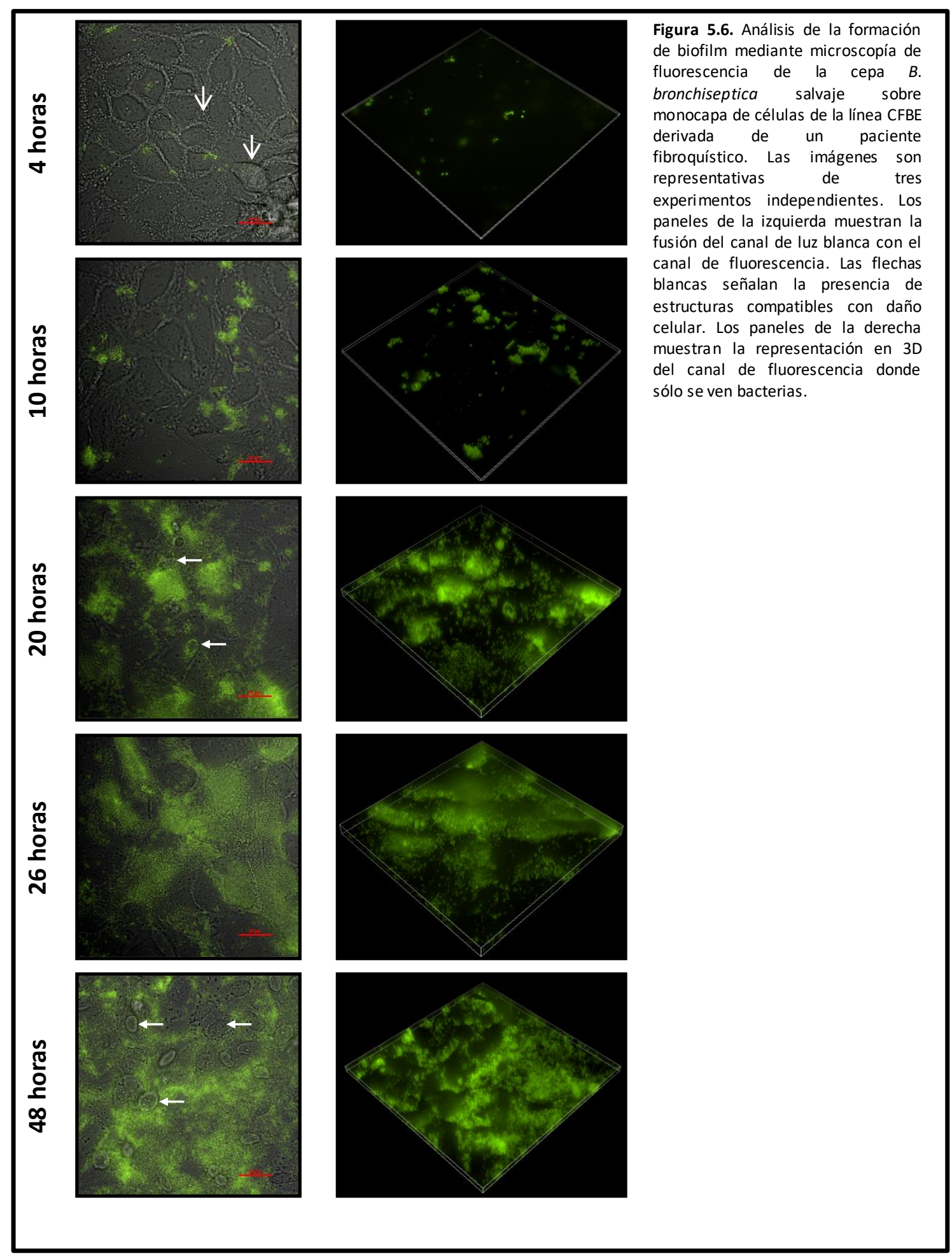

Entre las 20 y las 48 horas observamos un incremento importante en el número de bacterias adheridas a la superficie celular, así como también el desarrollo de aglomerados bacterianos en estructuras complejas que presentan características de biofilms. En estos tiempos se vio incrementada aún más la presencia de células con signos de daños (flechas blancas). 


\section{Capítulo 5}

En todos los tiempos de incubación indicados anteriormente se analizó también la capacidad de formación de biofilm de las cepas $\Delta b r t A$ y $\Delta / a p G$.

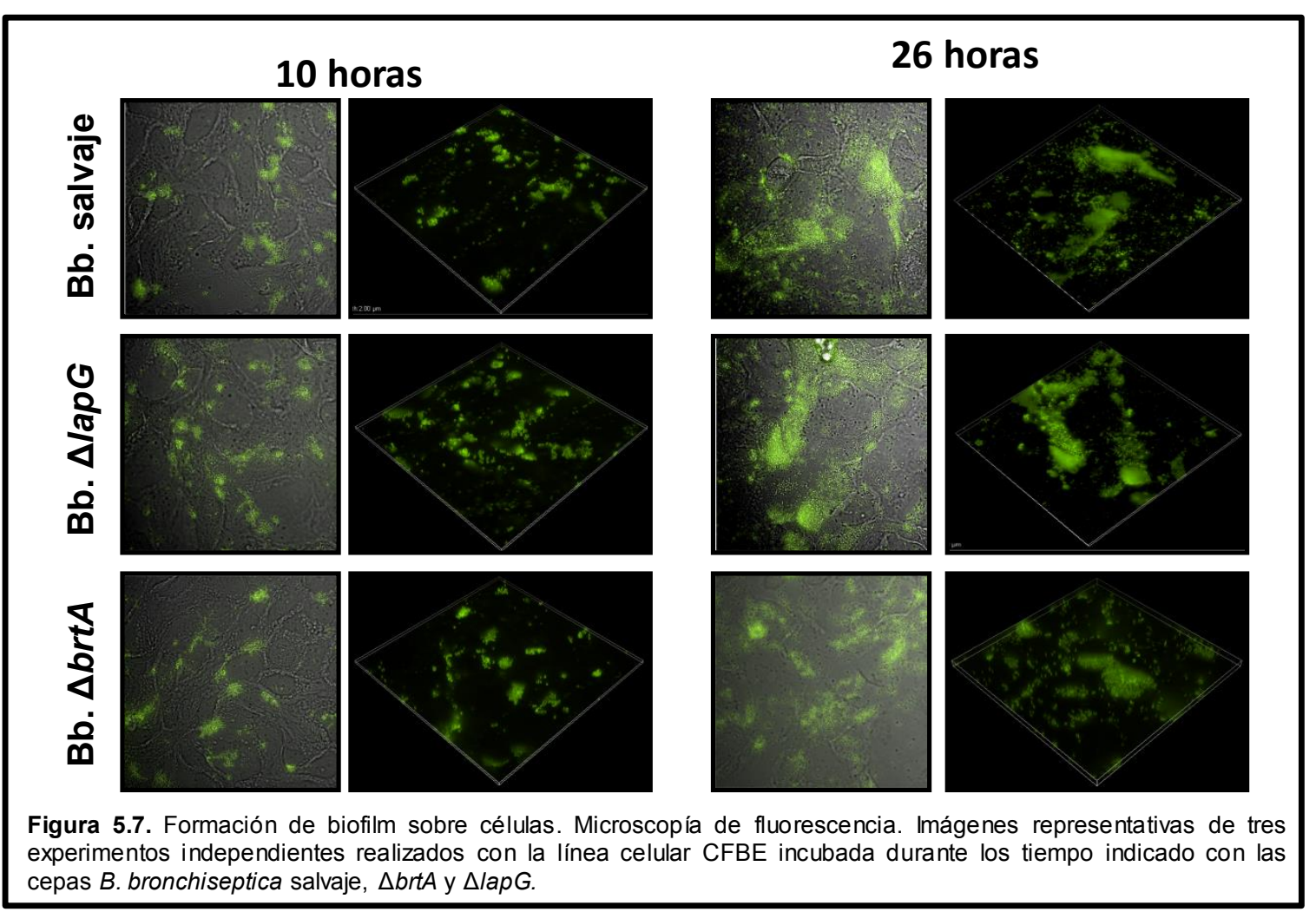

La Figura 5.7 muestra imágenes representativas de los experimentos de formación de biofilm sobre monocapa celular analizados mediante microscopia de fluorescencia de las cepas $\triangle b r t A$ y $\triangle l a p G$ en comparación a la cepa salvaje utilizada como control. Si bien estos experimentos fueron realizados a tiempos de incubación de 4, 10, 20, 26 y 48 horas, en la Figura 6.7 se muestran sólo a modo representativos los resultados de los tiempos de incubación de 10 y 26 horas.

En ninguno de los tiempos analizados encontramos diferencias significativas entre la capacidad de adhesión (tiempos cortos) o de formación de biofilm (tiempos largos) entre las cepas $\Delta b r t A, \Delta l a p G$ y la cepa control $B$. bronchiseptica salvaje. Todas las cepas presentaron una cinética de formación de biofilm similar en las condiciones analizadas. A las 4 horas se observaba principalmente la presencia de bacterias aisladas y esporádicamente la formación de cúmulos. A partir de las 10 horas se observaba la presencia de estructuras más complejas que se desarrollaban de manera similar hasta las 26 y 48 horas de incubación.

Si bien estos resultados podrían indicar que en las condiciones evaluadas LapG y BrtA no tienen un rol importante en la adhesión y formación de biofilm, la toxicidad 
observada sobre las células de la línea CFBE podría conspirar contra el óptimo desarrollo del experimento y posterior análisis de los resultados.

\section{Conclusiones y discusión}

Antes del comienzo del presente capítulo presentamos evidencia que confirmaba el rol del sistema de proteínas Lap (LapD, LapG y BrtA) en la formación de biofilm de $B$. bronchiseptica. En todos los experimentos realizados hasta el momento, la formación de biofilm fue analizada sobre superficies abiótica, inertes. Si bien esos resultados indicaban un claro rol de $L_{a p G_{B b}}$ y BrtA en los procesos de formación de biofilm tanto en superficies hidrofóbicas como en superficies hidrofílicas, restaba por indagar rol de estas proteínas en un contexto más cercano a su ambiente natural. Por ese motivo decidimos evaluar el comportamiento de cepas de $B$. bronchiseptica desarrolladas durante este trabajo en el contexto del modelo murino de colonización, en un nuevo modelo de transmisión y en ensayos de formación de biofilm sobre células.

Recientemente, el grupo de investigación de la Universidad de Osaka (Osaka, Japón) liderado por Yasuhiko Horiguchi, evaluó la capacidad de colonización y persistencia de un mutante brtA en un modelo animal de ratas Wistar ${ }^{260}$. Este grupo determinó que el número de UFC/mg de tráquea en ratas infectadas con la cepa $B$. bronchiseptica $\triangle b r t A$ no difería significativamente del número de UFC/mg recuperadas de ratas infectadas con la cepa salvaje en todo el rango de tiempo analizado (entre 3 y 60 días) ${ }^{260}$. En este mismo sentido, nuestros propios resultados de experimentos de colonización con ratones $\mathrm{BALB} / \mathrm{c}$ no mostraron una reducción significativa en la capacidad de colonización de la cepa $\Delta b r t A$ en comparación a la cepa salvaje usada como control. Si bien esos resultados no fueron capaces de demostrar un rol importante de BrtA durante el proceso de infección, resultados del grupo de Y. Horiguchi reportados previamente y confirmados en el mencionado trabajo, indican que BrtA se expresa durante la infección en ese modelo animal ${ }^{260,287}$.

Resulta fundamental destacar que en dos experimentos independientes encontramos diferencias estadísticamente significativas entre la cepa que sobre expresa lapG y su control y entre, la cepa $\triangle l a p G$ y su respectivo control. Si bien estos resultados no brindan información acerca de cuál podría ser el rol de las proteínas Lap en el transcurso de la infección, sí constituyen una evidencia importante a favor de que despeñan algún rol en este proceso.

Durante el desarrollo de los experimentos de colonización con la cepa $\Delta l a p G$, llamó poderosamente nuestra atención la virulencia que esta cepa presentaba sobre algunos ratones infectados con ella. Incluso, uno de los ratones que presentaba mayores 


\section{Capítulo 5}

signos de enfermedad también presentaba, en pulmón, un número de UFC/mL notablemente alto $\left(5.10^{8}\right.$ frente a un promedio de $1.10^{6}$ para ese tiempo). Un comportamiento similar a este fue destacado por J. Melvin al analizar ensayos de colonización con la cepa deficiente en la hemaglutinina filamentosa, $\Delta f h a B^{288}$. Los ensayos de infección con la cepa $B$. bronchiseptica $\triangle f h a B$, al igual que los realizados en este trabajo con $\triangle l a p G$, muestran un comportamiento bimodal. En ensayos de colonización realizados con ratones de la línea C57BL/6 se observó que 3 días postinoculación, un grupo de ratones infectados con la cepa $\triangle$ fha $B$ presentaba una carga bacteriana de $10^{7}$ UFC en pulmón mientras que otros animales presentaban $10^{3}$ UFC $^{288}$. Si bien hasta el momento no hay explicaciones para este comportamiento los signos de enfermedad desarrollados por estos ratones permitirían especular que la deleción de lapG, podría inducir una respuesta inmunológica exagerada debido a la presencia anormal de algún factor, muy probablemente BrtA. Hacen falta experimentos adicionales para poder asegurar este especulación, pero es un línea de trabajo sobre la cual podría avanzar este proyecto de investigación. Para avanzar en esa línea sería importante comenzar por analizar el perfil de respuesta inmunológica que presentan las cepas $\Delta l a p G, \Delta b r t A$ en comparación a la cepa salvaje.

Utilizando un modelo murino alternativo analizamos el rol de BrtA en otra etapa del ciclo infectivo de $B$. bronchiseptica. El recientemente desarrollado modelo murino de transmisión, nos permitió analizar el rol de BrtA durante esta parte del proceso ${ }^{285}$. Esta etapa del ciclo infectivo de Bordetella ha sido una de las etapas más difíciles de abordar debido a la falta de modelos adecuados para su estudio. El grupo de Eric Harvill ha demostrado que el receptor de la inmunidad innata TLR4 (Toll-like receptor 4) está involucrado en el control de las infecciones de $B$. bronchiseptica limitando su capacidad de transmisión desde huéspedes infectados a individuos sanos. Ratones deficientes en el receptor TLR4 presentan una mayor tendencia a la transmisión de la infección, evento que es raramente observado entre ratones salvajes o deficientes en otros componentes del sistema inmune. Utilizando este modelo murino evaluamos la capacidad de la cepa $\triangle b r t A$ de trasmitirse ente hospedadores. Si bien no encontramos diferencias estadísticamente significativas entre el número de bacterias recuperadas entre ratones contagiados con la cepa salvaje y la cepa $\triangle b r t A$, resulta interesante destacar el hecho de que uno de los ratones que estuvo en contacto con otro ratón infectado con la cepa $\Delta b r t A$ no fue contagiado. Resultados similares a éste fueron encontrados por el grupo de Eric Harvill al evaluar un panel de 13 mutantes utilizando este modelo de transmisión. En el mencionado trabajo determinaron que una cepa que presenta la deleción del locus involucrado en la síntesis del exopolisacárido de B. bronchiseptica (EPS) es incapaz de transmitirse en este modelo experimental ${ }^{235}$. Pero además, encontraron que las cepas 
$\triangle$ fhaB, $\triangle$ fimBCD (fimbria), $\triangle b s c N$ (sistema de secreción tipo III), $\Delta / p x O$ (LPS), y $\Delta e p s$ (EPS) si bien pueden transmitirse no lo hacen de la misma manera que la cepa salvaje ${ }^{235}$. La cepa $\Delta b r t A$, que en nuestras manos también presentó un leve defecto de transmisión, podría demostrar que BrtA podría ser parte de este grupo de factores que si bien participan del proceso de transmisión no son imprescindibles.

Durante el desarrollo de este capítulo también presentamos los experimentos de formación de biofilm sobre una superficie biótica. B. bronchiseptica ha sido aislada de pacientes con fibrosis quística ${ }^{206,289}$. Por ese motivo consideramos significativa la utilización de una línea celular derivada de un paciente fibroquístico ya que presentaría un ambiente similar a lo que $B$. bronchiseptica podría encontrarse naturalmente. En ese grupo de experimentos vimos claramente cómo la formación de biofilm de $B$. bronchiseptica aumentaba en función del tiempo (Figura 5.6). Sin embargo, también encontramos signos de daño sobre la monocapa celular. Estos daños podrían estar causados por el sistema de secreción tipo III el cual ya ha sido reportado que genera efectos citotóxicos sobre cultivos celulares ${ }^{290}$. Al igual que otros patógenos Gram negativos, Bordetella spp. utiliza el sistema de secreción tipo III para translocar proteínas efectores hacia el citoplasma de células eucariotas. Estos efectores interfieren en los mecanismos de señalización normales induciendo cambios fisiológicos o incluso la muerte celular ${ }^{291}$. Si bien en los tiempos analizados no vimos diferencias significativas entre las cepas $\Delta b r t A, \Delta l a p G$ y la cepa salvaje usada como control, sería fundamental desarrollar un experimento alternativo para evitar la elevada toxicidad observada sobre las células. En el trabajo presentado recientemente por el grupo de Yasuhiko Horiguchi para el desarrollo de experimentos de adhesión a células eucariotas utilizaron una cepa de $B$ bronchiseptica deficiente en el sistema de secreción tipo III. Este diseño experimental fue propuesto a fin de evitar la toxicidad observada sobre las células y poder analizar el efecto de otras mutaciones sobre la formación de biofilm. Esta podría ser un alternativa a desarrollar en el futuro para analizar la contribución de LapG y BrtA en el proceso de formación de biofilm sobre la monocapa de células de la línea CFBE. Concretamente, para el desarrollo de nuevos experimentos de formación de biofilm sobre monocapa celular podrían rehacerse los mutantes delecionales $\Delta l a p G$ y $\Delta b r t A$ sobre la cepa $B$ bronchiseptica $\Delta b s c N$ la cual presenta niveles de citotoxicidad menores a los de la cepa salvaje ${ }^{290}$.

En conclusión, presentamos evidencia de que el sistema Lap podría tener un rol durante el proceso de infección en ratones. Evidentemente el rol que cumple estas proteínas durante el desarrollo de la infección no es decisivo para el avance de la misma ya que la cepa $\triangle b r t A$ aún es capaz de infectar. Sin embargo, es importante avanzar en la comprensión que estas proteínas tienen sobre el desarrollo de la infección. 

Capítulo 6

Efecto de albúmina y calcio en la

función y localización de BrtA 



\section{Introducción}

En un trabajo publicado en el año 2017, el equipo de investigación liderado por Erik Hewlett de la Universidad de Virginia (Estados Unidos) demostró que la seroalbúmina bovina (BSA) y el catión calcio generan un efecto sinérgico en Bordetella que induce un incremento en los niveles de secreción de la toxina adenilato ciclasa $(\mathrm{AC})^{292}$. Los niveles de BSA y $\mathrm{Ca}^{+2}$ analizados en ese trabajo corresponden a concentraciones encontradas en las secreciones de las vías respiratorias ${ }^{292}$. La interacción de AC con FHA inhibe la formación de biofilm en Bordetella spp ${ }^{229}$. Por lo tanto, es esperable que el BSA y $\mathrm{Ca}^{+2}$ tengan efectos sobre la formación de biofilm.

En el presente capítulo presentaremos ensayos realizados con el objetivo de

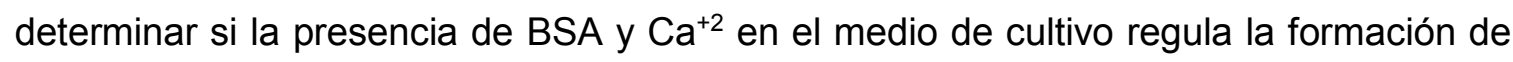

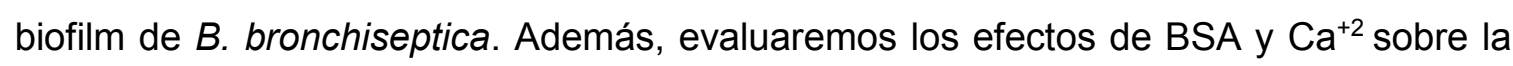
secreción de BrtA, adhesina que comparte con AC algunas propiedades estructurales.

\section{BSA y $\mathrm{Ca}^{+2}$ modulan la formación de biofilm en $B$. bronchiseptica}

Hasta el momento no existen reportes acerca del efecto que BSA y $\mathrm{Ca}^{+2}$, en los niveles reportados por Gonyar et al. ${ }^{292}$, podrían tener sobre la formación de biofilm de Bordetella spp. Con el objetivo de analizar el efecto de estos compuestos sobre la formación de biofilm en $B$. bronchiseptica realizamos ensayos de cultivo en microplacas en medio de cultivo SS y en SS suplementado con BSA y $\mathrm{Ca}^{+2}$. Estos ensayos fueron realizados en $0 \mathrm{mM}$ y en 2,0 $\mathrm{mM}$ de ácido nicotínico.

La Figura 6.1 muestra los resultados de estos ensayos. El análisis directo de las fosas teñidas con cristal violeta muestra que la presencia de BSA y $\mathrm{Ca}^{+2}$ inhibió por completo la formación de biofilm en $0 \mathrm{mM}$ de ácido nicotínico. El análisis cuantitativo de esta condición muestra una reducción del $85 \%$ en los valores de absorbancia a $595 \mathrm{~nm}$. Si comparamos estos valores con los valores de absorbancia obtenidos para las fosas control sin inocular vemos que no presentan diferencias. Esto podría indicar que en presencia de BSA y $\mathrm{Ca}^{+2}$ ni siquiera hay bacterias adheridas a la superficie de las fosas, lo cual sugiere que BSA y $\mathrm{Ca}^{+2}$ podrían estar inhibiendo alguna etapa inicial del proceso de formación de biofilm. 


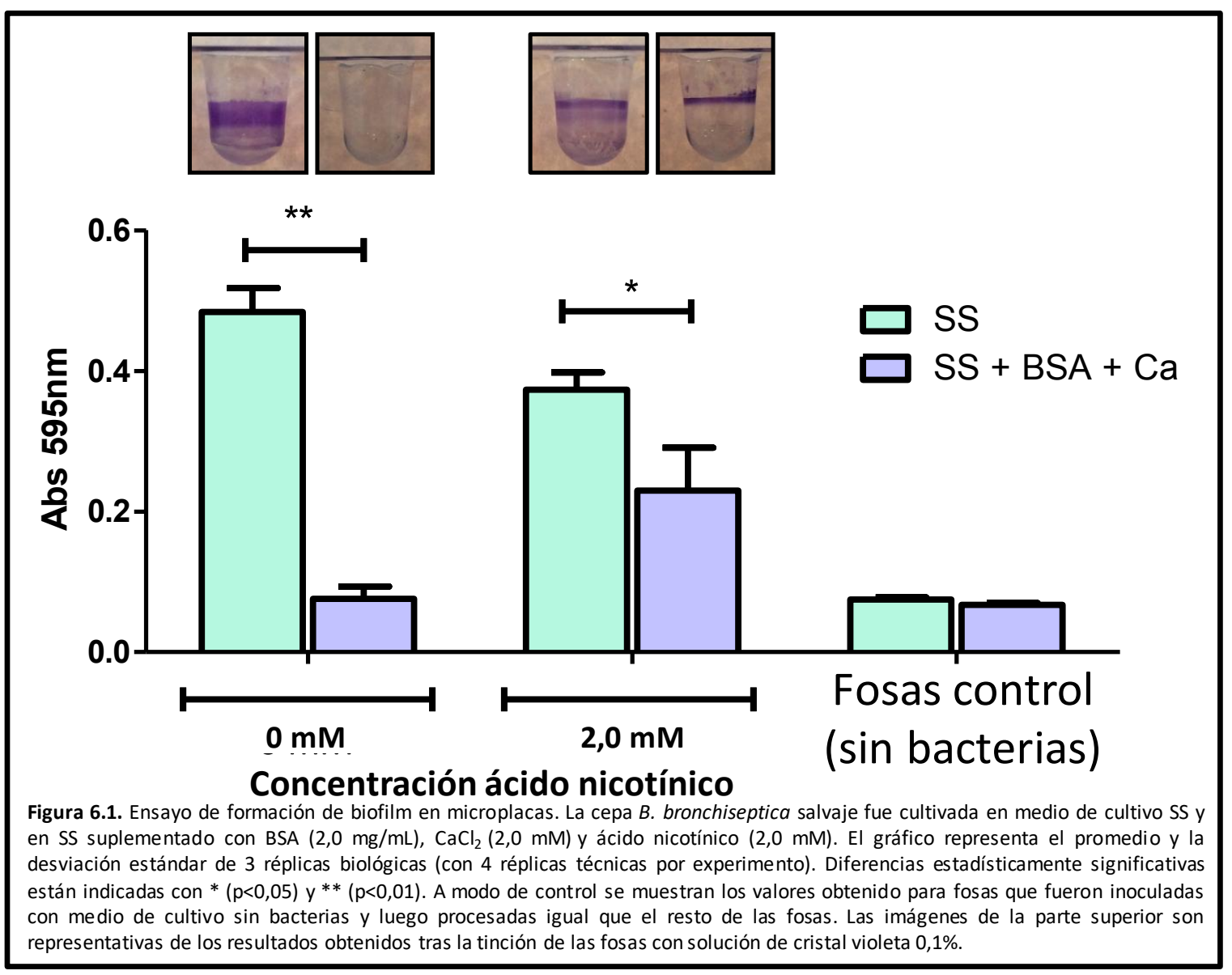

En 2,0 mM de ácido nicotínico, BSA y $\mathrm{Ca}^{+2}$ generaron un cambio en las características macroscópicas del biofilm formado. En las fosas con cultivos en SS la formación de biofilm se aprecia como una banda de coloración intensa en la región de la interfase entre el aire y la suspensión bacteriana. Por debajo de esta zona se observa una región de menor intensidad de color.

Esta región se hace cada vez menos intensa a medida que aumenta la distancia a la interfase hasta prácticamente desaparecer hacia el fondo de la fosa. En las fosas suplementadas con $\mathrm{BSA}$ y $\mathrm{Ca}^{+2}$, por el contrario, sólo se observa la formación de biofilm en la interfase ente el aire y la suspensión bacteriana. Aunque resulta difícil estimarlo mediante esta técnica, la intensidad del color en esta región pareciera ser mayor en las fosas suplementadas con BSA y $\mathrm{Ca}^{+2}$ en comparación a las fosas cultivadas con SS tradicional. Asimismo, no se observa la presencia de tinción por debajo de la línea de la interfase. El análisis cuantitativo de esta condición muestra que los valores de absorbancia a $595 \mathrm{~nm}$ presentan una reducción del $40 \%$ en las fosas suplementadas con $\mathrm{BSA}$ y $\mathrm{Ca}^{+2}$. Estos resultados sugieren que, en presencia de 2,0 $\mathrm{mM}$ de ácido nicotínico, la adhesión de las bacterias a la superficie estaría favorecida en la interfase respecto de la zona sumergida. Las propiedades macroscópicas del biofilm formado en esta condición 
son similares a las características que presentan los biofilms reportados en otras especies como $P$. fluorescens en donde, en este sistema de cultivo, la formación es bien definida en la interfase y prácticamente nula por debajo de ésta ${ }^{293}$.

La ausencia absoluta de biofilm cuando la bacteria es cultivada en el medio SS sin modificaciones nos llevó a considerar inicialmente la posibilidad de que el efecto de BSA y $\mathrm{Ca}^{+2}$ fuera inespecífico y particularmente de naturaleza fisicoquímica. Sin embargo, el comportamiento diferencial entre las condiciones $0 \mathrm{mM}$ y 2,0 mM de ácido nicotínico sugiere que debe haber un mecanismo fisiológicamente relevante que podría ser importante para la regulación de la formación de biofilm mediada por $\mathrm{BSA}$ y $\mathrm{Ca}^{+2}$.

\section{Análisis de la formación de biofilm sobre otras superficies}

En el Capítulo 3 analizamos los efectos de la deleción de brtA sobre la formación de biofilm en plástico y en vidrio. A través de los experimentos presentados en esa sección demostramos que las propiedades de la superficie constituyen una variable experimental que debe ser considerada a la hora de analizar el fenotipo de biofilm. Los experimentos de formación de biofilm sobre vidrio presentados en ese capítulo fueron realizados en tubos de ensayo. En este capítulo presentaremos ensayos de formación de biofilm utilizando un diseño experimental alternativo, diseñado y puesto a punto durante el transcurso de este trabajo de tesis.

En este caso utilizamos un diseño experimental derivado del protocolo usado para las observaciones al microscopio electrónico de barrido (SEM). Brevemente, recordemos que para el desarrollo de esos experimentos los cultivos son realizados en tubos de microcentrífuga de $1,5 \mathrm{~mL}$ de polipropileno (plástico). En estos cultivos se sumergen cubreobjetos cortados manualmente manera tal de quedar semi sumergidos en la suspensión bacteriana. Los pasos finales del protocolo de preparación de las muestras para SEM consisten en una etapa de deshidratación, secado por punto crítico y metalizado (ver detalles en el Capítulo 9; Materiales y Métodos). Para la observación directa de la formación de biofilm sobre vidrio remplazamos estas etapas por una incubación de la muestra en solución de cristal violeta $0,1 \%$ p/v. De esta manera las técnicas de observación de biofilm por SEM y por observación directa sólo se diferencian en la etapa final. Los tubos de microcentrífuga donde se realiza el cultivo con el vidrio semi sumergido también pueden ser procesados de la misma manera y así evaluar simultáneamente la formación de biofilm en dos superficies diferentes utilizando la misma suspensión bacteriana. 


\section{Capítulo 6}

La Figura 6.2 muestra un resultado típico obtenido para un ensayo de formación de biofilm realizado con la cepa $B$. bronchiseptica salvaje según el protocolo descripto en el párrafo anterior.

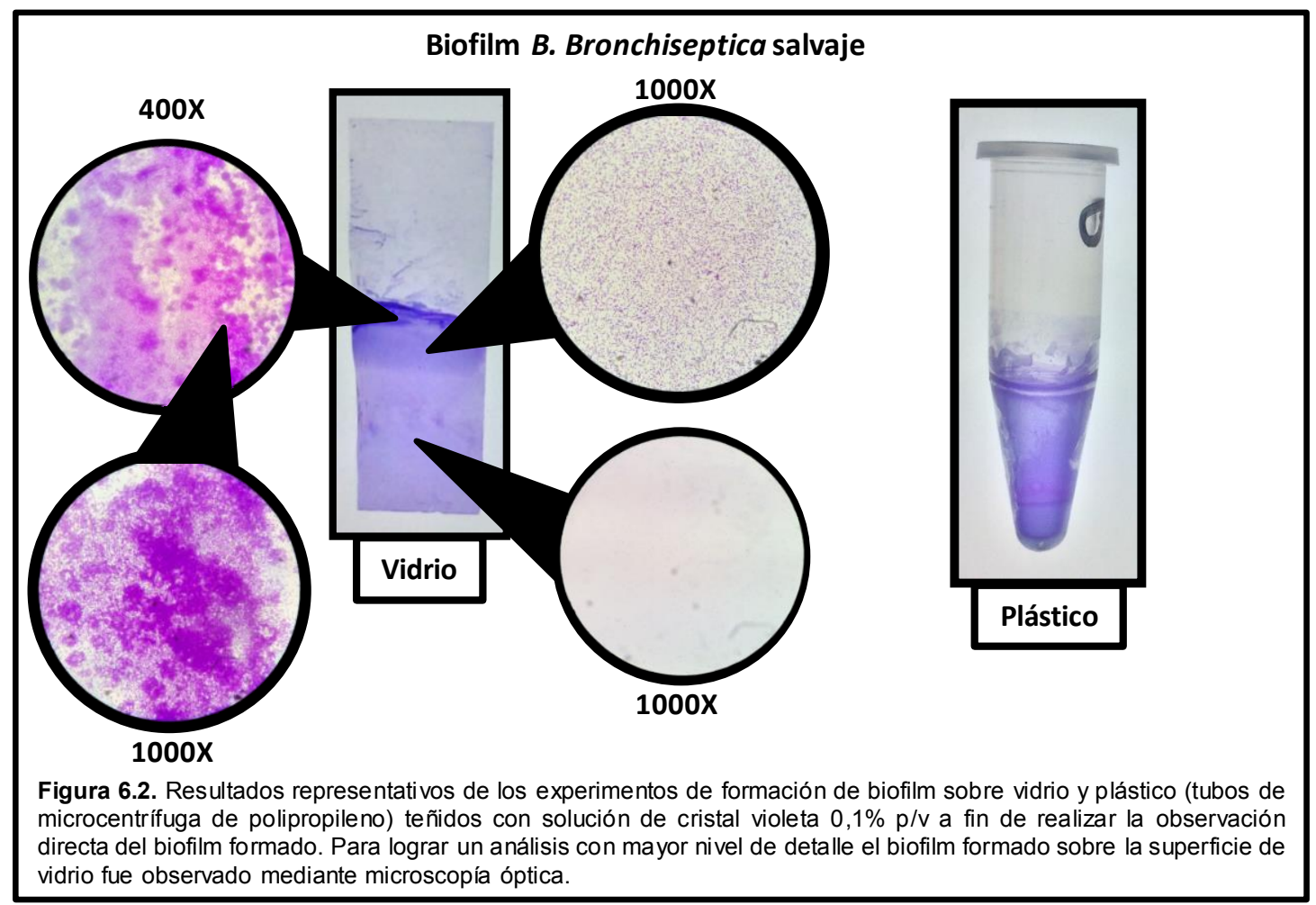

Al analizar el cubreobjeto sobre el cual se produjo la formación de biofilm de la cepa salvaje lo que puede verse es una coloración intensa en la región del vidrio donde se encontraba la interfase entre la suspensión bacteriana y el aire. Por debajo de esta línea se observa una zona de intensidad menor y finalmente una zona de baja coloración desde ese punto hasta el extremo inferior del vidrio. Cada una de estas regiones fue analizada utilizando microscopía óptica.

La observación de la región superior, utilizando aumentos de 400X y 1000X, muestra aglomeraciones típicas de estructuras del tipo de biofilm. Mediante esta estrategia no es posible observar bacterias aisladas ni los detalles de esas estructuras. Esta es la región que analizamos mediante SEM en los experimentos presentados previamente en el Capítulo 3 y el Capítulo 4.

La inspección de la región inmediatamente inferior muestra una zona de bacterias adheridas a la superficie, pero no se observan grandes agregados. Resulta difícil mediante microscopía óptica determinar si se trata de bacterias aisladas o pequeños agregados de unas pocas bacterias. 
En la región del vidrio que queda entre la zona descripta previamente y el límite inferior también se observa, a simple vista, una coloración azul. Sin embargo, la inspección microscópica de esta región no muestra la presencia de bacterias adheridas a la superficie. Es importante tener presente que, durante la etapa de tinción, el vidrio es sumergido por completo en la solución de cristal violeta. De manera tal que la región por encima de la interfase queda sumergida igual que la región por debajo. Es decir que la leve coloración de la región inferior del vidrio podría deberse a algún componente del medio de cultivo que se adhiere a la superficie de vidrio, pero no puede ser visualizado mediante microscopía óptica.

No existen, reportes acerca de las característica ni las causas que llevan a $B$. bronchiseptica a desarrollar biofilms estructurados de esta manera. Es probable que la limitación en oxígeno que se produce por debajo de la interfase en cultivos estáticos sea una de las causas que conlleva a una reducción en la formación de biofilm desde la interfase hacia las zonas más sumergidas del vidrio.

En la imagen 6.2 también se muestra el resultado obtenido al teñir con solución de cristal violeta el tubo de microcentrífuga donde se realizó el cultivo. En primer lugar, se aprecia claramente que la suspensión bacteriana se adhiere a la superficie de manera diferente a como lo hace en sobre la superficie de vidrio. En el tubo de plástico no es posible distinguir las 3 regiones que destacamos al analizar la formación de biofilm en vidrio. La tinción de la superficie es homogénea desde la zona de la interfase hasta el fondo el tubo y si bien se aprecia la formación de un anillo, no se distingue una región más intensa en la interfase aire-líquido.

Este ensayo demuestra que las propiedades de la superficie definen las características del biofilm que se desarrolla sobre ella. La superficie plástica (polipropileno) del tubo de microcentrífuga y la superficie de vidrio (silicato) están expuestas a la misma suspensión bacteriana y sin embargo las características de los biofilms formados sobre ellas son de aspecto diferente.

Considerando el análisis presentado en los párrafos anteriores realizamos ensayos de formación de biofilm sobre vidrios semi sumergidos en condiciones modulantes de ácido nicotínico en presencia o no de BSA y $\mathrm{Ca}^{+2}$. 


\section{Capítulo 6}

En la Figura 6.3 y 6.4 se observan los resultados de los ensayos de formación de biofilm realizados utilizando el protocolo descripto en los párrafos anteriores. Estos ensayos fueron analizados mediante la observación directa de los biofilms teñidos con solución de cristal violeta (Figura 6.3) y mediante microscopía electrónica de barrido (Figura 6.4).

Como describimos previamente en el vidrio incubado en medio SS se observa una coloración violeta intensa en la región

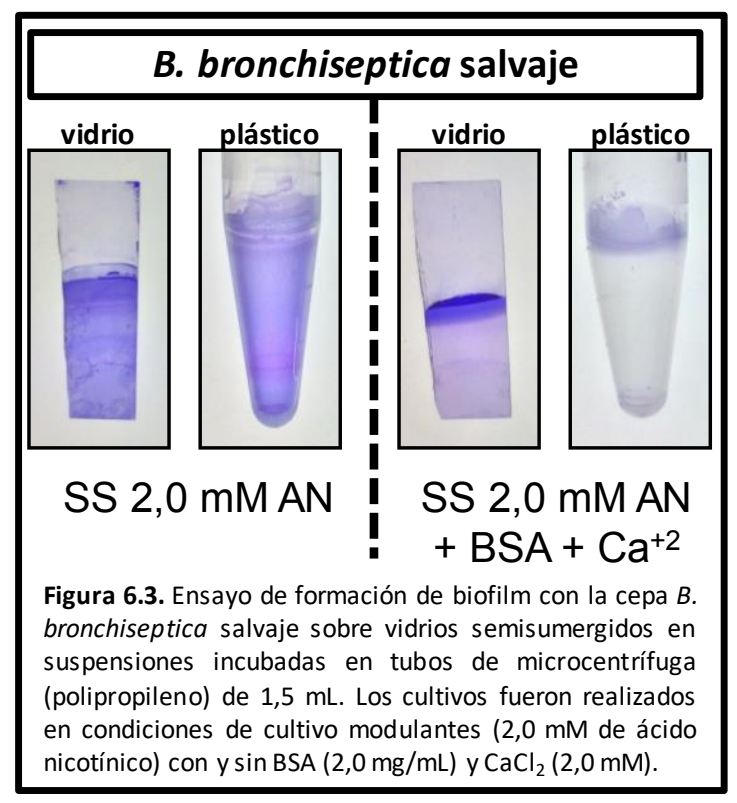
correspondiente a la interfase aire-líquido y una reducción paulatina de la intensidad desde esta región hasta el borde inferior del vidrio (Figura 6.3). El agregado de BSA y $\mathrm{Ca}^{+2}$ modifica las características macroscópicas del biofilm formado. Analizando la superficie de vidrio puede verse una coloración muy intensa sobre la interfase (Figura 6.3). También se aprecia una región, inmediatamente por debajo de la interfase, en donde la intensidad de la coloración es menor. Por debajo de esta zona y hasta el borde inferior del vidrio se observa una coloración mucho más tenue en comparación a la misma zona del vidrio sumergido en SS sin agregado de BSA y $\mathrm{Ca}^{+2}$ (Figura 6.3).

Analizando los tubo de plástico se observan diferencias importantes entre los tubos que contenían SS y los tubos con SS suplementado con BSA y $\mathrm{Ca}^{+2}$. La tinción de los tubos que contenían cultivos en SS muestra una coloración homogénea desde la superficie hasta el fondo del tubo, tal como describimos algunos párrafos más arriba. En presencia de BSA y $\mathrm{Ca}^{+2}$ sólo se observa una leve coloración en la interfase aire-líquido que luego desaparece rápidamente hasta el fondo del tubo.

A diferencia de lo que sucede en cultivos en condiciones $\mathrm{Bvg}+(0 \mathrm{mM}$ de ácido nicotínico) donde el agregado de BSA y $\mathrm{Ca}^{+2}$ inhibe la formación de biofilm (Figura 6.1), mediante esta estrategia no podemos asegurar si BSA y $\mathrm{Ca}^{+2}$ aumenta o disminuye la formación de biofilm en condiciones de cultivo con 2,0 mM de ácido nicotínico. Con el objetivo de obtener información a nivel microscópico, utilizamos microscopía electrónica de barrido (SEM) para analizar el efecto de BSA y $\mathrm{Ca}^{+2}$ sobre la formación de biofilm en esta condición. La Figura 6.4 muestra que el biofilm formado por la cepa B. bronchiseptica salvaje en SS suplementado con 2,0 mM de ácido nicotínico presenta grandes aglomerados de bacterias con un importante desarrollo en altura. Por el contrario, la presencia de BSA y $\mathrm{Ca}^{+2}$ induce una disminución en el tamaño de los agregados, así como también una reducción en la altura de los mismos. También se observa la presencia 
de matriz extracelular, que no había sido apreciada en ninguno de los experimentos de microscopía realizados previamente.

En base a estas observaciones confirmamos que la presencia de $\mathrm{BSA}$ y $\mathrm{Ca}^{+2}$ en el medio de cultivo también reduce la formación de biofilm en condiciones de 2,0 mM de ácido nicotínico.

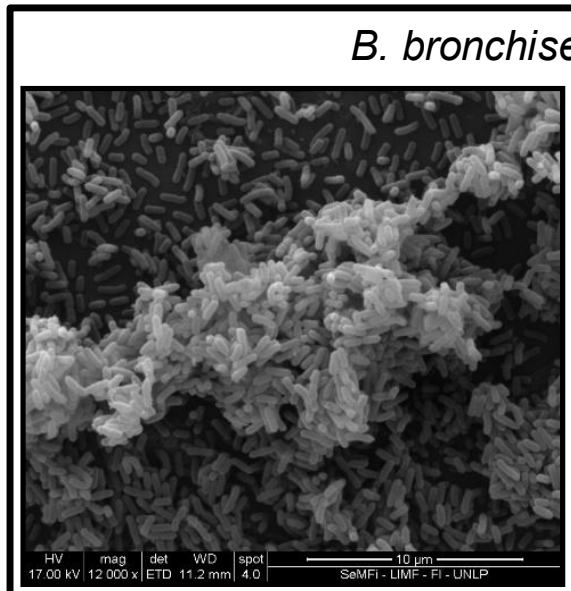

SS 2,0 mM AN

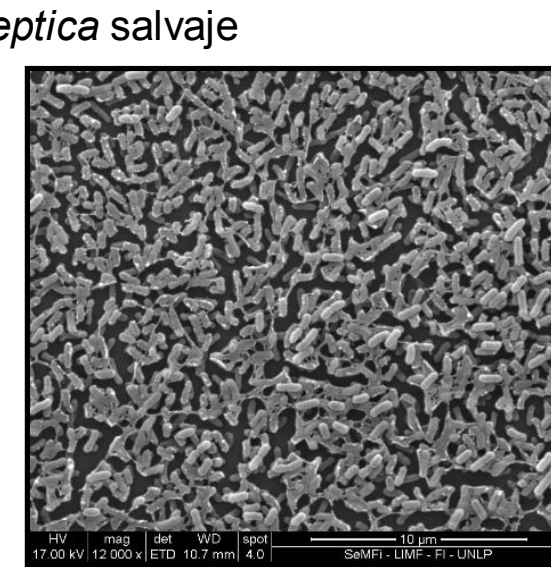

SS 2,0 mM AN

$\mathrm{BSA}+\mathrm{Ca}^{+2}$

Figura 6.4. Análisis de la formación de biofilm mediante microscopía electrónica de barrido. Se muestran imágenes representativas de biofilms de la cepa $B$. bronchiseptica salvaje formados sobre vidrio. Los cultivos fueron realizados en condiciones de cultivo modulantes $(2,0 \mathrm{mM}$ de ácido nicotínico $)$ con y $\sin \mathrm{BSA}(2 \mathrm{mg} / \mathrm{mL})$ y $\mathrm{CaCl}_{2}(2,0 \mathrm{mM})$ durante 24 horas sin agitación.

\section{Análisis del rol de BrtA en la regulación de la formación de biofilm mediada por BSA y $\mathrm{Ca}^{+2}$}

Los resultados de la sección anterior demuestran que, en condiciones modulantes (2,0 mM de ácido nicotínico), la presencia de BSA y $\mathrm{Ca}^{+2}$ en el medio de cultivo genera una disminución de la formación de biofilm en $B$. bronchiseptica. Previamente hemos demostrado que BrtA es una adhesina involucrada en la formación de biofilm y el efecto de la deleción de brtA se hace especialmente evidente en cultivos realizados en esas mismas condiciones de ácido nicotínico (Capítulo 3). Estas observaciones sugieren la posibilidad de que el efecto de BSA y $\mathrm{Ca}^{+2}$ este mediado por la adhesina BrtA. Recordemos que la localización en membrana de BrtA está controlada por la proteasa LapG. Por lo tanto, si BSA y $\mathrm{Ca}^{+2}$ reducen la cantidad de BrtA a través de un mecanismo mediado por LapG, la cepa $\triangle l a p G$ debería ser insensible al agregado de BSA y $\mathrm{Ca}^{+2}$.

Para comenzar a analizar esta hipótesis realizamos ensayos de formación de biofilm en microplacas en medio de cultivo SS y en medio SS suplementado con BSA y $\mathrm{Ca}^{+2}$. Para este experimento realizamos cultivos en condiciones $\mathrm{Bvg}+\mathrm{y}$ en condiciones 


\section{Capítulo 6}

modulantes (2,0 $\mathrm{mM}$ de ácido nicotínico). A modo de control también incluimos la cepa $\Delta b r t A$.

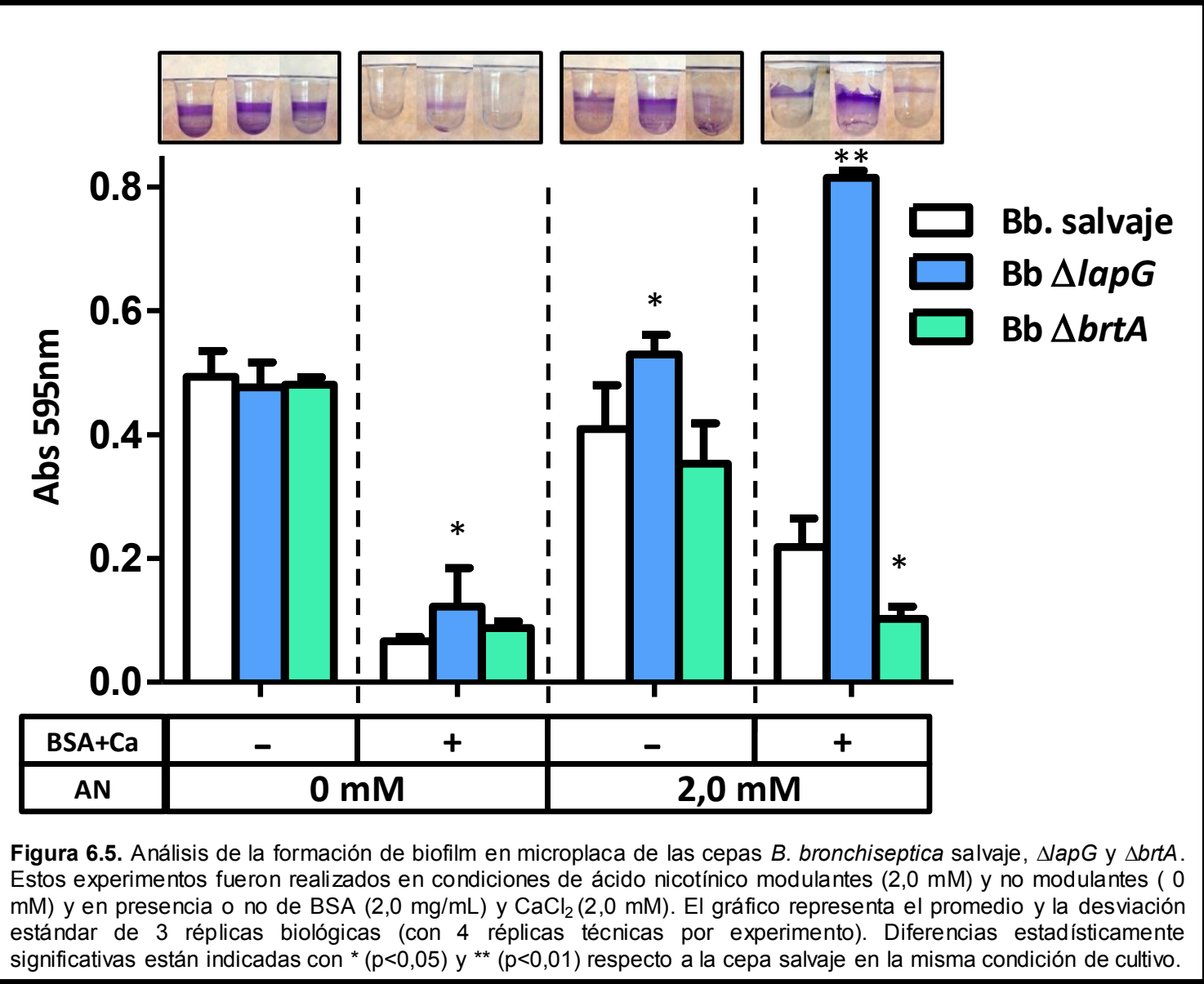

La Figura 6.5 muestra los efectos del agregado de $\mathrm{BSA} \mathrm{Ca}^{+2}$ al medio de cultivo sobre la formación de biofilm de las cepas $B$. bronchiseptica salvaje $\Delta / a p G$ y $\Delta b r t A$.

En primer lugar, vemos nuevamente que, en condiciones de cultivo Bvg $+(0 \mathrm{mM}$ ácido nicotínico), la adición de $\mathrm{BSA}$ y $\mathrm{Ca}^{+2}$ al medio de cultivo inhibe por completo la formación de biofilm de la cepa salvaje. En estas condiciones la deleción de brtA no genera ninguna diferencia respecto de la cepa salvaje. Tanto en las fosas correspondientes a la cepa salvaje como en las de la cepa $\Delta b r t A$ no se evidencian signos de adhesión o formación de biofilm. Por el contrario, en las fosas de cultivo correspondientes a la cepa $\triangle / a p G$ vemos la presencia de una línea suave en la región que se encuentra en la interfase entre el aire y la suspensión bacteriana. La cuantificación de estas fosas muestra que deleción de lapG genera un incremento significativo en los valores de absorbancia a $595 \mathrm{~nm}$ respecto de las fosas correspondientes a la cepa salvaje $(p<0.05)$. 
Como puede verse en la Figura 6.5, en condiciones de cultivo modulantes (2,0 $\mathrm{mM}$ de ácido nicotínico), tanto la cepa $B$. bronchiseptica salvaje como las cepas $\Delta l a p G$ y $\triangle b r t A$ son capaces de formar biofilm tanto en el medio SS como en el medio SS suplementado con BSA y $\mathrm{Ca}^{+2}$. Si comparamos las características macroscópicas de los biofilms formados por las tres cepas en presencia de BSA y $\mathrm{Ca}^{+2}$ encontramos algunas diferencias interesantes. En la cepa salvaje, tal como describimos antes, la formación de biofilm se concentra en la interfase y no presenta una región de baja intensidad de color por debajo de esta zona. A su vez, en la cepa $\Delta b r t A$ se observa que la intensidad del color en la interfase es menor que para la cepa salvaje. Por el contrario, la cepa $\Delta l a p G$ presenta en la interfase una intensidad mucho mayor que la de la cepa salvaje. Asimismo, por debajo de esta región se distingue una zona de menor intensidad que no encontramos en las otras cepas.

Al comparar los valores de absorbancia a $595 \mathrm{~nm}$ de las tres cepas en presencia de BSA y $\mathrm{Ca}^{+2}$ vemos que las diferencias encontradas entre las cepas mutantes y la cepa salvaje son mayores que las diferencias en el medio SS tradicional. En estas condiciones, la deleción de lap $G$ induce un aumento de $\sim 375 \%$ en la capacidad de formación de biofilm de $B$. bronchiseptica respecto de la cepa salvaje $(p<0.01)$. El fenotipo de la cepa $\Delta b r t A$ también se ve acentuado por la presencia de BSA y $\mathrm{Ca}^{+2}$ en el medio de cultivo. Tal como describimos en el Capítulo 3, la deleción de brtA genera una reducción del $\sim 15 \%$ en la formación de biofilm en el medio SS tradicional (Figura 6.5 y Figura 3.2). Sin embargo, en el medio de cultivo suplementado con BSA y $\mathrm{Ca}^{+2}$ esa reducción se acentúa y en estas condiciones la capacidad de formación de biofilm de la cepa $\triangle b r t A$ sólo representa el $\sim 50 \%$ de la capacidad de la cepa salvaje.

\section{Efecto de BSA y $\mathrm{Ca}^{+2}$ sobre la formación de biofilm en vidrio o en plástico}

Para complementar los resultados presentados en la sección anterior, analizamos la formación de biofilm en vidrios semi sumergidos y en los tubos de plástico de polipropileno donde se realizan estos cultivos. Para el desarrollo de estos experimentos utilizamos condiciones de cultivo modulantes $(2,0 \mathrm{mM}$ de ácido nicotínico) y evaluamos el efecto de la adición de BSA y $\mathrm{Ca}^{+2}$. 


\section{Capítulo 6}

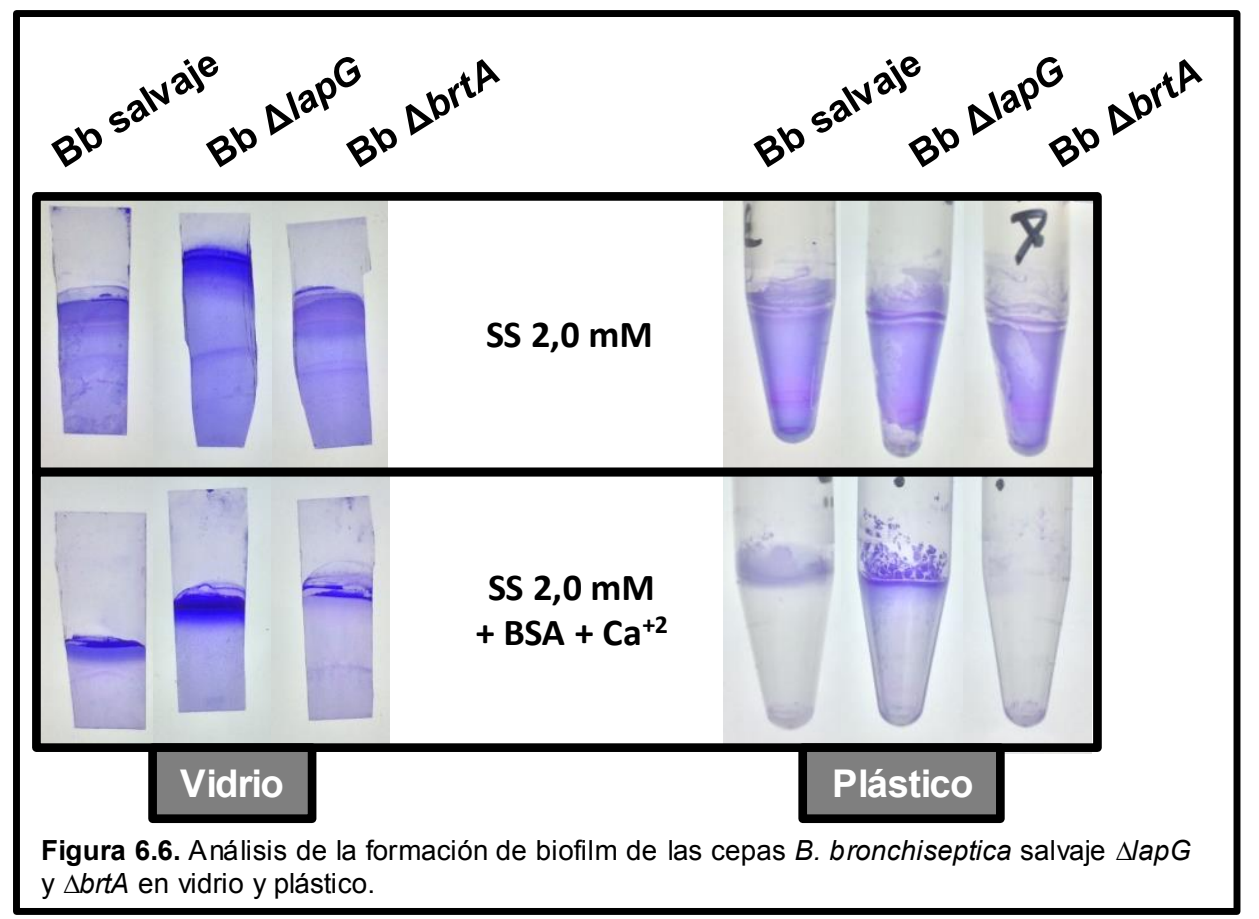

En la Figura 6.6 se muestran imágenes representativas de los resultados de formación de biofilm sobre superficies de vidrio y de plástico en 2,0 $\mathrm{mM}$ de ácido nicotínico con y sin suplemento de BSA y $\mathrm{Ca}^{+2}$.

Analizando los vidrios incubados en medio SS tradicional vemos las mismas diferencias que habíamos destacado previamente en los ensayos de formación de biofilm en microplaca. Puede observarse que en estas condiciones la cepa $\Delta / a p G$ presenta una capacidad de formación de biofilm superior a la de la cepa salvaje mientras que lo contrario ocurre con la cepa $\triangle b r t A$. Si bien estos resultados se aprecian con claridad sobre la superficie de vidrio, no se observan diferencias importantes sobre la superficie de plástico de los tubos de microcentrífuga incubados en la misma condición.

El análisis de los resultados obtenidos para los cultivos suplementados con BSA y $\mathrm{Ca}^{+2}$ muestra que la cepa $\Delta / a p G$, en comparación a la cepa salvaje, presenta una coloración más intensa en la interfase aire-líquido en la superficie de vidrio. A diferencia de los resultados observados en los experimentos de formación de biofilm en microplaca, ambas cepas presentan, por debajo de la zona de la interfase, una región de coloración menos intensa. Sin embargo, en la cepa $\Delta / a p G$ esta región es más ancha que en la cepa salvaje. La cepa $\Delta b r t A$, por el contrario, presenta una reducción en la formación de biofilm en comparación a la condición sin $\mathrm{BSA}$ y $\mathrm{Ca}^{+2}$. Llamativamente, la tinción con cristal violeta observada en la interfase parece superior en intensidad a la coloración que toma esta región en el medio sin $\mathrm{BSA}_{\text {y }} \mathrm{Ca}^{+2}$. Por debajo de esta región, no se observan signos de adhesión o formación de biofilm. Si analizamos los tubos de microcentrífuga donde fueron incubadas las suspensiones bacterianas, en esta condición vemos que las 
diferencias en la capacidad de formación de biofilm de las cepas son más acentuadas en comparación a la superficie de vidrio. Esto demuestra nuevamente la importancia de considerar las características intrínsecas de las superficies como una variable adicional de los experimentos de formación de biofilm. En los tubos de microcentrífuga se observa una capacidad mayor de la cepa $\triangle l a p G$ de formar biofilm sobre la interfase aire-liquido respecto de las otras cepas. En particular, en estas condiciones la cepa $\Delta b r t A$ se vio completamente impedida de desarrollar biofilm.

\section{Análisis de la formación de biofilm mediante microscopía electrónica de barrido (SEM)}

A fin de profundizar en los detalles microscópicos de los biofilms formados por las cepas usadas en el experimento de la sección anterior, realizamos un ensayo de SEM. Para este ensayo se realizaron cultivos de 24 horas en condiciones modulantes (2,0 mM de ácido nicotínico) en presencia o no de $\mathrm{BSA}$ y $\mathrm{Ca}^{+2}$. Las imágenes registradas corresponden a aumentos de 6.000X y 24.000X y fueron obtenidas de la región del vidrio que se encontraba en la interfase entre la suspensión bacteriana y el aire.

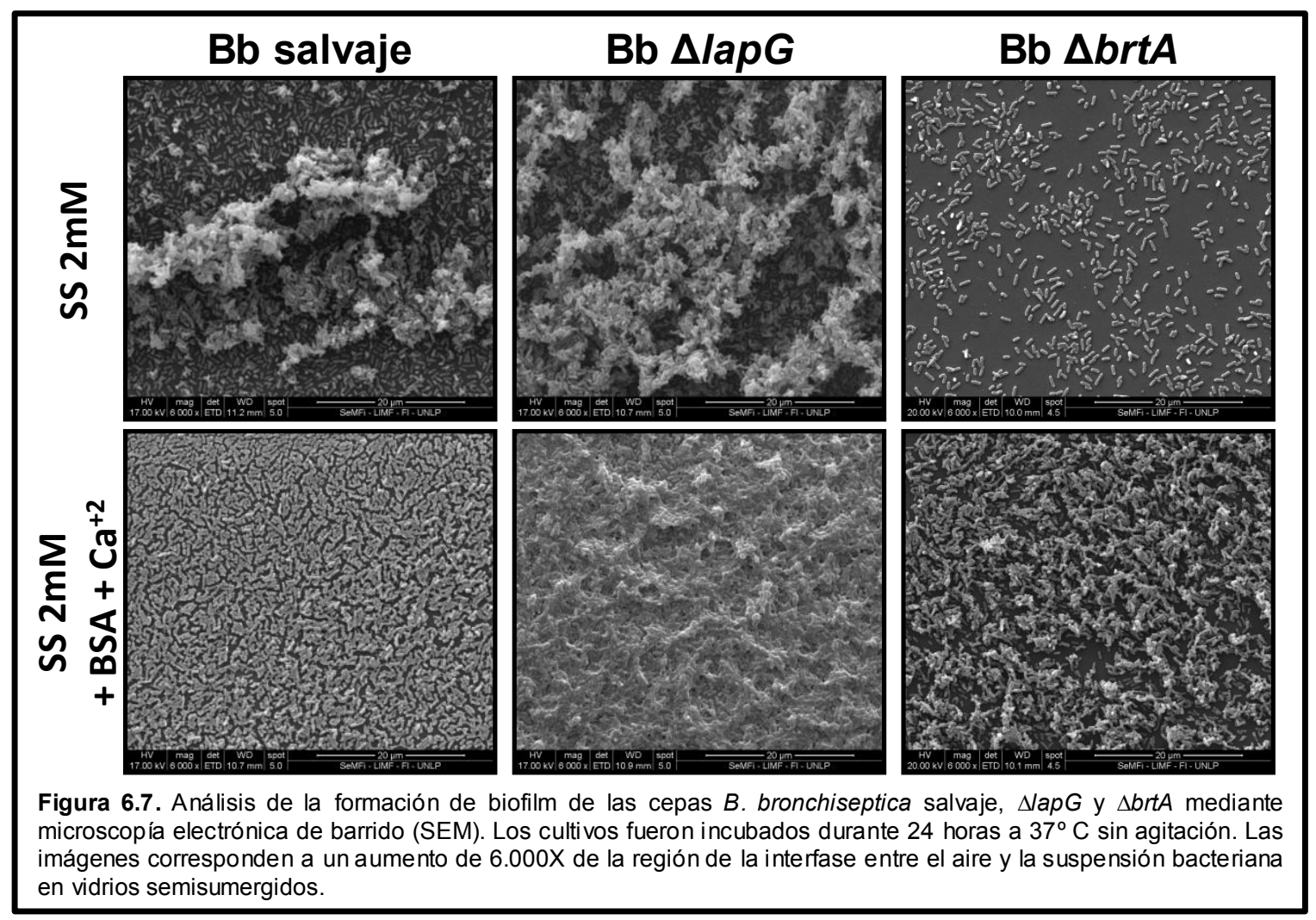

La Figura 6.7 muestra imágenes representativas del análisis por microscopía electrónica de barrido de las cepas $B$. bronchiseptica salvaje, $\Delta b r t A$ y $\Delta l a p G$. Estas 


\section{Capítulo 6}

imágenes corresponden al aumento de 6.000X que permite obtener una visión general de la estructura de los biofilms formados.

Comenzando por la cepa salvaje, en el medio SS tradicional, podemos distinguir tres tipos de estructuras. En primer lugar, encontramos algunas bacterias que se hayan adheridas a la superficie pero que no están en contacto con ninguna otra bacteria. En esta condición de cultivo no se llega a cubrir la totalidad de la superficie y aún es posible encontrar regiones del vidrio que no han sido ocupadas por bacterias. En segundo lugar, se puede observar algunos agregados en forma de microcolonias de entre 5 y 20 bacterias. Por último, se destacan estructuras con gran desarrollo en altura y un número de bacterias que, si bien no es posible contar mediante esta técnica, superan largamente las cientos de bacterias. Continuando con el análisis de esta condición, vemos que la cepa $\triangle l a p G$ forma grandes agregados de bacterias que son más numerosos y de mayor altura en comparación a los formados por la cepa salvaje. Asimismo, a diferencia de la cepa salvaje, encontramos pocas bacterias aisladas. Es importante destacar que, tal como apreciamos en otros ensayos, en esta condición de cultivo no se distingue la presencia de matriz extracelular. En estas condiciones, la cepa $\Delta b r t A$ presenta sólo unas pocas bacterias adheridas a la superficie y no se observa contacto entre las bacterias.

Analizando las imágenes de la condición de cultivo correspondiente al medio SS suplementado con BSA y $\mathrm{Ca}^{+2}$, vemos nuevamente cambios considerables en las estructuras formadas. Al igual que describimos en el análisis de la Figura 6.4, el agregado de $\mathrm{BSA}$ y $\mathrm{Ca}^{+2}$ genera en la cepa salvaje la formación de estructuras de menor número de bacterias y menor desarrollo de altura en comparación a la condición de cultivo en SS tradicional. Nuevamente vemos que en esta condición no se observan estructuras que desarrollen una altura mayor a $\sim 5$ bacterias. Tampoco se distinguen bacterias aisladas y se observa una gran cantidad de canales entre los agregados. Estos canales representan regiones de la superficie no ocupados por bacterias. En esta condición sí se observa la presencia de matriz extracelular que conecta a todas las bacterias. El análisis de la cepa $\Delta / a p G$ muestra una densidad de bacterias mucho mayor que la observada para la cepa salvaje. A diferencia de la cepa salvaje no es posible distinguir zonas de la superficie que no hayan sido ocupadas por bacterias. En esta cepa, la matriz extracelular parece ser tan abundante que cubre por completo la estructura del biofilm. Este biofilm no presenta la formación observada anteriormente de estructuras desarrolladas rodeadas por canales, sino que presenta una estructura desordenada. Llamativamente, en la región analizada (interfase aire-líquido) la cepa $\Delta b r t A$ presentó un número mayor de bacterias en comparación a los cultivos en SS tradicional. Esto podría explicar la observación que realizamos anteriormente de que la intensidad de la tinción en la interfase parecía superior en el medio con BSA y $\mathrm{Ca}^{+2}$. 


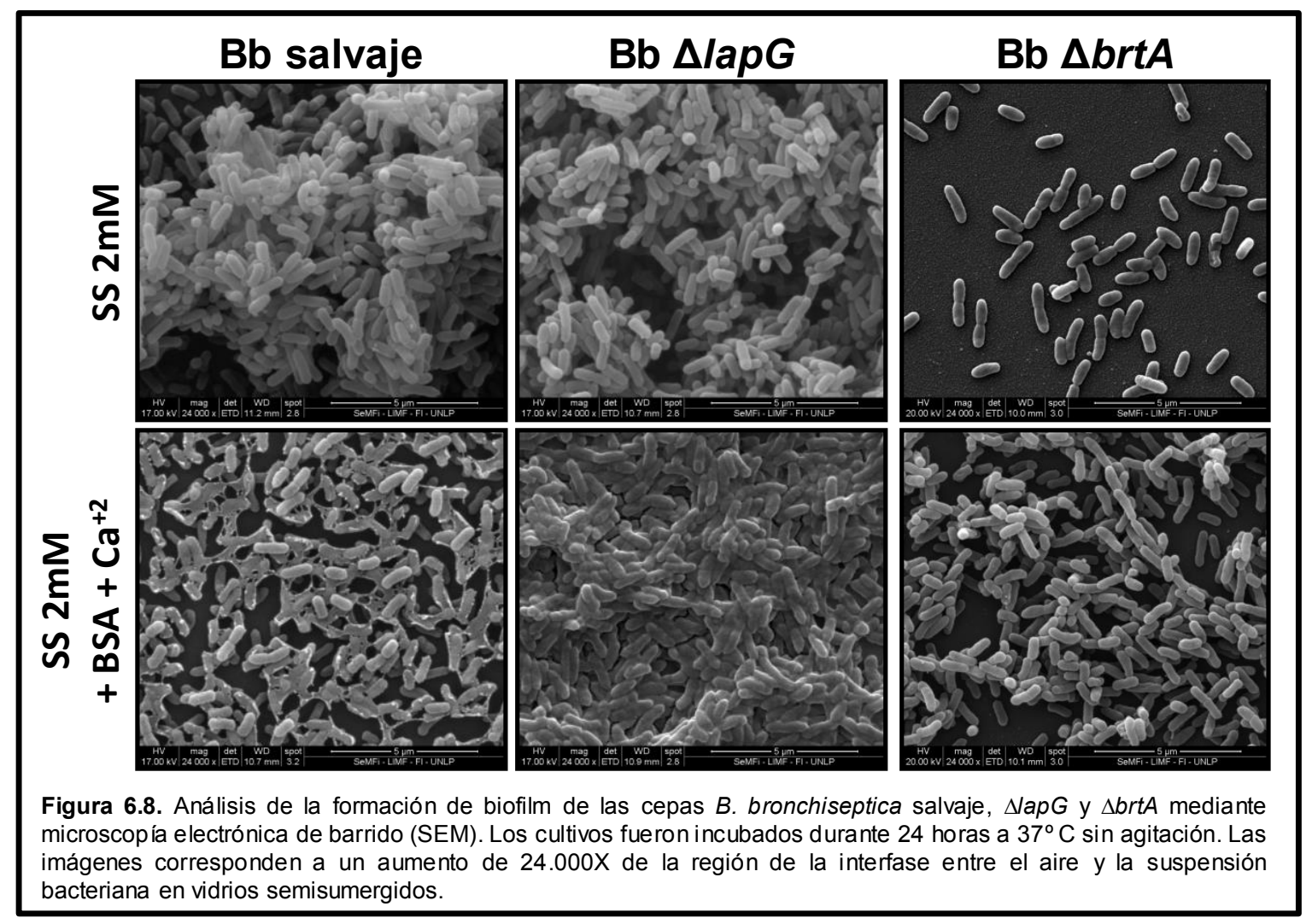

En la Figura 6.8 podemos observar imágenes tomadas con el aumento de 24.000X, máximo aumento que es posible alcanzar con el microscopio electrónico utilizado. Este aumento no permite apreciar la estructura global de los biofilms formados, pero permite analizar el aporte individual de cada bacteria a la estructura general. Comparando las imágenes de la cepa salvaje con la cepa $\Delta / a p G$, en el medio de cultivo SS, no se observan diferencias a esta escala. Mediante este aumento confirmamos que en estas condiciones no se distingue la presencia de matriz extracelular.

La comparación a esta escala de los biofilms formados en medio SS suplementado con BSA y $\mathrm{Ca}^{+2}$ sí muestra diferencias entre las cepas $B$. bronchiseptica salvaje, $\triangle b r t A$ y $\triangle l a p G$. Se puede observar que la cepa salvaje forma una red de matriz extracelular que mantiene conectadas a todas las bacterias. A pesar de esto, casi no se observan bacterias pegadas entre sí. Estas dos observaciones representan claras diferencias entre el biofilm formado en el medio SS tradicional y el formado en el medio suplementado con $\mathrm{BSA}$ y $\mathrm{Ca}^{+2}$. En la cepa $\triangle / a p G$, no sólo se aprecia una gran cantidad de matriz extracelular, sino que todas las bacterias están en íntimo contacto con alguna otra bacteria.

Por último, realizamos un análisis de la región de los vidrios que se encontraba sumergida inmediatamente por debajo de la línea de la interfase. Para estudiar esta zona 


\section{Capítulo 6}

se analizaron imágenes con un aumento de $1.600 \mathrm{X}$ y para poder alcanzar un mayor nivel de detalle realizamos un aumento digital de las imágenes obtenidas por microscopía.

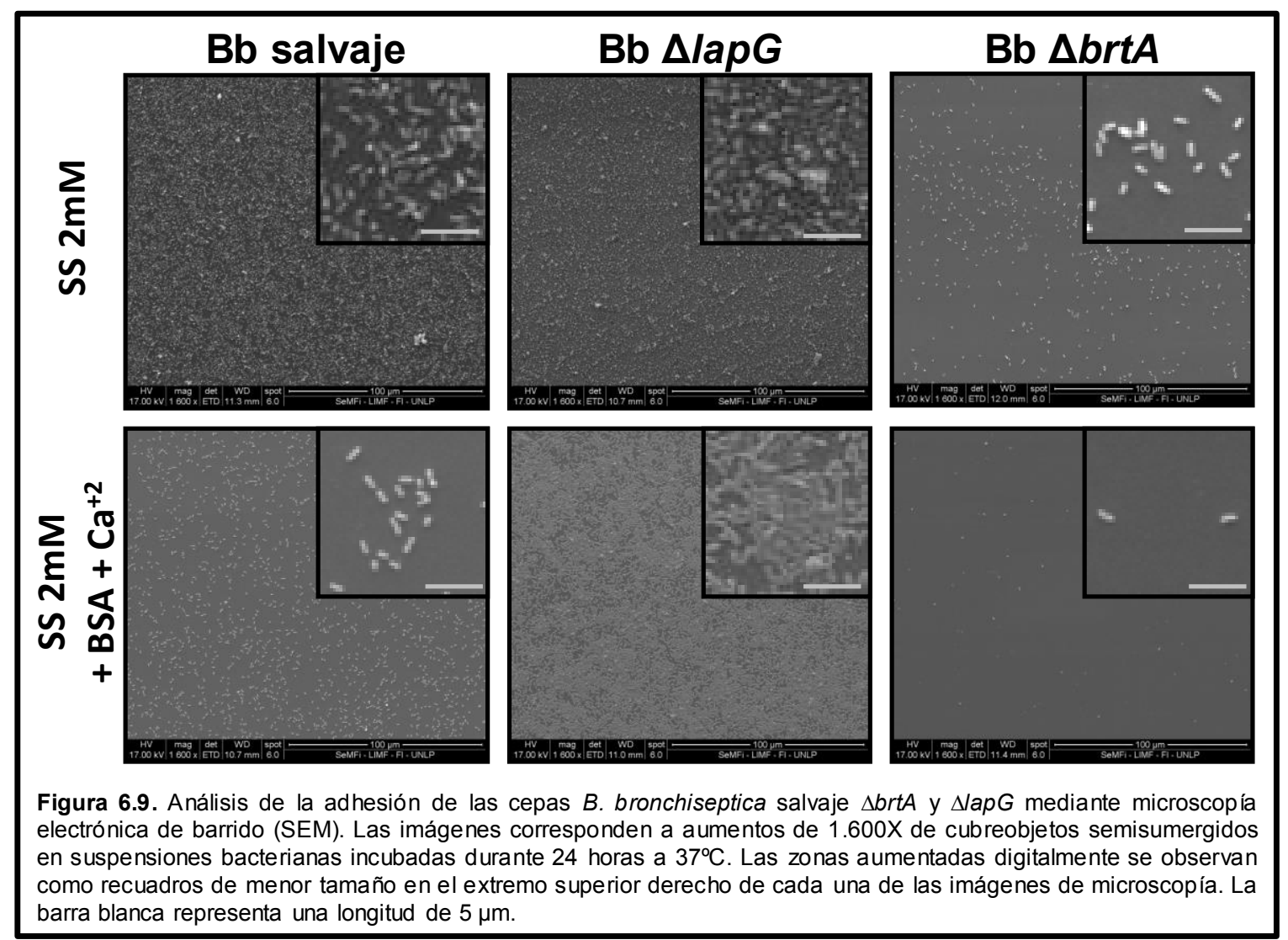

En las imágenes de la Figura 6.9 puede verse que en esta región no hay un gran desarrollo de estructuras sino simplemente adhesión de bacterias a la superficie.

Al analizar las imágenes correspondientes a los cultivos realizados en medio SS, vemos que para la cepa $B$. bronchiseptica salvaje la mayoría de las bacterias se encuentran aisladas y existen espacios vacíos entre ellas (aproximadamente 400 bacterias $\left(\mathrm{mm}^{2}\right.$ ). Esporádicamente se encuentran cúmulos de unas pocas bacterias formando microcolonias de hasta $\sim 10$ bacterias. En estas mismas condiciones la cantidad de bacterias de la cepa $\triangle b r t A$ es notablemente menor (aproximadamente 280 bacterias $\left(\mathrm{mm}^{2}\right.$ ). En esta cepa también se observan bacterias aisladas, pero no fue posible encontrar ningún cúmulo de más de dos bacterias. La cepa $\Delta / a p G$, por el contrario, presenta una cantidad de bacterias por unidad de superficie mucho mayor que la cepa salvaje ( $>400$ bacterias $/ \mathrm{mm}^{2}$ ). En las imágenes ampliadas digitalmente puede apreciarse que no existen aéreas que no estén ocupadas por bacterias. Además, es frecuente encontrar cúmulos de bacterias en forma de microcolonias.

La adición de BSA y $\mathrm{Ca}^{+2}$ al medio de cultivo presenta efectos diferentes en la cepa $\triangle l a p G$ comparada con la cepa salvaje y $\triangle b r t A$. La cepa salvaje presenta una 
capacidad de adhesión menor respecto de la condición de cultivo en SS (menos de 300 bacterias $/ \mathrm{mm}^{2}$ ). Lo mismo sucede con $\Delta b r t A$ (menos de 40 bacterias $/ \mathrm{mm}^{2}$ ). En concordancia con las observaciones de la región de la interfase, la cepa $\Delta / a p G$ aumenta su adhesión a la superficie como consecuencia del agregados de BSA y $\mathrm{Ca}^{+2}$. Si bien se observan algunas áreas vacías, las regiones donde hay acumulación de bacterias presentan una densidad bacteriana mayor que en la condición de SS.

Los resultados de los ensayos de microscopía electrónica de barrido refuerzan la hipótesis de BrtA como una adhesina involucrada en la formación de biofilm en $B$. bronchiseptica. En estas condiciones experimentales BrtA estaría involucrada en la adhesión a la superficie, así como también en la interacción entre células.

\section{BSA y $\mathrm{Ca}^{+2}$ inducen aumento en la secreción de BrtA}

Bumba et al. recientemente demostraron que el plegamiento del dominio RTX en la porción C-terminal de la adenilato ciclasa (AC) de B. pertussis y B. bronchiseptica constituye la fuerza impulsora para la secreción de esta proteína a través del conducto del sistema de secreción tipo $\left.\right|^{135}$. Las regiones de repeticiones presentes en el dominio RTX son capaces de unir $\mathrm{Ca}^{+2}$ y como consecuencia de esa unión se producen cambios conformacionales que son críticos para una secreción eficiente de la adenilato ciclasa ${ }^{135,294}$. BrtA también es una proteína RTX por lo que BSA y $\mathrm{Ca}^{+2}$ también podrían tener efectos sobre su mecanismo de secreción. Para evaluar esa posibilidad decidimos analizar el sobrenadante de cultivo en presencia de BSA y $\mathrm{Ca}^{+2}$ en búsqueda de BrtA.

El desarrollo de un método de detección específico es un paso fundamental para poder avanzar en la comprensión del rol de esta adhesina en la biología de $B$. bronchiseptica. Con este objetivo diseñamos un plan para introducir un epitope de hemaglutinina $(\mathrm{HA})$ como fusión transcripcional en la secuencia de BrtA. Este epitope nos permitió localizar a la proteína BrtA utilizando anticuerpos monoclonales anti-HA. La marca de hemaglutinina $(\mathrm{HA})$ fue introducida mediante doble recombinación homóloga después del residuo de valina 2291. De esta forma, la marca HA queda localizada en una región de BrtA que quedaría expuesta por fuera de la membrana plasmática y que es liberada al sobrenadante tras la acción de LapG.

Para evaluar los efectos de BSA y $\mathrm{Ca}^{+2}$ sobre la localización de BrtA realizamos cultivos de la cepa $B$. bronchiseptica con la marca de hemaglutinina como fusión transcripcional a BrtA (Bb-HA). Los cultivos fueron realizados en medio SS tradicional y en medio SS suplementado con BSA y $\mathrm{Ca}^{+2}$. Estas son las mismas condiciones de cultivo en las que Gonyar et al. demostraron que se estimula la secreción de adenilato ciclasa ${ }^{292}$. 


\section{Capítulo 6}

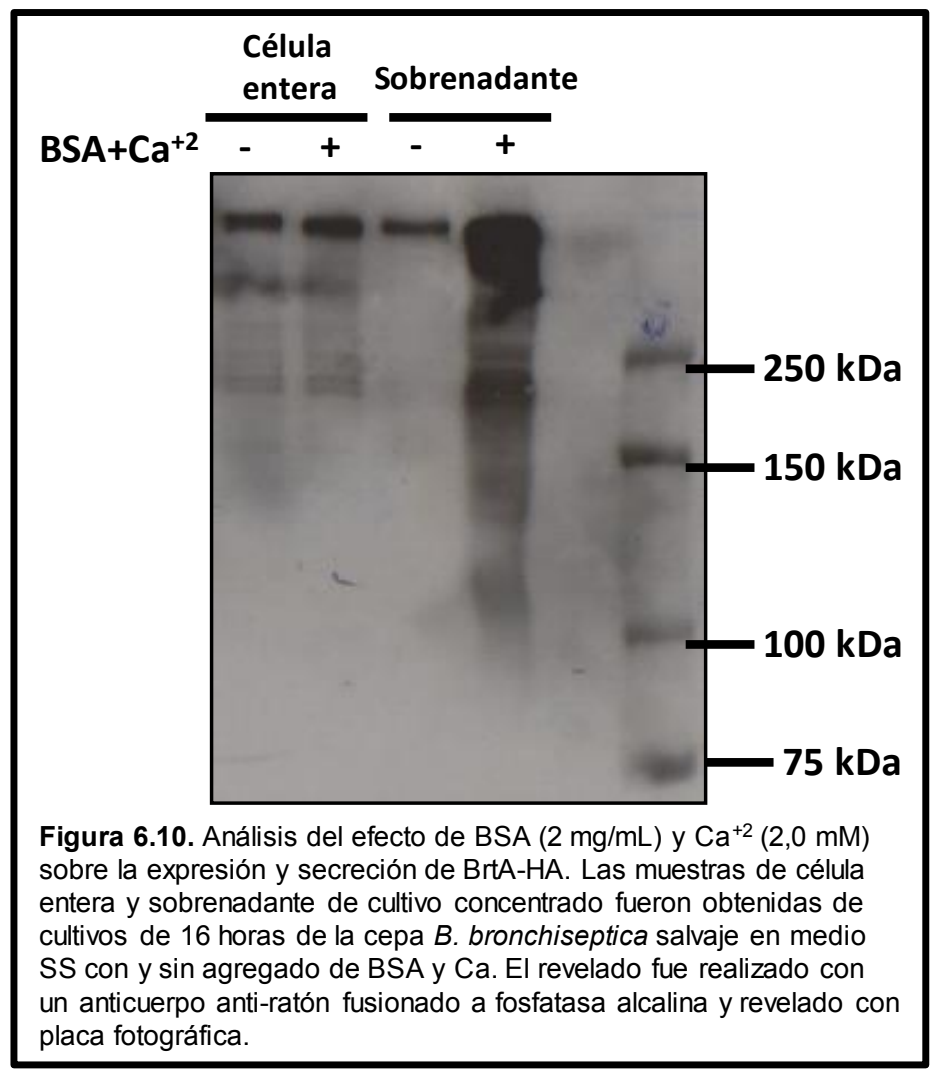

La Figura 6.10 muestra los resultados del análisis de las muestras de célula entera y sobrenadante de cultivo de $B$. bronchiseptica (Bb-HA) en SS y SS suplementado con BSA y $\mathrm{Ca}^{+2}$ realizado a través de Western blot.

En primer lugar, este ensayo nos permitió estimar el peso molecular de BrtA. Para esto, determinamos la movilidad electroforética de los patrones de peso molecular y realizamos un ajuste lineal de las variables Log (PM) y movilidad. A partir de la regresión lineal y la movilidad electroforética de la banda de la calle número uno determinamos que el peso molecular de BrtA-HA sería de 331,6 kDa. Considerando que el epitope de hemaglutinina incrementa el peso molecular de BrtA en solo 3,5 kDa, este valor estimado debería ser cercano a la masa molar de BrtA. Por lo tanto, considerando las limitaciones de este método podemos estimar que el peso molecular de BrtA es de aproximadamente $330 \mathrm{kDa}$.

La presencia de bandas en las calles correspondientes a célula entera demuestra que en ambas condiciones de cultivo hay expresión de BrtA. La identificación de BrtA en muestras provenientes de cultivos realizados en condiciones Bvg+ confirma que en la cepa B. bronchiseptica $9.73 \mathrm{H}+$, BrtA se expresa en fase virulenta.

La comparación de las bandas en las muestras de célula entera indica que habría un aumento en los niveles de expresión de BrtA en las bacterias cultivadas en el medio suplementado con BSA y $\mathrm{Ca}^{+2}$. Por otro lado, el análisis de las muestras de sobrenadante 
indica que la presencia de BSA y $\mathrm{Ca}^{+2}$ induce un incremento en la secreción de BrtA. Estos resultados indicarían que BrtA incrementa su expresión y secreción en presencia de cantidades fisiológicas de BSA y $\mathrm{Ca}^{+2}$

\section{Conclusiones y discusión}

Los resultados presentados en este capítulo constituyen la primera descripción del efecto sinérgico de BSA y $\mathrm{Ca}^{+2}$ sobre la formación de biofilm y la secreción de BrtA en $B$. bronchiseptica. Las concentraciones de BSA $(2,0 \mathrm{mg} / \mathrm{mL})$ y de $\mathrm{Ca}^{+2}(2,0 \mathrm{mM})$ utilizadas corresponden a concentraciones fisiológicas encontradas en las secreciones de las vías respiratorias ${ }^{292}$. Recientemente Gonyar et al. demostraron que la presencia de $\mathrm{BSA}$ y $\mathrm{Ca}^{+2}$, en estas concentraciones, en el medio de cultivo de Bordetella, potencia la secreción de la toxina adenilato ciclasa $(\mathrm{AC})^{292}$.

La adenilato ciclasa, no sólo es una toxina con capacidad de interferir en los mecanismos de señalización de las células eucariotas ${ }^{194}$, sino que también modula la formación de biofilm. La interacción entre la adhesina FHA y AC resulta inhibitoria para las primeras etapas de la formación de biofilm ${ }^{229}$. Por este motivo es que decidimos evaluar el efecto de BSA y $\mathrm{Ca}^{+2}$ sobre la formación de biofilm.

Para el análisis general de los resultados presentados en este capítulo, resulta importante distinguir que es necesario comparar el efecto de BSA y $\mathrm{Ca}^{+2}$ sobre la cepa salvaje y sobre mutantes en factores del sistema Lap. Pero también es interesante realizar, en forma independiente, el análisis de los efectos que tienen las deleciones de brtA y lapG en este medio de cultivo que lo hacen fisiológicamente relevante.

Mediante ensayos de formación de biofilm en microplaca (Figura 6.1) y sobre superficie de vidrio y plástico (Figura 6.3) demostramos que la presencia de BSA y $\mathrm{Ca}^{+2}$ inhibe por completo la formación de biofilm de $B$. bronchiseptica en condiciones de cultivo no modulantes (Bvg+). Los mecanismos moleculares que conducen a esta inhibición de la formación de biofilm es una línea de trabajo sobre la cual es importante seguir avanzando en el futuro cercano. Con el objetivo de determinar si la AC secretada al medio de cultivo constituye el factor que inhibe la formación de biofilm, sería importante caracterizar el comportamiento de la cepa $\triangle c y a A$ (mutante en $A C$ ). Si el efecto observado

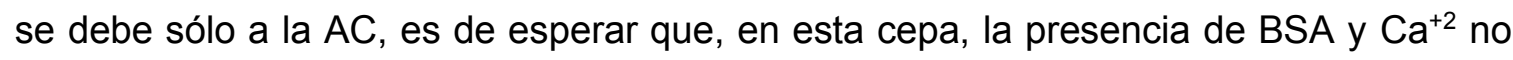
inhiba la formación de biofilm.

A diferencia de la cepa salvaje, en estas condiciones de cultivo, la cepa $B$. bronchiseptica $\triangle \mathrm{J} a p G$ sí fue capaz de formar biofilm (Figura 6.5). A partir de esta observación surge la pregunta de si esa capacidad de formación de biofilm es debido a la presencia de BrtA u otra adhesina que podría ser regulada por LapG. Como 


\section{Capítulo 6}

mencionamos en el Capítulo 4, LapG podría regular también la localización de FhaL y FhaS. A fin de determinar si el biofilm observado en esas condiciones se debe a BrtA u a otro factor, sería importante evaluar el fenotipo de formación de biofilm de la cepa $\triangle l a p G$ $\Delta b r t A$. Si el doble mutante mantuviera la capacidad de formación de biofilm esto indicaría que LapG tendría otro sustrato además de BrtA.

En este capítulo además evaluamos el efecto de la adición de BSA y $\mathrm{Ca}^{+2}$ en condiciones modulantes $(2,0 \mathrm{mM})$. Debido a que la deleción de brtA y lapG es especialmente importante en esta condición de modulación, realizamos un análisis más profundo. El efecto de BSA y $\mathrm{Ca}^{+2}$ sobre la formación de biofilm en esta condición es distinto del efecto observado en condiciones no modulantes. La adición de BSA y $\mathrm{Ca}^{+2}$ no inhibe la formación de biofilm de la cepa $B$. bronchiseptica salvaje, sino que la reduce (Figura 6.1). Los resultado iniciales obtenidos en cultivos en microplacas posteriormente fueron confirmados mediante la observación por microscopía electrónica de barrido (Figura 6.4).

Con el objetivo de profundizar en la descripción del efecto de BSA y $\mathrm{Ca}^{+2}$ sobre la formación de biofilm y el rol de BrtA en este proceso, pusimos a punto una nueva estrategia de análisis de formación de biofilm. Adaptamos un protocolo para analizar en forma directa la formación de biofilm sobre vidrio mediante tinción con una solución de cristal violeta. En paralelo vimos que también era posible teñir los tubos de plástico en donde hacíamos los cultivos y de esta manera obtener resultados de formación de biofilm sobre dos superficies diferentes utilizando la misma suspensión bacteriana. Este nuevo diseño experimental nos permitió poner de manifiesto el efecto que las propiedades de la superficie ejercen sobre la formación de biofilm. El análisis de estos resultados nos condujo a la observación de que en presencia de BSA y $\mathrm{Ca}^{+2}$ y sobre la superficie de plástico de polipropileno de los tubos de microcentrífuga es la condición de cultivo en donde el efecto de las deleciones de brtA y lapG se hace más notorio. Este resultado sugiere que BrtA podría aumentar la hidrofobicidad de la superficie bacteriana y por ese motivo vemos mejor el efecto en este tipo de superficie. A fin de comprender mejor el rol de BrtA en la formación de biofilm sería importante avanzar en la caracterización de las propiedades de superficie de $B$. bronchiseptica y la contribución de la adhesina BrtA. La proteína LapF de $P$. putida es una adhesina involucrada en las interacciones célula-célula y es fundamental para las etapas de maduración del biofilm ${ }^{69}$. Esta adhesina aumenta la hidrofobicidad de la superficie celular favoreciendo las interacciones que mantienen unidas entre sí a las bacterias ${ }^{295}$. Aprovechando las claras diferencias encontradas entre la cepa salvaje, $\triangle b r t A$ y $\Delta l a p G$, esta condición de cultivo puede ser usada en experimentos futuros para profundizar en los mecanismos de regulación de las proteínas Lap en B. bronchiseptica. 
De acuerdo los resultados de microscopía electrónica de barrido mostrados en las Figuras 6.7, 6.8 y 6.9 BrtA podría contribuir a las interacciones célula-célula de forma semejante a como LapF lo hace en $P$. putida. Asimismo, estos experimentos demuestran que BrtA también estaría involucrada en la interacción con la superficie. Estos resultados se corresponden con resultados mostrados en capítulos anteriores (Capítulo 3, Figura 3.2). BrtA, al igual que LapA de $P$. fluorescens, estaría además involucrada en la adhesión a la superficie ${ }^{261}$. Está hipótesis también fue avalada por el reciente trabajo publicado de Nishikawa et al. en el cual postulan a BrtA como una adhesina involucrada en la interacción a la superficie ${ }^{260}$. En conjunto, estos resultados indicarían que en $B$. bronchiseptica, BrtA estaría involucrada tanto en la interacción inicial de la bacteria a la superficie como en etapas posteriores de la formación de biofilm en la interacción entre células.

Las cepas $\triangle$ lapG y $\triangle b r t A$ ya fueron caracterizadas mediante experimentos presentados en los capítulos anteriores. Nuestros propios resultados demuestran que en 2,0 $\mathrm{mM}$ de ácido nicotínico $\triangle \mathrm{lapG}$ presenta una capacidad de formación de biofilm superior a la de la cepa salvaje. Contrariamente, la cepa $\Delta b r t A$, en esas condiciones de ácido nicotínico tiene menor capacidad de formación de biofilm en comparación a la cepa salvaje. La adición de BSA y $\mathrm{Ca}^{+2}$ al medio de cultivo potenció significativamente los efectos de las mutaciones lapG y brtA. La cepa $\triangle$ lapG presentó una capacidad de formación de biofilm $\sim 375 \%$ superior a la de la cepa salvaje. Esta observación indicaría que en presencia de BSA y $\mathrm{Ca}^{+2}$ las proteínas Lap de $B$. bronchiseptica tendrían un rol particularmente importante.

La adición de BSA y $\mathrm{Ca}^{+2}$ también indujo la aparición de matriz extracelular en los biofilms de las cepas salvaje y $\triangle$ lapG. Esto sugiere que BSA y $\mathrm{Ca}^{+2}$ también estimularía la síntesis de componentes de la matriz extracelular. Hasta el momento, no hay reportes de que $\mathrm{BSA}$ o $\mathrm{Ca}^{+2}$ induzcan un aumento en la producción de matriz extracelular en otras bacterias. Dado que las concentraciones usadas se correlacionan con los niveles de BSA y $\mathrm{Ca}^{+2}$ presentes en las vías respiratorias, el avance en esta línea de investigación podría ser sumamente importante para la comprensión de los mecanismos que dirigen la formación de biofilm in vivo durante el desarrollo de infecciones.

Por último, evaluamos el efecto de BSA y $\mathrm{Ca}^{+2}$ sobre la secreción de BrtA. BrtA, al igual que $A C$ pertenece a la familia de las proteínas RTX. Ambas proteínas son secretadas través de un sistema de secreción tipo $\mathrm{I}^{135,260}$. Bumba et al. demostraron que el plegamiento del dominio RTX inducido por $\mathrm{Ca}^{+2}$ resulta la fuerza impulsora para la secreción de AC. Posteriormente Gonyar et al. demostraron que BSA, en presencia de $\mathrm{Ca}^{+2}$ potencia significativamente la secreción de AC. Considerando estos datos decidimos evaluar si la presencia de BSA y $\mathrm{Ca}^{+2}$ también influía en la secreción de BrtA. 


\section{Capítulo 6}

Como resultado de estos experimentos encontramos que la presencia de BSA y $\mathrm{Ca}^{+2}$ estimulan la secreción y probablemente la expresión de BrtA. Esto podría explicar que en condiciones modulantes la presencia de BSA y $\mathrm{Ca}^{+2}$ indujo un aumento de $\sim 375 \%$ en la capacidad de formación de biofilm de la cepa lapG en comparación a la cepa salvaje.

Mediante los ensayos de Western blot, presentamos una nueva evidencia de que en la cepa $9.73 \mathrm{H}+$ BrtA se expresa en fase Bvg+. Esto, sumado a los resultados de identificación por huella peptídica (Capítulo 3, Figura 3.3) y los resultados de RT-PCR indicarían que BrtA a diferencia de lo postulado por Nishikawa et al. se expresa en Bvg+. Estos ensayos nos permitieron estimar el tamaño de BrtA y confirmar, tal como creíamos, que los resultados de secuenciación del genoma que habíamos obtenido antes eran incorrectos. Según nuestras estimaciones BrtA de la cepa $9.73 \mathrm{H}+$ tendría un peso molecular aproximado de $330 \mathrm{kDa}$. En base a este dato y considerando que la masa de cada repetición CADG-IDR1-VCBS-IDR2 sería de $22 \mathrm{kDa}$, la adhesina BrtA de la cepa $9.73 \mathrm{H}+$ podría tener 7 repeticiones en la zona media de su secuencia.

Los resultados de Gonyar et al. así como los presentados a lo largo de este capítulo demuestran que $B$. bronchiseptica presenta una respuesta postranscripcional a la presencia de BSA y $\mathrm{Ca}^{+2}$. A mediados de 2018, Gestal et al. presentaron un trabajo donde evaluaban los cambios en el perfil de expresión génica de $B$. bronchiseptica en presencia de suero o sangre. Los resultados informados demuestran que $B$. bronchiseptica es capaz de sensar y responder con cambios transcripcionales a compuestos presentes en sangre y suero ${ }^{296}$. Esto sugiere que los resultados presentados en este capítulo podrían ser parte de un mecanismo de respuesta transcripcional y postranscripcional disparada durante la etapa de vida de $B$. bronchiseptica dentro de sus huéspedes.

Este capítulo constituye el principio de una área de estudio muy interesante en la fisiología de $B$. bronchiseptica. El rol de BSA y $\mathrm{Ca}^{+2}$ y los mecanismos moleculares que gobiernan la respuesta a estos elementos podrían conducir a la comprensión de procesos importantes entre la interacción de $B$. bronchiseptica y sus hospedadores. A lo largo de este capítulo hemos presentado información importante que sentará las bases para los estudios finales de este trabajo de tesis y futuros proyectos dentro del laboratorio. 


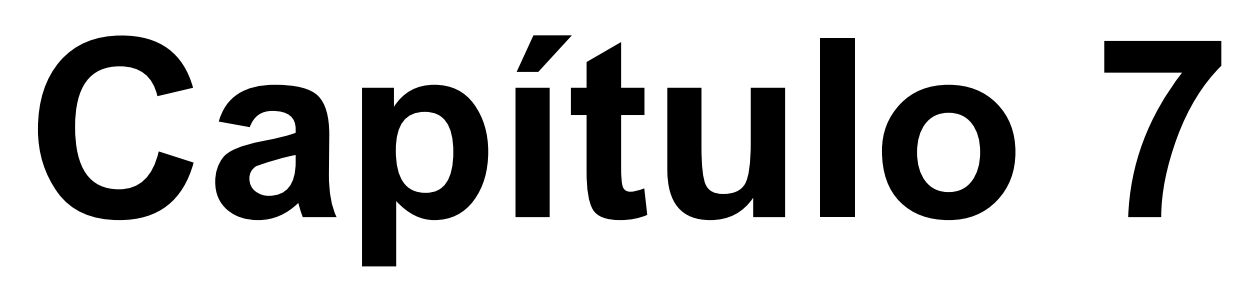

Regulación de la formación de biofilm

\author{
a través de c-di-GMP
}





\section{Introducción}

Antes del comienzo de este trabajo de tesis doctoral, nuestro grupo de investigación describió por primera vez el rol del segundo mensajero c-di-GMP en el control de la movilidad y la formación de biofilm en B. bronchiseptica ${ }^{224}$. En ese contexto, este trabajo de tesis se inició con el objetivo de determinar qué mecanismos moleculares se encuentran detrás del proceso de regulación de la formación de biofilm. Como describimos en Capítulo 2, a través de la inspección in silico del genoma de $B$. bronchiseptica encontramos un grupo de genes que podrían ser parte de este mecanismo de control. Gracias al trabajo realizado en la caracterización de estas secuencias aportamos evidencia de que BB1184, BB1185 y BB1186 forman parte de un sistema de proteínas análogo al sistema Lap descripto exhaustivamente en $P$. fluorescens. BB1184, BB1185 y BB1186 son LapD, LapG y la adhesina de la familia de LapA, BrtA.

La evidencia experimental presentada hasta el momento muestra que el sistema Lap de $B$. bronchiseptica funciona de manera equivalente a como lo hace en $P$. fluorescens $s^{84,130,276}$. Sobre la base de esa evidencia, es de esperar que el segundo mensajero c-di-GMP constituya la molécula de señalización que controla el funcionamiento de estas proteínas también en $B$. bronchiseptica.

A lo largo de este capítulo analizaremos si efectivamente las proteínas Lap de $B$. bronchiseptica están involucradas en el control de la formación de biofilm a través de cdi-GMP. Asimismo, ahondaremos en los mecanismos moleculares que dirigen la actividad de $\operatorname{LapD}_{\mathrm{Bb}}$ y nos enfocaremos en la búsqueda de diguanilato ciclasas involucradas de manera directa en el control de este sistema.

Una de las grandes incógnitas alrededor del segundo mensajero c-di-GMP, ha sido siempre cómo es posible que procesos celulares diferentes se encuentren regulados a través del mismo mensajero sin que exista interferencia entre ellos ${ }^{79}$. Recientemente, el grupo de investigación liderado por George O’Toole, de la Universidad de Dartmouth (Hanover, NH, Estados Unidos), describió el rol específico de la diguanilato ciclasa GcbC en el control del funcionamiento de $\operatorname{LapD}_{\mathrm{Pf}}{ }^{123,143,297}$. Este grupo de trabajos constituyen un aporte esencial a la comprensión de los mecanismos existentes detrás de los procesos regulados por este segundo mensajero La interacción física entre GcbC y LapDPf confiere a la mencionada diguanilato ciclasa la habilidad de regular la formación de biofilm a través de las proteínas Lap, de manera específica y sin interferir en otros procesos también regulados por c-di-GMP ${ }^{124}$. Sobre la base de estos resultados, es de esperar que LapD de $B$. bronchiseptica presente interacciones de este tipo con al menos alguna diguanilato ciclasa. Durante este capítulo presentaremos los resultados de la búsqueda de la o las diguanilato ciclasas que alimentan de manera específica al sistema Lap a través de 


\section{Capítulo 7}

$\mathrm{LapD}_{\mathrm{Bb}}$. Al igual que en los capítulos anteriores, nuestro abordaje combinará la utilización de herramientas bioinformáticas, con técnicas de biología molecular e ingeniería genética.

\section{$\operatorname{Lap~}_{\mathrm{Bb}}$ es un factor necesario en la regulación de la formación de biofilm a través de c-di-GMP}

La evidencia experimental presentada hasta el momento da cuenta de que el sistema de proteínas Lap de $B$. bronchiseptica tiene un funcionamiento equivalente al funcionamiento del sistema Lap en $P$. fluorescens. Considerando este modelo, $L_{a p D} D_{B b}$ sería un factor necesario para la regulación de la formación de biofilm a través de c-diGMP. Sin embargo, hasta el momento no hemos demostrado que c-di-GMP participe en el control de este grupo de proteínas en B. bronchiseptica.

Según nuestra hipótesis $\operatorname{LapD}_{\mathrm{Bb}}$ responde a los niveles citoplasmáticos de c-diGMP. De esta manera, cuando estos niveles son elevados adopta una conformación tal que le permite mantener unida a $\mathrm{LapG}_{\mathrm{Bb}}$ al otro lado de la membrana. Esto permitiría a la adhesina BrtA localizarse sobre la membrana externa y así se vería incrementada la capacidad de la bacteria de formar biofilm.

Para poner a prueba este modelo obtuvimos la cepa B. bronchiseptica $\triangle l a p D$ y evaluamos su comportamiento en un contexto de elevados niveles de c-di-GMP. A fin de aumentar de manera artificial los niveles de c-di-GMP y poder contrastar nuestra hipótesis, utilizamos la diguanilato ciclasa de B. bronchiseptica BdcA (BB3576). Nuestro grupo ha demostrado que la sobreexpresión de BdcA produce un aumento global en los niveles de c-di-GMP y esto incrementa la capacidad de formación de biofilm en comparación a la cepa salvaje ${ }^{224}$. Si $\operatorname{LapD}_{\mathrm{Bb}}$ es un factor necesario para la regulación de la formación de biofilm a través de c-di-GMP, la deleción de lapD en un contexto de elevados niveles de c-di-GMP debería reducir los niveles de formación de biofilm en comparación a la cepa salvaje en la misma condición.

Para inducir un aumento en los niveles citoplasmáticos de c-di-GMP utilizamos la

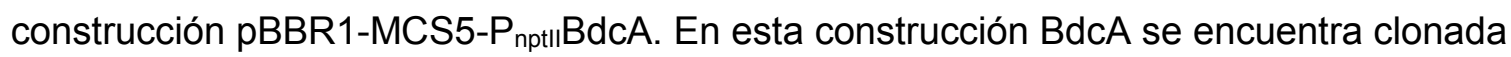
bajo el control del promotor fuerte $\mathrm{P}_{\text {nptll }}{ }^{224}$.

Para la obtención de la cepa $B$. bronchiseptica $\triangle / a p D$ amplificamos por PCR regiones adyacentes a la secuencia lapD (BB1184). La clonación de estas regiones, así como la selección de los clones mutantes fue realizada de manera idéntica a como fuera descripta previamente para las cepas $\triangle b r t A$ y $\Delta / a p G$. La deleción limpia de la secuencia lapD fue confirmada mediante PCR. 
Para evaluar la formación de biofilm realizamos cultivos de 24 horas en microplacas con concentraciones de ácido nicotínico que abarcaron todas las fases de virulencia ( $0 \mathrm{mM}$; 0,5 mM; 2,0 mM y 4,0 mM). Para visualizar y cuantificar los resultados de estos experimentos utilizamos la técnica de tinción por cristal violeta descripta previamente.

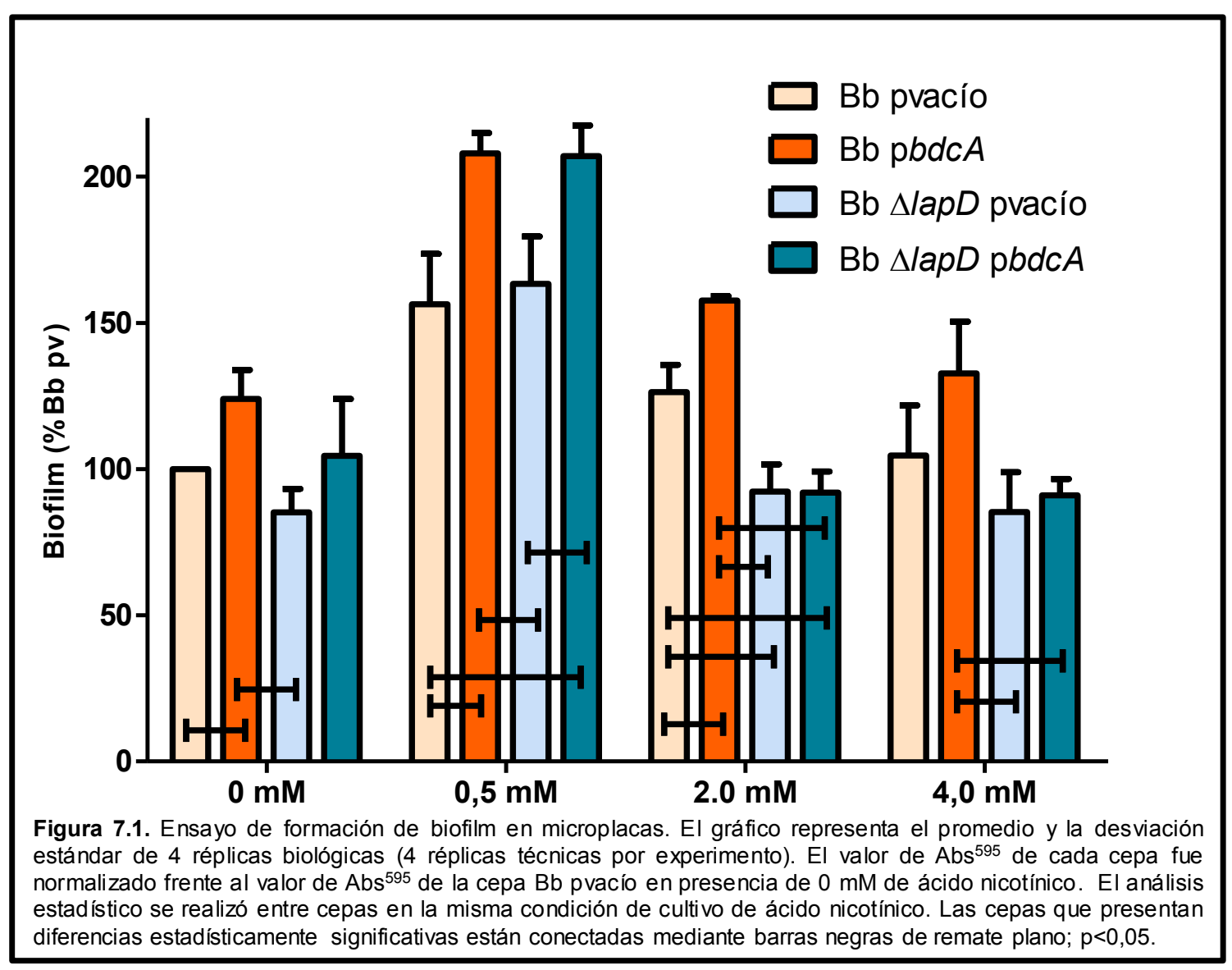

Los resultados de la Figura 7.1 muestran que la sobreexpresión de BdcA en la cepa salvaje induce un aumento estadísticamente significativo en la formación de biofilm en presencia de $0 \mathrm{mM}, 0,5 \mathrm{mM}$ y $2,0 \mathrm{mM}$ de ácido nicotínico. Esto confirma que el aumento en los niveles de c-di-GMP, logrado mediante la sobreexpresión de BdcA, incrementa la capacidad de formación de biofilm de la cepa salvaje en todas las fases de virulencia tal como fuera observado previamente en nuestro laboratorio ${ }^{224}$.

En cultivos con concentración de ácido nicotínico de $0,5 \mathrm{mM}$ la deleción de lapD no generó una reducción en los niveles de formación de biofilm en comparación a la cepa salvaje. Asimismo, puede verse que la sobreexpresión de BdcA indujo un aumento en la formación de biofilm tanto en la cepa salvaje como en la cepa $\triangle / a p D$. Este resultado indicaría que en esta condición existen mecanismos alternativos a las proteínas Lap que regulan la formación de biofilm a través de c-di-GMP. 


\section{Capítulo 7}

Por otro lado, en condiciones de cultivo que presentan una concentración de ácido nicotínico de 2,0 $\mathrm{mM}$ la cepa $\triangle \mathrm{apD}$ presentó una capacidad de formación de biofilm menor a la cepa salvaje $(p<0,05)$. Además, a diferencia de lo que ocurre en el entorno de la cepa salvaje, en el entorno $\Delta / a p D$, la sobreexpresión de BdcA no generó aumentos en la formación de biofilm. Esta observación indica que, en estas condiciones de cultivo, LapD es necesaria para la formación de biofilm mediada por c-di-GMP. No resulta sorprendente que esta sea la condición en la que LapD influye en el fenotipo de formación de biofilm ya que previamente habíamos destacado que esta es la condición en la cual las cepas $\triangle b r t A$ y $\Delta l a p G$ presentaban las características fenotípicas más sobresalientes.

Los resultados obtenidos en presencia de ácido nicotínico 4,0 $\mathrm{mM}$ son similares a los resultados obtenidos en 2,0 mM. En esta condición, la sobreexpresión de BdcA en el entorno de la cepa salvaje indujo una formación de biofilm superior a la inducida en el contexto de la cepa $\triangle / a p D$.

Los resultados presentados en esta sección fortalecen la idea de capítulos anteriores que indican que BrtA es importante para la formación de biofilm en $B$. bronchiseptica. Aquí en particular pusimos en evidencia que LapD es parte del mecanismo de control de la formación de biofilm a través de c-di-GMP.

\section{Búsqueda de diguanilato ciclasas involucradas en el metabolismo de c-di-GMP}

Los resultados presentados en la sección anterior aportan evidencia de que c-diGMP actúa como segundo mensajero en la regulación del funcionamiento de las proteínas Lap en B. bronchiseptica. Esto constituye un paso fundamental hacia la descripción mecanística del funcionamiento de este sistema. Frente a este escenario surge como nuevo horizonte la búsqueda de factores que regulen los niveles de c-diGMP controlando así este sistema de proteínas.

La síntesis de c-di-GMP está catalizada por enzimas denominadas diguanilato ciclasas. Estas proteínas catalizan la conversión de dos moléculas de GTP en una molécula de c-di-GMP liberando pirofosfato $\left(\mathrm{PP}_{\mathrm{i}}\right)$ como subproducto de la reacción ${ }^{79}$. La actividad diguanilato ciclasa de estas proteínas se encuentra dirigida por el dominio denominado GGDEF ${ }^{298}$. El ciclo metabólico del segundo mensajero es completado por fosfodiesterasas específicas para c-di-GMP encargadas de degradarlo hasta pGpG por enzimas que contienen el dominio EAL o hasta GMP por enzimas que presentan dominios HD-GYP ${ }^{79}$. 
Para avanzar en la descripción del funcionamiento del sistema Lap en $B$. bronchiseptica es preciso determinar cuál o cuáles son las diguanilato ciclasas que participan de manera específica de la regulación de este sistema. Con este objetivo analizamos el genoma de $B$. bronchiseptica en busca de posibles diguanilato ciclasas y para ello utilizamos dos estrategias diferentes:

\begin{tabular}{|c|c|}
\hline $\begin{array}{l}\text { Utilizamos el programa de base on-line } \\
\text { SMART (Simple Modular Architecture } \\
\text { Research Tool) }{ }^{330} \text {. Este servidor posee una } \\
\text { herramienta a través de la cual es posible } \\
\text { buscar dominios definidos en la secuencia } \\
\text { completa de un genoma. La rapidez y } \\
\text { sencillez que posee este acercamiento } \\
\text { implica una ventaja para iniciar el estudio de } \\
\text { diguanilato ciclasas en B. bronchiseptica. Sin } \\
\text { embargo, la misma sencillez de este abordaje } \\
\text { condiciona la calidad de los resultados } \\
\text { obtenidos. El algoritmo utilizado por la } \\
\text { herramienta SMART suele pasar por alto } \\
\text { dominios ligeramente divergentes de la } \\
\text { secuencia consenso. }\end{array}$ & $\begin{array}{l}\text { Estrategia \#2 } \\
\text { Utilizamos secuencias conocidas para } \\
\text { realizar una búsqueda mediante la } \\
\text { herramienta BLAST (Basic Local Alignment } \\
\text { Search Tool) del servidor NCBI (National } \\
\text { Center for Biotechnology Information) }{ }^{333} \text {. Para } \\
\text { la búsqueda de dominios compatibles con } \\
\text { actividad diguanilato ciclasa utilizamos } \\
\text { secuencias de dos dominios GGDEF de } \\
\text { demostrada actividad y amplia descripción en } \\
\text { bibliografía. Las secuencias utilizadas como } \\
\text { base de esta búsqueda fueron las secuencias } \\
\text { de los dominios GGDEF de PleD de } \\
\text { Caulobacter crescentus }{ }^{94} \text { y DgcZ (también } \\
\text { conocida como YdeH) de Escherichia coli }{ }^{334} \text {. }\end{array}$ \\
\hline
\end{tabular}

Para el desarrollo de ambas estrategias utilizamos a la cepa B. bronchiseptica RB50 como el organismo sobre el cual realizamos las búsquedas.

La Tabla 7.1 muestra el resultado de la búsqueda in silico de secuencias compatibles con diguanilato ciclasas en $B$. bronchiseptica. Esta búsqueda arrojó como resultado la presencia de catorce secuencias con dominios GGDEF en el genoma de $B$. bronchiseptica. En cuatro de las secuencias encontradas, el dominio GGDEF es el único dominio reconocible mediante estas estrategias (BB0991, BB2626, BB3903 y BB4664). Dentro de este grupo, tres secuencias corresponderían a proteínas de membrana mientras que sólo una de ellas está anotada como proteína citosólica. Diez de las proteínas con dominios GGDEF además presentan otros dominios como parte de su secuencia, característica muy común entre proteínas del metabolismo de c-di-GMP. Este segundo grupo de proteínas podemos dividirlo en aquellas que tienen dominios de unión a ligando (BB1960-globina-, BB2660-CACHE-, BB2790-PAS-, BB3114-PAS y GAF- y BB3576-CACHE-) y sólo una que posee un dominio de transducción de señales (BB1220). Esto implica que c-di-GMP, al igual que en otros organismos participaría de procesos de sensado ambiental y transducción en señales intracelulares. Además, 


\section{Capítulo 7}

encontramos un subgrupo de secuencias que presenta simultáneamente dominos GGDEF y EAL. La presencia de dominios GGDEF y EAL en la misma proteína es una característica comúnmente encontrada en proteínas del metabolismo de c-di-GMP ${ }^{299}$.

\begin{tabular}{|c|c|c|c|c|c|c|}
\hline & Locus & Nombre & $\begin{array}{c}\text { Tamaño } \\
\text { (aminoácidos) }\end{array}$ & Localización probable & $\begin{array}{l}\text { Secuencia del } \\
\text { sitio activo }\end{array}$ & Otros dominios \\
\hline \multicolumn{7}{|c|}{ GGDEF } \\
\hline 1 & BB0991 & $\mathrm{BdcH}$ & 387 & membrana & GGEEF & \\
\hline 2 & BB1220 & $\mathrm{Bdcl}$ & 567 & membrana & GGDEF & TCS \\
\hline 3 & BB1960 & & 475 & citoplasma & GGEEF & globina \\
\hline 4 & BB2626 & BdcG & 385 & membrana & GGEEF & \\
\hline 5 & BB2660 & & 500 & membrana & GADEF & CACHE \\
\hline 6 & BB2790 & BdcD & 315 & citoplasma & GGEEF & PAS \\
\hline 7 & BB3114 & BdcC & 475 & citoplasma & GGEEF & PAS, GAF \\
\hline 8 & BB3576 & BdcA & 540 & membrana & GGEEF & CACHE \\
\hline 9 & BB3903 & BdcB & 251 & citoplasma & GGDEF & \\
\hline 10 & BB4664 & BdcE & 380 & membrana & GGDEF & \\
\hline \multicolumn{7}{|c|}{ GGDEF + EAL } \\
\hline 11 & BB1184 & LapD & 658 & membrana & NGSDF/ - & \\
\hline 12 & BB2109 & & 960 & membrana & NGSDF/ - & \\
\hline 13 & BB2957 & & 600 & citoplasma & GGDDF/ - & $\mathrm{NC} I I I$ \\
\hline 14 & BB3317 & & 691 & membrana & GGDEF/ - & \\
\hline
\end{tabular}

La secuencia BB1220 presenta una particular importancia ya que podría tratarse del sensor de membrana de un sistema de dos componentes. Corriente arriba de esta secuencia encontramos la secuencia BB1219 que presenta un dominio de unión a ADN. Esto refuerza la idea de que el par BB1220-BB1219 podría tratarse de un sistema de dos componentes regulado por c-di-GMP.

La presencia de dominios GGDEF en las 14 secuencias descriptas previamente no es suficiente para asegurar que todas ellas tengan capacidad de sintetizar c-di-GMP. En los genomas bacterianos es común encontrar secuencias que poseen dominios GGDEF divergentes de los dominios catalíticamente activos. En muchos casos, estas proteínas siguen siendo parte de la red de regulación a través de c-di-GMP. Si bien no poseen la capacidad de síntesis muchas veces mantienen la habilidad para unir el segundo mensajero a través del sitio I de inhibición alostérica. Con el objetivo de avanzar hacia la comprensión de cuáles de las 14 secuencias podrían codificar para diguanilato ciclasas activas realizamos un alineamiento de los dominios GGDEF de estas secuencias junto a los dominos de las diguanilato ciclasas PleD, de C. crescentus, y DgcZ, de E. coli (descripta originalmente como $\mathrm{YdeH}$ ). Los resultados de la alineación se presentan a continuación, la secuencia de cada posible sitio activo está incorporada en la tabla 7.1 descripta anteriormente. 


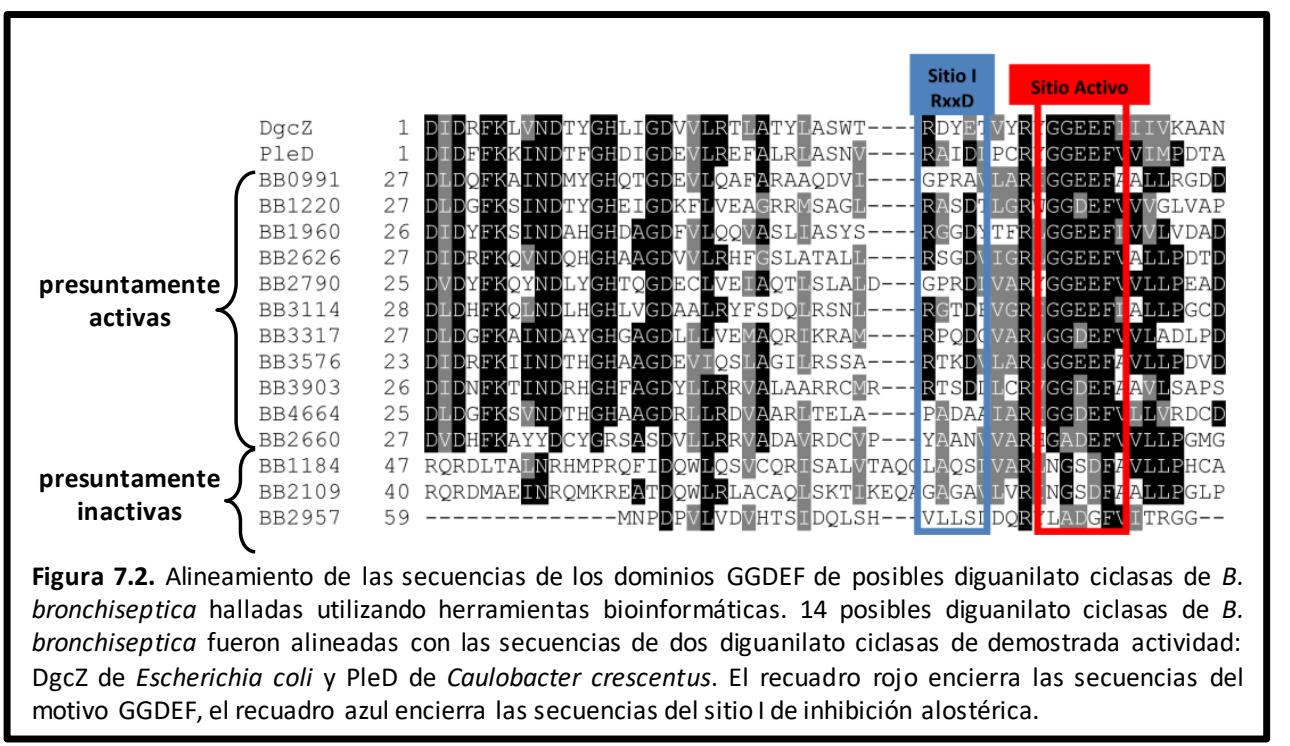

El alineamiento de los dominios GGDEF de las posible diguanilato ciclasas de $B$. bronchiseptica con los dominios GGDEF de las diguanilato ciclasas PleD y DgcZ (YdeH) demuestra que 11 de las secuencias encontradas presentan motivos que han sido descriptos en otras diguanilato ciclasas activas (Figura 7.2). De los 14 dominios alineados, 7 de ellos presentan la secuencia -GGEEF- mientras que dos de ellos presentan la secuencia canónica -GGDEF-. Por otro lado, las secuencias BB2660, BB2109, BB2957 presentan motivos que no han sido descriptos en ninguna diguanilato ciclasa activa (Figura 7.2).

En lo sucesivo, presentaremos el abordaje experimental desarrollado a fin de analizar cuál o cuáles son las diguanilato ciclasas involucradas en el control de LapD y las proteínas Lap en $B$. bronchiseptica.

\section{Diseño y evaluación de un sistema reportero para la búsqueda de diguanilato ciclasas que interaccionen con $\mathrm{LapD}_{\mathrm{Bb}}$}

Con el objetivo de determinar cuál o cuáles diguanilato ciclasas interaccionan de manera específica con $L_{a p D} D_{B b}$ nos propusimos un abordaje experimental que incluyó la expresión heteróloga de proteínas GGDEF de $B$. bronchiseptica en $P$. fluorescens.

$P$. fluorescens es uno de los organismos modelo en el área de estudio de biofilms y en la regulación de este proceso a través de c-di-GMP. Como consecuencia de ello existe abundante información acerca del funcionamiento de los mecanismos moleculares que dirigen estos procesos. Asimismo, es un organismo que no presenta grandes dificultades de cultivo y manipulación genética. La cepa $P$. fluorescens $\triangle 4 D G C$ constituye un modelo ideal para el estudio de posibles diguanilato ciclasas. Esta cepa presenta la característica de que cuatro diguanilato ciclasas involucradas en la formación de biofilm 


\section{Capítulo 7}

han sido delecionadas (GcbA, GcbB, GcbC y WspR) ${ }^{273}$. En el contexto de esta cepa, la expresión de diguanilato ciclasas activas de $P$. fluorescens genera un aumento en la formación de biofilm. Por este motivo, nuestro grupo de investigación ha aprovechado esta cepa en el pasado como una herramienta para el estudio de diguanilato ciclasas de B. bronchiseptica. Si la expresión de una proteína con dominio GGDEF genera un aumento en la formación de biofilm, es una evidencia importante para sostener que dicha proteína es una diguanilato ciclasa activa. Sin embargo, en nuestra experiencia, ninguna diguanilato ciclasa es capaz de generar un aumento equivalente al que genera la diguanilato ciclasa propia de $P$. fluorescens GcbC.

Los resultados presentados en el Capítulo 4 muestran que $\operatorname{LapD}_{\mathrm{Bb}}$ y $\operatorname{LapD}_{\mathrm{Pf}}$ presentan diferencias importantes en la superficie involucrada en la interacción con diguanilato ciclasas (Figura 4.4). Esta observación sugiere que LapDPf no podría interaccionar correctamente con ninguna diguanilato ciclasas de B. bronchiseptica. Según nuestra hipótesis, este motivo podría explicar el hecho de que ninguna diguanilato ciclasa de $B$. bronchiseptica es capaz de inducir un aumento en la formación de biofilm similar al que logra producir $\mathrm{GcbC}$ de $P$. fluorescens. Si bien esto podría ser considerado una limitación del modelo de estudio, por el contrario, consideramos que esta propiedad podría ser aprovechada para realizar una búsqueda generalizada de diguanilato ciclasas que interaccionen con $\mathrm{LapD}_{\mathrm{Bb}}$.

Con el objetivo de diseñar un sistema reportero para la búsqueda de diguanilato ciclasas que alimenten a $L_{a p D} D_{B b}$ reemplazamos, la copia cromosómica de lap $D_{P f}$ por la secuencia de $l a p D_{B b}$. Según nuestra hipótesis, aquella diguanilato ciclasa que interaccione eficientemente con $\mathrm{LapD}_{\mathrm{Bb}}$ será capaz de inducir un aumento mayor en la formación de biofilm en comparación a aquellas que no lo hagan.

Como primer paso construimos la cepa $P$. fluorescens $\triangle 4$ DGC $\triangle l a p D:: l a p D_{B b}(P f$ $\triangle 4 D G C-L_{a p D} D_{\text {Bb }}$ y con el objetivo de probar la funcionalidad de nuestro nuevo sistema reportero, decidimos analizar el efecto de la sobreexpresión de la diguanilato ciclasa de $P$. fluorescens GcbC. De acuerdo con nuestra hipótesis, $\operatorname{LapD}_{\mathrm{Bb}}$ y $\mathrm{GcbC}$ no interaccionarían eficientemente y en consecuencia la sobreexpresión de GcbC en esta cepa no debería inducir un aumento significativo en la formación de biofilm.

La Figura 7.3 muestra los resultados de los ensayos de formación de biofilm en microplaca realizados a fin de determinar la funcionalidad del sistema reportero desarrollado. 


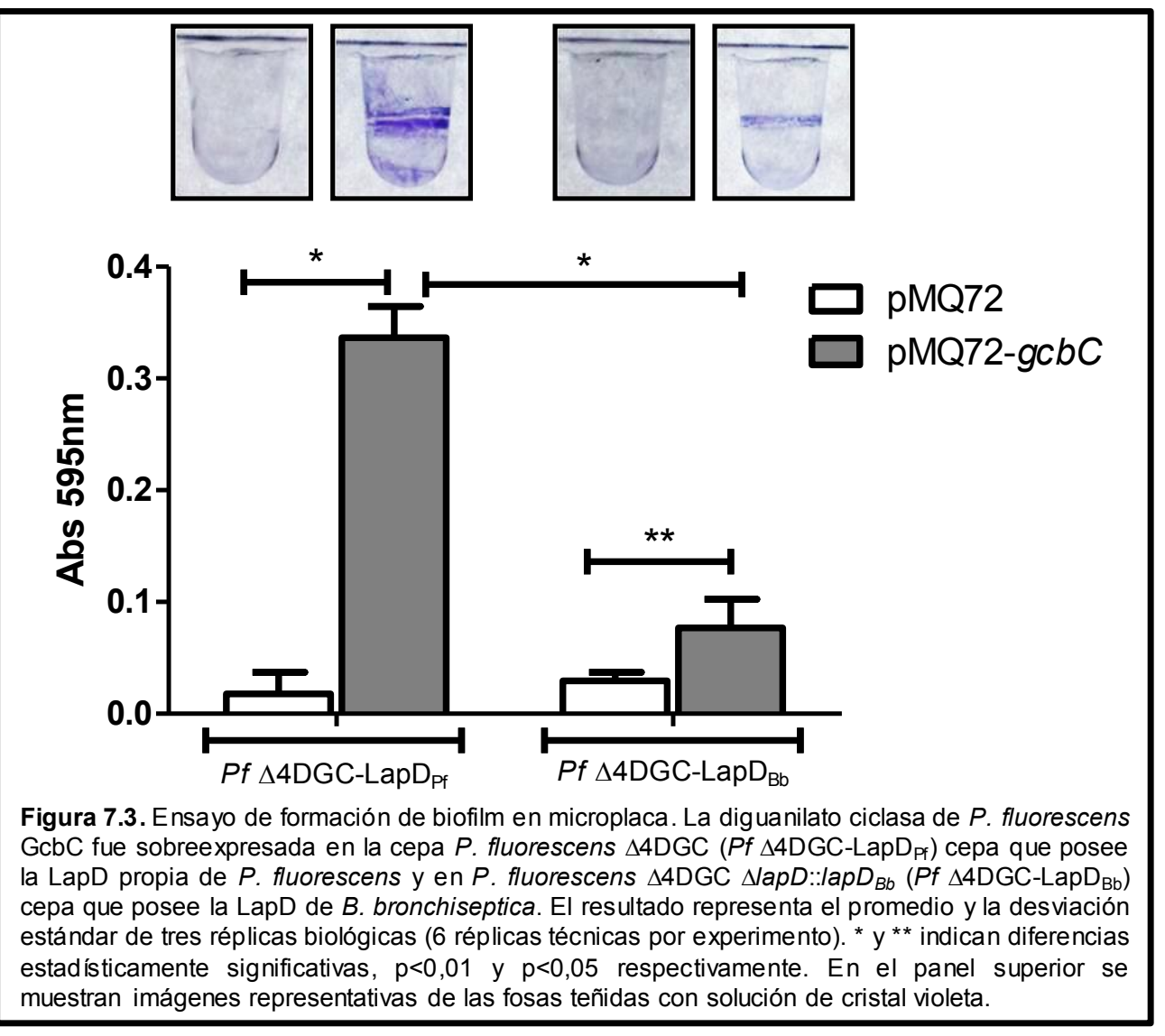

En primer lugar, tal como se encuentra descripto en la bibliografía, los resultados muestran que la cepa $P$. fluorescens $\triangle 4$ DGC presenta una capacidad nula de formación de biofilm ${ }^{273}$. En segundo lugar, en el contexto de esta cepa, la sobre expresión de GcbC induce un aumento significativo de la formación de biofilm $(p<0,01)$. Estos resultados también reproducen los reportados previamente ${ }^{273}$. Por otro lado, el reemplazo de LapD $\mathrm{Pf}_{\mathrm{Pf}}$ por $L_{a p D} D_{B b}$ no genera diferencias fenotípicas en la cepa $\triangle 4 D G C$. Por último, tal como esperábamos, la expresión de $\mathrm{GcbC}$ en el contexto de la cepa que posee $\operatorname{LapD}_{\mathrm{Bb}}$ no induce un aumento en la formación de biofilm de la misma magnitud que en la cepa que posee la $L_{a p D}$. En sintonía con nuestra hipótesis, este resultado sugiere que la interacción ineficiente entre $G c b C$ y $L_{a p D}$ es lo que generaría una menor formación de biofilm.

A partir de este resultado consideramos apropiado utilizar esta cepa para evaluar proteínas con dominios GGDEF B. bronchiseptica que pudieran interactuar con $\mathrm{LapD}_{\mathrm{Bb}}$.

\section{Expresión heteróloga de posibles diguanilato ciclasas de $B$. bronchiseptica en la cepa modelo $P$. fluorescens}

Con el objetivo de buscar cuál o cuáles son las diguanilato ciclasas que alimentan a LapD en $B$. bronchiseptica, realizamos el ensayo de expresión heteróloga en la cepa 


\section{Capítulo 7}

híbrida $P$. fluorescens $\triangle 4 \mathrm{DGC}$-LapD $\mathrm{Bb}_{\mathrm{Bb}}$. Según nuestra hipótesis, en el contexto de esta cepa, las diguanilato ciclasas de $B$. bronchiseptica que sean capaces de interaccionar eficientemente con $\mathrm{LapD}_{\mathrm{Bb}}$ serán aquellas que generen un aumento mayor en la capacidad de formación de biofilm.

Para analizar cuantitativamente este fenómeno realizamos ensayos de formación de biofilm en microplaca. Como primer paso del análisis utilizamos 5 proteínas con dominios GGDEF de B. bronchiseptica y la diguanilato ciclasa de $P$. fluorescens GcbC como control. En todos los casos las proteínas fueron expresadas desde un plásmido multicopia bajo el control del promotor fuerte $P_{B A D}$.

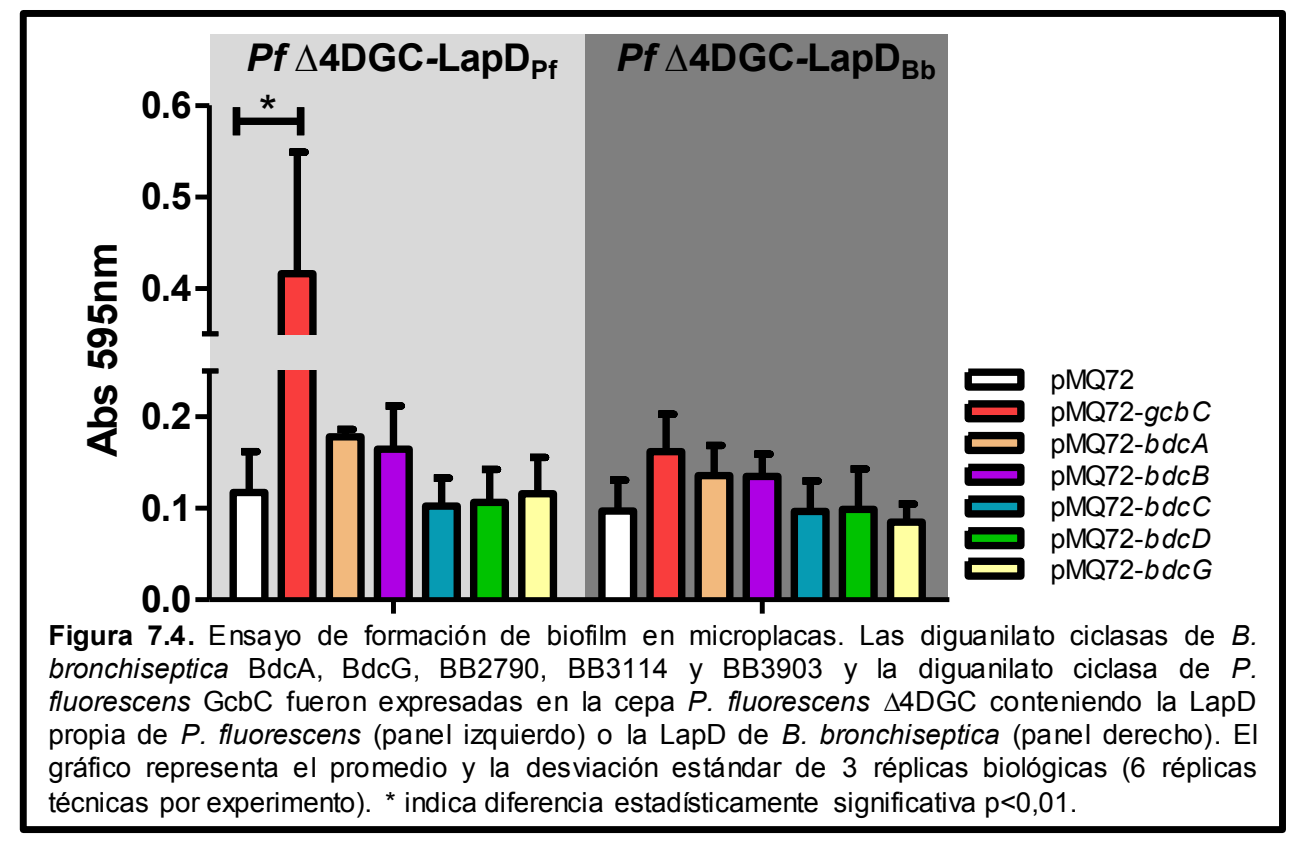

La Figura 7.4 muestra los resultados obtenidos para la sobreexpresión de la diguanilato ciclasa GcbC y cinco proteínas GGDEF de $B$. bronchiseptica en la cepa $P$. fluorescens $\triangle 4 D G C$-LapD $D_{P f}$ (panel izquierdo del gráfico) y en la cepa $P$. fluorescens $\triangle 4 D G C-$ LapD $_{\mathrm{Bb}}$ (panel derecho del gráfico).

Analizando el gráfico vemos nuevamente que GcbC genera un aumento significativo en la formación de biofilm en presencia de $\operatorname{LapD}_{P f}(p<0,01)$ pero no lo hace en presencia de $\operatorname{LapD}_{\mathrm{Bb}}$. Asimismo, ninguna de las 5 proteínas GGDEF de $B$. bronchiseptica fue capaz de inducir un aumento en la formación de biofilm semejante al generado por GcbC en su contexto natural. Además, en presencia de $\operatorname{LapD}_{\mathrm{Bb}}$, la sobreexpresión de GcbC generó un aumento en la formación de biofilm similar a las diguanilato ciclasa de B. bronchiseptica BdcA y BdcB. Dada la baja sensibilidad del método diseñado para determinar posibles interacciones con $\mathrm{LapD}_{\mathrm{Bb}}$ analizamos algunas 
variables que no habían sido consideradas previamente. Esos resultados serán descriptos en la siguiente sección.

\section{LapG $G_{P f}$ podría no interactuar correctamente con Lap $D_{B b}$}

Tal como mencionamos anteriormente, la sobreexpresión de diguanilato ciclasas activas en la cepa $P$. fluorescens $\triangle 4 D G C$ induce un aumento en la formación de biofilm. Este aumento se da como consecuencia de que, frente al aumento en los niveles citoplasmáticos de c-di-GMP, LapG se mantiene unida a LapD en el lado periplasmático de la membrana interna. Frente a esta condición la adhesina LapA se mantiene asociada en la membrana externa y contribuye al aumento en la formación de biofilm. Recordemos que la sobre expresión de $\mathrm{GcbC}$ en la cepa Pf $\triangle 4 D G C-L a p D_{\mathrm{Bb}}$ generó un leve aumento en la formación de biofilm. Este resultado indica que $L a p G_{p f}$ puede ser retenida por $\mathrm{LapD}_{\mathrm{Bb}}$ cuando la expresión de una diguanilato ciclasa activa induce aumentos en los niveles de c-di-GMP citoplasmáticos. Si la interacción entre $\operatorname{LapD}_{\mathrm{Bb}}$ y $\operatorname{LapG}_{\mathrm{Pf}}$ no fuera efectiva, no sería posible lograr ni siquiera un mínimo aumento en la formación de biofilm. Sin embargo, cabe la posibilidad de que esa interacción no sea suficientemente eficaz como para que $L_{a p D}$ Bb mantenga unida a $L a p G_{p f}$ de la misma manera en que lo hace la propia LapD $D_{\text {Pf. }}$

Con el objetivo de analizar esta hipótesis, a fin de considerar una mejora en este sistema de expresión o bien descartarlo definitivamente analizamos la estructura de la región periplasmática de $L_{a p D} D_{\mathrm{Bb}} \mathrm{y} L a p D_{\mathrm{pf}}$.

Si bien existe una estructura cristalográfica de la porción periplasmática de $L_{a p} D_{\mathrm{Pf}}$ (depositada en la base de datos PDB bajo el código 3PJV ${ }^{253}$ ) estudios posteriores demostraron que esa estructura presentaba defectos originados durante el proceso de cristalización. La estructura correcta de la porción periplasmática de LapD fue determinada utilizando la LapD de L. pneumophila ${ }^{249}$. Por lo tanto, para analizar las estructura de la porción periplasmática de $\operatorname{LapD}_{\mathrm{Bb}} \mathrm{y} \mathrm{LapD}_{\mathrm{Pf}}$ utilizamos la función "one to one" del software Phyre2 para modelar las secuencias de ambas LapD utilizando como molde la estructura cristalográfica de LapD de L. pneumophila depositada bajo el código $4 u 64$.

Figura 7.5 presenta los modelados de las secuencias periplasmáticas de $\operatorname{LapD}_{\mathrm{Bb}}$ y LapD $D_{\text {Pf. }}$ Ambos modelados arrojaron un nivel de confianza del $100 \%$ indicando que ambas secuencias pudieron ser exitosamente modeladas utilizando la estructura propuesta. 


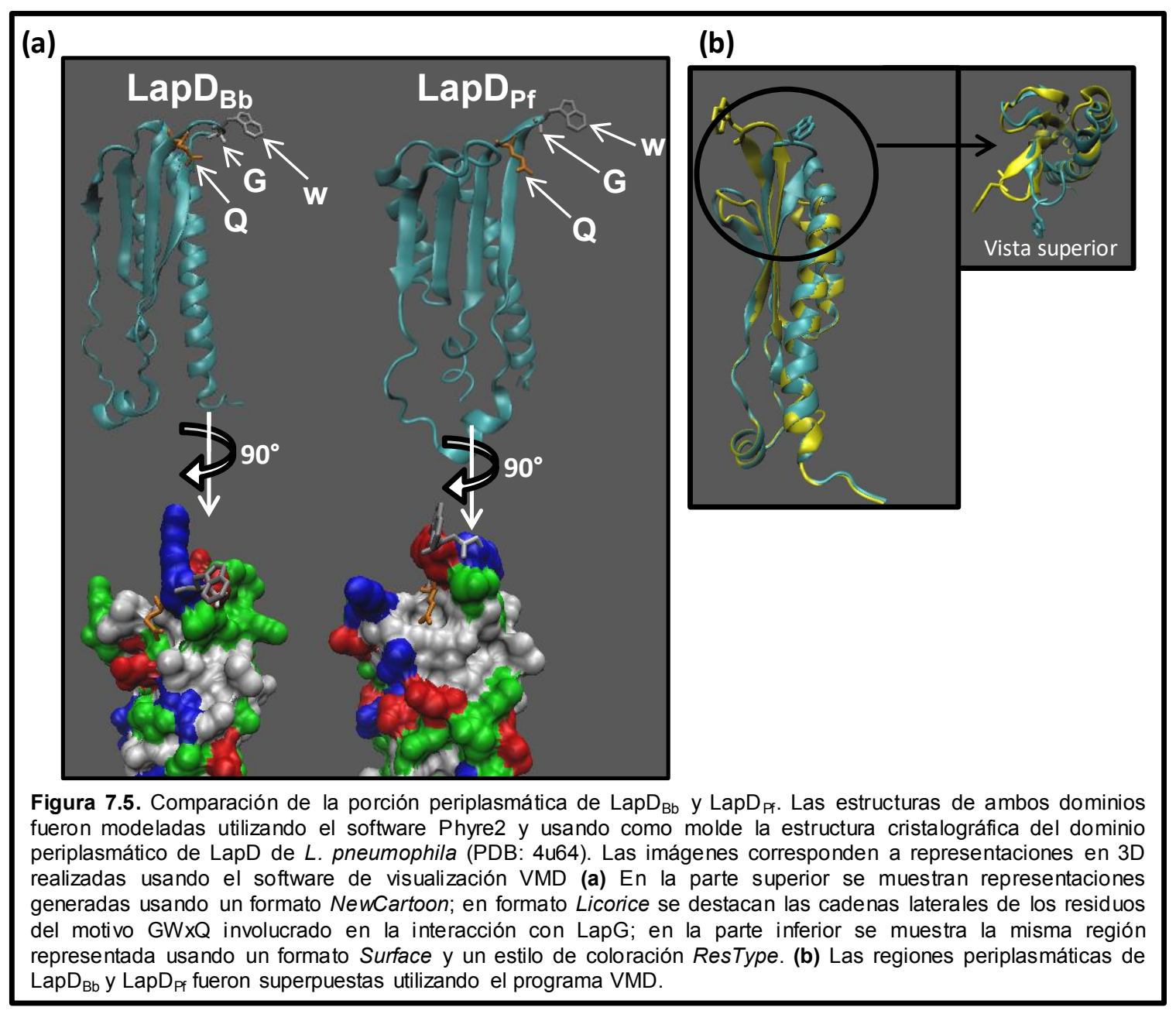

Recordemos que el análisis de la secuencia y estructura de la porción periplasmática de LapD en $P$. fluorescens condujo a la identificación de la región de interacción entre LapD y LapG. El motivo 124-GWxQ-127 ubicado en un loop formado entre las láminas $\beta 3$ y $\beta 4$ constituye la porción más sobresaliente de la superficie de la porción periplasmática de $\operatorname{LapD}_{\mathrm{Pf}}($ Figura 7.5) y está involucrado en la interacción con LapG $^{250}$. Tal como está descripto para $P$. fluorescens, LapD $_{\mathrm{Bb}}$ posee conservada esa región. Sin embargo, si analizamos la región adyacente al motivo $G W \times Q$ podemos ver algunas diferencias entre $L_{a p D}$ y $L_{\mathrm{PapD}}$. Mientras en $\operatorname{LapD}_{\mathrm{Pf}}$ el motivo $G W \times \mathrm{Q}$ está rodeado por una región netamente no polar, en $\mathrm{LapD}_{\mathrm{Bb}}$ encontramos que esta región presenta una zona con carga positiva hacia arriba y una zona polar hacia abajo (Figura 7.5.a panel inferior). Además, podemos ver que la orientación del residuo de triptófano (W) en una y otra estructura es ligeramente diferente (Figura 7.5.b).

Si bien en nuestro análisis hemos identificado los residuos de LapD que son indispensable para la interacción con LapG no podemos descartar que la presencia de algunos residuos diferenciales opere en contra de la interacción $\operatorname{LapD}_{\mathrm{Bb}}$-LapG $\mathrm{Ff}_{\mathrm{pf}}$ Una posible explicación podría ser que exista un impedimento estérico entre las superficies 
de contacto o bien una repulsión electrostática originada en la presencia de residuos de muy diferente naturaleza.

Aunque nuestro análisis no incluyó al total de las proteínas GGDEF codificadas en el genoma de $B$. bronchiseptica, los resultados obtenidos hasta el momento nos llevaron a suspender la búsqueda mediante esta estrategia. En base a este análisis consideramos apropiado abandonar los experimentos con la cepa $P$. fluorescens $\triangle 4 D G C$ en pos de buscar una estrategia de análisis alternativa.

\section{Búsqueda de diguanilato ciclasas que interaccionen con $\operatorname{LapD}_{\mathrm{Bb}}$ mediante modelado molecular}

Frente a la imposibilidad de determinar qué diguanilato ciclasa es capaz de interactuar con $\mathrm{LapD}_{\mathrm{Bb}}$ mediante la estrategia de expresión heteróloga presentada en la sección anterior, decidimos utilizar un enfoque predictivo basado en el trabajo de Dahlstrom et al. ${ }^{123}$. En el mencionado trabajo se describieron las regiones de interacción entre LapD y GcbC en $P$. fluorescens. Los mismos autores de este trabajo destacaron y presentaron evidencia de que el análisis de las regiones de interacción puede ser utilizado con carácter predictivo. Es decir que es posible determinar qué diguanilato ciclasa tiene capacidad de interactuar con LapD analizando la zona de interacción de las posibles diguanilato ciclasas ${ }^{123}$.

$P$. fluorescens posee más de 50 proteínas predichas que podrían estar involucradas en la red de regulación de c-di-GMP. De este grupo de proteínas, 16 son capaces de interaccionar físicamente con LapD $D_{\text {ff }}$ y 15 de ellas son proteínas de membrana ${ }^{124}$. Por este motivo, para la búsqueda de diguanilato ciclasas que pudieran interactuar con $\operatorname{LapD}_{\mathrm{Bb}}$ en $B$. bronchiseptica nos enfocamos en el estudio de las secuencias que contuvieran un domino GGDEF compatible con el desarrollo de la actividad enzimática y que además presentara secuencias predichas como proteínas de membrana. Incorporando estas consideraciones en el análisis, el número de secuencias se reduce de 14 a 6 (BdcA, BdcG, BdcH, Bdcl, BdcE y BB3317). Para llevar adelante el análisis propuesto, realizamos el modelado molecular de los dominios GGDEF de las mencionadas proteínas. Posteriormente, usando el programas de visualización VMD y utilizando una representación del tipo Surface y un estilo de coloración ResType, analizamos la forma y distribución de carga de las regiones de interacción en búsqueda de estructuras compatibles con la interacción con el dominio $E A L$ de $L_{a p D_{B b}}$. 


\section{Capítulo 7}

(a)
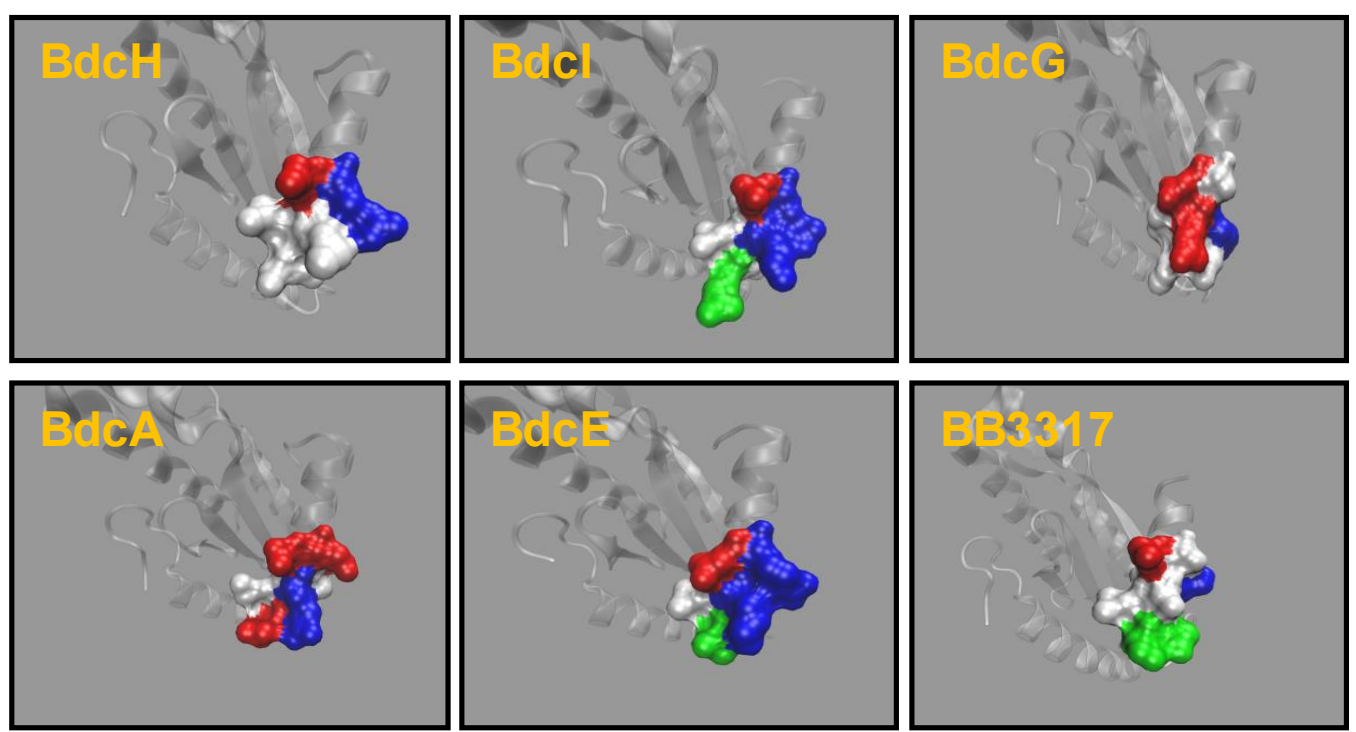

(b)

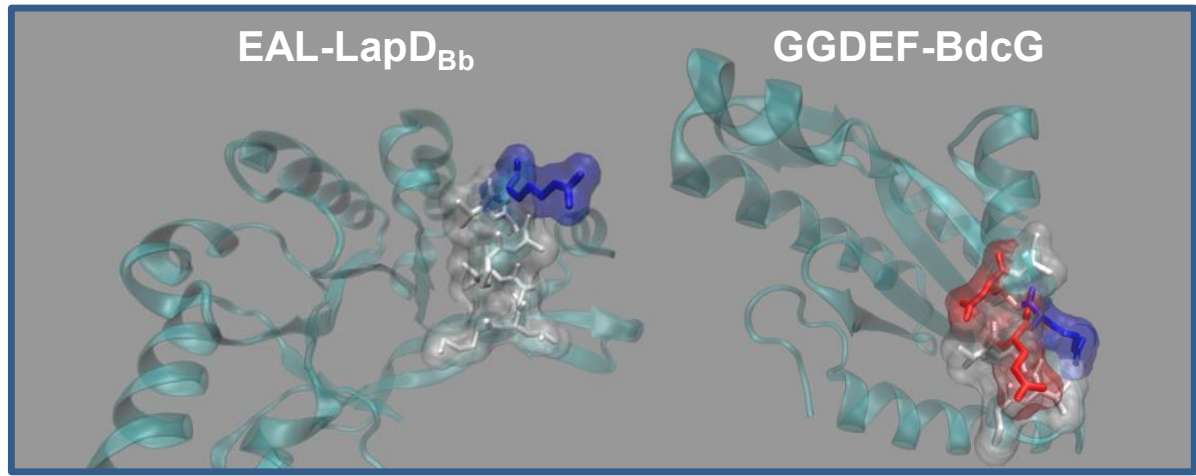

(c)

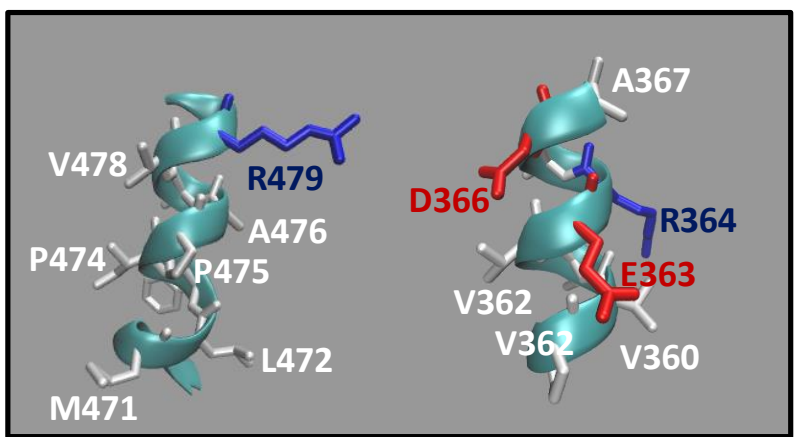

Figura 7.6. Modelado molecular de los dominios GGDEF de las posibles diguanilato ciclasas que podrían interaccionar con $\operatorname{LapD}_{\mathrm{Bb}}$. (a) Las representaciones de los dominios GGDEF fueron realizadas usando un estilo NewCartoon y una coloración gris transparente. Las región de interacción fue representada con un estilo Surface y coloreada con un estilo ResType. (b) EI dominio EAL de $L_{a p D}$ yb el dominio GGDEF de BdcG fueron representados utilizando un estilo NewCartoon y una coloración verde transparente. Las regiones de interacción fueron representadas utilizando un estilo Surface transparente. (c) Las cadenas laterales de los residuos involucrados en la interacción entre $\operatorname{LapD}_{\mathrm{Bb}}$ y $B d c G$ fueron representados utilizando un formato Licorice y coloreadas usando el modo ResType. Estas representaciones fueron usadas para predecir la interacción entre $\operatorname{LapD}_{\mathrm{Bb}}$ y $\mathrm{BdcG}$.

En la Figura 7.6 se muestran las representaciones de los modelados de los dominios GGDEF de las 6 diguanilato ciclasas analizadas. Todos los modelados fueron realizados utilizando la función Intensive de Phyre2 que permite realizar el modelado por 
comparación contra todas la base de datos de proteínas cristalizadas. Todos los modelados arrojaron un nivel de confianza del $100 \%$.

A partir del análisis realizado consideramos que el dominio GGDEF de BdcG (BB2626) es aquel que presenta mayores posibilidades de interactuar con LapD $_{\mathrm{Bb}}$. Como puede verse en la Figura 7.6.a y 7.6.b el área de interacción de BdcG presenta una superficie dominada por residuos de aminoácidos con cadenas laterales ácidas y cadenas laterales no polares. Esta superficie podría interactuar con la región propuesta de $\operatorname{LapD}_{\mathrm{Bb}}$ la cual presenta residuos con cadenas laterales básicas y así como también residuos no polares (Figura 7.6.b y c).

\section{$\mathrm{BdcA}$, otro candidato a interactuar físicamente con $\mathrm{LapD}_{\mathrm{Bb}}$}

Nuestro grupo ha demostrado, hace algunos años, que la formación de biofilm en B. bronchiseptica está regulada, en parte, a través de c-di-GMP ${ }^{224}$. Durante el desarrollo de esos estudios, se utilizó la proteína BdcA (BB3576) para inducir aumentos en los niveles de c-di-GMP y así demostrar los efectos que este segundo mensajero tenía sobre los fenotipos de movilidad y formación de biofilm. El fuerte impacto que tiene la sobreexpresión de BdcA en la formación de biofilm plantea dos posibles escenarios. La primera explicación podría ser que BdcA tuviera una actividad suficientemente grande como para que, al ser sobreexpresada, induzca mecanismos de regulación con los cuales naturalmente no está asociada. Una segunda hipótesis podría ser que la sobreexpresión de BdcA impacte fuertemente sobre la formación de biofilm porque efectivamente es parte de un mecanismo molecular encargado de regular ese proceso. Si este fuera el caso, no podemos descartar que lo hiciera a través las proteínas Lap. Por ende, resulta necesario evaluar la posibilidad de que BdcA interaccione físicamente con LapD $\mathrm{Bb}_{\mathrm{Bb}}$.

Una segunda evidencia sugiere la posibilidad de que BdcA podría interaccionar físicamente con $L a p D_{\mathrm{Bb}}$. Ha sido descripto en $P$. fluorescens que la interacción física entre $L_{a p D}$ y $G c b C$ es un proceso necesario para el control de la formación de biofilm. De todas las proteínas GGDEF de B. bronchiseptica, BdcA es una de las dos que presentan una organización de dominios similar a GcbC (CACHE-GGDEF).

Los motivos expuestos anteriormente posicionan a BdcA como un candidato a evaluar entre las diguanilato ciclasas que podrían interactuar con LapD $\mathrm{Bb}_{\mathrm{Bb}}$.

\section{BdcA y BdcG interaccionan físicamente con $L_{a p D}$}

Con el objetivo de poner a prueba la capacidad de BdcA y de BdcG de asociarse físicamente con $\mathrm{LapD}_{\mathrm{Bb}}$ decidimos utilizar una estrategia de doble híbrido en bacteria

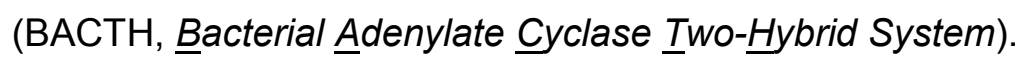




\section{Capítulo 7}

La metodología de BACTH es una herramienta versátil para evaluar interacciones proteína-proteína in vivo ${ }^{300}$. Asimismo, es una estrategia ampliamente utilizada en el estudio de interacciones entre proteínas de membrana ${ }^{301,302}$, motivo por el cual fue seleccionada para desarrollar este estudio. La estrategia está basada en la utilización de la enzima adenilato ciclasa (AC) de $B$. pertussis como reportero de la interacción de proteínas candidatas $^{303}$ (Figura 7.7).

A

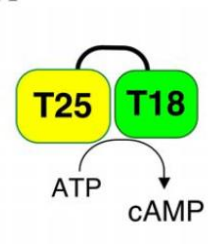

B

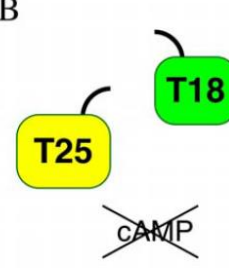

$\mathrm{C}$

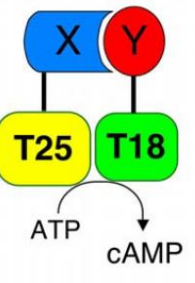

$\mathrm{D}$

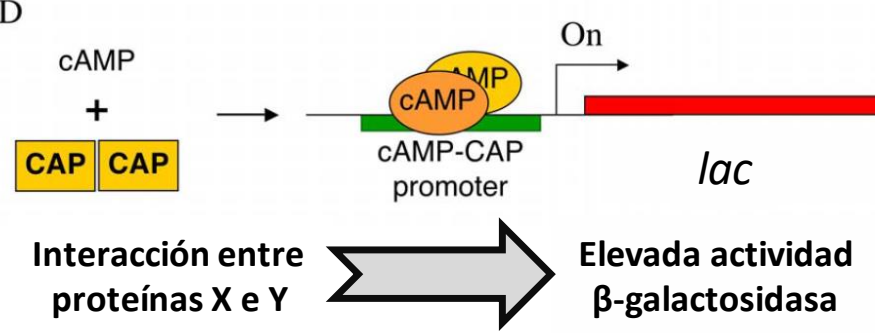

Figura 7.7. Esquema del funcionamiento del sistema de doble híbrido en bacteria (BACTH).

El dominio catalítico de esta enzima puede ser dividido en dos fragmentos denominados T25 y T18 ${ }^{304}$. Cuando estos fragmentos son co-expresados en vectores independientes, no se observa actividad adenilato ciclasa (Figura 7.7.B). Si embargo, si son co-expresados como parte de fusiones transcripcionales a proteínas con capacidad de interaccionar entre sí, se reconstituye funcionalmente el dominio AC y recupera su actividad (Figura 7.7.C). Finalmente, el AMPc producido activa la expresión de algunos operones como por ejemplo el de degradación de lactosa el cual contiene el gen que codifica para la enzima $\beta$-galactosidasa ${ }^{300}$ (Figura 7.7.D). De esta manera, la determinación de la actividad $\beta$-galactosidasa constituye una medida cuantitativa de la capacidad de interacción de las proteínas candidatas.

Basándonos en los reportes previos de Dahlstrom et al. ${ }^{123}$ decidimos clonar los genes $l a p D_{B b}, b d c A$ y $b d c G$ en los vectores pKNT25 y pUT18. De esta manera los genes mencionados fueron clonados al extremo N-terminal de los fragmentos T25 y T18 (en ambos vectores) de manera tal que estos últimos quedaran localizados hacia el espacio citoplasmático. En la Tabla 7.2 puede verse las distintas combinaciones de fusiones transcripcionales usadas para evaluar la interacción entre $\operatorname{LapD}_{\mathrm{Bb}}$, BdcA y BdcG. 


\begin{tabular}{|c|c|}
\hline Fusiones transcripcionales & Interacción puesta a prueba \\
\hline 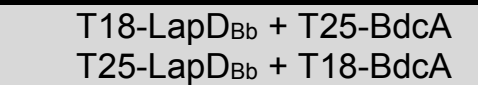 & LapD $_{\text {Bb }}$ Vs BdcA \\
\hline $\begin{array}{l}\text { T18-LapD } D_{\mathrm{Bb}}+\mathrm{T} 25-\mathrm{BdcG} \\
\text { T25-LapD } \\
\mathrm{Bb}\end{array}$ & LapD $_{\mathrm{Bb}}$ Vs BdcG \\
\hline T18-BdcA + T25-BdcA & BdcA Vs BdcA \\
\hline T18-BdcA + T25-BdcG & BdcG Vs BdcG \\
\hline T25-BdcA + T18-BdcG & BdcA Vs BdcG \\
\hline
\end{tabular}

Como control positivo del ensayo se utilizaron las construcciones pKT25-zip y pUT18C-zip que presentan el motivo leucine zipper como fusiones transcripcionales a los fragmentos T25 y T18 respectivamente. Este dominio está presente en proteínas de unión al ADN y tiene la capacidad de dimerizar. Como control negativo se utilizaron los vectores pUT18 y pKNT25 vacíos.

La Figura 7.8 muestra los resultados de los experimentos de BACTH con las proteínas $\operatorname{LapD}_{\mathrm{Bb}}$, BdcA y BdcG. En primer lugar, observamos que el control positivo presenta valores de Unidades de Miller (UM) significativamente mayores de los valores del control negativo $(p<0.01)$. En segundo lugar, analizando las dos combinaciones de fusiones transcripcionales utilizadas para evaluar la interacción entre $\operatorname{LapD}_{\mathrm{Bb}}$ y $B d c A$ vemos que sólo una de ellas presenta diferencias significativas frente al control negativo. La combinación T18-LapD $\mathrm{Bb}_{\mathrm{Bb}}+\mathrm{T} 25-\mathrm{BdcA}$ presenta valores de UM significativamente mayores a los del control negativo $(p<0.01)$. Sin embargo, la combinación T25-LapD $\mathrm{Bb}+$ T18-BdcA no presente diferencias. Este resultado suele aparecer en algunos experimentos de BACTH motivo por el cual es preciso realizar las fusiones transcripcionales tanto al fragmento T25 como al fragmento T18. Por ejemplo, en un estudio del interactoma de las proteínas de división celular de E. coli, Karimova et al. demostraron que FtsW fusionada a T25 es funcional pero no lo es fusionada T18 ${ }^{302}$.

A fin de confirmar que la fusión transcripcional T18-BdcA podría no ser funcional, evaluamos su capacidad de inducir actividad $\beta$-galactosidasa en combinación con la fusión transcripcional T25-BdcA. La actividad de BdcA como diguanilato ciclasa fue demostrada previamente por nuestro laboratorio ${ }^{224}$. Para el desarrollo de esta actividad, es condición necesaria la dimerización de BdcA. Por lo tanto, la combinación T25-BdcA + T18-BdcA debería arrojar resultados positivos si es que ambas construcciones son funcionales. En la Figura 7.8 puede verse que esta combinación no arroja valores de UM diferentes del control negativo. El análisis combinado de los dos resultados presentados hasta el momento permite deducir que la fusión transcripcional T18-BdcA no es funcional a los fines del experimento de BACTH. 


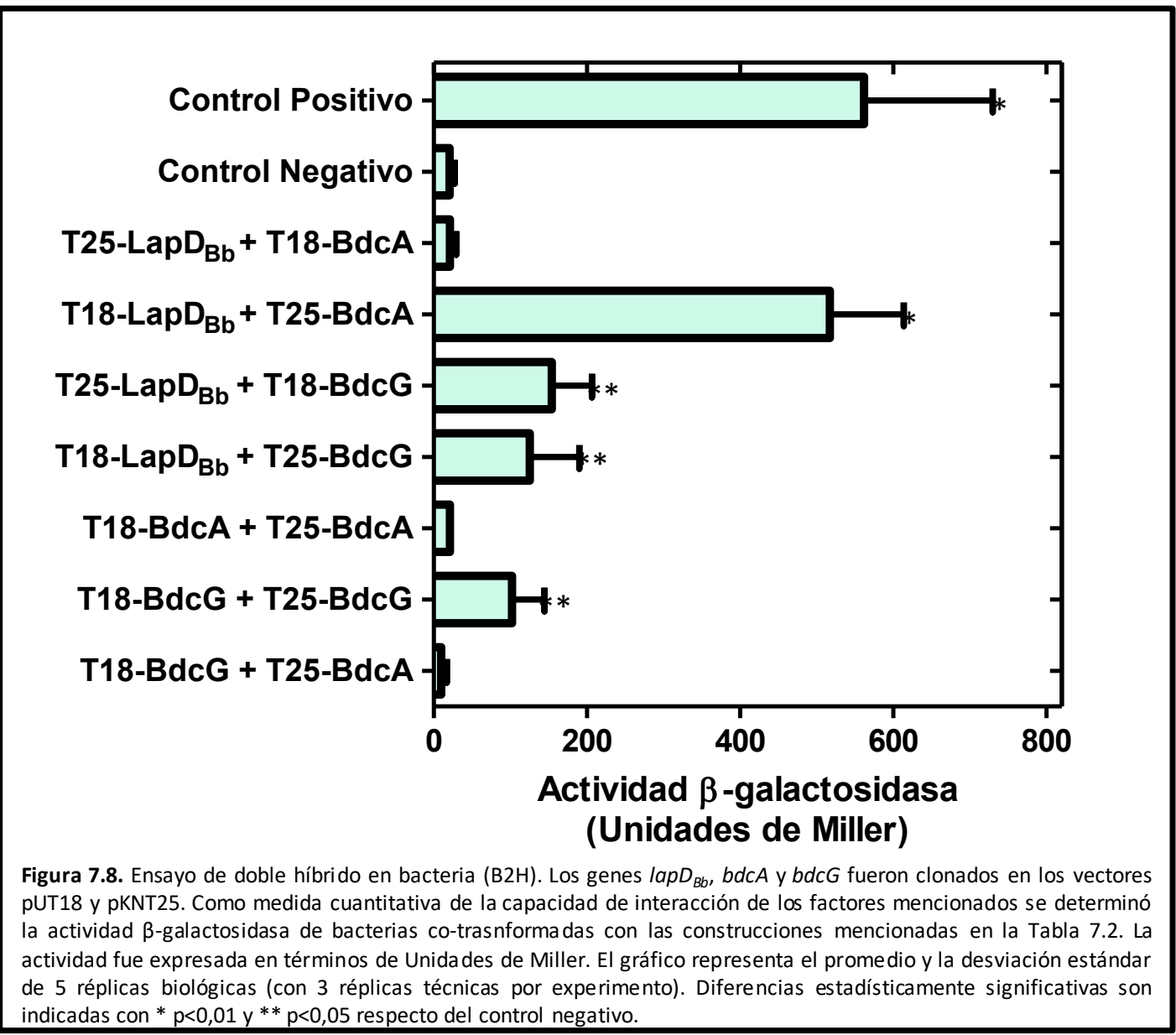

Por otro lado, como puede verse en la Figura 7.8, las dos combinaciones de fusiones transcripcionales utilizadas para evaluar la interacción entre $L_{a p} D_{B b}$ y $B d c G$ arrojan valores de UM significativamente mayores que el control negativo $(p<0,05)$.

Considerando la diferencia entre los valores de UM obtenidos para la interacción $\operatorname{LapD}_{\mathrm{Bb}}-B d c A$ y $\operatorname{LapD}_{\mathrm{Bb}}-B d c G$ nos preguntamos si esta última combinación podría estar arrojando un resultado "falso positivo". Consideramos la posibilidad de que la mera coexpresión de proteínas de membrana arroje valores de UM basales ligeramente superiores a los del control negativo. Para evaluar esta posibilidad utilizamos las fusiones T25-BdcA y T18-BdcG. Como puede verse en la Figura 7.6 la co-expresión de fusiones transcripcionales a BdcA y BdcG arrojó resultados de UM que no son significativamente diferentes a los del control negativo. Este resultado confirma que la actividad medida para el par $\mathrm{LapD}_{\mathrm{Bb}}-\mathrm{BdcG}$ no resulta de la simple co-expresión de proteínas de membrana, sino que da cuenta de una efectiva interacción entre las mencionadas proteínas.

Tal como destacan Giacalone et al. diferencias en valores de UM pueden reflejar diferencias de afinidad entre las proteínas evaluadas ${ }^{305}$. La diferencia encontrada entre los valores de UM para la interacción $\mathrm{LapD}_{\mathrm{Bb}}-\mathrm{BdcA}$ frente a los valores para la interacción 
$\mathrm{LapD}_{\mathrm{Bb}}-B d c G$ podría reflejar una diferencia en la afinidad de $\mathrm{LapD}_{\mathrm{Bb}}$ por $B d c A$ y $B d c G$. Este resultado podría indicar que, en las condiciones experimentales del ensayo de $B A C T H, L_{a p D}$ posee una afinidad mayor por BdcA que por BdcG.

$B d c G$, a diferencia de BdcA, es un factor que aún no ha sido estudiado en $B$. bronchiseptica. Para avanzar en la descripción de esta posible diguanilato ciclasa analizamos su capacidad de dimerización. Tal como puede apreciarse en la Figura 7.8 la combinación de fusiones transcripcionales T18-BdcG + T25-BdcG arroja valores significativamente mayores a los del control negativo $(p<0,05)$. Esto indicaría que BdcG sería capaz de dimerizar, condición que es necesaria para desarrollar actividad diguanilato ciclasa.

Los resultados de los experimentos de BACTH sugieren que LapD $D_{\mathrm{Bb}}$ interaccionaría tanto con la diguanilato ciclasa de membrana BdcA como con la posible diguanilato ciclasa de membrana BdcG.

\section{BdcG no presenta actividad diguanilato ciclasa en el modelo de doble híbrido en bacteria}

Tal como mencionamos antes, el sitio activo del dominio GGDEF de BdcG presenta aminoácidos que son compatibles con la actividad diguanilato ciclasa (Tabla 7.2). Con el objetivo de determinar si BdcG es una diguanilato ciclasa activa analizamos los niveles de c-di-GMP en el modelo de doble híbrido en bacteria.

Recientemente, Giacalone et al. demostraron que la interacción física entre $\operatorname{LapD}_{\mathrm{Pf}}$ y $\mathrm{GcbC}$ incrementa la actividad diguanilato ciclasa de esta última ${ }^{305}$. Nuestros experimentos de BACTH muestran BdcG interacciona físicamente con $\mathrm{LapD}_{\mathrm{Bb}}$. Por lo tanto, especulamos que la falta de actividad diguanilato ciclasa observada podría deberse a que BdcG debe interactuar con LapDBb para activarse y catalizar la síntesis de c-diGMP. Con el objetivo de evaluar si BdcG tiene actividad determinamos los niveles de cdi-GMP en la cepa BTH101 cotransformada con T18-LapD $\mathrm{Bb}_{\mathrm{Bb}}$ y T25-BdcG. Como control negativo de este experimento incluimos la cepa BTH101 cotransformada con plásmidos vacíos. Como control positivo de este experimento incluimos la cepa cotransformada con T18-LapD $D_{\mathrm{Bb}}+\mathrm{T} 25-\mathrm{BdcA}$. La determinación de la concentración de c-di-GMP fue realizada mediante cromatografía líquida acoplada a un espectrómetro de masa (LC-MS). 


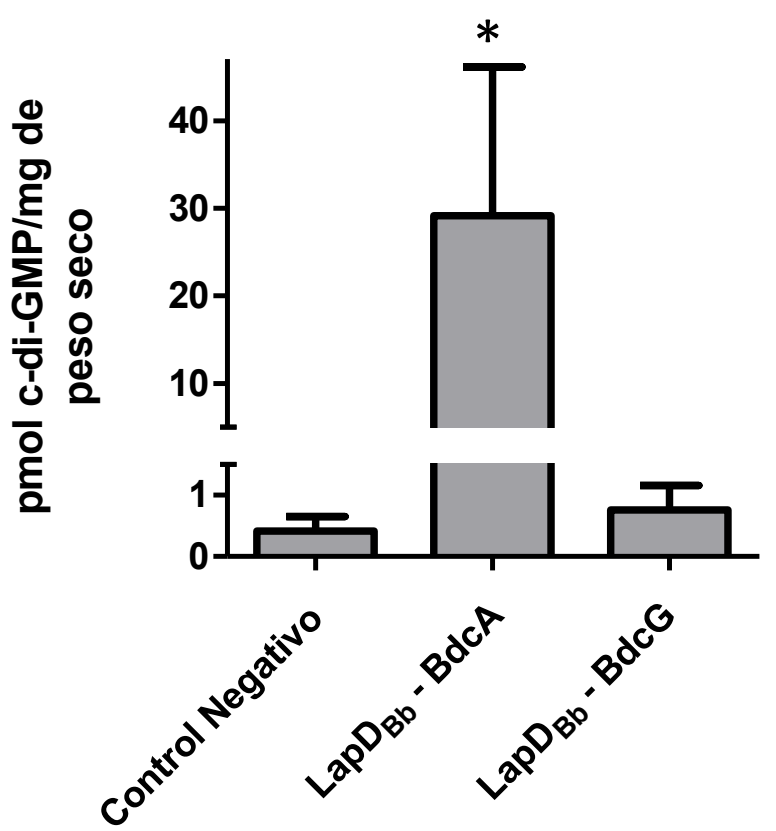

Figura 7.9. Cuantificación de c-di-GMP en el modelo de doble híbrido en bacteria (BACTH). Se determinó la cantidad de c-di-GMP en la cepa $E$. coli BTH101 co-transformada con las contracciones pUT18Zip+pKNT25ZIP (control negativo), pUT18-LapD $\mathrm{Bb}_{\mathrm{Bb}}+$ pKNT25-BdcA y pUT18-LapD $\mathrm{Bb}_{\mathrm{Bb}}+$ pKNT25-BdcG. El gráfico representa el valor promedio y la desviación estándar de 3 réplicas biológicas. * indica diferencia estadísticamente significativa respecto del control negativo, $p<0.01$.

Como se puede apreciar en la Figura 7.9, los niveles basales de c-di-GMP de la cepa BTH101 son suficientemente bajos como para poder determinar aumentos en la cantidad total de este segundo mensajero. La proteína BdcA incrementa los niveles de cdi-GMP en el entorno de la cepa BTH101 ( $p<0.01$ ). Esto, por un lado, corrobora que BdcA es una diguanilato ciclasa activa y por otro lado demuestra que el diseño experimental permite determinar aumentos en los niveles de c-di-GMP.

Por el contrario, la proteína BdcG no indujo un aumento en los niveles de c-diGMP. Por lo tanto, estos resultados no permiten confirmar si BdcG es una diguanilato ciclasa activa.

\section{BdcG regula la formación de biofilm en $B$. bronchiseptica}

Los experimentos realizados hasta el momento con BdcG ha sido todos de naturaleza heteróloga. BdcG fue sobreexpresada en $P$. fluorescens y en $E$. coli. Los resultados de esos experimentos no demuestran que BdcG pueda ser una diguanilato ciclasa activa. Frente a estos resultados consideramos la posibilidad de que para que BdcG desarrolle su actividad diguanilato ciclasa precise algún factor que está ausente en los organismos experimentales utilizados. Este factor podría bien ser una proteína que está ausente en $P$. fluorescens o $E$. coli o bien una señal ambiental que no se encuentra en las condiciones de cultivo de los organismos antes mencionados. 
Para avanzar en la descripción de BdcG y evaluar su posible actividad diguanilato ciclasa decidimos analizar los efectos de su sobreexpresión sobre la formación de biofilm en B. bronchiseptica. Como primer acercamiento realizamos experimentos de formación de biofilm en microplacas barriendo todo el rango de concentraciones de ácido nicotínico (0 mM - 4,0 mM). Como control de este experimento utilizamos la cepa B. bronchiseptica transformada con el plásmido vacío.

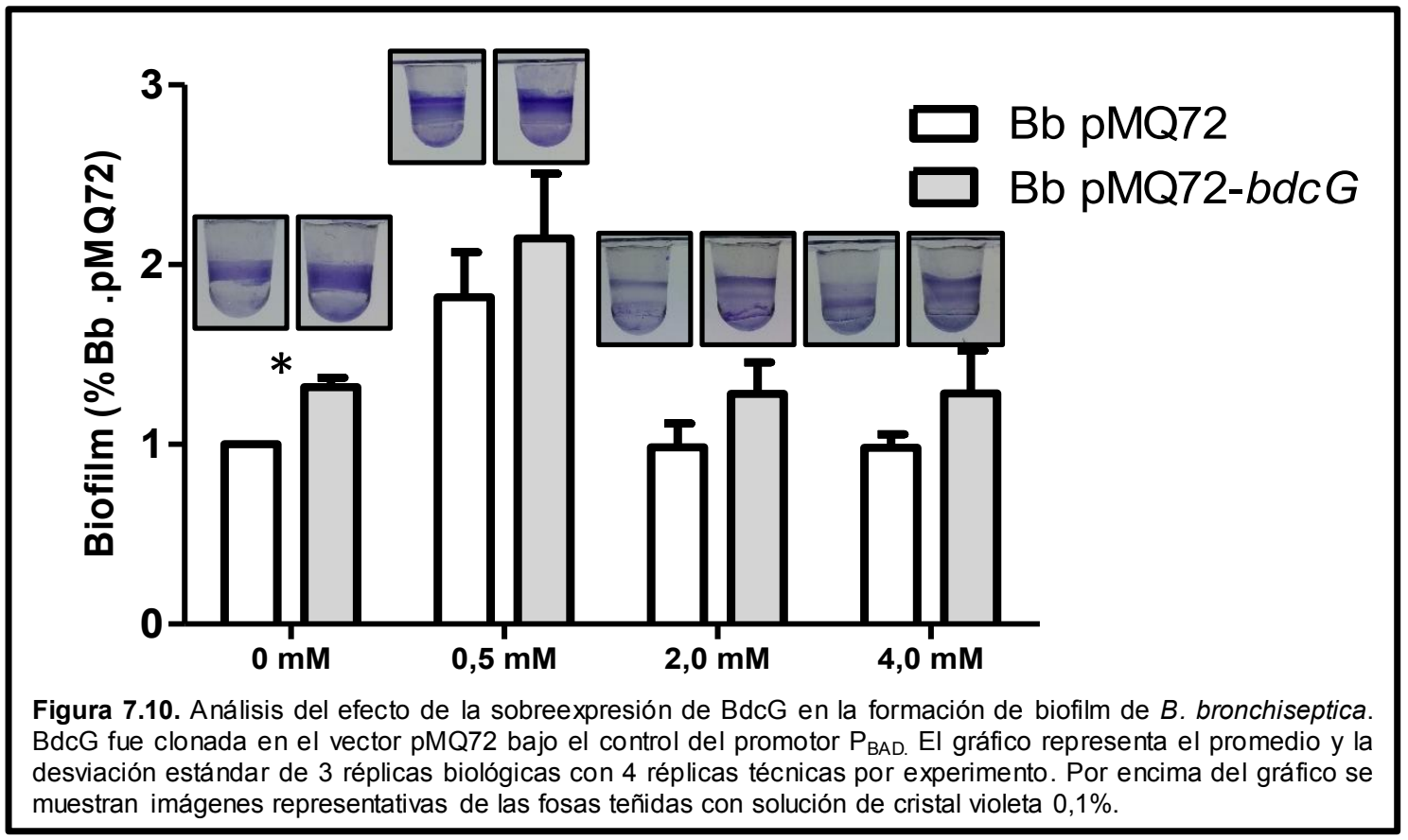

La Figura 7.10 muestra los resultados de la sobre expresión de BdcG en $B$. bronchiseptica. El análisis cuantitativo de estos resultados mostró diferencias significativas en la formación de biofilms entre las cepas en condiciones de cultivo de 0 $\mathrm{mM}$ de ácido nicotínico. Si embargo, el análisis visual de las fosas teñidas con cristal violeta sistemáticamente mostró diferencias en las características macroscópicas de los biofilms también en condiciones de cultivos con 2,0 mM y 4,0 mM de ácido nicotínico. La sobreexpresión de BdcG desde el plásmido multicopia pMQ72 indujo un aumento apreciable en la cantidad de biofilm formado en las condiciones de ácido nicotínico $0 \mathrm{mM}$, 2,0 mM y 4,0 mM.

El resultado obtenido indicaría que BdcG es un diguanilato ciclasa activa capaz de regular la formación de biofilm en $B$. bronchiseptica.

\section{Rol de BdcA y BdcG en la formación de biofilm}

Los resultados presentados hasta el momento sugieren que BdcA y BdcG interaccionan con $\mathrm{LapD}_{\mathrm{Bb}}$ de forma tal de alimentarla directamente con c-di-GMP. Esta 


\section{Capítulo 7}

señal sería transferida por $\operatorname{LapD}_{\mathrm{Bb}}$ al otro lado de la membrana plasmática en donde mantendría unida a $\mathrm{LapG}_{\mathrm{Bb}}$ previniendo así el desprendimiento de BrtA.

Según el modelo que estamos considerando ambas diguanilato ciclasas podrían estar involucradas en la formación de biofilm a través de $L_{a p D_{B b}}$. Si nuestro modelo es correcto, al eliminar el aporte de al menos una de ellas, LapD $_{\mathrm{Bb}}$ tendría menos C-di-GMP disponible y esto debería impactar de manera negativa en la formación de biofilm. En este contexto, $\operatorname{LapD}_{\mathrm{Bb}}$ no tendría suficiente c-di-GMP para mantener unida a $L_{a p G_{B b}}$ al otro lado de la membrana y ésta quedaría liberada para clivar a BrtA y desprenderla de la membrana externa. Si cada una de las diguanilato ciclasas hace un aporte al nivel total de c-di-GMP es esperable que la deleción de una sola de ellas no genere una reducción total en la formación de biofilm. Por ende, esperaríamos que la deleción de ambas diguanilato ciclasas genere un defecto mayor al de cada una de ellas por separado. A fin de contrastar esta hipótesis analizamos la capacidad de formación de biofilm de las cepas B. bronchiseptica $\triangle b d c A, \Delta b d c G$ y el doble mutante $\triangle b d c A \Delta b d c G$.

Para el desarrollo de este experimento analizamos la formación de biofilm en diferentes superficies (microplaca, vidrio y plástico). Considerando que el rol de BrtA se aprecia sustancialmente mejor en el medio de cultivo suplementado con BSA y $\mathrm{Ca}^{+2}$ (Capítulo 6, Figura 6.5) los efectos de las deleciones de $b d c A$ y $b d c G$ fueron analizados en estas condiciones de cultivo. A modo de control también incluimos a la cepa $\triangle b r t A$ en el análisis.

En la Figura 7.11.a se muestran imágenes representativas de los resultados obtenidos en los experimentos de formación de biofilm en microplacas. En estas imágenes se puede apreciar, tal como describimos en el Capítulo 6 (Figura 6.5) que, en estas condiciones de cultivo la deleción de brtA reduce la formación de biofilm. El análisis cuantitativo del biofilm formado por esta cepa también muestra diferencias estadísticamente significativas con respecto a la cepa salvaje (Figura 7.11.b). El análisis de los resultados de formación de biofilm de las cepas mutantes nuevamente muestra que el procesamiento cuantitativo de estos experimentos no siempre se correlaciona con lo observado de manera directa. El análisis de las fosas teñidas con cristal violeta en todos los experimentos mostró una reducción en la cantidad de biofilm de las cepas $\triangle b d c A$ y $\triangle b d c A \triangle b d c G$ con respecto a la cepa salvaje. Sin embargo, también se observa que estas cepas presentan un cantidad de biofilm mayor que la cepa $\triangle b r t A$. Por otro lado, el biofilm formado por la cepa $\Delta b d c G$ no presentó ninguna diferencia respecto de la cepa salvaje. 


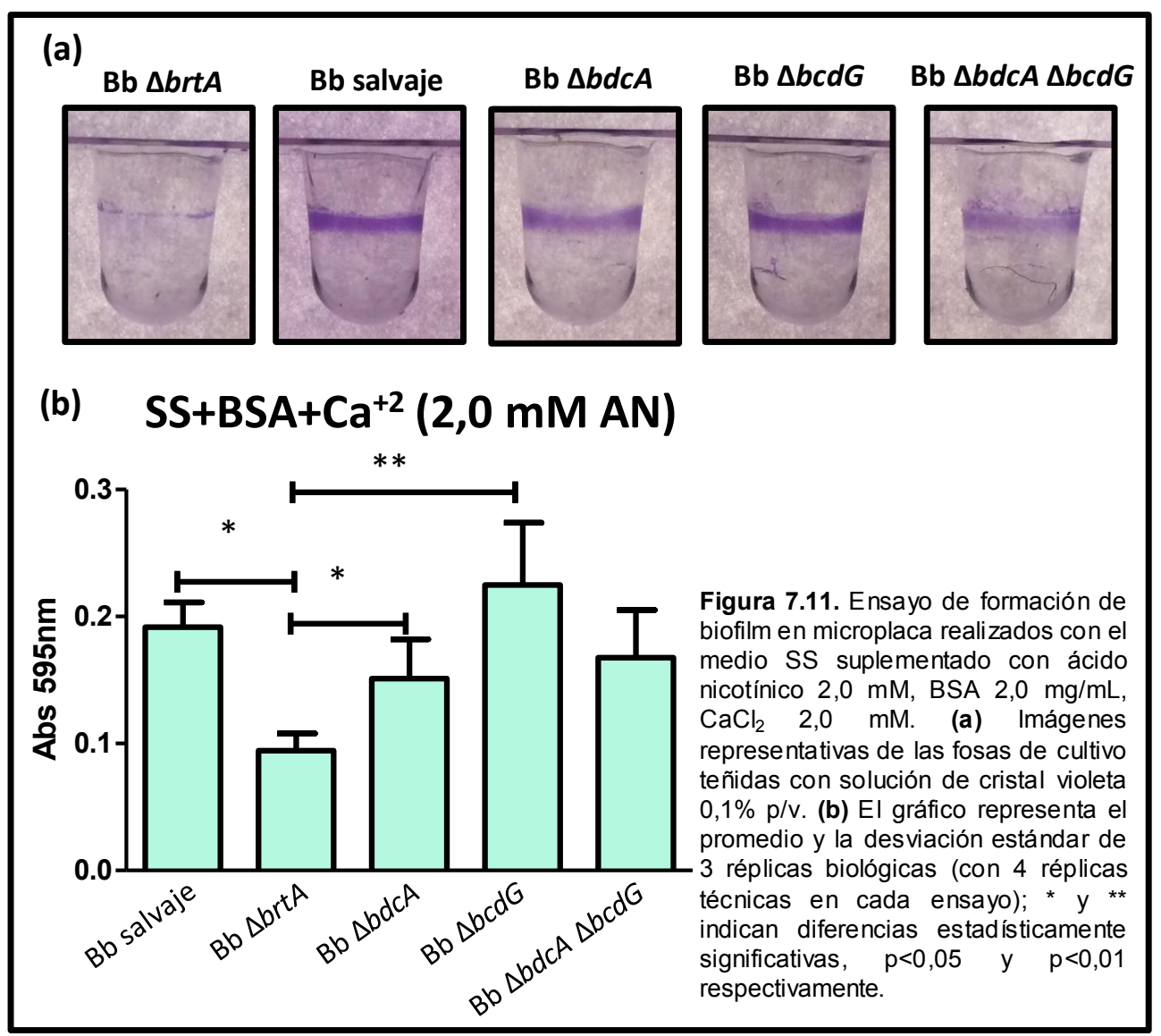

La capacidad de formación de biofilm de estas cepas también fue analizada en ensayos sobre superficies de vidrio y plástico. En la Figura 7.12 pueden verse imágenes representativas de los experimentos de formación de biofilm sobre vidrios semi sumergidos en cultivos realizados dentro de tubos de microcentrífuga de plástico.

Como puede verse en la Figura 7.11 la cepa salvaje forma un biofilm bien definido sobre la interfase entre en aire y la suspensión bacteriana (tanto en vidrio como en plástico). Como destacamos previamente, en el caso del vidrio se distingue una región densamente coloreada y una región menos teñida inmediatamente por debajo de ésta. La deleción de $b r t A$, tal como describimos anteriormente impacta en la formación de biofilm disminuyendo su cantidad en ambas regiones. La deleción de bdcA genera una reducción en la formación de biofilm mucho más grande que la reducción que había sido destacada en el experimento en microplacas. Por el contrario, la deleción de bdcG no genera defectos en la formación de biofilm en comparación a la cepa salvaje. 


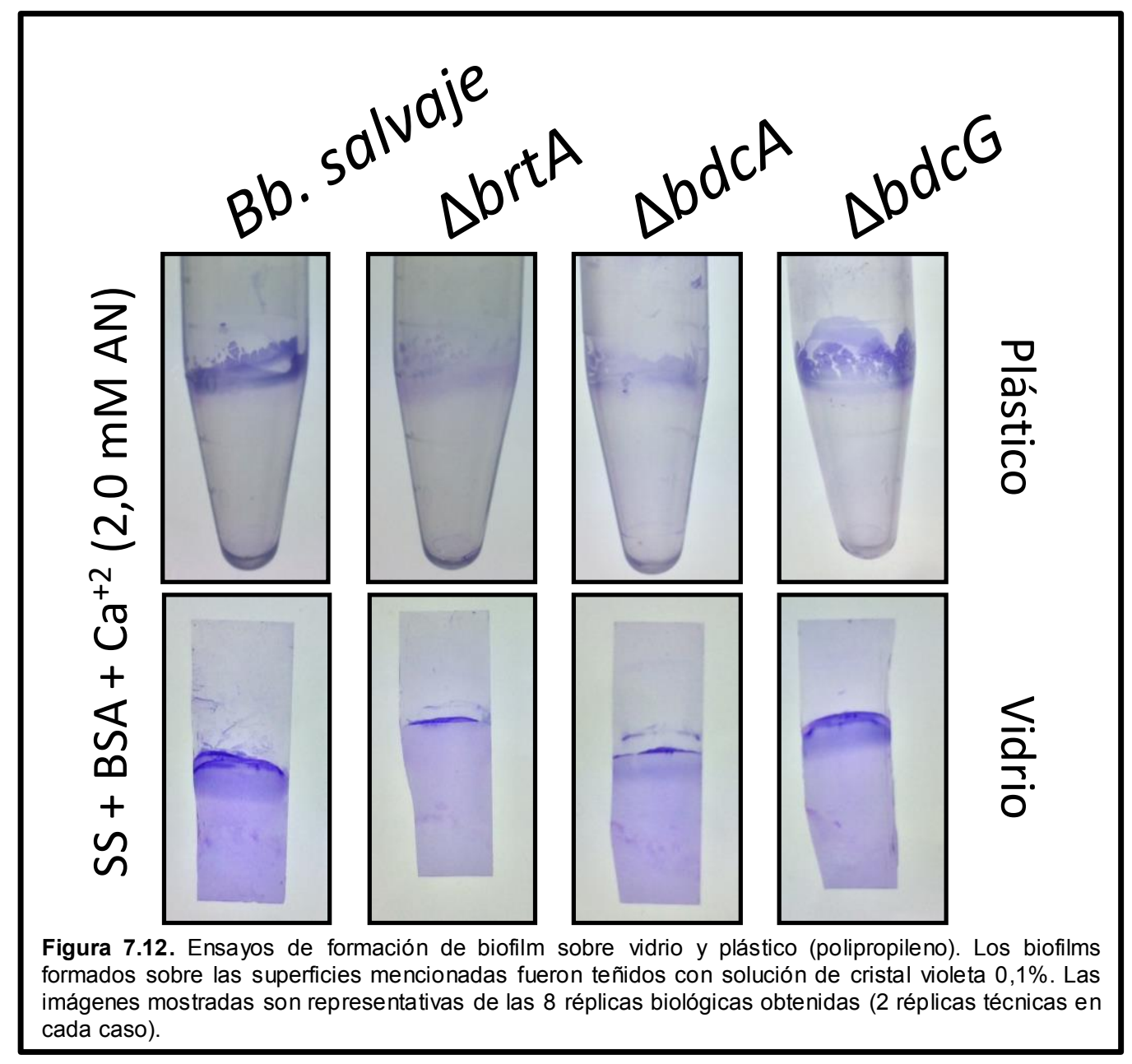

\section{BdcA regula la localización de BrtA}

En las secciones anteriores demostramos, en primer lugar, que $L_{a p D} D_{B b}$ interacciona físicamente con las diguanilato ciclasas BdcA y BdcG. En segundo lugar, analizamos el impacto sobre la formación de biofilm de las deleciones individuales de $b d c A$ y $b d c G$, así como también la deleción simultánea de ambos genes. El defecto en la formación de biofilm que presenta la cepa $\triangle b d c A$ es esperable que se deba a una disminución en la cantidad de BrtA localizada en la membrana plasmática.

Con el objetivo de analizar el impacto de esas deleciones sobre la cantidad de BrtA en la membrana plasmática, utilizamos el ensayo de dot blot presentado previamente. Para este experimento realizamos cultivos suplementados con $\mathrm{BSA}$ y $\mathrm{Ca}^{+2}$ y una concentración de ácido nicotínico de 2,0 mM ya que se trata de la condición en la cual el efecto de la deleción fue más significativo. A modo de control incluimos la cepa $\triangle l a p G$ que, de acuerdo con los resultados presentados a lo largo de este trabajo debería presentar una mayor cantidad de BrtA en membrana. La cepa $\triangle / a p D$ que debería poseer menor cantidad de BrtA en membrana también fue utilizada como control. 
Adicionalmente, se incluyó como control interno del experimento la cepa $\Delta b r t A$ no marcada con la fusión transcripcional de hemaglutinina. Esta cepa se utilizó como control de los niveles basales de reconocimiento de los anticuerpos utilizados.

El procesamiento y análisis de la muestra fue realizado de manera idéntica a como fuera presentado anteriormente en este trabajo, pero las imágenes fueron registradas utilizando un equipo Odyssey CLx (LI-COR).

Figura 7.13. Ensayo de dot blot. Este ensayo se utilizó para determinar la cantidad de BrtA-HA localizada sobre la membrana plasmática en mutantes de las proteínas Lap de $B$. bronchiseptica y en las posibles diguanilato ciclasas que podrían regular el sistema. Para el revelado del dot blot se utilizaron anticuerpos específicos anti-HA. Para el revelado se utilizó un equipo Odyssey CLx (LI-COR). Para la cuantificación de los resultados se utilizó el programa Image $\mathrm{J}$ y se determinó la densidad integrada de cada mancha. El promedio de cada cepa de cada ensayo fue normalizado respecto al valor obtenido para la cepa salvaje en ese mismo experimento. El gráfico representa el promedio y la desviación estándar de 3 réplicas biológicas ( 5 réplicas técnicas por experimento).

* indica diferencia estadísticamente significativa respecto de la cepa $B$. bronchiseptica salvaje $(p<0,01)$.

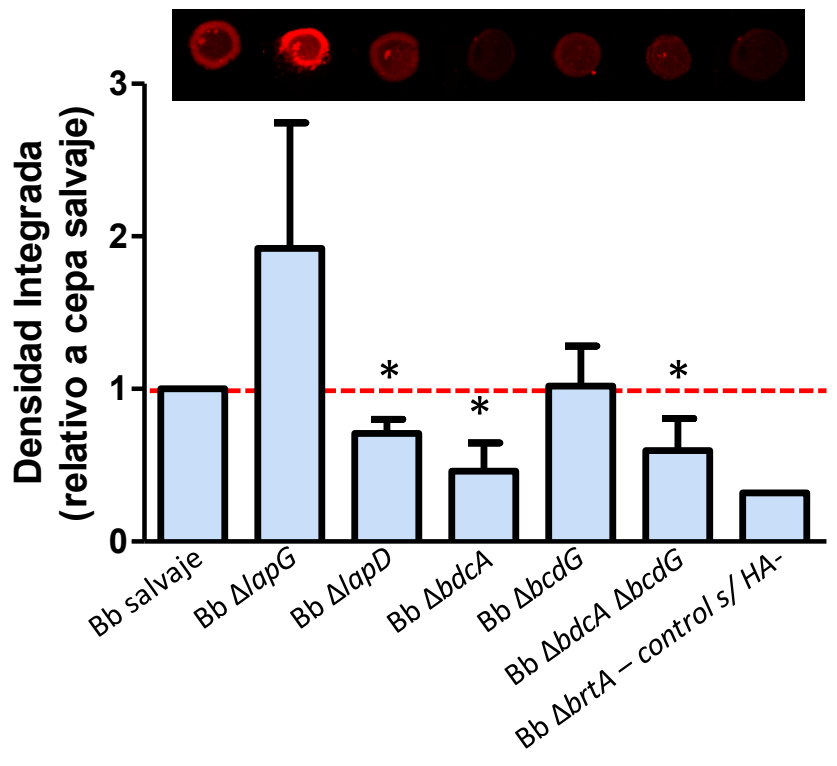

La Figura 7.13 muestra los resultados obtenidos de los experimentos de dot blot realizados a fin de determinar el rol de $b d c A$ y $b d c G$ en la localización de la adhesina BrtA. En las condiciones de este experimento, la intensidad de la coloración roja es directamente proporcional a la cantidad de BrtA localizada sobre la membrana plasmática. Los resultados muestran que la cepa $\Delta b r t A$ (que no posee marca de hemaglutinina) presenta una intensidad casi imperceptible lo cual indica que el anticuerpo utilizado no presenta reactividad cruzada con otros componentes de la membrana plasmática. El análisis del resultado de la cepa $\triangle / a p G$ muestra un aumento en la intensidad indicando un incremento en la cantidad de BrtA localizada en membrana en esta cepa. En sentido contrario, y tal como esperábamos, la cepa $\Delta / a p D$ presenta una intensidad significativamente inferior a la de la cepa salvaje $(p<0,05)$. Esto confirma que la deleción de $\operatorname{lap} D$ conduce a una reducción en la cantidad de BrtA en membrana.

Los resultados de las deleciones de las diguanilato ciclasas muestran que sólo la deleción de $b d c A$ tuvo consecuencias sobre la intensidad observada. La cepa $\Delta b d c A$ presenta una intensidad significativamente menor que la cepa salvaje $(p<0,05)$ indicando una reducción en la cantidad de BrtA en membrana. Contrariamente, la deleción de bdcG 


\section{Capítulo 7}

no repercutió significativamente sobre la intensidad de las manchas indicando que esta deleción no altera la localización de brtA en las condiciones de este ensayo. Asimismo, la doble deleción de $b d c A$ y $b d c G$ presenta diferencias significativas respecto de la cepa salvaje. A la luz de los resultados de este mismo experimento, esta diferencia podría estar originada exclusivamente por la deleción de $b d c A$.

Estos resultados constituyen una evidencia de que en las condiciones experimentales desarrolladas BdcA, pero no BdcG regula la localización de BrtA.

\section{Conclusiones y discusión}

Los resultados previos al inicio de este capítulo demuestran que B. bronchiseptica posee un sistema de proteínas asociado a la regulación de la formación de biofilm análogo al sistema Lap de $P$. fluorescens. Previamente demostramos que las secuencias BB1184, BB1185 y BB1186 codifican para LapD, LapG y BrtA en B. bronchiseptica. En el capítulo final de esta tesis, realizamos el análisis del rol del segundo mensajero c-diGMP en el control de este grupo de proteínas.

En primer lugar, evaluamos la hipótesis de que $L_{a p D} D_{B b}$ es un factor necesario para la regulación de la formación de biofilm a través de c-di-GMP. Los resultados mostraron que en presencia de 2,0 mM de ácido nicotínico la sobreexpresión de la diguanilato ciclasa BdcA en el entorno de la cepa $\triangle l a p D$ no fue capaz de inducir un aumento en los niveles de biofilm como lo hace en la cepa salvaje. Esto confirmaría que en esta condición el sistema Lap sería el principal sistema de regulación de la formación de biofilm a través de c-di-GMP. En otras condiciones de cultivo los resultados obtenidos fueron diferentes. En 0,5 mM de ácido nicotínico la sobreexpresión de BdcA generó aumentos en la formación de biofilm tanto en la cepa salvaje como en la cepa $\Delta / a p D$. Por un lado, este resultado confirma que en esta condición existen mecanismos de regulación de la formación de biofilm mediados por c-di-GMP ${ }^{224}$. Por otro lado, sugiere que esos mecanismos serían independientes de $\operatorname{LapD}_{\mathrm{Bb}}$. Como conclusión de esta parte del capítulo, demostramos que $\mathrm{LapD}_{\mathrm{Bb}}$ es importante para la formación de biofilm en las mismas condiciones en las que previamente habíamos demostrado que el rol de LapG y BrtA era más importante.

Posteriormente nos enfocamos en la búsqueda de diguanilato ciclasas involucradas de manera directa en la regulación de la formación de biofilm a través de LapD, LapG y BrtA. En primer lugar, realizamos un análisis in sílico del genoma de $B$. bronchiseptica en búsqueda de secuencias con dominios GGDEF que pudieran codificar para diguanilato ciclasas. Utilizando dos estrategias diferentes, el análisis arrojó como resultado la presencia de 14 secuencias con dominios GGDEF en el genoma de $B$. 
bronchiseptica RB50 (Tabla 7.1). No resulta sorprendente que muchas de estas secuencias presenten, además del dominio GGDEF, dominios asociados involucrados en la unión a ligandos (PAS, GAF, CACHE, etc.). Esto permite inferir que, en $B$. bronchiseptica, la red de regulación a través de c-di-GMP está involucrada en la trasducción de señales ambientales en respuestas fisiológicas ${ }^{306}$. El número de posibles diguanilato ciclasas codificadas en el genoma de B. bronchiseptica da cuenta de la existencia de un sofisticado mecanismo de control en torno a los procesos regulados por este segundo mensajero.

En particular nuestro objetivo se direccionó hacia la búsqueda de aquella o aquellas diguanilato ciclasas involucradas en la regulación de la formación de biofilm a través de las proteínas Lap. En la bacteria Pectobacterium atrosepticum, las secuencias codificantes para proteínas Lap se encuentran cerca de la secuencia codificante de la diguanilato ciclasa ECA3270 265 . Por el contrario, en el genoma de B. bronchiseptica, al igual que en $P$. fluorescens o $P$. putida, no hay secuencias codificantes para proteínas GGDEF en las cercanías de las secuencias lapD, lapG y brtA. De esta manera descartamos la cercanía en el genoma como un criterio de elección para una posible diguanilato ciclasa involucrada en el control de las proteínas Lap.

Con el objetivo de buscar un método que nos permitiera analizar el mayor número de secuencias posible, desarrollamos una estrategia de expresión heteróloga. Esta estrategia se basó en la expresión de proteínas con dominios GGDEF de $B$. bronchiseptica en la cepa $P$. fluorescens $\triangle 4 D G C$ en la cual reemplazamos la LapD propia de $P$. fluorescens por la LapD de $B$. bronchiseptica. Nuestra hipótesis sostenía que sólo aquellas diguanilato ciclasas que fueran capaces de interaccionar correctamente con $\mathrm{LapD}_{\mathrm{Bb}}$ generarían un aumento en la formación de biofilm semejante al que produce la diguanilato ciclasa de $P$. fluorescens $G c b C$ en la cepa $\triangle 4 D G C$. Como resultado de estos experimentos no logramos encontrar una proteína que indujera aumentos en la formación de biofilm como los que esperábamos.

Navarro et al. demostraron que la interacción entre $L a p D_{P f}$ y $L a p G_{P f}$ depende del motivo $G W x Q$ localizado en la porción periplasmática de $\operatorname{LapD}_{\mathrm{Pf}^{139}}$. El residuo de triptófano $(W)$ de este motivo es parte de una superficie que se encuentra expuesta al periplasma y accesible a LapG pf $_{\text {cuando }}$ LapDPf une c-di-GMP al otro lado de la membrana ${ }^{139}$. Tal como demostramos en el Capítulo 2, LapD $_{\mathrm{Bb}}$ tiene conservado el motivo GWxQ. Sin embargo, en este capítulo encontramos que la zona adyacente al motivo $G W x Q$ es diferente en $L_{a p D}$ y $L_{\text {Ba }} D_{\mathrm{Pf}}$. Una interacción poco eficiente entre $\operatorname{LapD}_{\mathrm{Bb}}$ y LapG $\mathrm{Pf}_{\mathrm{f}}$ podría explicar el hecho de que ninguna proteína GGDEF fue capaz de generar grandes aumentos en la formación de biofilm en $P$. fluorescens (Figura 7.4). Una manera de superar este obstáculo y poder utilizar este sistema como método de análisis 


\section{Capítulo 7}

para diguanilato ciclasas de $B$. bronchiseptica podría ser reemplazar la porción periplasmática de $\operatorname{LapD}_{\mathrm{Bb}}$ por la de $\mathrm{LapD}_{\mathrm{Pf}}$ de manera tal de no comprometer la interacción LapD-LapG. Este diseño experimental será evaluado en el futuro para poder realizar un análisis de todas las diguanilato ciclasas de $B$. bronchiseptica.

Otras posibles explicaciones al resultado de este experimento podrían ser que la interacción entre $\mathrm{LapD}_{\mathrm{Bb}}$ y las diguanilato ciclasas o bien la activación misma de la enzima precise de algún factor que no esté presente en $P$. fluorescens. Otro escenario posible sería que $L a p D_{B b}$ no esté presente en la misma cantidad que $L a p D_{P f}$. Si bien la secuencia $l a p D_{B b}$ fue clonada bajo el promotor nativo de $l a p D_{P f}$, podría suceder que $L_{a p} D_{B b}$ fuera menos estable que $L_{a p} D_{\text {Pf }}$ y por ende hubiera menor cantidad de la proteína heteróloga.

Frente a la gran cantidad de incógnitas que podrían explicar el resultado obtenido decidimos abandonar esta estrategia y buscar métodos alternativos para avanzar en la búsqueda de diguanilato ciclasas que regularan el sistema Lap en $B$. bronchiseptica.

Para avanzar en nuestra búsqueda de diguanilato ciclasas involucradas en la regulación de la formación de biofilm a través de LapD en $B$. bronchiseptica nos propusimos un abordaje bioinformático para buscar candidatos a interaccionar con la hélice- $\alpha$ del dominio $E A L$ de $\operatorname{LapD}_{\mathrm{Bb}}$. Con este objetivo modelamos los dominios GGDEF de todas las posibles diguanilato ciclasas de membrana que habíamos encontrado previamente. Como resultado de este análisis encontramos que el domino GGDEF de BdcG presentaba una forma y distribución de carga compatible con la interacción con el dominio $E A L$ de $\operatorname{LapD}_{\mathrm{Bb}}$.

BdcA fue otra diguanilato ciclasas analizada debido a que presenta una estructura de dominios igual a GcbC de P. fluorescens.

Los resultados de los experimentos de BACTH confirmaron que tanto BdcA como BdcG son capaces de interaccionar físicamente con $\operatorname{LapD}_{\mathrm{Bb}}$. La diferencia en magnitud en los valores de actividad $\beta$-galactosidasa de la interacción $\operatorname{LapD}_{\mathrm{Bb}}-\mathrm{BdcA}$ y $\operatorname{LapD}_{\mathrm{Bb}}-B d c G$ podrían dar cuenta de una diferente afinidad entre las proteínas mencionadas en las condiciones analizadas.

A partir de los resultados de BACTH surgió la necesidad de demostrar si BdcG presentaba actividad diguanilato ciclasa. En experimentos de expresión heteróloga no fue posible demostrar que BdcG fuera una diguanilato ciclasa activa (Figuras 7.6 y 7.9 ), sin embargo, los experimentos de sobreexpresión en $B$. bronchiseptica sí lo sugieren (Figura 7.10). La sobreexpresión de BdcG indujo un leve aumento en la formación de biofilm en condiciones de cultivo con $0 \mathrm{mM}, 2,0 \mathrm{mM}$ y 4,0 $\mathrm{mM}$ de ácido nicotínico. Esto indicaría que en $B$. bronchiseptica BdcG sí es una diguanilato ciclasa activa.

A partir de los resultados de BACTH surgió la necesidad de demostrar si BdcG presentaba actividad diguanilato ciclasa. En experimentos de expresión heteróloga no 
fue posible demostrar que BdcG fuera una diguanilato ciclasa activa (Figuras 7.4 y 7.9 ), sin embargo, los experimentos de sobreexpresión en $B$. bronchiseptica sí lo sugieren (Figura 7.9). La sobreexpresión de BdcG indujo un leve aumento en la formación de biofilm en condiciones de cultivo con $0 \mathrm{mM}, 2,0 \mathrm{mM}$ y 4,0 mM de ácido nicotínico. Esto indicaría que en $B$. bronchiseptica BdcG sí es una diguanilato ciclasa activa.

Dado que BdcG y BdcA son diguanilato ciclasas activas en $B$. bronchiseptica y que interaccionan con $\mathrm{LapD}_{\mathrm{Bb}}$, postulamos que la presencia de BrtA en membrana externa se encuentra regulada por la actividad de ambas enzimas. Así, ante alguna señal aún desconocida, BdcG y BdcA generarían c-di-GMP que se uniría a $\operatorname{LapD}_{\mathrm{Bb}}$ evitando que BrtA sea clivada y liberada al medio extracelular. De esta manera $B$. bronchiseptica en estas condiciones formaría biofilm. Por el contrario, en ausencia de actividad diguanilato ciclasa por parte de estas enzimas, BrtA sería clivada por LapG $_{\mathrm{Bb}}$ y $B$. bronchiseptica no formaría biofilm. Si el modelo es correcto, la deleción de bdcA o bdcG debería inducir un fenotipo similar al de situaciones de baja actividad de las enzimas como por ejemplo la disminución en la formación de biofilm.

La observación directa de los biofilms formados sobre vidrio y en tubos de microcentrífuga muestra una clara reducción en la capacidad de formación de biofilm como consecuencia de la deleción de $b d c A$. La deleción de $b d c G$, por el contrario, no generó defectos en la formación de biofilm en ninguna de las condiciones evaluadas. Asimismo, al evaluar el impacto de estas deleciones sobre la localización de BrtA se vio que, mientras que la cepa $\triangle b d c A$ presentó una cantidad menor de BrtA en membrana la cepa $\Delta b d c G$ no presentó alteraciones.

Este resultado plantea la incógnita de cuál es el rol de BdcG en el mecanismo de regulación de las proteínas Lap. La Figura 7.9 muestra que la sobreexpresión de BdcG generó cambios en las características macroscópicas del biofilm en 2,0 mM y 4,0 mM de ácido nicotínico. Si bien sabemos que en estas condiciones las proteínas Lap son importantes para la regulación de la formación de biofilm a través de c-di-GMP (Figura 7.1), no podemos asegurar que ese aumento de biofilm sea a través de LapD, LapG y BrtA. Para demostrar esto sería importante sobre expresar BdcG en el entorno de la cepa B. bronchiseptica $\triangle l a p D$. Si el aumento observado en la formación de biofilm en la Figura 7.9 es a través de LapD, en esta cepa no deberíamos ver ese aumento. Asimismo, también será importante introducir una mutación puntual en el sitio activo de BdcG a fin de confirmar que el aumento en la formación de biofilm se da como consecuencia de su actividad diguanilato ciclasa.

Las herramientas bioinformáticas utilizadas no nos permitieron determinar si BdcG presenta otros dominios además del dominio GGDEF. El alineamiento de la secuencia aminoacídica de BdcG contra toda la base de datos de proteínas de NCBI, no 


\section{Capítulo 7}

nos llevó a resultados que nos permitieran avanzar en la caracterización de esta proteína. Dado que las proteínas del metabolismo de c-di-GMP suelen participar de mecanismos de transducción de señales, es posible que BdcG sense alguna señal que no está presente en las condiciones de cultivo en las que fueron realizados los experimentos. Esto podría explicar el hecho de que, si bien BdcG interacciona con $\operatorname{LapD}_{\mathrm{Bb}}$ en el entorno de BACTH, la sobreexpresión en B. bronchiseptica sólo generó un leve aumento en la formación de biofilm. Giacalone et al. demostraron que GcbC aumenta su actividad y afinidad por $L_{a p D} D_{P f}$ en presencia de citrato ${ }^{143}$. Por lo tanto, BdcG también podría necesitar una señal específica para aumentar su actividad. Asimismo, en este contexto cabe destacar que el resultado que demuestra que BdcG interacciona con $L_{a p D}$ Bb fue realizado en un sistema heterólogo (la cepa E. coli BTH101). Este resultado no nos permite asegurar que en las condiciones en las que realizamos nuestros experimentos con $B$. bronchiseptica $\operatorname{LapD}_{\mathrm{Bb}}$ y $B d c G$ efectivamente interaccionen. No podemos descartar que la interacción entre $\operatorname{LapD}_{\mathrm{Bb}}$ y $B d c G$ se produzca en condiciones que no fueron reproducidas en nuestros experimentos y por ese motivo no logramos demostrar que BdcG influya en la localización de BrtA. En este sentido, Dahlstrom et al., recientemente publicaron un análisis generalizado del rol de todas las proteínas GGDEF de $P$. fluorescens en presencia de 188 nutrientes diferentes ${ }^{124}$. Este trabajo demuestra que mientras la deleción de una diguanilato ciclasa especifica puede no generar consecuencias en una determinada condición, la misma deleción puede ser crítica simplemente modificando la fuente de carbono o nitrógeno del medio de cultivo. EI mencionado trabajo, también muestra que la deleción de la gran mayoría de las proteínas GGDEF de $P$. fluorescens presenta defectos en la formación de biofilm en alguna de las condiciones de cultivo estudiadas ${ }^{124}$. Considerando que ese trabajo incluyó el análisis de 188 condiciones diferentes, esto da cuenta de lo sofisticada y finamente regulada que está la red de regulación a través de c-di-GMP.

En conclusión, a lo largo de este capítulo hemos presentado evidencia que sustenta la hipótesis de que c-di-GMP regula la formación de biofilm a través de las proteínas Lap en $B$. bronchiseptica. Hemos profundizado en detalles mecanísticos de este proceso y determinado que las diguanilato ciclasas BdcA y BdcG interaccionan físicamente con $L_{a p D} D_{B b}$. Asimismo, demostramos que en las condiciones experimentales utilizadas BdcA controla la localización de BrtA y así regula la formación de biofilm. Finalmente, el hecho de que la cepa $B$. bronchiseptica $\triangle b d c G$ no haya presentado diferencias en comparación a la cepa salvaje no implica que esta proteína no sea relevante en la fisiología de esta bacteria, sino que será necesario buscar alternativas experimentales para encontrar alguna condición en la que sí sea importante. 


\section{Capítulo 8}

Conclusiones generales 



\section{Conclusiones generales}

Los trabajos de Irie et al. y Misrha et al. publicados casi en simultáneo en los años 2004 y 2005 dieron el puntapié inicial para el estudio de la formación de biofilm en bacterias del género Bordetella ${ }^{197,223}$. Desde ese momento diversos grupos de investigación han descripto el rol de adhesinas, exopolisacáridos, ADN extracelular y otros componentes en la formación de biofilm ${ }^{227,230,236,240,307,308}$ pero ninguno se ha enfocado en el estudio de los mecanismos de señalización interna que dirigen estos procesos. En el año 2013 nuestro grupo de investigación publicó un artículo en el cual se describió el rol del segundo mensajero c-di-GMP en la regulación de la formación de biofilm y movilidad de $B$. bronchiseptica. En ese trabajo se demostró que el aumento en los niveles de c-di-GMP generados por la sobre expresión de la diguanilato ciclasa BdcA generaba un aumento en la formación de biofilm y una reducción en la movilidad de $B$. bronchiseptica $^{224}$. Los resultados de ese trabajo constituyen la primera evidencia del rol de este segundo mensajero en la biología de esta bacteria y sentó las bases para el comienzo de este trabajo de Tesis Doctoral. Este proyecto surgió con el objetivo de determinar cuáles eran los mecanismos moleculares que se encontraban detrás de la regulación de la formación de biofilm descripta por Sisti et al. ${ }^{224}$.

Diversos trabajos han demostrado la capacidad de bacterias del género Bordetella de formar biofilm in vivo ${ }^{201,207,236,307}$. Además, diversos autores postulan que esta habilidad estaría asociada a la capacidad de las especies de este género de persistir en sus huéspedes durante largos períodos de tiempo $197,223,227,232,307$. Frente a este contexto, el estudio de los mecanismos moleculares que dirigen la formación de biofilm a través de c-di-GMP puede aportar herramientas para comprender procesos vitales de la patogénesis de estas bacterias.

La búsqueda inicial de qué factores podrían estar detrás del proceso de regulación mediado por c-di-GMP nos llevó hasta un grupo de genes cuyo rol en la formación de biofilm estaba bien estudiado en otras bacterias. Las secuencias BB1184, BB1185 y BB1186 presentaban características estructurales y de secuencia compartidas con LapD, LapG y LapA de $P$. fluorescens. A través de un plan de investigación que combinó el uso de herramientas de microbiología, biología molecular y bioinformática logramos determinar que los genes encontrados corresponden a la adhesina BrtA, la proteasa LapG y el sensor de c-di-GMP LapD en B. bronchiseptica.

El sistema de dos componentes BvgAS constituye el regulador maestro de muchos de los factores de virulencia en Bordetella ${ }^{144}$. Asimismo, los trabajos pioneros de Irie et al. y Mishra et al. demostraron que la formación de biofilm está controlada por el sistema BvgAS ${ }^{197,223}$. Frente a esta evidencia, resultaba indispensable abordar el estudio 
de las proteínas Lap en relación con sistema BvgAS. Por este motivo, para el desarrollo de los experimentos utilizamos condiciones de cultivo que abarcaban todas las fases de virulencia de $B$. bronchiseptica.

Nuestros resultados indican que las proteínas Lap de B. bronchiseptica serían el mecanismo de regulación de biofilm a través de c-di-GMP más importante en condiciones de cultivo en las que no se expresan los factores de virulencia vag. Este resultado sugiere que las proteínas Lap podrían tener un rol fundamental en la formación de biofilm en condiciones en las que el sistema de dos componentes se encuentra modulado. Históricamente se ha considerado que la fase avirulenta (Bvg-) de Bordetella (aquella en la cual el sistema BvgAS está modulado) no es necesaria durante el proceso de infección ${ }^{173}$. Los primeros estudios con cepas bloqueadas en fase Bvg+ y Bvgdemostraron que la fase Bvg+ es necesaria y suficiente para el desarrollo de infecciones mientras que el bloqueo en fase Bvg- resulta perjudicial para el establecimiento de la infección ${ }^{173}$. El modelo tradicional considera a la fase Bvg+ como la fase en la cual la bacteria se encontraría in vivo y a la fase Bvg- como la condición en la que la bacteria se encontraría en el ambiente ${ }^{144}$. Sin embargo, en los últimos años se ha presentado evidencia que pone en jaque el antiguo concepto de que la fase Bvg- no es necesaria durante la infección. En estudios recientes se ha demostrado que algunos genes fase avirulenta se expresarían in vivo durante el transcurso de una infección ${ }^{287}$. Esta nueva evidencia hace replantear antiguas nociones sobre la biología de Bordetella y el rol de las fases de virulencia en este contexto. Frente a este panorama, resulta inapropiado arriesgar si el rol la adhesina BrtA sería más importante in vivo o ex vivo.

Nuestros resultados de ensayos de colonización en ratones demostraron que la sobreexpresión de LapG redujo la capacidad de colonización de $B$ bronchiseptica mientras que la deleción de lapG indujo una capacidad de colonización superior en comparación a la cepa salvaje. Esta evidencia sustenta la hipótesis de un rol de las proteínas Lap in vivo. Otros resultados sustentan la hipótesis de que BrtA también podría ser importante in vivo. Mediante ensayos de Western blot determinamos que la presencia de $\mathrm{BSA}$ y $\mathrm{Ca}^{+2}$, en concentraciones similares a las que se hallan en el epitelio respiratorio, generó un aumento en la secreción de BrtA. Otros autores han postulado que la suplementación del medio de cultivo con BSA y $\mathrm{Ca}^{+2}$ simularía condiciones fisiológicamente relevantes como las que Bordetella puede encontrarse durante el transcurso de una infección ${ }^{292}$. Este resultado podría sugerir que BrtA tendría un rol durante el proceso de infección. La porción secretada de BrtA podría contribuir a la formación de biofilm o bien participar de otros procesos. Las adhesinas FHA y fimbria, están involucradas en la formación de biofilm pero también tienen funciones inmunomoduladoras ${ }^{309,310}$. Hasta el momento no ha sido descripto en ninguna bacteria el 
rol de la porción liberada de proteínas tipo LapA. Por lo tanto, esto constituye un área interesante para profundizar en el futuro.

En la parte final de este trabajo nos enfocamos en determinar qué diguanilato ciclasas podrían regular de manera específica el funcionamiento de las proteínas Lap en B. bronchiseptica. Esta parte del trabajo nos llevó a profundizar la utilización de herramientas bioinformáticas y de modelado molecular. Gracias a este enfoque, postulamos que la posible diguanilato ciclasa BdcG podría interactuar físicamente con LapD. Asimismo, la estructura de dominios de BdcA y la relación encontrada entre la sobre expresión y la formación de biofilm por Sisti et al. ${ }^{224}$ y en este trabajo, sugerían que esta diguanilato ciclasa también podría interactuar con LapD.

Los resultados de BACTH demostraron que ambas diguanilato ciclasas son capaces de interaccionar con LapD. Esta capacidad de interacción sugiere que tanto BdcA como BdcG podrían regular la localización de la adhesina BrtA a través de LapDLapG. Experimentos de formación de biofilm sobre diferentes superficies y experimentos de dot blot demostraron que, en las condiciones estudiadas, sólo BdcA y no BdcG regula la formación de biofilm y la localización de la adhesina BrtA. Estos resultados nos llevaron a preguntarnos por qué BdcG podría interactuar con LapD si no regula la localización de BrtA. P. fluorescens tiene 4 diguanilato ciclasas que, en medio de cultivo mínimo, conteniendo glicerol y triptona como fuente de carbono y nitrógeno regulan la formación de biofilm: WspR, GcbA, GcbB y GcbC ${ }^{273}$. Sin embargo, sólo GcbC y GcbB regulan la localización de LapA; WspR y GcbA actúan a través de mecanismos aún no descriptos. La deleción de otras 19 posibles diguanilato ciclasas, en esas mismas condiciones no genera ningún efecto sobre la formación de biofilm, mientras que la deleción de otras 6 diguanilato ciclasas aumenta la formación de biofilm ${ }^{273}$. Trabajos como éste, donde se aborda el estudio de los procesos regulados por c-di-GMP de manera sistemática y generalizada ponen en evidencia la existencia de mecanismos de regulación altamente sofisticados detrás de este segundo mensajero. Frente a este escenario complejo, no resulta extraño que, en las condiciones experimentales ensayadas, la diguanilato ciclasa de $B$. bronchiseptica BdcG no presente un fenotipo diferente al de la cepa salvaje. Nuestros resultados sugieren que BdcG podría regular la localización de la adhesina BrtA, sin embargo, será necesario ampliar el número de condiciones experimentales hasta dar con aquella en la que esta diguanilato ciclasa sea necesaria para la regulación de la formación de biofilm.

Cuando en el año 2013 nuestro grupo de investigación describió que c-di-GMP regulaba la formación de biofilm en $B$. bronchiseptica, se abrió un camino de preguntas en torno a cuáles eras los mecanismos moleculares detrás de los fenotipos regulados por este segundo mensajero. Los resultados de este trabajo de tesis aportan nueva evidencia 


\section{Capítulo 8-CONCLUSIONES GENERALES}

para seguir transitando el camino de la descripción del rol de c-di-GMP en la biología de esta bacteria. A partir de los resultado mostrados a lo largo de esta Tesis Doctoral es posible considerar que la regulación de la formación de biofilm dependiente de c-di-GMP, en $B$. bronchiseptica, sigue un modelo como el de la Figura 8.1.

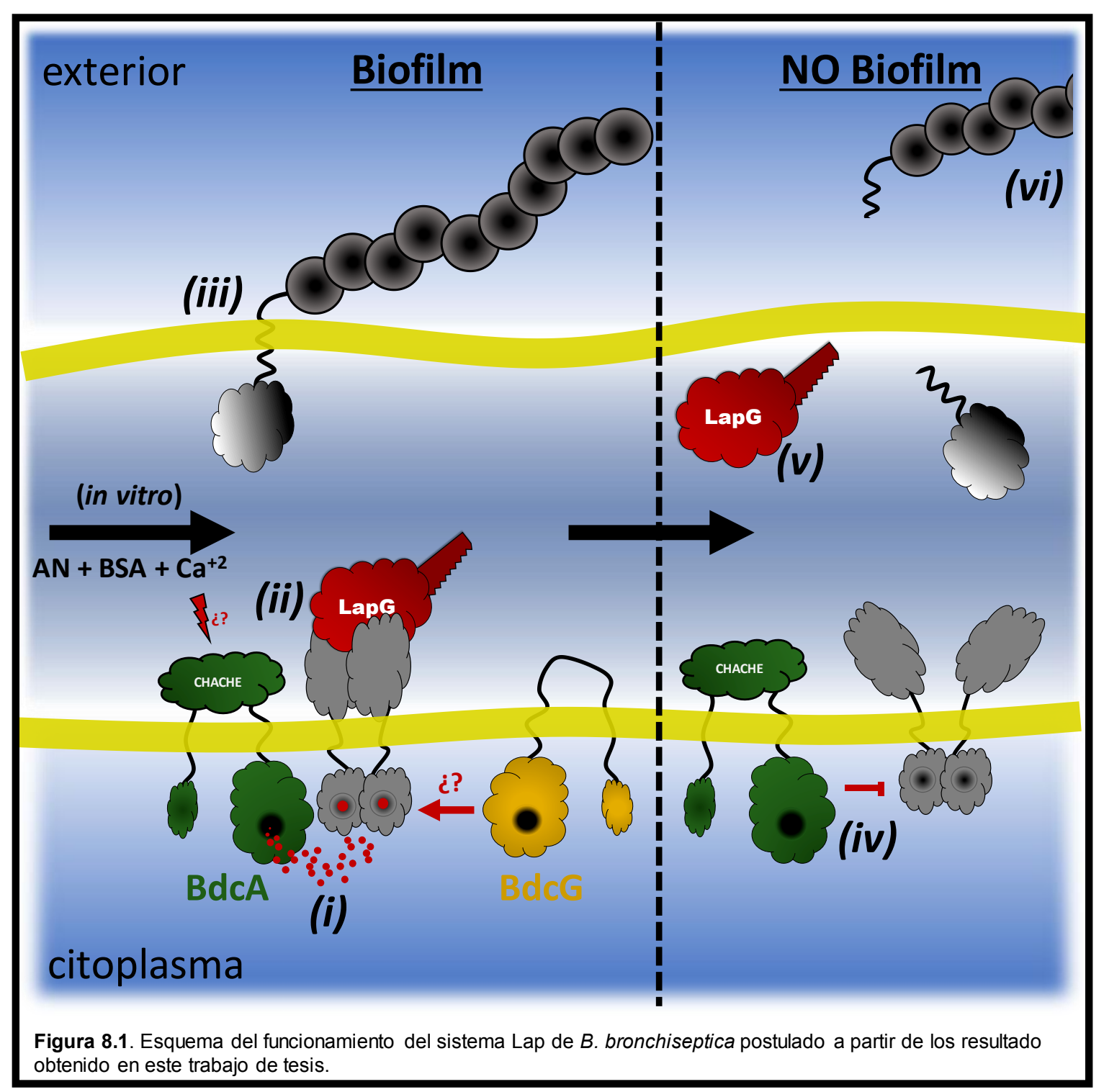

(i) la proteína integral de membrana LapD es regulada en forma específica por la diguanilato ciclasa BdcA. La regulación de LapD por parte de BdcA podría desarrollarse de dos maneras diferentes o complementarias. El primer escenario sugiere que LapD y BdcA sólo interaccionarían como respuesta a una señal ambiental que sería sensada por BdcA (probablemente a través de su dominio periplasmático CACHE). Esta señal, sumada a la interacción física LapD-BdcA activaría a la diguanilato ciclasa. Un segundo escenario posible es que BdcA y LapD interaccionen de forma constitutiva. En presencia 
de esta hipotética señal (sensada por BdcA) esta interacción podría verse fortalecida lo cual a su vez podría aumentar la actividad de BdcA. En cualquiera de los dos casos planteados la interacción física LapD-BdcA sumado a la activación de la diguanilato ciclasa generaría un aumento local en los niveles de c-di-GMP en las cercanías de LapD. (ii) frente al aumento de los niveles de c-di-GMP LapD adopta una conformación que le permite mantener retenida a la proteasa periplasmática LapG al otro lado de la membrana interna. (iii) de esta manera, la adhesina BrtA es mantenida sobre la superficie celular y contribuye con la capacidad de la bacteria de formar biofilm. (iv) frente a cambios en el ambiente que generen la desaparición de la hipotética señal o bien la aparición de una señal inhibitoria, el sistema podría responder modificando la actividad de BdcA o la afinidad BdcA-LapD. En estas condiciones BdcA podría no interaccionar físicamente con LapD o bien inhibir su actividad diguanilato ciclasa o ambas cosas de manera que los niveles de c-di-GMP en el entorno de LapD se reducirían. ( $v$ ) Frente a este cambio, LapD ya no podría mantener retenida a LapG al otro lado de la membrana plasmática. (vi) la proteasa LapG difunde libremente por el periplasma hasta clivar el extremo $\mathrm{N}$-terminal de BrtA de manera tal de liberarla de la membrana plasmática. En esta condición $B$. bronchiseptica pierde a una adhesina importante para la formación de biofilm. Esta condición podría representar la respuesta a dos situaciones diferentes. Por un lado, podría permitir a una bacteria que está formando parte de un biofilm, desprenderse y retornar al medio en búsqueda de nuevos nichos de colonización. Otra posibilidad es que, en una bacteria planctónica, esta condición inhiba su capacidad de adhesión a la superficie y desarrollo de biofilm. En este modelo, aún resulta impreciso cuál sería el rol de la diguanilato ciclasa BdcG en el control del funcionamiento de las proteínas Lap. Tal como mencionamos anteriormente, su rol más importante podría estar dado en condiciones de cultivo diferentes de las evaluadas durante nuestros experimentos.

Los resultados presentados en este trabajo de Tesis Doctoral han dado respuestas para incorporar nuevos elementos al modelo de funcionamiento de la regulación de la formación de biofilm mediada por c-di-GMP en $B$. bronchiseptica. Asimismo, estas respuestas han abierto las puertas a nuevas preguntas que deberán ser abordadas en el futuro para desentrañar el complejo mecanismo de regulación gobernado por c-di-GMP. 



\section{Capítulo 9}

Materiales y Métodos 



\section{Plásmidos}

La siguiente tabla presenta en forma detallada los vectores y las construcciones utilizadas y realizadas durante este trabajo.

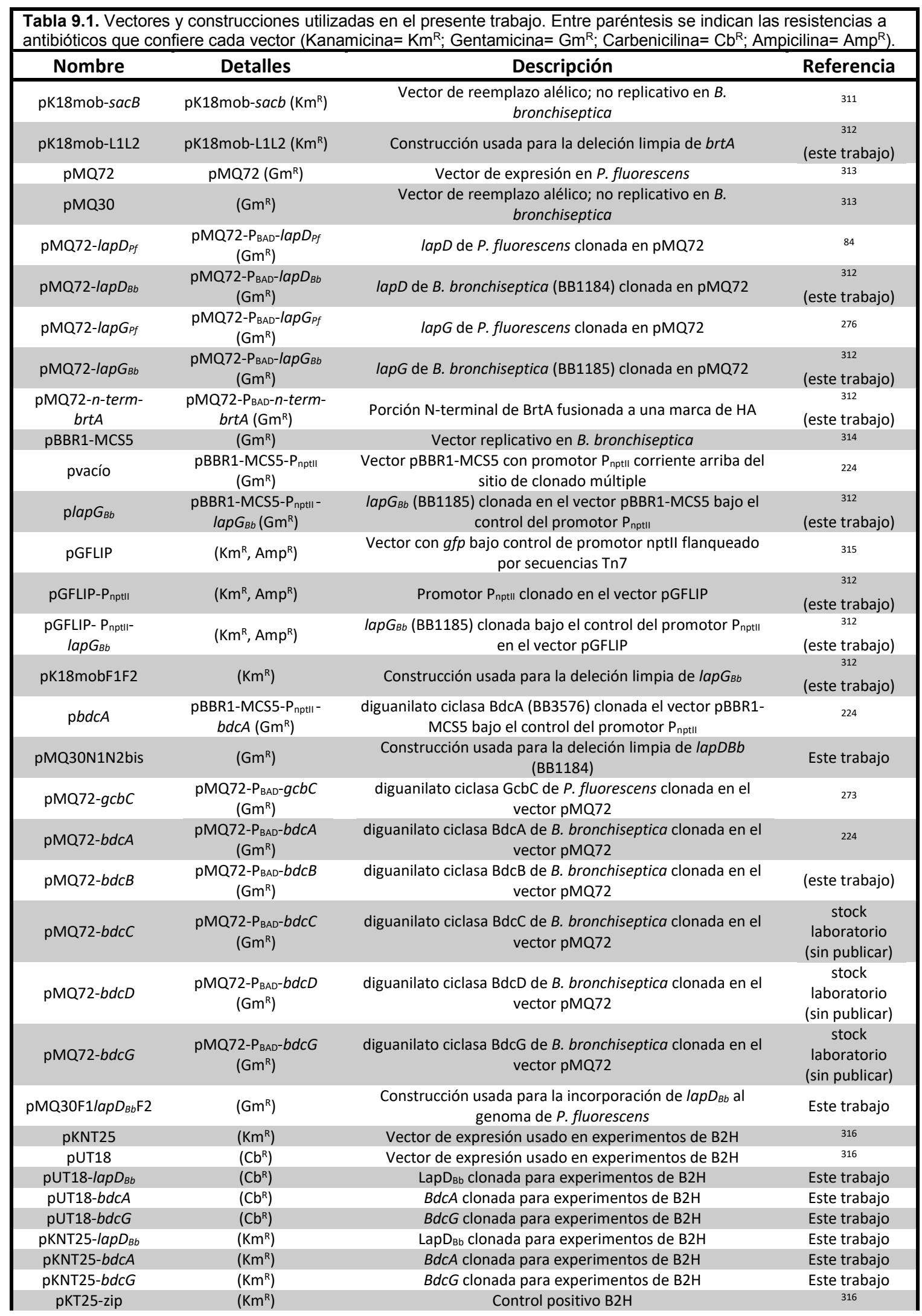




\section{Capítulo 9}

\begin{tabular}{|c|c|c|c|}
\hline pUT18C-zip & $\left(\mathrm{Cb}^{\mathrm{R}}\right)$ & Control positivo $\mathrm{B} 2 \mathrm{H}$ & 316 \\
\hline $\begin{array}{l}\text { pMQ30F1KmF2 } \\
\text { (3576) }\end{array}$ & $\left(\mathrm{Gm}^{\mathrm{R}}\right)$ & Construcción usada para interrupción de $b d c A$ & $\begin{array}{c}\text { stock } \\
\text { laboratorio } \\
\text { (sin publicar) }\end{array}$ \\
\hline pMQ30A1A2 & $\left(\mathrm{Gm}^{\mathrm{R}}\right)$ & Construcción usada para deleción limpia de $b d c G$ & Este trabajo \\
\hline PMQ30X1HAX2 & $\left(\mathrm{Gm}^{\mathrm{R}}\right)$ & $\begin{array}{l}\text { Construcción usada para introducir fusión transcripcional de } \\
\qquad \text { HA en brtA }\end{array}$ & Este trabajo \\
\hline pTNS3 & & Vector de expresión de la transposasa $\mathrm{Tn} 7$ & $\begin{array}{c}\text { Stock } \\
\text { laboratorio }\end{array}$ \\
\hline pTinyLapA & $\left(\mathrm{Gm}^{\mathrm{R}}\right)$ & $\begin{array}{l}\text { Vector que contiene la secuencia del epitope de } \\
\text { hemaglutinina }\end{array}$ & $\begin{array}{c}\text { Stock } \\
\text { laboratorio }\end{array}$ \\
\hline
\end{tabular}

\section{Organismos utilizados}

\section{Bordetella bronchiseptica}

Condiciones de cultivo. Todas las cepas $B$. bronchiseptica utilizadas en este trabajo fueron aisladas a partir de un stock almacenado a $-80^{\circ} \mathrm{C}$.

(i) Medio líquido. Para el cultivo de las cepas de B. bronchiseptica en medio líquido se utilizó el medio de cultivo definido SS (Sainer-Scholte) $)^{317}$. La incubación de cultivos en medio líquido fue realizada a $37^{\circ} \mathrm{C}$ con agitación (160 rpm).

(ii) Medio de cultivo sólido. Para el cultivo de cepas de B. bronchiseptica en medio sólido se utilizó el mismo medio SS suplementado con Complemento y sangre de carnero desfibrinada 10\% v/v (SS-sangre) y se adicionó agar hasta una concentración final de $3,0 \%$ p/v. Para el cultivo en medio sólido también se utilizó BGA (Bordet Gengou Agar; marca Difco) suplementado con sangre de carnero desfibrinada 10\% v/v. La incubación de repiques en medio sólido fue realizada a $37^{\circ} \mathrm{C}$ durante $48-72$ horas.

Cepas. Para el desarrollo de este trabajo se utilizó la cepa $B$. bronchiseptica $9.73 \mathrm{H+}$, un aislamiento de conejo caracterizado originalmente como LPS liso, BvgAS+, AC +, PRN+, $\mathrm{FHA}+, \mathrm{StrR}^{245}$. Todas las modificaciones genéticas (deleciones y sobre expresiones) fueron realizadas sobre el mencionado aislamiento. Las cepas utilizadas y desarrolladas durante el transcurso de este trabajo se detallan en la siguiente tabla:

\begin{tabular}{|c|c|c|c|}
\hline$\#$ & Nombre & Descripción & Referencia \\
\hline 1 & Bb salvaje & B. bronchiseptica $9.73 \mathrm{H}+$ (cepa salvaje) & 245 \\
\hline 2 & $\mathrm{Bb} \Delta b r t A(\triangle B B 186)$ & Deleción limpia brtA & ${ }^{312}$ (este trabajo) \\
\hline 3 & Bb pvacío & Bb pBBR1-MCS5-P & 224 \\
\hline 4 & $\mathrm{Bb}$ plap $G_{B b}$ & Bb pBBR1-MCS5-P nptI- $-a p G_{B b}$ & ${ }^{312}$ (este trabajo) \\
\hline 5 & $\mathrm{Bb}-\mathrm{GFP}$ & Bb::gfp::nptll & ${ }^{312}$ (este trabajo) \\
\hline 6 & Bb-GFP-LapG ${ }_{\mathrm{Bb}}(\mathrm{BB} 1185)$ & $\mathrm{Bb}:: g f p:: n p t / 1:: / a p G_{B b}$ & ${ }^{312}$ (este trabajo) \\
\hline 7 & $\mathrm{Bb} \Delta / a p G$ & Deleción limpia lapG & ${ }^{312}$ (este trabajo) \\
\hline 8 & Bb $\Delta / a p G$ pvacío & $\mathrm{Bb} \Delta / a p G_{B b} \mathrm{pBBR} 1-\mathrm{MCS} 5-\mathrm{P}_{\mathrm{nptII}}$ & ${ }^{312}$ (este trabajo) \\
\hline 9 & $\mathrm{Bb} \Delta / a p G$ plap $G_{B b}$ & $\mathrm{Bb} \Delta / a p G_{B b} \mathrm{pBBR} 1-\mathrm{MCS} 5 \mathrm{P}_{\mathrm{nptI}} / a p G_{B b}$ & ${ }^{312}$ (este trabajo) \\
\hline 10 & $\mathrm{Bb} \Delta / \mathrm{apD}$ & Deleción limpia $l a p D_{B b}$ & Este trabajo \\
\hline 11 & $\mathrm{Bb} \Delta / a p D$ pvacío & $\mathrm{Bb} \Delta / a p D_{B b}$ pBBR1-MCS5- $\mathrm{P}_{\text {nptll }}$ & Este trabajo \\
\hline 12 & $\mathrm{Bb} \mathrm{pbdcA}$ & Bb pBBR1-MCS5-P $P_{n t t I}-b d c A$ & 224 \\
\hline 13 & $\mathrm{Bb} \Delta / a p D \mathrm{pbdcA}$ & $\mathrm{Bb} \Delta / a p D_{B b} \mathrm{pBBR} 1-\mathrm{MCS} 5-\mathrm{P}_{\mathrm{nptII}}-b d c A$ & Este trabajo \\
\hline 14 & $\mathrm{Bb} \Delta b d c A$ & $\mathrm{Bb} b d c A:: K m$ & stock laboratorio (sin publicar) \\
\hline 15 & $\mathrm{Bb} \Delta b d c G$ & $\mathrm{Bb} \Delta b d c G$ & Este trabajo \\
\hline
\end{tabular}




\begin{tabular}{|lccc}
16 & $\mathrm{Bb} \Delta b d c A \Delta b d c G$ & $\mathrm{Bb} b d c A:: \mathrm{Km} \Delta b d c G$ & Este trabajo \\
17 & $\mathrm{Bb}-\mathrm{HA}$ & B. bronchiseptica salvaje con marca HA en BrtA & Este trabajo \\
18 & $\mathrm{Bb} \Delta l a p G-H A$ & $B b \Delta l a p G$ con marca HA en BrtA & Este trabajo \\
19 & $\mathrm{Bb} \Delta l a p D-H A$ & $B b \Delta l a p D$ con marca HA en BrtA & Este trabajo \\
20 & $\mathrm{Bb} \Delta b d c A-H A$ & $B b b d c A:: K m$ con marca HA en BrtA & Este trabajo \\
21 & $\mathrm{Bb} \Delta b d c G-H A$ & $B b \Delta b d c G$ con marca HA en BrtA & Este trabajo \\
22 & $\mathrm{Bb} \Delta b d c A \Delta b d c G-H A$ & $B b b d c A:: K m \Delta b d c G$ con marca HA en BrtA & Este trabajo \\
\hline
\end{tabular}

\section{Pseudomonas fluorescens}

Condiciones de cultivo. Las cepas de $P$. fluorescens fueron aisladas a partir de un stock almacenado a $-80^{\circ} \mathrm{C}$. Para el aislamiento se utilizó LB (lysogeny broth) sólido y las placas fueron incubadas a $30^{\circ} \mathrm{C}$ durante 16 horas. Para la realización de cultivos líquidos se utilizó medio LB. Los cultivos fueron incubados a $30^{\circ} \mathrm{C}$, durante 16 horas con agitación (160 rpm).

Cepas. Las cepas de $P$. fluorescens utilizadas a lo largo de presente trabajo se detallan en la siguiente tabla:

\begin{tabular}{|c|c|c|c|}
\hline$\#$ & Nombre & Descripción & Referencia \\
\hline 1 & Pf pMQ72 & $\begin{array}{l}\text { P. fluorescens 01; cepa salvaje con control de carga de } \\
\text { plásmido }\end{array}$ & 293 \\
\hline 2 & Pf $\Delta / a p D$ pvacío & Pf $\triangle$ lapD pMQ72 & 84 \\
\hline 3 & Pf $\Delta / a p D$ plapD $D_{P f}$ & Pf $\triangle$ lapD pMQ72-lapD ${ }_{p f}$ & 84 \\
\hline 4 & Pf $\triangle / a p D$ plap $D_{B b}$ & Pf $\triangle l a p D$ pMQ72-lap $D_{B b}$ & este trabajo \\
\hline 5 & Pf $\Delta / a p G$ plapG $P f$ & Pf $\Delta / a p G$ pMQ72-lapG $P f$ & 140 \\
\hline 6 & $P f \Delta l a p G$ plap $G_{B b}$ & Pf $\Delta / a p G$ pMQ72-lapG $G_{B b}$ & este trabajo \\
\hline 7 & Pf $\triangle 4 \mathrm{DGC}$ pMQ72 & Pf $\Delta w s p R \Delta g c b A \Delta g c b B \Delta g c b C$ pMQ72 & 293 \\
\hline 8 & Pf $\triangle 4$ DGC pgcbC & Pf $\triangle 4$ DGC pMQ72-gcbC & 293 \\
\hline 9 & Pf $\triangle 4$ DGC pbdcA & Pf $\triangle 4$ DGC pMQ72-bdcA & este trabajo \\
\hline 10 & Pf $\triangle 4$ DGC $p b d c G$ & Pf $\triangle 4$ DGC pMQ72-bdcG & este trabajo \\
\hline 11 & Pf $\triangle 4 \mathrm{DGC} \mathrm{p} B B 2790$ & Pf $\triangle 4 \mathrm{DGC}$ pMQ72-BB2790 & este trabajo \\
\hline 12 & Pf $\triangle 4$ DGC p3114 & Pf $\triangle 4 \mathrm{DGC}$ pMQ72-3114 & este trabajo \\
\hline 13 & Pf $\triangle 4$ DGC p3903 & Pf $\triangle 4$ DGC pMQ72-3903 & este trabajo \\
\hline 14 & Pf $\Delta 4$ DGC-LapD $D_{\text {вb }}$ & Pf $\triangle 4$ DGC $\triangle / a p D:: / a p D_{B b}$ pMQ72 & este trabajo \\
\hline 15 & Pf $\triangle 4$ DGC-LapD Bb $_{\text {p }} g c b C$ & Pf $\triangle 4$ DGC $\triangle$ lapD::lapD $D_{B b}$ pgcbC & este trabajo \\
\hline 16 & Pf $\triangle 4$ DGC-LapD $D_{\mathrm{Bb}} \mathrm{p} b d c A$ & Pf $\triangle 4$ DGC $\triangle l a p D:: l a p D_{B b} \mathrm{pbdcA}$ & este trabajo \\
\hline 17 & $P f \Delta 4$ DGC-LapD $\mathrm{Bb}_{\mathrm{Bb}} \mathrm{p} b d c B$ & Pf $\triangle 4$ DGC $\triangle l a p D:: l a p D_{B b} \mathrm{pbdcB}$ & este trabajo \\
\hline 18 & Pf $\triangle 4$ DGC-LapD $\mathrm{Bb}_{\mathrm{Bb}} \mathrm{p} b d c C$ & Pf $\triangle 4$ DGC $\triangle$ lapD::lap $D_{B b} \mathrm{pbdcC}$ & este trabajo \\
\hline 19 & Pf $\triangle 4$ DGC-LapD $D_{\text {вb }} \mathrm{pbdcD}$ & Pf $\triangle 4$ DGC $\triangle l a p D:: / a p D_{B b} \mathrm{p} b d c D$ & este trabajo \\
\hline 20 & Pf $\triangle 4$ DGC-LapD $D_{\text {Bb }}$ pbdcG & Pf $\triangle 4$ DGC $\triangle$ lapD::lapD $D_{B b}$ pbdcG & este trabajo \\
\hline
\end{tabular}

\section{Escherichia coli}

Condiciones de cultivo. Para el cultivo de E. coli se utilizó el medio LB líquido y sólido. En ambos casos, los cultivos fueron incubados a $37^{\circ} \mathrm{C}$.

Cepas. Las cepas S71-1 y DH5-a fueron utilizadas como medio de propagación de las construcciones genéticas indicadas en la Tabla 9.1. La cepa E. coli BTH101 fue utilizada para el desarrollo de los experimentos de doble híbrido en bacteria debido a que esta cepa es deficiente en adenilato ciclasa (cyaA). 


\section{Antibióticos}

A lo largo de este trabajo se utilizaron antibióticos cada vez que el organismo utilizado, por su resistencia natural o para propagar un vector, lo requería. En todos los casos el antibiótico correspondiente fue adicionado al medio de cultivo a partir de un stock concentrado (1000X) almacenado a $-20^{\circ} \mathrm{C}$. Los stocks fueron preparados con agua desionizada y filtrados con filtros de $0,2 \mu \mathrm{m}$ de tamaño de poro.

La cepa $B$. bronchiseptica $9.73 \mathrm{H}+$ es naturalmente resistente a estreptomicina $\left(S t^{R}\right)^{245}$ por lo que este antibiótico fue utilizado en todos los ensayos que incluyeran cultivos con este organismo.

En la siguiente tabla se detallan las concentraciones de cada antibiótico utilizadas para cada organismo:

\begin{tabular}{|l|c|c|ccc|}
\hline \multicolumn{1}{|c|}{} & \multicolumn{3}{c|}{ E. coli } \\
\hline Antibióticos & B. bronchiseptica & P. fluorescens & S17-1 & DH5- $\boldsymbol{\alpha}$ & BTH101 \\
\hline Gentamicina & 50 & 30 & 10 & 10 & - \\
Kanamicina & 80 & - & 25 & 25 & 50 \\
Estreptomicina & $200^{a}$ & - & - & - & 100 \\
Carbenicilina & - & - & - & - & 50 \\
\hline Tabla 9.4. Antibióticos utilizados en este trabajo. Todos los valores están expresados en unidades de $\mu \mathrm{g} / \mathrm{mL}$. \\
"-" significa que ese antibiótico no fue utilizado para trabajar con esa cepa en este trabajo. \\
a Excepto en placas de cultivo usadas para recuento de UFC en ensayos de colonización donde se usó una \\
concentración de estreptomicina de 100 $\mu \mathrm{g} / \mathrm{mL}$. \\
\hline
\end{tabular}

\section{Conservación y almacenamiento de cepas}

Las cepas obtenidas durante el transcurso de este trabajo fueron almacenadas en su medio de cultivo correspondiente suplementado con glicerol. Se utilizaron concentraciones de glicerol de $50 \% \mathrm{v} / \mathrm{v}$ y $25 \% \mathrm{v} / \mathrm{v}$ para el almacenamiento a $-20^{\circ} \mathrm{C}$ y $80^{\circ} \mathrm{C}$ respectivamente.

\section{Preparación de células electrocompetentes de $E$. coli}

La preparación de células de E. coli S17-1 y DH5-a electrocompetentes se llevó a cabo mediante la técnica de Tung y $\mathrm{Chow}^{318}$. Como primer paso de este protocolo, se realizaron aislamientos a partir de stocks almacenados a $-80^{\circ} \mathrm{C}$. Estos aislamientos fueron realizados en medio LB sin antibióticos. En paralelo se realizaron controles en placas de LB suplementadas con $\mathrm{Gm}$ y Km. Estas placas fueron incubadas durante 24 horas a $37^{\circ} \mathrm{C}$. Al día siguiente se tomó biomasa de la placa de aislamiento y se inocularon $5 \mathrm{~mL}$ de medio de cultivo LB sin antibiótico. Este cultivo fue incubado durante toda la noche a $37^{\circ} \mathrm{C}$ con agitación (160 rpm). $250 \mu \mathrm{L}$ de este cultivo fueron utilizados para inocular $250 \mathrm{~mL}$ de medio LB. Este cultivo fue incubado a $37^{\circ} \mathrm{C}$ con agitación hasta $\mathrm{DO}_{600}=0,6-0,8$. Llegado 
este punto, el cultivo fue enfriado en hielo durante 15 minutos y partir de este momento se trabajó en frío durante el transcurso de todo el protocolo. El cultivo fue centrifugado a $5.000 \mathrm{xg}$ durante 20 minutos a $4^{\circ} \mathrm{C}$, el sobrenadante fue descartado y el paquete celular fue resuspendido suavemente en $50 \mathrm{~mL}$ de glicerol estéril $10 \% \mathrm{v} / \mathrm{v}$. Este lavado se repitió en dos oportunidades más. Finalmente, las células fueron resuspendidas en $1000 \mu \mathrm{L}$ de glicerol estéril $10 \% \mathrm{v} / \mathrm{v}$ y la suspensión bacteriana obtenida fue fraccionada de a $50 \mu \mathrm{L}$ y almacenada a $-80^{\circ} \mathrm{C}$ hasta su utilización. Previo a su utilización se realizó un chequeo de la eficiencia de transformación de las electrocompetentes preparadas. Aquellos lotes que presentaron una eficiencia de transformación de $10^{6}-10^{8} \mathrm{UFC} / \mathrm{ng}$ DNA fueron utilizados. Los lotes que presentaron eficiencias menores fueron descartados.

\section{Preparación de células electrocompetentes de $\boldsymbol{P}$. fluorescens}

El protocolo utilizado está basado en la descripción original de A. Smith y B. Iglewski para la obtención de electrocompetentes de $P$. aeruginosa ${ }^{319}$.

Las células electrocompetentes de $P$. fluorescens fueron preparadas en el momento en fue necesario utilizarlas. La cepa $P$. fluorescens salvaje o los mutantes correspondientes fueron inoculados en placa de cultivo de LB a partir de los stocks almacenados a $-80^{\circ} \mathrm{C}$. Estas placas fueron incubadas durante toda la noche a $30^{\circ} \mathrm{C}$. Colonias aisladas de estas placas fueron utilizadas para inocular $4 \mathrm{~mL}$ de medio de cultivo LB e incubado durante toda la noche a $30^{\circ} \mathrm{C}$ con agitación (160 rpm). Luego de esta incubación el cultivo fue fraccionado en partes iguales en tubos de microcentrífuga de 2 $\mathrm{mL}$. Estos tubos fueron centrifugados durante 2 minutos a $7.000 \mathrm{xg}$ a temperatura ambiente. El sobrenadante fue descartado y el material celular de cada tubo fue resuspendido en $2 \mathrm{~mL}$ de solución estéril de sacarosa $300 \mathrm{mM}$. Luego de otro paso de centrifugación el material celular fue resuspendido en $1 \mathrm{~mL}$ y juntado en un mismo tubo. Posteriormente se realizó un nuevo paso de centrifugación siguiendo las indicaciones previas. Finalmente, el material celular fue resuspendido en $100 \mu \mathrm{L}$ de solución de sacarosa $300 \mathrm{mM}$. Esta suspensión fue mantenida en hielo hasta el momento de ser utilizada. Para el protocolo de electroporación fueron utilizados $30 \mu \mathrm{L}$ de suspensión.

\section{Electroporación}

Las electro transformaciones fueron llevadas a cabo utilizando un equipo Gene Pulser (BioRad) en cubetas de 0,2 $\mathrm{mL}$ utilizando las condiciones recomendadas por el fabricante $(25 \mu \mathrm{F}, 200 \Omega, 2,5 \mathrm{kV})$. Luego de la electro transformación se adicionó inmediatamente $1 \mathrm{~mL}$ de medio LB sin antibiótico y se incubó durante 1 hora a $37^{\circ} \mathrm{C}(E$. coli) o $30^{\circ} \mathrm{C}(P$. fluorescens), a fin de permitir la expresión de los factores de resistencia 


\section{Capítulo 9}

a antibiótico incorporados durante la transformación. Finalmente, las células fueron plaquedas en medio LB conteniendo el antibiótico correspondiente e incubadas a $37^{\circ} \mathrm{C}$ ó $30^{\circ} \mathrm{C}$ hasta el día siguiente.

\section{Conjugación}

Este protocolo es una modificación del método de Simon et $a^{\beta 20}$. Se realizó un aislamiento de la cepa $B$. bronchiseptica aceptora en medio BGA-sangre suplementado con Str. Esta placa fue incubada durante 72 horas a $37^{\circ} \mathrm{C}$. A las 48 horas se realizó un aislamiento de la cepa donadora E. coli S17-1 en medio LB sólido suplementado con el antibiótico correspondiente ( $\mathrm{Gm}$ para construcciones derivadas del pMQ30, pMQ72 o pBBR1-MCS5 o Km para pK18mob-sacb). Esta placa fue incubada durante 16 horas a $37^{\circ} \mathrm{C}$. Transcurrido ese período de incubación, biomasa de esta placa fue tomada para inocular $5 \mathrm{~mL}$ de medio de cultivo LB suplementado con antibiótico. Este cultivo fue incubado durante 6 horas a $37^{\circ} \mathrm{C}$ con agitación (160 rpm). Transcurrido ese tiempo se tomó $1 \mathrm{~mL}$ de cultivo y se realizó un lavado con $1 \mathrm{~mL}$ de medio de cultivo $\mathrm{LB}$ sin antibiótico. Para ello, la alícuota de cultivo fue centrifugada a $2.500 \mathrm{xg}$ durante 5 minutos, el sobrenadante de la centrifugación fue descartado y el paquete celular fue suavemente resuspendido en LB sin antibiótico. Biomasa proveniente de la placa de cultivo de $B$. bronchiseptica fue resuspendida suavemente en el mismo tubo conteniendo la cepa de E. coli S17-1 donadora. Este tubo fue centrifugado a $2.500 \mathrm{xg}$ durante 5 minutos, el sobrenadante descartado y el paquete celular conteniendo ambas bacterias fue resuspendido en $50 \mu \mathrm{L}$ de LB. Se preparó una placa de BGA-sangre sin antibiótico y se esparcieron $50 \mu \mathrm{L}$ de solución de $\mathrm{MgCl}_{2} 2 \mathrm{M}$. El material celular del paso anterior fue plaqueado en forma de una gota sobre la placa de BGA. A modo de control también se realizaron repiques de la cepa donora $\$ 17-1$ y la cepa $B$. bronchiseptica aceptora. Esta placa fue incubada durante toda la noche a $37^{\circ} \mathrm{C}$. El material celular de la gota de conjugación fue resuspendido en $1 \mathrm{~mL}$ de buffer fosfato. Se prepararon diluciones seriadas $1 / 10$ y se plaquearon en medio BGA-sangre suplementado con Str y el antibiótico correspondiente al plásmido transferido.

Nota: el protocolo de conjugación usado para la obtención de mutantes en $B$. bronchiseptica se realizó de manera semejante con la única modificación que se utilizó LB $\sin \mathrm{NaCl}$ para el lavado y la resuspención de las bacterias. Debido a que la presencia de $\mathrm{NaCl}$ resulta contraproducente para el desarrollo del protocolo de contra selección con sacarosa que se realizó posteriormente (ver más adelante en este capítulo). 


\section{Preparación de ADN plasmídico}

Para el aislamiento de ADN plasmídico se utilizó la técnica descripta por M. Green y J. Sambrook de mini-preparación plasmídica por lisis alcalina (miniprep) ${ }^{321}$. Esta técnica fue usada para la recuperación de plásmidos de E. coli o B. bronchiseptica. Se tomó una alícuota de cultivo líquido de hasta 16 horas de incubación y se la centrifugó durante 5 minutos a $8.000 \mathrm{xg}$. El pellet de esta centrifugación fue resuspendido en $200 \mu \mathrm{L}$ de solución P1. Paralelamente se preparó solución P2 mediante la combinación de partes iguales de solución P2A y P2B. $200 \mu \mathrm{L}$ de solución P2 fueron adicionados a la suspensión bacteriana y se mezcló suavemente por inversión. Finalmente se adicionaron $200 \mu \mathrm{L}$ de solución P3 y nuevamente se mezcló por inversión. La suspensión obtenida fue centrifugada a $16.000 \mathrm{xg}$ durante 15 minutos. El sobrenadante de esta centrifugación fue separado cuidadosamente a fin de no arrastrar material del precipitado. La purificación del ADN plasmídico del sobrenadante colectado fue realizada de acuerdo a la técnica de unión sílica descripta por J. Boyle y A. Lew ${ }^{322}$. Se adicionaron $10 \mu \mathrm{L}$ de suspensión de sílica y se agitó la suspensión durante 10 segundos. Posteriormente se centrifugó a $16.000 \mathrm{xg}$ durante 10 segundos. El precipitado de esta centrifugación fue resuspendido en $300 \mu \mathrm{L}$ de solución de lavado. Este proceso fue repetido en una segunda oportunidad y finalmente el precipitado de sílica fue resuspendido en $30 \mu \mathrm{L}$ de agua desionizada estéril. La suspensión de sílica fue incubada durante 5 minutos en baño de agua a $65^{\circ} \mathrm{C}$ y posteriormente fue centrifugada durante 1 minuto a $16.000 \mathrm{xg}$. Finalmente, el sobrenadante conteniendo el plásmido purificado fue separado y cuantificado antes de ser almacenado $\mathrm{a}-20^{\circ} \mathrm{C}$.

Para la preparación de ADN plasmídico también se utilzaron los kits comerciales QIAprep Spin Miniprep (Qiagen) y AccuPrep Plasmid Mini Extraction Kit (Bioneer). En ambos casos, para el desarrollo del protocolo de extracción se siguieron las indicaciones de los proveedores.

\section{Preparación de ADN genómico}

Para la purificación de ADN genómico se utilizó el kit QIAamp DNA Mini (Qiagen) y se siguieron las instrucciones de la empresa proveedora.

\section{Preparación de ARN mensajero y retro transcripción}

Para la obtención de ARNm y retro trascripción se utilizó el kit Reverse Transcription System (Promega) y se siguieron las especificaciones del fabricante. 


\section{Capítulo 9}

\section{Determinación de la concentración de ADN y ARN}

Para la determinación de la concentración de $A D N$ en muestras de $A D N$ genómico, ADN plasmídico o ADN provenientes de purificación de gel y para la cuantificación de ARN de las preparaciones de ARNm se utilizó un equipo NanoDrop 1000 (Thermo Scientific). La absorbancia a $260 \mathrm{~nm}$ fue utilizada como medida de concentración y la relación de absorbancias 260/280 como criterio de pureza ( 1,8 fue tomado como valor de referencia para muestras de ADN puras y $\sim 2,0$ para muestras de ARN).

\section{Reacción en cadena de la polimerasa (PCR)}

Para la amplificación de secuencias genéticas con fines de clonación o secuenciación se utilizaron las siguientes ADN polimerasas comerciales con actividad 3'5' correctora de errores: HiFi (KAPA Biosystems), PFU (PB-L Productos Bio-Lógicos), VELOCITY (Bioline) y Phusion (Thermo Fisher Scientific). Para la amplificación de secuencias genéticas con fines de control y chequeo de construcciones se utilizaron las siguientes ADN polimerasas comerciales sin actividad correctora de errores: Taq (KAPA Biosystems), Taq (Genbiotech) y EasyTaq (TransGene Biotech).

En todos los casos se utilizaron condiciones de ciclado, concentración de primers, concentración de $\mathrm{Mg}^{+2}$, cantidad de enzima y cantidad de ADN molde de acuerdo con las especificaciones de los protocolos suministrados por las empresas proveedoras.

Debido a que genoma de $B$. bronchiseptica presenta un contenido de $G+C$ del $68,07 \%{ }^{153}$, para la amplificación de secuencias a partir de ADN de $B$. bronchiseptica se adicionó dimetilsulfóxido (DMSO) en una concentración final de 3,0\% v/v a fin de reducir la temperatura de hibridación de los primers. Para la puesta a punto de las condiciones de ciclado de cada reacción de PCR se realizó un gradiente de temperaturas de hibridación entre las temperaturas límites recomendadas por los proveedores. Aquella temperatura que arrojara los mejores resultados luego fue utilizada en una segunda ronda de amplificación a fin de obtener una cantidad de amplicón suficiente para continuar con los protocolos de clonación o chequeo de construcciones. Los resultados de cada reacción de PCR fueron analizados mediante electroforesis en geles de agarosa de concentración $0,8-1,5 \% \mathrm{p} / \mathrm{v}$.

\section{Electroforesis en geles de agarosa}

Las electroforesis en geles de agarosa fueron utilizadas para analizar los resultados de reacciones de $\mathrm{PCR}$, digestiones con enzimas de restricción y purificaciones de ADN total y plasmídico. La concentración de agarosa utilizada fue adaptada de 
acuerdo con las necesidades de cada caso según el esquema que se detalla a continuación:

\begin{tabular}{|c|c|}
\hline Fragmento esperado & Concentración Agarosa (\% p/v) \\
\hline $3000-7000 \mathrm{pb}$ & 0,8 \\
$1500-3000 \mathrm{pb}$ & 1,0 \\
\hline $200-1500 \mathrm{pb}$ & 1,5 \\
\hline
\end{tabular}

Durante la preparación de las soluciones de agarosa se adicionó el colorante Syber Safe (Invitrogen) según las indicaciones del proveedor. Para la preparación de los geles y para la corrida electroforética se utilizó buffer TBE 0,5X. Las corridas electroforéticas fueron realizadas a 85-120 V utilizando una fuente PowerPac (BioRad). Para la visualización de los resultados se utilizó una fuente de luz azul incorporada a un equipo transiluminador.

\section{Purificación de ADN desde geles de agarosa}

Esta técnica se utilizó como parte de los protocolos de clonado cuando, en electroforesis en geles de agarosa, el producto de la reacción de PCR mostraba la presencia de más de una banda. Para este procedimiento se prepararon geles de agarosa de $0,8 \% \mathrm{p} / \mathrm{v}$ independientemente del tamaño del amplicón esperado. Las calles del gel fueron adaptadas para poder sembrar 30-50 $\mu \mathrm{L}$ del producto de la reacción de PCR. Las corridas electroforéticas fueron realizadas a $85 \mathrm{~V}$ hasta obtener una clara separación entra la banda del tamaño esperado y las bandas correspondientes a productos de amplificación inespecíficos. Para la purificación se utilizó el kit comercial AccuPrep Gel Purification (Bioneer) y para el desarrollo del protocolo se siguieron las indicaciones del proveedor.

\section{Uso de enzimas de restricción}

La digestión de vectores plasmídicos o productos de PCR se realizó utilizando el siguiente esquema:

\begin{tabular}{|c|c|}
\hline ADN & $1,0 \mu \mathrm{g}$ \\
\hline Buffer & $5,0 \mu \mathrm{L}$ \\
\hline BSA $(1 \mu \mathrm{g} / \mu \mathrm{L})$ & $5,0 \mu \mathrm{L}$ \\
\hline Enzima & $1,0 \mu \mathrm{L}$ \\
\hline Agua desionizada estéril & cantidad necesaria \\
\hline Volumen final & $50,0 \mu \mathrm{L}$ \\
\hline
\end{tabular}

En todos los casos se utilizó el buffer, las condiciones de incubación (tiempo y temperatura) y las condiciones de inactivación (cuando fue necesario) recomendadas en los protocolos suministrados por las empresas proveedoras (Invitrogen, Promega y New England BioLabs). 


\section{Ligaciones}

Las reacciones de ligación fueron realizadas utilizando una relación molar (amplicón: vector) $=(3: 1)$. En todos los casos se utilizó la herramienta web nebiocalculator (New England BioLabs) para determinar la masa de amplicón necesaria para satisfacer la condición mencionada anteriormente. Las mezclas de ligación fueron realizadas siguiendo el esquema que se detalla a continuación:

\begin{tabular}{|c|c|}
\hline Vector digerido & $50 \mathrm{ng}$ \\
\hline Inserto & cantidad necesaria \\
\hline Buffer & $2,0 \mu \mathrm{L}$ \\
\hline Ligasa T4 & $1,0 \mu \mathrm{L}$ \\
\hline Agua desionizada estéril & cantidad necesaria \\
\hline Volumen final & $20,0 \mu \mathrm{L}$ \\
\hline
\end{tabular}

Las mezclas de ligación fueron incubadas durante 3 horas a temperatura ambiente. Finalmente, fueron dializadas para eliminar las sales del buffer de la ligasa y para esto se utilizaron filtros de nitrocelulosa de 0,25 $\mu \mathrm{m}$ (Millipore). Este último paso permitió utilizar $10 \mu \mathrm{L}$ de ligación para el protocolo de electroporación y así obtener mejores rendimientos de transformación.

\section{Electroforesis en SDS-PAGE}

Las corridas electroforéticas se realizaron en geles de poliacrilamida en condiciones desnaturalizantes (SDS-PAGE) de acuerdo a la metodología descripta por Laemmli ${ }^{323}$. El gel de apilamiento o stacking se preparó en una concentración de $4 \%$ de poliacrilamida (acrilamida:bisacrilamida 30:0,8) con solución reguladora de Tris- $\mathrm{HCl} 1,0$ $\mathrm{M}(\mathrm{pH}=6,8)$ y SDS $10 \% \mathrm{p} / \mathrm{v}$, mientras que el gel de separación se preparó en una concentración de $12,5 \%$ de poliacrilamida (acrilamida : bisacrilamida 30:0,8) con solución reguladora Tris- $\mathrm{HCl} 1,0 \mathrm{M}(\mathrm{pH}=8,8)$ y SDS $10 \% \mathrm{p} / \mathrm{v}$. Las corridas se realizaron en equipos Miniprotean II (BioRad) durante 60 a 90 minutos a $100 \mathrm{~V}$ en buffer Tris-HCl $50 \mathrm{mM}$ $(\mathrm{pH}=8,3)$ con glicina $370 \mathrm{mM}$ y SDS $10 \% \mathrm{p} / \mathrm{v}$. Para las corridas electroforéticas realizadas para ensayos con BrtA se utilizó un gel de separación de concentración de 7,5\% de poliacrilamida y las corridas se realizaron durante 120 a 180 minutos a $100 \mathrm{~V}$. Para la tinción de los geles de poliacrilamida y visualización de los perfiles electroforéticos obtenidos se utilizó solución de Coomasie Blue R-250. 


\section{Western blot}

Las muestras de proteínas sometidas a SDS-PAGE fueron transferidas a membranas de nitrocelulosa mediante el equipo Mini Trans-Blot transfer Cell (BioRad) según las indicaciones del fabricante. En primera instancia se armó el dispositivo de transferencia con el gel a transferir y la membrana previamente tratada con buffer de transferencia. Una vez armado, se le aplicó sobre el mismo una diferencia de potencial de $100 \mathrm{~V}$ durante 1 hora en baño de agua-hielo. En el caso particular de los ensayos realizados a fin de determinar la presencia de BrtA se utilizó un tiempo de transferencia de 2 horas debido al gran tamaño de esta proteína. Luego se procedió al bloqueo de la membrana durante 1 hora a temperatura ambiente con solución de seroalbúmina bovina (BSA) 3,0\% p/v en TBS (TBS-BSA). Posteriormente se reemplazó la solución de bloqueo por una solución de TBS-BSA conteniendo el anticuerpo primario. La membrana fue incubada con esa solución durante toda la noche a $4^{\circ} \mathrm{C}$ y con agitación suave. Transcurrida esa incubación se retiró la solución del anticuerpo y se realizaron seis lavados con Tween 80 0,05\% v/v en TBS. Se adicionó el segundo anticuerpo policlonal conjugado con peroxidasa HRP disuelto en TBS-BSA y se incubó con agitación lenta durante 2,5 horas a temperatura ambiente. Se retiró la solución del segundo anticuerpo y se realizaron tres lavados con TBS-BSA y un lavado final con TBS. Para el revelado se utilizó el sustrato quimioluminiscente comercial "Clarity Western ECL" (BioRad) y la adquisición de las imágenes se realizó con placa fotográfica.

\section{Dot blot}

Para los ensayos de Dot Blot se inocularon $5 \mathrm{~mL}$ de medio de cultivo con una $\mathrm{DO}=0,05-0,1$ ( $\mathrm{DO}_{600}$ en el caso de $P$. fluorescens y $\mathrm{DO}_{650}$ en el caso de $B$. bronchiseptica). Estos cultivos fueron incubados durante $16-18$ horas a $37^{\circ} \mathrm{C}$ con agitación (160 rpm). Transcurrido el período de incubación se tomaron alícuotas de 1,5 $\mathrm{mL}$ y se colocaron en hielo. Paralelamente se tomó $1 \mathrm{~mL}$ para realizar medidas de DO. Las muestras de los diferentes cultivos fueron normalizadas por dilución de acuerdo a la muestra que presentaba el menor valor de $\mathrm{DO}_{650}$. Las diluciones fueron centrifugadas $16.000 \mathrm{xg}$ durante un minuto. El paquete celular fue lavado 2 veces con $1 \mathrm{~mL}$ de medio K10-T en el caso de ensayo con $P$. fluorescens o con SS en el caso del ensayo con B. bronchiseptica. El pellet del último lavado fue resuspendido en medio K10-T o SS según correspondía. 5 $\mu \mathrm{L}$ de estas suspensiones fueron colocados en forma de gota en membranas de nitrocelulosa. Cada muestra fue analizada por triplicado. La membrana de dejó secando 16 horas a temperatura ambiente. Luego fue bloqueada y revelada siguiendo el mismo protocolo que para el Western blot. 


\section{Capítulo 9}

La realización de los dot blot del Capítulo 7 (Figura 7.13) fue realizada de manera idéntica a la descripta en esta sección, pero la adquisición de las imágenes fue realizada mediante de un equipo Odyssey CLx (LI-COR).

Para el procesamiento cuantitativo de los resultados se tomaron fotografías de las membrana reveladas y se utilizó el protocolo de cuantificación recomendado por los desarrolladores del programa Image ${ }^{274}$ para estos casos. En el caso de los dot blot de la Figura 4.2 la imagen fue digitalmente invertida para que el fondo fuera negro y las manchas blancas (recomendación del desarrollador). En el caso de los experimentos que incluyeron la adquisición de las imágenes mediante el sistema Odyssey CLx (LI-COR) esto no fue necesario debido a que el fondo en la imagen adquirida ya era negro. Se utilizó la función "integrated density", se seleccionó el área ocupada por cada mancha y se midió la densidad integrada. Se realizaron entre 4 y 6 réplicas técnicas por experimento. El promedio de las réplicas técnicas de cada cepa fue normalizado frente al promedio de las réplicas técnicas de la cepa salvaje.

\section{Cuantificación de proteínas mediante el método de Bradford}

Para la cuantificación de proteínas se utilizó el método de Bradford ${ }^{324}$. Este método se basa en el cambio de color del colorante Comassie Brilliant Blue G-250 en presencia de distintas concentraciones de proteínas. La interacción del colorante con aminoácidos básicos y aromáticos provoca un cambio en su máximo de absorción, de 465 nm a 595 $\mathrm{nm}$ (rojo y azul, respectivamente). Para determinar la concentración de proteínas en una muestra dada, se realizaron diluciones $1 / 5,1 / 10$ y 1/50. En forma paralela se realizó la medida de muestras de BSA de concentración conocida a fin de realizar una curva de calibración $(0,05 \mathrm{mg} / \mathrm{mL} ; 0,1 \mathrm{mg} / \mathrm{mL} ; 0,2 \mathrm{mg} / \mathrm{mL} ; 0,4 \mathrm{mg} / \mathrm{mL}$ y $0,5 \mathrm{mg} / \mathrm{mL})$. Tanto las muestras como la curva de calibración fueron medidas por triplicado. Se determinó la absorbancia a $595 \mathrm{~nm}$ de las diferentes diluciones y de la curva de calibración. La concentración de la muestra fue determinada a partir de la dilución que presentaba valores de absorbancia dentro del rango de la curva de calibración. Utilizando el valor de absorbancia a $595 \mathrm{~nm}$ y mediante interpolación de la curva de calibración se determinó la cantidad de proteína en la muestra problema.

Para la realización de estos ensayos se utilizó reactivo de Bradford comercial (BioRad) y BSA comercial (Sigma Aldrich) 


\section{Clonación por recombinación in vivo en Saccharomyces cerevisiae}

Breve descripción de la técnica. Esta estrategia de clonado se basa en el aprovechamiento de la maquinaria de reparación del ADN por doble recombinación en la levadura Saccharomyces cerevisiae (InvSc1, Invitrogen) ${ }^{313}$. El vector de clonado digerido y el/los amplicones a ser clonados son introducidos en la levadura mediante transformación por shock térmico. La maquinaria de reparación del ADN de la propia levadura reconoce el vector digerido y los fragmentos de ADN como material a reparar y utiliza su propia maquinaria para unir los fragmentos homólogos por doble recombinación (Figura 9.1). Esta estrategia fue utilizada para la clonación de secuencias para expresión (vector pMQ72) o mutación (vector pMQ30).

Vectores aptos para clonación mediante esta estrategia. Los vectores utilizados en este trabajo para realizar este tipo de clonaciones fueron los vectores pMQ30 y pMQ72 (Anexo 1, Figura 9.2). Los requisitos que deben cumplir estos vectores son: $i$ ) tener un origen de replicación apto para $S$. cerevisiae; ii) tener un centrómero; iii) tener un marcador de selección apto para $S$. cerevisiae; iv) tener un origen de replicación apto para E. coli; $v$ ) tener un marcador de selección apto para E. coli (estos dos últimos además deben ser aptos para el organismo donde vaya a ser utilizado posteriormente, en este caso B. bronchiseptica) (Figura 9.1.a)

Digestión del vector. El vector donde se deseaba realizar la clonación fue linealizado mediante una digestión enzimática utilizando enzimas de restricción (Figura 9.1.b). En este trabajo de tesis se utilizó la enzima Smal la cual posee un sitio de restricción dentro del sitio de clonado múltiple de los vectores pMQ30 y pMQ72.

Diseño de primers. Los primers utilizados para esta estrategia de clonación deben ser especialmente diseñados para este fin. Para el diseño de los primers debe considerarse que en el extremo 5' de cada uno se debe incorporar una secuencia de entre 20 y 40 nucleótidos complementaria al sitio del vector donde se desea clonar el producto de PCR (Figura 9.1.c, recuadro rojo y recuadro violeta).

Amplificación por PCR. La o las secuencias a ser clonadas fueron amplificadas mediante una PCR tradicional. 


\section{Capítulo 9}

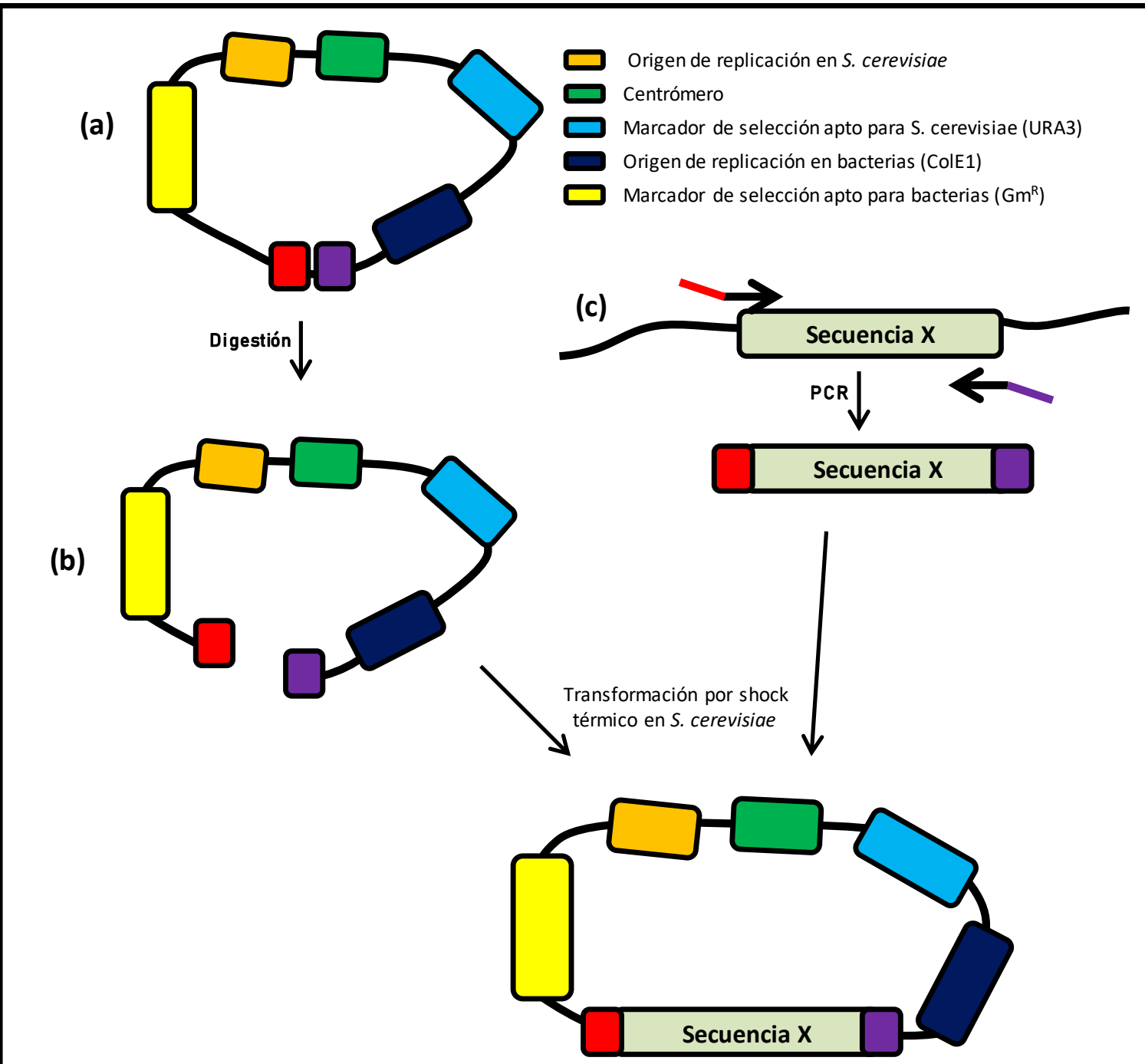

Figura 9.1. Esquema del proceso de clonación por doble recombinación homóloga en la levadura S. cerevisiae.

Protocolo de clonación. Una alícuota de la levadura almacenada a $-80^{\circ} \mathrm{C}$ fue aislada en placa conteniendo medio de cultivo sólido YPD. Esta placa fue incubada durante toda la noche a $30^{\circ} \mathrm{C}$. Colonias aisladas fueron usadas para inocular un cultivo líquido en medio YPD e incubada durante toda la noche a $30^{\circ} \mathrm{C}$ con agitación (160 rpm). Se tomaron cuatro alícuotas de $0,5 \mathrm{~mL}$ y se centrifugaron durante 10 segundos a $8.000 \mathrm{xg}$. Los pellets obtenidos fueron resuspendidos en $0,5 \mathrm{~mL}$ de buffer TE y centrifugados nuevamente. Estos pellets fueron resuspendidos, esta vez en $0,5 \mathrm{~mL}$ de solución Lazy Bones. A estas suspensiones se adicionaron vector, producto de PCR y ADN de esperma de salmón (dependiendo si se trataba de la clonación o los controles) de acuerdo con siguiente esquema: 


\begin{tabular}{rrrcc}
\hline & & Vector & Producto PCR & ADN de esperma de salmón \\
\hline $\mathbf{1}$ & Clonación & $30 \mathrm{ng}$ (digerido) & $50 \mu \mathrm{L}$ & $20 \mu \mathrm{L}$ \\
$\mathbf{2}$ & Control negativo I (plásmido digerido) & $30 \mathrm{ng}$ (digerido) & - & $20 \mu \mathrm{L}$ \\
$\mathbf{3}$ & Control negativo II (levadura) & - & - & $20 \mu \mathrm{L}$ \\
4 & Control positivo & $30 \mathrm{ng}$ (sin digerir) & - & $20 \mu \mathrm{L}$ \\
\hline
\end{tabular}

Estas suspensiones fueron agitadas vigorosamente durante un minuto e incubadas durante 3 días a temperatura ambiente. Transcurrido este tiempo se realizó un shock térmico de 10 minutos a $42^{\circ} \mathrm{C}$. Las suspensiones fueron lavadas dos veces con buffer TE y plaqueadas en medio selectivo URA3-. Estas placas fueron incubadas durante 3 a 5 días hasta aparición de colonias blancas en las placas correspondientes a la clonación y al control positivo.

Para la recuperación de las construcciones su realizó un protocolo de obtención de ADN plasmídico utilizando kits comerciales siguiendo las instrucciones del fabricante con algunas modificaciones. La biomasa de levaduras fue recolectada de la placa de cultivo con $2 \mathrm{~mL}$ de agua desionizada estéril utilizando espátula de Drigalsky. La suspensión se centrifugó durante 10 segundos a $8.000 \mathrm{xg}$ y el pellet fue resuspendido en $250 \mu \mathrm{L}$ de solución la solución 1 del kit (solución de resuspensión). Luego se adicionaron $250 \mu \mathrm{L}$ de la solución de lisis y $250 \mu \mathrm{L}$ de perlas de vidrio de $0,5 \mathrm{~mm}$. Esta mezcla fue agitada vigorosamente durante 2 minutos tras lo cual se la dejó reposar durante 5 minutos a $4^{\circ} \mathrm{C}$. Transcurrido ese tiempo se adicionaron $350 \mu \mathrm{L}$ de solución de precipitación previamente enfriada en hielo. Esta suspensión fue mezclada por inversión y finalmente se la dejó reposar en hielo durante 5 minutos. Luego fue centrifugada durante 10 minutos a $16.000 \mathrm{xg}$ a temperatura ambiente y se continuó con el protocolo de obtención de ADN plasmídico según las indicaciones del proveedor del kit sin ninguna otra modificación. El material plasmídico recuperado fue transformado por electroporación en una cepa de $E$. coli S17-1 electrocompetente. Como paso final del protocolo de clonación se evaluó la presencia de la construcción deseada mediante PCR.

\section{Estrategia para la obtención de mutantes por deleción limpia en}

\section{B. bronchiseptica}

Para el desarrollo del protocolo de obtención de mutantes se utilizaron los vectores no replicativos en $B$. bronchiseptica pK18mob-sacB $\left(\mathrm{Km}^{\mathrm{R}}\right)$ y pMQ30 $\left(\mathrm{Gm}^{\mathrm{R}}\right)$ (Anexo 1, Figura 9.2). Ambos vectores poseen en su secuencia el cassette codificante para el gen $s a c B$ el cual permite la selección de dobles recombinantes por contra selección. Todas las cepas mutantes construidas en este trabajo fueron obtenidas por deleción limpia. Para la obtención de las cepas mutantes, regiones de 600 a 800 pares 


\section{Capítulo 9}

de bases adyacentes a la secuencia a ser eliminada fueron amplificadas por PCR. Para la clonación en el vector PMQ30 se utilizó una estrategia basada en la recombinación homóloga in vivo en la levadura $S$. cerevisiae ${ }^{313}$. Para la clonación en el vector pK18mobsacB se utilizó una estrategia basada en el uso de ligasa y enzimas de restricción. Los vectores recombinantes fueron transformados por electroporación en la cepa conjugativa Escherichia coli S17-1. La transferencia de la construcción a $B$. bronchiseptica se realizó mediante conjugación (ver protocolo de conjugación aparte). Brevemente, la mezcla de conjugación fue resuspendida en buffer fosfato y se prepararon diluciones seriadas 1/10. Estas diluciones fueron plaqueadas en medio BGA-sangre suplementado con $\mathrm{Str}$ y $\mathrm{Gm}$ o $\mathrm{Km}$ a $37^{\circ} \mathrm{C}$ hasta aparición de colonias hemolíticas (entre 3 y 5 días).

\section{Protocolo de contra selección con sacarosa}

Para la selección de clones doble recombinantes utilizamos una estrategia de contra selección basada en la utilización del gen sacB de Bacillus subtilis ${ }^{325}$. En presencia de sacarosa, la expresión de este gen confiere toxicidad a la bacteria que lo posee ${ }^{326}$. En la bibliografía existen reportes contradictorios acerca del uso de este sistema de selección en Bordetella spp. C Inatsuka et al. reportaron problemas para utilizar este sistema de contra selección en $B$. bronchiseptica ${ }^{327}$. Sin embargo reportes previos dan cuenta de un uso exitoso de esta estrategia ${ }^{198,328}$.

Debido a la existencia de poca información, los detalles experimentales descriptos a continuación fueron puestos a punto durante el desarrollo de este trabajo de tesis.

Para el desarrollo de este protocolo se tomaron colonias hemolíticas de las placas de conjugación. Estas colonias fueron repicadas en dos placas en forma de réplica. Por un lado, se repicaron en medio de cultivo BGA-sangre suplementado con antibióticos y por otro lado en LB sin NaCl suplementado con sacarosa 15\% p/v (LB-sac). Estas placas fueron incubadas durante 24 horas a $37^{\circ} \mathrm{C}$. Aquellos repiques que crecieron óptimamente en BGA-sangre y no crecieron en LB-sac fueron utilizados para inocular un cultivo de 5 $\mathrm{mL}$ en medio SS suplementado con Str. Este cultivo fue incubado toda la noche a $37^{\circ} \mathrm{C}$ con agitación (160 rpm). Transcurrido el tiempo de incubación se prepararon diluciones $10^{-1}$ a $10^{-6}$ y fueron plaquedas en paralelo en medio de cultivo LB-sac y en LB (control). Estas placas fueron incubadas 24 horas a $37^{\circ} \mathrm{C}$. Aquellas colonias que crecieron en la placa de LB-sac fueron repicadas en BGA-sangre e incubadas 24 horas a $37^{\circ} \mathrm{C}$. Estas colonias corresponden a dobles recombinantes. Finalmente se realizó una evaluación 
mediante PCR para identificar aquellos clones recombinantes que fueran mutantes delecionales.

\section{Construcción de la cepa B. bronchiseptica-HA}

La marca de hemaglutinina (HA) fue introducida mediante doble recombinación homóloga después del residuo de valina 2291 de BrtA. Esta localización implica que el epitope HA se localiza inmediatamente después de la región de repeticiones de BrtA. La elección de esta región se basó en informes previos de resultados en $P$. fluorescens los cuales demuestran que en LapA está región queda expuesta hacia el lado externo de la membrana plasmática ${ }^{126}$. Este diseño permite evaluar la localización de BrtA-HA mediante dot blot además de analizar su secreción mediante Western blot. Para la incorporación de la secuencia codificante para el epitope HA en el marco de lectura de brtA se amplificaros los fragmentos BrtA-HA-1 y BrtA-HA-2 de $\sim 750$ pares de bases adyacentes al codón que codifica para la valina 2291. Paralelamente, la secuencia codificante para HA fue amplificada desde el vector pTinyLapA. Las secuencias BrtA-HA1, HA y BrtA-HA-2 fueron clonadas en el vector pMQ30 mediante la estrategia de doble recombinación homóloga en levaduras ${ }^{313}$. Esta construcción fue utilizada para introducir la marca de HA en la posición mencionada, mediante doble recombinación homóloga. Para esto se empleó la estrategia de contra selección con sacarosa. La introducción de la marca de HA fue analizada mediante PCR y secuenciación de manera tal de confirmar que el producto obtenido conservara el marco de lectura de brtA.

\section{Construcción de cepas de $B$. bronchiseptica fluorescentes}

Para la construcción de cepas fluorescentes que pudieran ser utilizadas en ensayos de microscopía de fluorescencia utilizamos el vector pGFLIP ${ }^{199}$ (Anexo 1, Figura 9.2). El vector pGFLIP contiene secuencias Tn7L y Tn7R alrededor de i) un sitio de clonado múltiple, ii) la secuencia codificante para neomicina fosfotransferasa II (factor de resistencia a $\mathrm{Km}$ ) y iii) la secuencia de gen gfp de la proteína verde fluorescente. En presencia de la transposasa $T n 7$ las secuencias $T n 7 L$ y Tn7R dirigen la recombinación sitio específica del material que se encuentra entre ellas a un sitio att $\operatorname{Tn} 7$ ubicado entre los genes glmS y BB4801 del genoma de B. bronchiseptica. Las bacterias transformadas finalmente adquieren fluorescencia GFP y resistencia a Km. La incorporación de material genético en esta zona no genera ningún efecto en la biología de $B$. bronchiseptica ${ }^{315}$.

Para la transformación de $B$. bronchiseptica se realizó una conjugación triparental. La transposasa $T n 7$ está codificada por las secuencias $t n s A B C D$ presentes en el vector pTNS3 (Anexo 1, Figura 9.2). La cepa E. coli pTNS3 fue incluida en el protocolo de 


\section{Capítulo 9}

conjugación junto a la cepa $E$. coli S17-1 donora y la cepa $B$. bronchiseptica aceptora. En estas condiciones, el vector pGFLIP proveniente de la cepa donora es transferido a $B$. bronchiseptica al igual que el vector pTNS3. La expresión de la transposasa Tn7 dirige la recombinación sitio específica de las secuencias internas a los sitios Tn7L y Tn7R hasta el mencionado sitio att Tn7. Una vez concluido el protocolo de conjugación, la correcta localización de la construcción fue evaluada utilizando los primers gfpseqR y glmSF. El protocolo presentado previamente fue utilizado para la construcción de las cepas $B$. bronchiseptica-GFP y $B$. bronchiseptica-GFP-LapG $\mathrm{Bb}_{\mathrm{Bb}}$.

\section{Reemplazo de $L a p D_{P f}$ por $\operatorname{LapD}_{\mathrm{Bb}}$ en la cepa $P$. fluorescens $\triangle$ 4DGC}

La secuencia del gen $\operatorname{lap}_{B b}$ fue introducida en el genoma de $P$. fluorescens $\triangle 4 D G C$ en reemplazo de la secuencia nativa lap $D_{P f}$. Este procedimiento se realizó mediante doble recombinación homóloga y la selección de los dobles recombinantes fue facilitada mediante el uso de la estrategia de contra selección con sacarosa.

Diseño y clonación de la construcción. Se amplificaron por PCR fragmentos de $\sim 400$ pares de bases adyacentes a la secuencia codificante de lap $D_{P f}$ (secuencias F1 y F2). Paralelamente se amplificó la secuencia codificante de $l a p D_{B b}$. Los fragmentos F1, F2 y $l a p D_{B b}$ fueron clonados en el vector $\mathrm{pMQ} 30$ mediante la estrategia de recombinación in vivo en S. cerevisiae ${ }^{313}$. Esta estrategia llevó a la obtención de la construcción pMQ30F1/ap $D_{B b} \mathrm{~F} 2$ la cual fue trasformada en $E$. coli S17-1 mediante electroporación y almacenadas $\mathrm{a}-80^{\circ} \mathrm{C}$.

Conjugación. Para la trasformación de $P$. fluorescens utilizamos una estrategia de conjugación. Se tomaron alícuotas de $1 \mathrm{~mL}$ de cultivos de 16 horas de las cepas $P$. fluorescens $\triangle 4 \mathrm{DGC}$ y $E$. coli $\mathrm{pMQ} 30 \mathrm{~F} 1 / a p D_{B b} \mathrm{~F} 2$ y se centrifugaron durante 5 minutos a $8.000 \mathrm{xg}$. Se realizaron 2 lavados con medio LB. Ambos pellets fueron resuspendidos en $25 \mu \mathrm{L}$ de medio de cultivo LB y combinados en un tubo. La mezcla de conjugación fue plaqueda en forma de gota en un placa de LB sin antibiótico. A modo de control, en esta misma placa se realizaron repiques de las cepas aisladas de $P$. fluorescens y $E$. coli. Esta placa fue incubada durante toda la noche a $30^{\circ} \mathrm{C}$. Transcurrido este período de incubación, el material celular de la gota de conjugación fue resuspendido en $100 \mu \mathrm{L}$ de medio LB. $50 \mu \mathrm{L}$ de esta suspensión fueron plaqueados en medio de cultivo LB suplementado con $\mathrm{Gm}(20 \mu \mathrm{g} / \mathrm{mL})$ y cloranfenicol $(30 \mu \mathrm{g} / \mathrm{mL})$. De forma análoga, los controles fueron resuspendidos y plaquedos. Estas placas fueron incubadas durante toda la noche a $30^{\circ} \mathrm{C}$. Colonias aisladas de la placa de conjugación fueron repicadas en medio LB suplementado con $\mathrm{Gm}(25 \mu \mathrm{g} / \mathrm{mL})$ e incubadas durante todas la noche a $30^{\circ} \mathrm{C}$. 
Contra selección con sacarosa. Biomasa de las placas anteriores fue tomada para inocular $5 \mathrm{~mL}$ de medio de cultivo LB sin antibiótico y se incubó durante 16 horas a $30^{\circ} \mathrm{C}$. A partir de este cultivo se prepararon diluciones $10^{-2}$ a $10^{-4}$ y se plaquearon en medio de cultivo LB $\sin \mathrm{NaCl}$ suplementado con sacarosa $10 \% \mathrm{p} / \mathrm{v}$. Estas placas fueron incubadas durante toda la noche a $30^{\circ} \mathrm{C}$. Colonias crecidas en estas placas fueron analizadas mediante PCR a fin de seleccionar los dobles recombinantes que hubieran incorporado la secuencia $l_{a p} D_{B b}$ en lugar de $l a p D_{P f}$. Con este objetivo, se utilizaron primers específicos que hibridan en la secuencia de $\operatorname{lap}_{B b}$ y no la hacen en $l a p D_{P f}$.

\section{Ensayos de formación de biofilm en microplacas de PVC}

Para el desarrollo de los experimentos de formación de biofilm en placas multipocillo se utilizaron las placas Corning 96 Well Clear PVC Assay Microplate (SigmaAldrich). Las microplacas de cultivo utilizadas fueron esterilizadas mediante radiación UV. Con el objetivo de eliminar el efecto borde que puede aparecer en este sistema de cultivo, las placas fueron cortadas en tiras de 2 columnas por 8 filas. De esta manera, todas las fosas de cultivo se encontraban sometidas a las mismas condiciones de aireación. A lo largo de este trabajo se realizaron diversos ensayos de formación de biofilm en microplacas de PVC con los organismos B. bronchiseptica y $P$. fluorescens. A continuación, se detallan las condiciones de cultivo utilizadas para cada uno de los organismos:

B. bronchiseptica: Las cepas incluidas en el diseño del experimento fueron aisladas en medio BGA-sangre suplementado con Str y el antibiótico correspondiente al vector plasmídico en caso de que fuera necesario. Estas placas fueron incubadas durante 72 horas a $37^{\circ} \mathrm{C}$. Colonias hemolíticas provenientes de estas placas fueron repicadas en medio SS-sangre suplementado con antibióticos. Estas placas fueron incubadas durante 48 horas a $37^{\circ} \mathrm{C}$. Se tomó biomasa proveniente de la zona de la placa que presentaba colonias aisladas y se prepararon suspensiones bacterianas de $\mathrm{DO}_{650}=1,0$. En forma paralela se prepararon alícuotas de medio de cultivo SS suplementado con antibióticos y diferentes concentraciones de ácido nicotínico. Estas alícuotas fueron fraccionadas de a $450 \mu \mathrm{L}$. A esta alícuota se adicionaron $50 \mu \mathrm{L}$ de la suspensión bacteriana de manera tal de alcanzar una $\mathrm{DO}_{650}=0,1$. Estas suspensiones fueron colocadas en las fosas de las placas de cultivo ( $100 \mu \mathrm{L}$ por fosa por cuatriplicado) e incubadas durante 24 horas a $37^{\circ} \mathrm{C}$ en cámara húmeda.

$\boldsymbol{P}$. fluorescens. Las cepas a ensayar fueron aisladas en placas de LB suplementadas con $\mathrm{Gm}$ e incubadas durante 24 horas a $30^{\circ} \mathrm{C}$. Se tomó biomasa de estas placas para inocular cultivos de $5 \mathrm{~mL}$ suplementados con $\mathrm{Gm}$. Estos cultivos fueron incubados 


\section{Capítulo 9}

durante toda la noche a $30^{\circ} \mathrm{C}$ con agitación. A partir de estos cultivos se prepararon suspensiones bacterianas de $\mathrm{DO}_{600}=1,0$. En forma paralela se prepararon alícuotas de $900 \mu \mathrm{L}$ de medio de cultivo K10-T suplementado con arabinosa $0,2 \%$ p/v (en esta etapa no se utilizaron antibióticos). A estas alícuotas se adicionaron $100 \mu \mathrm{L}$ de las suspensiones bacterianas preparadas previamente para obtener suspensiones de $\mathrm{DO}_{600}=0,1$. Estas suspensiones fueron utilizadas para inocular las placas de cultivo (100 $\mu \mathrm{L}$ por fosa, por sextuplicado). Las placas inoculadas fueron incubadas durante 6 horas a $30^{\circ} \mathrm{C}$ en cámara húmeda.

Las siguientes etapas del protocolo de formación de biofilm fueron iguales para los dos organismos.

Lavado, fijación y secado. Transcurrido el período de incubación la suspensión bacteriana fue removida y descartada. Las placas de cultivo fueron lavadas dos veces con agua destilada e incubadas durante 15 minutos a $37^{\circ} \mathrm{C}$.

Tinción. Para la tinción de las fosas de cultivo se utilizó solución de cristal violeta $0,1 \%$ p/v. En cada fosa se colocaron $120 \mu \mathrm{L}$ de solución de cristal violeta y se incubó durante 30 minutos en cámara húmeda a fin de evitar la evaporación de la solución y deposición del colorante. Luego de la incubación, las fosas fueron lavadas dos veces con agua destilada. Luego se dejaron a temperatura ambiente hasta secado completo de las fosas.

Registro de los resultados. En este punto se tomaron imágenes para analizar la formación de biofilm de manera cualitativa y luego se avanzó hacia la etapa de revelado. Revelado. Para el revelado de los ensayos de biofilm en microplacas se colocaron 125 $\mu \mathrm{L}$ de solución de ácido acético $33 \% \mathrm{v} / \mathrm{v} .100 \mu \mathrm{L}$ de la solución obtenida fueron transferidos a placas de fondo plano. Estas placas fueron medidas en un espectrofotómetro a $595 \mathrm{~nm}$.

\section{Ensayos de formación de biofilm en tubos de vidrio}

Cultivo. Para el desarrollo de estos ensayos, las cepas $B$. bronchiseptica salvaje y $B$. bronchiseptica $\triangle b r t A$ fueron aisladas en medio BGA-sangre y repicadas en medio SSsangre de manera análoga a la explicada antes para los ensayos de formación de biofilm en microplaca. Luego se tomó biomasa proveniente de la región de las placas que contenían colonias aisladas y se prepararon suspensiones en medio SS de $\mathrm{DO}_{650}=1,0$. En forma paralela se prepararon alícuotas de medio de cultivo SS suplementado con antibióticos y ácido nicotínico (2,0 mM). 1,8 mL de estas alícuotas fueron colocados en tubos cónicos de $15 \mathrm{~mL}$ y posteriormente se adicionaron $200 \mu \mathrm{L}$ de las suspensiones preparadas previamente de manera tal de alcanzar una $D_{650}=0,1$. Dos $\mathrm{mL}$ de estas 
suspensiones fueron colocados en tubos de vidrio estériles e incubados durante 24,48 y 96 horas a $37^{\circ} \mathrm{C}$.

Fijación. Transcurrido el tiempo de incubación, la suspensión bacteriana fue retirada y descartada. Los tubos fueron lavados dos veces con agua destilada. Posteriormente se colocaron 2,5 $\mathrm{mL}$ de solución de glutaraldehído en PBS 2,5\% v/v y se realizó una incubación de 2 horas a $4^{\circ} \mathrm{C}$.

Tinción. La solución de glutaraldehído fue retirada y descartada. Se adicionaron 2,5 mL de solución de cristal violeta $0,1 \% \mathrm{p} / \mathrm{v}$ y se realizó una incubación de 30 minutos a temperatura ambiente. Transcurrido este tiempo se retiró la solución de cristal violeta y los tubos fueron lavados dos veces con agua destilada. Finalmente, los tubos fueron dejados a temperatura ambiente hasta completo secado del material.

Registro de los resultados. Estos experimentos fueron fotografiados y la formación de biofilm fue analizada de manera cualitativa.

\section{Ensayos de formación de biofilm sobre cubreobjetos semi sumergidos}

Esta estrategia experimental, desde el cortado de los vidrios hasta la forma de cultivo en tubos de microcentrífuga, los lavados, la fijación y el revelado fue puesta a punto durante el desarrollo de este trabajo de tesis.

Preparación del material. Se utilizó un lápiz con punta de diamante para realizar cortes longitudinales en cubreobjetos de $20 \mathrm{~mm}$ x $20 \mathrm{~mm}$. Los cortes fueron realizados para obtener una superficie de $20 \mathrm{~mm} \times 8 \mathrm{~mm}$ y posteriormente fueron limpiados utilizando solución de etanol en agua $70 \% \mathrm{v} / \mathrm{v}$. En forma paralela se tomaron tubos de plástico (polipropileno) de microcentrífuga estériles a los cuales se les cortó la tapa. Los cubreobjetos cortados fueron introducidos dentro de los tubos de microcentrífuga y esterilizados mediante radiación UV. Finalmente, los tubos conteniendo los cubreobjetos cortados fueron introducidos dentro de una cámara húmeda mientras se prepararon las suspensiones bacterianas que serían incubadas dentro de estos tubos.

Cultivo. Las cepas elegidas para el desarrollo de estos experimentos fueron inicialmente aisladas en medio BGA-sangre y repicadas en medio SS-sangre de manera análoga a la explicada antes para los ensayos de formación de biofilm en microplaca. De las placas de SS-sangre se tomó biomasa de la zona que contenía colonias aisladas y se prepararon suspensiones de $\mathrm{DO}_{650}=1,0$ en medio SS. En forma paralela se prepararon alícuotas de $900 \mu \mathrm{L}$ medio de cultivo SS suplementado con antibióticos y ácido nicotínico. Asimismo, se prepararon alícuotas de $900 \mu \mathrm{L}$ medio de cultivo SS suplementado con antibióticos, 


\section{Capítulo 9}

ácido nicotínico, BSA $(2,0 \mathrm{mg} / \mathrm{mL})$ y $\mathrm{CaCl}_{2}(2,0 \mathrm{mM}) .100 \mu \mathrm{L}$ de las suspensiones bacterianas fueron adicionados a las alícuotas de medio de cultivo de manera tal de alcanzar una $D^{6} O_{60}=0,1$. Cuatrocientos cincuenta $\mu \mathrm{L}$ de estas suspensiones fueron colocados dentro de los tubos conteniendo los cubreobjetos. Se realizaron duplicados técnicos de cada cepa y cada condición de cultivo. La descarga de esta suspensión fue realizada con sumo cuidado a fin de evitar la que la misma tocara las zonas superiores del cubreobjetos de vidrio y evitar la formación de burbujas. De esta manera el cubreobjetos de vidrio queda semi sumergido en la suspensión bacteriana. Los tubos fueron incubados durante 24 horas a $37^{\circ} \mathrm{C}$ en cámara húmeda.

Fijación. Antes de comenzar, se prepararon tubos de microcentrífuga conteniendo 750 $\mu \mathrm{L}$ de solución fijadora de glutaraldehído en PBS $2,5 \% \mathrm{v} / \mathrm{v}$. Terminado el tiempo de incubación, los cubreobjetos fueron retirados de la suspensión bacteriana y sumergidos 2 veces en buffer fosfato a fin de eliminar las bacterias que no estuvieran adheridas a la superficie. Estos vidrios fueron sumergidos en los tubos conteniendo la solución fijadora de glutaraldehído $2,5 \% \mathrm{v} / \mathrm{v}$ preparados previamente. La suspensión bacteriana remanente en los tubos de microcentrífuga fue retirada suavemente con pipeta y descartada. Posteriormente se adicionaron $750 \mu \mathrm{L}$ de solución fijadora de glutaraldehído $2,5 \% \mathrm{v} / \mathrm{v}$. Tanto los cubreobjetos y los tubos de microcentrífuga fueron incubados durante 2 horas a $4^{\circ} \mathrm{C}$.

Tinción. Antes de comenzar, se prepararon tubos de microcentrífuga conteniendo 750 $\mu \mathrm{L}$ de solución de cristal violeta $0,1 \% \mathrm{p} / \mathrm{v}$. Terminado el tiempo de incubación, los cubreobjetos fueron retirados de la solución fijadora de glutaraldehído y colocados dentro de los tubos con cristal violeta. Posteriormente, la solución fijadora de glutaraldehído contenida en los tubos de microcentrífuga donde se habían realizado los cultivos fue retirada con pipeta. A estos tubos se adicionaron $750 \mu \mathrm{L}$ de solución de cristal violeta $0,1 \% \mathrm{p} / \mathrm{v}$. Los cubreobjetos y los tubos de microcentrífuga fueron incubados durante 30 minutos a temperatura ambiente en cámara húmeda. Terminado el tiempo de incubación los cubreobjetos fueron retirados y sumergidos 2 veces en agua destilada a fin de eliminar los restos de colorante. En forma paralela se retiró el colorante de los tubos de microcentrífuga y se realizaron 2 lavados con $1 \mathrm{~mL}$ de agua destilada. Todo el material fue dejado a temperatura ambiente hasta el completo secado.

Registro de los resultados. Estos experimentos fueron fotografiados y la formación de biofilm fue analizada de manera cualitativa. 


\section{Ensayos de formación de biofilm sobre monocapa celular}

Línea celular. Para el desarrollo de los experimentos de adhesión y formación de biofilm sobre una superficie biótica fue utilizada la línea celular CFBE (Cystic Fibrosis-derived epithelial cells) derivada de un paciente con fibrosis quística ${ }^{281}$. Las células fueron mantenidas en frascos T-75 (Thermo Fisher Scientific) con $12 \mathrm{~mL}$ en medio de cultivo MEM (Invitrogen) suplementado con suero fetal bovino $(10 \% \mathrm{v} / \mathrm{v})$; penicilina, Str; Lglutamina $(2,0 \mathrm{mM})$; plasmocina $(12,5 \mu \mathrm{g} / \mathrm{mL})$ y puromicina $(25,0 \mu \mathrm{g} / \mathrm{mL})$. Los cultivos de la línea CFBE fueron mantenidos a $37^{\circ} \mathrm{C}$ en cámaras de cultivos con $5 \%$ de $\mathrm{CO}_{2}$. El medio de cultivo agotado fue removido cada 72 horas y reemplazado por medio de cultivo fresco. La evolución de las células fue seguida utilizando un microscopio óptico invertido.

Preparación de la monocapa celular. Las células cultivadas en frascos T-75 fueron mantenidas hasta alcanzar un nivel de confluencia del $75-80 \%$. En ese momento se tomaron células para inocular las placas de 24 pocillos con o sin disco de vidrio de 35 $\mathrm{mm}$ de espesor en el fondo (Invitrogen). Las placas con disco de vidrio fueron utilizadas para los ensayos de microscopía de fluorescencia mientras que las placas sin disco de vidrio fueron usadas para recuentos de UFC adheridas a la monocapa. Para esto, el medio de cultivo agotado fue removido y se realizó un lavado suave con $4 \mathrm{~mL}$ de buffer fosfato. La solución de lavado fue removida cuidadosamente y se adicionaron $4 \mathrm{~mL}$ de buffer fosfato con tripsina. Para realizar el tratamiento con tripsina y desprender las células de la monocapa se incubó a $37^{\circ} \mathrm{C}$ durante 5 minutos o hasta observación del despegado de las células del fondo de la botella. Posteriormente, se adicionaron $10 \mathrm{~mL}$ de medio de cultivo fresco a fin de detener el tratamiento con tripsina (el suero fetal bovino presente en el medio de cultivo inhibe la actividad de la tripsina y protege a las células de daño posterior). La suspensión de células fue transferida a un tubo cónico de $50 \mathrm{~mL}$ y luego fue centrifugada durante 3 minutos a $650 \mathrm{xg}$. El sobrenadante de cultivo fue removido y el paquete celular fue resuspendido en $2 \mathrm{~mL}$ de medio de cultivo fresco. De esta suspensión se tomaron $10 \mu \mathrm{L}$ para realizar el recuento celular. Posteriormente se preparó una suspensión de $5.10^{4}$ células $/ \mathrm{mL}$ y se colocó $1 \mathrm{~mL}$ por fosa en placas de 24 pocillos. Estos cultivos fueron mantenidos a $37^{\circ} \mathrm{C}$ en cámaras de cultivos con $5 \%$ de $\mathrm{CO}_{2}$. El medio de cultivo agotado fue renovado a las 72 horas por medio de cultivo fresco. Durante todo el tiempo de cultivo la integridad de las células y la formación de la monocapa fue monitoreada mediante observaciones con microscopio óptico invertido. Alrededor del quinto día de incubación las fosas presentaban una confluencia del 100\%. En ese momento fueron utilizadas para el desarrollo de los experimentos de adhesión y formación de biofilm. 


\section{Capítulo 9}

Preparación de los cultivos bacterianos. Las cepas $B$. bronchiseptica salvaje, $\triangle b r t A$ y $\triangle$ lapG fueron aisladas en medio BGA-sangre y repicadas en medio SS-sangre tal como se describió previamente. Se tomó biomasa de la zona de la placa que presentaba colonias aisladas y se prepararon suspensiones de $\mathrm{DO}_{650}=0,05$ en medio de cultivo MEM suplementado con L-glutamina (L-Gln; 2,0 mM). Paralelamente, el sobrenadante de cultivo de las placas de 24 pocillos fue removido y se realizó un lavado con $500 \mu \mathrm{L}$ de medio de cultivo MEM suplementado con L-Gln. Quinientos $\mu \mathrm{L}$ de la suspensión bacteriana fueron colocados en cada pocillo. Se realizaron triplicados de cada una de las cepas y tiempos que se analizaron. En estas condiciones las placas fueron incubadas durante 1 hora a $37^{\circ} \mathrm{C}$ en cámara con ambiente de $5 \%$ de $\mathrm{CO}_{2}$. Transcurrido este tiempo el medio de cultivo fue removido de manera de eliminar las bacterias que no se hubieran adherido a la monocapa celular. Se realizó un lavado con $500 \mu \mathrm{L}$ de medio de cultivo MEM suplementado con L-Gln y L-arginina (L-Arg; 0,4\% p/v). Finalmente, se adicionaron $500 \mu \mathrm{L}$ de medio de cultivo MEM suplementado con L-Gln y L-Arg y se incubó durante el tiempo indicado de acuerdo al desarrollo de cada experimento.

Recuento. Se realizaron recuentos de bacterias planctónicas en el sobrenadante de cultivo y de bacterias adheridas a la monocapa celular. Para estos experimentos se utilizó un tiempo de incubación de 21 horas. Transcurrido este tiempo se tomaron $100 \mu \mathrm{L}$ del sobrenadante de cultivo y se realizaron diluciones seriadas a fin de realizar el recuento de UFC/mL. Las diluciones fueron plaqueadas en medio BGA-sangre e incubadas $37^{\circ} \mathrm{C}$ durante 48 horas, momento en el cual se realizó el recuento de UFC. Para realizar el recuento de bacterias adheridas a la monocapa celular se descartó el sobrenadante de cultivo remanente y se adicionaron $250 \mu \mathrm{L}$ de buffer fosfato. De forma mecánica presionando con la punta del tip sobre el fondo de la fosa se disgregó la monocapa celular y se tomaron $100 \mu \mathrm{L}$ de esta suspensión. Se realizaron diluciones seriadas a fin de determinar número de UFC/mL. Las diluciones fueron plaqueadas en medio BGA-sangre e incubadas $37^{\circ} \mathrm{C}$ durante 48 horas, momento en el cual se realizó el recuento de UFC.

Microscopía de fluorescencia. Los ensayos de microscopía de fluorescencia sobre la monocapa celular se realizaron a tiempos de incubación de 4, 10, 20, 26 y 48 horas. Al tiempo indicado para cada experimentos se removió el sobrenadante de cultivo y se realizaron dos lavados suaves con buffer fosfato. El disco de vidrio sobre el que se desarrolló la monocapa celular fue removido y colocado sobre un cubreobjetos. Para la visualización de las células y bacterias se utilizó un objetivo de inmersión de 100X. Este experimento fue realizado utilizando un microscopio Nikon Eclipse Ti con módulo de spinning disk. 


\section{Identificación de BrtA por Huella Peptídica}

La identificación por huella pepetídica fue realizada mediante la tecnología MALDI-TOF (Matrix Assisted Laser Desorption/lonization- Time of Flight) ${ }^{268}$ en el servicio del Centro de Estudios Químicos y Biológicos por Espectrometría de Masa (CEQUIBIEM). La preparación de las muestras fue realizada en el laboratorio de acuerdo con el protocolo que detalla a continuación. Esta técnica fue utilizada con el objetivo de identificar una muestra de proteína proveniente de experimentos de electroforesis en SDS-PAGE.

Digestión tríptica in-gel. Concluida la corrida electroforética el gel fue teñido con colorante Coomassie Blue el cual es apto para el desarrollo del resto del protocolo. La banda de elevado peso molecular fue cortada del gel y transferida a una placa multipocillos. Esta muestra fue lavada con $100 \mu \mathrm{L}$ de agua desionizada y acetonitrilo para eliminar los restos de colorante Coomassie Blue (2 lavados de 10 minutos cada uno con agitación moderada). La muestra fue incubada con $20 \mu \mathrm{L}$ de solución de ditriotreitol (DTT) $5 \mathrm{mM}$ en bicarbonato de amonio $25 \mathrm{mM}$ durante 30 minutos a $60^{\circ} \mathrm{C}$. Posteriormente se realizó un lavado con $100 \mu \mathrm{L}$ de acetonitrilo. Luego se realizó una incubación de 15 minutos a temperatura ambiente, en oscuridad, con $20 \mu \mathrm{L}$ de solución de iodoacetamida $55 \mathrm{mM}$ y bicarbonato de amonio $25 \mathrm{mM}$. A continuación, se realizó un nuevo lavado con solución de bicarbonato de amonio $25 \mathrm{mM}$ y seguidamente la muestra fue deshidratada mediante 3 lavados con acetonitrilo. Cuando la muestra tomó una apariencia completamente blanca y deshidratada fue rehidratada con $5 \mu \mathrm{L}$ de solución de bicarbonato de amonio $25 \mathrm{mM}$ conteniendo tripsina (20 $\mathrm{gg} / \mathrm{mL}$, Promega). La muestra fue incubada durante 45 minutos a $4^{\circ} \mathrm{C}$ hasta observar una apariencia que confirmara la rehidratación de la misma. Finalmente, la muestra fue cubierta con una solución 25 mM de bicarbonato de amonio e incubada a $37^{\circ} \mathrm{C}$ durante toda la noche de manera tal que se produjera la digestión in gel.

Obtención de la huella peptídica mediante espectrometría de masa (EM). Para realizar el análisis por espectrometría de masa se utilizó la matriz a-ciano-4hidroxi-ácido cinámico, en una concentración $0,2 \mathrm{~g} / \mathrm{L}$ preparada en una solución $50 \%$ acetonitrilo / $0,25 \%$ TFA. La muestra junto con la matriz en una relación 1:1 fue colocada en el soporte MTP Anchor Chip TM 600/384 TF y se dejó secar durante 10 minutos a temperatura ambiente antes de realizar el análisis por espectroscopía de masa. El espectro de la muestra se obtuvo luego empleando un equipo Ultraflex II Tof-Tof (Bruker Daltonics). Los parámetros utilizados fueron los siguientes: potencia del láser $31-50 \%$, frecuencia del láser $100 \mathrm{~Hz}, 100$ shots por disparo, voltaje de aceleración $20 \mathrm{kV}$, detección de masa 800-3500 Da, señal deflectada por debajo de $850 \mathrm{Da}$, ganancia del detector $1650 \mathrm{~V}$, 


\section{Capítulo 9}

ganancia electrónica $100 \mathrm{mV}$. Los espectros fueron analizados utilizando el software Flex Analysis (Bruker Daltonics) y calibrados internamente utilizando los picos conocidos de autólisis de la tripsina.

Identificación de proteínas y herramientas bioinformáticas. La identificación de la proteína presente en la muestra fue realizada mediante el software MASCOT ${ }^{269}$ (Matrix Science a http://matrixscience.com) utilizando los siguientes parámetros de búsqueda: (i) Especie: Bacteria (Eubacteria); (ii) Enzima: tripsina con posibilidad de un error en la digestión; (iii) modificaciones postraduccionales fijas: carbamidometilación; (iv) tolerancia peptídica, \pm 0,2 Da; (v) carga del péptido: 1+; (v) masa: monoisotópica; (vi) masa de la proteína: irrestricta.

\section{Microscopía electrónica de barrido (SEM)}

La técnica de microscopía electrónica de barrido (SEM) fue utilizada para la observación de biofilms formados sobre vidrios semi sumergidos. Por este motivo, el protocolo utilizado para estos ensayos comparte algunas etapas con el protocolo de formación de biofilm sobre cubreobjetos semi sumergidos descripto previamente. La etapa de Cultivo y la etapa de Fijación son idénticas en ambos protocolos. La única diferencia reside en que, para la observación por SEM, los tubos de microcentrífuga usados en la etapa de cultivo no fueron posteriormente procesados, solo se continuó el protocolo con los cubreobjetos. Las etapas descriptas a continuación son exclusivas del protocolo de observación mediante SEM.

Deshidratación. Se realizó un tren de deshidratación con alcohol etílico. Para este procedimiento se prepararon soluciones de etanol-PBS $20 \%, 50 \%, 70 \%$ y $90 \%$ v/v. Luego de la etapa de fijación, los cubreobjetos fueron incubados durante 1 hora en cada solución de manera de tal de aumentar gradualmente la concentración de etanol. Las muestras fueron finalmente almacenadas en etanol absoluto hasta el momento de ser procesadas. Secado y Metalizado. El secado fue realizado mediante la técnica de punto crítico. Y el metalizado fue realizado con oro. Estos procedimientos fueron hechos por el servicio de microscopía electrónica de barrido y microanálisis del LIMF (Facultad de IngenieríaUNLP).

Observación y registro de los resultados. Las observaciones microscópicas fueron realizadas en: (i) el Centro de Investigación y Desarrollo en Ciencias Aplicadas (CINDECA-CONICET-UNLP) utilizando un microscopio Philips SEM 505 y (ii) en el servicio de microscopía electrónica de barrido y microanálisis del LIMF (Facultad de Ingeniería-UNLP) utilizando un microscopio FEI, Quanta 200. 


\section{Microscopía de fluorescencia}

La técnica de microscopía de florescencia fue utilizada para la observación de biofilms formados sobre cubreobjetos de vidrio. Si bien esta técnica también fue usada para el análisis de biofilms sobre monocapa celular, los detalles de esos experimentos se detallan en la sección "Ensayos de formación de biofilm sobre monocapa celular".

Preparación del material. Para los ensayos de microscopía de florescencia se utilizaron cubreobjetos de $20 \mathrm{~mm} \times 20 \mathrm{~mm}$ enteros. Estos cubreobjetos fueron limpiados con solución de etanol en agua $70 \%$ v/v y colocados dentro de tubos cónicos estériles de 50 $\mathrm{mL}$. Los cubreobjetos fueron colocados de manera tal de que uno de sus vértices quedara apuntando hacia abajo. Los tubos conteniendo los cubreobjetos fueron nuevamente esterilizados mediante radiación UV.

Preparación de los cultivos. Para el desarrollo de este experimento las cepas a ensayar fueron aisladas en BGA-sangre y repicadas en SS-sangre tal como describimos previamente. Posteriormente se prepararon suspensiones bacterianas de $\mathrm{DO}_{650}=1,0$. En paralelo se prepararon alícuotas de medio de cultivo SS suplementado con Str y Gm y otra alícuota suplementada con antibióticos y ácido nicotínico $(0,5 \mathrm{mM}) .1,8 \mathrm{~mL}$ de estas alícuotas fueron colocados en tubos cónicos de $50 \mathrm{~mL}$ y se adicionaron $200 \mu \mathrm{L}$ de las suspensiones bacterianas de manera tal de alcanzar una $\mathrm{DO}_{650}=0,1$. Estas suspensiones fueron colocadas dentro de los tubos cónicos de $50 \mathrm{~mL}$ conteniendo los cubreobjetos. Estos tubos fueron incubados durante 24 horas a $37^{\circ} \mathrm{C}$, sin agitación.

Observación al microscopio. Transcurrido este tiempo de incubación los cubreobjetos fueron retirados de los tubos cónicos y uno de los lados fue limpiado delicadamente utilizando Kimwipes (Kimtech). Este paso es fundamental para evitar que el lado del cubreobjetos que no es enfocado interfiera con la observación. Paralelamente se preparó un portaobjetos conteniendo una gota de $20 \mu \mathrm{L}$ de buffer fosfato. El lado del cubreobjetos donde se encontraba el biofilm fue montado boca abajo sobre la gota depositada en el portaobjetos. Finalmente, los bordes del cubreobjetos fueron sellados a la base portaobjetos utilizando esmalte para uñas. Este paso evita la deshidratación de la muestra y movimientos en el cubreobjetos que podrían destruir la estructura de biofilm. Estas muestras fueron observadas en un microscopio de fluorescencia Nikon Eclipse Ti con módulo de spinning disk.

\section{Ensayos de actividad de LapG}

Las cepas $E$. coli plap $G_{B b}$, plap $G_{P f}$ y pn-term-brtA fueron repicadas en forma de aislamiento en placas de LB suplementadas con $\mathrm{Gm}$. Estas placas fueron incubadas durante 24 horas a $37^{\circ} \mathrm{C}$. Colonias aisladas de estas placas fueron usadas para inocular 


\section{Capítulo 9}

$5 \mathrm{~mL}$ de medio de cultivo LB suplementado con $\mathrm{Gm}$ y fueron incubados durante 16 horas a $37^{\circ} \mathrm{C}$. Cincuenta $\mu \mathrm{L}$ de estos cultivos fueron usados para inocular $50 \mathrm{~mL}$ de medio de cultivo LB suplementado con $\mathrm{Gm}$. Estos cultivos fueron incubados a $37^{\circ} \mathrm{C}$ con agitación (160 rpm) hasta $\mathrm{DO}_{600}=0,6-0,8$. En este punto, los medios de cultivo fueron suplementados con $500 \mu \mathrm{L}$ de solución de arabinosa $20 \% \mathrm{p} / \mathrm{v}$ a fin de inducir la expresión de las secuencias que se encuentran bajo el control del promotor $P_{B A D}$. Los cultivos se mantuvieron en incubación durante 4 horas más. Terminado este período de incubación, los cultivos fueron centrifugados a $5.000 \mathrm{xg}$ durante 20 minutos a $4^{\circ} \mathrm{C}$. El sobrenadante de estos cultivos fue descartado y el pellet fue resuspendido en $1 \mathrm{~mL}$ de buffer LapA. Posteriormente, las bacterias fueron lisadas mediante sonicación utilizando un sonicador de punta marca Sonics (Vibra-cell). Se utilizó un $80 \%$ de potencia y pulsos de 10 segundos. Entre pulsos las muestras fueron mantenidas en hielo. Se realizaron entre 6 pulsos por muestra hasta observar la clarificación que indicaba la lisis de las bacterias. A continuación, se realizó una centrifugación a $13.000 \mathrm{xg}$ durante 10 minutos a $4^{\circ} \mathrm{C}$. El sobrenadante de esta centrifugación fue separado y almacenado a $-20^{\circ} \mathrm{C}$. A partir de estos sobrenadantes se prepararon las mezclas de reacción tal como se detalla en la siguiente tabla:

\begin{tabular}{l|c|ccc}
\hline & LapG $_{\mathrm{Bb}}$ & LapG $_{\mathrm{pf}}$ & n-term-BrtA & $\mathrm{CaCl}_{2}$ \\
\hline Reacción \#1 & $50 \mu \mathrm{L}$ & - & $50 \mu \mathrm{L}$ & - \\
Reacción \#2 & $50 \mu \mathrm{L}$ & - & $50 \mu \mathrm{L}$ & $10 \mathrm{mM}$ \\
Reacción \#3 & - & $50 \mu \mathrm{L}$ & $50 \mu \mathrm{L}$ & - \\
\hline \multicolumn{4}{r}{ Tabla 9.5. Mezclas de reacción utilizadas para el ensayo d actividad in vitro de LapG $_{B b .}$}
\end{tabular}

Tabla 9.5. Mezclas de reacción utilizadas para el ensayo d actividad in vitro de $L_{a p G_{B b}}$.

Las mezclas de reacción fueron mantenidas durante 2 horas a temperatura ambiente. Transcurrido este tiempo se adicionó buffer Laemmli 6X. Las muestras fueron incubadas durante 15 minutos en baño de agua a ebullición y luego sometidas a 10 minutos de sonicación en baño de agua a temperatura ambiente. Finalmente, fueron analizadas mediante SDS-PAGE y Western blot utilizando un anticuerpo primerio antiHA.

\section{Obtención de muestras de sobrenadante y célula entera para la detección de BrtA-HA y LapA-HA}

Detección de BrtA-HA. La cepa $B$. bronchiseptica con la fusión transcripcional del epitope HA a BrtA fue aislada en medio BGA sangre y repicada en medio SS-sangre tal como indicamos previamente. Biomasa proveniente de esta última placa fue usada para 
inocular $50 \mathrm{~mL}$ de medio de cultivo SS. Se preparó un cultivo suplementado con Str y otro cultivo suplementado con Str, seroalbúmina bovina (BSA, 2,0 mg/mL) y $\mathrm{CaCl}_{2}(2,0 \mathrm{mM})$. Estos cultivos fueron incubados durante 16 horas a $37^{\circ} \mathrm{C}$ con agitación (160 rpm).

Detección de LapA-HA. Las cepas $P$. fluorescens con la fusión transcripcional del epitope HA a LapA fueron aisladas en medio LB suplementado con $\mathrm{Gm}$ e incubas durante toda la noche a $30^{\circ} \mathrm{C}$. Biomasa proveniente de estas placas fue usada para inocular 50 $\mathrm{mL}$ de medios de cultivo LB suplementados con $\mathrm{Gm}$. Estos cultivos fueron incubados durante 16 horas a $30^{\circ} \mathrm{C}$ con agitación (160 rpm).

De acá en adelante los protocolos utilizados para la detección de BrtA-HA o LapAHA fueron iguales. Transcurrido el tiempo de incubación indicado, los cultivos fueron centrifugados durante 20 minutos a $5.000 \mathrm{xg}$. Cuarenta $\mathrm{mL}$ de sobrenadante fueron tratados con un cocktail inhibidor de proteasas según las especificaciones del fabricante (Roche) y filtrados utilizando filtros de $0,22 \mu \mathrm{m}$ de bajo pegado de proteína (Mille GV) a fin de eliminar bacterias remanentes luego de la centrifugación. El sobrenadante de cultivo fue concentrado utilizando filtros Amicon Ultra de $100 \mathrm{kDa}$ (Millipore) de manera tal de conservar sólo aquellas proteínas de mayor peso molecular. El sobrenadante concentrado fue mantenido en hielo mientras se continuó con el procesamiento del pellet de la primera centrifugación. Este pellet fue suavemente resuspendido en $1 \mathrm{~mL}$ de buffer LapA. Posteriormente se centrifugó durante 10 minutos a $16.000 \mathrm{xg}$ y el paquete celular obtenido fue nuevamente resuspendido a $750 \mu \mathrm{L}$ de buffer LapA. Esta suspensión fue lisada mediante sonicación utilizando un sonicador de punta marca Sonics (Vibra-cell) según el mismo esquema experimental detallado anteriormente. Posteriormente se centrifugó durante 30 minutos a $10.000 \mathrm{xg}$ a $4^{\circ} \mathrm{C}$. El pellet de esta centrifugación fue descartado y el sobrenadante guardado para continuar su procesamiento. Finalmente, las muestras de sobrenadante de cultivo concentradas obtenidas previamente y las muestras de célula entera fueron cuantificadas mediante el método de Bradford. Para la detección de BrtA-HA se realizó electroforesis en geles de SDS-PAGE de concentración $7,5 \%$. La corrida electroforética se mantuvo durante 2 horas y media a $100 \mathrm{~V}$. Posteriormente se realizó la transferencia de las proteínas a membranas de nitrocelulosa mediante Western blot y finalmente se realizó el revelado utilizando un anticuerpo primario anti-HA.

\section{Plan de inmunización para la obtención de suero anti-BrtA}

El siguiente plan de inmunización fue utilizado con el objetivo de obtener suero anti-BrtA. 


\section{Capítulo 9}

Preparación del agente inmunógeno. Se utilizaron muestras de proteína BrtA obtenida de geles de SDS-PAGE como inmunógeno. Los geles de SDS-PAGE fueron realizados con muestras de sobrenadante de cultivos de la cepa $B$. bronchiseptica salvaje cultivada en medio SS complementado con Str incubado durante 16 horas a $37^{\circ} \mathrm{C}$ con agitación (160 rpm). El sobrenadante de cultivo fue concentrado utilizando filtros Amicon Ultra de 100 kDa (Millipore) de manera tal de conservar sólo aquellas proteínas de mayor peso molecular. Treinta y cinco $\mu \mathrm{L}$ de las muestras de sobrenadante concentrado fueron sembradas en gel de poliacrilamida $7,5 \%$ y la corrida electroforética fue realizada durante 2 horas y media a $100 \mathrm{~V}$. El gel fue teñido con solución de Coomasie Blue R250 y la banda correspondiente a BrtA (identificada previamente mediante la técnica de huella peptídica) fue cortada para utilizar como inmunógeno. Esta banda fue disgregada en forma mecánica utilizando bisturí y posteriormente transferida a un tubo de microcentrífuga de $1,5 \mathrm{~mL}$ en donde se adicionaron $50 \mu \mathrm{L}$ de adyuvante de Freund.

Plan de inmunización. Se utilizó un ratón BALB/c de 5 semanas de edad. Este ratón fue inoculado por vía intraperitoneal con muestras de BrtA obtenida de geles de SDS-PAGE. Se realizaron 3 inoculaciones con una frecuencia de 15 días. La primera inoculación fue realizada con adyuvante de Freund completo y las siguiente 2 inoculaciones con adyuvante incompleto. Para la obtención de muestras de suero el ratón fue anestesiado con isofluorano y la muestra fue obtenida mediante sangrado por seno retro orbital. El seguimiento del plan de inmunización fue realizado mediante ensayos de Western blot utilizando las muestras de sobrenadante de cultivo concentrado.

\section{Modelo murino de infección}

A lo largo de este trabajo, el modelo murino de infección fue utilizado para la realización de ensayos de colonización y transmisión entre roedores. Para la preparación de las suspensiones bacterianas usadas para inocular a los animales se realizaron aislamientos de las cepas de B. bronchiseptica en medio de cultivo BGA- sangre suplementado con los antibióticos correspondientes. Tras 72 horas de incubación a $37^{\circ} \mathrm{C}$ se tomó biomasa de estas placas para preparan las suspensiones bacterianas en buffer fosfato. La cantidad de UFC/mL, así como el volumen de suspensión administrado, fue indicado oportunamente en el Capítulo 5 en la presentación de cada uno de los ensayos. Los ratones fueron inoculados por vía intranasal con la precaución de inocular en forma pareja ambas narinas. A los tiempos indicados, los ratones fueron sacrificados mediante dislocación cervical. Los pulmones y las narices fueron extraídos y colocados en $1 \mathrm{~mL}$ de buffer fosfato. Posteriormente fueron homogeneizados y se prepararon diluciones seriadas. Cien $\mu \mathrm{L}$ de estas diluciones fueron plaquedos en BGA-sangre e incubadas 
durante $48-72$ horas a $37^{\circ} \mathrm{C}$. Transcurrido ese tiempo de incubación las colonias fueron contadas y se determinó el número de UFC por órgano.

\section{Doble híbrido en bacteria (BACTH)}

Esta estrategia fue utilizada para evaluar la capacidad de $\operatorname{LapD}_{\mathrm{Bb}}$, BdcA y BdcG de interactuar físicamente in vivo.

Diseño de primers. Con el objetivo de que las secuencias clonadas quedaran en el mismo marco de lectura que las secuencias T25 y T18, para el diseño de los primers fueron consideradas las siguientes condiciones. Los primers Forward $(F w)$ debían comenzar exactamente en el sitio de inicio de la traducción de la secuencia a clonar. Los primers Reverse $(R v)$ debían finalizar en el último codón antes del codón de STOP del gen correspondiente. La secuencia -cgcgcgccaagcttg- fue añadida al extremo 5' de los primers $F w$, esta secuencia contiene el sitio de reconocimiento de la enzima de restricción HindIII. La secuencia -gcgcgcgctctagagt- fue añadida al extremo 5' de los primers Reverse, esta secuencia contiene el sitio de restricción de la enzima Xbal.

Clonación. Los productos de PCR de las secuencias $l a p D_{B b}$, bdcA y bdcG y los vectores pUT18 y pKNT25 fueron digeridos con las enzimas de restricción Xbal y HindllI. Los productos digeridos fueron ligados utilizando la ligasa T4. Los protocolos de digestión y ligación utilizados fueron descriptos previamente en este capítulo. Las construcciones fueron transformadas por electroporación en cepas E. coli DH5- $\alpha$. Las cepas obtenidas fueron almacenadas a $-80^{\circ} \mathrm{C}$.

Preparación plásmidos. Las cepas de E. coli con las construcciones desarrolladas fueron repicadas en medio de cultivo LB suplementado con $\mathrm{Km} 50 \mu \mathrm{g} / \mathrm{mL}$ (para las construcciones derivadas del vector pKNT25) o con carbenicilina (Cb) $50 \mu \mathrm{g} / \mathrm{mL}$ (para las construcciones derivadas del vector pUT18). Estas placas fueron incubadas durante 24 horas a $37^{\circ} \mathrm{C}$. Biomasa proveniente de estas placas fue usada para inocular $5 \mathrm{~mL}$ de medio de cultivo LB suplementado con los antibióticos correspondientes. Estos cultivos fueron incubados durante 16 horas a $37^{\circ} \mathrm{C}$ con agitación. Para la obtención de los plásmidos se utilizó el kit QIAprep Spin Miniprep (Qiagen) siguiendo las indicaciones del fabricante y se cuantificaron utilizando un equipo NanoDrop 1000 (Thermo Scientific). Finalmente, las preparaciones de plásmidos fueron diluidas hasta alcanzar una concentración de $25 \mathrm{ng} / \mu \mathrm{L}$.

Cotransformación de la cepa E. coli BTH 101. Para cada una de las réplicas biológicas realizadas se cotransformaron bacterias electrocompetentes de la cepa BTH101 con las construcciones a analizar. Las cepas BTH101 transformadas no fueron almacenadas. Para la cotransformación se utilizaron $2 \mu \mathrm{L}$ de cada una de las preparaciones de 


\section{Capítulo 9}

plásmidos (50 ng de plásmido). Las bacterias transformadas fueron inmediatamente resuspendidas en LB e incubadas a $37^{\circ} \mathrm{C}$ durante 1 hora. Se prepararon diluciones $1 / 10$, $1 / 100$ y $1 / 1000$ y se plaquearon en medio LB suplementado con $\mathrm{Km}(50 \mu \mathrm{g} / \mathrm{mL})$ y Cb $(50$ $\mu \mathrm{g} / \mathrm{mL}$ ). Estas placas fueron incubadas durante 20 horas a $28^{\circ} \mathrm{C}$ y posteriormente se realizó la medida de la actividad $\beta$-galactosidasa.

\section{Medida de actividad $\beta$-galactosidasa.}

Las determinaciones de actividad $\beta$-galactosidasa fueron utilizadas como medidas cuantitativas de los experimentos de doble híbrido en bacteria. El protocolo de medida de la actividad está basado en el trabajo de J. Miller ${ }^{329}$. Antes de comenzar con el protocolo de determinación de actividad se preparó buffer $Z$ 1X a partir de la solución almacenada $5 X$. Se adicionó $\beta$-mercaptoetanol hasta una concentración de $50 \mathrm{mM}$. En forma paralela se preparó solución de ONPG (Orto-nitrofenil- $\beta$-galactósido), sustrato de la reacción enzimática catalizada por la $\beta$-galactosidasa. El ONPG fue utilizado en una concentración de $4 \mathrm{mg} / \mathrm{mL}$ en buffer $Z$.

Para el desarrollo del experimento se seleccionaron las placas correspondientes a diluciones que presentaban entre 100 y 300 colonias. Las placas que presentaban un número mayor fueron descartadas debido a la posible aparición de falsos positivos. Las colonias de estas placas fueron resuspendidas en $500 \mu \mathrm{L}$ de buffer fosfato utilizando espátula Drigalsky. A partir de estas suspensiones se realizaron diluciones hasta obtener suspensiones de $\mathrm{DO}_{600}=1,0$. Se tomaron alícuotas de $100 \mu \mathrm{L}$ de cada suspensión (por triplicado) y se transfirieron a tubos de microcentrífuga de $1,5 \mathrm{~mL}$.

A cada suspensión se adicionó de manera sucesiva $900 \mu \mathrm{L}$ de buffer $Z, 50 \mu \mathrm{L}$ de cloroformo y $25 \mu \mathrm{L}$ de SDS $0,1 \% \mathrm{p} / \mathrm{v}$. Estas mezclas fueron agitadas vigorosamente durante 10 segundos y luego se las dejó reposar durante 5 minutos hasta observar una clara separación de las fases acuosa y orgánica. Luego se adicionaron $500 \mu \mathrm{L}$ de la solución de ONPG y se aguardó 5 minutos a que transcurra la reacción. La reacción fue detenida por agregado de $500 \mu \mathrm{L}$ de solución de $\mathrm{Na}_{2} \mathrm{CO}_{3} 1,0 \mathrm{M}$. Cien $\mu \mathrm{L}$ de cada mezcla de reacción fueron transferidos a una placa de 96 fosas de fondo plano y se determinó la absorbancia a $420 \mathrm{~nm}$ y $550 \mathrm{~nm}$. Estas medidas de absorbancia fueron utilizadas para calcular la actividad $\beta$-galactosidasa expresada en Unidades de Miller. 


$$
\mathrm{UM}=\frac{\mathrm{Abs}_{420}-1.75 \times \mathrm{Abs}_{550}}{\mathrm{t}(\mathrm{min}) \times \mathrm{Abs}_{600} \times \mathrm{Vol}(\mathrm{mL})} \times 1000
$$

El O-nitrofenol, producto de la degradación enzimática del ONPG, presenta un pico máximo de absorbancia a $420 \mathrm{~nm}$. Por lo tanto, la medida de absorbancia a esa longitud de onda es proporcional a la actividad $\beta$-galactosidasa presente en la solución. Los restos celulares presentes en el medio de reacción también contribuyen a la absorbancia total a esa longitud de onda. Con el objetivo de restar el aporte de estos restos celulares, se realiza la media a $550 \mathrm{~nm}$. Debido a que la absorbancia de los restos celulares a $550 \mathrm{~nm}$ es 1,75 veces menor que a $420 \mathrm{~nm}$, es necesario aplicar este factor antes de realizar la sustracción. El denominador de la ecuación de Miller contiene 3 factores normalizadores: i) el tiempo de la reacción enzimática, ii) la absorbancia de la suspensión bacteriana y iii) el volumen de suspensión utilizado.

\section{Determinación de la cantidad de c-di-GMP en E. coli BTH 101}

Para este ensayo se partió de las placas de cultivo del ensayo de doble híbrido en bacteria. Biomasa proveniente de estas placas fue utilizada para inocular cultivos de medio LB de $5 \mathrm{~mL}$ suplementados con $\mathrm{Km}(50 \mu \mathrm{g} / \mathrm{mL})$ y $\mathrm{Cb}(50 \mu \mathrm{g} / \mathrm{mL})$. Estos cultivos fueron incubados durante 13 horas a $37^{\circ} \mathrm{C}$ con agitación. Alícuotas de estos cultivos fueron tomadas para inocular cultivos de $50 \mathrm{~mL}$ de medio LB hasta alcanzar un $\mathrm{DO}_{600}=0,04$. Los cultivos fueron incubados durante 4 horas a $37^{\circ} \mathrm{C}$ con agitación. Se realizaron triplicado de cada uno de estos cultivos. Transcurrido el tiempo de incubación se midió la $\mathrm{DO}_{600}$ y se realizaron diluciones a fin de normalizar los cultivos frente al valor de aquel que presentó el valor más bajo. Se tomaron $40 \mathrm{~mL}$ y se centrifugaron durante 10 minutos a $5.000 \mathrm{xg}$ a $4^{\circ} \mathrm{C}$. El sobrenadante de esta centrifugación fue descartado y el precipitado fue resuspendido en $250 \mu \mathrm{L}$ de buffer de extracción. Estas suspensiones fueron incubadas durante 30 minutos a $-20^{\circ} \mathrm{C}$. transcurrido ese tiempo las muestras fueron centrifugadas durante 5 minutos a $16.000 \mathrm{xg}$ a $4^{\circ} \mathrm{C}$. Doscientos $\mu \mathrm{L}$ del sobrenadante obtenido fueron transferidos a otro tubo y se adicionaron $8 \mu \mathrm{L}$ de solución de $\left(\mathrm{NH}_{4}\right)_{2} \mathrm{HCO}_{3} 15 \% \mathrm{p} / \mathrm{v}$ a fin de ajustar el $\mathrm{pH}$ a un valor de 7,5 . Estas muestras fueron mantenidas en hielo seco hasta continuar con el procesamiento. La determinación de la cantidad de c-di-GMP fue realizada por el servicio especializado de la Universidad de Michigan (Estados Unidos). Este procedimiento fue realizado mediante cromatografía líquida acoplada a un espectrómetro de masa (LC-MS) utilizando los quipos LC-20AD 


\section{Capítulo 9}

HPLC system (Shimadzu) y Finnigan TSQ Quantum Discovery MAX triplequadrupole (Thermo Electron).

\section{Análisis estadísticos}

Los análisis estadísticos de este trabajo fueron realizados mediante los programas Infostat (Facultad de Ciencias Agropecuarias-Universidad Nacional de Córdoba) y Excel. Se utilizó el estadístico ANOVA cuando los datos a ser analizados cumplían con la condición de distribución normal y homogeneidad de varianza. En caso contrario se utilizó el estadístico test de Student para muestras con varianzas desiguales.

\section{Otras herramientas utilizadas}

La representación gráfica de los resultados cuantitativos de este trabajo fue realizada utilizando el software GraphPad Versión 5. Para el diseño y presentación de las figuras se utilizaron los programas Power Point y Adobe Photoshop. La escritura del texto fue realizada utilizando el programa Word. El programa VMD ${ }^{275}$ (Universidad de Illinois) fue usado para la visualización de los modelos tridimensionales de proteínas. El programa ImageJ (versión FIJI) fue utilizado para la resolución semicuantitativa de los ensayos de dot blot. Para el diseño y visualización de secuencias nucleotídicas se utilizaron los programas NTI vector y Snap Gene.

Además, se utilizaron las herramientas de base online que se describen a continuación: BLASTN y BLASTP para la búsqueda y alineación de secuencias nucleotídicas y proteicas respectivamente; SMART ${ }^{330}$, para el análisis de dominios de secuencias proteicas; Clustal Omega ${ }^{331}$, BOXSHADE y WebLogo ${ }^{332}$ para realizar y colorear alineamientos múltiples de secuencias; $\mathrm{DOOR}^{271}$, para la búsqueda de operones en el genoma de $B$. bronchiseptica; MASCOT $^{269}$ para la identificación de BrtA a partir de los datos espectrometría de masa y $\mathrm{Phyre}^{257}$ para el modelado de estructuras secundarias de proteínas. 


\section{Anexo 1. Vectores de clonado y expresión}

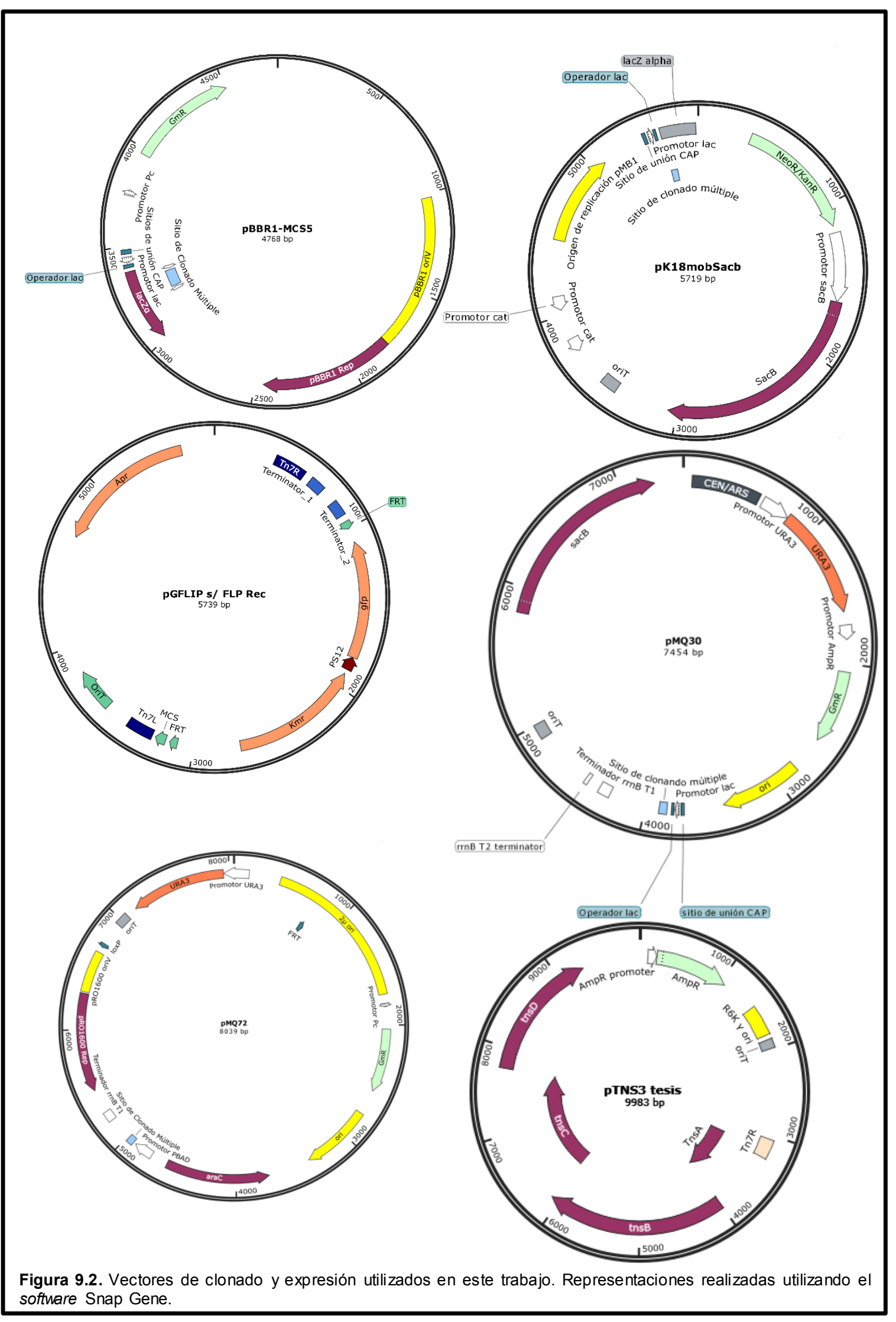




\section{Anexo 2. Primers utilizados}

Tabla 9.6. Primers utilizados en el presente trabajo. Las bases subrayadas indican secuencias que no tienen homología con el genoma de $B$. bronchiseptica y fueron usadas para la estrategia de doble recombinación in vivo con S. cerevisiae o mediante uso ligasa y enzimas de restricción.

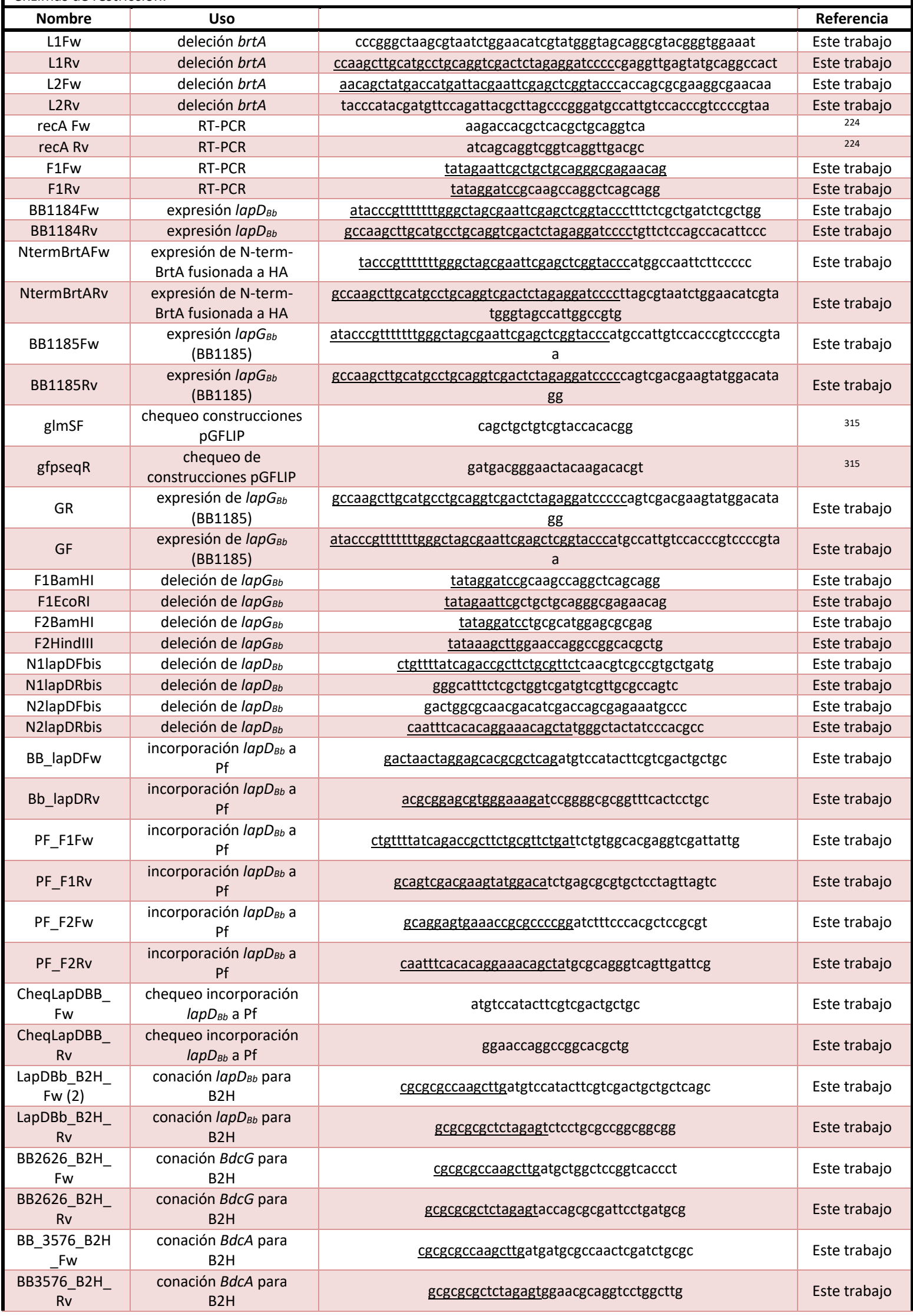


Anexo

\begin{tabular}{|c|c|c|c|}
\hline mut2626A1Fw & deleción de $b d c G$ & ttatcagaccgcttctgcgttctgatgaattcgagatcaaggatttgacg & Este trabajo \\
\hline mut2626A1Rv & deleción de $b d c G$ & ggcctgcttggccgcgtacaacgctcccagcgtcaccaggctcgacag & Este trabajo \\
\hline mut2626A2Fw & deleción de $b d c G$ & ctgtcgagcctggtgacgctgggagcgttgtacgcggccaagcaggcc & Este trabajo \\
\hline mut2626A2Rv & deleción de $b d c G$ & caatttcacacaggaaacagctatgaagcttcaaatggctagaatgctag & Este trabajo \\
\hline $\begin{array}{c}\text { Cheq_mut262 } \\
\text { 6_Fw }\end{array}$ & chequeo mutante $b d c G$ & agcgcgagttcatcaacagc & Este trabajo \\
\hline BrtA-HA-R2 & $\begin{array}{c}\text { fusión transcripcional } \\
\text { HA }\end{array}$ & caatttcacacaggaaacagctatgcccttctcggtgtaggtgtagc & Este trabajo \\
\hline BrtA-HA-F2 & $\begin{array}{c}\text { fusión transcripcional } \\
\text { HA }\end{array}$ & gacgttccagattacgctgctgtgctgcacagcaaccagcag & Este trabajo \\
\hline BrtA-HA-R1 & $\begin{array}{c}\text { fusión transcripcional } \\
\text { HA }\end{array}$ & aacatcgtatgggtagagcagcgttaccgatgcaatgccg & Este trabajo \\
\hline BrtA-HA-F1 & $\begin{array}{c}\text { fusión transcripcional } \\
\text { HA }\end{array}$ & atcagaccgcttctgcgttctgatcagtgtcgagacgtccatcagc & Este trabajo \\
\hline HA_Fw & $\begin{array}{c}\text { fusión transcripcional } \\
\text { HA }\end{array}$ & ggtgctgcacagcaaccagctacccatacgatgttcctgactatgcg & Este trabajo \\
\hline HA_Rv & $\begin{array}{c}\text { fusión transcripcional } \\
\text { HA }\end{array}$ & ttgccgttgaactgtacctgagcgtaatctggaacgtcatatggatagg & Este trabajo \\
\hline $\begin{array}{c}\text { Cheq_brtAHA_ } \\
\text { Fw }\end{array}$ & $\begin{array}{c}\text { chequeo fusión } \\
\text { transcripcional } \mathrm{HA} \text { a } \\
\text { brtA }\end{array}$ & acatgggttcgcagatcacc & Este trabajo \\
\hline$\underset{\mathrm{Rv}}{\text { Cheq_brtAHA_ }}$ & $\begin{array}{c}\text { chequeo fusión } \\
\text { transcripcional HA a } \\
\text { brtA }\end{array}$ & acgctgttcttgccgttgc & Este trabajo \\
\hline brtA_Seq1_Fw & secuenciación brtA & tataccgtcaccatcacggc & Este trabajo \\
\hline brtA_Seq1_Rv & secuenciación brtA & gacggtgtaggtgatggagg & Este trabajo \\
\hline brtA_Seq2_Fw & secuenciación brtA & acaatgacggcgtctacaccg & Este trabajo \\
\hline brtA_Seq2_Rv & secuenciación brtA & gctgatggacgtctcgacac & Este trabajo \\
\hline gfpseqR & chequeo cepas GFP & gatgacgggaactacaagacacgt & 315 \\
\hline gImSF & chequeo cepas GFP & cagctgctgtcgtaccacacgg & 315 \\
\hline Q30VerifyF & $\begin{array}{c}\text { chequeo de } \\
\text { construcciones en } \\
\text { pMQ30 }\end{array}$ & gagtcagtgagcgaggaag & $\begin{array}{c}\text { Stock } \\
\text { laboratorio }\end{array}$ \\
\hline Q30VerifyR & $\begin{array}{c}\text { chequeo de } \\
\text { construcciones en } \\
\text { pMQ30 }\end{array}$ & cagaccgcttctgcgttctg & $\begin{array}{c}\text { Stock } \\
\text { laboratorio }\end{array}$ \\
\hline pUT18_Rv & $\begin{array}{c}\text { chequeo de } \\
\text { construcciones en } \\
\text { pUT18 }\end{array}$ & ccacaacaagtcgatgcgttc & Este trabajo \\
\hline pUT18_Fw & $\begin{array}{c}\text { chequeo de } \\
\text { construcciones en } \\
\text { pUT18 }\end{array}$ & gttagctcactcattaggcaccc & Este trabajo \\
\hline pKNT25_Rv & $\begin{array}{c}\text { chequeo de } \\
\text { construcciones en } \\
\text { pKNT25 }\end{array}$ & gatgccatcgagtacggctg & Este trabajo \\
\hline pKNT25_Fw & $\begin{array}{c}\text { chequeo de } \\
\text { construcciones en } \\
\text { pKNT25 }\end{array}$ & gttagctcactcattaggcaccc & Este trabajo \\
\hline M13Fw -40 & $\begin{array}{c}\text { chequeo de } \\
\text { construcciones en } \\
\text { pBBR1-MCS5 }\end{array}$ & gtaaaacgacggccagt & $\begin{array}{c}\text { stock } \\
\text { laboratorio }\end{array}$ \\
\hline M13Rv -40 & $\begin{array}{l}\text { chequeo de } \\
\text { construcciones en } \\
\text { pBBR1-MCS5 }\end{array}$ & ggaaacagctatgaccatg & $\begin{array}{c}\text { stock } \\
\text { laboratorio }\end{array}$ \\
\hline
\end{tabular}




\section{Anexo 3. Medios de Cultivo}

\begin{tabular}{|c|c|c|}
\hline \multicolumn{2}{|l|}{$\overline{B G A}$} & \\
\hline $\begin{array}{r}\text { Agar Bordet Gengou } \\
\text { Glicerol } \\
\text { Sangre } \\
\end{array}$ & $\begin{array}{l}30 \mathrm{~g} / \mathrm{L} \\
10 \% \mathrm{p} / \mathrm{v} \\
10 \% \mathrm{v} / \mathrm{v}\end{array}$ & \\
\hline \multicolumn{3}{|c|}{ SS (Stainer-Scholte) } \\
\hline \multicolumn{2}{|c|}{$\begin{array}{r}\text { glutamato de sodio } \\
\text { L-prolina } \\
\mathrm{NaCl} \\
\mathrm{KH}_{2} \mathrm{PO}_{4} \\
\mathrm{KCl} \\
\mathrm{MgCl}_{2} \cdot 6 \mathrm{H}_{2} \mathrm{O} \\
\mathrm{CaCl}_{2} \cdot 2 \mathrm{H}_{2} \mathrm{O} \\
\mathrm{Tris}-\mathrm{HCl} \\
\mathrm{pH} \\
\text { Agar (opcional para medio semi sólido) } \\
\end{array}$} & $\begin{array}{c}570 \mathrm{mM} \\
20 \mathrm{mM} \\
530 \mathrm{mM} \\
36 \mathrm{mM} \\
20 \mathrm{mM} \\
5 \mathrm{mM} \\
1,4 \mathrm{mM} \\
120 \mathrm{mM} \\
7,20 \\
15 \mathrm{~g} / \mathrm{L} \\
\end{array}$ \\
\hline \multicolumn{3}{|c|}{ Complemento para medio de cultivo SS (1000X) } \\
\hline \multicolumn{2}{|c|}{$\begin{array}{r}\text { L-cisteína } \\
\mathrm{FeSO}_{4} .7 \mathrm{H}_{2} \mathrm{O} \\
\text { Ácido ascórbico } \\
\text { Ácido nicotínico } \\
\mathrm{HCl} \\
\end{array}$} & $\begin{array}{l}4 \% \mathrm{p} / \mathrm{v} \\
1 \% \mathrm{p} / \mathrm{v} \\
2 \% \mathrm{p} / \mathrm{v} \\
0,4 \% \mathrm{p} / \mathrm{v} \\
10 \% \mathrm{v} / \mathrm{v} \\
\end{array}$ \\
\hline \multicolumn{3}{|c|}{ LB (Lysogeny broth) } \\
\hline $\begin{array}{l}\text { Extracto de } \\
\text { Ágar (opcional para me }\end{array}$ & $\begin{array}{r}\text { Triptona } \\
\mathrm{NaCl} \\
\text { e levadura } \\
\text { dio sólido) } \\
\end{array}$ & $\begin{array}{c}10 \mathrm{~g} / \mathrm{L} \\
5 \mathrm{~g} / \mathrm{L} \\
5 \mathrm{~g} / \mathrm{L} \\
15 \mathrm{~g} / \mathrm{L} \\
\end{array}$ \\
\hline \multicolumn{2}{|l|}{ K10-T } & \\
\hline $\begin{array}{r}\text { Triptona } \\
\text { Glicerol } \\
\mathrm{MgSO}_{4} \\
\mathrm{~K}_{2} \mathrm{HPO}_{4} \\
\text { Tris- } \mathrm{HCl} \\
\mathrm{pH} \\
\end{array}$ & $\begin{array}{l}20 \% \mathrm{p} / \mathrm{v} \\
20 \% \mathrm{v} / \mathrm{v} \\
1 \mathrm{M} \\
1 \mathrm{M} \\
1 \mathrm{M} \\
7,40 \\
\end{array}$ & \\
\hline URA $3^{-}$ & & \\
\hline $\begin{array}{r}\text { YNB } \\
\text { CSM } \\
\text { Glucosa } \\
\text { Agar }\end{array}$ & $\begin{array}{c}6,7 \mathrm{~g} / \mathrm{L} \\
0,76 \mathrm{~g} / \mathrm{L} \\
15 \mathrm{~g} / \mathrm{L} \\
20 \mathrm{~g} / \mathrm{L}\end{array}$ & \\
\hline
\end{tabular}




\section{Anexo 4. Soluciones}

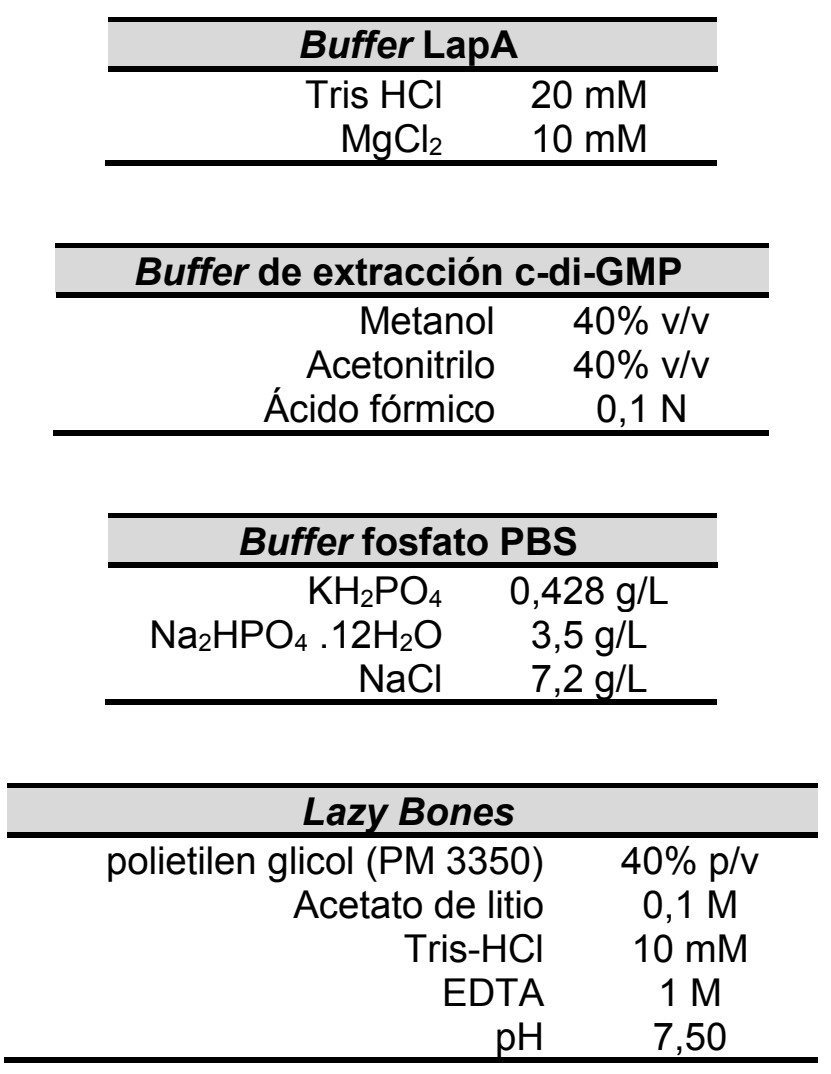

\begin{tabular}{rc}
\hline Buffer Z \\
\hline $\mathrm{Na}_{2} \mathrm{HPO}_{4}$ & $60 \mathrm{mM}$ \\
$\mathrm{NaH}_{2} \mathrm{PO}_{4}$ & $40 \mathrm{mM}$ \\
$\mathrm{KCl}$ & $10 \mathrm{mM}$ \\
$\mathrm{MgSO}_{4}$ & $1 \mathrm{mM}$ \\
$\mathrm{pH}$ & 7,00 \\
\hline
\end{tabular}

Solución de Coomaise Blue R250 Coomasie R250 0,2\%p/v Metanol $\quad 40 \% \mathrm{v} / \mathrm{v}$ Ácido acético $20 \% \mathrm{v} / \mathrm{v}$ 


\begin{tabular}{rc}
\hline Buffer TE \\
\hline Tris-HCl & $10 \mathrm{mM}$ \\
EDTA & $1 \mathrm{mM}$ \\
$\mathrm{pH}$ & 8,00 \\
\hline
\end{tabular}

\begin{tabular}{rc}
\hline Buffer TBS (Tris-Sodio) \\
\hline Tris- $\mathrm{HCl}$ & $0,5 \mathrm{M}$ \\
$\mathrm{NaCl}$ & $1,5 \mathrm{mM}$ \\
\hline
\end{tabular}

\begin{tabular}{cc}
\hline \multicolumn{2}{c}{ Suspensión de sílica } \\
\hline sílica & $2,0 \mathrm{~g}$ \\
agua destilada & $15,0 \mathrm{~mL}$ \\
\hline
\end{tabular}

\begin{tabular}{rc}
\hline TBE 10X \\
\hline Tris-HCl & $1,0 \mathrm{M}$ \\
Ácido bórico & $1,0 \mathrm{M}$ \\
EDTA & $0,02 \mathrm{M}$ \\
\hline
\end{tabular}

Buffer de transferencia Western blot Glicina $\quad 1,0 \mathrm{M}$ Metanol $20 \% \mathrm{v} / \mathrm{v}$ Tris- $\mathrm{HCl} \quad 0,025 \mathrm{M}$

\begin{tabular}{cc}
\multicolumn{2}{c}{ Soluciones de miniprep } \\
Solución P1 \\
Tris-HCl & $50 \mathrm{mM}$ \\
EDTA & $10 \mathrm{mM}$ \\
$\mathrm{pH}$ & 8,00 \\
Solución P2A & \\
NaOH & $0,1 \mathrm{mM}$ \\
Solución P2B & \\
SDS & $1 \% \mathrm{p} / \mathrm{v}$ \\
Solución P3 & \\
pH & $1,5 \mathrm{M}$ \\
Acetato de potasio & 5,5 \\
\hline
\end{tabular}

Solución de Lavado de sílica 10X $\mathrm{NaCl} \quad 50 \mathrm{mM}$

Tris- $\mathrm{HCl} \quad 10 \mathrm{mM}$

EDTA $2,5 \mathrm{mM}$

etanol $50 \% \mathrm{v} / \mathrm{v}$

$\mathrm{pH} \quad 7,5$

\section{Solución de lavado de sílica $1 \mathrm{X}$ \\ solución de lavado 10X $10 \% \mathrm{v} / \mathrm{v}$ \\ etanol $50 \% \mathrm{v} / \mathrm{v}$}


Buffer Laemmli 6X

SDS

$2 \% \mathrm{p} / \mathrm{V}$

Glicerol

$1 \% \mathrm{v} / \mathrm{v}$

EDTA $\quad 0,02 \mathrm{M}$

Tris $\mathrm{HCl} \quad 0,05 \mathrm{M}$

$\mathrm{pH} \quad 6,8$ 
Anexo 5: Proteínas Lap

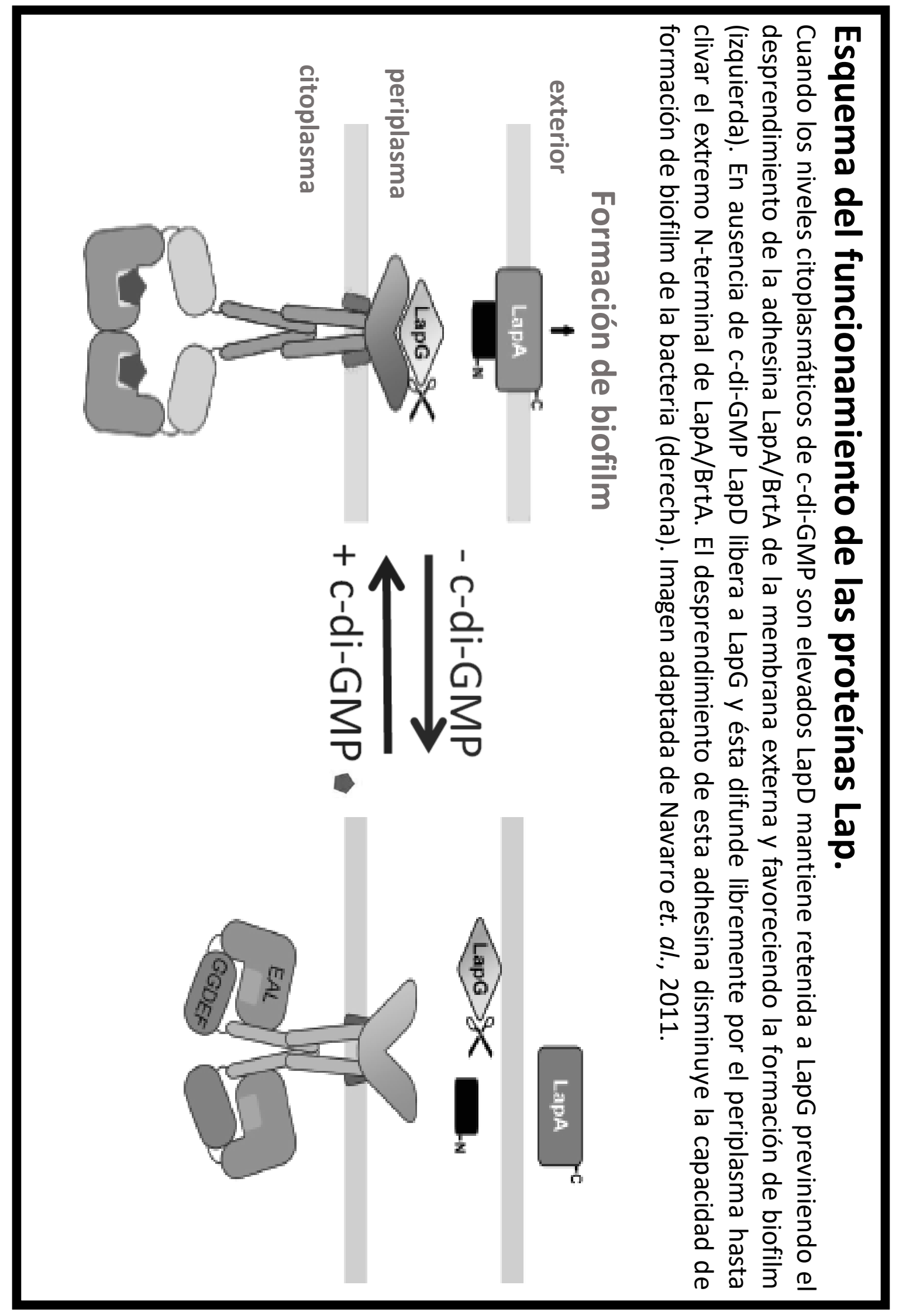




\section{Bibliografía}

1. Costerton, J. W., Geesey, G. G. \& Cheng, K. J. How bacteria stick. Sci. Am. 238, 86-95 (1978).

2. Ehrlich, G. D. \& Arciola, C. R. From Koch's postulates to biofilm theory. The lesson of Bill Costerton. Int. J. Artif. Organs 35, 695-699 (2012).

3. Høiby, N. A short history of microbial biofilms and biofilm infections. Apmis 125, 272-275 (2017).

4. Zobell, C. E. \& Allen, E. C. The Significance of Marine Bacteria in the Fouling of Submerged Surfaces. J. Bacteriol. 29, 239-51 (1935).

5. Rakestraw, N. W. Studies on the biology and chemistry of the gulf of Maine. Biol. Bull. 64, 149-158 (1933).

6. Holah, J. T. \& Kearney, L. R. Introduction to Biofilms in the Food Industry. in Biofilms - Science and Technology 35-41 (Springer Netherlands, 1992).

7. Morton, L. H. G. \& Surman, S. B. Biofilms in biodeterioration - a review. Int. Biodeterior. Biodegrad. 34, 203-221 (1994).

8. Videla, H. A. Biofilms and corrosion interactions on stainless steel in seawater. Int. Biodeterior. Biodegrad. 34, 245-257 (1994).

9. Flemming, H.-C. Relevance of biofilms for the biodeterioration of surfaces of polymeric materials. Polym. Degrad. Stab. 59, 309-315 (1998).

10. Geesey, G. G., Mutch, R., Costerton, J. W. \& Green, R. B. Sessile bacteria: An important component of the microbial population in small mountain streams. Limnol. Oceanogr. 23, 1214-1223 (1978).

11. McCoy, W. F., Bryers, J. D., Robbins, J. \& Costerton, J. W. Observations of fouling biofilm formation. Can. J. Microbiol. 27, 910-917 (1981).

12. Donlan, R. M. \& Costerton, J. W. Biofilms: survival mechanisms of clinically relevant microorganisms. Clin. Microbiol. Rev. 15, 167-93 (2002).

13. Høiby, N. et al. Pseudomonas aeruginosa infection in cystic fibrosis. Diagnostic and prognostic significance of Pseudomonas aeruginosa precipitins determined by means of crossed immunoelectrophoresis. Scand. J. Respir. Dis. 58, 65-79 (1977).

14. Bjarnsholt, T. et al. Pseudomonas aeruginosa biofilms in the respiratory tract of cystic fibrosis patients. Pediatr. Pulmonol. 44, 547-558 (2009).

15. Hall-Stoodley, L. et al. Direct Detection of Bacterial Biofilms on the Middle-Ear Mucosa of Children With Chronic Otitis Media. JAMA 296, 202 (2006).

16. Homøe, P., Bjarnsholt, T., Wessman, M., Sørensen, H. C. F. \& Johansen, H. K. Morphological evidence of biofilm formation in Greenlanders with chronic suppurative otitis media. Eur. Arch. Oto-Rhino-Laryngology 266, 1533-1538 (2009).

17. Nistico, L. et al. Adenoid reservoir for pathogenic biofilm bacteria. J. Clin. Microbiol. 49, 1411-20 (2011).

18. Marrie, T. J., Nelligan, J. \& Costerton, J. W. A scanning and transmission electron microscopic study of an infected endocardial pacemaker lead. Circulation 66, 1339-1341 (1982).

19. Waar, K., Degener, J. E., Luyn, M. J. van \& Harmsen, H. J. Fluorescent in situ hybridization with specific DNA probes offers adequate detection of Enterococcus faecalis and Enterococcus faecium in clinical samples. J. Med. Microbiol. 54, 937944 (2005).

20. Costerton, J. W. et al. New methods for the detection of orthopedic and other biofilm infections. FEMS Immunol. Med. Microbiol. 61, 133-140 (2011).

21. Schuurmans, M. M., Palheiros Marques, M., Freitag, L., Zinkernagel, A. S. \& Achermann, Y. Biofilm Formation in a Permanent Tracheal Stent Implanted for Twenty-Five Years. Respiration 90, 327-328 (2015).

22. Gristina, A. G., Oga, M., Webb, L. X. \& Hobgood, C. D. Adherent bacterial colonization in the pathogenesis of osteomyelitis. Science 228, 990-3 (1985).

23. Marrie, T. J. \& Costerton, J. W. Mode of growth of bacterial pathogens in chronic 
polymicrobial human osteomyelitis. J. Clin. Microbiol. 22, 924-33 (1985).

24. Sedghizadeh, P. P. et al. Microbial Biofilms in Osteomyelitis of the Jaw and Osteonecrosis of the Jaw Secondary to Bisphosphonate Therapy. J. Am. Dent. Assoc. 140, 1259-1265 (2009).

25. Cryer, J., Schipor, I., Perloff, J. R. \& Palmer, J. N. Evidence of bacterial biofilms in human chronic sinusitis. ORL. J. Otorhinolaryngol. Relat. Spec. 66, 155-8 (2004).

26. $\mathrm{Li}, \mathrm{H}$. et al. Relationship between bacterial biofilm and clinical features of patients with chronic rhinosinusitis. Eur. Arch. Oto-Rhino-Laryngology 269, 155-163 (2012).

27. Bjarnsholt, T. et al. Why chronic wounds will not heal: a novel hypothesis. Wound Repair Regen. 16, 2-10 (2008).

28. Kirketerp-Møller, K. et al. Distribution, organization, and ecology of bacteria in chronic wounds. J. Clin. Microbiol. 46, 2717-22 (2008).

29. James, G. A. et al. Biofilms in chronic wounds. Wound Repair Regen. 16, 37-44 (2008).

30. Stapleton, F. \& Dart, J. Pseudomonas keratitis associated with biofilm formation on a disposable soft contact lens. Br. J. Ophthalmol. 79, 864-5 (1995).

31. Costerton, J. W., Stewart, P. S. \& Greenberg, E. P. Bacterial biofilms: a common cause of persistent infections. Science 284, 1318-1322 (1999).

32. Ciofu, O., Rojo-Molinero, E., Macià, M. D. \& Oliver, A. Antibiotic treatment of biofilm infections. Apmis 125, 304-319 (2017).

33. Tolker-nielsen, T. Pseudomonas aeruginosa biofilm infections: From molecular biofilm biology to new treatment possibilities. Apmis 122, 1-51 (2014).

34. Elasri, M. O. \& Miller, R. V. Study of the response of a biofilm bacterial community to UV radiation. Appl. Environ. Microbiol. 65, 2025-31 (1999).

35. de Carvalho, C. C. C. R. Biofilms: Microbial Strategies for Surviving UV Exposure. in Advances in experimental medicine and biology 996, 233-239 (2017).

36. Harrison, J. J. et al. Metal resistance in Candida biofilms. FEMS Microbiol. Ecol. 55, 479-491 (2006).

37. Koechler, S., Farasin, J., Cleiss-Arnold, J. \& Arsène-Ploetze, F. Toxic metal resistance in biofilms: diversity of microbial responses and their evolution. Res. Microbiol. 166, 764-773 (2015).

38. Zhou, L. et al. Effects of pH, Temperature and Salinity on Extracellular Polymeric Substances of Pseudomonasaeruginosa Biofilm with N-(3-Oxooxtanoyl)-LHomoserine Lactone Addition. Journal of Water Sustainability 2, (2014).

39. Chavez-Dozal, A. et al. Predation response of Vibrio fischeri biofilms to bacterivorus protists. Appl. Environ. Microbiol. 79, 553-8 (2013).

40. Roilides, E., Walsh, T. J., Simitsopoulou, M. \& Katragkou, A. How Biofilms Evade Host Defenses. in Microbial Biofilms, 2nd Edition 3, 287-300 (American Society of Microbiology, 2015).

41. Stewart, P. S. Antimicrobial Tolerance in Biofilms. Microbiol. Spectr. 3, (2015).

42. Hall, C. W. \& Mah, T. F. Molecular mechanisms of biofilm-based antibiotic resistance and tolerance in pathogenic bacteria. FEMS Microbiol. Rev. 41, 276301 (2017).

43. Olsen, I. Biofilm-specific antibiotic tolerance and resistance. Eur. J. Clin. Microbiol. Infect. Dis. 34, 877-886 (2015).

44. van Gestel, J., Vlamakis, H. \& Kolter, R. Division of Labor in Biofilms: the Ecology of Cell Differentiation. Microbiol. Spectr. 3, MB-0002-2014 (2015).

45. Webb, J. S., Givskov, M. \& Kjelleberg, S. Bacterial biofilms: Prokaryotic adventures in multicellularity. Curr. Opin. Microbiol. 6, 578-585 (2003).

46. Stoodley, P., Sauer, K., Davies, D. G. \& Costerton, J. W. Biofilms as Complex Differentiated Communities. Annu. Rev. Microbiol. 56, 187-209 (2002).

47. Stewart, P. S. \& Franklin, M. J. Physiological heterogeneity in biofilms. Nat. Rev. Microbiol. 6, 199-210 (2008).

48. Jefferson, K. K. What drives bacteria to produce a biofilm? FEMS Microbiol. Lett. 236, 163-173 (2004). 
49. O'Toole, G., Kaplan, H. B. \& Kolter, R. Biofilm Formation as Microbial Development. Annu. Rev. Microbiol. 54, 49-79 (2000).

50. da Silva Meira, Q. G., de Medeiros Barbosa, I., Alves Aguiar Athayde, A. J., de Siqueira-Júnior, J. P. \& de Souza, E. L. Influence of temperature and surface kind on biofilm formation by Staphylococcus aureus from food-contact surfaces and sensitivity to sanitizers. Food Control 25, 469-475 (2012).

51. Villanueva, V. D., Font, J., Schwartz, T. \& Romaní, A. M. Biofilm formation at warming temperature: acceleration of microbial colonization and microbial interactive effects. Biofouling 27, 59-71 (2011).

52. Giaouris, E., Chorianopoulos, N. \& Nychas, G.-J. E. Effect of Temperature, pH, and Water Activity on Biofilm Formation by Salmonella enterica Enteritidis PT4 on Stainless Steel Surfaces as Indicated by the Bead Vortexing Method and Conductance Measurements. Journal of Food Protection 68, (2005).

53. Dewanti, R. \& Wong, A. C. L. Influence of culture conditions on biofilm formation by Escherichia coli O157:H7. Int. J. Food Microbiol. 26, 147-164 (1995).

54. Aboulkacem, A., Barguigua, A., Maroui, I., Timinouni, M. \& Belhaj, A. Influence of both media carbon source and strains variety on the Biofilms formation ability by Pseudomonas aeruginosa. 12, 190-198 (2014).

55. Ruhal, R. et al. A multivariate approach to correlate bacterial surface properties to biofilm formation by lipopolysaccharide mutants of Pseudomonas aeruginosa. Colloids Surfaces B Biointerfaces 127, 182-191 (2015).

56. Persat, A. et al. The mechanical world of bacteria. Cell 161, 988-997 (2015).

57. Stoodley, P. et al. The influence of fluid shear and $\mathrm{AICl} 3$ on the material properties of Pseudomonas aeruginosa PAO1 and Desulfovibrio sp. EX265 biofilms. Water Sci. Technol. 43, 113-20 (2001).

58. Serra, D. O., Richter, A. M., Klauck, G., Mika, F. \& Hengge, R. Microanatomy at cellular resolution and spatial order of physiological differentiation in a bacterial biofilm. MBio 4, 1-12 (2013).

59. Klauck, G., Serra, D. O., Possling, A. \& Hengge, R. Spatial organization of different sigma factor activities and c-di-GMP signalling within the three-dimensional landscape of a bacterial biofilm. Open Biol. 8, 180066 (2018).

60. Serra, D. O. \& Hengge, R. Experimental Detection and Visualization of the Extracellular Matrix in Macrocolony Biofilms. in Methods in molecular biology (Clifton, N.J.) 1657, 133-145 (2017).

61. Pratt, L. a. \& Kolter, R. Genetic analysis of Escherichia coli biofilm formation: Roles of flagella, motility, chemotaxis and type I pili. Mol. Microbiol. 30, 285-293 (1998).

62. O'Toole, G. A. \& Kolter, R. Initation of biofilm formation in Pseudomans fluorescens WC365 proceeds via multiple, convergent signalling pathways: a genetic analysis. Mol. Microbiol. 28, 449-461 (1998).

63. Hinsa, S. M., Espinosa-Urgel, M., Ramos, J. L. \& O'Toole, G. A. Transition from reversible to irreversible attachment during biofilm formation by Pseudomonas fluorescens WCS365 requires an ABC transporter and a large secreted protein. Mol. Microbiol. 49, 905-918 (2003).

64. Caiazza, N. C. \& O'Toole, G. A. SadB Is Required for the Transition from Reversible to Irreversible Attachment during Biofilm Formation by Pseudomonas aeruginosa PA14. J. Bacteriol. 186, 4476-4485 (2004).

65. Ivanov, I. E. et al. Atomic force and super-resolution microscopy support a role for LapA as a cell-surface biofilm adhesin of Pseudomonas fluorescens. Res. Microbiol. 163, 685-91 (2012).

66. Hinsa, S. M. \& O'Toole, G. a. Biofilm formation by Pseudomonas fluorescens WCS365: a role for LapD. Microbiology 152, 1375-83 (2006).

67. O'Toole, G. a \& Kolter, R. Flagellar and twitching motility are necessary for Pseudomonas aeruginosa biofilm development. Mol Microbiol 30, 295-304 (1998).

68. Sauer, K. \& Camper, A. K. Characterization of Phenotypic Changes in Pseudomonas putida in Response to Surface-Associated Growth. J. Bacteriol. 183, 
6579-6589 (2001).

69. Martínez-Gil, M., Yousef-Coronado, F. \& Espinosa-Urgel, M. LapF, the second largest Pseudomonas putida protein, contributes to plant root colonization and determines biofilm architecture. Mol. Microbiol. 77, 549-561 (2010).

70. Tielen, P., Strathmann, M., Jaeger, K.-E., Flemming, H.-C. \& Wingender, J. Alginate acetylation influences initial surface colonization by mucoid Pseudomonas aeruginosa. Microbiol. Res. 160, 165-176 (2005).

71. Franklin, M. J. \& Ohman, D. E. Identification of algF in the alginate biosynthetic gene cluster of Pseudomonas aeruginosa which is required for alginate acetylation. J. Bacteriol. 175, 5057-65 (1993).

72. Davies, D. G. \& Geesey, G. G. Regulation of the alginate biosynthesis gene algC in Pseudomonas aeruginosa during biofilm development in continuous culture. Appl. Environ. Microbiol. 61, 860-7 (1995).

73. Flemming, H. C. \& Wingender, J. The biofilm matrix. Nat. Rev. Microbiol. 8, 623633 (2010).

74. Sutherland, I. W. Biofilm exopolysaccharides: a strong and sticky framework. Microbiology 147, 3-9 (2001).

75. Ghafoor, A., Hay, I. D. \& Rehm, B. H. A. Role of Exopolysaccharides in Pseudomonas aeruginosa Biofilm Formation and Architecture. Appl. Environ. Microbiol. 77, 5238-5246 (2011).

76. Sauer, K., Camper, A. K., Ehrlich, G. D., Costerton, J. W. \& Davies, D. G. Pseudomonas aeruginosa displays multiple phenotypes during development as a biofilm. J. Bacteriol. 184, 1140-54 (2002).

77. Petrova, O. E. \& Sauer, K. Escaping the biofilm in more than one way: desorption, detachment or dispersion. Curr. Opin. Microbiol. 30, 67-78 (2016).

78. Ross, P. et al. Regulation of cellulose synthesis in Acetobacter xylinum by cyclic diguanylic acid. Nature 325, 279-281 (1987).

79. Römling, U., Galperin, M. Y. \& Gomelsky, M. Cyclic di-GMP: the first 25 years of a universal bacterial second messenger. Microbiol. Mol. Biol. Rev. 77, 1-52 (2013).

80. Jenal, U., Reinders, A. \& Lori, C. Cyclic di-GMP: Second messenger extraordinaire. Nat. Rev. Microbiol. 15, 271-284 (2017).

81. Chou, S. H. \& Galperin, M. Y. Diversity of cyclic di-GMP-binding proteins and mechanisms. J. Bacteriol. 198, 32-46 (2016).

82. Krasteva, P. V., Giglio, K. M. \& Sondermann, H. Sensing the messenger: the diverse ways that bacteria signal through c-di-GMP. Protein Sci. 21, 929-48 (2012).

83. Schirmer, T. C-di-GMP Synthesis: Structural Aspects of Evolution, Catalysis and Regulation. J. Mol. Biol. 428, 3683-3701 (2016).

84. Newell, P. D., Monds, R. D. \& Toole, G. a O. LapD is a bis-(3',5')-cyclic dimeric GMP-binding protein that regulates surface attachment by Pseudomonas fluorescens Pf0-1. PNAS 106, (2009).

85. Hickman, J. W., Tifrea, D. F. \& Harwood, C. S. A chemosensory system that regulates biofilm formation through modulation of cyclic diguanylate levels. Proc. Natl. Acad. Sci. 102, 14422-14427 (2005).

86. Simm, R., Morr, M., Kader, A., Nimtz, M. \& Römling, U. GGDEF and EAL domains inversely regulate cyclic di-GMP levels and transition from sessibility to motility. Mol. Microbiol. 53, 1123-1134 (2004).

87. Paul, R. et al. Cell cycle-dependent dynamic localization of a bacterial response regulator with a novel di-guanylate cyclase output domain. Genes Dev. 18, 715727 (2004).

88. Tischler, A. D. \& Camilli, A. Cyclic diguanylate (c-di-GMP) regulates Vibrio cholerae biofilm formation. Mol. Microbiol. 53, 857-869 (2004).

89. Zähringer, F., Lacanna, E., Jenal, U., Schirmer, T. \& Boehm, A. Structure and Signaling Mechanism of a Zinc-Sensory Diguanylate Cyclase. Structure 21, 1149 1157 (2013). 
90. Sarenko, O. et al. More than Enzymes That Make or Break Cyclic Di-GMP — Local Signaling in the Interactions of GGDEF/EAL Domain Protein of Escherichia Coli. MBio 8, e01639-17 (2017).

91. Deepthi, A., Liew, C. W., Liang, Z. X., Swaminathan, K. \& Lescar, J. Structure of a diguanylate cyclase from Thermotoga maritima: Insights into activation, feedback inhibition and thermostability. PLoS One 9, 1-9 (2014).

92. Wan, $X$. et al. Globins synthesize the second messenger bis-(3'-5')-cyclic diguanosine monophosphate in bacteria. J. Mol. Biol. 388, 262-70 (2009).

93. Burns, J. L. et al. Oxygen and Bis $\left(3^{\prime}, 5^{\prime}\right)$-cyclic Dimeric Guanosine Monophosphate Binding Control Oligomerization State Equilibria of Diguanylate Cyclase-Containing Globin Coupled Sensors. Biochemistry 55, 6642-6651 (2016).

94. Paul, R. et al. Activation of the diguanylate cyclase PleD by phosphorylationmediated dimerization. J. Biol. Chem. 282, 29170-29177 (2007).

95. De, N., Navarro, M. V. A. S., Raghavan, R. V \& Sondermann, H. Determinants for the activation and autoinhibition of the diguanylate cyclase response regulator WspR. J. Mol. Biol. 393, 619-33 (2009).

96. Tamayo, R., Pratt, J. T. \& Camilli, A. Roles of cyclic diguanylate in the regulation of bacterial pathogenesis. Annu. Rev. Microbiol. 61, 131-48 (2007).

97. Wassmann, P. et al. Structure of BeF3- -modified response regulator PleD: implications for diguanylate cyclase activation, catalysis, and feedback inhibition. Structure 15, 915-27 (2007).

98. Schmidt, A. J., Ryjenkov, D. A. \& Gomelsky, M. The Ubiquitous Protein Domain EAL Is a Cyclic Diguanylate-Specific Phosphodiesterase: Enzymatically Active and Inactive EAL Domains. J. Bacteriol. 187, 4774-4781 (2005).

99. Orr, M. W. et al. Oligoribonuclease is the primary degradative enzyme for $\mathrm{pGpG}$ in Pseudomonas aeruginosa that is required for cyclic-di-GMP turnover. Proc. Natl. Acad. Sci. U. S. A. 112, E5048-57 (2015).

100. Tchigvintsev, A. et al. Structural Insight into the Mechanism of c-di-GMP Hydrolysis by EAL Domain Phosphodiesterases. J. Mol. Biol. 402, 524-538 (2010).

101. Sundriyal, A. et al. Inherent regulation of EAL domain-catalyzed hydrolysis of second messenger cyclic di-GMP. J. Biol. Chem. 289, 6978-6990 (2014).

102. Bellini, D. et al. Crystal structure of an HD-GYP domain cyclic-di-GMP phosphodiesterase reveals an enzyme with a novel trinuclear catalytic iron centre. Mol. Microbiol. 91, 26-38 (2014).

103. Ryan, R. P. \& Dow, J. M. Intermolecular interactions between HD-GYP and GGDEF domain proteins mediate virulence-related signal transduction in Xanthomonas campestris. Virulence 1, 404-408 (2010).

104. Slater, H., Alvarez-Morales, A., Barber, C. E., Daniels, M. J. \& Dow, J. M. A twocomponent system involving an HD-GYP domain protein links cell-cell signalling to pathogenicity gene expression in Xanthomonas campestris. Mol. Microbiol. 38, 986-1003 (2000).

105. Ryan, R. P. et al. Cell-cell signaling in Xanthomonas campestris involves an HDGYP domain protein that functions in cyclic di-GMP turnover. Proc. Natl. Acad. Sci. 103, 6712-6717 (2006).

106. Ryan, R. P. et al. Cell-cell signal-dependent dynamic interactions between HDGYP and GGDEF domain proteins mediate virulence in Xanthomonas campestris. Proc. Natl. Acad. Sci. 107, 5989-5994 (2010).

107. Amikam, D. \& Galperin, M. Y. PilZ domain is part of the bacterial c-di-GMP binding protein. Bioinformatics 22, 3-6 (2006).

108. Habazettl, J., Allan, M. G., Jenal, U. \& Grzesiek, S. Solution structure of the PilZ domain protein PA4608 complex with cyclic di-GMP identifies charge clustering as molecular readout. J. Biol. Chem. 286, 14304-14314 (2011).

109. Rezácová, P., Borek, D., Moy, S. F., Joachimiak, A. \& Otwinowski, Z. Crystal structure and putative function of small Toprim domain-containing protein from Bacillus stearothermophilus. Proteins 70, 311-319 (2008). 
110. Beyhan, S., Odell, L. S. \& Yildiz, F. H. Identification and characterization of cyclic diguanylate signaling systems controlling rugosity in Vibrio cholerae. J. Bacteriol. 190, 7392-7405 (2008).

111. Lee, V. T. et al. A cyclic-di-GMP receptor required for bacterial exopolysaccharide production. Mol. Microbiol. 65, 1474-1484 (2007).

112. Duerig, A. et al. Second messenger-mediated spatiotemporal control of protein degradation regulates bacterial cell cycle progression. Gene Dev. 23, 93-104 (2009).

113. Hickman, J. W. \& Harwood, C. S. Identification of FleQ from Pseudomonas aeruginosa as a c-di- GMP-responsive transcription factor. Mol. Microbiol. Microbiol 69, 206-221 (2008).

114. Krasteva, P. V. et al. Vibrio cholerae vpst regulates matrix production and motility by directly sensing cyclic di-GMP. Science (80-. ). 327, 866-868 (2010).

115. Smith, K. D., Shanahan, C. A., Moore, E. L., Simon, A. C. \& Strobel, S. A. Structural basis of differential ligand recognition by two classes of bis-(3'-5')-cyclic dimeric guanosine monophosphate-binding riboswitches. Proc. Natl. Acad. Sci. 108, 77577762 (2011).

116. Bordeleau, E. \& Burrus, V. Cyclic-di-GMP signaling in the Gram-positive pathogen Clostridium difficile. Curr. Genet. (2015).

117. Hengge, R. et al. Systematic nomenclature for GGDEF and EAL domain-containing c-di-GMP turnover proteins of Escherichia coli. J. Bacteriol. JB.00424-15 (2015).

118. Povolotsky, T. L. \& Hengge, R. Genome-Based Comparison of Cyclic Di-GMP Signaling in Pathogenic and Commensal Escherichia coli Strains. J. Bacteriol. 198, 111-26 (2016).

119. Merritt, J. H. et al. Specific Control of Pseudomonas aeruginosa SurfaceAssociated Behaviors by Two c-di-GMP Diguanylate Cyclases. MBio 1, (2010).

120. Massie, J. P. et al. Quantification of high-specificity cyclic diguanylate signaling. Proc. Natl. Acad. Sci. U. S. A. 109, 12746-51 (2012).

121. Abel, S. et al. Regulatory Cohesion of Cell Cycle and Cell Differentiation through Interlinked Phosphorylation and Second Messenger Networks. Mol. Cell 43, 550 560 (2011).

122. Bobrov, A. G., Kirillina, O., Forman, S., Mack, D. \& Perry, R. D. Insights into Yersinia pestis biofilm development: topology and co-interaction of $\mathrm{Hms}$ inner membrane proteins involved in exopolysaccharide production. Environ. Microbiol. 10, 1419-1432 (2008).

123. Dahlstrom, K. M., Giglio, K. M., Collins, A. J., Sondermann, H. \& Toole, A. O. 0416 Contribution of Physical Interactions to Signaling Specificity between a Diguanylate Cyclase and Its Effector.pdf. 6, 1-11 (2015).

124. Dahlstrom, K. M. et al. A Multimodal Strategy Used By A Large c-di-GMP Network. (2017).

125. Park, Y.-S., Dutta, S., Ann, M., Raaijmakers, J. M. \& Park, K. Promotion of plant growth by Pseudomonas fluorescens strain SS101 via novel volatile organic compounds. Biochem. Biophys. Res. Commun. 461, 361-365 (2015).

126. Monds, R. D., Newell, P. D., Gross, R. H. \& O'Toole, G. a. Phosphate-dependent modulation of c-di-GMP levels regulates Pseudomonas fluorescens Pf0-1 biofilm formation by controlling secretion of the adhesin LapA. Mol. Microbiol. 63, 656-679 (2007).

127. Boyd, C. D. et al. Structural features of the Pseudomonas fluorescens biofilm adhesin LapA required for LapG-dependent cleavage, biofilm formation, and cell surface localization. J. Bacteriol. 196, 2775-2788 (2014).

128. Schwarz, E. M. \& Benzer, S. Calx, a Na-Ca exchanger gene of Drosophila melanogaster. Proc. Natl. Acad. Sci. U. S. A. 94, 10249-10254 (1997).

129. Matsuoka, S., Nicoll, D. a, He, Z. \& Philipson, K. D. Regulation of cardiac $\mathrm{Na}(+)-$ $\mathrm{Ca2}+$ exchanger by the endogenous XIP region. J. Gen. Physiol. 109, 273-86 (1997). 
130. Boyd, C. D., Chatterjee, D. \& Sondermann, H. LapG, Required for Modulating Biofilm Formation by Pseudomonas fluorescens Pf0-1, Is a Calcium-Dependent Protease. 194, 4406-4414 (2012).

131. Colombatti, A. \& Bonaldo, P. The superfamily of proteins with von Willebrand factor type A-like domains: one theme common to components of extracellular matrix, hemostasis, cellular adhesion, and defense mechanisms. Blood 77, 2305-2315 (1991).

132. Konto-Ghiorghi, Y. et al. Dual role for pilus in adherence to epithelial cells and biofilm formation in Streptococcus agalactiae. PLoS Pathog. 5, (2009).

133. Kuchma, S. L. et al. Cyclic-di-GMP-mediated repression of swarming motility by Pseudomonas aeruginosa: The pilY1 gene and its impact on surface-associated behaviors. J. Bacteriol. 192, 2950-2964 (2010).

134. Welch, R. A. Pore-forming cytolysins of Gram-negative bacteria. Mol. Microbiol. 5, 521-528 (1991).

135. Bumba, L. et al. Calcium-Driven Folding of RTX Domain $\beta$-Rolls Ratchets Translocation of RTX Proteins through Type I Secretion Ducts. Mol. Cell 62, 47-62 (2016).

136. Smith, T. J., Font, M. E., Kelly, C. M., Sondermann, H. \& O'Toole, G. A. An Nterminal retention module anchors the giant adhesin LapA of Pseudomonas fluorescens at the cell surface: A novel subfamily of type I secretion systems. J. Bacteriol. 200, (2018).

137. Ferris, H. U. et al. The mechanisms of HAMP-mediated signaling in transmembrane receptors. Structure 19, 378-385 (2011).

138. Schultz, J. E., Kanchan, K. \& Ziegler, M. Intraprotein signal transduction by HAMP domains: A balancing act. Int. J. Med. Microbiol. 305, 243-251 (2015).

139. Navarro, M. V. A. S. et al. Structural Basis for c-di-GMP-Mediated Inside-Out Signaling Controlling Periplasmic Proteolysis. 9, (2011).

140. Newell, P. D., Boyd, C. D., Sondermann, H. \& O\&apos;Toole, G. a. A c-di-GMP effector system controls cell adhesion by inside-out signaling and surface protein cleavage. PLoS Biol. 9, (2011).

141. Cooley, R. B. et al. Cyclic di-GMP-regulated periplasmic proteolysis of a Pseudomonas aeruginosa type $\mathrm{Vb}$ secretion system substrate. J. Bacteriol. JB.00369-15 (2015).

142. Newell, P. D., Yoshioka, S., Hvorecny, K. L., Monds, R. D. \& O'Toole, G. A. Systematic analysis of diguanylate cyclases that promote biofilm formation by Pseudomonas fluorescens Pf0-1. J. Bacteriol. 193, 4685-4698 (2011).

143. Giacalone, D. et al. Ligand-Mediated Biofilm Formation via Enhanced Physical Interaction between a Diguanylate Cyclase and Its Receptor. MBio 9, e01254-18 (2018).

144. Mattoo, S., Cotter, P. a \& Miller, J. F. Mechanisms of Bordetella pathogenesis. Front. Biosci. 6, 168-186 (2001).

145. Bordet, J. \& Gengou, O. Le microbe de la coqueluche. Les Ann. I'Institut Pasteur 731-741 (1906).

146. Bordet, J. \& Gengou, O. Le microbe de la coqueluche. Les Ann. I'Institut Pasteur Tome 21, 720-722 (1907).

147. Ferry, N. A preliminary report of the bacterial findings in canine distemper. Am. Vet. Rev 37, 499-504 (1910).

148. Mochizuki, M., Yachi, A., Ohshima, T., Ohuchi, A. \& Ishida, T. Etiologic Study on Upper Respiratory Infections of Household Dogs. J. Vet. Med. Sci. 70, 563-569 (2008).

149. Soumana, I. H., Linz, B. \& Harvill, E. T. Environmental origin of the genus Bordetella. Front. Microbiol. 8, 1-10 (2017).

150. Connor, S. P. O. et al. Bordetella holmesii sp . nov ., a new gram-negative species associated with septicemia. 33, 1-7 (1995).

151. Mazengia, E., Silva, E. A., Peppe, J. A., Timperi, R. \& George, H. Recovery of 
Bordetella holmesii from patients with pertussis-like symptoms: Use of pulsed-field gel electrophoresis to characterize circulating strains. J. Clin. Microbiol. 38, 2330 2333 (2000).

152. Weigand, M. R., Changayil, S., Kulasekarapandian, Y. \& Tondella, M. L. Complete Genome Sequences of Two Bordetella hinzii Strains Isolated from Humans. Genome Announc 3, 3-4 (2015).

153. Parkhill, J. et al. Comparative analysis of the genome sequences of Bordetella pertussis, Bordetella parapertussis and Bordetella bronchiseptica. Nat. Genet. 35, 32-40 (2003).

154. Goodnow, R. a. Biology of Bordetella bronchiseptica. Microbiol. Rev. 44, 722-738 (1980).

155. Register, K. B. et al. Draft Genome Sequences of 53 Genetically Distinct Isolates of Bordetella bronchiseptica Representing 11 Terrestrial and Aquatic Hosts. Genome Announc. 3, e00152-15 (2015).

156. Jorgenson, D., Farrington, O. \& Richard, D. Prevalence of Bordetella bronchiseptica in certain wild mammals and birds in central lowa. 19, 192-199 (1966).

157. Woolfrey, B. F. \& Moody, J. A. Human infections associated with Bordetella bronchiseptica. Clin. Microbiol. Rev. 4, 243-55 (1991).

158. Wallet, F., Perez, T., Armand, S., Wallaert, B. \& Courcol, R. J. Pneumonia due to Bordetella bronchiseptica in a cystic fibrosis patient: 16S rRNA sequencing for diagnosis confirmation. J. Clin. Microbiol. 40, 2300-1 (2002).

159. Brady, C., Ackerman, P., Johnson, M. \& McNamara, J. Bordetella bronchiseptica in a pediatric Cystic Fibrosis center. J. Cyst. Fibros. 13, 43-48 (2014).

160. Valencia, M. E., Enríquez, A., Camino, N. \& Moreno, V. Bordetella bronchiseptica pneumonia in patients with HIV. Enferm. Infecc. Microbiol. Clin. 22, 502-3 (2004).

161. Rath, B. A., Register, K. B., Wall, J., Sokol, D. M. \& Van Dyke, R. B. Persistent Bordetella bronchiseptica Pneumonia in an Immunocompetent Infant and Genetic Comparison of Clinical Isolates with Kennel Cough Vaccine Strains. Clin. Infect. Dis. 46, 905-908 (2008).

162. Lo Re, V. et al. Infected branchial cleft cyst due to Bordetella bronchiseptica in an immunocompetent patient. J. Clin. Microbiol. 39, 4210-2 (2001).

163. Karamooz, E., Yap, V. L., Barker, A. F. \& Metersky, M. L. Bordetella bronchiseptica in non-cystic fibrosis bronchiectasis. Respir. Med. Case Reports 25, 187-188 (2018).

164. Bjørnstad, O. N. \& Harvill, E. T. Evolution and emergence of Bordetella in humans. Trends Microbiol. 13, 355-359 (2005).

165. Weiss, A. A., Melton, A. R., Walker, K. E., Andraos-Selim, C. \& Meidl, J. J. Use of the promoter fusion transposon Tn5 lac to identify mutations in Bordetella pertussis vir-regulated genes. Infect. Immun. 57, 2674-82 (1989).

166. Weiss, A. A. \& Falkow, S. Genetic analysis of phase change in Bordetella pertussis. Infect. Immun. 43, 263-9 (1984).

167. Herrou, J. et al. Molecular Evolution of the Two-Component System BvgAS Involved in Virulence Regulation in Bordetella. PLoS One 4, e6996 (2009).

168. Karimova, G., Bellalou, J. \& Ullmann, A. Phosphorylation-dependent binding of BvgA to the upstream region of the cyaA gene of Bordetella pertussis. Mol. Microbiol. 20, 489-96 (1996).

169. Steffen, P., Goyard, S. \& Ullmann, A. Phosphorylated BvgA is sufficient for transcriptional activation of virulence-regulated genes in Bordetella pertussis. EMBO J. 15, 102-9 (1996).

170. Roy, C. R. \& Falkow, S. Identification of Bordetella pertussis regulatory sequences required for transcriptional activation of the fhaB gene and autoregulation of the bvgAS operon. J. Bacteriol. 173, 2385-92 (1991).

171. Scarlato, V., Prugnola, A., Aricó, B. \& Rappuoli, R. Positive transcriptional feedback at the bvg locus controls expression of virulence factors in Bordetella pertussis. 
Proc. Natl. Acad. Sci. U. S. A. 87, 6753-7 (1990).

172. Boucher, P. E., Murakami, K., Ishihama, A. \& Stibitz, S. Nature of DNA binding and RNA polymerase interaction of the Bordetella pertussis BvgA transcriptional activator at the fha promoter. J. Bacteriol. 179, 1755-63 (1997).

173. Cotter, P. a. \& Miller, J. F. BvgAS-mediated signal transduction: Analysis of phaselocked regulatory mutants of Bordetella bronchiseptica in a rabbit model. Infect. Immun. 62, 3381-3390 (1994).

174. Fuchslocher, B., Millar, L. L. \& Cotter, P. A. Comparison of bipA alleles within and across Bordetella species. Infect. Immun. 71, 3043-52 (2003).

175. De Tejada, G. M. et al. Neither the Bvg- phase nor the vrg6 locus of Bordetella pertussis is required for respiratory infection in mice. Infect. Immun. 66, 2762-2768 (1998).

176. Merkel, T. J., Barros, C. \& Stibitz, S. Characterization of the bvgR Locus of Bordetella pertussis. J. Bacteriol. 180, 1682-1690 (1998).

177. Cotter, P. A. \& Jones, A. M. Phosphorelay control of virulence gene expression in Bordetella. Trends Microbiol. 11, 367-373 (2003).

178. Manetti, R., Aricò, B., Rappuoli, R. \& Scarlato, V. Mutations in the linker region of BvgS abolish response to environmental signals for the regulation of the virulence factors in Bordetella pertussis. Gene 150, 123-7 (1994).

179. Miller, J. F. et al. Constitutive sensory transduction mutations in the Bordetella pertussis bvgS gene. J. Bacteriol. 174, 970-9 (1992).

180. Fernández, J., Sisti, F., Bottero, D., Gaillard, M. E. \& Hozbor, D. Constitutive expression of bvgR-repressed factors is not detrimental to the Bordetella bronchiseptica-host interaction. Res. Microbiol. 156, 843-850 (2005).

181. Coutte, L. et al. The multifaceted RisA regulon of Bordetella pertussis. Sci. Rep. 6, 32774 (2016).

182. Knapp, S. \& Mekalanos, J. J. Two trans-acting regulatory genes (vir and mod) control antigenic modulation in Bordetella pertussis. J. Bacteriol. 170, 5059-66 (1988).

183. Martínez de Tejada, G., Miller, J. F. \& Cotter, P. a. Comparative analysis of the virulence control systems of Bordetella pertussis and Bordetella bronchiseptica. Mol. Microbiol. 22, 895-908 (1996).

184. Finn, T. M., Shahin, R. \& Mekalanos, J. J. Characterization of vir-activated TnphoA gene fusions in Bordetella pertussis. Infect. Immun. 59, 3273-9 (1991).

185. Deora, R., Bootsma, H. J., Miller, J. F. \& Cotter, P. A. Diversity in the Bordetella virulence regulon: transcriptional control of a Bvg-intermediate phase gene. Mol. Microbiol. 40, 669-83 (2001).

186. Cummings, C. A., Bootsma, H. J., Relman, D. A. \& Miller, J. F. Species- and StrainSpecific Control of a Complex, Flexible Regulon by Bordetella BvgAS. J. Bacteriol. 188, 1775-1785 (2006).

187. Williams, C. L. \& Cotter, P. a. Autoregulation is essential for precise temporal and steady-state regulation by the Bordetella BvgAS phosphorelay. J. Bacteriol. 189, 1974-1982 (2007).

188. Nicholson, T. L., Buboltz, A. M., Harvill, E. T. \& Brockmeier, S. L. Microarray and functional analysis of growth phase-dependent gene regulation in Bordetella bronchiseptica. Infect. Immun. 77, 4221-4231 (2009).

189. Stockbauer, K. E., Fuchslocher, B., Miller, J. F. \& Cotter, P. A. Identification and characterization of BipA, a Bordetella Bvg-intermediate phase protein. Mol. Microbiol. 39, 65-78 (2001).

190. Sukumar, N., Mishra, M., Sloan, G. P., Ogi, T. \& Deora, R. Differential Bvg phasedependent regulation and combinatorial role in pathogenesis of two Bordetella paralogs, BipA and BcfA. J. Bacteriol. 189, 3695-704 (2007).

191. Scarlato, V., Aricò, B. \& Rappuoli, R. DNA topology affects transcriptional regulation of the pertussis toxin gene of Bordetella pertussis in Escherichia coli and in vitro. J. Bacteriol. 175, 4764-71 (1993). 
192. Kinnear, S. M., Boucher, P. E., Stibitz, S. \& Carbonetti, N. H. Analysis of BvgA activation of the pertactin gene promoter in Bordetella pertussis. J. Bacteriol. 181, 5234-41 (1999).

193. Cotter, P. a \& Miller, J. F. A mutation in the Bordetella bronchiseptica bvgS gene results in reduced virulence and increased resistance to starvation, and identifies a new class of Bvg-regulated antigens. Mol. Microbiol. 24, 671-685 (1997).

194. Melvin, J. a, Scheller, E. V, Miller, J. F. \& Cotter, P. a. Bordetella pertussis pathogenesis: current and future challenges. Nat Rev Microbiol. 12, 274-288 (2014).

195. Mattoo, S. \& Cherry, J. D. Molecular Pathogenesis, Epidemiology, and Clinical Manifestations of Respiratory Infections Due to Bordetella pertussis and Other Bordetella Subspecies. Clin. Microbiol. Rev. 18, 326-382 (2005).

196. Cotter, P. a \& Miller, J. F. A mutation in the Bordetella bronchiseptica bvgS gene results in reduced virulence and increased resistance to starvation, and identifies a new class of Bvg-regulated antigens. Molecular microbiology 24, 671-685 (1997).

197. Irie, Y., Mattoo, S. \& Yuk, M. H. The Bvg virulence control system regulates biofilm formation in Bordetella bronchiseptica. J. Bacteriol. 186, 5692-5698 (2004).

198. Akerley, B. J., Cotter, P. a \& Miller, J. F. Ectopic expression of the flagellar regulon alters development of the Bordetella-host interaction. Cell 80, 611-620 (1995).

199. Byrd, M. S., Mason, E., Henderson, M. W., Scheller, E. V. \& Cotter, P. a. An improved recombination-based in vivo expression technology-like reporter system reveals differential cyaA gene activation in Bordetella species. Infect. Immun. 81, 1295-1305 (2013).

200. Abe, H. et al. Detection of genes expressed in Bordetella bronchiseptica colonizing rat trachea by in vivo expressed-tag immunoprecipitation method. Microbiol. Immunol. 59, 249-261 (2015).

201. Conover, M. S., Sloan, G. P., Love, C. F., Sukumar, N. \& Deora, R. The Bps polysaccharide of Bordetella pertussis promotes colonization and biofilm formation in the nose by functioning as an adhesin. Mol. Microbiol. 77, 1439-55 (2010).

202. Giles, C. J., Smith, I. M., Baskerville, A. J. \& Brothwell, E. Clinical bacteriological and epidemiological observations on infectious atrophic rhinitis of pigs in southern England. Vet. Rec. 106, 25-8 (1980).

203. Rutter, J. M. Quantitative observations on Bordetella bronchiseptica infection in atrophic rhinitis of pigs. Vet. Rec. 108, 451-4 (1981).

204. Nicholson, T. L., Brockmeier, S. L. \& Loving, C. L. Contribution of Bordetella bronchiseptica filamentous hemagglutinin and pertactin to respiratory disease in swine. Infect. Immun. 77, 2136-2146 (2009).

205. Harvill, E. T., Cotter, P. a \& Miller, J. F. Pregenomic Comparative Analysis between Bordetella bronchiseptica RB50 and Bordetella pertussis Tohama I in Murine Models of Respiratory Tract Infection. Infect. Immun. 67, 6109-18 (1999).

206. El Khatib, N. et al. Persistent Bordetella bronchiseptica infection in a child with cystic fibrosis: Relationship to bacterial phenotype. J. Cyst. Fibros. 14, E13-5 (2015).

207. Sloan, G. P., Love, C. F., Sukumar, N., Mishra, M. \& Deora, R. The Bordetella Bps Polysaccharide Is Critical for Biofilm Development in the Mouse Respiratory Tract. 189, 8270-8276 (2007).

208. Serra, D. O. et al. FHA-mediated cell-substrate and cell-cell adhesions are critical for Bordetella pertussis biofilm formation on abiotic surfaces and in the mouse nose and the trachea. PLoS One 6, (2011).

209. Berne, C., Ducret, A., Hardy, G. G. \& Brun, Y. V. Adhesins Involved in Attachment to Abiotic Surfaces by Gram-Negative Bacteria. Microbiol. Spectr. 3, (2015).

210. Mazar, J. \& Cotter, P. A. Topology and maturation of filamentous haemagglutinin suggest a new model for two-partner secretion. Mol. Microbiol. 62, 641-654 (2006).

211. Ishibashi, Y., Relman, D. A. \& Nishikawa, A. Invasion of human respiratory 
epithelial cells by Bordetella pertussis: Possible role for a filamentous hemagglutinin Arg-Gly-Asp sequence and a5 $\beta 1$ integrin. Microb. Pathog. 30, 279288 (2001).

212. Ruoslahti, E. \& Pierschbacher, M. D. New perspectives in cell adhesion: RGD and integrins. Science 238, 491-7 (1987).

213. Prasad, S. M., Yin, Y., Rodzinski, E., Tuomanen, E. I. \& Masure, H. R. Identification of a carbohydrate recognition domain in filamentous hemagglutinin from Bordetella pertussis. Infect. Immun. 61, 2780-2785 (1993).

214. Saukkonen, K., Cabellos, C., Burroughs, M., Prasad, S. \& Tuomanen, E. Integrinmediated localization of Bordetella pertussis within macrophages: role in pulmonary colonization. J. Exp. Med. 173, 1143-9 (1991).

215. Menozzi, F. D. et al. Heparin-inhibitable lectin activity of the filamentous hemagglutinin adhesin of Bordetella pertussis. Infect. Immun. 62, 769-78 (1994).

216. Cotter, P. a. et al. Filamentous hemagglutinin of Bordetella bronchiseptica is required for efficient establishment of tracheal colonization. Infect. Immun. 66, 5921-5929 (1998).

217. Coutte, L., Antoine, R., Drobecq, H., Locht, C. \& Jacob-Dubuisson, F. Subtilisinlike autotransporter serves as maturation protease in a bacterial secretion pathway. EMBO J. 20, 5040-5048 (2001).

218. Coutte, L. et al. Role of adhesin release for mucosal colonization by a bacterial pathogen. J. Exp. Med. 197, 735-42 (2003).

219. Gerlach, R. G. \& Hensel, M. Protein secretion systems and adhesins: The molecular armory of Gram-negative pathogens. Int. J. Med. Microbiol. 297, 401415 (2007).

220. Mattoo, S., Miller, J. F. \& Cotter, P. A. Role of Bordetella bronchiseptica Fimbriae in Tracheal Colonization and Development of a Humoral Immune Response Role of Bordetella bronchiseptica Fimbriae in Tracheal Colonization and Development of a Humoral Immune Response. 68, 2024-2033 (2000).

221. Locht, C., Geoffroy, M. C. \& Renauld, G. Common accessory genes for the Bordetella pertussis filamentous hemagglutinin and fimbriae share sequence similarities with the papC and papD gene families. EMBO J. 11, 3175-83 (1992).

222. Irie, Y., Mattoo, S. \& Yuk, M. H. The Bvg Virulence Control System Regulates Biofilm Formation in Bordetella bronchiseptica. 186, 5692-5698 (2004).

223. Mishra, M. et al. The BvgAS Signal Transduction System Regulates Biofilm Development in Bordetella. 187, 1474-1484 (2005).

224. Sisti, F., Ha, D. G., O'Toole, G. A., Hozbor, D. \& Fernández, J. Cyclic-di-GMP signalling regulates motility and biofilm formation in Bordetella bronchiseptica. Microbiol. (United Kingdom) 159, 869-879 (2013).

225. Parise, G., Mishra, M., Itoh, Y., Romeo, T. \& Deora, R. Role of a putative polysaccharide locus in Bordetella biofilm development. J. Bacteriol. 189, 750-60 (2007).

226. Nicholson, T. L., Conover, M. S. \& Deora, R. Transcriptome Profiling Reveals Stage-Specific Production and Requirement of Flagella during Biofilm Development in Bordetella bronchiseptica. PLoS One 7, (2012).

227. Cattelan, N., Dubey, P., Arnal, L., Yantorno, O. M. \& Deora, R. Bordetella biofilms: a lifestyle leading to persistent infections. Pathog. Dis. 74, ftv108 (2016).

228. Cotter, P. A. \& Jones, A. M. Phosphorelay control of virulence gene expression in Bordetella. Trends Microbiol. 11, 367-373 (2003).

229. Hoffman, C. et al. Bordetella adenylate cyclase toxin interacts with filamentous haemagglutinin to inhibit biofilm formation in vitro. Mol. Microbiol. 103, 214-228 (2017).

230. Nicholson, T. L. et al. The Bordetella Bps polysaccharide is required for biofilm formation and enhances survival in the lower respiratory tract of swine. Infect. Immun. 85, 1-15 (2017).

231. Wang, X., Preston, J. F. \& Romeo, T. The pgaABCD locus of Escherichia coli 
promotes the synthesis of a polysaccharide adhesin required for biofilm formation. J. Bacteriol. 186, 2724-34 (2004).

232. Conover, M. S. et al. BpsR modulates Bordetella biofilm formation by negatively regulating the expression of the Bps polysaccharide. J. Bacteriol. 194, 233-42 (2012).

233. Brickman, T. J. \& Armstrong, S. K. The Bordetella bronchiseptica nic locus encodes a nicotinic acid degradation pathway and the 6-hydroxynicotinate-responsive regulator BpsR. Mol. Microbiol. 108, 397-409 (2018).

234. Guragain, M. et al. The Transcriptional Regulator BpsR Controls the Growth of Bordetella bronchiseptica by Repressing Genes Involved in Nicotinic Acid Degradation. J. Bacteriol. 200, e00712-17 (2018).

235. Dewan, K. K. et al. An Extracellular Polysaccharide Locus Required for Transmission of Bordetella bronchiseptica. J. Infect. Dis. 216, 899-906 (2017).

236. Conover, M. S., Mishra, M. \& Deora, R. Extracellular DNA Is Essential for Maintaining Bordetella Biofilm Integrity on Abiotic Surfaces and in the Upper Respiratory Tract of Mice. 6, (2011).

237. Allesen-Holm, M. et al. A characterization of DNA release in Pseudomonas aeruginosa cultures and biofilms. Mol. Microbiol. 59, 1114-1128 (2006).

238. Binnenkade, L., Teichmann, L. \& Thormann, K. M. Iron Triggers $\lambda$ So Prophage Induction and Release of Extracellular DNA in Shewanella oneidensis MR-1 Biofilms. Appl. Environ. Microbiol. 80, 5304-5316 (2014).

239. Serra, D. et al. Continuous nondestructive monitoring of Bordetella pertussis biofilms by Fourier transform infrared spectroscopy and other corroborative techniques. Anal. Bioanal. Chem. 387, 1759-1767 (2007).

240. Cattelan, N. et al. Outer membrane protein OmpQ of Bordetella bronchiseptica is required for mature biofilm formation. Microbiology 162, 351-363 (2016).

241. Monds, R. D. \& Toole, G. A. O. The developmental model of microbial biofilms : ten years of a paradigm up for review. 73-87 (2009).

242. Beloin, C. \& Ghigo, J.-M. Finding gene-expression patterns in bacterial biofilms. Trends Microbiol. 13, 16-19 (2005).

243. Gaca, A. O., Colomer-Winter, C. \& Lemos, J. A. Many means to a common end: the intricacies of (p)ppGpp metabolism and its control of bacterial homeostasis. J. Bacteriol. 197, 1146-56 (2015).

244. Sugisaki, K. et al. Role of (p)ppGpp in biofilm formation and expression of filamentous structures in Bordetella pertussis. Microbiol. (United Kingdom) 159, 1379-1389 (2013).

245. Le Blay, K., Gueirard, P., Guiso, N. \& Chaby, R. Antigenic polymorphism of the lipopolysaccharides from human and animal isolates of Bordetella bronchiseptica. Microbiology 143, 1433-1441 (1997).

246. El-Kirat-Chatel, S., Beaussart, A., Boyd, C. D., O'Toole, G. a. \& Dufreîne, Y. F. Single-cell and single-molecule analysis deciphers the localization, adhesion, and mechanics of the biofilm adhesin LapA. ACS Chem. Biol. 9, 485-494 (2014).

247. Newell, P. D., Boyd, C. D., Sondermann, H. \& O'Toole, G. a. A c-di-GMP effector system controls cell adhesion by inside-out signaling and surface protein cleavage. PLoS Biol. 9, e1000587 (2011).

248. Taylor, B. L. Aer on the inside looking out: Paradigm for a PAS-HAMP role in sensing oxygen, redox and energy. Mol. Microbiol. 65, 1415-1424 (2007).

249. Cooley, R. B., Donnell, J. P. O. \& Sondermann, H. Coincidence detection and bidirectional transmembrane signaling control a bacterial second messenger receptor. 1-19 (2016). doi:10.7554/eLife. 21848

250. Chatterjee, D. et al. Mechanistic insight into the conserved allosteric regulation of periplasmic proteolysis by the signaling molecule cyclic-di-GMP. Elife 3, 1-29 (2014).

251. Römling, U., Liang, Z.-X. \& Dow, J. M. Progress in Understanding the Molecular Basis Underlying Functional Diversification of Cyclic Dinucleotide Turnover 
Proteins. J. Bacteriol. 199, e00790-16 (2017).

252. Krasteva, P. V. \& Sondermann, H. Versatile modes of cellular regulation via cyclic dinucleotides. Nat. Chem. Biol. 13, 350-359 (2017).

253. Navarro, M. V. a S. et al. Structural basis for c-di-GMP-mediated inside-out signaling controlling periplasmic proteolysis. PLoS Biol. 9, (2011).

254. Appleman, J. A., Chen, L. L. \& Stewart, V. Probing conservation of HAMP linker structure and signal transduction mechanism through analysis of hybrid sensor kinases. J. Bacteriol. 185, 4872-4882 (2003).

255. Hulko, M. et al. The HAMP Domain Structure Implies Helix Rotation in Transmembrane Signaling. Cell 126, 929-940 (2006).

256. Chatterjee, D., Boyd, C. D., O Toole, G. A. \& Sondermann, H. Structural Characterization of a Conserved, Calcium-Dependent Periplasmic Protease from Legionella pneumophila. 194, 4415-4425 (2012).

257. Kelly, L. A., Mezulis, S., Yates, C., Wass, M. \& Sternberg, M. The Phyre2 web portal for protein modelling, prediction, and analysis. Nat. Protoc. 10, 845-858 (2015).

258. Lesk, A. M. Introduction to genomics. (Oxford University Press, 2012).

259. Lewis, E. A. \& Murphy, K. P. Isothermal Titration Calorimetry. in Protein-Ligand Interactions 001-016 (Humana Press, 2005). doi:10.1385/1-59259-912-5:001

260. Nishikawa, S. et al. The bvg-repressed gene brtA, encoding biofilm-associated surface adhesin, is expressed during host infection by Bordetella bronchiseptica. Microbiol Immunol 60(2), 93-105 (2016).

261. Hinsa, S. M., Espinosa-Urgel, M., Ramos, J. L. \& O'Toole, G. a. Transition from reversible to irreversible attachment during biofilm formation by Pseudomonas fluorescens WCS365 requires an ABC transporter and a large secreted protein. Mol. Microbiol. 49, 905-918 (2003).

262. Chatterjee, D., Boyd, C. D., Toole, G. A. O. \& Sondermann, H. Structural Characterization of a Conserved, Calcium-Dependent Periplasmic Protease from Legionella pneumophila. 194, 4415-4425 (2012).

263. Yousef, F. \& Espinosa-Urgel, M. In silico analysis of large microbial surface proteins. Res. Microbiol. 158, 545-550 (2007).

264. Zhou, G., Yuan, J. \& Gao, H. Regulation of biofilm formation by BpfA, BpfD, and BpfG in Shewanella oneidensis. Front. Microbiol. 6, 1-11 (2015).

265. Perez-Mendoza, D. et al. A multi-repeat adhesin of the phytopathogen, Pectobacterium atrosepticum, is secreted by a Type I pathway and is subject to complex regulation involving a non-canonical diguanylate cyclase. Mol. Microbiol. 82, 719-733 (2011).

266. Syed, K. A. et al. The Vibrio cholerae flagellar regulatory hierarchy controls expression of virulence factors. J. Bacteriol. 191, 6555-70 (2009).

267. O'Toole, G. a. Microtiter dish biofilm formation assay. J. Vis. Exp. 10-11 (2011). doi:10.3791/2437

268. Hillenkamp, F., Karas, M., Beavis, R. C. \& Chait, B. T. Matrix-Assisted Laser Desorption/Ionization Mass Spectrometry of Biopolymers. Anal. Chem. 63, (1991).

269. Perkins, D. N., Pappin, D. J. C., Creasy, D. M. \& Cottrell, J. S. Probability-based protein identification by searching sequence databases using mass spectrometry data. Electrophoresis 20, 3551-3567 (1999).

270. Gogichaeva, N. V., Williams, T. \& Alterman, M. A. MALDI TOF/TOF Tandem Mass Spectrometry as a New Tool for Amino Acid Analysis. J. Am. Soc. Mass Spectrom. 18, 279-284 (2007).

271. Mao, F., Dam, P., Chou, J., Olman, V. \& Xu, Y. DOOR: A database for prokaryotic operons. Nucleic Acids Res. 37, 459-463 (2009).

272. Dam, P., Olman, V., Harris, K., Su, Z. \& Xu, Y. Operon prediction using both genome-specific and general genomic information. Nucleic Acids Res. 35, 288298 (2007).

273. Newell, P. D., Yoshioka, S., Hvorecny, K. L., Monds, R. D. \& O\&apos;Toole, G. a. 
Systematic analysis of diguanylate cyclases that promote biofilm formation by Pseudomonas fluorescens Pf0-1. J. Bacteriol. 193, 4685-4698 (2011).

274. Schindelin, J. et al. Fiji: an open-source platform for biological-image analysis. Nat. Methods 9, 676-682 (2012).

275. Hsin, J., Arkhipov, A., Yin, Y., Stone, J. E. \& Schulten, K. Using VMD - An Introductory Tutorial. Curr. Protoc. Bioinformatics CHAPTER, Unit-5.7 (2008).

276. Newell, P. D., Boyd, C. D., Sondermann, H. \& Toole, G. A. O. A c-di-GMP Effector System Controls Cell Adhesion by Inside-Out Signaling and Surface Protein Cleavage. 9, (2011).

277. Antoine, R. \& Locht, C. Isolation and molecular characterization of a novel broad host range plasmid from Bordetella bronchiseptica with sequence similarities to plasmids from Gram positive organisms. Mol. Microbiol. 6, 1785-1799 (1992).

278. Byrd, M. S., Mason, E., Henderson, M. W., Scheller, E. V \& Cotter, P. a. An improved recombination-based in vivo expression technology-like reporter system reveals differential cyaA gene activation in Bordetella species. Infect. Immun. 81, 1295-305 (2013).

279. Smith, T. J., Sondermann, H. \& O'Toole, G. A. Type 1 Does The Two-Step: Type 1 Secretion Substrates With A Functional Periplasmic Intermediate. J. Bacteriol. (2018). doi:10.1128/JB.00743-17

280. Nicholson, T. L. Construction and validation of a first-generation Bordetella bronchiseptica long-oligonucleotide microarray by transcriptional profiling the Bvg regulon. BMC Genomics 8, 220 (2007).

281. Zeitlin, P. L. et al. A Cystic Fibrosis Bronchial Epithelial Cell Line: Immortalization by Adeno-12-SV40 Infection. Am. J. Respir. Cell Mol. Biol. 4, 313-319 (1991).

282. Weyrich, L. S. et al. Resident microbiota affect bordetella pertussis infectious dose and host specificity. J. Infect. Dis. 209, 913-921 (2014).

283. Sisti, F. et al. In vitro and in vivo characterization of a Bordetella bronchiseptica mutant strain with a deep rough lipopolysaccharide structure. Infect. Immun. 70, 1791-1798 (2002).

284. Nicholson, T. L. et al. Phenotypic modulation of the virulent bvg phase is not required for pathogenesis and transmission of Bordetella bronchiseptica in swine. Infect. Immun. 80, 1025-1036 (2012).

285. Rolin, O. et al. Toll-Like Receptor 4 Limits Transmission of Bordetella bronchiseptica. PLoS One 9, e85229 (2014).

286. Register, K. B., Sukumar, N., Palavecino, E. L., Rubin, B. K. \& Deora, R. Bordetella bronchiseptica in a paediatric cystic fibrosis patient: possible transmission from a household cat. Zoonoses Public Health 59, 246-50 (2012).

287. Abe, H. et al. Detection of genes expressed in Bordetella bronchiseptica colonizing rat trachea by in vivo expressed-tag immunoprecipitation method. Microbiol. Immunol. 59, 249-261 (2015).

288. Melvin, J. A., Scheller, E. V, Noël, C. R. \& Cotter, P. A. New Insight into Filamentous Hemagglutinin Secretion Reveals a Role for Full-Length FhaB in Bordetella Virulence. MBio 6, 12-15 (2015).

289. Sukumar, N., Nicholson, T. L., Conover, M. S., Ganguly, T. \& Deora, R. Comparative Analyses of a Cystic Fibrosis Isolate of Bordetella bronchiseptica Reveal Differences in Important Pathogenic Phenotypes. Infect. Immun. 82, 16271637 (2014).

290. Yuk, M. H., Harvill, E. T. \& Miller, J. F. The BvgAS virulence control system regulates type III secretion in Bordetella bronchiseptica. Mol. Microbiol. 28, 945-59 (1998).

291. Lee, C. A. Type III secretion systems: machines to deliver bacterial proteins into eukaryotic cells? Trends Microbiol. 5, 148-156 (1997).

292. Gonyar, L. A., Gray, M. C., Christianson, G. J., Mehrad, B. \& Hewlett, E. L. Albumin, in the presence of calcium, elicits a massive increase in extracellular Bordetella adenylate cyclase toxin. Infect. Immun. 85, 1-19 (2017). 
293. Newell, P. D., Yoshioka, S., Hvorecny, K. L., Monds, R. D. \& O'Toole, G. a. Systematic analysis of diguanylate cyclases that promote biofilm formation by Pseudomonas fluorescens Pf0-1. J. Bacteriol. 193, 4685-98 (2011).

294. O'Brien, D. P. et al. Calcium-dependent disorder-to-order transitions are central to the secretion and folding of the CyaA toxin of Bordetella pertussis, the causative agent of whooping cough. Toxicon 149, 37-44 (2018).

295. Lahesaare, A. et al. LapF and Its Regulation by Fis Affect the Cell Surface Hydrophobicity of Pseudomonas putida. PLoS One 11, e0166078 (2016).

296. Gestal, M. C. et al. Blood or Serum Exposure Induce Global Transcriptional Changes, Altered Antigenic Profile, and Increased Cytotoxicity by Classical Bordetellae. Front. Microbiol. 9, 1969 (2018).

297. Dahlstrom, K. M., Giglio, K. M., Sondermann, H. \& O'Toolea, G. A. The inhibitory site of a diguanylate cyclase is a necessary element for interaction and signaling with an effector protein. J. Bacteriol. 198, 1595-1603 (2016).

298. Ryjenkov, D. a, Tarutina, M., Moskvin, O. V \& Gomelsky, M. Cyclic Diguanylate Is a Ubiquitous Signaling Molecule in Bacteria: Insights into Biochemistry of the GGDEF Protein Domain. J Bacteriol 187, 1792-1798 (2005).

299. Hengge, R. Principles of c-di-GMP signalling in bacteria. Nat. Rev. Microbiol. 7, 263-273 (2009).

300. Battesti, A. \& Bouveret, E. The bacterial two-hybrid system based on adenylate cyclase reconstitution in Escherichia coli. Methods 58, 325-334 (2012).

301. Ouellette, S. P., Karimova, G., Davi, M. \& Ladant, D. Analysis of membrane protein interactions with a bacterial adenylate cyclase-based two-hybrid (BACTH) technique. Curr. Protoc. Mol. Biol. 2017, 20.12.1-20.12.24 (2017).

302. Karimova, G., Dautin, N. \& Ladant, D. Interaction Network among Escherichia coli Membrane Proteins Involved in Cell Division as Revealed by Bacterial Two-Hybrid Analysis Interaction Network among Escherichia coli Membrane Proteins Involved in Cell Division as Revealed by Bacterial Two-Hybrid. J. Bacteriol. 187, 2233-2243 (2005).

303. Karimova, G., Pidoux, J., Ullmann, A. \& Ladant, D. A bacterial two-hybrid system based on a reconstituted signal transduction pathway. Proc. Natl. Acad. Sci. U. S. A. 95, 5752-6 (1998).

304. Ladant, D. \& Ullmann, A. Bordatella pertussis adenylate cyclase: a toxin with multiple talents. Trends Microbiol. 7, 172-6 (1999).

305. Giacalone, D. et al. Ligand-Mediated Biofilm Formation via Enhanced Physical Interaction Between a Diguanylate Cyclase and Its Receptor. bioRxiv 9, 212183 (2017).

306. D’Argenio, D. a. \& Miller, S. I. Cyclic di-GMP as a bacterial second messenger. Microbiology 150, 2497-2502 (2004).

307. Serra, D. O. et al. FHA-mediated cell-substrate and cell-cell adhesions are critical for Bordetella pertussis biofilm formation on abiotic surfaces and in the mouse nose and the trachea. PLoS One 6, (2011).

308. Irie, Y., Preston, A. \& Yuk, M. H. Expression of the primary carbohydrate component of the Bordetella bronchiseptica biofilm matrix is dependent on growth phase but independent of Bvg regulation. J. Bacteriol. 188, 6680-6687 (2006).

309. Mattoo, S., Miller, J. F. \& Cotter, P. A. Role of Bordetella bronchiseptica fimbriae in tracheal colonization and development of a humoral immune response. Infect. Immun. 68, 2024-33 (2000).

310. Scheller, E. V., Melvin, J. A., Sheets, A. J. \& Cotter, P. A. Cooperative roles for fimbria and filamentous hemagglutinin in Bordetella adherence and immune modulation. MBio 6, 1-11 (2015).

311. Kvitko, B. H. \& Collmer, A. Construction of Pseudomonas syringae pv. tomato DC3000 Mutant and Polymutant Strains. in Methods in molecular biology (Clifton, N.J.) 712, 109-128 (2011).

312. Ambrosis, N., Boyd, C. D., O Toole, G. A., Fernández, J. \& Sisti, F. Homologs of 
the LapD-LapG c-di-GMP Effector System Control Biofilm Formation by Bordetella bronchiseptica. PLoS One 11, e0158752 (2016).

313. Shanks, R. M. Q., Caiazza, N. C., Hinsa, S. M., Toutain, C. M. \& O'Toole, G. a. Saccharomyces cerevisiae-based molecular tool kit for manipulation of genes from gram-negative bacteria. Appl. Environ. Microbiol. 72, 5027-5036 (2006).

314. Kovach, M. E., Phillips, R. W., Elzer, P. H., Roop, R. M. \& Peterson, K. M. pBBR1MCS: a broad-host-range cloning vector. Biotechniques 16, 800-2 (1994).

315. Byrd, M. S., Mason, E., Henderson, M. W., Scheller, E. V. \& Cotter, P. a. An improved recombination-based in vivo expression technology-like reporter system reveals differential cyaA gene activation in Bordetella species. Infect. Immun. 81, 1295-1305 (2013).

316. Karimova, G., Ullmann, A. \& Ladant, D. Protein-protein interaction between Bacillus stearothermophilus tyrosyl-tRNA synthetase subdomains revealed by a bacterial two-hybrid system. J. Mol. Microbiol. Biotechnol. 3, 73-82 (2001).

317. Stainer, D. W. \& Scholte, M. J. A Simple Chemically Defined Medium for the Production of Phase I Bordetella pertussis. J. Gen. Microbiol. 63, 211-220 (1970).

318. Tung, W. L. \& Chow, K. C. A modified medium for efficient electrotransformation of E. coli. Trends Genet. 11, 128-129 (1995).

319. Smith, A. W. \& Iglewski, B. H. Transformation of Pseudomonas aeruginosa by electroporation. Nucleic Acids Res. 17, 10509 (1989).

320. Simon, R., Priefer, U. \& Pühler, A. A Broad Host Range Mobilization System for In Vivo Genetic Engineering: Transposon Mutagenesis in Gram Negative Bacteria. Bio/Technology 1, 784-791 (1983).

321. Green, M. R. \& Sambrook, J. Preparation of Plasmid DNA by Alkaline Lysis with Sodium Dodecyl Sulfate: Minipreps. Cold Spring Harb. Protoc. 2016, pdb.prot093344 (2016).

322. Boyle, J. S. \& Lew, A. M. An inexpensive alternative to glassmilk for DNA purification. Trends Genet. 11, 8 (1995).

323. Laemmli, U. K. Cleavage of Structural Proteins during the Assembly of the Head of Bacteriophage T4. Nature 227, 680-685 (1970).

324. Bradford, M. M. A rapid and sensitive method for the quantitation of microgram quantities of protein utilizing the principle of protein-dye binding. Anal. Biochem. 72, 248-254 (1976).

325. Reyrat, J. M., Pelicic, V., Gicquel, B. \& Rappuoli, R. Counterselectable markers: Untapped tools for bacterial genetics and pathogenesis. Infect. Immun. 66, 40114017 (1998).

326. Pelicic, V., Reyrat, J. M., Gicquel, B., Pelicic, V. \& Reyrat, J. Expression of the Bacillus subtilis sacB gene confers sucrose sensitivity on mycobacteria. 178, (1996).

327. Inatsuka, C. S. et al. Pertactin is required for Bordetella species to resist neutrophilmediated clearance. Infect. Immun. 78, 2901-2909 (2010).

328. Stibitz, S. Allelic retrieval: a scheme to facilitate the repeated isolation of a specific segment of the Bordetella pertussis chromosome. Gene 208, 183-189 (1998).

329. Miller, J. H. Experiments in molecular genetics. (Cold Spring Harbor Laboratory, 1972).

330. Schultz, J., Milpetz, F., Bork, P. \& Ponting, C. P. SMART, a simple modular architecture research tool: Identification of signaling domains. Proc. Natl. Acad. Sci. 95, 5857-5864 (1998).

331. Sievers, F. \& Higgins, D. G. Clustal Omega. Curr. Protoc. Bioinforma. 2014, 3.13.13.13.16 (2014).

332. Crooks, G. E., Hon, G., Chandonia, J.-M. \& Brenner, S. E. WebLogo: A Sequence Logo Generator. Genome Res. 14, 1188-1190 (2004).

333. Altschul, S. F., Gish, W., Miller, W., Myers, E. W. \& Lipman, D. J. Basic local alignment search tool. J. Mol. Biol. 215, 403-10 (1990).

334. Boehm, A. et al. Second messenger signalling governs Escherichia coli biofilm 
induction upon ribosomal stress. Mol. Microbiol. 72, 1500-1516 (2009). 